Franca Ruhwedel

\title{
Eigentümerstruktur und Unternehmenserfolg
}

Eine theoretische und empirische Analyse deutscher börsennotierter Unternehmen 


\section{Franca Ruhwedel}

\section{Eigentümerstruktur und Unternehmenserfolg}

Der Einfluss von Großaktionären auf die Unternehmenspolitik wird unter dem Stichwort Deutschland $A G$ bereits seit langem diskutiert und gewinnt im Zuge der aktuellen CorporateGovernance-Diskussion erneut an Bedeutung. Die Wirkung von Kapital- bzw. Stimmrechtsblöcken auf den Unternehmenswert ist bisher jedoch weder theoretisch noch empirisch eindeutig geklärt. Franca Ruhwedel nimmt vor diesem Hintergrund eine umfassende theoretische und empirische Analyse des Zusammenhangs zwischen Eigentümer- bzw. Stimmrechtsstruktur deutscher Aktiengesellschaften und dem Unternehmenserfolgvor. Sie analysiert zunächst dieAnreizstrukturen von Großaktionären mithilfe eines agencytheoretischen Instrumentariums. Die abgeleiteten Hypothesen überprüft die Autorin anschließend im Rahmen einer empirischen Untersuchung, die den Einfluss der Eigentümer- und Stimmrechtsstruktur auf den Unternehmenserfolg für 238 CDAX-Unternehmen im Zeitraum von 1997 bis 2000 analysiert.

Franca Ruhwedel, geborene Hillebrandt, geboren 1973 in Münster, studierte nach ihrer Ausbildung zur Bankkauffrau Betriebswirtschaftslehre an der Westfälischen Wilhelms-Universität in Münster. Nach ihrem Abschluss als Diplom-Kauffrau wechselte sie an die Ruhr-Universität Bochum, wo sie von 1999 bis zu ihrer Promotion 2003 als wissenschaftliche Mitarbeiterin am Lehrstuhl für Internationale Unternehmensrechnung (Prof. Dr. Bernhard Pellens) tätig war. 
Eigentümerstruktur und Unternehmenserfolg 


\section{BOCHUMER BEITRÄGE ZUR UNTERNEHMUNGSFÜHRUNG UND UNTERNEHMENSFORSCHUNG}

Herausgegeben von Prof. Dr. Michael Abramovici,

Prof. Dr. Dr. h.c. mult. Walther Busse von Colbe, Prof. Dr. Dr. h.c. Werner H. Engelhardt, Prof. Dr. Roland Gabriel, Prof. Dr. Jochen Hundsdoerfer, Prof. Dr. Arno Jaeger, Prof. Dr. Gert Laßmann, Prof. Dr. Wolfgang Maßberg, Prof. Dr. Bernhard Pellens, Prof. Dr. Marion Steven, Prof. Dr. Rolf Wartmann, Prof. Dr. Brigitte Werners

Band 68

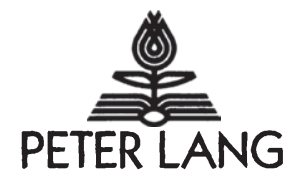

Frankfurt am Main - Berlin - Bern - Bruxelles - New York - Oxford - Wien 
Franca Ruhwedel

\section{Eigentümerstruktur und Unternehmenserfolg}

Eine theoretische und empirische Analyse deutscher börsennotierter Unternehmen

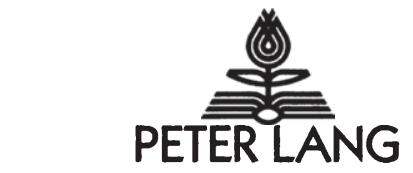

Europäischer Verlag der Wissenschaften 


\title{
Bibliografische Information Der Deutschen Bibliothek
}

Die Deutsche Bibliothek verzeichnet diese Publikation in der Deutschen Nationalbibliografie; detaillierte bibliografische

Daten sind im Internet über $<\mathrm{http}: / / \mathrm{dnb}$.ddb.de $>$ abrufbar.

Open Access: The online version of this publication is published on www. peterlang.com and www.econstor.eu under the international Creative Commons License CC-BY 4.0. Learn more on how you can use and share this work: http://creativecommons.org/licenses/by/4.0.

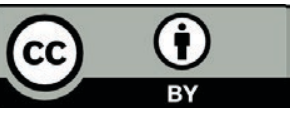

This book is available Open Access thanks to the kind support of ZBW Leibniz-Informationszentrum Wirtschaft.

Zugl.: Bochum, Univ., Diss., 2003

\section{Gedruckt auf alterungsbeständigem, säurefreiem Papier.}

\author{
D294 \\ ISSN 0175-7105 \\ ISBN 3-631-51735-1 \\ ISBN 978-3-631-75497-9 (eBook) \\ (C) Peter Lang GmbH \\ Europäischer Verlag der Wissenschaften \\ Frankfurt am Main 2003 \\ Alle Rechte vorbehalten.
}

Das Werk einschließlich aller seiner Teile ist urheberrechtlich geschützt. Jede Verwertung außerhalb der engen Grenzen des Urheberrechtsgesetzes ist ohne Zustimmung des Verlages unzulässig und strafbar. Das gilt insbesondere für

Vervielfältigungen, Übersetzungen, Mikroverfilmungen und die Einspeicherung und Verarbeitung in elektronischen Systemen.

Printed in Germany 123467

www.peterlang.de 


\section{Geleitwort}

Unter dem Schlagwort „Corporate Governance“ wird in den vergangenen Jahren auch in Deutschland die Ausgestaltung von Unternehmensleitung und -kontrolle intensiv diskutiert. Ein wichtiges Element der Corporate Governance, die Einflussnahme von Großaktionären auf die Unternehmenspolitik, bleibt bei dieser Diskussion jedoch weitestgehend unberücksichtigt. Dies erstaunt insbesondere vor dem Hintergrund der besonderen Relevanz dieser Fragestellung, die aus den konzentrierten Eigentümerstrukturen gerade am deutschen Kapitalmarkt resultiert.

Die Wirkung von Großaktionären auf den Unternehmenserfolg ist bisher weder theoretisch noch empirisch hinreichend geklärt. Zielsetzung der Dissertation von Frau Ruhwedel ist vor diesem Hintergrund die umfassende theoretische und empirische Analyse des Zusammenhangs zwischen Eigentümer- bzw. Stimmrechtsstruktur deutscher Aktiengesellschaften und ihrem durch verschiedene Kennzahlen abgebildeten Erfolg. Die umfassende Analyse der Anreizstrukturen von Großaktionären mit Hilfe des agencytheoretischen Instrumentariums im Rahmen des theoretischen Teils trägt dabei ebenso zum Erkenntnisfortschritt bei wie die empirische Untersuchung, die sowohl hinsichtlich ihrer Gesamtkonzeption als auch hinsichtlich ihres auch divergierende Stimm- und Cash-Flow-Rechte umfassenden breiten Untersuchungsgegenstandes in der Eigentümerstrukturforschung in Deutschland bisher unerforschte Bereiche beleuchtet.

Im theoretischen Teil arbeitet Frau Ruhwedel zunächst die verschiedenen Erklärungsansätze des Verhaltens von Großaktionären unter verschiedenen Rahmenbedingungen systematisch auf und gibt einen umfassenden Überblick über den Stand der Forschung. Die stringent abgeleiteten Hypothesen werden anschlieBend in der empirischen Analyse systematisch mittels verschiedener ökonometrischer Verfahren überprüft. Die erzielten Ergebnisse leisten einen wichtigen Beitrag zu einer wissenschaftlichen Fundierung der Diskussion um den Einfluss von Großaktionären innerhalb der „Deutschland $\mathrm{AG}^{\text {“. }}$.

Frau Ruhwedel hat sich mit ihrer empirischen Untersuchung über den Zusammenhang zwischen Eigentümerstruktur und Unternehmenserfolg eine überaus wichtige und hochaktuelle Thematik ausgewählt, die in der deutschen Literatur bisher nur ansatzweise bearbeitet wurde. Es liegt eine argumentenreiche Untersuchung mit vielfältigen eigenständigen empirischen Forschungsergebnissen vor, von deren praktischer Relevanz sicher auszugehen ist. 
Franca Ruhwedel - 978-3-631-75497-9 


\section{Vorwort}

Diese Arbeit wurde im Juni 2003 von der wirtschaftswissenschaftlichen Fakultät der Ruhr-Universität Bochum, an der ich am Lehrstuhl für Internationale Unternehmensrechnung von September 1999 bis Juni 2003 als wissenschaftliche Mitarbeiterin beschäftigt war, als Dissertation angenommen. Die vier Lehrstuhljahre sind für mich sowohl in beruflicher als auch in privater Hinsicht eine wunderschöne Zeit gewesen, weshalb ich an dieser Stelle all jenen danken möchte, die hierzu beigetragen haben.

Die engagierte Lehre meines damals noch in Münster tätigen Chefs, Prof. Dr. Bernhard Pellens, hat mich nach Abschluss meines Studiums bewogen, von der Uni Münster nach Bochum in den „Pott" zu wechseln. Ein Wechsel, der letztendlich viel mehr war, als nur der Wechsel an eine andere Universität und den ich nie bereut habe. Ein ganz herzlicher Dank gilt daher meinem „Chef": Danke, dass Sie mich nach Bochum gelockt haben und danke für die vielen spannenden Projekte, die ich an Ihrem Lehrstuhl (auch und insbesondere jenseits der Rechnungslegung) durchführen konnte! Ich denke, nur an wenigen Lehrstühlen haben Promovenden vergleichbare Chancen und vor allen Dingen ähnlich viel Spaß bei der Arbeit. Als Zweitgutachter hat die Arbeit Prof. Dr. Stephan Paul betreut, dem ich für seine wertvollen Hinweise ebenso herzlich danken möchte wie für die kurzfristige Begutachtung. Dem Institut für Unternehmungsführung und Unternehmensforschung danke ich für die Aufnahme der Arbeit in ihre Schriftenreihe.

(Mit-)entscheidend für den $\mathrm{Spa} ß$ bei der Arbeit waren meine lieben Kollegen, denen ich hier ebenfalls danke: Ralf Schremper (Danke für so einiges (du weißt schon...) und deine gute Freundschaft auch und insbesondere in deiner NachLehrstuhl-Zeit!), Kerstin Basche (Danke für die Motivation zweimal die Woche schwimmen zu gehen, deine Unterstützung gegen die Männerherrschaft (;) und dafür, dass du mir eine gute Freundin geworden bist!), Marc Richard (Danke für die Bonbons und dein immer freundliches Lächeln!), Thorsten Sellhorn (Danke für die schöne Anfangszeit im gemeinsamen Büro!), Nils Crasselt (Danke für das Hochhalten der „Fahne des internen ReWe“!), Rolf Uwe Fülbier (Danke für den Ansporn, endlich jede zweite Bahn zu kraulen!) sowie den anderen, die ebenfalls dazu beigetragen haben die Zeit zu der zu machen, die sie war: Andreas Bonse, Karsten Detert, Joachim Gassen, Ralf Jödicke sowie unsere beiden „Neuen“ Stefan Neuhaus und Uwe Nölte.

Neben einer eher indirekten Unterstützung haben viele Menschen auch ganz direkt am Entstehen dieses Buches mitgewirkt: Durch die Tiefen der Eigentümerstrukturtheorie haben sich lesenderweise gekämpft mein Mann Peter, meine 
Kollegen Nils, Ralf, Thorsten, Marc und Jan Duch sowie insbesondere Prof. Werner Smolny, der sich trotz seines Wechsels an die Uni Ulm die Zeit genommen hat, meine empirische Vorgehensweise intensiv und kritisch weiterzubegleiten. Daneben gilt ein lieber Dank den Rettern von Rechtschreibung und formaler Einheitlichkeit: meinen Eltern Carla und Franz-Josef Hillebrandt. Außerdem den fleißigen Hilfskräften unseres Lehrstuhls für die Literaturbeschaffung und Timm Dolezych, der sich mit mir gemeinsam durch so manchen Datenfriedhof gekämpft hat. Ein lieber Dank geht auch an meine Freunde, die sich die teilweise wiederkehrende Leier einer Promovendin klaglos angehört haben: Hier sei insbesondere Judith Schremper, Uta Wagner und Eva Thomas gedankt; sowie Peter Hillebrandt für seine Motivation in der Anfangsphase meiner Diss.

Damit bin ich bei dem wichtigsten Bereich angekommen, dem privaten. Ich danke meinen lieben Eltern - dafür, dass sie mir immer und jederzeit das Gefühl gegeben haben, uneingeschränkt und vorbehaltlos für mich da zu sein. Meinen Schwiegereltern Renate und Willi sowie der ganzen Ruhwedel-Familie für die liebevolle Aufnahme. Und schließlich meinem geliebten Mann Peter, den ich während meiner Diss-Zeit kennen gelernt habe. Dieses Buch und die Uni Bochum mit ihrem Gebäude GC werden für mich immer Symbol dessen sein, was ich in ihm gefunden habe; so viel mehr, als ich hier in Worten sagen könnte. Mit ihm unmittelbar verbunden unserem Sohn Ole, der wenige Wochen nach der Schlussbesprechung dieser Arbeit zur Welt gekommen ist: Dafür, dass er mir in der Endphase der Diss eine nahezu unendliche Gelassenheit gegeben hat - seine Lebenszeichen in meinem Bauch haben mich immer wieder daran erinnert, dass es noch andere Dinge im Leben gibt als die Diss... Ich widme die Arbeit daher meiner Familie: meinen Eltern, Ole und Peter.

Bochum, im Juli 2003

Franca Ruhwedel 


\section{Inhaltsverzeichnis}

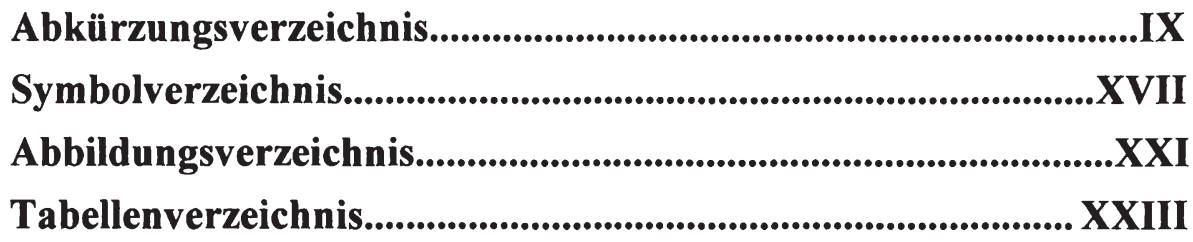

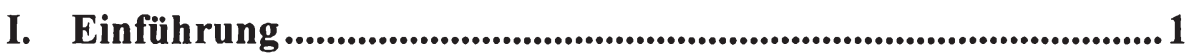

1 Problemstellung und Ziel der Arbeit..................................................... 1

2 Aufbau der Untersuchung ......................................................... 5

II. Rolle der Aktionäre in der Aktiengesellschaft .........................9

1 Grundlagen der Aktiengesellschaft ................................................. 9

1.1 Charakterisierung und Bedeutung ............................................... 9

1.2 Historische Entwicklung........................................................ 12

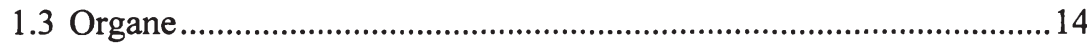

2 Rechtsstellung der Aktionäre ..................................................... 18

2.1 Fundierung im Gesellschafts- und Kapitalmarktrecht......................18

2.2 Rechte und Pflichten des Aktionärs..............................................21

2.2.1 Einlage- und Treuepflicht .............................................21

2.2.2 Cash-Flow-Rechte.............................................................23

2.2.3 Informationsrechte ..........................................................25

2.2.4 Herrschaftsrechte ...........................................................27

2.2.4.1 Teilnahme- und Rederecht auf der Hauptversamm-

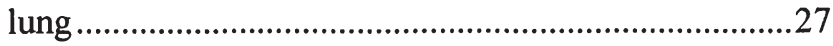

2.2.4.2 Stimmrecht ......................................................28

2.2.5 Durchsetzung der Aktionärsrechte ......................................332

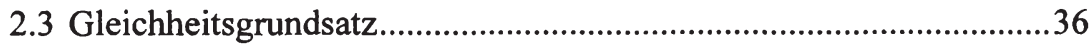


2.4 Besonderheiten im Konzern..........................................................37

3 Charakterisierung und Bedeutung verschiedener Aktionärstypen .......... 39

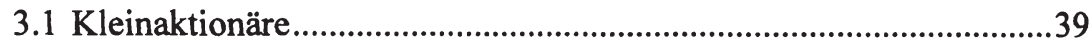

3.2 Großaktionäre .....................................................................44

3.2.1 Institutionelle Investoren .................................................40

3.2.2 Nicht-institutionelle Großaktionäre ....................................42

3.3 Aktionärsstrukturen im internationalen Vergleich .........................44

3.4 Ursachen alternativer Aktionärsstrukturen ...................................47

3.5 Transparenz über Eigentümer- und Stimmrechtsstrukturen in Deutschland. .50

3.5.1 Erfordernis von Transparenz ..............................................55

3.5.2 Transparenzanforderungen nach deutschem Recht .................51

3.5.2.1 Regelungen des Wertpapierhandelsgesetzes................51

3.5.2.2 Publizität im Rahmen der periodischen Berichterstattung ................................................................55

3.5.3 Empirische Untersuchung zum Publizitätsverhalten im Geschäftsbericht.............................................................56

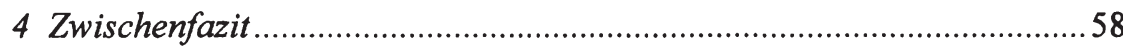

\section{III. Ökonomische Analyse der Kontrollfunktion von Aktio-} nären....................................................................................60

1 Erfordernis und Auswirkungen der Managementkontrolle durch Aktionäre. 60

1.1 Abgrenzung der Aktionärskontrolle ..........................................60

1.1.1 Ökonomisches und rechtliches Verständnis ..........................60

1.1.2 Einordnung der Aktionärskontrolle in das CorporateGovernance-System .63

1.2 Agency-Beziehung zwischen Management und Anteilseignern.......66

1.2.1 Grundlagen der Agency-Theorie 66

1.2.1.1 Abgrenzung innerhalb der Neuen Institutionenökonomik 
1.2.1.2 Verfügungsrechtsdelegation als Ursache von Agency-Konflikten......................................................70

1.2.1.3 Free-Rider-Problematik in Publikumsgesellschaften.

1.2.2 Mechanismen zur Reduzierung des Principal-AgentKonflikts .74

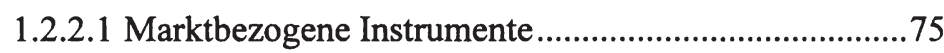

1.2.2.2 Unternehmensinterne Instrumente ................................77

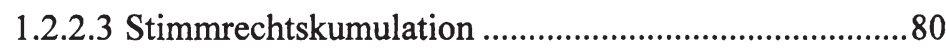

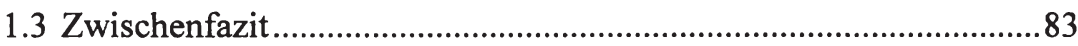

2 Auswirkung von Eigentümer- und Stimmrechtsstruktur auf die

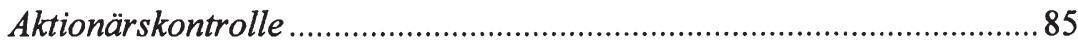

2.1 Wissenschaftstheoretische Grundlagen .............................................. 85

2.1.1 Agency-Beziehung zwischen Aktionärsgruppen........................85

2.1.2 Eigenkapitalstruktur und Unternehmenswert .............................86

2.2 Aktionärskontrolle bei Kongruenz von Stimm- und Cash-Flow-

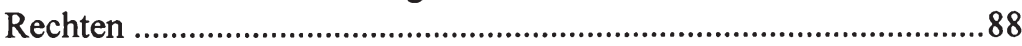

2.2.1 Theorien zur Anreizwirkung von Blockbildungen.....................88

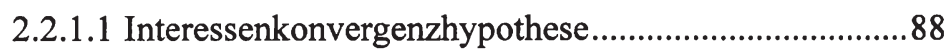

2.2.1.2 Ausbeutungshypothese................................................92

2.2.1.3 Nichtlinearitätshypothese .............................................96

2.2.1.4 Sonstige Hypothesen ...................................................98

2.2.2 Relevanz der Identität des Großaktionärs...............................103

2.3 Aktionärskontrolle bei fehlender Kongruenz von Stimm- und

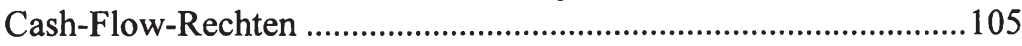

2.3.1 Theorie zur Anreizwirkung unterproportionaler Cash-

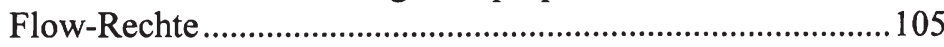

2.3.2 Ursachen für das Auseinanderfallen von Stimm- und

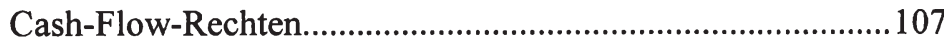

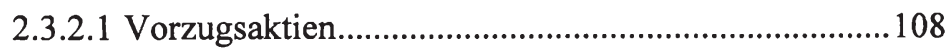

2.3.2.2 Eigenkapitalpyramiden.............................................110

2.3.2.3 Sonstige Ursachen ......................................................112

2.3.3 Bedeutung unterproportionaler Cash-Flow-Rechte.................114 
2.4 Theoretische Modellierung des Zusammenhangs zwischen

Eigentümerstruktur und Unternehmenserfolg 116

2.4.1 Überblick über theoretische Arbeiten zur Eigentümer- und Stimmrechtsstruktur

2.4.2 Eigenes Modell

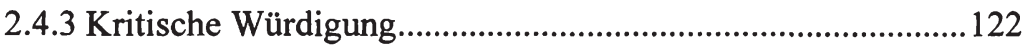

2.5 Hypothesenbildung .................................................................. 123

2.5.1 Hypothesen zum Kapital- bzw. Stimmrechtsanteil des Großaktionärs

2.5.2 Hypothesen zu unterproportionalen Cash-Flow-Rechten.......127

2.5.3 Hypothese zu konkurrierenden Minderheitsaktionären..........129

2.5.4 Hypothesen zur Identität des Großaktionärs

\section{Empirische Untersuchung zum Zusammenhang zwischen Eigentümer- bzw. Stimmrechtsstruktur und Unterneh- menserfolg}

1 Stand der empirischen Forschung.

1.1 Studien für internationale Kapitalmärkte 133

1.2 Studien für den deutschen Kapitalmarkt.......................................136

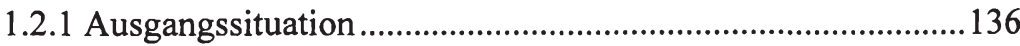

1.2.2 Deskriptive Studien......................................................... 138

1.2.3 Performancestudien.......................................................... 142

1.2.3.1 Regressionsanalysen zur Performance....................... 142

\subsubsection{Event-Studies und Long-Run-Performance-} Studies

1.3 Zwischenfazit

2 Grundlagen der empirischen Untersuchung....

2.1 Multivariate Regressionsanalyse

2.1.1 Überblick über das Verfahren

2.1.2 Bewertung der Schätzgüte

2.1.3 Überprüfung der Regressionsvoraussetzungen. 
2.2 Berücksichtigung besonderer ökonometrischer Probleme bei der Analyse von Eigentümerstrukturen ......................................... 158

2.2.1 Endogenität der abhängigen Variablen................................. 158

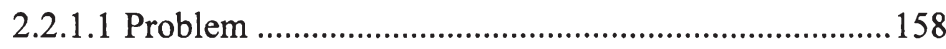

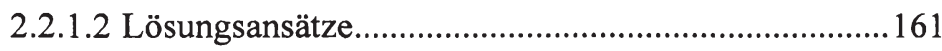

2.2.1.2.1 Auswahl des Regressionsmodells .....................161

2.2.1.2.2 Verwendung von Panel-Daten........................... 164

2.2.2 Fehlende bzw. falsch spezifizierte Variablen ....................... 168

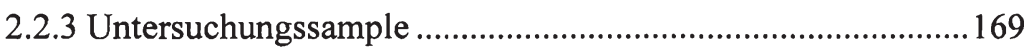

2.2.4 Messfehler.................................................................... 170

2.2.5 Berücksichtigung der ökonometrischen Problemfelder in vorhandenen Studien...................................................... 170

2.3 Forschungsdesign der eigenen empirischen Untersuchung............ 173

2.3.1 Auswahl der Variablen ................................................... 173

2.3.1.1 Abhängige Variable............................................... 173

2.3.1.2 Variablen zur Eigentümer- und Stimmrechtsstruktur................................................................. 176

2.3.1.2.1 Variablen zur Eigentümerstruktur .....................176

2.3.1.2.2 Variablen zur Stimmrechtsstruktur .................... 179

2.3.1.2.3 Variablen zur Diskrepanz zwischen Kapitalund Stimmrechtsanteil

2.3.1.2.4 Zusammenfassung der Variablen zur

Eigentümer- und Stimmrechtsstruktur ............... 184

2.3.1.3 Kontrollvariablen ................................................. 186

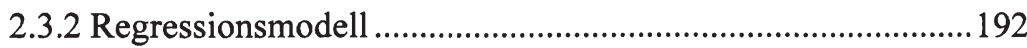

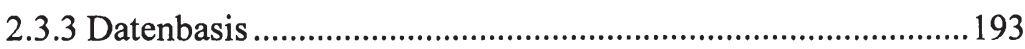

2.3.3.1 Sampleauswahl ................................................. 193

2.3.3.2 Daten zur Eigentümer- und Stimmrechtsstruktur ......195

2.3.3.3 Jahresabschluss- und Kapitalmarktdaten ...................197

3 Ergebnisse der empirischen Untersuchung ......................................200

3.1 Eigentümer- und Stimmrechtsstrukturen am deutschen

Kapitalmarkt ...................................................................200

3.1.1 Allgemeine Unternehmenscharakteristika.........................200

3.1.2 Eigentümerstrukturen...................................................202 


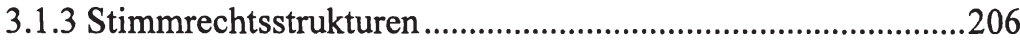

3.1.4 Abweichungen zwischen Kapital- und Stimmrechten............209

3.1.4.1 Höhe der Kapital- und Stimmrechtsanteile .................209

3.1.4.2 Instrumente zur Schaffung abweichender Kapitalund Stimmrechtsanteile ............................................211

3.1.4.3 Relevanz der Identität des Aktionärs ..........................213

3.1.4.4 Relevanz der Indexzugehörigkeit................................217

3.1.5 Kernergebnisse der deskriptiven Analyse ..............................219

3.2 Eigentümer- bzw. Stimmrechtsstrukturen und Unternehmens-

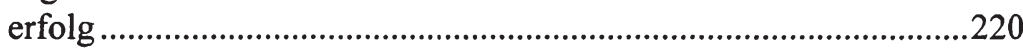

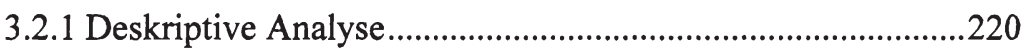

3.2.2 Untersuchungsaufbau der Regressionsanalysen ......................223

3.2.3 Einfluss der Stimmrechtsstruktur auf den Unternehmens-

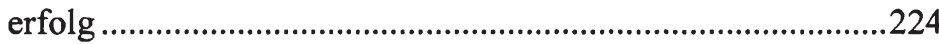

3.2.3.1 Univariate Regressionsanalysen..................................224

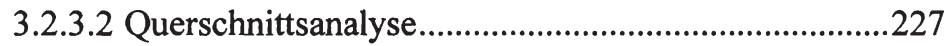

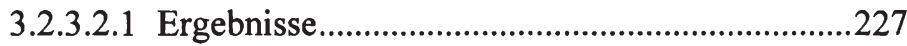

3.2.3.2.2 Überprüfung der Regressionsvoraus setzungen ..........................................................233

3.2.3.2.3 Stabilitätstests ....................................................236

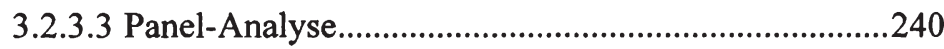

3.2.3.3.1 Panel-Modell ohne unternehmensspezifische Effekte..................................................................240

3.2.3.3.2 Panel-Modell mit unternehmensspezifischen

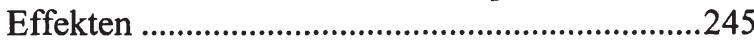

3.2.4 Überprüfung auf Endogenität - Einfluss des Unternehmenserfolgs auf die Stimmrechtsstruktur .................................248

3.2.4.1 Umkehrung der Kausalität ..........................................248

3.2.4.2 Granger- und Durbin-Wu-Hausman-Test ...................251

3.2.4.3 Stabilitätstest mit 2SLS ...............................................253

3.2.4.4 Zwischenfazit .............................................................255

3.2.5 Einfluss sonstiger Eigentümerstrukturvariablen auf den Unternehmenserfolg..............................................................256

3.2.5.1 Konzentrationsmaße..................................................256

3.2.5.2 Multiple Großaktionäre .................................................258 


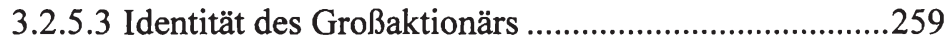

3.2.5.4 Relevanz der Indexzugehörigkeit..............................262

3.2.6 Einfluss abweichender Stimm- und Cash-Flow-Rechte auf den Unternehmenswert ..........................................................264

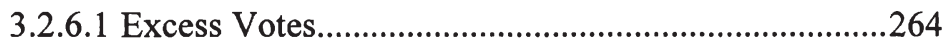

3.2.6.2 Vorzugsaktien und Pyramiden .....................................266

3.2.7 Kernergebnisse der Regressionsanalysen ...............................268

V. Zusammenfassung der Ergebnisse und Ausblick ...................272

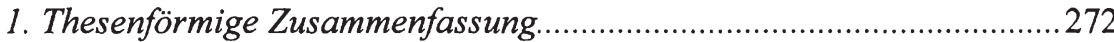

2. Rechtspolitische Schlussfolgerungen und Ausblick ............................2.277

\section{Anhang A}

Theoretische Modelle zur Anreizwirkung alternativer

Kapital- und Stimm rechtsstrukturen ............................................ 282

\section{Anhang B}

Empirische Studien zum Aktionärsstruktur-PerformanceZusammenhang ................................................................................ 288

Anhang B.1

Internationale Studien ...................................................................... 288

Anhang B.2

Regressionsanalysen zum Aktionärsstruktur-Performance-Zusam menhang in Deutschland - Allgemein ausgerichtete Studien

\section{Anhang B.3}

Regressionsanalysen zum Aktionärsstruktur-Performance-Zusammenhang in Deutschland - Studien für eine Aktionärsgruppe

\section{Anhang B.4}

Regressionsanalysen zum Aktionärsstruktur-Performance-Zusam menhang in Deutschland - Einfluss der Aktionärsstruktur auf performanceverwandte Variablen 


\section{Anhang D}

Liste der Sampleunternehmen

Literaturverzeichnis 328 


\section{Abkürzungsverzeichnis}

2SLS 2 stage least squares (Zweistufige Kleinste-Quadrate-Methode)

Abb. Abbildung

ABl. EG Amtsblatt der Europäischen Gemeinschaften

Abs. Absatz

AcP Archiv für die civilistische Praxis (Zeitschrift)

ADHGB Allgemeines Deutsches Handelsgesetzbuch

adj. adjusted/adjustiert(e)

AER American Economic Review (Zeitschrift)

AFE Advances in Financial Economics (Zeitschrift)

AG Aktiengesellschaft, Die Aktiengesellschaft (Zeitschrift)

AK Kontrolle durch ausländischen Aktionär

AktG Aktiengesetz

AMR Academy of Management Review (Zeitschrift)

ANOVA Analysis of Variance

APCIMS Association of Private Client Investment Managers and Stockbrokers

ar. arithmetische(s)

AR The Accounting Review (Zeitschrift)

Aufw. Aufwand

BAnz. Bundesanzeiger

BAFin Bundesanstalt für Finanzdienstleistungsaufsicht

BAWe Bundesaufsichtsamt für den Wertpapierhandel

BB Betriebs-Berater (Zeitschrift)

BBV Brutto Betriebsvermögen

$\mathrm{BCW} \quad$ Business and the Contemporary World (Zeitschrift)

best. bestimmte(r)

BFuP Betriebswirtschaftliche Forschung und Praxis

BGB Bürgerliches Gesetzbuch

BGBl. Bundesgesetzblatt

BGH Bundesgerichtshof

BGHZ Entscheidungssammlung des BGH in Zivilsachen 
BJoE The Bell Journal of Economics (Zeitschrift)

BJoEMS The Bell Journal of Economics and Management Science (Zeitschrift)

BLUE best linear unbiased estimator

BW Buchwert

bzgl. bezüglich

bzw. beziehungsweise

c Regressionskonstante

CAR cumulative average abnormal return

CDAX Composite DAX

CF Cash Flow

CFR Cash-Flow-Recht/e

CG Corporate Governance (Zeitschrift)

CLR Cardozo Law Review (Zeitschrift)

ColLR Columbia Law Review (Zeitschrift)

c.p. ceteris paribus

DAI Deutsches Aktieninstitut

DAX Deutscher Aktienindex

DB Der Betrieb (Zeitschrift)

DBW Die Betriebswirtschaft (Zeitschrift)

DCGK Deutscher Corporate Governance-Kodex

DJT Deutscher Juristentag

DStR Deutsches Steuerrecht (Zeitschrift)

DSW Deutsche Schutzvereinigung für Wertpapierbesitz e.V.

DVFA Deutsche Vereinigung für Finanzanalyse und Anlageberatung e.V.

ed. editor

EER European Economic Review (Zeitschrift)

EFR European Finance Review (Zeitschrift)

EG Europäische Gemeinschaft

EJ The Economic Journal (Zeitschrift)

EK Eigenkapital

EKR Eigenkapitalrendite

engl. englisch 
EP Economic Policy (Zeitschrift)

EPS earnings per share

EPR Economic Policy Review (Zeitschrift)

et al. et alii

etc. et cetera

EU Europäische Union

e.V. eingetragener Verein

EWS Empirische Wirtschafts- und Sozialforschung (Zeitschrift)

f./ff. folgende/fortfolgende

FAK Familienkontrolle

FAZ Frankfurter Allgemeine Zeitung

FE Financial Economics (Zeitschrift)

FGG Gesetz über die Angelegenheiten der freiwilligen Gerichtsbarkeit

FinDAG Finanzdienstleistungsaufsichtsgesetz

FK Fremdkapital

FM Financial Management (Zeitschrift)

Fn. Fußnote

FR The Financial Review (Zeitschrift)

F\&E Forschung und Entwicklung

GA Großaktionär

GAK Großaktionärskontrolle

GCCG German Code of Corporate Governance

gem. gemäß

GER German Economic Review (Zeitschrift)

GK Gesamtkapital

GKR Gesamtkapitalrendite

GLJ The Georgetown Law Journal (Zeitschrift)

GLS Generalized Least Squares

GmbH Gesellschaft mit beschränkter Haftung

GMM General Method of Moments

H Herfindahl-Index

HBR Harvard Business Review (Zeitschrift)

HGB Handelsgesetzbuch 
HJLPP Harvard Journal of Law \& Public Policy (Zeitschrift)

HLR Harvard Law Review (Zeitschrift)

h.M. herrschende Meinung

Hrsg. Herausgeber

HV Hauptversammlung

IAS International Accounting Standard

IASB International Accounting Standards Board

i.B.a. in Bezug auf

i.d.R. in der Regel

IIK Kontrolle durch institutionelle Investoren

IJoEB International Journal of the Economics of Business (Zeitschrift)

INF Die Information über Steuer und Wirtschaft (Zeitschrift)

insb. insbesondere

IPO Initial Public Offering

IRLE International Review of Law and Economics (Zeitschrift)

i.V.m. in Verbindung mit

IV-Methode Instrumentalvariablen-Methode

JCL Journal of Corporation Law (Zeitschrift)

JEP Journal of Economic Perspectives (Zeitschrift)

JF Jahresfehlbetrag

JFQA Journal of Financial and Quantitative Analysis (Zeitschrift)

Jg. Jahrgang

JHR The Journal of Human Resources (Zeitschrift)

JIE The Journal of Industrial Economics (Zeitschrift)

JITE Journal of Institutional and Theoretical Economics/ Zeitschrift für die gesamte Staatswissenschaft

JLEO Journal of Law, Economics and Organization (Zeitschrift)

JLS Journal of Law and Society (Zeitschrift)

JoACF Journal of Applied Corporate Finance (Zeitschrift)

JoAE Journal of Accounting and Economics (Zeitschrift)

JoASA Journal of the American Statistical Association (Zeitschrift)

JoB Journal of Business (Zeitschrift)

JoCF Journal of Corporate Finance (Zeitschrift) 


$\begin{array}{ll}\text { JoE } & \text { Journal of Econometrics (Zeitschrift) } \\ \text { JoES } & \text { Journal of Economic Surveys (Zeitschrift) } \\ \text { JoF } & \text { The Journal of Finance (Zeitschrift) } \\ \text { JoFE } & \text { Journal of Financial Economics (Zeitschrift) } \\ \text { JoFI } & \text { Journal of Financial Intermediation (Zeitschrift) } \\ \text { JoIE } & \text { The Journal of Industrial Economics (Zeitschrift) } \\ \text { JoLE } & \text { Journal of Law and Economics (Zeitschrift) } \\ \text { JoMCB } & \text { Journal of Money, Credit, and Banking (Zeitschrift) } \\ \text { JoPE } & \text { Journal of Political Economy (Zeitschrift) } \\ \text { JoPM } & \text { Journal of Portfolio Management (Zeitschrift) } \\ \text { JoRSS } & \text { Journal of the Royal Statistical Society (Zeitschrift) } \\ \text { JoWB } & \text { Journal of World Business (Zeitschrift) } \\ \text { JÜ } & \text { Jahresüberschuss } \\ \text { JWE } & \text { Japan and the World Economy (Zeitschrift) } \\ \text { k.A. } & \text { keine Angaben } \\ \text { KAGG } & \text { Gesetz über Kapitalanlagegesellschaften } \\ \text { Kap. } & \text { Kapitel } \\ \text { KapCoRiLiG Kapitalgesellschaften- und Co-Richtlinie-Gesetz } \\ \text { KGaA } & \text { Kommanditgesellschaft auf Aktien } \\ \text { KK } & \text { Kredit und Kapital } \\ \text { KonTraG } & \text { Gesetz zur Kontrolle und Transparenz im Unternehmensbereich } \\ \text { KoR } & \text { Kapitalmarktorientierte Rechnungslegung (Zeitschrift) } \\ \text { KZSS } & \text { Kölner Zeitschrift für Soziologie und Sozialpsychologie } \\ \text { LBO } & \text { Leveraged Buyout } \\ \text { LR } & \text { likelihood ratio } \\ \text { MAK } & \text { Mehrheitsaktionärskontrolle } \\ \text { MCFJ } & \text { Midland Corporate Finance Journal (Zeitschrift) } \\ \text { MDE } & \text { Managerial and Decision Economics (Zeitschrift) } \\ \text { MfU } & \text { Markt für Unternehmenskontrolle } \\ \text { mind. } & \text { mindestens } \\ \text { Mio. } & \text { Millionen } \\ \text { MK } & \text { Managementkontrolle } \\ \text { MLR } & \text { Michigan Law Review (Zeitschrift) } \\ & \end{array}$


Mrd. Milliarden

MU Mutterunternehmen

MW Marktwert

MWBW Marktwert/Buchwert-Verhältnis

m.w.N. mit weiteren Nachweisen

NaStraG Gesetz zur Namensaktie und zur Erleichterung der Stimmrechtsausübung

natürl. natürliche

NJW Neue juristische Wochenschrift (Zeitschrift)

No. Number

Nr. Nummer

NYSE New York Stock Exchange

Ö Öffentliche Hand

o.ä. oder ähnliche

obs. observed

o. Jg. ohne Jahrgang

OECD Organization for Economic Cooperation and Development

ÖK Kontrolle durch die öffentliche Hand

OLS Ordinary Least Squares

ORDO Jahrbuch für die Ordnung von Wirtschaft und Gesellschaft

PBFJ Pacific-Basin Finance Journal (Zeitschrift)

PER price earnings ratio

PublG Publizitätsgesetz

Q Tobin's Q

QJoE Quarterly Journal of Economics (Zeitschrift)

QRoEB Quarterly Review of Economics and Business (Zeitschrift)

RBER Review of Business \& Economic Research (Zeitschrift)

RESET regression specification error test

RGBl. Reichsgesetzblatt

RIW Recht der Internationalen Wirtschaft (Zeitschrift)

RJE Rand Journal of Economics (Zeitschrift)

Rn. Randnummer

RoES Review of Economic Studies (Zeitschrift) 


$\begin{array}{ll}\text { RoIO } & \text { Review of Industrial Organisation (Zeitschrift) } \\ \text { RoISI } & \text { Review of the International Statistical Institute (Zeitschrift) } \\ \text { S. } & \text { Seite } \\ \text { SCLR } & \text { Southern California Law Review (Zeitschrift) } \\ \text { SEC } & \text { Securities and Exchange Commission } \\ \text { SEJ } & \text { Southern Economic Journal (Zeitschrift) } \\ \text { SG } & \text { Schmalenbach-Gesellschaft - Deutsche Gesellschaft für Betriebs- } \\ & \text { wirtschaft e.V. } \\ \text { SLR } & \text { Stanford Law Review (Zeitschrift) } \\ \text { SMJ } & \text { Strategic Management Journal (Zeitschrift) } \\ \text { sog. } & \text { sogenannt(e) } \\ \text { Sp. } & \text { Spalte } \\ \text { Std.abw. } & \text { Standardabweichung } \\ \text { StR } & \text { Stimmrecht/e } \\ \text { SWI } & \text { Steuer und Wirtschaft International (Zeitschrift) } \\ \text { SzU } & \text { Schriften zur Unternehmensführung } \\ \text { Tab. } & \text { Tabelle } \\ \text { TransPuG } & \text { Transparenz- und Publizitätsgesetz } \\ \text { u. } & \text { und } \\ \text { u.a. } & \text { unter anderem } \\ \text { u.ä. } & \text { und ähnliche(r) } \\ \text { UmwG } & \text { Umwandlungsgesetz } \\ \text { Unt. } & \text { Unternehmen } \\ \text { UR } & \text { Umsatzrendite } \\ \text { URL } & \text { Unified Ressource Locator } \\ \text { US-GAAP } & \text { United States Generally Accepted Accounting Principles } \\ \text { v. } & \text { von } \\ \text { versch. } & \text { verschiedene(r) } \\ \text { VFE } & \text { Vermögens-, Finanz- und Ertragslage } \\ \text { vgl. } & \text { vergleiche } \\ \text { vol. } & \text { Volume } \\ \text { WiSt } & \text { Wirtschaftswissenschaftliches Studium (Zeitschrift) } \\ \text { WISU } & \text { Das Wirtschaftsstudium (Zeitschrift) } \\ \text { WM } & \text { Wertpapier-Mitteilungen (Zeitschrift) } \\ & \end{array}$


WPg Die Wirtschaftsprüfung (Zeitschrift)

WpHG Wertpapierhandelsgesetz

WpÜG Wertpapiererwerbs- und Übernahmegesetz

WULQ Washington University Law Quarterly (Zeitschrift)

YLJ Yale Law Journal (Zeitschrift)

z.B. zum Beispiel

ZBB Zeitschrift für Bankrecht und Bankwirtschaft

ZEW Zentrum für Europäische Wirtschaftsforschung

ZfB Zeitschrift für Betriebswirtschaft

zfbf Zeitschrift für betriebswirtschaftliche Forschung

$\mathrm{ZfgK} \quad$ Zeitschrift für das gesamte Kreditwesen

ZfO Zeitschrift für Organisation

ZfP Zeitschrift für Planung

ZGR Zeitschrift für Unternehmens- und Gesellschaftsrecht

ZHR Zeitschrift für das gesamte Handelsrecht und Wirtschaftsrecht

ZIP Zeitschrift für Wirtschaftsrecht

z.G. zu Gunsten

z.T. $\quad$ zum Teil 


\section{Symbolverzeichnis}

\begin{tabular}{|c|c|}
\hline$>$ & ist größer als \\
\hline$<$ & ist kleiner als \\
\hline$\geq$ & ist größer gleich \\
\hline$\leq$ & ist kleiner gleich \\
\hline$=$ & ist gleich \\
\hline$\neq$ & ist ungleich \\
\hline$\alpha$ & Regressionskonstante \\
\hline ß & Beta-Faktor \\
\hline$\beta_{j}$ & Regressionskoeffizient (Parameter) der j-ten erklärenden Größe \\
\hline$\hat{\delta}_{j}$ & $\begin{array}{l}\text { Regressionskoeffizient (Parameter) der j-ten erklärenden Größe im } \\
\text { Rahmen der reduzierten Schätzfunktion }\end{array}$ \\
\hline$\varepsilon_{i t}$ & $\begin{array}{l}\text { White-Noise-Störterm, nimmt die nicht erklärten, über Zeit und } \\
\text { Unternehmen variierenden Einflussfaktoren auf }\end{array}$ \\
\hline$\forall$ & für alle \\
\hline$\epsilon$ & ist Element von \\
\hline$\Pi$ & Produkt \\
\hline$\sum$ & Summe \\
\hline$\sigma$ & Standardabweichung \\
\hline$\sigma^{2}$ & Varianz \\
\hline$a_{i}$ & über die Zeit konstante, unternehmensspezifische Effekte \\
\hline A & Ausländer \\
\hline AA5 & Anzahl Aktionäre mit StA > 5\% \\
\hline $\mathrm{ABW}$ & $\begin{array}{l}\text { Dummy-Variable für Abweichungen zwischen Kapital- und } \\
\text { Stimmrechtsanteil }\end{array}$ \\
\hline $\operatorname{adj} . r^{2}$ & korrigiertes lineares Bestimmtheitsmaß \\
\hline $\mathrm{AI}$ & Anlagenintensität \\
\hline Auto & Automobile, Transport \& Logistics \\
\hline B & Branche \\
\hline $\mathrm{BaRe}$ & Basic Resources \\
\hline c & $\begin{array}{l}\text { Anteil des Aktionärs am Eigenkapital der Gesellschaft/ } \\
\text { Regressionskonstante }\end{array}$ \\
\hline CF & Cash Flow \\
\hline
\end{tabular}




\begin{tabular}{|c|c|}
\hline Chem & Chemicals \\
\hline Con & Construction \\
\hline $\mathrm{ConCy}$ & Consumer Cyclical \\
\hline $\operatorname{cov}$ & Kovarianz \\
\hline $\mathrm{D}_{\mathrm{jt}}$ & unternehmensbezogener, temporärer Durchschnittswert \\
\hline DW & Durbin-Watson-Statistik \\
\hline $\mathrm{E}$ & Erwartungswert \\
\hline EKR & Eigenkapitalrendite \\
\hline $\mathrm{EV}$ & Excess Votes \\
\hline $\mathrm{F}$ & Wert der F-Statistik, Familie \\
\hline FI & Finanzintermediär \\
\hline FoBe & Food \& Beverages \\
\hline GA2 & Dummy-Variable für zweiten Großaktionär \\
\hline GKR & Gesamtkapitalrendite \\
\hline $\mathrm{H}$ & Herfindahl-Index \\
\hline HStA & Herfindahl-Index berechnet auf Basis von StAi \\
\hline $\mathrm{i}$ & Laufindex für Regressionsobjekte, Beobachtungswerte \\
\hline I & $\begin{array}{l}\text { Zahl der Regressionsobjekte bzw. Beobachtungswerte, Indus- } \\
\text { trieunternehmen }\end{array}$ \\
\hline IASUSG & Dummy-Variable für die Bilanzierung nach IAS oder US-GAAP \\
\hline Id & Identität des Großaktionärs \\
\hline Ind & Industrials \\
\hline IVG & Immaterielle Vermögensgegenstände \\
\hline $\mathrm{j}$ & Laufindex für Regressoren \\
\hline $\mathrm{J}$ & Zahl der Regressoren \\
\hline $\mathrm{k}$ & $\begin{array}{l}\text { dem kontrollierenden Aktionär entstehende Kosten aufgrund der } \\
\text { Realisierung von private benefits/Laufindex für Kontrollvariablen }\end{array}$ \\
\hline $\mathrm{KA}_{\mathrm{i}}$ & $\begin{array}{l}\text { Kapitalanteil des größten Aktionärs an der Spitze der Konzernpy- } \\
\text { ramide }\end{array}$ \\
\hline $\mathrm{KAD}_{\mathrm{i}}$ & Kapitalanteil des i-ten direkt beteiligten Aktionärs \\
\hline $\begin{array}{l}\text { KAD25 } \\
(50,75)\end{array}$ & $\begin{array}{l}\text { Dummy-Variable für Aktionär mit einem Kapitalanteil > } 25 \% \\
(50 \%, 75 \%)\end{array}$ \\
\hline KV & Kontrollvariablen \\
\hline In & natürlicher Logarithmus \\
\hline
\end{tabular}




\begin{tabular}{|c|c|}
\hline LR & likelihood ratio \\
\hline $\mathbf{M}$ & Management \\
\hline Mach & Machinery \\
\hline MWBW & Marktwert/Buchwert-Verhältnis \\
\hline Ö & Öffentliche Hand \\
\hline ÖK & Kontrolle durch die öffentliche Hand \\
\hline $\mathrm{p}$ & $\begin{array}{l}\text { Anteil der Cash Flows, die dem kontrollierenden Aktionär aus } \\
\text { private benefits zufließen }\end{array}$ \\
\hline $\mathrm{PhHe}$ & Pharma \& Health Care \\
\hline p-Wert & $\begin{array}{l}\text { Wahrscheinlichkeit, einen beobachteten Prüfgrößenwert oder ei- } \\
\text { nen in Richtung der Alternative extremeren Wert zu erhalten (Irr- } \\
\text { tumswahrscheinlichkeit) }\end{array}$ \\
\hline PY & Pyramiden-Dummy \\
\hline $\mathrm{r}^{2}$ & lineares Bestimmtheitsmaß \\
\hline $\mathrm{RES}_{\mathrm{t}}$ & Variable gebildet aus dem Residuum der Schätzung für Periode $t$ \\
\hline Ret & Retail \\
\hline $\mathbf{s}$ & Anteil des Aktionärs an den Stimmrechten der Gesellschaft \\
\hline$s_{\hat{\beta}_{j}}$ & Standardfehler des Regressionskoeffizienten des j-ten Regressors \\
\hline $\mathrm{SKAD}_{\mathrm{i}}$ & $\begin{array}{l}\text { Summe der Kapitalanteile der i größten direkt beteiligten Aktionä- } \\
\text { re }\end{array}$ \\
\hline SoTeMe & Software, Telecommunication, Media \\
\hline SStA4 & Summe der Stimmrechtsanteile der vier größten Aktionäre \\
\hline $\mathrm{StA}_{\mathrm{i}}$ & Durch die Pyramidenmutter kontrollierter Stimmrechtsanteil \\
\hline $\begin{array}{l}\text { StAD25 } \\
(50,75)\end{array}$ & $\begin{array}{l}\text { Dummy Variable für Aktionär mit einem Stimmrechtsanteil } \\
>25 \%(50 \%, 75 \%)\end{array}$ \\
\hline $\mathrm{t}$ & Wert der t-Statistik, Laufindex für Zeitpunkte \\
\hline $\mathrm{T}$ & Anzahl Zeitpunkte \\
\hline Tech & Technology \\
\hline$u_{i}$ & Wert der Störvariablen (Residuum) des Objekts i \\
\hline $\mathrm{U}$ & Nutzen des kontrollierenden Aktionärs/logarithmierter Umsatz \\
\hline Util & Utilities \\
\hline VA & Vorzugsaktien-Dummy \\
\hline VG & Verschuldungsgrad \\
\hline W & Wachstum \\
\hline $\mathrm{x}_{\mathrm{ji}}$ & Wert der j-ten erklärenden Größe (Regressor) des Objekts i \\
\hline
\end{tabular}


X Datenmatrix

$\mathrm{y}_{\mathrm{i}} \quad$ Wert der zu erklärenden Größe (Regressand) des Objekts i 


\section{Abbildungsverzeichnis}

Abb. 1: Abgrenzung von Kapital- und Stimmrechtsanteil.................................

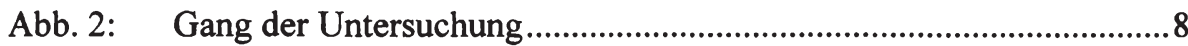

Abb. 3: Anzahl Aktiengesellschaften und Börsenkapitalisierung....................10

Abb. 4: Kompetenzen der Hauptversammlung .............................................17

Abb. 5: Kompetenzgefüge der Organe der Aktiengesellschaft.........................18

Abb. 6: Konkretisierung des aktienrechtlichen Aktionärsschutzes..................32

Abb. 7: Entwicklung des Aktienbesitzes in Deutschland ................................43

Abb. 8: Mitteilungs- und Veröffentlichungspflichten nach dem WpHG........53

Abb. 9: Corporate-Governance-System …………...........................................64

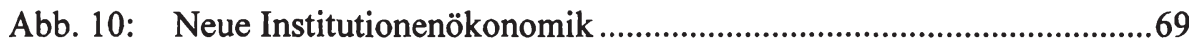

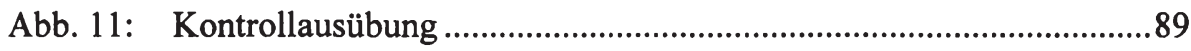

Abb. 12: Dimensionen von private benefits ................................................93

Abb. 13: Kontrollausübung unter Berücksichtigung von private benefits........94

Abb. 14: Kontrollausübung unter Berücksichtigung nichtlinearer private

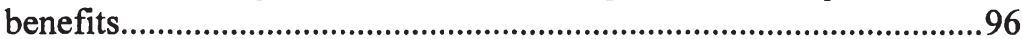

Abb. 15: Kontrollausübung unter Berücksichtigung abweichender

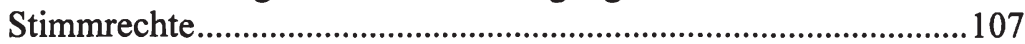

Abb. 16: Wirkung von Vorzugsaktien auf die Aktionärskontrolle ..................108

Abb. 17: Eigenkapitalpyramide am Beispiel der RWE AG...............................111

Abb. 18: Ausprägungen von Kapital- und Stimmrechtsstruktur...................... 115

Abb. 19: Modelle zur Anreizwirkung alternativer Kapital- und Stimm-

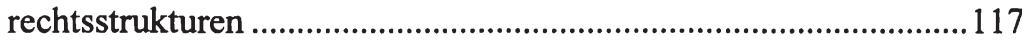

Abb. 20: Forschungsdesign bestehender Studien...........................................172

Abb. 21: Entscheidungsbaum Konzernpyramide............................................182

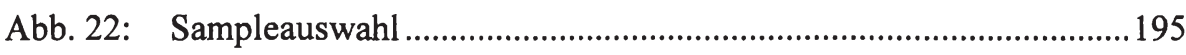

Abb. 23: Kapitalanteile des größten direkt beteiligten Anteilseigners

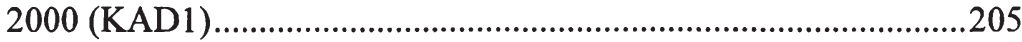

Abb. 24: Stimmrechtsanteile des größten Aktionärs nach Häufigkeiten ........208

Abb. 25: Stimmrechtsanteile des größten Anteilseigners 2000 (StA1) .........210

Abb. 26: Ebenen der Konzernpyramide .......................................................212

Abb. 27: Nichtlinearer Zusammenhang zwischen MWBW und StA1 ..........232 


\section{Abbildungen im Anhang:}

Abb. A 1: Kerndichteschätzer und Normal-Quantil-Plot (Modell 1b)

.313 


\section{Tabellenverzeichnis}

Tab. 1: Minderheitenrechte in Abhängigkeit alternativer Kapitalanteile.......36

Tab. 2: Aktionärsstruktur in ausgewählten Industrieländern, Stand 1995 ....44

Tab. 3: Angaben zur Aktionärsstruktur .........................................................56

Tab. 4: Freiwillige Angaben zur Aktionärsstruktur.........................................58

Tab. 5: Kontrolldefinitionen im deutschen Recht ........................................62

Tab. 6: Anreizstrukturen alternativer Großaktionärstypen............................104

Tab. 7: Internationale Aktionärsstruktur-Performance-Studien: Vergleichsstudien ............................................................................134

Tab. 8: Internationale Aktionärsstruktur-Performance-Studien:

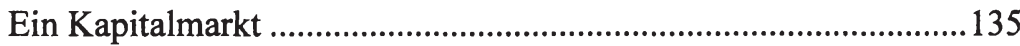

Tab. 9: Deskriptive Studien zur Aktionärsstruktur in Deutschland .............140

Tab. 10: Regressionsvoraussetzungen ............................................................. 154

Tab. 11: Variablen zur Eigentümer- und Stimmrechtsstruktur ........................ 186

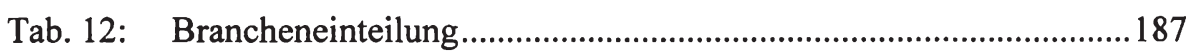

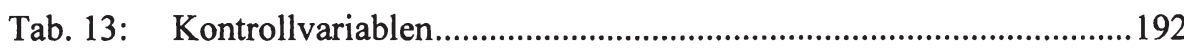

Tab. 14: Allgemeine Unternehmenscharakteristika der Sampleunternehmen, 2000 ...................................................................................201

Tab. 15: Branchenverteilung der Sampleunternehmen in Prozent..................202

Tab. 16: Kapitalstruktur der Sampleunternehmen..........................................203

Tab. 17: Kapitalstruktur der Sampleunternehmen (kumuliert) ......................204

Tab. 18: Herfindahl-Index der Kapitalanteile (KAD) .....................................204

Tab. 19: Identität des größten Anteilseigners, 2000 (KA1) .............................205

Tab. 20: Stimmrechtsstruktur der Sampleunternehmen ...................................207

Tab. 21: StA1 in bisherigen empirischen Studien ...........................................207

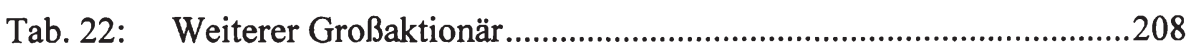

Tab. 23: Anzahl Großaktionäre ………………….....................................209

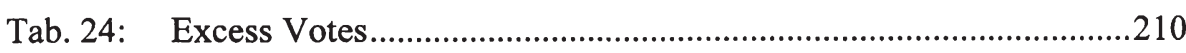

Tab. 25: Divergenzen zwischen Kapital- und Stimmrechtsanteilen ..............211

Tab. 26: Vorzugsaktien und Pyramiden nach Identität des größten Aktionärs 
Tab. 27: Kapital- und Stimmrechtsanteile nach Identität des größten Aktionärs .215

Tab. 28: Divergenzen zwischen Kapital- und Stimmrechtsanteilen nach Identität des größten Aktionärs (Excess Votes)

Tab. 29: Kapital- und Stimmrechtsanteile nach Indexzugehörigkeit .............217

Tab. 30: Vorzugsaktien und Pyramiden nach Indexzugehörigkeit ................218

Tab. 31: Divergenzen zwischen Kapital- und Stimmrechtsanteilen nach Indexzugehörigkeit (Excess Votes)..............................................218

Tab. 32: Rentabilität nach Eigentümerstrukturkriterien................................221

Tab. 33: Rentabilität nach Identität des Großaktionärs .................................223

Tab. 34: Univariate Regressionsanalyse ....................................................226

Tab. 35: Regressionsergebnisse Modell 1a ....................................................228

Tab. 36: Regressionsergebnisse Modell 1b ..................................................231

Tab. 37: Regressionsergebnisse Modell 1d und Modell 1e.............................237

Tab. 38: Regressionsergebnisse Modell 1f....................................................239

Tab. 39: Ergebnisse der Einzelschätzungen 1997-2000, Modell 2 ................240

Tab. 40: Regressionsergebnisse Modell 3b ...............................................242

Tab. 41: Regressionsergebnisse Modell 4 ...................................................246

Tab. 42: Regressionsergebnisse Modell 5b ..................................................250

Tab. 43: Granger Kausalitätstest.................................................................251

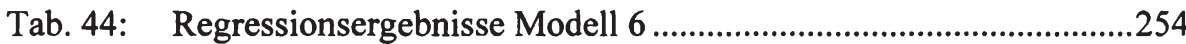

Tab. 45: Regressionsergebnisse Modell 7a ..................................................256

Tab. 46: Regressionsergebnisse Modell 8a - Variante I ..................................260

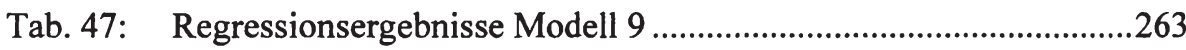

Tab. 48: Regressionsergebnisse Modell 10a .................................................264

Tab. 49: Regressionsergebnisse Modell 10b …………..................................266

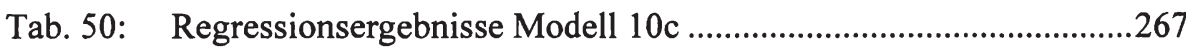

Tab. 51: Zusammenfassung der Hypothesen und Ergebnisse .........................271

\section{Tabellen im Anhang:}

Tab. A 1: Allgemeine Unternehmenscharakteristika der Sampleunternehmen, 1999 
Tab. A 2: Allgemeine Unternehmenscharakteristika der Sampleunternehmen, 1998 .305

Tab. A 3: Allgemeine Unternehmenscharakteristika der Sampleunternehmen, 1997 .306

Tab. A 4: Herfindahl-Index der Stimmrechtsanteile (StA) 306

Tab. A 5 Probit Regression - Nutzung von Vorzugsaktien nach Identität .307

Tab. A 6: Probit Regression - Nutzung von Pyramiden nach Identität ...........307

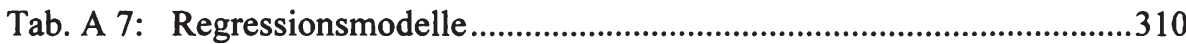

Tab. A 8: RESET-Test (MWBW und StA1) ................................................311

Tab. A 9: Regressionsergebnisse Modell 1c ......................................................311

Tab. A 10: White-Test (Modell 1b).................................................................312

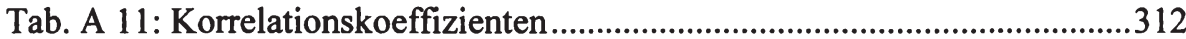

Tab. A 12: Überprüfung der Normalverteilungsannahme (Modell 1b) .............313

Tab. A 13: Regressionsergebnisse Modell 3b, MWBW nur auf Basis

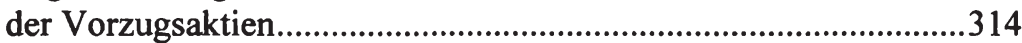

Tab. A 14: Regressionsergebnisse Modell 3a .....................................................315

Tab. A 15: Breusch-Godfrey-Test (Modell 3b)...............................................316

Tab. A 16: White-Test (Modell 3b)................................................................317

Tab. A 17: Regressionsergebnisse Modell 3c …................................................

Tab. A 18: Regressionsergebnisse Modell 3d und Modell 3e.............................318

Tab. A 19: Regressionsergebnisse Modell 5a ................................................319

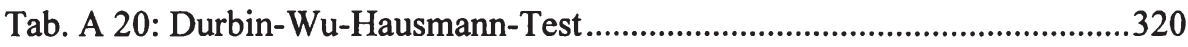

Tab. A 21: Regressionsergebnisse Modell 7b …………......................................321

Tab. A 22: Regressionsergebnisse Modell 7c .....................................................321

Tab. A 23: Regressionsergebnisse Modell 7d ......................................................322

Tab. A 24: Regressionsergebnisse Modell 7e ……………..............................322

Tab. A 25: Regressionsergebnisse Modell 8a - Variante II.................................323

Tab. A 26: Regressionsergebnisse Modell 8b ……………….............................323 
Franca Ruhwedel - 978-3-631-75497-9 


\section{Einführung}

\section{Problemstellung und Ziel der Arbeit}

Während die optimale Ausgestaltung des Verhältnisses zwischen Eigen- und Fremdkapital bereits seit langem Gegenstand der Diskussion in Forschung und Praxis ist, ${ }^{1}$ rückt die Gestaltung der Eigentümerstruktur erst in den letzten Jahren zunehmend in den Mittelpunkt des Interesses. Zwar formuliert Kretschmann bereits 1976 ,Das Interesse einer Unternehmung, ihre Aktionäre nach ihren sozialen Merkmalen [...] zu kennen, erklärt sich aus ihrer Funktion, den Nutzen ihrer Aktionäre zu optimieren," ${ }^{\prime 2}$ erst im Zuge der Corporate-Governance-Diskussion der letzten Jahre wird jedoch unternehmensseitig vermehrt das Potenzial erkannt, das die kapitalmarktorientierte Ausgestaltung von Leitung und Kontrolle des Unternehmens birgt: ${ }^{3}$ Knapp $80 \%$ der im Rahmen einer Studie befragten institutionellen Investoren halten eine höhere Bewertung von Unternehmen mit einer funktionsfähigen Corporate Governance für gerechtfertigt; ${ }^{4}$ empirisch lassen sich niedrigere Kapitalkosten nachweisen. ${ }^{5}$ Die Eigentümerstruktur ist zentraler Bestandteil des Kontrollsystems des Unternehmens und somit zentrales Element der Corporate Governance, die im Rahmen dieser Arbeit als die Ausgestaltung von Leitung und Kontrolle des Unternehmens verstanden wird.

In der Vergangenheit bestand innerhalb deutscher Aktiengesellschaften häufig Unkenntnis über die Identität der eigenen Aktionäre. Erst durch die rasche Verbreitung von Namensaktien seit der Umsetzung des NaStraG in 2001 sowie verschärfter Meldepflichten im Zuge der WpHG-Kodifizierung herrscht in vielen Unternehmen ${ }^{6}$ erstmals Transparenz über die Zusammensetzung ihrer Akti-

$1 \quad$ Vgl. Modigliani/Miller (1958, 1963); Jensen/Meckling (1976); Myers/Majluf (1984); Zwiebel (1996), einen Überblick gibt Noth (1996), S. 176-179.

2 Kretschmann (1976), S. 4.

3 Vgl. Gierl/Praxmarer (2001). Für eine Abgrenzung von Corporate Governance vgl. insb. Shleifer/Vishny (1997), sowie Turnbull (1997), S. 181-184; Schneider (2000a), S. 2413f; Böckli (2000), S. 133f.; Salzberger (2000), S. 210f.; Becht et al. (2002).

4 Konkret besteht die Bereitschaft, für deutsche Unternehmen mit guter Corporate Governance einen durchschnittlich $13 \%$ höheren Aktienkurs zu akzeptieren. Befragt wurden 200 institutionelle Investoren aus 30 Ländern. Vgl. McKinsey \& Co. (2002), S. 3f.

5 Vgl. jüngst die Studien von Drobetz/Schillhofer (2003), bzw. Drobetz et al. (2003) und Gompers et al. (2003).

6 Im Mittelpunkt der Analyse steht die Rechtsform der Aktiengesellschaft. Die Begriffe „Unternehmen“" und „Gesellschaft" werden daher im Rahmen dieser Arbeit grundsätzlich synonym zum Begriff „Aktiengesellschaft“ verwendet. 
onärsstruktur. ${ }^{7}$ Verbesserte Publizitätsvorschriften sowie freiwillige Angaben der Unternehmen führen dazu, dass auch die Kapitalmarktteilnehmer von der zunehmenden Transparenz profitieren können. ${ }^{8}$

Der deutsche Kapitalmarkt ist seit jeher - insbesondere auch im internationalen Vergleich - geprägt durch die Dominanz von Großaktionären, Verflechtungen großer Konzerne untereinander und einen geringen Streubesitzanteil. ${ }^{9}$ Unter dem

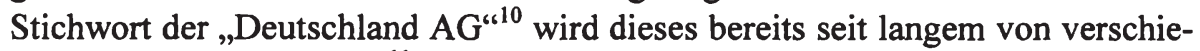
densten Seiten kritisiert; ${ }^{11}$ ein Bedeutungsgewinn von Kleinaktionären wird nicht erst seit dem Börsengang der Deutschen Telekom AG politisch gewünscht. ${ }^{12}$ Dabei gilt jedoch, dass die Wirkung von Großaktionären auf den Unternehmenswert bisher weder theoretisch noch empirisch eindeutig erklärt ist die geführte Diskussion somit einer wissenschaftlichen Fundierung über weite Strecken entbehrt.

Im Wesentlichen werden zwei konträre Argumente vorgebracht, die für bzw. gegen einen Großaktionär sprechen: ${ }^{13}$ So gilt zum einen, dass ein Großaktionär aufgrund seines großen finanziellen Engagements einen besonderen Anreiz hat, das Management zu kontrollieren und somit grundsätzlich in der Lage ist, Unternehmenswertminderungen aufgrund einer Eigennutzorientierung der Organmitglieder zu verhindern. Der Großaktionär unterliegt nicht der so genannten „rationalen Apathie“, die kleinere Aktionäre von der Ausübung der Aktionärs-

7 Vgl. zu mangelnder Transparenz bereits kritisch Berndsen (1959), S. 417. Zum Bedeutungsgewinn der Namensaktien Huep (2000), S. 1623; Grunmann/Soehlke (2001), S. 576; Merkt (2000), S. 86-90; Goedsche (2002). Zu den Publizitätsvorschriften des WpHG vgl. Becht (1997), S. 56-60, 114-117; Witt (1998); Schneider (1999).

8 Seit dem Jahr 2000 haben Aktiengesellschaften nach $\S 160$ Abs. 1 S. 8 AktG die in Beachtung der Regelungen des WpHG gemachten Angaben im Anhang anzugeben. Die Änderung erfolgte mit dem KapCoRiLiG. Vgl. Schneider (1999), Rn. 37-69.

9 Vgl. die internationalen Vergleichsstudien von Becht/Röell (1999); La Porta et al. (1998, 1999); Gugler (2001); Barca/Becht (2001), zu Verflechtungen in Deutschland Aleff/Ste$\operatorname{den}(2001)$.

10 Der Begriff der Deutschland AG wurde maßgeblich geprägt durch Adams (1994). Vgl. auch Wenger (1997), S. 255, sowie jüngst Beyer (2002).

11 Die überwiegend kritische Sichtweise teilen Wissenschaftler und Aktionärsschützer ebenso wie Teile der involvierten Manager selbst. Vgl. etwa Adams (1994); Söhler (2001); Beyer (2002).

12 Bereits im Jahre 1958 wurde im Deutschen Bundestag durch den Wirtschaftsminister die mangelnde Kenntnis über Aktionärsstrukturen und Streubesitzanteile beklagt. Vgl. Berndsen (1959), S. 418.

13 Vgl. für einen Überblick alternativer Sichtweisen von Kapitalbündelungen bei Großaktionären Shleifer/Vishny (1997), die zudem eine Einordnung in den Gesamtzusammenhang der Corporate Governance vornehmen. 
kontrolle abhält: ${ }^{14}$ Bei konstanten Kosten einer Kontrollausübung steht der daraus resultierende Nutzen in Form von steigenden Dividenden und Kursen für Aktionäre mit kleineren Kapitalanteilen in keinem angemessenen Verhältnis. Dieser Vorteil von Kapitalbündelungen bei Großaktionären wird insbesondere im angelsächsischen Raum hervorgehoben, wo die öffentliche Wahrnehmung positiver geprägt ist als in Deutschland: „Large shareholders thus address the agency problem in that they both have a general interest in profit maximization, and enough control over the assets of the firm to have their interests respected $^{\text {"15. }}$. Roe formuliert im Hinblick auf den Einfluss von Kreditinstituten in Deutschland: „bankers' experience and networks make them valuable ${ }^{\text {(16 }}$.

In Deutschland dominiert hingegen eine eher negative Wahrnehmung von Unternehmensnetzwerken, Großaktionären und deren Entsendung in den Aufsichtsrat: „Das schier undurchdringliche Geflecht von Beteiligungen und Überkreuzbeteiligungen [...] hemmt die Innovationsfähigkeit der deutschen Wirtschaft ${ }^{\text {"17 }}$; es läge ein „Kontrollprinzip der Vetternwirtschaft ${ }^{\text {“18 }}$ vor. Aktionäre mit größeren Kapitalblöcken können ihr Einflusspotenzial nicht nur zur Ausübung von Kontrolle, sondern darüber hinaus auch zur Realisierung privater Vorteile und damit zu Lasten der anderen Aktionäre nutzen. ${ }^{19}$ Wie Erhardt/Nowak formulieren: „Germany, for a long time the paradise world of private benefits ${ }^{\text { } 20}$. Als Beispiel sei der Abschluss von nicht marktgerechten Lieferantenverträgen mit dem Großaktionär genannt, oder etwa - für den Fall, dass der Großaktionär ein Kreditinstitut ist - die Beeinflussung des Managements in Richtung einer risikoaversen Investitionspolitik, um das eigene Kreditengagement abzusichern. Ein Problembewusstsein lassen die handelnden Akteure häufig vermissen, wie folgendes Zitat von Klaus-Peter Müller, Vorstandsvorsitzender der Commerzbank AG verdeutlicht: „Die delegierten Vertreter im Aufsichtsrat [...] üben zwar Einfluss aus, aber stets aus wohlverstandenem Eigeninteresse in konstruktiver

14 Vgl. zum Free-Rider-Problem in Publikumsaktiengesellschaften grundlegend Grossman/Hart (1980).

15 Shleifer/Vishny (1997), S. 754. Vgl. auch die Beiträge in dem Sammelband von Baums (1993) zu „Institutional Investors and Corporate Governance“, sowie mit weiteren Beispielen Becht/Böhmer (2003), S. 30.

16 Roe (1994), S. 175, ähnlich Hallett (1990), S. 83. Vgl. mit zahlreichen Zitaten auch Edwards/Fischer (1994), S. 1-7.

17 Heinemann/Gröninger/Augat (2001), S. 13.

18 Gerke (2002), S. 1.

19 Vgl. Barclay/Holderness (1989), S. 372; Harris/Raviv (1989), S. 256; Bebchuk (1999), S. 28; Shleifer/Vishny (1997), S. 758; Ang/Cole/Lin (2000), S. 81; Dyck/Zingales (2002), S. 6-8.

20 Ehrhardt/Nowak (2002), S. 23. 
Form.“21 Gerade dieses Eigeninteresse des Großaktionärs kann jedoch aus Sicht aller Aktionäre problematisch sein, sofern keine Interessenkonvergenz besteht.

Die Diskussion um die Vor- und Nachteile alternativer Eigenkapitalstrukturen greift jedoch zu kurz, wenn nicht zusätzlich zur Kapital- auch die Stimmrechtsstruktur betrachtet wird. ${ }^{22}$ Stimmrechte an einer Gesellschaft gehen nicht notwendigerweise in gleichem Maße mit den Cash-Flow-Rechten aus der Kapitalbeteiligung einher. Die Cash-Flow- bzw. Vermögensrechte umfassen alle finanziellen Leistungen aus der Aktie, wie z.B. Dividenden, Bezugsrechte und Liquidationserlös. ${ }^{23}$ Sie korrespondieren in der Regel mit dem gehaltenen Kapitalanteil. Abweichungen zum Stimmrechtsanteil können sich z.B. durch die Emission von stimmrechtslosen Vorzugsaktien ergeben. Gleiches gilt auch im Fall von Eigenkapitalpyramiden, mittels derer der Mehrheitsaktionär des Mutterunternehmens die Stimmrechtsmehrheit auch in den mehrheitlich gehaltenen Tochterunternehmen hält, ohne dort unmittelbar eigenes Kapital zu investieren. ${ }^{24}$ Die für diese Arbeit zentrale Differenzierung zwischen Stimm- und Cash-FlowRecht gibt die folgende Abb. 1 wieder:

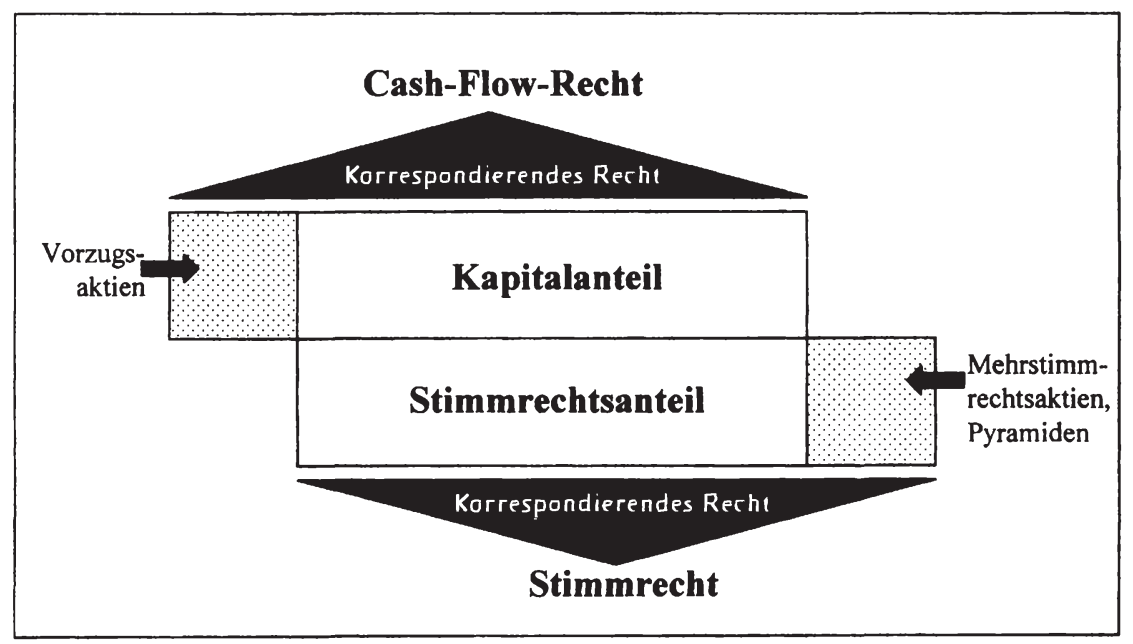

Abb. 1: Abgrenzung von Kapital- und Stimmrechtsanteil

21 Müller (2002), S. 510.

22 Kapitalstruktur wird im Folgenden synonym mit Eigenkapitalstruktur gebraucht, Kapitalanteil wird grundsätzlich mit Eigenkapitalanteil gleichgesetzt.

23 Die Begriffe Cash-Flow-Recht und Vermögensrecht werden im Folgenden synonym verwandt.

24 Vgl. zu den verschiedenen Instrumenten zur Schaffung abweichender Stimm- und CashFlow-Rechte insb. die Beiträge von Bianchi/Bianco/Enriques (2001); Bebchuk/Kraakman/Triantis (2000); Claessens et al. (2000); Cronqvist/Nilsson (2002), zur Wirkung von Konzernpyramiden auch Pellens (1994), S. 162-167. 
Abweichende Stimm- und Cash-Flow-Rechte bergen stärker als One-ShareOne-Vote-Strukturen die Gefahr der privaten Vorteilsnahme des kontrollierenden Aktionärs, da seine Anreize zur Ausübung von Kontrolle aufgrund des geringeren Kapitalanteils begrenzt sind.

Aus diesem Kontext heraus wurden immer wieder verschiedene Regulierungsbestrebungen unternommen und teilweise umgesetzt. Vorzugsaktien sind in einzelnen Börsensegmenten nicht mehr zulässig ${ }^{25}$ bzw. werden durch neue Regelungen zur Indexzusammensetzung sanktioniert, ${ }^{26}$ die Entflechtung von Beteiligungsnetzwerken wird durch die Steuerfreiheit von Veräußerungsgewinnen stimuliert, ${ }^{27}$ private Kleinanleger werden durch steuerliche Regelungen zum Aktienkauf angehalten ${ }^{28}$ und bei der Europäischen Union denkt man derzeit über eine Sanktionierung von Konzernpyramiden nach. ${ }^{29}$ Fraglich ist jedoch, ob Stimmrechtsbündelungen bei Großaktionären tatsächlich einen negativen Einfluss auf den Unternehmenserfolg ausüben oder ob sie die Corporate Governance - zumindest unter den in Deutschland gegebenen Rahmenbedingungen unterstützen.

Da diese Frage aus wissenschaftlicher Sicht bisher weitgehend ungeklärt ist, ist die Zielsetzung der vorliegenden Arbeit die umfassende Analyse der Wirkung alternativer Eigentümer- und Stimmrechtsstrukturen unter besonderer Berücksichtigung der Rahmenbedingungen am deutschen Kapitalmarkt.

\section{Aufbau der Untersuchung}

Die Arbeit ist unterteilt in einen theoretischen und einen empirischen Teil. Ziel der theoretischen Analyse ist es, die Beziehung zwischen verschiedenen Aktionärsgruppen erstmals umfassend in einen theoretischen Bezugsrahmen einzuordnen. Dabei sollen Effizienzaussagen über alternative Eigentümer- und Stimmrechtsstrukturen aus theoretischer Sicht abgeleitet werden, um sie anschließend empirisch zu testen. Dazu erfolgt im Anschluss an die Schilderung

25 Vgl. Deutsche Börse AG (2000), S. 6.

26 Vgl. Hoffknecht (2001), S. 24; Schnell (2002), S. 11.

27 Vgl. Uhlmann (2000), S. 2; Hillebrandt (2001), S. 711f.; Wenger (2000), S. 177; van Lieshaut (2000), S. 191.

28 Vgl. zu den Neuerungen des dritten bzw. vierten Finanzmarktförderungsgesetz Weisgerber (1998); Rudolph (2002); Kugler/Rittler (2002).

29 So heißt es im Konsultationspapier der EU-Expertengruppe zum Gesellschaftsrecht: „Pyramidenstrukturen werfen spezifische Probleme auf. Sie führen insofern zu „AgencyKosten", als durch sie die privaten Vorteile der Kontrolle und Interessenkonflikte ansteigen, und können daher zu Lasten der Minderheitsaktionäre gehen.“ Vgl. Expertengruppe Europäisches Gesellschaftsrecht (2002), S. 35, erläuternd Wiesner (2003). 
des Untersuchungsaufbaus in Kapitel II zunächst eine Abgrenzung der Rolle der Aktionäre in der Aktiengesellschaft aus einer primär juristischen Sichtweise. Die präzise Analyse der rechtlichen Möglichkeiten und Pflichten erlaubt in der folgenden Untersuchung die Einschätzung diskretionärer Handlungsspielräume und zeigt Ansatzpunkte für einzelne Aktionäre, private Vorteile zu realisieren. Darauf aufbauend sollen verschiedene Aktionärstypen charakterisiert und ein kurzer Überblick über ihre Bedeutung in Deutschland gegeben werden. Kapitel II schließt mit einem Überblick über die verschiedenen Publizitätspflichten zur Aktionärsstruktur und einer empirischen Erhebung der Publizität zur Aktionärsstruktur in Geschäftsberichten.

In Kapitel III wird die Kontrollfunktion von Aktionären einer ökonomischen Analyse unterzogen. Als Methodik zur Ableitung von theoretischen Aussagen über die Vor- und Nachteile von Kapital- bzw. Stimmrechtsblöcken soll die mikroökonomische Gleichgewichtsanalyse der Principal-Agent-Theorie herangezogen werden, deren Übertragbarkeit auf das vorliegende Problemfeld zunächst kritisch zu überprüfen sein wird. Dabei ist es Ziel, die Bedeutung der unterschiedlichen Konfliktebenen innerhalb einer Aktiengesellschaft - Management/Aktionäre versus verschiedene Aktionärsgruppen untereinander - speziell am deutschen Kapitalmarkt herauszuarbeiten und verschiedene Theorieansätze zur Wirkung von Großaktionären zu systematisieren, gegebenenfalls unter Berücksichtigung deutscher Besonderheiten zu ergänzen und kritisch zu würdigen.

Dazu soll zunächst die Aktionärskontrolle abgegrenzt und in das Gesamtsystem der Corporate Governance eingeordnet werden. Anschließend wird ein Überblick über die aus einer Verfügungsrechtsdelegation resultierenden AgencyKonflikte zwischen Management und Anteilseignern sowie potenzielle Lösungsmechanismen neben der unmittelbaren Aktionärskontrolle gegeben. Darauf aufbauend werden die Auswirkungen alternativer Eigentümer- und Stimmrechtsstrukturen auf die Aktionärskontrolle in zwei Schritten analysiert. $\mathrm{Zu}$ nächst wird der Fall kongruenter Stimm- und Cash-Flow-Rechte betrachtet und die verschiedenen, teilweise konträren Hypothesen zum Einfluss von Kapitalbündelungen werden vorgestellt. Anschließend wird der Sonderfall überproportionaler Stimmrechte betrachtet und seine Wirkung theoretisch analysiert. Der daran anschließende Abschnitt ist den formalen Modellen gewidmet, die die Beziehung zwischen verschiedenen Aktionärsgruppen abgebildet haben. Neben einem Überblick über verschiedene bestehende Arbeiten wird ein Beispielmodell für einen im Rahmen dieser Arbeit relevanten Sachverhalt entwickelt.

Aufbauend auf den Ergebnissen des theoretischen Teils werden anschließend Hypothesen für die empirische Untersuchung formuliert. In die Hypothesenbildung fließen die Ergebnisse der theoretischen Analyse ebenso ein wie die Er- 
gebnisse anderer empirischer Studien, wobei hier die Besonderheiten des deutschen Kapitalmarkts zu berücksichtigen sein werden.

Ziel der empirischen Analyse in Kapitel IV ist die Erhebung des Status Quo der Aktionärs- und Stimmrechtsstrukturen in deutschen Aktiengesellschaften, um darauf aufbauend die im theoretischen Teil abgeleiteten Hypothesen über die Auswirkungen von Kapital- bzw. Stimmrechtsbündelungen für den deutschen Kapitalmarkt zu überprüfen. Dazu wird zunächst ein Überblick über den Stand der empirischen Forschung auf dem Gebiet der Eigentümer- und Stimmrechtsstrukturen gegeben und die relevanten ökonometrischen Verfahren werden vorgestellt. Die empirischen Ergebnisse umfassen zunächst eine deskriptive Analyse der Eigentümer- und Stimmrechtsstrukturen der 238 Sampleunternehmen während des Untersuchungszeitraums von 1997 - 2000. Darüber hinaus wird der Zusammenhang zwischen den Eigentümer- bzw. Stimmrechtsstrukturen und dem Unternehmenserfolg mittels verschiedener ökonometrischer Methoden analysiert. Im Rahmen der Untersuchungen kommen verschiedene Verfahren der multivariaten Regressionsanalyse zum Einsatz, die den besonderen Problemen von Eigentümerstrukturstudien Rechnung tragen. Die Untersuchungsergebnisse werden verschiedenen Stabilitätstests unterzogen.

In Kapitel V werden abschließend die wesentlichen Untersuchungsergebnisse zunächst thesenförmig zusammengefasst. Darüber hinaus wird ein Ausblick gegeben und mögliche rechtspolitische Schlussfolgerungen, die sich aus den Untersuchungsergebnissen ergeben, werden diskutiert.

Die folgende Abb. 2 fasst den Gang der Untersuchung zusammen: 


\section{Kapitel I: Einführung}
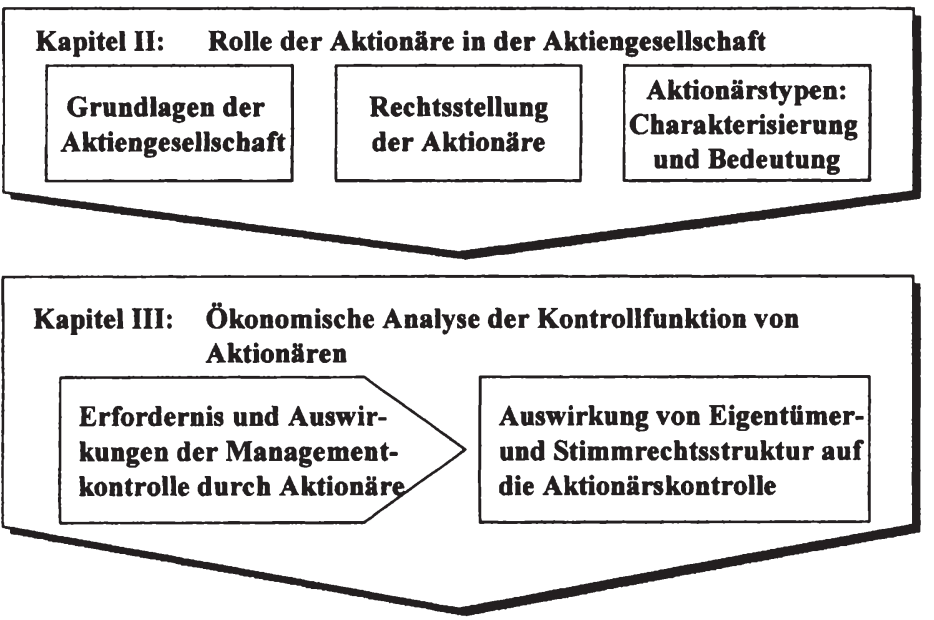

Kapitel IV: Empirische Untersuchung zum Zusammenhang zwischen Eigentümer- bzw. Stimmrechtsstruktur und Unternehmenserfolg

Stand der Forschung und ökonometrische Grundlagen

Deskriptive Analyse der Eigentümer- u. Stimmrechtsstrukturen

\begin{tabular}{|l|l|}
\hline $\begin{array}{l}\text { Überprüfung } \\
\text { alternativer } \\
\text { Testverfahren } \\
\text { auf Eignung }\end{array}$ & \multicolumn{1}{|c|}{ Value Relevance Study: } \\
\hline $\begin{array}{c}\text { Eigentümer- } \\
\text { und Stimmrechts- } \\
\text { strukturen }\end{array}$ & $\begin{array}{c}\text { Unterneh- } \\
\text { menserfolg }\end{array}$ \\
\hline
\end{tabular}

Kapitel V: Zusammenfassung der Ergebnisse und Ausblick

Abb. 2: Gang der Untersuchung

Die vorliegende Arbeit soll damit einen Beitrag zur positiven CorporateGovernance-Forschung liefern, deren Ziel die Erklärung der Zusammenhänge zwischen einzelnen Elementen des Corporate-Governance-Systems sowie insbesondere des Zusammenhangs zwischen Unternehmenskontrolle und Performance ist. ${ }^{30}$ Dieses Ziel soll sowohl im Rahmen der theoretischen als auch der empirischen Analyse verfolgt werden, um so einen Beitrag zum Verständnis der diesbezüglichen Zusammenhänge am deutschen Kapitalmarkt zu leisten.

30

Vgl. Jensen (1993), S. 873. 


\section{Rolle der Aktionäre in der Aktiengesellschaft}

Zielsetzung des zweiten Kapitels ist die Klärung wesentlicher Grundbegriffe. Rechte und Pflichten des Aktionärs im Verhältnis zu den anderen Organen sollen aufgezeigt werden, um in der späteren Analyse identifizieren zu können, an welcher Stelle etwa ein Machtmissbrauch durch Großaktionäre vorliegen könnte. Neben der Charakterisierung der verschiedenen Aktionärstypen in Kapitel II.3 wird darüber hinaus ein Überblick über die Transparenzvorschriften zur Aktionärsstruktur gegeben. Im Folgenden soll zunächst kurz auf die Rechtsform der Aktiengesellschaft eingegangen werden.

\section{Grundlagen der Aktiengesellschaft}

\subsection{Charakterisierung und Bedeutung}

Die Rechtsform der Aktiengesellschaft wird geregelt durch das AktG von 1965. ${ }^{31}$ Sie ermöglicht die Bündelung verschiedenster Anleger und Anlagebeträge bei einem auf die Einlage begrenzten Risiko. ${ }^{32}$ Ein unternehmerisches Engagement für den Einzelnen ist auch ohne spezifisches Know-how möglich, da die Unternehmensführung auf ein angestelltes Management übertragen wird. ${ }^{33}$ Aktiengesellschaften verfolgen als Unternehmen Formal- und Sachziele, wobei das ökonomische Formalziel sich bei der Aktiengesellschaft in der Marktwertsteigerung konkretisiert. ${ }^{34}$

Die Aktiengesellschaft ist in Deutschland traditionell die Rechtsform insbesondere für große Unternehmen mit erheblichem Finanzierungsbedarf. Ende Juli 2002 gab es in Deutschland 14.409 Aktiengesellschaften. ${ }^{35}$ Im Vergleich zur Gesellschaft mit beschränkter Haftung, von der Ende 1999534.528 in Deutschland registriert waren, ist die Bedeutung der Aktiengesellschaft damit noch eher

31 Die folgenden Ausführungen zu Aktiengesellschaften und zur Rechtsstellung der Aktionäre betreffen im Wesentlichen auch Kommanditgesellschaften auf Aktien (KGaA), auf die hier nicht im Detail eingegangen werden soll. Vgl. zu den Besonderheiten Raiser (2001), S. 359-392; Heße/Enders (2001), S. 235; Jansch (1999), S. 54-56, sowie ausführlich Decker (1994); Grafmüller (1994); Ammenwerth (1997).

32 Vgl. Busse von Colbe/Pellens (1998), S. 19; Heße/Enders (2001), S. 211.

33 Vgl. Jansch (1999), S. 21; Renner (1999), S. 1f.; Ruhwedel (2002), S. 30.

34 Vgl. zu Zielsetzungen in Aktiengesellschaften Macharzina (1999), S. 155; Albach (2001); Lücke (2001); Ruhwedel (2002), S. 18-22.

35 Inklusive KGaA. Vgl. DAI (2002), S. 01-1. 
gering. ${ }^{36}$ Dennoch ist ein starker Bedeutungsgewinn der Rechtsform der Aktiengesellschaft nicht zu übersehen, seit 1997 hat sich ihre Anzahl mehr als verdreifacht. ${ }^{37}$ Das Grundkapital der deutschen Aktiengesellschaften und Kommanditgesellschaften auf Aktien belief sich per Juli 2002 auf 169 Mrd. Euro. ${ }^{38}$ Getrieben wird die jüngere Entwicklung insbesondere durch kleine und mittlere Unternehmen, die zunehmend bereits bei Gründung die Rechtsform der Aktiengesellschaft wählen, um mittelfristig den organisierten Kapitalmarkt als Finanzierungsquelle in Anspruch nehmen zu können. ${ }^{39}$

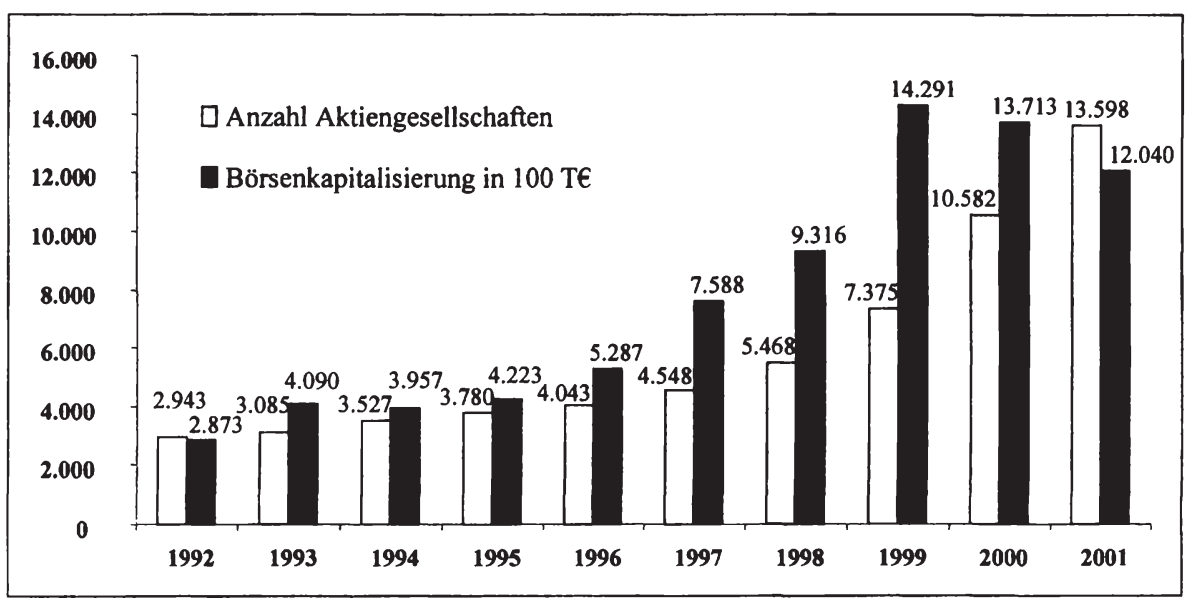

Abb. 3: Anzahl Aktiengesellschaften und Börsenkapitalisierung ${ }^{40}$

Aktiengesellschaften können nach verschiedenen Kriterien systematisiert werden. ${ }^{41}$ Für die hier vorliegende Untersuchung ist neben der Aktionärsstruktur insbesondere die Börsennotierung von Bedeutung. Der organisierte Kapitalmarkt wird in Deutschland im internationalen Vergleich erst in geringem Umfang genutzt; die Börsenkapitalisierung per Ende 2001 betrug lediglich 58,1 \% des Bruttoinlandsproduktes, die Marktkapitalisierung belief sich auf 1.204 Mrd.

36 Für GmbHs liegen keine aktuelleren Zahlen vor. Vgl. DAI (2002), S. 01-2. Einen Überblick über die Bedeutung der Rechtsformen im internationalen Vergleich gibt Wymeersch (1995), S. 300.

37 Von 4.548 auf 14.409, inklusive KGaA. Vgl. DAI (2002), S. 01-1.

38 Vgl. DAI (2002), S. 01-1.

39 Einen Durchbruch stellte hier das 1994 in Kraft getretene „Gesetz für kleine Aktiengesellschaften und zur Deregulierung des Aktienrechts" und insbesondere die Schaffung des inzwischen wieder abgeschafften Börsensegmentes „Neuer Markt“ in 1997 dar. Vgl. zur kleinen AG Lutter (1994); Rust/Ulbert (1995), zum Neuen Markt bspw. Hidding (2000); Riess/Altmann (2001); Bessler/Kurth/Thies (2001), S. 226.

40 Inklusive KGaA. Vgl. DAI (2002), S. 02-1, 05-1.

41 Vgl. Schmidt (2002), S. 771-775; Jansch (1999), S. 21-25; Ruhwedel (2002), S. 30. 
Euro. ${ }^{42}$ Die EU-Länder bringen es im Schnitt auf $86,1 \%$ des Bruttoinlandsproduktes, die USA sogar auf $136 \%{ }^{43}$ Die Zahl der inländischen börsennotierten Aktien ist indes von 1996 bis 2001 um 13,7\% auf 912 gestiegen; ein - wenn auch durch die Baisse der Jahre 2001 und 2002 gebremster - Aufwärtstrend ist somit unverkennbar. ${ }^{44} \mathrm{Da}$ im Rahmen dieser Untersuchung der an der Marktbewertung gemessene Unternehmenserfolg in Abhängigkeit von alternativen Aktionärs- und Stimmrechtsstrukturen untersucht werden soll, wird die Argumentation im Folgenden ausschließlich auf börsennotierte Gesellschaften abgestellt. Davon unbenommen besitzt die grundsätzliche Problematik einer optimalen Aktionärsstruktur jedoch auch für nicht börsennotierte Gesellschaften Relevanz.

Hinsichtlich der Aktionärsstruktur wird in der Literatur unterschieden zwischen Publikumsgesellschaften und Aktiengesellschaften, die über einen oder mehrere Großaktionäre verfügen, im englischen Sprachraum „closely held corporations “. ${ }^{45}$ Publikumsgesellschaften zeichnen sich durch eine große Anzahl Aktionäre aus; insbesondere verfügt kein Aktionär über ein Aktienpaket, das ihm einen wesentlichen Einfluss auf das Management ermöglicht. ${ }^{46}$ Große Aufmerksamkeit genießt diese Unternehmensform bereits seit der vielzitierten Veröffentlichung von Berle/Means (1932), die die Machtkonzentration beim Management als Folge des Streubesitzes konstatierten. ${ }^{47}$ Publikumsgesellschaften sind i.d.R. börsennotiert. Eine einheitliche oder gar gesetzlich kodifizierte Definition, ab welchem Streubesitzanteil eine Aktiengesellschaft als Publikumsgesellschaft zu klassifizieren ist, existiert nicht. Als möglicher Trennwert könnte z.B. ein Streubesitz von mehr als $25 \%$ angesetzt werden, der bei vollständiger Anwesenheit aller Aktionäre auf der Hauptversammlung eine Zustimmung zumindest eines Teils der Kleinaktionäre zu einer Satzungsänderung bedingen würde. ${ }^{48}$ Sofern jedoch etwa bei einem Streubesitzanteil von über $40 \%$ ein Mehrheitsaktionär vorhanden ist, erscheint eine Klassifizierung als Publikumsgesellschaft trotz des

Vgl. DAI (2002), S. 05-1, 05-3.

Vgl. DAI (2002), S. 05-3.

Vgl. DAI (2002), S. 02-1.

45 Für eine detailliertere Einteilung vgl. Schmidt (2001), S. 771-775. Da sich die verschiedenen Sonderformen jedoch in die hier getroffene Systematisierung eingliedern lassen, wird auf ihre Darstellung verzichtet.

46 Vgl. Jensen (1989), S. 64; Franke (1997), S. 57; Busse von Colbe/Pellens (1998), S. 587; Jansch (1999), S. 21f.; Renner (1999), S. 1; Ruhwedel (2002), S. 29f.

47 Weniger Aufmerksamkeit wurde den früher erschienenen Veröffentlichungen von Lippmann (1914); Veblen (1923); Carver (1925); Ripley (1927) und Wormser (1931) zuteil.

48 Ein Indiz könnte auch das Regelwerk des Neuen Marktes sein, das einen Mindeststreubesitz von grundsätzlich $25 \%$ für ein Listing vorsieht. Vgl. Regelwerk Neuer Markt, Punkt $3.10(1)$. 
hohen Streubesitzanteils nicht mehr gerechtfertigt, die Aktiengesellschaft ist vielmehr „closely held“. Im Ergebnis erscheint somit die Festlegung auf einen konkreten Trennwert wenig sinnvoll, vielmehr ist für jeden Einzelfall zu entscheiden, ob eine Publikumsgesellschaft vorliegt. ${ }^{49}$

\subsection{Historische Entwicklung}

Die Rechtsform der Aktiengesellschaft wurde nicht zu einem bestimmten Zeitpunkt künstlich geschaffen, vielmehr haben sich ihre Vorläufer aus Bedürfnissen der Marktteilnehmer heraus gebildet. ${ }^{50}$ Bereits im 15. Jahrhundert wurden in Genua und Mailand erste Gesellschaften gegründet, die durch Haftungsbeschränkung und Übertragbarkeit der Anteile gekennzeichnet waren. ${ }^{51}$ Im 17. Jahrhundert kam es in Teilen Europas zur Gründung so genannter „Handelskompagnien" zur Finanzierung des kolonialen Handels. ${ }^{52}$ Erste aktienrechtliche Regulierungen erfolgten mit dem Code de Commerce in Frankreich und dem Preußischen Gesetz über die Aktiengesellschaften von $1843 .{ }^{53}$ Eine umfassende Kodifizierung des Rechts der Aktiengesellschaft erfolgte erstmalig innerhalb des ADHGB von 1861. Dabei wurden auch die heute noch vorhandenen Organe kodifiziert. ${ }^{54}$ Weitere Präzisierungen des Rechts erfolgten mit den Aktienrechtsnovellen von 1870 und $1884 .{ }^{55}$ Von Bedeutung waren hier insbesondere die Einführung der Gründungsfreiheit und die nachhaltige Verbesserung der Rechtsstellung der Aktionäre durch Stärkung der Generalversammlung, sodass die Novelle von 1884 von Mülbert als „Geburtsstunde des modernen Aktienrechts" charakterisiert wird. ${ }^{56}$

49 In der Regel werden die großen, im DAX bzw. MDAX notierten Gesellschaften Publikumsgesellschaften sein, da für die Zugehörigkeit zum Index seit Juli 2002 die Höhe des Free Float entscheidet. Vgl. Luther (2002).

50 Vgl. Lehmann (1895), S. 5f.; Sombart (1917), S. 143; Schmidt (2002), S. 761. Für einen nach wirtschaftspolitischen Leitbildern systematisierten historischen Überblick des Rechts der Aktiengesellschaft vgl. Gassen (2000), S. 51-77; Hofmann (1998), S. 48-57.

51 Vgl. Juhnke (1995), S. 20f.; Schneider (2001), S. 86f; Schmidt (2002), S. 761. Noch weiter zurück geht Lehmann (1898), S. 5, der darauf hinweist, dass bereits das griechische Recht Kolonialgesellschaften auf Aktien kannte.

52 Vgl. Steinitzer (1908), S. 14-22; Juhnke (1995), S. 21f.; Schmidt (2002), S. 761, ausführlicher Raiser (2001), S. 3f.

53 Vgl. ausführlich Juhnke (1995), S. 23; Raiser (2001), S. 5.

54 Vgl. Vogel (1980), S. 20 f.; Assmann (1992), Rn. 71; Raiser (2001), S. 5. Einen Überblick über die zahlenmäßige Entwicklung der Aktiengesellschaften gibt Pross (1965), S. 45-50.

55 Vgl. Auerbach (1873) für einen Überblick über die Reform von 1870.

56 Mülbert (1996), S. 55, 59, sowie Vogel (1980), S. 21 f. 
Mit dem AktG 1937 wurde im 20. Jahrhundert das Recht der Aktiengesellschaft aus dem HBG herausgelöst. Die Reform war durch eine Begrenzung der Vertragsfreiheit sowie die Konkretisierung der Aufgaben der Organe mit einer Stärkung des Vorstandes gegenüber dem Aufsichtsrat gekennzeichnet. ${ }^{57}$ Mit dem heute noch gültigen AktG von 1965 wurde das Aktienrecht erneut an geänderte Rahmenbedingungen angepasst. Wesentliche Änderungen waren insbesondere eine Stärkung der Hauptversammlung gegenüber der Verwaltung i.V.m. verbessertem Individual- und Minderheitenschutz der Aktionäre, ein Ausbau der Informationspflichten des Vorstands und Änderungen im Bereich der Rechnungslegung sowie Neuregelungen für Konzerne. ${ }^{58}$ Die Individualrechte des Aktionärs wurden gestärkt, nachdem zuvor primär die Hauptversammlung Rechte wahrnehmen konnte. ${ }^{59}$

In den neunziger Jahren wurde das Aktienrecht - zunehmend geprägt nicht nur durch das Gesellschafts- sondern auch durch das Kapitalmarktrecht ${ }^{60}$ - mittels verschiedenster Gesetze reformiert. ${ }^{61}$ Wenn auch ein umfassendes Reformwerk wie das AktG von 1965 seither ausgeblieben ist, so unterliegt das Aktienrecht in jüngerer Zeit einem kontinuierlichen Wandel. Ein breiteres Bewusstsein für Fragen der Corporate Governance, das zunächst Ausdruck fand in Empfehlungskatalogen verschiedener Gremien, ${ }^{62}$ hat 2002 seinen Niederschlag im Transparenzund Publizitätsgesetz (TransPuG) gefunden. Es regelt neben verschiedenen Informationspflichten des Vorstands insbesondere die in dem neuen $\S 161 \mathrm{AktG}$ kodifizierte Comply-or-Explain-Regelung zu Fragen der Corporate Governance. ${ }^{63}$ Börsennotierte Aktiengesellschaften müssen, wenn sie Teile des Deutschen Corporate Governance Kodex nicht anerkennen, hierüber im Geschäftsbericht berichten. $^{64}$

57 Vgl. Heits (1940), S. 13; Vogel (1980), S. 22-25; Schmidt (2002), S. 762f.; Spindler (1998), S. 55, sowie ausführlich Mülbert (1996), S. 55-62. Eine ausführliche Darstellung auch der kleineren Änderungen zwischen 1884 und 1937 liefert Juhnke (1995), S. 29-37.

58 Vgl. Schmidt (2002), S. 764; Henn (1998), S. 3.

59 Vgl. Mülbert (1996), S. 62f.

60 Zur zunehmenden Bedeutung des Kapitalmarktrechts vgl. Spindler (1998); Möllers (1999); Schiessl (1999); Wymeersch (2001).

61 Vgl. zu den verschiedenen Einzelgesetzen (KonTraG, NaStraG, KapAEG, KapCoRiLiG etc.) im Einzelnen Ernst/Seibert/Stuckert (1998); Claussen (1998); Hommelhoff/Mattheus (1998); Berrar (2001), S. 54-63; Hasselbach/Schumacher (2000), S. 271-273; Spindler (2000), S. 428-433; Goedsche (2002); Noack (2002).

62 Vgl. insbesondere Grundsatzkommission Corporate Governance (2000), sowie Berliner Initiativkreis German Code of Corporate Governance (2000).

63 Vgl. Regierungskommission DCGK (2002); Noack (2002); Seibert (2002).

64 Vgl. Regierungskommission DCGK (2002); Ulmer (2002). 
Der knappe Überblick macht deutlich, dass das für Aktionäre relevante Recht kein monolithischer Block ist sondern sich dynamisch weiterentwickelt. Mit der Vielzahl der Gesetzgebungen in jüngerer Zeit trägt der Gesetzgeber der gestiegenen Bedeutung der Rechtsform Aktiengesellschaft Rechnung und versucht, insbesondere den Interessen der zunehmenden Anzahl an Kleinaktionären sowie der Internationalisierung Rechnung zu tragen. ${ }^{65}$

\subsection{Organe}

Bevor in Kapitel I.2.2 die Rechtsstellung der Aktionäre im Einzelnen betrachtet wird, soll kurz die Kompetenzverteilung zwischen den verschiedenen Organen der Aktiengesellschaft - Vorstand, Aufsichtsrat und Hauptversammlung - beleuchtet werden. ${ }^{66}$ Kodifiziert sind die Regelungen zur Verfassung der Aktiengesellschaft im vierten Teil des AktG, in $\S \S 76-147$.

Dem Vorstand der Gesellschaft obliegt die Leitung, Geschäftsführung und Vertretung der Aktiengesellschaft ( $\S 76$ Abs. 1, 77 Abs. 1, 78 Abs. 1 AktG). ${ }^{67} \mathrm{Er}$ wird für maximal fünf Jahre vom Aufsichtsrat bestellt, die Wiederbestellung ist möglich. Der Vorstand zählt nicht zum abhängig beschäftigten Personal der Aktiengesellschaft und nimmt stattdessen eigenverantwortlich die Unternehmerfunktion wahr. ${ }^{68}$ Der Vorstand agiert dabei selbständig und weisungsfrei, die Eigentümer haben keine unmittelbaren Einfluss- und Kontrollmöglichkeiten. ${ }^{69}$ Nur für bestimmte Arten von Geschäften, die in der Geschäftsordnung festgelegt werden, ist die Zustimmung des Aufsichtsrates erforderlich. ${ }^{70}$ Der Vorstand ist zudem zu einer umfangreichen Berichterstattung gegenüber dem Aufsichtsrat verpflichtet, die erstmals mit dem KonTraG, dann erneut mit dem TransPuG

$65 \mathrm{Zu}$ Entwicklungstendenzen im europäischen Gesellschaftsrecht vgl. Hopt (1998); van Hulle (2000); Jahn/Herfs-Röttgen (2001); Schulz/Geismar (2001).

66 Vgl. Henn (1998), S. 241f. Ausführlich auch Schmidt (2002), S. 407-433. Einen Überblick über das dualistische System der Unternehmensverwaltung gibt Lutter (1995). Schneider (2000) vergleicht das deutsche System ausführlich mit internationalen Regelungen.

67 Zur Abgrenzung der verschiedenen Tätigkeitsfelder ausführlich Ruhwedel (2002), S. 37 39.

68 Vgl. Meyer-Landrut (1970), § 76, Rn. 2; Dose (1975), S. 40; Raiser (2001), S. 137f.; Mertens (1996), § 76, Rn. 4; Schmidt (2002), S. 812f.; Henn (1998), S. 296.

69 Vgl. Großmann (1980), S. 8; Schmidt (2002), S. 804; Jansch (1999), S. 33; Heße/Enders (2001), S. 224.

70 Vgl. Kübler (1999), S. 186; Ruhwedel (2002), S. 53-57. Deren Festlegung in der Geschäftsordnung wurde durch das TransPuG kodifiziert. Vgl. Bundesjustizministerium (2001), S. 33-36. 
weiter ausgedehnt wurde. ${ }^{71}$ Bei der Ausübung ihrer Tätigkeiten haben die Vorstandsmitglieder die "Sorgfalt eines ordentlichen und gewissenhaften Geschäftsleiters anzuwenden" ( 993 Abs. 1 S. 1 AktG). Im Falle einer Pflichtverletzung haftet der Vorstand gesamtschuldnerisch; Schadenersatzansprüche können durch den Aufsichtsrat oder durch Aktionäre geltend gemacht werden. ${ }^{72}$

Der Aufsichtsrat dient den Aktionären zur mittelbaren Einflussnahme. Gemäß $\S 84$ Abs. 1, 3 sowie $\S 111$ Abs. 1, 2 AktG obliegen dem Aufsichtsrat die Bestellung, Abberufung und insbesondere die Überwachung der Geschäftsführung. ${ }^{73}$ Mitglied im Aufsichtsrat sind Vertreter der Anteilseigner und der Arbeitnehmer. Letztere werden nach den Regeln der verschiedenen Mitbestimmungsgesetze bestellt. ${ }^{74}$ Die Vertreter der Aktionäre werden auf Vorschlag des Aufsichtsrates selbst von der Hauptversammlung für höchstens fünf Jahre mit einfacher Mehrheit in der Regel mittels einer Listenwahl gewählt. ${ }^{75}$ Die Aktionäre sind zwar an die Wahlvorschläge der Verwaltung nicht gebunden, die Durchsetzung alternativer Kandidaten scheitert in der Praxis jedoch regelmäßig an fehlenden Mehrheiten. Eine Regelung, die die zwingende Berücksichtigung von Vertretern der Klein- oder Minderheitsaktionäre vorsieht, existiert im deutschen Recht nicht. ${ }^{76}$ Der Tätigkeitsbereich des Aufsichtsrates bezieht sich zwar allgemein auf Überwachungsaufgaben, ist jedoch nicht auf eine reine Ex-Post-Kontrolle beschränkt, ${ }^{77}$ vielmehr greift die so genannte gestaltende Überwachung aktiv in das Unternehmungsgeschehen ein; der Aufsichtsrat hat umfangreiche Aus-

71 Vgl. Raiser (2001), S. 137f.; Ruhwedel (2002), S. 51f.; Seibert (2002); Noack (2002); Bosse (2002), zu den Auswirkungen auf die Konzernrechnungslegung Busse von Colbe (2002). Zur Begründung der Neuregelungen des TransPuG vgl. Bundesjustizministerium (2001), S. 25-30.

72 Sofern die Aktionäre mind. $5 \%$ des Grundkapitals vertreten. Vgl. Raiser (2001), S. 158176; Schmidt (2002), S. 816-818; Hommelhoff/Matthäus (1998), S. 259; Kübler (1999), S. 187f.; Kau (2000); Park (2001); Ruhwedel (2002), S. 44.

73 Vgl. Semler (1996), S. 55; Potthoff/Trescher (2001), S. 67. Ausführlich auch Blies (2000), S. 26-54; Malik (1997), S. 154-204; Martens (2000), S. 17-24; Ruhwedel (2002), S. 49-57.

74 Vgl. Raiser (2001), S. 182; Kübler (1999), S. 190, 409-415.

75 Vgl. Raiser (2001), S. 187-189; Hüffer (2002), § 102 AktG, Rn. 6; Semler (1999), S. 67. Die Satzung kann zudem die Entsendung von Vertretern einzelner Aktionäre vorsehen Kübler (1999), S. 190; Ruhwedel (2002), S. 47.

76 Wenngleich ein Verhältniswahlrecht im Gesetzgebungsverfahren zum AktG diskutiert wurde. Vgl. Raiser (2001), S. 188.

77 Vgl. Wagner (1998), S. 76; Gawrisch (2000), S. 20; Ruhwedel (2002), S. 49-52 m.w.N. Zu Neuregelungen durch das KonTraG vgl. auch Feddersen (2000); Scheffler (2000). 
kunftsrechte, ${ }^{78}$ auf Basis derer er den Vorstand berät und hat in verschiedenen Punkten zudem eine Alleinentscheidungsbefugnis. ${ }^{79}$

Obwohl das Gesetz keine Hierarchie zwischen den einzelnen Organen vorsieht und die Zuständigkeiten der Hauptversammlung beschränkt sind, so wird sie dennoch regelmäßig als „oberstes Organ ${ }^{\text {“80 }}$ der Aktiengesellschaft tituliert (Regelungen in $\S \S 118-147$ AktG). In der Hauptversammlung bilden die Aktionäre den Willen der Gesellschaft durch Beschlüsse, der einzelne Aktionär wirkt hierbei durch Ausübung seines Stimmrechts mit. ${ }^{81}$ Für Schmidt ist die Hauptversammlung der „Sitz der Aktionärsdemokratie“"82. Entscheidend ist jedoch, dass die Regelungen des AktG die Hauptversammlung von der eigentlichen Führung der Gesellschaft praktisch vollständig ausschließen und die Kompetenzverteilung zwischen den Organen auch nur begrenzt durch Satzungsregelungen geändert werden kann. ${ }^{83}$

Die so genannten Grundlagenbeschlüsse (Satzungsänderungen, Kapitalmaßnahmen, Auflösung, Eingliederungen) entscheidet die Hauptversammlung mit $3 / 4$-Mehrheit des vertretenen Grundkapitals, ansonsten genügt eine einfache Mehrheit bzw. alternative Mehrheiten, die die Satzung vorsehen kann.$^{84}$ Im Einzelnen sind die Zuständigkeiten der Hauptversammlung auf folgende Sachverhalte begrenzt: ${ }^{85}$

78 Die im AktG kodifizierten Auskunftsrechte des Aufsichtsrates wurden durch das TransPuG im Jahr 2002 ausgeweitet. Vgl. Bundesjustizministerium (2001), S. 25-30.

79 Entscheidenden Einfluss übt der Aufsichtsrat insbesondere durch die Besetzung des Vorstandes, die Ausgestaltung des Anreizsystems seiner Mitglieder und die Mitentscheidung in bestimmten Fragen der Geschäftsführung aus. Vgl. ausführlich Ruhwedel (2002), S. 53-57; Semler (1996), S. 56-58; Wagner (1998), S. 72f.

80 Vogel (1980), S. 34; v. Rechenberg (1986); Kübler (1999), S. 194f.; Henn (1998), S. 243, sowie bereits Wiethölter (1961), S. 82.

81 Vgl. Obermüller/Werner/Winden (2001), S. 2. Zur geschichtlichen Entwicklung der Hauptversammlung vgl. Juhnke (1995), S. 157-167.

82 Schmidt (2002), S. 837.

83 Vgl. Raiser (2001), S. 225; Jansch (1999), S. 49f.; Kübler (1999), S. 194, 196.

84 Vgl. Henn (1998), S. 372-376. Zu ablauftechnischen Details wie z.B. Einberufung und Leitung der Hauptversammlung vgl. ausführlich Obermüller/Werner/Winden (2001).

85 Vgl. Schmidt (2002), S. 838f.; Henn (1998), S. 243; Kübler (1999), S. 195. Zu weiteren Befugnissen, die in der Satzung vorgesehen sein können (z.B. Einsetzung von Beiräten) vgl. Henn (1998), S. 350. Zur Relevanz des Holzmüller-Urteils für die Kompetenzen der Hauptversammlung vgl. Raiser (2001), S. $228 f$. 


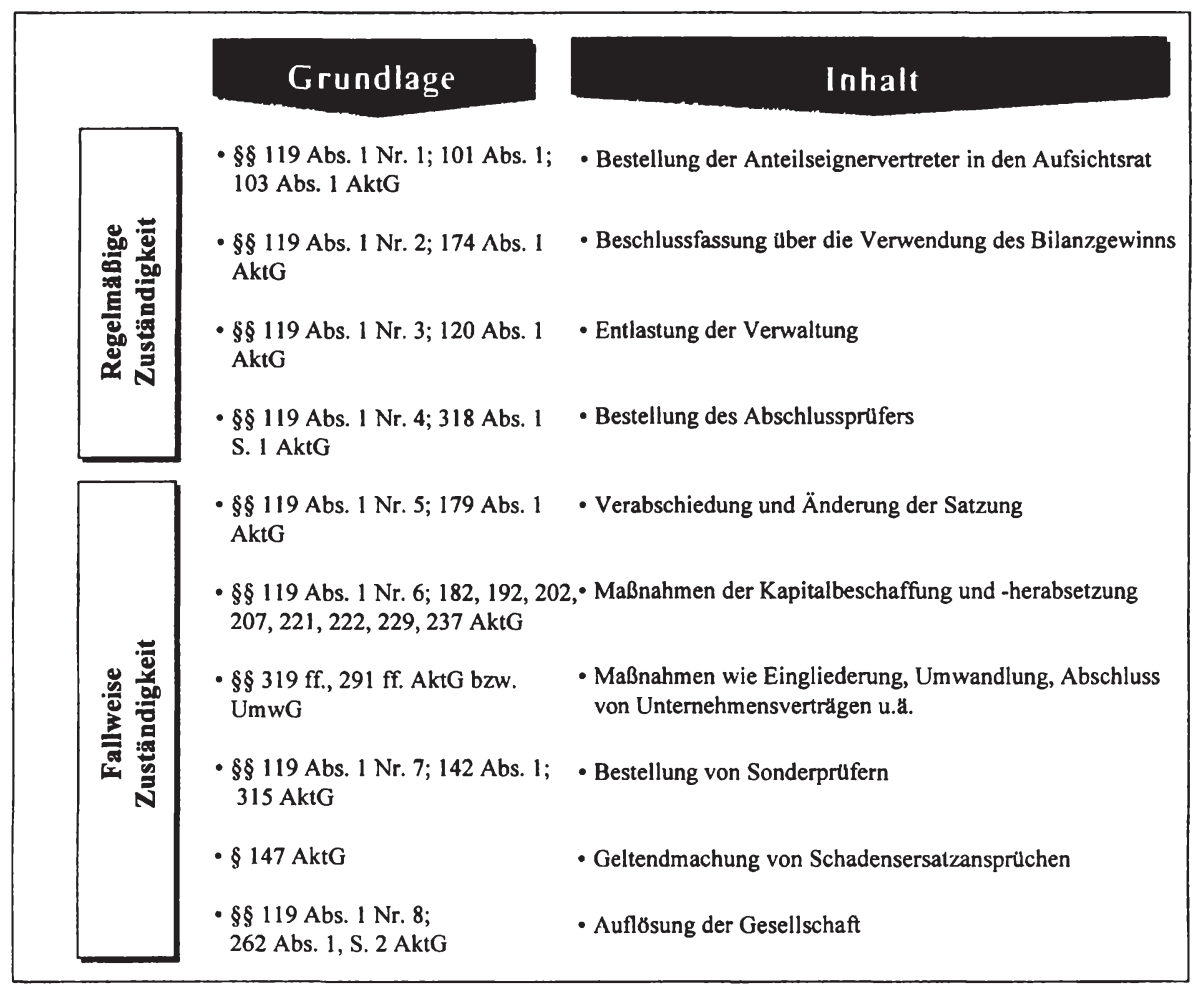

Abb. 4: Kompetenzen der Hauptversammlung

Im Ergebnis stehen der Hauptversammlung somit zwar einige zentrale Befugnisse zu, von großer Bedeutung ist jedoch, dass eine Entscheidung über Fragen der Geschäftsführung nur auf explizites Verlangen des Vorstandes fallweise möglich ist. ${ }^{86}$ Somit kommt dem formal obersten Organ der Aktiengesellschaft zwar eine Entscheidungsbefugnis in Grundsatzfragen zu, die fehlenden Eingriffsmöglichkeiten in das strategische und operative Tagesgeschäft lassen die Hauptversammlung jedoch insgesamt als „zahnlosen Tiger“ erscheinen. ${ }^{87} \mathrm{Im}$ Rahmen der Hauptversammlung agieren die Aktionäre als Gesamtheit, die Einflussnahmemöglichkeit des einzelnen Aktionärs begrenzt sich auf die Stimmabgabe. Abb. 5 gibt einen zusammenfassenden Überblick über das Kompetenzgefüge der Organe der Aktiengesellschaft.

\footnotetext{
86 Vgl. § 119 Abs. 2 AktG.

87 Zur Stellung der Hauptversammlung in der Rechtswirklichkeit auch Juhnke (1995), S. 167-172; Pellens/Bonse (1999), S. 853; Mehrfeld (1984), S. 44f.
} 


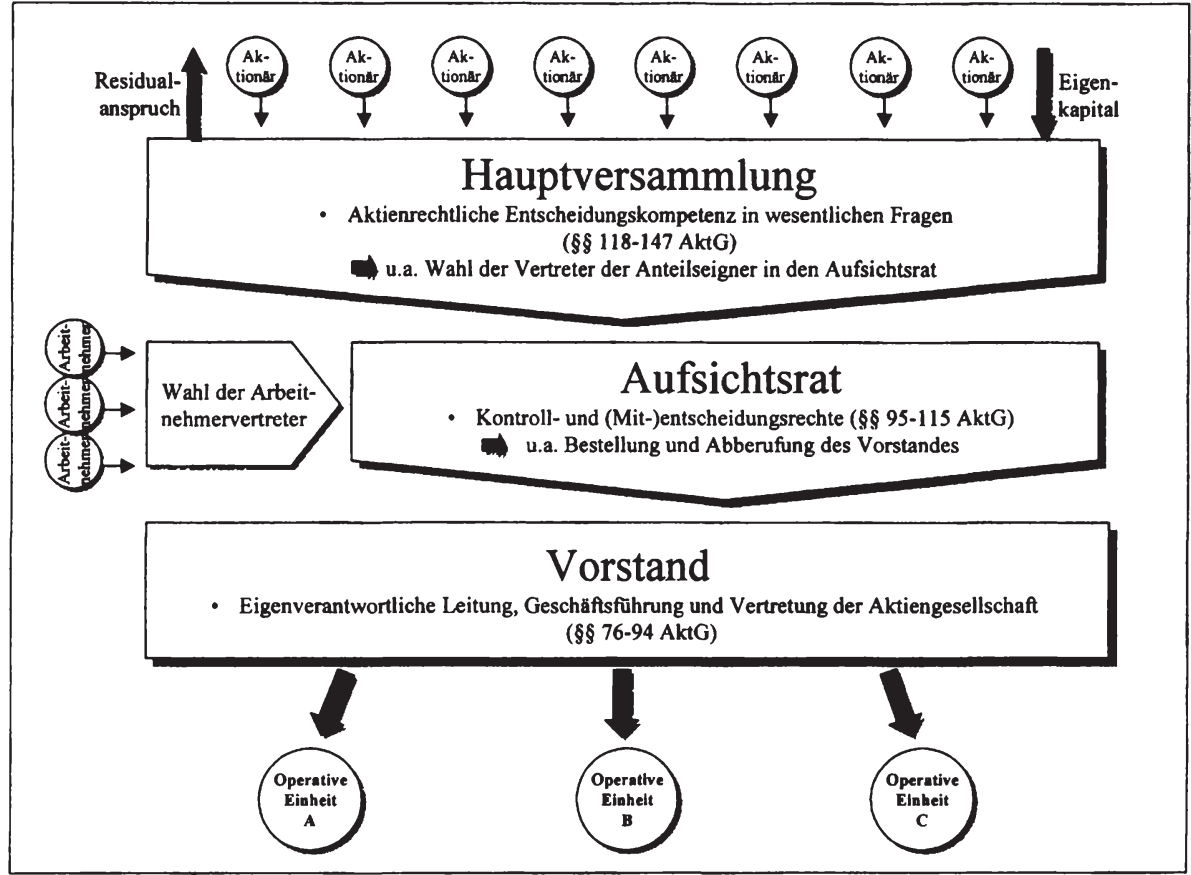

Abb. 5: Kompetenzgefüge der Organe der Aktiengesellschaft

Nachdem bislang die Aktionäre primär in Form ihres willensbildenden Organs „Hauptversammlung“ als monolithischer Block betrachtet wurden, wird im folgenden Kapitel die Rechtsstellung der Aktionäre bezogen auf den einzelnen Anteilseigner analysiert.

\section{Rechtsstellung der Aktionäre}

\subsection{Fundierung im Gesellschafts- und Kapitalmarktrecht}

Zielsetzung der Ausführungen in den weiterführenden Kapiteln wird es sein, die Möglichkeiten, Grenzen sowie Anreize zur Durchsetzung von direkter Aktionärskontrolle am deutschen Kapitalmarkt zu analysieren. Diesbezügliche Theorien wurden bisher in der Literatur primär unter Berücksichtigung des USamerikanischen Rechtsrahmens formuliert. Um einen eventuellen Einfluss der Rahmenbedingungen auf die später folgende Hypothesenbildung berücksichtigen zu können, wird im Folgenden ein Überblick über die grundlegenden Unterschiede zwischen der Fundierung der Aktionärsrechte im deutschen und im USamerikanischen Rechtssystem gegeben. 
Die Verankerung der Aktionärsrechte erfolgt grundsätzlich im Gesellschaftsund im Kapitalmarktrecht. ${ }^{88}$ Das Gesellschaftsrecht besitzt für alle Aktiengesellschaften Relevanz, das Kapitalmarktrecht entfaltet seine zusätzliche Rechtswirkung für börsennotierte bzw. kapitalmarktorientierte Unternehmen. Der Umfang der gesellschafts- bzw. kapitalmarktrechtlich kodifizierten Aktionärsrechte variiert international stark, für ihre Sicherstellung existieren zwei grundsätzliche Muster: Die möglichst umfassende Regulierung der einzelnen Rechte im Gesetz versus privatvertraglicher Lösungen, die sich zwischen den Beteiligten aufgrund marktlicher Koordinationsmechanismen auf der Basis gesetzlich nicht beschränkter Vertragsfreiheit ergeben. ${ }^{89}$ Das Vertrauen auf Regelungen des Marktes ist der Grundpfeiler des US-amerikanischen Gesellschafts- und Kapitalmarktrechts und kann durch unterschiedliche wirtschaftstheoretische Sichtweisen im Zuge der „Economic Analysis of Law“ gerechtfertigt werden. ${ }^{90}$ Effizienzverbesserungen sollen durch freiwillige Markttransaktionen erzielt werden, die z.B. durch eine Reduzierung von Transaktionskosten stimuliert werden. ${ }^{91}$ Der Staat stellt lediglich die Rechtswege bzw. Schiedsinstanzen zur Verfügung, die es den Vertragspartnern ermöglichen, ihre Vertragsansprüche im Konfliktfall durchzusetzen. ${ }^{92}$

Bezogen auf den Aktionärsschutz impliziert dies die Dominanz individueller vertraglicher Regelungen in Verbindung mit Anreizmechanismen, die eine Kongruenz der Ziele von Aktionär und Management sicherstellen sollen. ${ }^{93}$ Entsprechend sind weite Teile des Aktienrechts in den USA dispositives Recht. ${ }^{94}$ Das Gesellschaftsrecht ist Einzelstaatenrecht, es gilt das Recht desjenigen Staates, in dem die Gesellschaft gegründet wurde. Da viele Gesellschaften in der Vergangenheit das liberale Recht des Staates Delaware gewählt haben, hat sich auch das Recht anderer Staaten in den vergangenen Jahren in einem Wettbewerb der Rechtssysteme zunehmend liberalisiert und sieht heute weitgehende Satzungsau-

Zur ökonomischen Analyse des Rechts grundlegend Posner (1998), S. 401ff., der sich eines institutionenökonomischen Instrumentariums zur Analyse bedient. Darüber hinausgehend können auch neoklassische oder auch evolutorische Ansätze berücksichtigt werden, vgl. z.B. Fülbier (1998), S. 107-210, sowie Easterbrook/Fischel (1991), S. 212ff., im Wesentlichen basierend auf Coase (1937). Einen Überblick geben Ebke (1994), S. 9; Adams (2002), sowie der Sammelband von Assmann/Kirchner/Schanze (1993).

Zur Abgrenzung ausführlich Fülbier (1998), S. 33-36.

$\mathrm{Zu}$ verschiedenen Begründungsansätzen einer Regulierung des Aktienrechts vgl. Pellens (1994), S. 184-214; Fülbier (1998), S. 166-210. Vgl. zudem Pellens (2001), S. 23.

Vgl. Williamson (1985).

Vgl. Spindler (1998), S. 59; Pellens (2001), S. 23.

Vgl. Köndgen (1993), S. 128, 138; Ebke (1994), S. 9; Merkt (2003), S. 127.

Vgl. Spindler (1998), S. 57f.; Merkt (2003), S. 127. 
tonomie vor. ${ }^{95}$ Als Vorteil wird einem solchen wettbewerbsorientierten System der Rechtsbildung eine größere Flexibilität zugesprochen. ${ }^{96}$ Dennoch ist der Wettbewerb verschiedener Satzungsregelungen nicht unumstritten. ${ }^{97}$ So droht zumindest theoretisch die Gefahr eines "race to the bottom", wenn Unternehmen immer die Satzungsregelungen wählen, die einen möglichst geringen Aktionärsschutz gewährleisten. ${ }^{98}$ Voraussetzung für die Durchsetzung der besten Satzungsregelungen ist eine hohe Funktionsfähigkeit des Kapitalmarkts. ${ }^{99}$ Entsprechend erfolgen in den USA umfangreiche Regulierungen weniger im Gesellschafts- als vielmehr im Kapitalmarktrecht. ${ }^{100}$ Hier steht der Schutz des Aktionärs in seiner individuellen und insbesondere in seiner funktionenschützenden Komponente im Vordergrund, da es gilt, eine effiziente Allokation der Finanzressourcen auf dem Kapitalmarkt zu gewährleisten. ${ }^{101}$ Aktionärsschutz wird zu einem wesentlichen Teil als Anlegerschutz interpretiert und ist auf den anonymen Kleinaktionär börsennotierter Unternehmen zugeschnitten. ${ }^{102}$

In Deutschland, wo im Vergleich zu den USA der Anteil börsenotierter Unternehmen geringer ist, finden sich die wesentlichen Aktionärsschutzbestimmungen weniger im Kapitalmarkt- als vielmehr im Gesellschaftsrecht. ${ }^{103}$ Sie greifen damit für alle Aktiengesellschaften, auch für die nicht-börsennotierten und zeichnen sich durch umfangreiche Regulierungen und eine vergleichsweise geringe Satzungsautonomie aus. ${ }^{104}$ Für die börsennotierten Gesellschaften greift zusätzlich das Kapitalmarktrecht, das in den letzten Jahren zunehmend an Be-

95 Vgl. Schön (1996), S. 234; Spindler (1998), S. 57; Pellens (2001), S. 44f.; Merkt (2001), S. 143f.; Roe (2002).

96 Dodd/Leftwich (1980) weisen sogar positive Kapitalmarkteffekte eines Wechsels in liberalere Regulierungssysteme am Beispiel Delawares nach.

97 Zur Kritik an der ökonomischen Analyse des Rechts vgl. Schneider (1986), S. 163ff.; Elschen (1987), S. 225-231; Schmidtchen (1991), S. 317f.; Spindler (1998), S. 60.

98 Vgl. bereits Cary (1974), S. 663, sowie Hauser (1993); Schön (1996), S. 234f.; Spindler (1998), S. 54 m.w.N. insb. US-amerikanischer Quellen und S. 60, sowie Merkt (2001), S. 144, grundlegend bereits Hayek (1968). Die Suche nach der „besten“ Satzungsregelung ist zudem mit Transaktionskosten auf Unternehmens- und Aktionärsseite verbunden und kann mit mangelnder Transparenz einhergehen. Kritisch auch Sinn (1990). Vgl. zudem Spindler (1998), S. 59, 63f.; Oberender/Cachej (1999), S. 578-581.

99 Vgl. Schön (1996), S. 238; Ebke (1994), S. 24f. In anderem Zusammenhang ähnlich Pellens/Gassen (1998), S. 638.

100 Vgl. Merkt (2003), S. 126f.

101 Vgl. Koch/Schmidt (1981), S. 235-238. Zur Abgrenzung von Individual- und Funktionenschutz ausführlich Fülbier (1998), S. 159-162.

102 Vgl. Coffee (1996).

103 Vgl. Fülbier (1998), S. 34f.; Merkt (2003), S. 127.

104 Vgl. Assmann (1992), Einl. Rn. 10; Ebke (1994), S. 13. Zur Regulierung ausführlich Fülbier (1999). 
deutung gewonnen hat und in dem zahlreiche Aktionärsschutzbestimmungen verankert wurden. ${ }^{105}$ Kodifiziert wurden verschiedene Einzelregelungen, die zu einem großen Teil an das US-Recht angelehnt sind. ${ }^{106}$ So wurden einerseits die Publizitätsregeln verschärft (WpHG, KapAEG, KonTraG, TransPuG) und andererseits die Gestaltungsmöglichkeiten der Eigenkapitalfinanzierung (Bezugsrechtsausschluss, Aktienrückkauf, Namensaktien, Tracking Stocks etc.) ausgeweitet. ${ }^{107}$ Das Kapitalmarktrecht wird damit für börsennotierte Unternehmen zweiter wesentlicher Pfeiler des Aktienrechts. ${ }^{108}$ Somit ist zwar eine (überwiegend einseitige) Annäherung der beiden Rechtssysteme zu erkennen, in Deutschland sind indes nach wie vor die wesentlichen Teile des Aktienrechts Bestandteil des Gesellschafts- und nicht des Kapitalmarktrechts. ${ }^{109}$

Im Folgenden werden die Aktionärsrechte sowie die sie begründenden Aktionärspflichten im Einzelnen herausgearbeitet. Dabei steht zwar - entsprechend seiner Bedeutung - das Gesellschaftsrecht im Mittelpunkt, kapitalmarktrechtliche Regelungen fließen jedoch in die Betrachtung ein, soweit sie die Rechte und Pflichten des Aktionärs berühren.

\subsection{Rechte und Pflichten des Aktionärs}

\subsubsection{Einlage- und Treuepflicht}

Die „Hauptverpflichtung der Aktionäre“ ist gemäß $\S 54$ AktG die Leistung der Einlage, die gleichzeitig durch den Ausgabebetrag der Aktien bzw. den Kaufpreis in ihrer Höhe begrenzt wird. ${ }^{110}$ Die Festlegung einer zukünftigen Zahlungsverpflichtung oder einer Haftung ist nicht zulässig. ${ }^{111}$

105 Zur zunehmenden Bedeutung des Kapitalmarktrechts vgl. Spindler (1998); Möllers (1999); Schiessl (1999); Wymeersch (2001); Merkt (2003).

106 Vgl. Pellens/Bonse (1999), S. 872-874; Merkt (2003), S. 128. Bereits Großfeld (1968) diskutiert im Rahmen eines Rechtsvergleichs mit den USA die Möglichkeit eines wettbewerbsorientierten Aktienrechts auch in Deutschland.

107 Zu den einzelnen Neuregelungen vgl. Claussen (1998); Möllers (1999); Ulmer (1999).

108 Vgl. Möllers (1999), S. 434 zum Verhältnis von Kapitalmarkt- und Gesellschaftsrecht, außerdem Deckert/von Rüden (1998), S. 48f.; Ebke (1994), S. 22; Mülbert (1996), S. $107 \mathrm{f}$.

109 Ebenso Ebke (1994), S. 27. Entsprechendes gilt für weite Teile Kontinentaleuropas. Vgl. Lutter (2000), S. $10 \mathrm{f}$.

110 Vgl. Kübler (1999), S. 178; Heße/Enders (2001), S. 232.

111 Vgl. Raiser (2001), S. 108f. Zum Sonderfall der Nebenleistungs-AG vgl. Kübler (1999), S. 179. Sofern ausnahmsweise die Einlage nicht unmittelbar bei Gründung geleistet wird, sind ausschließlich Namensaktien auszugeben ( $§ 10 \mathrm{Abs} .2 \mathrm{AktG}$ ), um die spätere Geltendmachung der Forderung sicherzustellen. 
Der Begriff der Treuepflicht beinhaltet die Loyalität eines Mitglieds gegenüber seiner Gesellschaft, die sich in Förderungs- und Interessenwahrungspflichten, die über den allgemeinen Grundsatz von Treu und Glauben hinausgehen, konkretisiert. ${ }^{12}$ Für die Aktiengesellschaft wurde lange Zeit das Bestehen einer Treuepflicht aufgrund der geringen persönlichen Bindung der Aktionäre gegenüber ihrer Gesellschaft verneint. ${ }^{113}$ So ist aus dem Gesetz, abgesehen von der Einlagepflicht, auch keine weitere Verpflichtung unmittelbar abzuleiten. ${ }^{114}$ Dennoch wird die Treuepflicht in der Literatur heute differenzierter beurteilt. Für Kleinaktionäre, die eine eher anlegerbezogene Stellung in der Gesellschaft einnehmen, wird eine Treuepflicht nach wie vor überwiegend nicht gesehen. ${ }^{115} \mathrm{An}$ ders ist dies hingegen bei Großaktionären, die ein über die reine Geldanlage hinausgehendes Interesse an der Gesellschaft haben und dieses aufgrund ihrer erhöhten Einflussmöglichkeiten auch durchzusetzen vermögen. ${ }^{116}$ So formuliert Wellkamp: „dem Maß des Einflusses des Aktionärs [muss] das Maß seiner Verantwortung [...] entsprechen “"117. Die sich ergebende Treuepflicht besteht nicht nur gegenüber der Gesellschaft selbst, sondern verpflichtet insbesondere zu einem rücksichtsvollen Handeln gegenüber den Mitgesellschaftern. ${ }^{118}$

Die Treuepflicht gewährleistet für jeden einzelnen Aktionär einen Vertrauensschutz gegen verbandsschädigendes Verhalten der Mitaktionäre. ${ }^{119}$ Sie konkretisiert sich in der Praxis insbesondere in einem die Interessen der Mitaktionäre berücksichtigenden Abstimmungsverhalten auf der Hauptversammlung. ${ }^{120} \mathrm{Die}$ Sanktionen aufgrund einer Verletzung der Treuepflicht sind abhängig von der Art des Konflikts. Infrage kommen z.B. Schadenersatzansprüche oder Unterlassungsansprüche. ${ }^{121}$

112 Vgl. Schmidt (2002), S. 587-589. Im BGB finden sich diese allgemeinen Loyalitätspflichten in § 242. Vgl. Fillmann (1991), S. 161; Wellkamp (1998), S. 19.

113 Vgl. Hueck (1947), S. 14; Raiser (2001), S. 110f.; Schmidt (2002), S. 591; Kübler (1999), S. 179. Die Treuepflicht wird bereits seit Bestehen der Aktiengesellschaft diskutiert. Vgl. Esser (1938), S. 11; Lenssen (1938).

$114 \mathrm{Zu}$ im Einzelfall anwendbaren Paragraphen, die dennoch Pflichten begründen vgl. Raiser (2001), S. $111 \mathrm{f}$.

115 Vgl. Raiser (2001), S. 114; Kübler (1999), S. 179. Einen Überblick zur Treuepflicht im Schrifttum gibt Mülbert (1996), S. 252-255.

116 Vgl. Kübler (1999), S. 179.

117 Wellkamp (1998), S. 18. Ähnlich auch Mülbert (1996), S. 256.

118 Vgl. Raiser (2001), S. 113-116; Schmidt (2002), S. 588f.; Wellkamp (1998), S. 18.

119 Vgl. Wellkamp (1998), S. 19. Zum Umfang der Treuepflicht ausführlich S. $20 \mathrm{f}$.

120 Vgl. Wellkamp (1998), S. 21.

121 Vgl. zu Sanktionsmöglichkeiten Raiser (2001), S. 116-119; Schmidt (2002), S. 595-600. 
Für die Abgrenzung der verschiedenen Aktionärsrechte sind unterschiedliche Kriterien denkbar. So differenziert Kübler zum einen danach, wem das Recht zusteht in allgemeine Mitgliedschafts- und Sonderrechte und zum anderen nach dem Inhalt der Rechte. ${ }^{122}$ Bei der inhaltsbezogenen Systematisierung werden Cash-Flow- ${ }^{123}$, Herrschafts- ${ }^{124}$ und Informationsrechte unterschieden. ${ }^{125}$ Durch die Abgrenzung nach dem Inhalt der Rechte geht die Betrachtung über die rein verbandsrechtliche Sichtweise des Aktionärs hinaus, die Teilen der juristischen Literatur zugrunde liegt. ${ }^{126}$ Der Aktionär wird nicht ausschließlich als Mitglied einer Gesellschaft betrachtet sondern auch als (potenzieller) Anleger. ${ }^{127}$ Entsprechend soll hier die Abgrenzung nach dem Inhalt zugrunde gelegt werden. Da die Einflussmöglichkeiten der Aktionäre für die anschließende Untersuchung von zentraler Bedeutung sind, liegt der Schwerpunkt der Ausführungen auf den Herrschaftsrechten und hier insbesondere auf dem Stimmrecht. Zunächst sollen jedoch die Cash-Flow- und Informationsrechte betrachtet werden.

\subsubsection{Cash-Flow-Rechte}

Durch die Leistung seiner Einlage bzw. durch den Erwerb der Aktie erwirbt der Aktionär verschiedene vermögensbezogene Rechte, die Anspruch auf finanzielle Zahlungen aus der Aktie verbriefen. Im Einzelnen sind hier die folgenden zu nennen:

- ANSPRUCH AUf DividENDENZAHLUNG ( $\$ 58$ Abs. 4, 60 AktG)

Der Dividendenanspruch des Aktionärs bezieht sich auf den von der Hauptversammlung beschlossenen Bilanzgewinn ( $\$ \S 119$ Abs. 1 S. 2, 174 AktG). Sofern die Einstellungen in die gesetzliche Rücklage ( $\$ 150 \mathrm{AktG})$ oder Satzungsregelungen ${ }^{128}$ dem nicht im Wege stehen ( $\left.\$ 58 \mathrm{Abs} .4 \mathrm{AktG}\right)$, muss dieser mindestens $50 \%$ des Jahresüberschusses betragen ( $\S 58 \mathrm{Abs} .2 \mathrm{AktG}$ ). Die Höhe des Dividendenanspruchs richtet sich grundsätzlich nach dem An-

122 Vgl. Kübler (1999), S. 180-182

123 In der juristischen Literatur ist in diesem Zusammenhang häufig von „Vermögensrechten" die Rede. Die Begriffe werden hier synonym gebraucht.

124 In der juristischen Literatur ist in diesem Zusammenhang häufig von „Verwaltungsrechten" die Rede. Die Begriffe werden hier synonym gebraucht.

125 Siehe auch Kraft (1988), §11 Rn. 11; Pellens (1994), S. 46-51; Wellkamp (1998), S. 1; Pellens/Bonse (1999), S. 853; Groß (1997), sowie Schmidt (2002), S. 601-652. Vgl. zur funktionalen Klassifizierung auch Wellkamp (1998), S. 1.

126 Vgl. Lutter (1980), S. 84; Schmidt (2002), S. 547-550, sowie S. 566-654. Kritisch Mülbert (1996), S. 68-71; Wiedemann (1980), §§ 7-9; Hopt (1977), S. 389.

127 Vgl. Mülbert (1996), S. 72-74; Schneider (1999), Rn. 13, sowie Wilhelm (2001), S. 520.

128 Vgl. Wellkamp (1998), S. 106. 
teil am Grundkapital ( $§ 60 \mathrm{AktG})$, wobei Vorzugsaktionäre i.d.R. einen höheren Dividendenanspruch haben. ${ }^{129}$

- ANSPRUCh AUf ANTEIL AM LiQUidationserLös (§ 271 Abs. 1 AktG)

Im Falle der Auflösung der Gesellschaft wird das nach Abzug der Verbindlichkeiten verbleibende Vermögen der Gesellschaft entsprechend ihrer Anteilsquote unter den Aktionären verteilt.

- RÜCKZAHLUNGSANSPRUCH BEI KAPITALHERABSETZUNG ( $\$ 225$ Abs. 2 AktG) Im Falle eines Kapitalherabsetzungsbeschlusses ( $\$ 222$ Abs. 1 AktG) werden Teile des Grundkapitals an die Aktionäre zurückgewährt. Dieses ist jedoch nur unter Berücksichtigung von gläubigerschützenden Ausschüttungssperren ein halbes Jahr nach dem Beschluss zulässig. ${ }^{130}$

- BeZugsrecht ( $\$ 186$ Abs. 2 AktG)

Das gesetzliche Recht zum Bezug junger Aktien im Falle einer Kapitalerhöhung stellt einen Ausgleich für erlittene Vermögensverluste der Altaktionäre („Verwässerung“) dar und soll darüber hinaus jedem Aktionär die Möglichkeit geben, seinen Stimmrechtsanteil zu wahren. ${ }^{131}$

- Ausgleichs-, UMTAUSCH- UND ABFINDUNGSANSPRÜCHE ( $\S \S 375,383$ AktG, 12, 19 UmwG)

In verschiedenen Spezialfällen der Umwandlung, Verschmelzung und des Konzernrechts entstehen gesonderte Vermögensrechte. ${ }^{132}$

Für die verschiedenen Cash-Flow-Rechte gilt grundsätzlich ein Abspaltungsverbot, d.h. eine Übertragung einzelner Rechte auf Nichtgesellschafter ist unzulässig. ${ }^{133}$ Sobald jedoch ein bezifferbarer Anspruch - z. B. auf die Dividende eines Geschäftsjahres nach dem Gewinnverwendungsbeschluss der Hauptversammlung - entstanden ist, ändert sich die Rechtslage. Es entsteht ein schuldrechtlicher Anspruch (Gläubigerrecht), für den das Abspaltungsverbot nicht mehr gilt. ${ }^{134}$

129 Vgl. zu Vorzugsaktien ausführlich Kapitel III.2.3.2.1.

130 Vgl. Schmidt (2002), S. $907 f$.

131 Vgl. Lutter (1988), § 58, Rn. 79. Zu Details vgl. Wellkamp (1998), S. 138-142. Mit einer $3 / 4$-Mehrheit kann das Bezugsrecht von der Hauptversammlung ausgeschlossen werden, wenn die Kapitalerhöhung $10 \%$ des Grundkapitals nicht übersteigt und der Kurs der jungen Aktien den der alten nicht wesentlich unterschreitet (§186 Abs. 3 AktG). Vgl. ausführlich Wellkamp (1998), S. 142-163.

132 Vgl. hierzu detailliert Raiser (2001), S. 100f.

133 Vgl. Raiser (2001), S. 100f.

134 Der Anspruch kann somit selbständig abgetreten und gepfändet werden. Vgl. Raiser (2001), S. 101f. 


\subsubsection{Informationsrechte}

Bei den Informationsrechten das Aktionärs muss differenziert werden zwischen den klassischen Auskunftsrechten, die ausschließlich auf den aktuellen Aktionär als Verbandsmitglied abzielen, und den kapitalmarktorientierten Informationsrechten, die nicht nur aktuelle, sondern auch potenzielle Aktionäre und sonstige Marktteilnehmer schützen. ${ }^{135}$ Zugrunde gelegt wird somit erneut nicht die rein verbandsrechtlich orientierte Sichtweise des Aktionärs; sie wird erweitert um den kapitalmarktorientierten Blickwinkel. ${ }^{136}$

Das Auskunftsrecht des Aktionärs wurde erstmals im AktG 1937 mit der Begründung kodifiziert, dass das „Fragerecht [...] für den Aktionär die Grundlage der Stimmrechtsausübung“ bildet. ${ }^{137}$ Konkret legt $§ 175$ Abs. 2 AktG fest, dass jedem Aktionär Einsicht in Jahresabschluss, Lagebericht, Bericht des Aufsichtsrates und Vorschlag des Vorstandes zur Bilanzgewinnverwendung zu gewähren ist bzw. eine Abschrift zur Verfügung gestellt werden muss. ${ }^{138}$ In der Praxis wird der Geschäftsbericht nicht nur den aktuellen Aktionären, sondern auch sonstigen interessierten Personen kostenlos zur Verfügung gestellt. $§ 131$ Abs. 1 AktG hingegen betrifft ausschließlich die aktuellen Aktionäre, er regelt das Auskunftsrecht auf der Hauptversammlung. ${ }^{139}$ So hat der Vorstand auf Verlangen des Aktionärs Auskunft über Angelegenheiten der Gesellschaft zu geben, soweit sie zur sachgemäßen Beurteilung des Gegenstandes der Tagesordnung erforderlich sind; nur über die in Abs. 3 gesondert explizierten Sachverhalte darf er die Auskunft verweigern. ${ }^{140}$

135 Während der Großteil der Literatur eine Unterscheidung der Informationsrechte nicht vornimmt, findet sich eine Differenzierung auch bei Groß (1997), der individuelle und kollektive Informationsrechte unterscheidet.

136 Vgl. Mülbert (1996), S. 72-74, sowie Wilhelm (2001), S. 520. Einen aktuellen Überblick über die Informations- und Auskunftsrechte des Aktionärs gibt Henze (2002).

137 Vgl. Amtliche Begründung zum AktG 1937, S. 100f., sowie Mülbert (1996), S. 61, der die Auskunftsrechte des aktuellen Aktionärs als „ex-post-Anlegerschutz“ tituliert. Vgl. Mülbert (1996), S. 116.

138 Die Informationspflichten des Vorstands im Vorfeld der Hauptversammlung sind in $\S \S 121$ Abs. 3; 124 Abs. 1, 2; 125 Abs. 1 geregelt.

139 Zum Auskunftsrecht detailliert Hefermehl (1977); Obermüller/Werner/Winden (2001), S. 230-271.

140 Eine Ausdehnung oder Einschränkung des Informationsrechtes ist gem. §23 Abs. $5 \mathrm{AktG}$ nicht zulässig. Vgl. Schmidt (2002), S. 842. Der Vorstand ist verpflichtet, ausreichend Unterlagen und Hilfspersonen bereit zu halten, um auch Fragen beantworten zu können, für die er die Antwort ad hoc nicht geben kann. Vgl. Raiser (2001), S. 240f.; Trouet (1986), S. 1305. Eine Auskunftspflicht auch des Aufsichtsrats wird von der h.M. abgelehnt. Vgl. Groß (1997), S. 99 m.w.N. 
Gemäß § 131 Abs. 4 S. 1 AktG hat der Aktionär außerdem ein Anrecht auf alle Informationen, die einem anderen Aktionär wegen seiner Eigenschaft als Aktionär außerhalb der Hauptversammlung gegeben wurden. Die informationelle Gleichbehandlung aller (Aktionärs-)Gruppen ist in jüngerer Zeit verstärkt diskutiert worden und wurde im Deutschen Corporate Governance Kodex verankert. ${ }^{141}$ Erleidet der Aktionär in Folge einer fehlerhaften Auskunft einen Schaden, so ist die Gesellschaft, nach Meinung von Teilen der Rechtsliteratur auch der Vorstand selbst, schadenersatzpflichtig; unvollständige Information kann eine Anfechtungsklage nach sich ziehen. ${ }^{142}$

Vielfältige Regulierungen des Gesellschafts- und Kapitalmarktrechts bezüglich der Unternehmenspublizität stellen zwar Informationsrechte des Aktionärs dar, sie sind allerdings nicht an die verbandsrechtliche Position des aktuellen Aktionärs gebunden. Vielmehr sind es Informationsrechte aller Kapitalmarktteilnehmer. Aktionärsschutz konkretisiert sich in diesem Fall als Anlegerschutz. ${ }^{143}$ In der praktischen Ausgestaltung sind diese Informationsrechte Informationspflichten der Aktiengesellschaft. Damit liegt im Vergleich zu dem zuvor beschriebenen Auskunftsrecht auch kein Individualrecht des einzelnen Aktionärs vor, sondern ein Kollektivrecht. ${ }^{144}$ Im Einzelnen zu nennen sind alle Publizitätsregelungen, die die Entscheidungsgrundlage entweder für die Anlageentscheidung (potenzieller Aktionär) oder die Abstimmungs- bzw. Desinvestitionsentscheidung (aktueller Aktionär) verbessern. Von den Publizitätsregelungen des Kapitalmarktrechts sind speziell börsennotierte Aktiengesellschaften betroffen, die Regelungen des Gesellschaftsrechts betreffen i.d.R. alle Aktiengesellschaften. ${ }^{145}$ Von Bedeutung sind hier insbesondere die Verpflichtung zur Erstellung eines Börsenzulassungsprospekts ${ }^{146}$, die jährlichen Offenlegungspflichten, die Zwischenberichterstattung ${ }^{147}$ und die Ad-hoc-Publizität. ${ }^{148}$

141 Vgl. Regierungskommission DCGK (2002), Punkt 6.3; Schneider (2001a), S. B1.

142 Vgl. Raiser (2001), S. 247f.; Ebenroth/Wilken (1993), S. 1818f. Die persönliche Haftung der Organmitglieder soll künftig verschärft werden. Vgl. Bundesjustizministerium (2003).

143 Vgl. Mülbert (1996), S. 98.

144 Vgl. zur Differenzierung Groß (1997), S. 100.

145 So die Regelungen der $\S \S 325-328$ HGB. $\S 326$ HGB sieht für kleine Aktiengesellschaften Erleichterungen bei der Offenlegung vor, die gem. $\S \S 267$ Abs. 3 S. 2 für börsennotierte Gesellschaften jedoch entfallen.

146 Vgl. § 36 Abs. 3, 4 BörsG; §§ 13-47 BörsZulV, sowie z.B. Steiner (1998) m.w.N.

147 Vgl. § 44 Abs. 1 Nr. 3; Abs. 2 BörsG; § 65 BörsZulV bzw. § 44b BörsG; §§ 53-62 BörsZulV, sowie z.B. Dahl (1995); Henes (1995).

148 Vgl. § 15 WpHG, sowie Pellens/Bonse (1999), S. 864-866, ausführlich Fülbier (1998). Einen Überblick über das deutsche Publizitätssystem gibt Pellens (2001), S. 377-384. 
Im Ergebnis kann festgehalten werden, dass die Informationsrechte dazu dienen, dem Aktionär eine sachgemäße Ausübung seiner Herrschaftsrechte zu ermöglichen. Betrachtet man die Entwicklung der Vermögens- und Informationsrechte in den vergangenen Jahren, so fällt auf, dass sich die Informationslage - zumindest für die Aktionäre börsennotierter Gesellschaften - zwar deutlich verbessert hat, dieses jedoch einhergegangen ist mit einigen Einschränkungen der Vermögensrechte. ${ }^{149}$

\subsubsection{Herrschaftsrechte}

\subsubsection{Teilnahme- und Rederecht auf der Hauptversammlung}

Das Recht der Aktionäre auf Teilnahme an der Hauptversammlung wird ebenso wie das Rederecht im Gesetz nicht explizit erwähnt, da es sich nach herrschender Meinung um selbstverständliche Aktionärsrechte handelt. ${ }^{150} \S 118 \mathrm{AktG}$ legt fest, dass die Aktionäre ihre Rechte in der Hauptversammlung ausüben. ${ }^{151}$ Voraussetzung für die Ausübung ist die Möglichkeit der Teilnahme. Das Teilnahmerecht steht allen Aktionären zu, auch den stimmrechtslosen Vorzugsaktionären; es kann auf einen Vertreter des Aktionärs übertragen werden. ${ }^{152}$

Jedem Aktionär steht auf der Hauptversammlung zudem ein Rederecht zu, wie das Teilnahmerecht ist es grundsätzlich unentziehbar. ${ }^{153}$ Das Rederecht bezieht sich jedoch auf Angelegenheiten der Gesellschaft, der Redebeitrag muss somit Bezug zum diskutierten Tagesordnungspunkt haben. ${ }^{154}$ Um den ordnungsmäßigen Ablauf der Hauptversammlung zu gewährleisten, sind Einschränkungen des Rederechts zulässig, solange sie verhältnismäßig sind. ${ }^{155}$ Dabei ist $\mathrm{zu}$ beachten, dass eine Beschränkung der Redezeit das Auskunftsrecht gemäß $\S 131$ Abs. 1 $\mathrm{AktG}$ nicht tangiert, für Fragen ist gesonderte Zeit vorgesehen. ${ }^{156}$

149 So z.B. die Möglichkeit des Bezugsrechtsausschlusses. Zu weiteren Einschränkungen vgl. Pellens/Bonse (1999).

150 Vgl. Heits (1940), S. 15; Siepelt (1995); Quack (1996), S. 113; Wellkamp (1998), S. 33.

151 Vgl. Wellkamp (1998), S. 33; Obermüller/Werner/Winden (2001), S. 91.

152 Vgl. Schmidt (2002), S. 840.

153 Vgl. Wellkamp (1998), S. 33f. Es kann allerdings an die Erfüllung von Voraussetzungen geknüpft sein. Vgl. Obermüller/Werner/Winden (2001), S. 92-94.

154 Vgl. Quack (1996), S. 115; Siepelt (1995), S. 254; Obermüller/Werner/Winden (2001), S. 232-238.

$155 \mathrm{Zu}$ den Voraussetzungen mit Verweisen auf die einschlägige Rechtsprechung ausführlich Quack (1996), S. 114-118; Wellkamp (1998), S. 36-43.

156 Vgl. Wellkamp (1998), S. 37. 


\subsubsection{Stimmrecht}

Durch das Stimmrecht wirkt der Aktionär an der Willensbildung der Hauptversammlung mit. Dabei kann er über alle zur Abstimmung gestellten Anträge befinden und darüber hinaus eigene Anträge einbringen. ${ }^{157}$ Das Stimmrecht steht grundsätzlich jedem Aktionär als ein unentziehbares, nicht abspaltbares Recht aus seiner Mitgliedschaft zu, sofern er die Einlage vollständig geleistet hat. ${ }^{158}$ So heißt es in $\S 12$ Abs. 1 AktG: „Jede Aktie gewährt das Stimmrecht“, „Mehrstimmrechte sind“ gemäß Abs. 2 „unzulässig“. ${ }^{159}$ Das Stimmrecht wird somit nach Nennbeträgen ausgeübt, als einzige Ausnahme vom Prinzip des „OneShare-One-Vote" werden in börsennotierten Aktiengesellschaften Vorzugsaktien ohne Stimmrecht zugelassen.

Das Stimmrecht bietet dem Aktionär die Möglichkeit, bei wesentlichen Entscheidungen Einfluss zu nehmen und ist so Teil der Kompensation für das übernommene Risiko. ${ }^{160}$ Bereits in der Begründung zur Aktienrechtsnovelle 1884 heißt es entsprechend, das Stimmrecht sei das „vorzüglichste Recht des Aktionärs“'161. Aus der Begründung zum AktG 1937 geht hervor, dass eine „verschiedene Behandlung der Aktionäre, je nachdem ob sie Dauer-, Zufalls- oder eben nur Spekulationsaktionäre sind, ... nicht befürwortet werden [kann] $]^{\text {c162 }}$. Trotz der dem Stimmrecht allgemein zugewiesenen hohen Bedeutung ist die Inanspruchnahme des Rechts auf den Hauptversammlungen deutscher Aktiengesellschaften eher gering und in den letzten Jahren weiter rückläufig. Im Jahr 2000 betrug die Hauptversammlungspräsenz bei den DAX-Unternehmen nur $54 \% .{ }^{163}$ Ein wesentlicher Teil der stimmberechtigten (Klein-)Aktionäre übt zudem sein Stimmrecht nicht selbst aus, sondern delegiert es, z.B. an ein Kreditinstitut.

157 Vgl. Obermüller/Werner/Winden (2001), S. 73-79; Raiser (2001), S. 248f.; Wellkamp (1998a), S. 367. Grundlegend zum Stimmrecht Hirschman (1970).

158 Vgl. Esser (1938), S. 2f.; Schmidt (2002), S. 849. Die Kopplung an die Leistung der Einlage wurde mit dem AktG 1937 kodifiziert. Vgl. Heits (1940), S. 17.

$159 \S 12$ Abs. 1 S. 2. Mit dem KonTraG wurden Mehrfach- und Höchststimmrechte für börsennotierte Gesellschaften abgeschafft, sodass jeder Stammaktie grundsätzlich eine Stimme zukommt. Vgl. Baums/Schmitz (1998), S. 21; Wellkamp (1998a), S. 369; Marsch-Barner (1999); Hering/Olbrich (2001), S. 20. Zur Regelung vor Inkrafttreten des KonTraG Adams (1990); Zöllner/Noack (1991); Saenger (1997).

160 Vgl. Easterbrook/Fischel (1983), S. 403-406; Hartmann-Wendels (2001), Sp. $1346 \mathrm{f}$.

161 Entwurf Aktienrechtsnovelle 1884, S. 465.

162 AktG 1937, Amtliche Begründung, S. 11. Zur Rechtslage vor den Neuregelungen des AktG 1937 vgl. Höher (1929).

1631998 betrug sie noch $61 \%$. Vgl. DSW (2000). Vgl. zu einem Überblick über weitere Studien zur Hauptversammlungspräsenz Bott (2002), S. 411. Die dort ermittelten Präsenzwerte sind ähnlich gering. 
Die Delegation des Stimmrechts ist bereits seit der Aktienrechtsnovelle 1884 grundsätzlich zulässig. ${ }^{164}$ Im heutigen AktG regelt § 134 Abs. 3 AktG die Stimmrechtsausübung durch einen Bevollmächtigten, die an die schriftliche Erteilung einer der Gesellschaft vorzulegenden Vollmacht gebunden ist. Große Bedeutung hat das so genannte Depotstimmrecht, mit dem der Aktionär sein Kreditinstitut für i.d.R. 15 Monate widerrufbar bevollmächtigt, seine Interessen auf den anstehenden Hauptversammlungen zu vertreten. ${ }^{165}$ Dem Aktionär müssen im Vorfeld Informationen und Abstimmungsvorschläge zur Verfügung gestellt werden und er kann zu bestimmten Tagesordnungspunkten Weisungen erteilen, an die das Kreditinstitut gebunden ist (Kontraktionszwang) ${ }^{166}$ Anstelle eines Kreditinstituts kann die Vollmacht auch an Aktionärsvereinigungen ( $\$ 135$ Abs. 9 AktG) oder an die Verwaltung ( $(134$ Abs. 3 S. 3 AktG) übertragen werden. $^{167}$

Mit dem KonTraG wurde ein Versuch zur Beschränkung der vielzitierten „Bankenmacht" unternommen, indem weisungslose Dauervollmachten insbesondere dann unzulässig sind, wenn das Kreditinstitut mit mehr als $5 \%$ am Grundkapital der betroffenen Gesellschaft beteiligt ist. ${ }^{168}$ Für diese Fälle sieht $\S 135$ Abs. 1 S. 3 AktG eine ausdrückliche Weisung des Aktionärs zu den einzelnen Gegenständen der Tagesordnung vor, ebenso wie für die eigene Hauptversammlung des Kreditinstituts. ${ }^{169}$ Zudem wurden die Informationspflichten der Kreditinstitute über eventuelle Interessenkonflikte erweitert. ${ }^{170}$ Dennoch ist auch das derzeit gültige System nach wie vor Kritik ausgesetzt. ${ }^{171}$ Depotstimmrechte und

164 Vgl. Dahmann (1919), S. 56-63; Andreae (1930), S. 10-12. Das Stimmrecht kann grundsätzlich auch durch eine Legitimationszession gem. § 129 Abs. 3 AktG übertragen werden. Ihre praktische Bedeutung ist jedoch gering. Vgl. Raiser (2001), S. 258-265; Pellens (1994), S. 49, ausführlich Westermann (1996); Hoffmann (1999), S. 73-82, zu Neuregelungen des KonTraG Wellkamp (1998a), S. 370f.; Hoffmann (1999), S. 236-240; Reichert/Harbarth (2001), S. 447.

165 Vgl. Wellkamp (1998a), S. 369; ausführlich Schmidt (1994).

166 Vgl. Hüffer (2002), § 135, Rn. 19; Hoffmann (1999), S. 78. Bei der Erstellung der Vorschläge hat sich das Kreditinstitut gem. $\S 128$ Abs. 2 S. 2 „vom Interesse des Aktionärs leiten zu lassen". Zur Informationspflicht ausführlich Bachmann (1999).

167 Vgl. zum im Rahmen des NaStraG neu eingeführten Verwaltungsstimmrecht ausführlich Wiebe (2002).

168 Vgl. Wellkamp (1998a), S. 370. Die Kreditinstitute werden zudem in $\S 135$ Abs. 2 S. 6 verpflichtet, auf die alternativen Vertretungsmöglichkeiten gemäß $\S 125$ Abs. 1 S. 2 und $\S 135$ Abs. 9 hinzuweisen. Zu den Neuregelungen ausführlich Arnold (1998).

$169 \S 135$ Abs. 1 S. 2. Zur Ausübung des Depotstimmrechts auf der eigenen Hauptversammlung kritisch Adams (1997), S. $23 \mathrm{f}$.

${ }^{170} \S 128$ Abs. 2 AktG. Vgl. Arnold (1998), S. 276f.

171 Vgl. beispielhaft Wellkamp (1998), S. 12-14; Geldmacher (2000), S. 231-236, ausführlich Seger (1997). 
Stimmrechte aus eigenem Anteilsbesitz kumulieren sich in Einzelfällen so stark, dass ein einzelnes Kreditinstitut trotz eines eigenen Anteilsbesitzes von weniger als $20 \%$ auf der Hauptversammlung die Stimmrechtsmehrheit innehat. ${ }^{172}$ Dies gilt insbesondere unter Berücksichtigung der geringen Hauptversammlungspräsenzen. ${ }^{173}$ Hinzu kommt eine eventuelle Einflussnahme über Aufsichtsratsmandate. ${ }^{174}$ Die vollständige Abschaffung des Depotstimmrechts wurde seitens des Gesetzgebers dennoch bisher nicht in Erwägung gezogen, da man der Meinung war, dass dieses die Hauptversammlungspräsenzen bei Publikumsgesellschaften so weit reduzieren würde, ${ }^{175}$ dass die Gefahr von Zufallsmehrheiten oder der Dominanz einer aktiven Minderheit bestünde. ${ }^{176}$

$\S 136$ Abs. 1 AktG regelt die Möglichkeit des Stimmrechtsausschlusses in drei klar spezifizierten Fällen. Erstens darf ein Aktionär sein Stimmrecht nicht ausüben, wenn darüber Beschluss gefasst wird, ob er (1) zu entlasten oder (2) von einer Verbindlichkeit zu befreien ist oder (3) ob die Gesellschaft gegen ihn einen Anspruch geltend machen soll. ${ }^{177}$ Diese Regelung betrifft primär Mitglieder von Vorstand und Aufsichtsrat der Gesellschaft. Zweitens darf das Stimmrecht nicht ausgeübt werden, wenn die Mitteilungspflichten des $\S 21 \mathrm{Abs} .1 \mathrm{WpHG}$ über Änderungen der Beteiligungsstruktur nicht erfüllt sind. ${ }^{178}$ Neben dem expliziten Ausschluss von eigentlich stimmberechtigten Aktionären von einzelnen Entscheidungen besteht drittens die Möglichkeit der Emission einer separaten Aktiengattung ohne Stimmrecht (Vorzugsaktien) und die Festlegung von Höchststimmrechten; Letztere sind jedoch nur für nicht-börsennotierte Gesellschaften zulässig. ${ }^{179}$

172 Die sich hieraus ergebenden Interessenkonflikte sind Gegenstand zahlreicher wissenschaftlicher Beiträge. Vgl. beispielhaft Baums/v. Randow (1995); Wellkamp (1998), S. 12-14; Geldmacher (2000), S. 231-236.

173 Vgl. Fn. 163. Alle Kreditinstitute gemeinsam verfügen allein über ihre Depotstimmrechte regelmäßig über deutlich mehr als $75 \%$ der Stimmen von Publikumsgesellschaften. Vgl. Adams (1997), S. 22.

174 Vgl. Mülbert (1996a), S. E 1 ff.; Baums/v. Randow (1995); Schneider/Burgard (1996), S. 1761 .

175 Zur mangelnden Beteiligung der Kleinaktionäre aufgrund von „rationaler Apathie“ vgl. ausführlich Abschnitt III.1.2.1.3.

176 Vgl. Regierungsentwurf KonTraG (1997), S. 2063; Karst (1982), S. 62; Arnold (1998), S. 274. Grundsätzlich positiv auch Gorton/Schmidt (2000), S. 68f.

177 Vgl. zum Stimmrecht in eigener Angelegenheit ausführlich Heits (1940).

178 Vgl. Wilsing (1995), S. 2277. Zu den Mitteilungspflichten bei Erwerb kritischer Beteiligungsgrenzen vgl. ausführlich Abschnitt II.3.5.2.1.

$179 \S 134$ Abs. 1 S. 2 AktG. Die Beschränkung auf nicht-börsennotierte Gesellschaften erfolgte mit dem KonTraG. Vgl. Claussen (1996), S. 491-493; Claussen (1998), S. 181. 
Das Instrument der stimmrechtslosen Vorzugsaktie wurde in der heutigen Form mit dem AktG 1937 eingeführt. ${ }^{180}$ Vorzugsaktien sind in der Regel mit einem kumulativen Dividendenvorteil ausgestattet und verbriefen im Gegenzug kein Stimmrecht in der Hauptversammlung. Sie sind grundsätzlich im Rahmen der Regelungen des $\S 12$ Abs. 1 und der $\S \S 139-141$ AktG frei gestaltbar. Die Stimmrechtsbeschränkung verliert ihre Gültigkeit, wenn die Vorzugsdividende zwei Jahre in Folge nicht in vollem Umfang gezahlt wird. ${ }^{181}$ Ein Stimmrecht steht den Vorzugsaktionären darüber hinaus zu, wenn durch den Beschluss der mit der Aktie verbundene Vorzug unmittelbar oder mittelbar aufgehoben oder beschränkt wird ( $§ 141$ Abs. 1, 2 AktG). ${ }^{182}$ Vorzugsaktien dürfen nach $\S 139$ Abs. 2 AktG bis zur Hälfte des Grundkapitals ausgegeben werden.

Vorzugsaktien werden aufgrund ihrer Auswirkungen auf die Unternehmenskontrolle seit jeher kontrovers diskutiert, da sie den Stammaktionären eine im Verhältnis zur Kapitalbeteiligung überproportionale Einflussnahme sichern. ${ }^{183}$ Hierauf soll im Verlauf der Arbeit noch detailliert eingegangen werden.

\subsubsection{Durchsetzung der Aktionärsrechte}

Der aktienrechtliche Rechtsschutz bezieht sich auf drei grundlegende Bereiche: (1) die Vernichtung mangelhafter Hauptversammlungsbeschlüsse, (2) sonstige Klagemöglichkeiten sowie (3) den Minderheitenschutz. ${ }^{184}$ Abb. 6 gibt einen Überblick über die verschiedenen Instrumente:

180 Der Stimmrechtsbeschränkung lag der Gedanke zugrunde, dass viele Kleinaktionäre ohnehin an einer Mitentscheidung nicht interessiert seien. Vgl. Mülbert (1996), S. 60; Pellens/Hillebrandt (2001), S. 58, sowie bereits Albart (1955), S. 107; Schmidt (2002), S. 762f. Zur Debatte um ihre Einführung vgl. Höher (1929), S. 31-35; Bodem (1932).

181 Vgl. zu Ausgestaltungsmöglichkeiten und Rechtsgrundlagen Klein (1981), S. 22-78; Reckinger (1983), S. 217-219; Bezzenberger (1991), S. 43-112; Hüffer (2002), § 140, Rn. 5; Siebel (1997), S. 637, 645-659.

182 Vgl. Bezzenberger (1991a), S. 121f.; Baums (1994), S. 3; Hüffer (2002), § 141 AktG Rn. 1-11; Werner (1971), S. 69; Hillebrandt/Schremper (2001), S. 535.

$183 \mathrm{Zu}$ Stimmrechtsbündelungen mit Hilfe von Vorzugsaktien ausführlich Pellens/Hillebrandt (2001), S. 60f.

184 Vgl. Obermüller/Werner/Winden (2001), S. 477-479, 512f.; Hoffmann-Becking (2001), sowie Bischof (1998). 


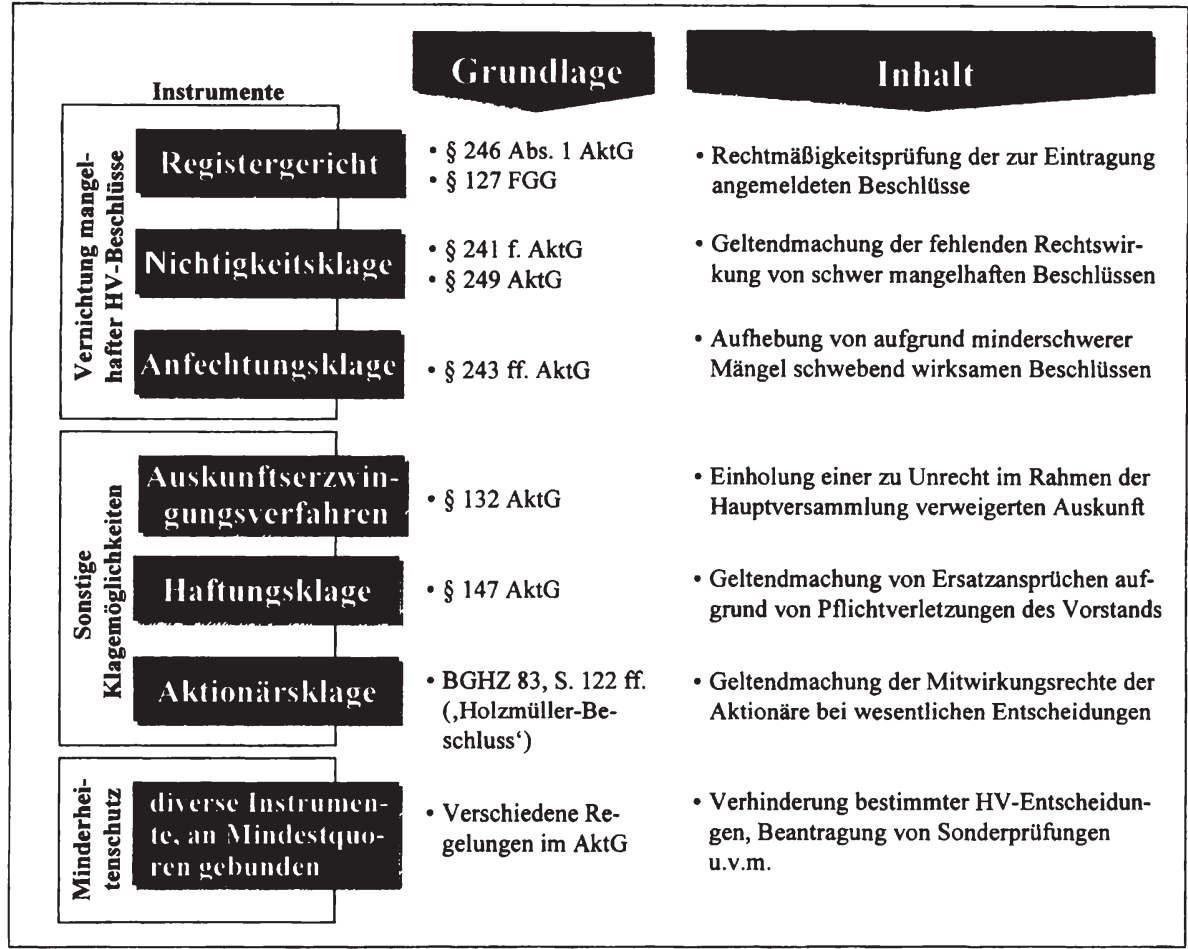

Abb. 6: Konkretisierung des aktienrechtlichen Aktionärsschutzes

\section{Ad 1) Vernichtung mangelhafter Hauptversammlungsbeschlüsse}

Das Registergericht übt eine Kontrollfunktion aus, indem es bei allen zur Eintragung in das Handelsregister angemeldeten Vorgängen eine Rechtmäßigkeitsprüfung durchführt. Im Falle einer Unwirksamkeit des Beschlusses oder bei Vorliegen einer Anfechtung kann die Eintragung verweigert werden. Das Registergericht stellt somit eine aus Sicht des Aktionärs objektive Prüfung der Rechtmäßigkeit der gefassten Beschlüsse sicher. ${ }^{185}$

Die Vernichtung mangelhafter Beschlüsse der Hauptversammlung umfasst die Geltendmachung der Nichtigkeit und die Anfechtungsklage. ${ }^{186} \S \S 241 \mathrm{ff}$. AktG regeln, in welchen Fällen Beschlüsse so große Mängel aufweisen, dass sie keine Rechtswirkung entfalten, also nichtig sind. ${ }^{187}$ Die Nichtigkeit eines Beschlusses kann grundsätzlich von jedermann auch ohne Klage geltend gemacht werden;

\footnotetext{
$185 \mathrm{Vgl}$. Obermüller/Werner/Winden (2001), S. 479.

186 Vgl. Kindl (2000).

$187 \mathrm{Vgl}$. Heße/Enders (2001), S. $232 \mathrm{f}$.
} 
die Nichtigkeitsklage selbst ist in $§ 249$ AktG geregelt. ${ }^{188} \mathrm{Da} \S 241 \mathrm{AktG}$ einen recht umfassenden Katalog nichtiger Beschlüsse aufstellt ist die Rechtssicherheit hier vergleichsweise groß, sodass die Geltendmachung der Nichtigkeit eher die Ausnahme darstellt. ${ }^{189}$

Problematischer als die Geltendmachung der Nichtigkeit gestaltet sich in der Praxis die Anfechtung von Hauptversammlungsbeschlüssen, die aufgrund eines minderschweren Mangels schwebend wirksam sind. ${ }^{190}$ Die Anfechtungsklage ist ebenso wie die Nichtigkeitsklage eine Mitgliedschaftsklage (,actio pro socio“), mit der der einzelne Aktionär Ansprüche der Gesellschaft im eigenen Namen geltend macht. ${ }^{191}$ Die Gründe für eine Anfechtung sind vielfältig und mit $\S 243$ AktG, der auf ,Verletzung des Gesetzes oder der Satzung“ abstellt, nicht abschließend kodifiziert. Besondere Relevanz besitzt in der Praxis die Anfechtung aufgrund von Verfahrensfehlern, so etwa der Verletzung von Informationsrechten. Sofern die Verwaltung eine zu einem Tagesordnungspunkt gestellte Aktionärsfrage nicht pflichtgemäß beantworten kann oder will, eröffnet dies die Möglichkeit einer Anfechtungsklage mit der Folge einer Registersperre für die Dauer des Prozesses. ${ }^{192}$ Diese Tatsache wurde in der Vergangenheit von einzelnen „Berufsaktionären“ missbraucht, sodass die Anfechtungsklage seit geraumer Zeit Gegenstand intensiver juristischer Diskussionen ist. ${ }^{193}$

In den vergangenen Jahren wurden die Möglichkeiten zur Durchsetzung der Aktionärsrechte insgesamt verbessert: Das Vierte Finanzmarktförderungsgesetz verschärft die Haftung der Organmitglieder bei fehlerhaften Ad-hoc-Meldungen und erhöht die Transparenzanforderungen für den Handel derselben in Aktien

188 Vgl. Schmidt (2002), S. 646f.

189 Einen detaillierten Überblick über die Ursachen der Nichtigkeit geben Obermüller/Werner/Winden (2001), S. 482-490.

190 Vgl. Heße/Enders (2001), S. 233; Obermüller/Werner/Winden (2001), S. 480; Wilhelm (2001), S. 520; Saenger (2002).

191 Vgl. Schmidt (2002), S. 645; Schanbacher (1999), S. 23-26 mit Verweis auf alternative Abgrenzungen des Begriffs ,,actio pro socio“.

192 Vgl. bereits Hefermehl (1977); Zöllner (1994), S. 339f., jüngst Wilhelm (2001), S. 520.

193 Vgl. nur beispielhaft Ulmer (1999); Zöllner (2000); Wilhelm (2001); Obermüller/Werner/Winden (2001), S. 539f., zu geplanten Maßnahmen Bundesjustizministerium (2003). Der 63. Deutsche Juristentag 2000 hat Vorschläge zur Reform der Anfechtungsklage unterbreitet, die die Anforderungen an die Erheblichkeit von Informationsmängeln und die Verhältnismäßigkeit der Klage erhöhen sollen. Ziel ist insbesondere die (zeitliche) Reduzierung von Registersperren, um die Handlungsfähigkeit der Unternehmen sicherzustellen. Vgl. 63. DJT (2000); Wilhelm (2001); Habersack (2001). Zu aktuellen Reformvorschlägen vgl. auch Saenger (2002). 
des eigenen Unternehmen (,directors dealings“). ${ }^{194}$ Über die im TransPuG kodifizierte Comply-or-Explain-Regelung des $\S 161$ AktG werden die Organmitglieder verpflichtet, ihre Handlungsmaßstäbe $\mathrm{zu}$ definieren und sie damit für ihre Aktionäre transparent zu machen. ${ }^{195}$ Diese Änderungen könnten die Durchsetzbarkeit der Aktionärsrechte begünstigen, da sie zu einer Konkretisierung der Pflichten der Organmitglieder führen.

\section{Ad 2) Sonstige Klagemöglichkeiten}

Mit der oben dargestellten Anfechtungs- und der Nichtigkeitsklage verfügen auch Kleinstaktionäre über ein Instrument, um gegen konkrete Hauptversammlungsbeschlüsse vorzugehen. ${ }^{196}$ Unabhängig von einer bestimmten Mindestbeteiligung ist auch das Auskunftserzwingungsverfahren gemäß $\S 132$ AktG. Es bietet den Aktionären die Möglichkeit, im Rahmen der Hauptversammlung verweigerte Informationen unabhängig von konkreten Beschlüssen einzuklagen. ${ }^{197}$

Sofern die Verwaltung Mitwirkungsrechte der Aktionäre außerhalb der Hauptversammlung verletzt, bietet die so genannte „Aktionärsklage“ Rechtsschutz. Diese Klagemöglichkeit, wenngleich nicht explizit im Gesetz verankert, besitzt besondere Relevanz bei Strukturmaßnahmen und wurde wesentlich durch die Rechtssprechung geprägt („Holzmüller-Beschluss“ des BGH). ${ }^{198}$ Geschützt wird die Mitentscheidungsbefugnis der Aktionäre in Fragen, die von ihren ökonomischen Auswirkungen einer Satzungsänderung gleichkommen. ${ }^{199}$ So urteilt der BGH: „Macht ein Aktionär [...] geltend, der Vorstand habe die notwendige Zustimmung nicht eingeholt, so kann er die Abwehrklage erheben." ${ }^{200}$

Von der Aktionärsklage aufgrund der Verletzung von Mitentscheidungskompetenzen $\mathrm{zu}$ trennen ist die Haftungsklage aufgrund von Pflichtverletzungen der Vorstandsmitglieder nach $\S 147 \mathrm{AktG}^{201}$ Die Haftung der Vorstandsmitglieder ist durch das KonTraG verschärft worden. ${ }^{202}$ Dennoch ist die Geltendmachung

\footnotetext{
194 Vgl. Viertes Finanzmarktförderungsgesetz; Rudolph (2002); Spindler (2002); Großmann/Nikoleyczik (2002); Kugler/Rittler (2002).

195 Vgl. Regierungskommission DCGK (2002); Noack (2002); Seibert (2002).

196 Vgl. Schiessl (1999), S. 444.

197 Vgl. Obermüller/Werner/Winden (2001), S. 265-270.

198 Vgl. BGHZ 83, S. 122ff.; Obermüller/Werner/Winden (2001), S. 479, $512 \mathrm{f}$.

199 Vgl. Schmidt (2002), S. $648 f$.

200 BGHZ 83, S. 134.

201 Vgl. Schmidt (2002), S. 651f.; Schiessl (1999), S. 449; Wellkamp (1998), S. 120-131. Einen Überblick über die Diskussion zur Organhaftung gibt Mertens (1996a).

202 Vgl. Ulmer (1999a), S. 292f. Wegweisend für eine Haftungsverschärfung war auch die „ARAG/Garmenbeck-Entscheidung“ des BGH vom 21.4.1997 (BGHZ 135, 244). Vgl. Schiessl (1999), S. 449; Ulmer (1999a), S. 294f.
} 
von Ersatzansprüchen der Gesellschaft in Deutschland erheblich schwieriger als beispielsweise in den USA mit dem System der (double) derivative suit. ${ }^{203}$ So ist ein an bestimmte Quoren geknüpftes Erzwingungsverfahren erforderlich. ${ }^{204}$

\section{Ad 3) Minderheitenschutz}

An bestimmte Mindestbeteiligungsquoten knüpfen auch die Minderheitenrechte an, die mit dem AktG 1965 als systematische Institution eingeführt wurden. ${ }^{205}$ Die folgende Tabelle gibt einen Überblick über die wichtigsten, an bestimmte Kapitalanteile geknüpfte Minderheitenrechte: ${ }^{206}$

\begin{tabular}{|c|c|}
\hline $\begin{array}{l}\text { Anteil am } \\
\text { Grundkapital } \\
\text { (KA) }\end{array}$ & Mit dem Kapitalanteil verbundene Rechte \\
\hline $\mathrm{KA}<5 \%$ & Keine besonderen Rechte \\
\hline $\begin{array}{c}\mathrm{KA} \geq 5 \% \\
\text { bzw. } \\
500.000 €\end{array}$ & $\begin{array}{l}\text { Einberufung der Hauptversammlung }{ }^{207} \text { und Aufnahme weiterer Tagesord- } \\
\text { nungspunkte }(\S 122 \mathrm{AktG}) \text {, Verlangung einer Mindestdividende von } 4 \% \\
(\S 254 \mathrm{Abs} .1 \mathrm{AktG}),{ }^{208} \text { Verhinderung der Eingliederung der Gesellschaft } \\
\text { durch Mehrheitsbeschluss ( }(320 \mathrm{AktG}) \text {, Beantragung von Sonderprüfun- } \\
\text { gen }(\S \S 258 \text { Abs. } 2 \text { S. } 3 ; 260 ; 315 \mathrm{AktG}) \text {, Verhinderung eines Squeeze } \\
\text { Out }^{209}\end{array}$ \\
\hline
\end{tabular}

203 Vgl. Romano (1991); Ulmer (1999a), S. 302-318; Pellens (2001), S. 57; Schmidt (2001), S. 122-129.

204 Vgl. Schiessl (1999), S. 448f., kritisch Ulmer (1999a), S. 292f. Die Einführung einer gesetzlich verankerten Aktionärsklage wird daher immer wieder gefordert und zur Zeit erneut diskutiert. Vgl. bereits Großfeld (1968), S. 224-312, sowie Ulmer (1999a), S. 339; jüngst Bundesjustizministerium (2003).

205 Vgl. Schenk (1997), S. 652; Henn (1998), Rn. 743.

206 Sofern nicht anders angegeben, beziehen sich alle Paragraphen auf das AktG. Die Aufzählung ist nicht abschließend. Vgl. Obermüller/Werner/Winden (2001), S. 214-229.

207 Die Einberufung der Hauptversammlung ist ausschließlich an den Kapitalanteil gebunden, eine Beteiligung von $500.000 €$ genügt in diesem Fall nicht.

208 Die Satzung kann jedoch vorsehen, dass Vorstand und Aufsichtsrat den gesamten Jahresüberschuss in andere Gewinnrücklagen einstellen dürfen. Vgl. § $58 \mathrm{Abs} .2 \mathrm{AktG}$.

209 Art. 7 WpÜG; vgl. Wenger/Kaserer/Hecker (2001), S. 320. Zum Verfahren des Squeeze Out vgl. Kallmeyer (2000); Habersack (2001). 


\begin{tabular}{|c|c|}
\hline $\begin{array}{l}\text { Anteil am } \\
\text { Grundkapital } \\
\text { (KA) }\end{array}$ & Mit dem Kapitalanteil verbundene Rechte \\
\hline $\begin{array}{c}\mathrm{KA} \geq 10 \% \\
\text { bzw. } \\
1 \text { Mio. } €\end{array}$ & $\begin{array}{l}\text { Abberufung von Aufsichtsratsmitgliedern }(\S 103 \text { Abs. } 3 \mathrm{~S} .3 \mathrm{AktG}) \text {, Be- } \\
\text { stellung von anderen als von der Verwaltung vorgesehenen Prüfern } \\
(\S \S 142 \mathrm{Abs} .2 \mathrm{~S} .1 \text {, Abs. } 4 \text { S. } 1 ; 147 \text { Abs. } 2 \mathrm{~S} .2 \text { AktG), Verlangen einer } \\
\text { gesonderten Entlastung einzelner Mitglieder der Verwaltung }(\S 120 \text { Abs. } 1 \\
\text { S. } 2 \text { AktG), Verhinderung eines befreienden Konzernabschlusses des Mut- } \\
\text { terunternehmens }(\S 291 \text { Abs. } 3 \text { S. } 1 \text { HGB })^{210} \text {, Klageerzwingungsrecht } \\
(\S 147 \mathrm{AktG})^{211}\end{array}$ \\
\hline $\begin{array}{l}\mathrm{KA} \geq 25 \% \\
\text { (auf } \mathrm{HV} \\
\text { vertreten) }\end{array}$ & $\begin{array}{l}\text { Sperrminorität, ermöglicht Verhinderung von Satzungsänderungen ( }(179 \\
\text { AktG), Kapitalerhöhungen }(\S \S 182,193 \mathrm{AktG}) \text {, Umwandlungen }(\S 162 \\
\text { AktG), Verschmelzungen }(\S \S 340,340 \mathrm{c} \text { AktG), Unternehmensverträgen } \\
\text { ( }(293 \mathrm{AktG}) \text { und der Auflösung }(\S 262 \mathrm{AktG})^{212}\end{array}$ \\
\hline
\end{tabular}

Tab. 1: Minderheitenrechte in Abhängigkeit alternativer Kapitalanteile

Für die Ausübung der Minderheitenrechte ist jeweils der Anteil am Grundkapital entscheidend. Die aktiven Minderheitenrechte, ${ }^{213}$ die verschiedenste Anträge bei Quoren von 5 bzw. $10 \%$ ermöglichen, können dementsprechend von Stammund Vorzugsaktionären genutzt werden ${ }^{214}$ Die passiven Minderheitenrechte, wie sie sich aus der Sperrminorität von $25 \%$ ergeben, stellen hingegen auf das bei der Beschlussfassung vertretene Grundkapital ab, sodass sich bei einer nicht vollständigen Vertretung der Stammaktionäre auf der Hauptversammlung abweichende Quoren ergeben.

\subsection{Gleichheitsgrundsatz}

Da im weiteren Verlauf der Untersuchung die Beziehung zwischen den einzelnen Aktionären und das Verhältnis unterschiedlicher Aktionärsgruppen zum Management immer wieder zentrales Thema sein wird, soll im Folgenden auf den Gleichbehandlungsgrundsatz eingegangen werden. In $\S 53$ a AktG ist die Gleichbehandlung der Aktionäre in dem Sinne gefordert, dass sie „unter gleichen Voraussetzungen gleich zu behandeln sind“. Als Gleichbehandlungsmaß-

210 Gilt ausschließlich bei $\mathrm{KA} \geq 10 \%$.

211 Das Klageerzwingungsrecht soll künftig bereits ab einem Anteil von 1\% (100.000 €) gelten. Vgl. Bundesjustizministerium (2003).

212 Während im deutschen Aktienrecht grundsätzlich Stimmrechts- und nicht Kapitalanteile von Bedeutung sind (mit Ausnahme von Grundlagenbeschlüssen), stellen die Minderheitenrechte auf Kapitalanteile ab. Vgl. Raiser (2001), S. 274.

213 Vgl. Pellens (1994), S. 50.

214 Vgl. Obermüller/Werner/Winden (2001), S. 218. 
stab für die Anzahl der Stimmrechte, die Höhe der Gewinnbeteiligung u.ä. wird für gewöhnlich die Höhe der Kapitalbeteiligung herangezogen. ${ }^{215}$ Absolute Gleichheit gilt bei den so genannten Hilfsrechten, die jedem Aktionär unabhängig von seiner Beteiligungshöhe zustehen, wie z.B. dem Recht auf Teilnahme an der Hauptversammlung.

Eine unzulässige Ungleichbehandlung liegt dann vor, wenn sie nicht im Einverständnis mit dem betroffenen Aktionär erfolgt, ihr ein sachlicher Grund fehlt bzw. sie nicht durch die Satzung abgedeckt ist. ${ }^{216}$ Satzungsgemäß ist eine Ungleichbehandlung verschiedener Aktionäre z.B. immer dann, wenn die Satzung Aktien mit unterschiedlichen Rechten ausstattet, also z.B. Vorzugsaktien emittiert. ${ }^{217}$ Der Gleichbehandlungsgrundsatz ist damit zwischen den verschiedenen Aktiengattungen bezogen auf die relevanten Ausstattungsmerkmale aufgehoben, er gilt jedoch nach wie vor zwischen den Aktionären einer Gattung. ${ }^{218}$ Der Gleichbehandlungsgrundsatz bezieht sich immer auf das Verhältnis zwischen Gesellschaft und Aktionären; im Gegensatz zu der zuvor diskutierten Treuepflicht betrifft er nicht das Verhältnis der Aktionäre untereinander. ${ }^{219}$ Hauptversammlungsbeschlüsse, die gegen den Gleichbehandlungsgrundsatz verstoßen, sind nach $§ 243$ Abs. 1 AktG anfechtbar. ${ }^{220}$

\subsection{Besonderheiten im Konzern}

Die im Verlauf des Kapitels diskutierten Schutzmechanismen gelten jeweils nur für die Aktionäre der jeweiligen Einzelunternehmung. ${ }^{221}$ Ist ein Unternehmen konzernverbunden, so ergeben sich Verschiebungen in der Verfügungsrechtsstruktur, die zu einer Aufweichung der im AktG kodifizierten Rechte für die An-

215 Vgl. Raiser (2001), S. 117; Lutter/Zöllner (1998), Rn. 8, 29f.; Hüffer (1999), Rn. 6.

216 Vgl. Hüffer (1999), Rn. 4, zu „sachlichen Gründen“ Rn. 10c; Hillebrandt/Schremper (2001), S. 535.

217 Vgl. Schmidt (2002), S. 462; Hüffer (1999), Rn. 5.

218 Vgl. Hillebrandt/Schremper (2001), S. 535f.; Raiser (2001), S. $117 \mathrm{f}$.

219 Vgl. Hüffer (1999), Rn. 4.

220 Vgl. Hüffer (1999), Rn. 12; Lutter/Zöllner (1998), Rn. 32f.

221 Vgl. Kirchner (1984), S. 233; Schenk (1997), S. 652. Die Diskussion um die Aktionärsrechte in konzernverbundenen Unternehmen ist nicht neu. Bereits 1935 hat Lehmann den „Konzern als Grundlage von Stimmrechtsproblemen“ identifiziert. Vgl. Lehmann (1935), S. 5. Vgl. außerdem die Arbeit von Traisbach (1934), zum „Stimmrecht der Muttergesellschaften und Tochtergesellschaften im Aktienrecht". 
teilseigner des Mutterunternehmens führen können. ${ }^{222}$ Konkret ergibt sich aus der Konzernbildung eine Kompetenzverlagerung auf die Verwaltungsorgane des Mutterunternehmens, die verschiedenste, eigentlich den Aktionären zugedachte Entscheidungen auf Konzernebene ohne Beteiligung der Anteilseigner treffen können. $^{223}$ Das Konzernrecht als mögliches Schutzinstrument beschreibt Schmidt ,als ein Rechtsgebiet, dessen Aufgabe sich auf den Schutz abhängiger Unternehmen, auf den Schutz außenstehender Gesellschafter und auf den Schutz der Gläubiger konzentriert“224. Ein eigenständiger, auf die Anteilseigner der Mutterunternehmung bezogener „Konzernaktionärsschutz" besteht bis heute nicht, er konkretisiert sich vielmehr durch richterliche Entscheidungen, die Analogien des Rechts der Einzelunternehmung bemühen. ${ }^{225}$

In der Praxis ist der größte Teil der deutschen, börsennotierten Aktiengesellschaften konzernverbunden. ${ }^{226}$ Für die vorliegende Untersuchung bedeutet dies, dass die vorgestellten Schutzmechanismen zwar bezogen auf die einzelne Gesellschaft so zutreffen, im konkreten Fall jedoch entweder durch Schutzbestimmungen für abhängige Unternehmen ergänzt werden oder - aus Sicht der Anteilseigner der Mutterunternehmung - in Einzelfällen nur begrenzt greifen.

Als Ergebnis der rechtlichen Analyse bleibt festzuhalten, dass dem Aktionär über sein Stimmrecht in der Hauptversammlung sowie indirekt über den Aufsichtsrat zumindest theoretisch ein Einflusspotenzial auf das Management der Aktiengesellschaft zukommt. Kleinaktionäre haben in der Praxis jedoch kaum Einflussmöglichkeiten, sie sind auf die Schutzbestimmungen des Gesellschaftsrechts angewiesen. Diese schützen jedoch nur vor juristisch relevanten Pflichtverletzungen des Managements und nicht vor schlechten Managementleistungen. Die so entstehenden Konfliktebenen zwischen Aktionären und Management einerseits und verschieden einflussreichen Aktionärsgruppen andererseits sind Bestandteil der Analyse von Kapitel III. Nachdem in der vorangegangenen rechtlichen Analyse die Eigenkapitalgeber als homogene Gruppe betrachtet

222 Vgl. Lutter (1985), S. 837; Pellens (1994), S. 1f.; Kratz (1995), S. 64-71; Schenk (1997), S. 653, sowie bereits Braeß/Karten (1967). Zu divergierenden Aktionärsrechten bei konzernverbundenen Unternehmen auch Kirchner (1984), S. 236-245; Mülbert (1996), S. 1736, mit Fokus auf das Informationsrecht Ebenroth/Wilken (1993).

223 Vgl. ausführlich Pellens (1994), S. 52-83, sowie Kirchner (1984), Fn. 39; Westermann (1986), S. 437-443.

224 Schmidt (2002), S. 491. Vgl. auch Kirchner (1984), S. 227f.; Schenk (1997), S. 654.

225 Vgl. Westermann (1986), S. 422-424; Pellens (1994), S. 83. Zu besonderen Aktionärsschutzbestimmungen bei Abhängigkeit vgl. Bischof (1998), S. 26. Zur Ausgestaltung des Konzernrechts sowie zu Reformvorschlägen ausführlich auch Schenk (1997a), S. $226 \mathrm{ff}$.

226 Vgl. Görling (1993); Pellens (1994), S. 314; Schenk (1997), S. 652f.; Busse von Colbe (2000), S. 299. 
wurden, sollen im Folgenden zunächst die unterschiedlichen Aktionärsgruppen differenziert werden.

\section{Charakterisierung und Bedeutung verschiedener Aktionärstypen}

\subsection{Kleinaktionäre}

Klein- oder Publikumsaktionäre werden dadurch charakterisiert, dass sie mit ihrem Stimmrechtsanteil keinen entscheidenden Einfluss auf die Unternehmenspolitik ausüben können. ${ }^{227}$ Aufgrund der geringen Möglichkeit, faktisch Einfluss auszuüben, zeigen Kleinaktionäre regelmäßig kein Interesse, die Geschicke ihres Unternehmens durch Teilnahme an der Hauptversammlung und Ausübung des Stimmrechts zu beeinflussen. Sofern Sie ihr Stimmrecht überhaupt ausüben, geschieht das häufig über das Depotstimmrecht der Kreditinstitute. ${ }^{228}$ Hauptmotive des Erwerbs von Aktien durch Kleinaktionäre sind entsprechend die Geldanlage und/oder Spekulation. ${ }^{229}$ In der Literatur werden sie daher teilweise unter die Gläubiger subsumiert, ${ }^{230}$ was aufgrund ihrer weitaus größeren Risikoposition jedoch verfehlt erscheint. ${ }^{231}$

Bis zu welchem Kapital- bzw. Stimmrechtsanteil ein Aktionär als Kleinaktionär anzusehen ist, kann nicht allgemeingültig beantwortet werden. Als Indiz könnte z.B. die Meldepflicht des WpHG dienen, die ab einer Stimmrechtskonzentration von $5 \%$ ausgelöst wird. ${ }^{232}$ Dabei ist jedoch zu berücksichtigen, dass ein wesentlicher Einfluss auf das Management in einer sehr breit gestreuten Gesellschaft mit zusätzlich geringer Hauptversammlungspräsenz bereits mit einem geringeren Anteil erzielt werden kann als in einer Gesellschaft mit mehreren, vergleichbar großen Aktionären.

\subsection{Großaktionäre}

Analog zur Abgrenzung der Kleinaktionäre ist das konstituierende Merkmal für einen Großaktionär die Möglichkeit, einen wesentlichen Einfluss auf die Unter-

\footnotetext{
227 Vgl. Jansch (1999), S. 22.

228 Vgl. hierzu Kapitel II.2.2.4.2.

229 So bereits Großfeld (1968), S. 191.

230 So z.B. Schreyögg/Steinmann (1981), S. 534; Jansch (1999), S. 67.

231 Aufgrund der geringeren Möglichkeit, sich über die Unternehmensentwicklung sachkundig zu informieren, ist das Risiko der Kleinanleger sogar oft höher als das der Großinvestoren. Diese werden eher in der Lage sein, eine Negativentwicklung zu erkennen und die Desinvestition einzuleiten.

232 Vgl. ausführlich Abschnitt II.3.5.
} 
nehmenspolitik auszuüben. Bei der Betrachtung von Großaktionären erscheint es sinnvoll, unterschiedliche Typen zu differenzieren, da diese jeweils unterschiedliche Interessenlagen aufweisen.

\subsubsection{Institutionelle Investoren}

Institutionelle Investoren sind dadurch gekennzeichnet, dass die Beteiligung an anderen Unternehmen für sie zum operativen Geschäft gehört und mit der Beteiligung keine strategischen Ziele, wie die Nutzung der unternehmerischen Ressourcen, verbunden sind. ${ }^{233} \mathrm{Zu}$ nennen sind hier primär Fondsgesellschaften, Beteiligungsgesellschaften, Versicherungen und Universalbanken ${ }^{234}$, wobei letztere eine Sonderstellung einnehmen. ${ }^{235}$

Fondsgesellschaften gehen Beteiligungen mit Kundengeldern ein, die sie als Sondervermögen getrennt vom eigenen Gesellschaftsvermögen verwalten $(\S 6$ Abs. 1 S. 3 KAGG) ${ }^{236}$ Eigentümer der Kapitalanlagegesellschaften sind in der Regel Kreditinstitute. ${ }^{237}$ Welche Interessen Fondsgesellschaften in ihrer Funktion als Großaktionär verfolgen, ist nur schwer eindeutig bestimmbar. ${ }^{238}$ Nach $\S$ 10 Abs. 1 KAGG sind Kapitalanlagegesellschaften zwar verpflichtet, bei der Ausübung der mit dem Sondervermögen verbundenen Stimm- und Gläubigerrechte ausschließlich im Interesse der Anteilsinhaber zu handeln. ${ }^{239}$ Im Einzelfall ist jedoch denkbar, dass die Interessen der Fonds-Anteilseigner denen des Mutterunternehmens der Investmentgesellschaften zuwiderlaufen. ${ }^{240}$ Dieses er-

233 Vgl. ähnlich Baums (1996), S. 324; Bassen (2002a), S. 15. Vgl. zur Rolle von institutionellen Investoren Salzberger (1999); Gillan/Starks (2000); Rock (1994); Smith (1996), ausführlich Fraune (1996), sowie Bassen (2002, 2002a), der eine Befragungsstudie zur Rolle von institutionellen Investoren in deutschen Unternehmen durchführt.

234 Die Bezeichnung Universalbanken wird hier gewählt, um sie von den Fondsgesellschaften abzugrenzen, die nach $\S 2$ Abs. 1 KAGG i.V.m. $\S 1$ Abs. 1 Nr. 6 KWG auch als Kreditinstitute gelten.

$235 \mathrm{Zu}$ einer Abgrenzung verschiedener Typen von institutionellen Investoren vgl. Bassen/Hauck (2001); Bassen (2002a), S. 14-16.

236 Eine Sonderform der Fondsgesellschaft sind Private-Equity- sowie Venture-Capital-Gesellschaften, die insbesondere in Wachstumsphasen (Venture-Capital-Gesellschaften) finanzielle Mittel auch an nicht-börsennotierte Unternehmen zur Verfügung stellen. Sie nehmen häufig über die Besetzung von Aufsichtsratsmandaten Einfluss auf die Geschäftsführung. Vgl. Kraft (2001); Golland/Heckemüller (2002) zu Private-Equity- sowie Gaida (2002); Taga/Forstner (2002) zu Venture-Capital-Gesellschaften.

237 Vgl. Schmidt et al. (1997), S. 103. Zu den Erwerbsgrenzen für einzelne Fonds und Investmentgesellschaften vgl. Fraune (1996), S. 77f.

238 Vgl. zum Verhalten von Fondsgesellschaften als Großaktionär grundlegend Faccio/Lasfer (2000), ausführlich auch Brancato (1997).

239 Vgl. auch Fraune (1996), S. 84f.

240 Vgl. Black (1990), S. 595-608; Blair (1995), S. 155-172. 
scheint insbesondere vor dem Hintergrund kritisch, dass die Kapitalanlagegesellschaften ihr Stimmrecht häufig nicht selbst ausüben, sondern es z.B. an ihre Depotbank, die in der Regel mit der Muttergesellschaft identisch ist, delegieren. $^{241}$

Beteiligungsgesellschaften erwerben ebenso wie Fondsgesellschaften Aktien verschiedener Gesellschaften. Die Finanzierung erfolgt jedoch nicht am Kapitalmarkt, sondern die Investitionen werden unmittelbar aus dem Gesellschaftsvermögen getätigt. Die Anreizstruktur ist somit klar definiert; das Abstimmungsverhalten einer Beteiligungsgesellschaft wird sich an den Interessen der eigenen Eigenkapitalgeber orientieren. Beteiligungsgesellschaften dienen vorwiegend größeren Bank- oder Versicherungskonzernen zur Bündelung ihrer strategischen Beteiligungen. ${ }^{242}$

Versicherungen erwerben Beteiligungen nicht nur zur Verfolgung strategischer Ziele, sondern darüber hinaus unter Renditegesichtspunkten zur Anlage ihrer Kundengelder. Für Versicherungen gilt, ebenso wie für Fondsgesellschaften, dass sie ihre Stimmrechte teilweise an befreundete Kreditinstitute delegieren. ${ }^{243}$ Universalbanken gehen darüber hinaus auch direkt Beteiligungen außerhalb ihres operativen Geschäfts ein, weshalb sie ebenfalls unter die institutionellen Investoren subsumiert werden. ${ }^{244}$ Die Motive von Kreditinstituten, Beteiligungen an Nicht-Finanzunternehmen zu erwerben, sind vielfältig. ${ }^{245}$ Neben der Anlage freier Mittel spielt die Möglichkeit der Einflussnahme eine große Rolle, da häufig zusätzliche Interessen aus einer Kreditbeziehung bestehen. ${ }^{246}$ Durch das Depotstimmrecht ihrer Kunden können Kreditinstitute über die eigenen Stimmrech-

241 Vgl. Baums (1996), S. 329; Schmidt et al. (1997), S. 103f. Vgl. jedoch $\S 10$ Abs. 1 S. 3 und 4 KAGG, die Stimmrechtsdelegationen nur in Einzelfällen zulassen. Mit Art. 3 Abs. 2 wurde zusätzlich die dauerhafte Bestellung unabhängiger Stimmrechtsvertreter durch die Kapitalanlagegesellschaft zulässig. Vgl. Noack (2002), S. 626.

242 Beteiligungsgesellschaften gründen häufig eigene Venture-Capital- oder Private-EquityGesellschaften zur Anlage ihrer Mittel. Vgl. hierzu Fußnote 236.

243 Vgl. Baums/Fraune (1995), S. 106f.; Blair (1995), S. 152f.; Baums (1996), S. 329; Schmidt et al. (1997), S. 106. Vgl. zur Anreizstruktur von Versicherungen im Rahmen der Aktienanlage ausführlich Fraune (1996), S. 58-75.

244 Vgl. Mülbert (1998), S. 448; Boehmer (2000), S. 121.

245 Einen Überblick über die verschiedenen Motive gibt Mülbert (1998).

246 Vgl. Baums/von Randow (1995), S. 448f., sowie Mülbert (1998), S. 458-484. 
te hinaus Einfluss geltend machen. ${ }^{247}$ Zusätzliche Macht ergibt sich aus eventuellen Aufsichtsratsmandaten. ${ }^{248}$

\subsubsection{Nicht-institutionelle Großaktionäre}

Die nicht-institutionellen Großaktionäre gliedern sich auf in Industrieunternehmen, öffentliche Haushalte, Familien, Privatpersonen und Stiftungen, wobei letztere regelmäßig unter die Familien subsumiert werden. Unter „Industrieunternehmen “249 werden im Rahmen dieser Arbeit auch alle Nicht-Finanzdienstleister aus dem Dienstleistungsbereich subsumiert. Ihnen ist gemein, dass sie ihre Beteiligungsentscheidung nicht nur unter Renditegesichtspunkten treffen, sonder häufig strategische Überlegungen einbeziehen. ${ }^{250}$ Öffentliche Beteiligungen an Aktiengesellschaften in großem Umfang sind seit den Privatisierungen im Luftverkehrs-, Energie- und Telekommunikationssektor seltener geworden. ${ }^{251}$ Sofern Familien einen größeren Anteil an einer Aktiengesellschaft halten, datiert dieses häufig auf eine Zeit zurück, in der die Gesellschaft noch nicht börsennotiert war. ${ }^{252}$ Zusätzlich zu den bisher genannten Gruppen werden Ausländer häufig als separate Aktionärsgruppe aufgeführt. Sinn macht die separate Erfassung der Ausländer dann, wenn die Tatsache, dass der Aktionär kein Inländer ist, die Willensbildung auf der Hauptversammlung stärker determiniert als die eigentliche Identität, die sich in der Zugehörigkeit zu einer der anderen Gruppen ausdrückt. Dies wäre vor dem Hintergrund denkbar, dass ausländische Aktionäre ihre Stimmrechte in der Praxis oft nur eingeschränkt wahrnehmen. ${ }^{253}$

Gemein ist allen Großaktionären, dass sie ihren Einfluss auf die Unternehmenspolitik nicht nur durch die Ausübung ihres Stimmrechts auf der Hauptversammlung wahrnehmen, sondern z.B. über Analystenpräsentationen und Einzelgespräche - ungeachtet des formellen Gleichbehandlungsgebots aller Aktionäre ${ }^{254}$

247 Vgl. die Ausführungen in Abschnitt II.2.2.4.2. Die so genannte „Macht der Banken“ ist seit Jahrzehnten immer wieder Gegenstand theoretischer Diskussion und empirischer Studien. Exemplarisch sei hier auf die Arbeiten von Cable (1985); Kaplan (1994); Perlitz/Seeger (1994); Edwards/Fischer (1994); Gorton/Schmid (2000); Franks/Mayer (1997, 1997a, 1998) und Edwards/Nibler (2000) verwiesen.

248 Vgl. Breuer (1998), S. 538; ausführlich Seger (1997); Brendel (2001).

249 Nicht-Finanzdienstleister umfassen Industrie- und Dienstleistungsunternehmen.

250 Vgl. zu Kriterien einer Beteiligungsentscheidung Hillebrandt (2001).

251 Vgl. La Porta et al. (2002), einen Überblick über verschiedene Studien zu Staatsbeteiligungen geben Sun/Tong/Tong (2002).

252 Vgl. Ehrhardt/Nowak (2002), S. 19-23, sowie Ehrhardt/Nowak (2002a), S. 25.

253 Vgl. Fraune (1996), S. 102f., sowie insb. S. 104-111; Schmidt et al. (1997), S. 107.

254 Vgl. § 53a AktG, sowie in Bezug auf die informelle Gleichbehandlung Regierungskommission DCGK (2002), Punkt 6.3. 
- regelmäßig einen direkten Kontakt zum Management haben. ${ }^{255}$ Je nachdem wie groß der Stimmrechtsanteil eines Aktionärs ist, wird über diese informellen Kontakte häufig großer Einfluss geltend gemacht, zumal ein größerer Kapitalbzw. Stimmrechtsanteil gelegentlich auch mit einem Sitz im Aufsichtsrat verbunden ist. $^{256}$

\subsection{Aktionärsstrukturen im internationalen Vergleich}

Charakteristisch für Deutschland ist der geringe Anteil von Aktiengesellschaften, die sich vollständig im Streubesitz befinden. Stattdessen verfügen die meisten Aktiengesellschaften über mindestens einen Großaktionär. Entsprechend befindet sich auch der größte Anteil der Aktien deutscher Gesellschaften in den Händen anderer Unternehmen; Privatpersonen halten hingegen nur $15 \%$ der Aktien. Die folgende Abbildung gibt einen Überblick über die Entwicklung des Aktienbesitzes in Deutschland.

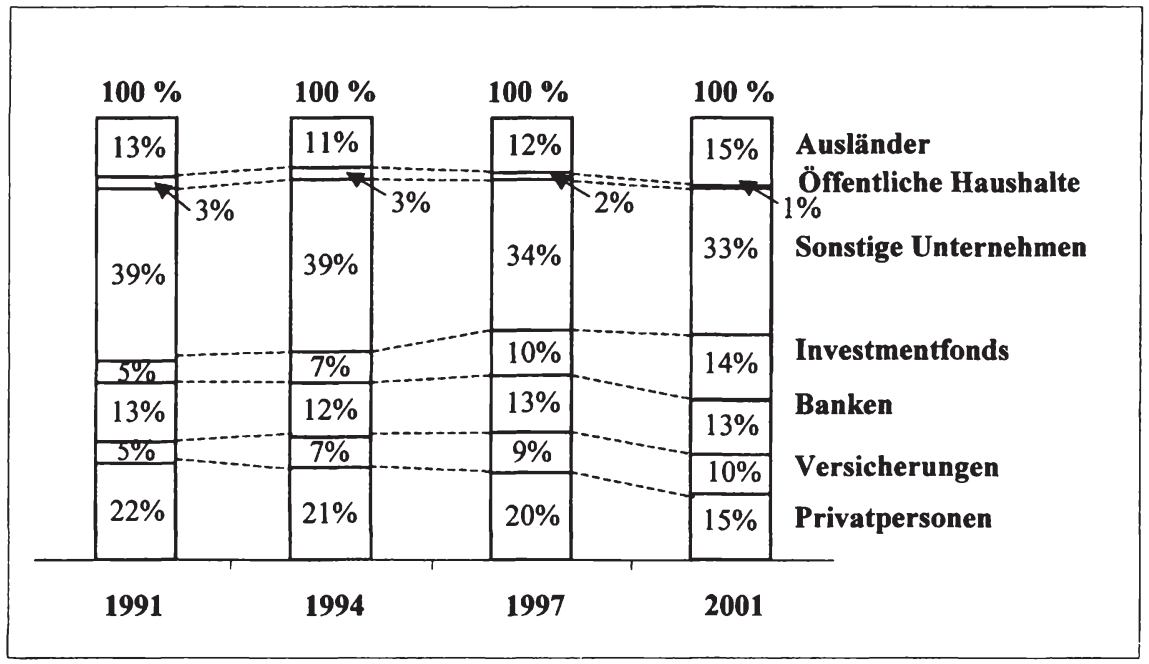

Abb. 7: Entwicklung des Aktienbesitzes in Deutschland ${ }^{257}$

Auffällig ist, dass der von Privatpersonen gehaltene Anteil seit 1991 deutlich zurückgegangen ist. ${ }^{258}$ Dieses könnte zunächst überraschen, da die private Akti-

Vgl. Gode (1996), S. 316; Mallin (2001), S. 118.

Vgl. Janßen (2001), S. 568.

Daten entnommen aus DAI (2002), S. 08.1-3.

Für ältere Daten, die jedoch auf einer anderen, nicht mehr verfügbaren Berechnungsgrundlage basieren und daher hier nicht ausgewiesen werden, vgl. Wolff (2000), S. 57. Seit den 1960er Jahren zurückgegangen ist jedoch insbesondere der Anteil der öffentlichen Haushalte, gewachsen sind die Beteiligungen von Versicherungen und Ausländern. 
enanlage seitdem stark gestiegen ist. ${ }^{259}$ Erklärbar wird die Entwicklung jedoch durch die parallele Zunahme börsennotierter Aktiengesellschaften insgesamt und den Bedeutungsgewinn der Investmentfonds, die einen Teil der privaten Mehrnachfrage absorbieren. ${ }^{260} \mathrm{Da}$ die private Alterssicherung künftig an Bedeutung gewinnen wird, erscheint hier weiteres Wachstum wahrscheinlich. ${ }^{261}$

Der hohe Anteil Aktien, der durch „sonstige Unternehmen“ gehalten wird, ist bereits ein Indiz dafür, dass die Beteiligungsstrukturen in Deutschland wesentlich durch Großaktionäre gekennzeichnet sind. Die große Bedeutung einzelner Großaktionäre in Verbindung mit vergleichsweise geringem Streubesitz ist wesentliches Element des deutschen Corporate-Governance-Systems. ${ }^{262}$ Charakteristisch ist neben den Einzelbeteiligungen der hohe Verflechtungsgrad einzelner Großkonzerne untereinander, ein Zustand der durch den von Adams maßgeblich geprägten Begriff der „Deutschland $\mathrm{AG}^{\text {“ }}$ beschrieben wird. ${ }^{263}$ Wie groß die Bedeutung des Aktienbesitzes durch Unternehmen, Banken und Versicherungen auch im internationalen Vergleich ist, zeigt die folgende Tabelle: ${ }^{264}$

\begin{tabular}{|c|c|c|c|c|c|c|c|}
\hline & 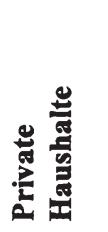 & 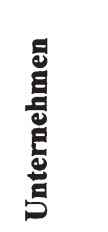 & 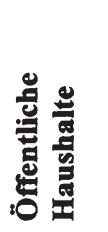 & 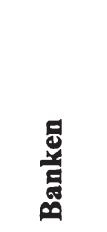 & 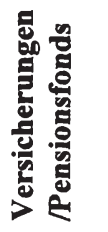 & 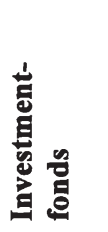 & 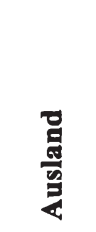 \\
\hline D & $14,6 \%$ & $42,1 \%$ & $4,3 \%$ & $10,3 \%$ & $12,4 \%$ & $7,6 \%$ & $8,7 \%$ \\
\hline $\mathbf{F}$ & $19,4 \%$ & $58,0 \%$ & $3,4 \%$ & $4,0 \%$ & $1,9 \%$ & $2,0 \%$ & $11,2 \%$ \\
\hline GB & $29,6 \%$ & $4,1 \%$ & $0,2 \%$ & $2,3 \%$ & $39,7 \%$ & $10,4 \%$ & $13,7 \%$ \\
\hline $\mathbf{J}$ & $22,2 \%$ & $31,2 \%$ & $0,5 \%$ & $13,3 \%$ & $10,8 \%$ & $11,7 \%$ & $10,3 \%$ \\
\hline USA & $36,4 \%$ & $15,0 \%$ & $0,0 \%$ & $0,2 \%$ & $31,3 \%$ & $13,0 \%$ & $4,2 \%$ \\
\hline
\end{tabular}

Tab. 2: Aktionärsstruktur in ausgewählten Industrieländern, Stand 1995

Die Zahlen deuten darauf hin, dass Deutschland, Frankreich und Japan einerseits sowie USA und Großbritannien andererseits vergleichbare Strukturen aufwei-

259 Vgl. $D A I(2002)$, S. 07.1-4-b.

260 Vgl. DAI (2002), S. 03-1-b, sowie Abschnitt II.1.1.

261 Vgl. Baums (1996), S. 330; Boehmer (2000), S. 121.

262 Grundlegend Shleifer/Vishny (1997). Vgl. auch Windolf/Beyer (1995), S. 1; Turnbull (1997), S. 181-184; Schneider (2000a), S. 2413f.; Böckli (2000), S. $133 f$.

263 Vgl. Adams (1994); Hillebrandt (2001). Wójcik (2001) stellt jedoch fest, dass von 1997 bis 2001 die Überkreuzbeteiligungen zurück gegangen sind.

264 Vgl. DAI (2002), S. 08.6-4. Aufgrund der unterschiedlichen Abgrenzung der einzelnen Aktionärsgruppen weichen die Zahlen von denen aus Abb. 7 ab. 
sen. Aufgrund des deutlich größeren Streubesitzanteils werden Letztere unter die „kapitalmarktorientierten“ Corporate-Governance-Systeme subsumiert, wohingegen die durch Großaktionäre charakterisierten Systeme als ,netzwerkorientiert" beschrieben werden. ${ }^{265}$ Die vielzitierte Studie von La Porta et al. (1998) erhebt die Aktionärsstruktur der jeweils 10 größten Unternehmen in 49 Ländern und systematisiert die Länder nach der Herkunft ihrer Rechtssysteme. Demzufolge sind netzwerkorientierte Systeme mit starker Kapitalkonzentration eher in Ländern mit Civil-Law- (Code-Law-)Rechtssystemen zu finden, während Nationen mit Common-Law- (Case-Law-)Rechtssystem eher ein marktorientiertes Corporate-Governance-System aufweisen, sodass die Ergebnisse aus obiger Tabelle nicht zufällig erscheinen. ${ }^{266}$

Wie groß die internationalen Unterschiede sind, verdeutlichen auch folgende Beispielzahlen: In Deutschland verfügt bei 43,8 \% der Unternehmen der größte Aktionär über $25 \%$ bis $75 \%$ der Stimmen. In den USA trifft dieses nur bei $5 \%$ aller Unternehmen zu. ${ }^{267}$ Stattdessen hält in den USA bei mehr als $50 \%$ der Unternehmen der größte Aktionär weniger als $5 \%$ der Stimmrechte; ein Zustand, der in Deutschland nur bei einem Prozent aller Unternehmen gegeben ist. ${ }^{268}$ Ein ähnliches Bild ergibt sich im Vergleich zu Großbritannien, wo der Median des Stimmrechtsanteils des größten Aktionärs bei $10 \%$ liegt, ggü. $52 \%$ in Deutschland. ${ }^{269}$ Dieser im internationalen Vergleich hohe Konzentrationsgrad hat in den vergangenen Jahren noch weiter zugenommen. ${ }^{270}$ Von verschiedenen Seiten wurde erwartet, dass von der seit Anfang 2002 geltenden Steuerfreiheit von

265 Vgl. die zahlreichen, vergleichenden Veröffentlichungen z.B. von Roe (1993); Moerland (1995); Franks/Mayer (1997); Becht/Röell (1999) mit empirischen Ergebnissen sowie die theoretischen Betrachtungen in den Sammelbänden von Hopt/Wymeersch (1997) und Feddersen/Hommelhoff/Schneider (1996), sowie die Vergleichsstudien von Coffee (1991) und Charkham (1994). Die Autoren verwenden teilweise nicht die Begriffe kapitalmarktund netzwerkorientiertes Corporate-Governance-System, sondern Insider- versus Outsider-System. Für einen Vergleich zwischen dem deutschen und dem japanischen System vgl. Blies (2000).

Vgl. La Porta et al. (1998), S. 1146-1151, sowie La Porta et al. (1999), S. 511. Zur Abgrenzung zwischen Code- und Common-Law-Rechtssystemen vgl. La Porta (1998), S. 1117-1119; Pellens (2001), S. 23f. Roe (2000) stellt fest, dass große Kapitalkonzentrationen insb. in sozialdemokratisch regierten Ländern zu finden sind.

267 Vgl. Becht/Röell (1999), S. 1053, mit ähnlichen Ergebnissen Faccio/Lang (2002).

268 Vgl. Becht/Röell (1999), S. 1051. Empirische Daten zur Situation in Deutschland finden sich auch bei Becht/Böhmer (2001). Einen internationalen Überblick geben La Porta et al. (1998, 1999), sowie der Sammelband von Barca/Becht (2001).

269 Vgl. Becht/Röell (1999), S. 1052 m.w.N. Köke findet für börsennotierte AGs sogar einen Anteil des größten Aktionärs von $58 \%$. Vgl. Köke (2000), S. 10, ähnlich Heiss/Köke (2001).

270 Vgl. Köke (2000), S. 13. 
Veräußerungserlösen ein Anreiz zum Abbau der Beteiligungsverflechtungen ausgehen würde. ${ }^{271}$ Bisher sind umfangreiche Entflechtungen jedoch ausgeblieben. ${ }^{272}$

Die Zahlen zeigen, dass der deutsche Kapitalmarkt durch ein umfangreiches System ein- und mehrstufiger Beteiligungen von Kapitalgesellschaften untereinander gekennzeichnet ist. Entsprechend sind $95 \%$ der börsennotierten Aktiengesellschaften konzernverbunden. ${ }^{273}$ Industrieunternehmen und Finanzintermediäre gemeinsam halten, gemessen an der Börsenkapitalisierung, Beteiligungen allein an börsennotierten Unternehmen von über $500 \mathrm{Mrd}$. $€$, hinzu kommen umfangreiche Beteiligungen an nicht börsennotierten Gesellschaften. ${ }^{274}$

Des Weiteren sei kurz auf die Identität der Großaktionäre eingegangen. Wenn in Deutschland ein Großaktionär vorhanden ist, so ist dieses häufig ein anderes Unternehmen, eine Bank oder eine Versicherung. In den USA und Großbritannien liegen größere Kapitalbeteiligungen hingegen überwiegend in der Hand von Investment- und Pensionsfonds. ${ }^{275}$ Aufgrund der Abwicklung der betrieblichen Altersversorgung über Pensionsfonds spielen Fondsgesellschaften einen deutlich größeren Einfluss als in Deutschland, wo diese erst in den letzten Jahren an Bedeutung gewonnen haben. ${ }^{276}$ Bereits im vergangenen Abschnitt wurde darauf eingegangen, dass die Anreizstruktur von Fondsgesellschaften mit der anderer Unternehmen nur begrenzt vergleichbar ist, da Letztere - zumindest prinzipiell die Interessen vieler kleiner Anleger repräsentieren. ${ }^{277}$

Die verschiedenen hier zitierten Untersuchungen beziehen sich teilweise auf die Eigentümer- und teilweise auf die Stimmrechtsstrukturen der Gesellschaften, was bei einem Vergleich der Ergebnisse zu berücksichtigen ist. Internationale Vergleichsstudien über das Abweichen der Stimmrechts- von der Eigentümerstruktur sind rar. ${ }^{278}$ Die bisherigen Ergebnisse deuten jedoch darauf hin, dass die

271 Vgl. Lang/Maydew/Shackelford (2001); Dorfs (2001); Hillebrandt (2001) m.w.N.

272 Vgl. o.V. (2002a), S. 21.

273 Vgl. Busse von Colbe (2000), S. 299; Salzberger (2000), S. 211.

274 Börsenkapitalisierung inländischer Aktiengesellschaften in Deutschland per Ende 2001: 1.204 Mrd. $€$, vgl. DAI (2002), S. 05-1.

275 Vgl. Tabelle 2.

276 Vgl. Faccio/Lasfer (2000), S. 72, ausführlich auch Roe (1991); Black (1992); Hadden (1993); Romano (1993); Salzberger (1999), für UK und Australien Stapledon (1996).

277 Mallin (2001) zeigt in seiner Untersuchung, dass die Aktivitäten von institutionellen Investoren im Rahmen der Unternehmenskontrolle geringer sind, als gemeinhin vermutet wird. Cassier (1962), S. 103, schreibt sogar noch: „Die Anteile der Investmentgesellschaften verkörpern Kapitaleigentum in der anspruchlosesten Form.“

278 Vgl. jedoch insbesondere die Studie von La Porta et al (1999). 
Übereinstimmung zwischen Cash-Flow- und Stimmrechten im angelsächsischen Raum größer ist als im kontinentaleuropäischen. Die Bedeutung von Vorzugsaktien ist dort ebenso geringer wie die pyramidenartiger Konzernstrukturen. ${ }^{279} \mathrm{La}$ Porta et al. zeigen, dass die Pyramidenbildung dazu führt, dass in Deutschland $20 \%$ der Stimmrechte einer Gesellschaft mit einem Kapitaleinsatz von durchschnittlich 18,6\% kontrolliert werden können; in den USA wird ein Kapitaleinsatz von $19,2 \%$, in Großbritannien von $20,0 \%$ benötigt. ${ }^{280}$

\subsection{Ursachen alternativer Aktionärsstrukturen}

Die hohe Bedeutung von Großaktionären, speziell Finanzintermediären in Deutschland geht auf die Aufbauphase nach dem zweiten Weltkrieg zurück, als viele Kredite in Beteiligungen umgewandelt wurden. ${ }^{281}$ Parallel dazu haben vergleichsweise schwach ausgeprägte Regelungen zum Aktionärsschutz ${ }^{282}$ in Verbindung mit einer weniger an den Informationsbedürfnissen der Eigenkapitalgeber als vielmehr am Gläubigerschutz ausgerichteten Rechnungslegung die Entwicklung eines effizienten Kapitalmarktes als Finanzierungsquelle für die Masse der Unternehmen erschwert. ${ }^{283}$ Der Kapitalmarkt nimmt neben der Kapitalallokationsfunktion jedoch auch eine Kontrollfunktion wahr, indem er schlechte Managementleistungen und damit verbundene schlechte Ergebnisse mittels fallender Kurse sanktioniert. ${ }^{284}$ Diese Kontrollfunktion hat der Kapitalmarkt in Deutschland zumindest in der Vergangenheit nur unzureichend wahrgenommen. ${ }^{285}$

In den USA hingegen hat der Kapitalbedarf der Schwerindustrie Ende des 19. Jahrhunderts in Verbindung mit ausgeprägten Aktionärsschutzbestimmungen bereits früh zu einem funktionsfähigen Kapitalmarkt mit großem Streubesitzan-

279 Vgl. zu den Ursachen einer fehlenden Kongruenz von Cash-Flow- und Stimmrechten ausführlich Kapitel III.2.3.2. Zur Bedeutung von Vorzugsaktien im internationalen Vergleich vgl. Pellens/Hillebrandt (2001), S. 58 m.w.N.

280 Vgl. La Porta et al. (1999), S. 499. Die Ergebnisse sind vor dem Hintergrund der sehr geringen Samplegröße jedoch vorsichtig zu bewerten.

281 Vgl. Lang/Maydew/Shackelford (2001), S. 10.

282 Vgl. La Porta et al. (1998), S. 1113, sowie den vergleichenden Überblick bei Apcims (2002). Zu Elementen des Aktionärsschutzes vgl. Bischof (1998).

283 Vgl. Lang/Maydew/Shackelford (2001), S. 10; La Porta et al. (1997), S. 1131.

284 Vgl. zum Konzept des „Marktes für Unternehmenskontrolle“ grundlegend Manne (1965); Grossman/Hart (1980), sowie Abschnitt III.1.2.2.1 dieser Arbeit.

285 Vgl. zur Nichtexistenz eines Kontrollmarktes in Deutschland Adams (1994), S. 153; Salzberger (2000), S. 211. Vgl. zu weiteren Gründen, die zur Herausbildung des hohen Konzentrationsgrades geführt haben Salzberger (2000), S. 213; Ball (1987), S. 62; Hillebrandt (2001), S. 715. 
teil geführt. ${ }^{286}$ Finanzintermediäre haben sich aufgrund verschiedenster gesetzlicher Beschränkungen nicht in gleichem Maße wie in Kontinentaleuropa etabliert. ${ }^{287}$ Noch bis Herbst 1999 verbot der Glass-Steagall Act von 1933 Bankenholdings den Erwerb von Unternehmensbeteiligungen über $5 \%{ }^{288}$ Bereits 1908 beschreibt Steinitzer die Ursachen der unterschiedlichen Strukturen wie folgt: „Ich glaube, die Ursache liegt darin, daß es in Amerika eine größere Anzahl flüssiger Riesenvermögen gab, in Deutschland aber nicht. [...] In Deutschland dagegen gab es nur eine Art großer, flüssiger Vermögen: die Bankiervermögen. “289

Da die Auslöser der heutigen Strukturen offensichtlich teilweise weit zurückliegen, erstaunt, dass die empirischen Studien nach wie vor so große Unterschiede offenbaren, obwohl allenthalben von Internationalisierung der Kapitalmärkte und Konvergenz die Rede ist. ${ }^{290}$ Einen Begründungsansatz für das Verharren in vorhandenen Systemen liefert die Theorie der Pfadabhängigkeit. ${ }^{291}$ Die Pfadabhängigkeit eines Systems ist gegeben, wenn die Ausgangsbedingungen dazu führen, dass eine Umstellung auf ein eigentlich effizienteres System nicht erfolgt, weil die Anpassungskosten zu hoch erscheinen. ${ }^{292}$ Ausschlaggebend sind

286 Vgl. Roe (1994), S. 3-5, sowie Bainbridge (1995), S.679. Zum Aktionärsschutz in den USA Pellens (2001), S. 61-69; Schröder (2001); Wüstemann (2002), S. $131 \mathrm{ff}$., sowie Abschnitt II.2.1.

287 Vgl. Holderness/Sheehan (2000), S. 155-158; Roe (1994), S. 54-59, sowie Schmidt (2001), S. 213-231. Roe (2000) führt die Herausbildung unterschiedlicher Strukturen auf das jeweilige politische Umfeld zurück.

288 Vgl. Jacobi (2000), S. 25; Mülbert (1998), S. 447; Salzberger (1999), S. 90; Black (1990), S. 551-553, für einen Überblick über rechtliche Beschränkungen. In Deutschland besteht nur eine Begrenzung bezogen auf das haftende Eigenkapital von Kreditinstituten. Die in $\S 12 \mathrm{ff}$. KWG formulierten Grenzen sind jedoch so hoch, dass sie die Beteiligungen kaum einschränken. Vgl. Hopt (1996), S. 248f.; Fraune (1996), S. 8. Zur Regulierung in den USA vgl. Roe (1993), S. 1930f.; Gerson/Barr (1996), S. 79.

289 Steinitzer (1908), S. XIV. Für einen Überblick über die Finanzierungshistorie deutscher Unternehmen vgl. Schmidt (2001), S. 264-268.

290 Vgl. Moerland (1995); Dziobek/Garrett (1998); Hommel/Riemer-Hommel (1999); Schmidt/Grohs (1999); Schmidt/Spindler (1999); Witt (2000); Boot/Macey (2000); Davies (2001); Teichmann (2001); Cheffins (2002); Schmidt/Hackethal/Tyrell (2002).

291 Vgl. Bebchuk/Roe (1999); Schmidt/Spindler (1999); Schmidt/Grohs (1999); Dziobek/Garrett (1998); Moerland (1995); Kole/Lehn (1997). Zur Herausbildung der Systeme Dunlavy (1998). Für chaos- und evolutionstheoretische Ansätze zur Erklärung von Rechts- und Wirtschaftssystemen vgl. Roe (1996).

292 Vgl. North (1990), S. 92-104, 112-116; Bebchuk/Roe (1999), S. 129f.; Berrar (2001), S. 68-70; Theurl/Polster (2002). 
dabei neben Effizienzüberlegungen die Eigeninteressen einzelner Marktteilnehmer: 293

Die derzeit gültigen Regeln zur Corporate Governance, die sich in Deutschland überwiegend im AktG niederschlagen, ${ }^{294}$ sind in einem Umfeld entstanden, das durch netzwerkorientierte Strukturen und durch großaktionärsdominierte Kapitalgesellschaften gekennzeichnet ist. Die einfache Übertragung einzelner Elemente einer anderen, beispielsweise durch großen Streubesitz gekennzeichneten Struktur, kann unter den hiesigen sozio-ökonomischen Bedingungen ineffizient sein. ${ }^{295}$ So könnte etwa die Abwesenheit von Großaktionären bei gleichzeitiger Abwesenheit eines funktionierenden Kontrollmarktes schwerwiegende Mängel in der Managementkontrolle zur Folge haben. Entscheidend ist die Konsistenz eines Corporate-Governance-Systems, in dem die einzelnen Elemente aufeinander abgestimmt sind. ${ }^{296}$ Eine Änderung hin zu einer neuen, in sich konsistenten Corporate-Governance-Struktur würde somit eine gleichzeitige umfangreiche Anpassung verschiedenster gesetzlicher Regelungen bedingen, die für die Volkswirtschaft mit erheblichen Kosten verbunden ist. Ein Übergang ist somit nur dann sinnvoll, wenn die Vorteile des neuen Systems die mit der Umstellung verbundenen Kosten überkompensieren.

Mit der aktuellen Struktur des Corporate-Governance-Systems sind zudem Vorteile für einzelne Gruppen verbunden, die daher versuchen werden, einen Strukturwandel aufgrund des damit verbundenen individuellen Machtverlustes zu verhindern. ${ }^{297}$ Um private Renten zu sichern, werden gesamtwirtschaftlich sinnvolle Reformen verhindert. ${ }^{298}$ So hat etwa ein Großaktionär, dessen individuell aus dem Unternehmen entziehbarer Cash Flow unter Berücksichtigung privater Vorteile größer ausfällt als bei Investition in verschiedene kleine Unternehmen, ${ }^{299}$ kein Interesse an Regelungen mit dem Ziel, die Kapitalkonzentration einzuschränken. Auch seitens des Managements sind Vorbehalte gegenüber einem aktiven Kontrollmarkt denkbar.

293 Vgl. ausführlich Bebchuk/Roe (1999); Schmidt/Spindler (1999).

294 Vgl. Schneider/Strenger (2000), S. 106-109.

295 Zur Relevanz der Rahmenbedingungen Cheffins (2000, 2002); Witt (2001), S. 82-93.

296 Vgl. Schmidt/Spindler (1999), S. 12f. So können sich alternative Governance-Mechanismen gegenseitig substituieren. Vgl. hierzu Booth/Cornett/Tehranian (2002); Firth/Fung/ Rui (2002).

297 Vgl. grundlegend Olson (1965).

298 Vgl. Kole/Lehn (1997), S. 421. Vgl. zu private benefits von Großaktionären ausführlich Kapitel III.2.2.1.2.

299 Vgl. mit Beispiel Schmidt/Spindler (1999), S. 13-15. 
Die immer wieder geforderte radikale Entflechtung des deutschen Kapitalmarktes und damit eine Abkehr von den gültigen Corporate-Governance-Strukturen ist demnach nur zu erwarten, wenn externe Anreize sowohl die Anpassungskosten an ein marktorientiertes System als auch die privaten Vorteile, die für die Marktteilnehmer aus dem aktuellen System resultieren, überkompensieren.

\subsection{Transparenz über Eigentümer- und Stimmrechtsstrukturen in Deutschland}

\subsubsection{Erfordernis von Transparenz}

Voraussetzung für die Durchführung der in Kapitel IV geplanten empirischen Untersuchung ist eine zumindest hinreichende Transparenz über die Eigentümer- und Stimmrechtsstrukturen deutscher börsennotierter Aktiengesellschaften. Um die Qualität der diesbezüglich in Deutschland vorliegenden Informationen abschätzen zu können, soll hier ein Überblick über die geltenden Publizitätsanforderungen sowie freiwillige Angaben der Unternehmen zur Aktionärsstruktur in ihren Geschäftsberichten gegeben werden. Zunächst erscheint es jedoch sinnvoll zu begründen, woraus die Erfordernis einer Transparenz über die Aktionärsstruktur einer Aktiengesellschaft resultiert.

Neben verschiedenen anderen Interessengruppen haben insbesondere aktuelle und potenzielle Aktionäre das Bedürfnis, die Eigentümer- und Stimmrechtsstruktur der Gesellschaft zu kennen. Sie können so das Kontrollpotenzial abschätzen, das von einem eventuell vorhandenen Großaktionär ausgeht und sich darüber hinaus ein Bild über mögliche Interessenkonflikte machen, die diesen Großaktionär von einer effizienten Kontrollausübung abhalten könnten. ${ }^{300}$ Aktionäre mit wesentlichen Stimmrechtsanteilen können im Vorfeld von Hauptversammlungen Koalitionen mit anderen Großaktionären bilden, um so die Entscheidungen auf der Hauptversammlung zu beeinflussen. Veränderungen der Stimmrechtsanteile im Zeitablauf ermöglichen zudem das frühzeitige Erkennen einer möglichen Übernahme und der damit möglicherweise verbundenen Wertänderung des Anteilsbesitzes. ${ }^{301}$

Neben den Anteilseignern hat auch der Staat ein Interesse an transparenten Beteiligungsstrukturen. ${ }^{302}$ Die Wahrnehmung seiner ordnungspolitischen Funktion

300 Vgl. Bott/Schleef (1998), S. 330f.; Kalss (1993), S. 616; Adams (1999), S. 86; Bott (2002), S. 177.

301 Vgl. Burgard (1992), S. 41; Bott/Schleef (1998), S. 331. Zu einer mit zunehmender Transparenz ggf. verbundenen eingeschränkten Wirksamkeit des Markts für Unternehmenskontrolle vgl. Grossman/Hart (1980), S. 60; Shleifer/Vishny (1986), S. 464.

302 Vgl. Bott (2002), S. 179. 
wird ihm erleichtert, wenn er eventuelle Konzentrationstendenzen, die zu einer beherrschenden Stellung einzelner Marktteilnehmer führen würde, frühzeitig erkennen kann. ${ }^{303}$ Die erhöhte Transparenz begünstigt zudem die Funktionsfähigkeit des Kapitalmarktes, sodass dem Ziel des Funktionenschutzes Rechnung getragen wird.

Die Kenntnis der Aktionärsstruktur ist darüber hinaus jedoch auch für das Management von zentraler Bedeutung. Sie erleichtert eine gezielte Ansprache einzelner Aktionärsgruppen und ermöglicht zudem die Abstimmung bedeutender Entscheidungen mit einflussreichen Aktionären. Verschiedenen Studien zufolge führt eine hohe Transparenz der Aktionärsstruktur zu einer Senkung der Kapitalkosten, was grundsätzlich im Sinne aller Unternehmensbeteiligten ist. $^{304}$

\subsubsection{Transparenzanforderungen nach deutschem Recht}

\subsubsection{Regelungen des Wertpapierhandelsgesetzes}

Trotz des von verschiedenen Seiten hieran bestehenden Interesses sind verlässliche Informationen über die Eigentümerstrukturen auf einer detaillierten Ebene in der Regel nicht verfügbar. In Deutschland lagen lange Zeit überhaupt nur freiwillige Informationen einzelner Großkonzerne über ihre Aktionärsstruktur vor. Erst die Beteiligungstransparenz-Richtlinie der Europäischen Gemeinschaft hat 1988 Veröffentlichungspflichten hinsichtlich der Stimmrechtsverhältnisse für im amtlichen Handel notierte Aktiengesellschaften geregelt. Seitdem besteht eine EU-weite Offenlegungspflicht, wenn eine natürliche oder juristische Person durch den Erwerb einer Beteiligung die Grenzen von $10 \%, 20 \%$, 33,33\%, $50 \%$ oder $66,66 \%$ der Stimmrechte einer börsennotierten Gesellschaft erreicht oder überschreitet bzw. durch einen Verkauf wieder unterschreitet. ${ }^{305}$ Von der Möglichkeit, im nationalen Recht strengere Schwellenwerte anzusetzen, ${ }^{306}$ hat der deutsche Gesetzgeber mit dem Wertpapierhandelsgesetz Gebrauch gemacht,

Vgl. Schneider/Burgard (1996), S. 1762.

304 Vgl. jüngst Drobetz et al. (2003), sowie ausführlich die Arbeit von Bott (2002), mit Verweisen auf die Studien von Botosan (2000) und Amihud/Mendelson (2000).

Vgl. Beteiligungstransparenz-Richtlinie, Art. 4; Deckert/von Rüden (1998), S. 50; Becht (1997), S. 56-60, 114-117; Bott (2002), S. 186f. Einen Überblick über internationale Regelungen zur Beteiligungstransparenz gibt Witt (1996), S. 117-138. Zur Abgrenzung des Erwerbsbegriffs vgl. Nottmeier/Schäfer (1997), S. 88f. Einen ausführlichen Überblick über die juristischen Grundlagen zur Offenlegung von Aktienbesitz gibt Arends (2000).

Vgl. Beteiligungstransparenz-Richtlinie, Art. 3 i.V.m. Art. 4 Abs. 1 S. 2. 
das die EU-Richtlinie zum 1.1.1995 in deutsches Recht umsetzte. ${ }^{307} \S 21 \mathrm{WpHG}$ regelt die Mitteilungspflichten des Meldepflichtigen, die Schwellenwerte liegen hier bei $5 \%, 10 \%, 25 \%, 50 \%$ und $75 \%$ der Stimmrechte. Von der Meldepflicht betroffen sind Erwerber von Anteilen an Gesellschaften mit Sitz im Inland, die an einem organisierten Markt innerhalb der Europäischen Union zugelassen sind. ${ }^{308} \mathrm{Da}$ auf Stimmrechte abgestellt wird, ist der Erwerb von Vorzugsaktien somit von der Regelung nicht betroffen. ${ }^{309}$ Die zusätzliche Meldung bei Überschreiten einer Schwelle bezogen auf den Kapitalanteil, wie sie Art. 4 Abs. 1 S. 4 der Richtlinie fakultativ vorsieht, wurde nicht umgesetzt. ${ }^{310}$ Erst zum 1. April 2002 wurde die Meldepflicht auf alle in einem „organisierten Markt“ gehandelten Aktiengesellschaften ausgedehnt, sodass neben den im amtlichen Handel notierten Gesellschaften auch die des geregelten Marktes betroffen sind. $^{311}$

$\S 21$ Abs. 1 des WpHG verpflichtet den Erwerber, das Erreichen bzw. Überoder Unterschreiten des Schwellenwertes sowohl der Gesellschaft als auch der Bundesanstalt für Finanzdienstleistungsaufsicht (BAFin) - vormals Bundesaufsichtsamt für den Wertpapierhandel (BAWe) - unverzüglich, spätestens innerhalb von sieben Kalendertagen mitzuteilen. ${ }^{312}$ Geht eine Meldung verspätet oder gar nicht ein und das BAFin erlangt davon Kenntnis, so werden Bußgeldbescheide verhängt. ${ }^{313}$ Die Gesellschaft muss nach $\S 25$ Abs. $1 \mathrm{WpHG}$ innerhalb von neun Tagen nach Zugang der Mitteilung nach $\S 21 \mathrm{WpHG}$ die Veränderung der Aktionärsstruktur in einem überregionalen Börsenpflichtblatt veröffentli-

307 Das WpHG wurde im Rahmen des zweiten Finanzmarktförderungsgesetzes kodifiziert. Vgl. Bott (2002), S. 187; Junge (1993), S. 474; Wilsing (1995), S. 2277; Schneider (1999), § 21, Rn. 1-4; Jahr (2002), S. 150f.

308 Vgl. BAWe (2001), S. 1f. Zur Bedeutung der unterschiedlichen Beteiligungsgrenzen für den Einfluss auf die Unternehmenspolitik vgl. Eckardt (1999), S. 27.

309 Eine besondere Problematik ergibt sich, wenn das Stimmrecht der Vorzugsaktien aufgrund von zwei dividendenlosen Jahren wieder auflebt, da sich aufgrund dessen die Stimmrechtsverteilung kurzfristig erheblich ändern kann und so Meldepflichten ausgelöst werden können. Vgl. ausführlich Wilsing (1995); Nottmeier/Schäfer (1997), S. 89; Bott (2002), S. 191.

310 Kritisch hierzu Witt (1998), S. 173.

311 Vgl. BAWe (2001a), S. 1; Sudmeyer (2002), S. 685.

312 Vgl. § 21 Abs. 1 S. 1 WpHG, sowie Schneider (1999). Zur Auslegung des Begriffs des „Erwerbs" vgl. Cahn (1997), S. 506f. Das BAWe ist durch die Kodifizierung des Gesetz über die Bundesanstalt für Finanzdienstleistungsaufsicht (FinDAG) zum 1. Mai 2002 im BAFin aufgegangen.

313 Im Jahr 2000 gingen beim BAWe 656 Mitteilungen ein, 146 Verstöße wurden registriert. Vgl. Bott (2002), S. 205. 
chen. ${ }^{314}$ Bis der Kapitalmarkt von einem Eigentümerwechsel Kenntnis erlangt, können somit bis zu 16 Tage vergehen. Abb. 8 gibt einen Überblick über den Mitteilungs- und Veröffentlichungsprozess.

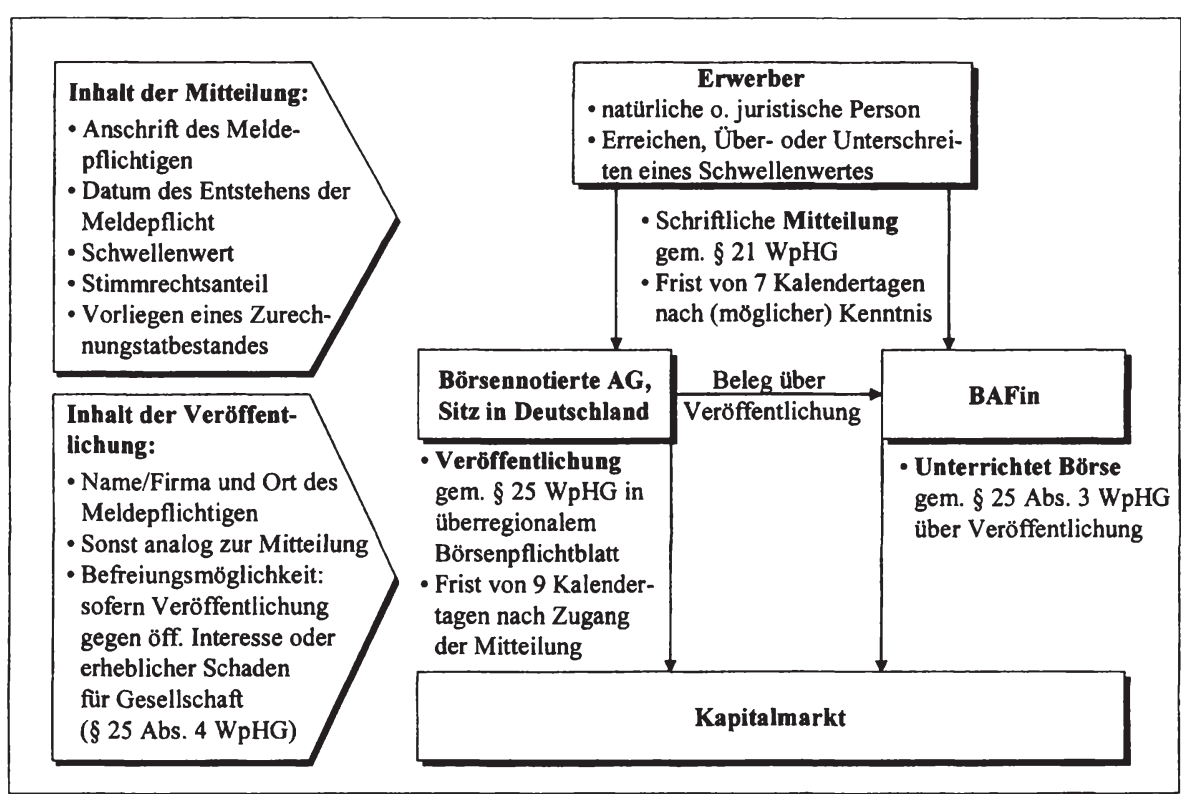

Abb. 8: Mitteilungs- und Veröffentlichungspflichten nach dem WpHG

Verfügt ein Aktionär zum Zeitpunkt des Börsengangs einer Gesellschaft über $5 \%$ oder mehr der Stimmrechte, so hat er ebenfalls eine Meldung entsprechend $\S 21$ Abs. 1 WpHG zu machen. ${ }^{315}$ Bei der Bestimmung des Stimmrechtsanteils sind den direkt gehaltenen gem. $§ 22$ Abs. 1 Stimmrechte hinzuzurechnen, über die er wirtschaftlichen Einfluss hat. ${ }^{316}$

314 Über die Mitteilung ist dem BAFin ein Beleg zuzusenden. Zu Sanktionen bei verspäteter oder ausgebliebener Mitteilung vgl. Sudmeyer (2002), S. 691; Witt (1998), S. 180-182. Zur Umsetzung vgl. Nottmeier/Schäfer (1997). Kritisch Bott/Schleef(1998), S. 332.

315 Vgl. § 21 Abs. 1a WpHG.

316 Insb. Stimmrechte von Tochterunternehmen sowie Stimmrechte über die er per Vollmacht verfügen kann. Vgl. Sudmeyer (2002), S. 687-689; Witt (1998), S. 175-177; Becht/Böhmer (2001), S. 149, ausführlich auch Arends (2000), S. 58-72. Kritisch hierzu Cahn (1997), S. 503; Becht/Böhmer (2001), S. 149. 
Für nicht börsennotierte Aktiengesellschaften ergibt sich aus $\S \S 20-21$ AktG eine Meldepflicht ab einem Kapitalanteil von $25 \%{ }^{317}$ Alle Aktiengesellschaften haben zudem ihre Gründungsmitglieder mit Namen und Wohnort bekannt zu machen (§ $40 \mathrm{AktG})$.

In der Vergangenheit gab es verschiedene Initiativen, die beiden gesetzlichen Grundlagen $\mathrm{zu}$ einem einheitlichen Regelungskomplex $\mathrm{zu}$ verbinden. ${ }^{318}$ Abgesehen von einigen kleineren Anpassungsmaßnahmen im Rahmen des 3. Finanzmarktförderungsgesetzes und des $\mathrm{KapCoRiLiG}^{319}$ waren diese jedoch bisher nicht von Erfolg gekrönt. An der bisherigen Regelung des WpHG werden insbesondere folgende Punkte kritisiert:

- Stimmrechte knapp unterhalb der Meldegrenze werden nicht erfasst, damit wird insbesondere eine auf verschiedene Mitglieder verteilte, signifikante Familienkontrolle oft nicht transparent. ${ }^{320}$

- Der Zeitraum zwischen Veränderung der Stimmrechtsstruktur und Kommunikation an den Kapitalmarkt beträgt bis zu 16 Tage.

- Informationen liegen ausschließlich über die Stimmrechtsstrukturen vor, nicht jedoch über die Eigentümerstrukturen. ${ }^{321}$

- Es werden keine Informationen über die tatsächliche Stimmrechtsausübung gegeben; insbesondere durch das Vollmachtsstimmrecht der Kreditinstitute ergeben sich erhebliche Abweichungen. ${ }^{322}$

- Die Transparenz bei Gruppenstrukturen ist insbesondere in den Fällen gering, in denen nicht börsennotierte Unternehmen Bestandteil der Ring- oder Überkreuzverflechtung sind. ${ }^{323}$

- Weitreichende Ausnahmeregelungen für Kapitalanlagegesellschaften, die jedoch seit 2002 eingeschränkt sind, führten zu mangelnder Transparenz. ${ }^{324} \mathrm{Die}$

317 Allerdings besteht eine Meldepflicht nach $\S 20 \mathrm{AktG}$ nur für Unternehmen, nicht für Privatpersonen. Da börsennotierte Unternehmen im Vordergrund der vorliegenden Arbeit stehen, wird auf die Regelungen für nicht-börsennotierte Aktiengesellschaften hier nicht weiter eingegangen. Vgl. jedoch Arends (2000), S. 9-43; Witt (1998); Becht/Böhmer (1999); Becht/Böhmer (2003), S. 30; Bott (2002), S. 230-235; Burgard (1990), S. 44-69.

318 Einen Überblick gibt Witt (1998), S. 172f. m.w.N. Kritisch zu den Parallelregelungen äußern sich auch Hopt (1995), S. 138f.; Neye (1996), S. 1854.

319 Vgl. hierzu den folgenden Abschnitt II.3.5.2.2.

320 Vgl. Bott/Schleef (1998), S. 332; Arends (2000), S. 121.

321 Vgl. Arends (2000), S. 124f.

322 Vgl. Becht/Böhmer (2001), S. 150; Becht/Böhmer (2003), S. 15-17.

323 Vgl. Bott (2002), S. 224-226.

324 Vgl. BAWe (2001a), S. 4f.; kritisch zu der alten Regelung Bott/Schleef (1998), S. 332f.; Bott (2002), S. 214-220. 
Zurechnung der Anteile zur Kapitalanlagegesellschaft gilt jedoch nur noch für Publikumsfonds, nicht mehr für Spezialfonds. ${ }^{325}$ Auch die erhöhte Meldeschwelle erst ab $10 \%$ der Stimmrechte gilt seit dem 1.4.2002 nicht mehr. ${ }^{326}$

- Die Sanktionsmöglichkeiten bei Verstößen gegen die Mitteilungspflicht sind begrenzt, da Sanktionen nur dann verhängt werden, wenn das BAFin Kenntnis von den Veränderungen der Stimmrechtsanteile erhält. ${ }^{327}$

\subsubsection{Publizität im Rahmen der periodischen Berichterstattung}

Seit dem Jahr 2000 haben Aktiengesellschaften nach $\S 160$ Abs. 1 S. 8 AktG die in Beachtung der Regelungen des WpHG gemachten Veröffentlichungen im Anhang anzugeben; somit werden Veränderungen der Stimmrechtsstruktur, die die relevanten Schwellenwerte des WpHG betreffen, im Geschäftsbericht publiziert. ${ }^{328}$ Im Gegensatz zur alten Fassung vor dem KapCoRiLiG werden durch den Bezug auf das WpHG auch die Beteiligungen von natürlichen Personen erfasst und die Schwellenwerte wurden gesenkt. ${ }^{329}$ Ausgewiesen werden darüber hinaus gem. § 160 Abs. 1 S. 7 AktG auch wechselseitige Beteiligungen.

$\S 285$ Nr. 11 HGB regelt außerdem, dass im Anhang Name und Sitz von denjenigen Unternehmen anzugeben ist, von denen die Gesellschaft $20 \%$ oder mehr des Kapitals hält; Anteile an börsennotierten Gesellschaften müssen angegeben werden, sofern sie $5 \%$ der Stimmrechte überschreiten. Als Anteile gelten dabei auch solche von abhängigen Unternehmen gem. $§ 16$ Abs. 4 AktG. ${ }^{330}$

Sofern Kontrolle über ein Unternehmen nicht durch eine Kapitalbeteiligung sondern z.B. aufgrund eines Beherrschungsvertrags ausgeübt werden kann, ist dies gem. § 294 AktG im Handelsregister einzutragen. ${ }^{331}$ Gleiches gilt für die Eingliederung gem. §319 AktG. Da die Handelsregister in Deutschland noch immer nicht in elektronischer Form vorliegen, sind diese Informationen - wenn-

325 Vgl. § 10 Abs. 1a KAGG, sowie Becht/Böhmer (1999), S. 28. Die Beschränkung der Sonderregelung auf Publikumsfonds erfolgte im Rahmen der Änderung des WpHG zum 1.4.2002. Vgl. BAWe (2001a), S. 4.

326 Vgl. $B A W e$ (2001a), S. 4.

327 Vgl. zu den Sanktionsmöglichkeiten Bott (2002), S. 204-208.

328 Meldungen gem. $\S 20 \mathrm{ff}$. AktG werden ebenso im Anhang ausgewiesen. Die Änderung erfolgte im Rahmen des KapCoRiLiG. Vgl. zu sonstigen Regelungen zur Offenlegung von Beteiligungen kritisch Schneider (1999), Rn. 37-69.

329 Die alte Fassung stellte ausschließlich auf Beteiligungen gem. § $21 \mathrm{AktG}$ ab.

$330 \mathrm{Zu}$ Befreiungsmöglichkeiten vgl. Schneider (1999), Rn. 61.

331 Vgl. auch § $298 \mathrm{AktG}$. 
gleich theoretisch verfügbar - in der Praxis nur unter erschwerten Bedingungen zu erlangen. ${ }^{332}$

\subsubsection{Empirische Untersuchung zum Publizitätsverhalten im Geschäftsbe- richt}

Durch die mit dem KapCoRiLiG in Kraft getretene Regelung des $\S 160$ Abs. 1 S. $8 \mathrm{AktG}$ werden börsennotierte Aktiengesellschaften erstmals verpflichtet, unter bestimmten Voraussetzungen Angaben zu ihrer Aktionärsstruktur im Geschäftsbericht zu publizieren. Um zu untersuchen, in welcher Form diese Verpflichtung umgesetzt wird und inwieweit es die Unternehmen gegebenenfalls auch zu einer darüber hinaus gehenden Publizität ermuntert, wurden die Geschäftsberichte der DAX100-Unternehmen des Jahres 2001 auf ihre Angaben zur Aktionärsstruktur hin untersucht. ${ }^{333}$ Dabei wurde zunächst differenziert in freiwillige Angaben und Pflichtangaben; bei den freiwilligen Angaben wurde zudem der Berichtsumfang analysiert. Konkret wurden folgende Angaben gefunden:

\begin{tabular}{l|l}
\hline Art der Angabe & $\begin{array}{l}\text { Unternehmen } \\
\text { in Prozent }\end{array}$ \\
\hline $\begin{array}{l}\text { Pflichtangabe im Anhang gem. } \\
\S 160 \text { Abs. 1 S. 8 AktG }\end{array}$ & $20 \%$ \\
$\begin{array}{l}\text { (Zusätzliche) freiwillige Anga- } \\
\text { ben zur Aktionärsstruktur }\end{array}$ & $76 \%$ \\
Keine Angaben & $17 \%$ \\
\hline
\end{tabular}

Tab. 3: Angaben zur Aktionärsstruktur

In $20 \%$ der Geschäftsberichte waren Angaben gemäß $\S 160$ Abs. 1 S. 8 AktG $\mathrm{zu}$ finden, die auf die einschlägigen WpHG-Paragraphen verweisen und den Text der WpHG-Meldung wiedergeben. Eine einheitliche Platzierung dieser Informationen im Anhang hat sich noch nicht herausgebildet, einige Unternehmen haben einen separaten Punkt für diese Berichterstattung aufgenommen, zehn Unternehmen berichten hierüber im Rahmen der Anhangsangaben zum Eigenkapital.

332 Vgl. Burgard (1990), S. 195f. Zu kartell-, versicherungs- und bankrechtlichen Offenlegungspflichten vgl. Schneider (1999), Rn. 63-68, sowie Burgard (1990), S. 142-150. Auf die Anzeigepflichten wird hier nicht näher eingegangen, da die darin enthaltenen Informationen nicht öffentlich zugänglich sind.

333 Untersucht wurden die Geschäftsberichte der Unternehmen, die zum Stichtag 1.7.2002 im DAX100 notiert waren. 
$76 \%$ der DAX100-Unternehmen machen freiwillige Angaben zu ihrer Aktionärsstruktur. Die Informationen werden in der Regel im ungeprüften Teil unter der Rubrik „Die Aktie“ positioniert. 14 Unternehmen machen freiwillige Angaben zur Aktionärsstruktur im Anhang. Von den 76 Unternehmen, die freiwillige Angaben publizieren, machen 68 (89,5\%) Angaben zur Identität der Aktionäre. „Umfassende“ Informationen, die eine differenzierte Zuordnung zu Privatanlegern, anderen Unternehmen, Investmentfonds u.ä. ermöglichen, liefern jedoch lediglich 13,2 \% der Unternehmen, die Angaben zur Identität machen (9 Unternehmen). Vielfach dominiert hingegen die alleinige Angabe des Streubesitzanteils ( $20 \%$ der Unternehmen, die Angaben zur Identität machen). Informationen dieser Art wurden als „knapp“ gewertet. Umfassende Informationen beinhalten hingegen immer auch Angaben über die Veränderungen zum Vorjahr.

Informationen zur regionalen Verteilung der Aktionäre finden sich in $33 \%$ der Geschäftsberichte. Die Güte der Berichterstattung in Bezug auf die regionale Verteilung ist sehr heterogen. Während 10 Unternehmen nur knapp zwischen „Inland“ und „Ausland“ differenzieren, liefert eine ebenso große Anzahl von Unternehmen detaillierte Angaben nach Ländern. Nur etwas mehr als die Hälfte der Unternehmen (53) gibt die Namen seiner Großaktionäre an. Hiervon geben 20 Unternehmen ausschließlich den Namen des größten Aktionärs an und nur zehn Unternehmen berichten ausführlich über verschiedene Großaktionäre, deren Anteile und eventuelle Veränderungen im Geschäftsjahr. Diese Zahl erscheint vor dem Hintergrund der großen Relevanz, die diese Information insbesondere für die Kleinaktionäre besitzt, gering. Die Kenntnis über die Identität des Großaktionärs ermöglicht, eventuelle Interessenkonflikte oder aber auch eine positive Einflussnahme, die ein solcher Aktionär auf das Management ausüben kann, einzuschätzen. ${ }^{334}$

Die folgende Tabelle gibt einen Überblick über die Güte der Berichterstattung im freiwilligen Teil in Abhängigkeit von der Identität der Aktionäre, ihrer regionalen Verteilung sowie der Namensnennung der Großaktionäre:

334 Vgl. Abschnitt 1 dieses Kapitels. 


\begin{tabular}{lrrrrrr}
\hline $\begin{array}{l}\text { Qualität der } \\
\text { Berichter- } \\
\text { stattung }\end{array}$ & $\begin{array}{c}\text { Identität der Ak- } \\
\text { tionäre }\end{array}$ & $\begin{array}{c}\text { Regionale } \\
\text { Herkunft }\end{array}$ & \multicolumn{3}{c}{$\begin{array}{c}\text { Namen der Groß- } \\
\text { aktionäre }\end{array}$} \\
\hline knapp & 27 & 39,7 & 10 & 30,3 & 20 & 37,7 \\
normal & 32 & 47,1 & 13 & 39,4 & 23 & 43,4 \\
umfassend & 9 & 13,2 & 10 & 30,3 & 10 & 18,9 \\
\hline Summe & $\mathbf{6 8}$ & $\mathbf{1 0 0}$ & $\mathbf{3 3}$ & $\mathbf{1 0 0}$ & $\mathbf{5 3}$ & $\mathbf{1 0 0}$ \\
\hline
\end{tabular}

Tab. 4: Freiwillige Angaben zur Aktionärsstruktur

Bei der Bewertung der Informationsgüte muss jedoch berücksichtigt werden, dass Unternehmen mit Inhaberaktien über die für eine umfassende Berichterstattung erforderlichen Informationen selbst nicht oder nur teilweise verfügen. Ebenso wenig kann eine Berichterstattung über die Namen der Großaktionäre von Gesellschaften erwartet werden, die vollständig im Streubesitz sind.

Große Unternehmen, die nach internationalen Rechnungslegungsstandards bilanzieren, gelten oft als auskunftsfreudiger in Bezug auf verschiedenste Informationen, die aus Aktionärssicht von Interesse sind. ${ }^{335}$ Es könnte daher vermutet werden, dass diese Unternehmen auch bei den Angaben zur Aktionärsstruktur Vorreiter sind. Mit Hilfe eines Chi-Quadrat-Unabhängigkeitstests wurde daher überprüft, ob zwischen den Angaben zur Aktionärsstruktur und der Unternehmensgröß $\mathrm{e}^{336}$ bzw. zwischen den Angaben zur Aktionärsstruktur und dem verwandten Rechnungslegungsstandard ein signifikanter Zusammenhang besteht. ${ }^{337}$ Ein solcher war jedoch auf einem Signifikanzniveau von $5 \%$ für keines der beiden Kriterien nachweisbar. Auf einem Signifikanzniveau von $10 \%$ wird die Nullhypothese der Unabhängigkeit zumindest für den Zusammenhang zwischen Publizitätsumfang zur Aktionärsstruktur und Marktkapitalisierung verworfen. Größere Unternehmen berichten demnach umfassender über ihre Aktionärsstruktur als kleine.

\section{Zwischenfazit}

Aufgabe des zweiten Kapitels war die Einordnung der Aktionäre in das Kompetenzgefüge der Aktiengesellschaft und die Differenzierung zwischen verschiedenen Aktionärstypen. Dabei wurden folgende Kernergebnisse herausgearbeitet:

\footnotetext{
335 Vgl. etwa die empirischen Ergebnisse von Ruhwedel/Schultze (2002), S. 627.

336 Die Unternehmensgröße wurde dabei anhand der Marktkapitalisierung gemessen.

337 Vgl. zum Chi-Quadrat-Unabhängigkeitstest Bamberg/Baur (2001), S. 202-204; Bleymüller/Gehlert/Gülicher (2002), S. 130-132.
} 
- Die Aktiengesellschaft wurde als Rechtsform identifiziert, die von ihrer Konstruktion her grundsätzlich geeignet ist, die Interessen großer und kleiner Anleger unabhängig von ihren betriebswirtschaftlichen Fähigkeiten und Anlagebeträgen gleichermaßen zu berücksichtigen.

- Den Aktionären kommt über die Hauptversammlung eine Entscheidungsbefugnis in Grundsatzfragen zu. Fehlende Eingriffsmöglichkeiten in strategische und operative Entscheidungen des Managements sowie begrenzte Klagemöglichkeiten schränken das formal „oberste Organ“ der Aktiengesellschaft jedoch erheblich ein.

- Bei den Aktionärsgruppen wird grob unterschieden zwischen Klein- und Großaktionären. Eine pauschale Klassifizierung erscheint nicht sinnvoll und sollte in Abhängigkeit von der Aktionärsstruktur im Einzelfall erfolgen. Das deutsche Corporate-Governance-System ist gekennzeichnet durch eine große Bedeutung von Großaktionären bei einem im internationalen Vergleich geringen Streubesitz.

- Die Transparenz über Aktionärsstrukturen in Deutschland ergibt sich im Wesentlichen aus dem WpHG. Eine Offenlegungspflicht besteht erst ab einem Stimmrechtsanteil von $5 \%$ und bis die Meldung über eine Veränderung des Stimmrechtsanteils den Kapitalmarkt erreicht, vergehen bis zu 16 Tage.

- Eine empirische Analyse der freiwilligen Berichterstattung über die Aktionärsstruktur in den 2001er Geschäftsberichten der DAX100-Unternehmen hat ergeben, dass viele, insbesondere der großen Gesellschaften Angaben zur Aktionärsstruktur machen. Die Angaben sind jedoch oft sehr unpräzise und wenig detailliert.

Im folgenden dritten Kapitel wird zunächst die Beziehung zwischen Management und Anteilseignern betrachtet und ein Überblick über die darauf aufbauende Principal-Agent-Theorie gegeben. Damit soll eine theoretische Fundierung des Instrumentariums erfolgen, mit dem im weiteren Verlauf des dritten Kapitels die Beziehung zwischen den Aktionärsgruppen analysiert werden soll. 


\section{III. Ökonomische Analyse der Kontrollfunktion von Akti- onären}

\section{Erfordernis und Auswirkungen der Managementkontrolle durch Aktionäre}

\subsection{Abgrenzung der Aktionärskontrolle}

\subsection{1 Ökonomisches und rechtliches Verständnis}

Im Rahmen von Kapitel II.2 wurden die Rechte und Pflichten des Aktionärs bereits aus einer primär juristischen Sicht beleuchtet. Im Folgenden werden Vermögens- und Informationsrechte zurückgestellt und die Analyse wird auf die Herrschafts- bzw. Kontrollrechte des Aktionärs fokussiert. Das Untersuchungsobjekt wird dabei über die rechtlichen Regelungen hinaus ausgedehnt und die Handlungsanreize des Aktionärs werden aus einer ökonomischen Perspektive betrachtet. $^{338}$

Für den Begriff der Aktionärskontrolle liegt keine allgemein akzeptierte Definition vor. ${ }^{339}$ Im Rahmen dieser Arbeit wird Aktionärskontrolle als die Ausübung von auf das Management gerichteter Kontrolle durch Aktionäre verstanden. ${ }^{340}$ Das Recht zur Kontrolle wird ökonomisch begründet mit dem Residualanspruch der Eigenkapitalgeber, der die Erfüllung ihrer monetären Ansprüche hinter die der anderen Anspruchsgruppen zurückstellt. ${ }^{341}$ Kontrolle beinhaltet dabei neben der Ex-post-Kontrolle insbesondere die zukunftsgerichtete Ex-ante-Kontrolle, die sich etwa in der Beeinflussung unternehmerischer Grundsatzentscheidungen manifestiert. ${ }^{342}$ Dabei wird davon ausgegangen, dass (einzelne) Aktionäre Einfluss auf das Management grundsätzlich auch außerhalb von Hauptversammlung

338 Vgl. zu den Verhaltensannahmen der handelnden Akteure ausführlich das folgende Kapitel III.1.2.1.

339 Vgl. Hartmann-Wendels (2001), Sp. 1341; Thom (1993), Sp. 1139.

340 Zum Kontrollbegriff vgl. Brink (1992); Thom (1993), Sp. 1140f.; Lück (1998).

341 Vgl. zur ökonomischen Rechtfertigung des Shareholder-Value-Ansatzes Bischoff (1994), S. 168ff.; Ballwieser (1994), S. 1377-1405; Schmidt/Spindler (1997); Bühner/Tuschke (1997); Matthes (2000), S. 5-17.

342 Diese weite Auffassung von Kontrolle hat sich in der juristischen und wirtschaftswissenschaftlichen Literatur weitgehend etabliert. Vgl. beispielhaft Thom (1993), Sp. 1140; Hartmann-Wendels (2001); Mertens (1996), Anm. $11 \mathrm{zu} \S 111$, ausführlich die weite Auffassung begründend auch Ruhwedel (2002), S. 13-16, 50-53, jeweils m.w.N. 
und Aufsichtsrat ausüben können. ${ }^{343}$ Somit ist nicht ausschlaggebend, ob diese Einflussnahme aufgrund von Stimmrechten, Verträgen o.ä. möglich wird ${ }^{344} \mathrm{Ak}$ tionärskontrolle wird daher nicht als reine „Überwachung“ verstanden, Überwachung ist vielmehr ein Bestandteil eines weiter gefassten Kontrollbegriffs. ${ }^{345}$

Damit entspricht die Abgrenzung von Aktionärskontrolle inhaltlich im Wesentlichen der Abgrenzung der englischen „corporate control”, die Jensen/Ruback wie folgt wählen: ,We define corporate control as the rights to determine the management of corporate resources - that is, the rights to hire, fire and set the compensation of top-level managers ${ }^{\text {(346 }}$. Der deutsche Begriff Unternehmenskontrolle ist demgegenüber stärker rechtlich geprägt und stellt im Gegensatz zur „corporate control“ primär auf die juristisch mögliche Ausübung von Kontrolle ab. ${ }^{347}$ Im deutschen Recht existiert keine einheitliche Abgrenzung des Kontrollbegriffs, vielmehr finden sich an verschiedensten Stellen mehr oder weniger explizit kodifizierte Definitionen, über die Tab. 5 einen Überblick gibt. $^{348}$

\begin{tabular}{lll}
\hline $\begin{array}{l}\text { Rechts- } \\
\text { grundlage }\end{array}$ & Regulierungsziel & Regulierungsinhalt \\
\hline HGB & Festlegung der & • Konzept der einheitlichen Leitung, Kapitalgesellschaft \\
& Konzernrech- & hält Beteiligung $>20 \%(\S 271$ Abs. 1) und übt ein- \\
& nungslegungs- & heitliche Leitung tatsächlich aus (§ 290 Abs. 1) \\
& pflicht; ${ }^{349}$ & - Stimmrechtsmehrheit, Bestellungs- und Abberu- \\
& Control-Kon- & fungsmöglichkeit der Organe, Satzungsregelung oder \\
& zept & Beherrschungsvertrag (§ 290 Abs. 2) \\
\hline
\end{tabular}

343 Ähnlich Schmid (1996), S. 403; Zeckhauser/Pound (1990), S. 153, ausführlich zum Kontrollbegriff in Publikumsgesellschaften auch Gottschlich (1996), S. 84-92.

344 Ähnlich Eisolt (1993), S. 348; Schenk (1997a), S. 8.

345 Vgl. Thom (1993), Sp. 1140, zu einer sehr engen Abgrenzung des Kontrollbegriffs.

346 Jensen/Ruback (1983), S. 5, ähnlich Fama/Jensen (1983), S. 308; Jarrell/Brickley/Netter (1988), S. 51; Shubik (1988), S. 45; Schmid (1996), S. 403; Geldmacher (2000), S. 52. Allgemeiner zum ,control“-Begriff vgl. Brown (2000).

347 Vgl. Ebke (1994), S. 10f.; Hartmann-Wendels stellt fest: „Diese Begriffsbestimmung, die auf die Kontrolle der Unternehmenspolitik (Corporate Control) abzielt, ist somit weiter gefasst als der gesetzliche Bedeutungsgehalt, in dem unter Kontrollrecht meist das Recht auf Auskunft und Einsichtnahme verstanden wird." Hartmann-Wendels (2001), Sp. 1341. Anders Weikert (2001), S. 69.

348 Eine ähnliche Übersicht findet sich auch bei Becht/Böhmer (1999). Vgl. zum deutschen Regelungskonzept mit Bezug auf die Konzernrechnungslegungspflicht ausführlich Sürken (1999), S. 29-44, außerdem Schenk (1997), S. 7-20.

349 Weitere Regelungen zur Konzernrechnungslegungspflicht sind im PublG kodifiziert. Vgl. ausführlich Böhmer (1986). Sonderregelungen finden sich zudem für einzelne Branchen, vgl. z.B. § 1 Abs. 6-8 KGW. 


\begin{tabular}{|c|c|c|}
\hline $\begin{array}{l}\text { Rechts- } \\
\text { grundlage }\end{array}$ & Regulierungsziel & Regulierungsinhalt \\
\hline AktG & $\begin{array}{l}\text { Definition ver- } \\
\text { bundener Unter- } \\
\text { nehmen }(\S 15)\end{array}$ & $\begin{array}{l}\text { Verbundene Unternehmen sind Unternehmen, die } \\
\text { - ...im Verhältnis zueinander in Mehrheitsbesitz oder } \\
\text { Mehrheitsbeteiligung (Stimmrechte) stehen }(\S 16) \\
\text { - ...abhängig bzw. herrschend sind }(\S 17) \\
\text {-...Konzernunternehmen sind ( }(18) \\
\text { - ... wechselseitig beteiligt sind }(\S 19) \text { oder } \\
\text {-...Vertragsteile eines Unternehmensvertrags sind ( }( \\
\text { 291f.) }\end{array}$ \\
\hline WpHG & $\begin{array}{l}\text { Meldepflichten } \\
\text { bei Über-/Unter- } \\
\text { schreiten best. Be- } \\
\text { teiligungshöhen }\end{array}$ & $\begin{array}{l}\text { - Meldepflicht bei Erwerb von mind. 5, 10, 25, } 50 \text { oder } \\
75 \% \text { der Stimmrechte (vgl. ausführlich Kapitel } \\
\text { II.3.5.2.1) }\end{array}$ \\
\hline GWB & $\begin{array}{l}\text { Definition herr- } \\
\text { schender Unter- } \\
\text { nehmen }\end{array}$ & $\begin{array}{l}\text { Verbundene Unternehmen gem. } \S 17,18 \text { AktG sind } \\
\text { als einheitliches Unternehmen zu sehen; üben mehrere } \\
\text { Unternehmen zusammen einen herrschenden Einfluss } \\
\text { aus, sind sie jeweils als herrschend anzusehen ( } § 36 \\
\text { Abs. 2) }\end{array}$ \\
\hline WpÜG & $\begin{array}{l}\text { Regelung von Un- } \\
\text { ternehmens- } \\
\text { übernahmen }\end{array}$ & $\begin{array}{l}\text { - Kontrolle ist das Halten von mindestens } 30 \% \text { der } \\
\text { Stimmrechte an der Zielgesellschaft ( }(29)\end{array}$ \\
\hline
\end{tabular}

Tab. 5: Kontrolldefinitionen im deutschen Recht

Die Übersicht macht deutlich, dass keine einheitliche kapital- oder stimmrechtsbezogene Grenze für Aktionärskontrolle existiert. Zwar liegt eine de jure Beherrschungsmöglichkeit immer ab einem Stimmrechtsanteil von über $50 \%$ vor; die niedrigeren, im HGB, WpÜG oder WpHG kodifizierten Grenzen lassen jedoch darauf schließen, dass auch der Gesetzgeber eine Einflussmöglichkeit bereits bei geringeren Kapital- bzw. Stimmrechtsanteilen als gegeben ansieht. Darüber hinaus führen die geringen Hauptversammlungspräsenzen zu einer de facto Einflussmöglichkeit bereits bei niedrigeren Stimmrechtsanteilen. ${ }^{350}$

In diesem Zusammenhang soll ausdrücklich darauf hingewiesen werden, dass die tatsächliche Ausübung von Aktionärskontrolle in der Praxis auch außerhalb dieser kodifizierten Stimmrechtsgrenzen geschehen kann und dieses auch im Rahmen der folgenden Ausführungen unterstellt wird. Jede unmittelbare Beein-

350 Vgl. Cahn (1997), S. 502f. Vgl. auch La Porta et al. (1999), sowie Faccio/Lang (2002), S. 369, die bereits bei einem Stimmrechtsanteil von über $20 \%$ bzw. Cronqvist/Nilsson (2002) von über $25 \%$ von einem „controlling owner“ sprechen. Andere Studien setzen die Grenze ähnlich niedrig. Vgl. ausführlich Anhang B. Zu Hauptversammlungspräsenzen in Deutschland vgl. Bott (2002), S. 411. 
flussung des Managements durch die Aktionäre, sei es über die Hauptversammlung, den Aufsichtsrat oder direkt, ist Ausdruck der so genannten „voice“Option des Aktionärs. Die Differenzierung der Aktionärskontrolle in „exit“ und "voice“ wurde bereits von Hirschman (1970) in die Literatur eingeführt. ${ }^{351}$ „Exit" beschreibt dabei die Möglichkeit des Aktionärs, Unzufriedenheit mit dem Management durch den Verkauf seiner Unternehmensanteile zum Ausdruck zu bringen und stellt damit als Drohpotenzial eine eher mittelbare Form der Aktionärskontrolle dar. ${ }^{352}$ Im Verhältnis zur „voice“-Option ist der ,exit" eine vergleichsweise passive bzw. anonyme Strategie. ${ }^{353}$ Für Kleinaktionäre ist die „exit"-Strategie aufgrund ihres geringen Stimmrechtsanteils dennoch häufig die einzige Option, worauf im Folgenden noch im Detail eingegangen wird. ${ }^{354}$

Bevor im weiteren Verlauf ausführlich hergeleitet wird, wie die Annahme der Kontrollausübung auch jenseits rechtlicher Beteiligungsgrenzen $\mathrm{zu}$ begründen ist, soll zunächst die Aktionärskontrolle in das Gesamtsystem der Corporate Governance eingeordnet werden.

\subsubsection{Einordnung der Aktionärskontrolle in das Corporate-Governance- System}

Corporate Governance wurde im Rahmen dieser Arbeit bereits als Ausgestaltung von Leitung und Kontrolle des Unternehmens abgegrenzt, die sich explizit nicht nur innerhalb des Unternehmens abspielt sondern insbesondere auch den Einfluss des Kapitalmarkts auf das Unternehmen umfasst. ${ }^{355}$ So formulieren Shleifer/Vishny in ihrem grundlegenden Aufsatz ganz allgemein "Corporate Governance deals with the ways in which suppliers of finance to corporations assure themselves of getting a return on their investment" ${ }^{356}$. Zielsetzung der Corporate Governance ist demnach die Erwirtschaftung einer risikoadjustierten Rendite für die Kapitalgeber des Unternehmens. Das Corporate-GovernanceSystem eines Landes bildet die Gesamtheit der unternehmensinternen und -ex-

351 Vgl. Hirschman (1970), S. 4.

352 Black (1990), S. 526f.; Coffee (1991), S. 1345-1359; Hawley/Williams (1996), S. 49; Steiger, (2000), S. 102f.; Weikert (2001), S. 58; Ruhwedel (2002), S. 219-224. Ähnlich, wenn auch noch nicht unter dem Titel, bereits Demsetz (1968).

353 Vgl. Steiger (2000), S. 103.

354 Vgl. Kapitel III.1.2.

355 Vgl. grundlegend Shleifer/Vishny (1997), S. 737; Turnbull (1997), S. 181-184; Schneider (2000a), S. 2413f. Einen systematisierenden Überblick gibt Böckli (2000), S. 133f., sowie Prigge (1999), S. 148. Für eine stichpunktartige Abgrenzung der Besonderheiten des deutschen Systems vgl. Böckli (2000), S. 133f.; Salzberger (2000), S. $210 \mathrm{f}$.

356 Shleifer/Vishny (1997), S. 737, ähnlich auch Hopt (2000a), S. 12; Gugler (2001), S. 3. 
ternen Regelungen zur Ausgestaltung der Corporate Governance. ${ }^{357}$ Abb. 9 gibt einen Überblick über die verschiedenen Beziehungsebenen des CorporateGovernance-Systems. ${ }^{358}$

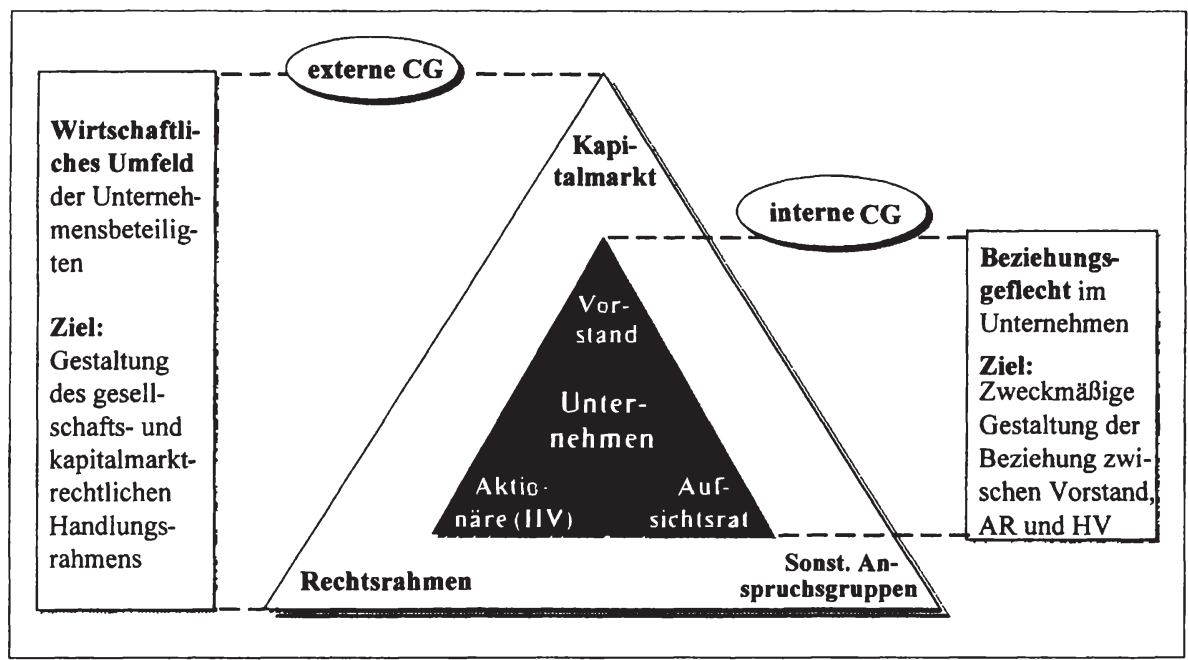

Abb. 9: Corporate-Governance-System

Die durch das innere Dreieck stilisierte interne Corporate Governance beschäftigt sich mit dem Beziehungsgeflecht der Organe der Aktiengesellschaft, also dem Verhältnis von Vorstand, Aufsichtsrat und Hauptversammlung, Ziel ist die zweckmäßige Gestaltung der Unternehmensführung. Dazu zählt insbesondere die Definition der Aufgabenbereiche der Organe über die gesetzlich kodifizierten Rechte und Pflichten hinaus, die Definition unternehmensinterner Prozesse und Informationswege sowie die Ausgestaltung der Vergütungssysteme. Grundsätzlich geschieht die Ausgestaltung der internen Corporate Governance innerhalb eines jeden Unternehmens. Durch die Entwicklung verschiedener Corporate-Governance-Kodizes in den vergangenen Jahren wurden verschiedenste De-

357 Vgl. zur Bedeutung unterschiedlicher Regelungsebenen Claussen/Bröcker (2000); Wentges (2001), S. 1109.

358 Von einem ,inneren“ und „äußeren“ Dreieck der Corporate Governance spricht auch Böckli (2000), S. 133, wenngleich deren Inhalt abweichend gesehen wird und er die Idee nicht weiter ausführt. Zwischen externer und interner Corporate Governance unterscheiden auch Romano (1993a); Suter (2000), S. 116. 
tailregelungen von außen in die Unternehmen hereingetragen. ${ }^{359}$ Dies gilt insbesondere seit der durch das TransPuG kodifizierte $\S 161$ AktG börsennotierte Aktiengesellschaften zu einem „Comply or Explain“ in Bezug auf den Deutschen Corporate Governance-Kodex (DCGK) verpflichtet. ${ }^{360}$

Corporate-Governance-Kodizes beinhalten damit nicht nur Regelungen der internen Corporate Governance, sie sind zudem ein Bestandteil der externen Corporate Governance, die den gesellschafts- und kapitalmarktrechtlichen Handlungsrahmen des Unternehmens abbildet. ${ }^{361}$ Dazu zählen insbesondere die Kapitalmarktbeschaffenheit, die Qualität sowie die Durchsetzbarkeit der Aktionärsrechte, aber auch das Steuersystem und die Ausgestaltung des Rechtssystems an sich, das die Erfüllung der Ansprüche anderer Unternehmensbeteiligter sicherstellt. ${ }^{362}$ Je nachdem, ob der internen oder der externen Corporate Governance in einer Volkswirtschaft mehr Gewicht zukommt, wird zwischen netzwerk- ${ }^{363}$ und marktorientierten Systemen; bzw. zwischen Insider- und Outsider-Systemen unterschieden. ${ }^{364}$

Die Ausführungen machen deutlich, dass insbesondere der hier als „externe Corporate Governance" bezeichnete Teil des Systems sehr breit ist und die Subsumtion vielfältigster Themenkomplexe unter das Schlagwort Corporate Governance zulässt. ${ }^{365}$ Die im Rahmen dieser Arbeit im Mittelpunkt stehende Aktio-

359 Vgl. zu den einzelnen Kodizes Grundsatzkommission Corporate Governance (2000); Berliner Initiativkreis German Code of Corporate Governance (2000), sowie die zusammenfassenden Beiträge von Claussen/Bröcker (2000); Hopt (2000); Pellens/Hillebrandt/Ulmer (2001); Peltzer/von Werder (2001); Schneider (2000a); Schneider/Strenger (2000); Strenger (2001); Sünner (2000); Volk (2001), mit internationaler Perspektive OECD (1999), sowie beispielsweise Böckli (2000); Seibert (1999). Vgl. Regierungskommission DCGK (2002); Seibert (2002).

361 Der hier als „externe Corporate Governance“ beschriebene Teilbereich deckt sich im Wesentlichen mit der angloamerikanischen Sichtweise des Begriffes. Vgl. Shleifer/Vishny (1997), S. 737f.; Deakin/Hughes (1997), S. 2; Halpern (2000), S. 4 f.

$362 \mathrm{Zu}$ den verschiedenen Elementen der externen Corporate Governance vgl. die zahlreichen Untersuchungen von La Porta et al., die verschiedene internationale Vergleichsstudien angestellt haben. Vgl. La Porta et al. (1998, 1999, 2000, 2002).

363 Netzwerkorientierte Corporate-Governance-Systeme werden in der Literatur teilweise auch als bankorientiert beschrieben. Vgl. z.B. Edwards/Fischer (1994), S. 1; La Porta et al. (2000), S. 17.

364 Vgl. Halpern (2000); Moerland (1995), S. 444; Hellwig (2000), S. 95ff.; Steiger (2000), S. 81-85; Rubach/Sebora (1998); Hopt/Wymeersch (1997); Nowak (1997), S. 57f.; Mayer (1998); Nassauer (2000), S. 168-178; Beck/Levine (2002). Marktorientierte Systeme finden sich insbesondere in Common-Law geprägten Nationen, z.B. in den USA, Deutschland ist hingegen Beispiel für Netzwerkorientierung. Vgl. Coffee (1999), S. $3 \mathrm{f}$.

365 Vgl. mit ähnlichem Fazit Prigge (1999), S. 150f. 
närskontrolle stellt jedoch ein Kernelement des Corporate-Governance-Systems dar. Sie nimmt insofern eine Sonderstellung ein, als dass sie sowohl im "inneren" als auch im "äußeren" Dreieck vertreten ist. Über die Hauptversammlung, indirekt über den Aufsichtsrat oder durch direkte Kontakte mit dem Management nehmen die Aktionäre ihre „voice"-Option im Rahmen des inneren Dreiecks wahr. Darüber hinaus steht ihnen die „exit“-Strategie zur Verfügung, also der Verkauf der Aktien bei Unzufriedenheit mit den Leistungen des Managements. Sie sind damit Bestandteil des Kapitalmarktes, also der externen Corporate Governance. Die Kontrollfunktion des Kapitalmarktes beschränkt sich darüber hinaus nicht nur auf die aktuellen Aktionäre. Der mögliche Kontrollerwerb durch Kapitalmarktteilnehmer mit dem Ziel der Realisierung von Wertsteigerungen durch Einsetzung eines neuen Managementteams übt auf die aktuelle Unternehmensleitung eine Kontrollfunktion aus. ${ }^{366}$

Im Folgenden soll zunächst theoretisch hergeleitet werden, woraus die Notwendigkeit einer Kontrolle des Managements in börsennotierten Aktiengesellschaften resultiert. Neben einem kurzen Überblick über die alternativen Kontrollbzw. Anreizmechanismen werden dann die möglichen Vor- und Nachteile der Aktionärskontrolle in ihren verschiedenen Spielarten einer ausführlichen Analyse unterzogen, um auf Basis der theoretischen Ergebnisse Hypothesen für die anschließende empirische Studie ableiten zu können.

\subsection{Agency-Beziehung zwischen Management und Anteilseignern}

\subsubsection{Grundlagen der Agency-Theorie}

\subsubsection{Abgrenzung innerhalb der Neuen Institutionenökonomik}

Zielsetzung der theoretischen Analyse des dritten Kapitels ist die Erklärung von Verhaltensweisen einzelner Aktionärsgruppen unter verschiedenen Rahmenbedingungen. Dabei sollen Effizienzaussagen über alternative Eigentümer- und Stimmrechtsstrukturen aus theoretischer Sicht abgeleitet werden, um sie im folgenden vierten Kapitel empirisch zu überprüfen. Voraussetzung hierfür ist das Vorliegen eines einheitlichen theoretischen Bezugsrahmens, der zur Ableitung von Effizienzaussagen herangezogen wird. Einen solchen Bezugsrahmen bietet die mikroökonomische Gleichgewichtsanalyse, die „Interdependenzen zwischen den Aktionen rational handelnder Akteure [analysiert, mit dem Ziel, das] Zustandekommen von Transaktionen auf Märkten und [die] Bildung von Preisen ${ }^{\text {‘367 }}$ zu erklären. ${ }^{368}$ Für die Erklärung der Verhaltensweisen von Individuen -

\footnotetext{
366 Vgl. zum so genannten Markt für Unternehmenskontrolle ausführlich Kapitel III.1.2.2.1.

367 Hax (1991), S. 52.
} 
hier Aktionären - stellt die Neue Institutionenökonomik einen geeigneten Modellhintergrund dar, ${ }^{369}$ da ihre Analyse aus dem Blickwinkel des methodologischen Individualismus erfolgt, somit nicht Aktionen von ganzen Unternehmen unterstellt werden, sondern diese aus der Perspektive des Individuums und seiner Entscheidungen untersucht werden. ${ }^{370}$

Zielsetzung der Neuen Institutionenökonomik ist die Erklärung von „Institutionen in einer Modellwelt, in der der Tausch mit Reibungsverlusten verbunden ist $^{\star 371}$. Institutionen werden verstanden als ein System formgebundener (formaler) und formungebundener (informaler) Regeln einschließlich der Vorkehrungen zu deren Umsetzung. ${ }^{372}$ Sie beabsichtigen die zielgerichtete Verhaltensbeeinflussung von Individuen mit verschiedensten Vertragsarten, um hierdurch Ordnung zu schaffen und Unsicherheit zu vermindern. ${ }^{373}$ Die Eignung dieser Forschungsrichtung für die Analyse ökonomischer Beziehungen ist deshalb so groß, weil die unterstellten Verhaltensannahmen der handelnden Akteure mit dem tatsächlichen Verhalten von Individuen weitgehend konform gehen. ${ }^{374} \mathrm{Im}$ Einzelnen wird begrenzte Rationalität und individuelle Nutzenmaximierung unterstellt, wobei die speziellen Annahmen abhängig sind von der jeweiligen For-

368 Zur Bedeutung mikroökonomischer Modelle für die Analyse von ökonomischen Sachverhalten ausführlich Kreps (1990), S. 7f.; Schmidt/Schor (1987); Richter (1990, 1991); Wolff (2000), S. 7-40 m.w.N., kritisch Schneider (1987).

369 Der Begriff der Neuen Institutionenökonomik wurde geprägt durch Williamson (1975), S. 1, der ihn jedoch noch primär für die Transaktionskostentheorie nutzte. Inzwischen wird der Begriff breiter interpretiert. Vgl. Richter/Bindseil (1995), S. 134. Gleichbedeutend findet sich in der Literatur der Begriff des Neoinstitutionalismus, gelegentlich ist auch allgemein von vertragstheoretischen Ansätzen die Rede. Vgl. Nemec (1999), S. 9.

370 Vgl. Wüstemann (2002), S. 27-33; Richter/Bindseil (1995), S. 132; Ruhwedel (2002), S. 67. Auf den neoklassischen Forschungszweig der Ökonomie soll an dieser Stelle nicht weiter eingegangen werden. Vgl. jedoch für eine Abgrenzung zur Neuen Institutionenökonomik Richter (1991), S. 398-401; Wolff (2000), S. 10-13 m.w.N.

371 Terberger (1994), S. 23, mit einer ausführlichen Ableitung der Begriffswelt. Die Idee der Reibungsverluste (später: Transaktionskosten) geht zurück auf Coase (1937) und Williamson (1975) mit umfangreichen Weiterentwicklungen. Der Begriff wurde geprägt durch Arrow (1969), S. 48. Für einen Überblick über die jüngeren Entwicklungen der Theorie der Unternehmung vgl. Zingales (2000).

372 Vgl. Richter/Furubotn (1999), S. 7, mit Verweis auf Schmoller (1900). Ähnlich Picot/Dietl/Franck (1997), S. 11f. North (1990), S. 3, sieht Institutionen als „the rules of the game in a society".

373 Vgl. North (1990), S. 3. Als Beispiele für Institutionen können Gesetze, Gerichtsurteile, Verträge oder organisatorische Regelungen genannt werden.

374 Vgl. Nemec (1999), S. 9; Geldmacher (2000), S. $12 \mathrm{f}$. 
schungsrichtung der Neuen Institutionenökonomik. ${ }^{375}$ Die Annahme der begrenzten Rationalität beinhaltet im Eigeninteresse nutzenmaximierende Akteure, deren Kapazität zur Aufnahme und Verarbeitung von Informationen begrenzt ist und die daher nicht alle objektiv relevanten Einflussgrößen betrachten. Entscheidungen werden unter der Restriktion subjektiv begrenzter Informationen getroffen; es wird satisfizierendes Verhalten, ${ }^{376}$ in einzelnen Modellen opportunistisches, also eigennütziges Verhalten unterstellt. ${ }^{377}$ Die Neue Institutionenökonomik geht von unvollkommenen Märkten und einer uneinheitlichen Informationsversorgung der Akteure aus. ${ }^{378}$

Mit diesem gemeinsamen Annahmenrahmen erlauben die verschiedenen Forschungszweige der Neuen Institutionenökonomik die Abbildung von Sachverhalten, die den strengen Annahmenrahmen der Neoklassik sprengen; wenngleich dieses häufig mit einem Verlust an Eindeutigkeit einhergeht, die die Modelle der Neoklassik prägt. ${ }^{379}$ Entsprechend haben weite Teile der Neuen Institutionenökonomik erklärenden (,positiven“) Charakter.

Die auf der Arbeit von Coase (1937) aufbauende Neue Institutionenökonomik wird regelmäßig in drei Forschungsrichtungen unterteilt. ${ }^{380}$ Neben der hier im Mittelpunkt stehenden Agency- bzw. Principal-Agent-Theorie sind die PropertyRights-Theorie ${ }^{381}$ und die Transaktionskostentheorie ${ }^{382}$ von Bedeutung. ${ }^{383}$ Abb.

375 Vgl. Furubotn/Richter (1995), S. 4f.; Kreps (1990), S. 744-747. Der Grad der unterstellten Rationalität schwankt je nach Art des institutionenökonomischen Modells. So unterstellt die Property-Rights-Theorie keine begrenzte, sondern nur eine individuelle Rationalität. Vgl. Richter/Bindseil (1995), S. 132; Ruhwedel (2002) S. 67.

$376 \mathrm{Zu}$ Spielarten von Verhaltensannahmen vgl. Simon $(1962,1972)$; Becker $(1957,1993)$, einen Überblick gibt Valcárcel (2002), S. 237-251, sowie Neus (2001), S. 3f.

377 Vgl. Williamson (1975).

378 Vgl. Wolff (2000), S. 15. Zur asymmetrischen Information vgl. Stiglitz/Weiss (1981); Spremann (1990). Für einen ausführlichen Überblick über die Annahmen vgl. auch Erlei/Leschke/Sauerland (1999), S. 44ff.; Geldmacher (2000), S. 13.

379 Vgl. Terberger (1994), S. 23.

380 Zur geschichtlichen Entwicklung vgl. Erlei/Leschke/Sauerland (1999), S. 27-55; Terberger (1994), S. 47-81.

381 Zielsetzung der Property-Rights-Theorie (Verfügungsrechtstheorie) ist die Erforschung und optimale Allokation von Verfügungsrechten (englisch: Property Rights). Vgl. grundlegend Coase (1937, 1960); Alchian/Demsetz (1972); Furubotn/Pejovich (1972).

382 Der Transaktionskostenansatz analysiert die im Zusammenhang mit Transaktionen, definiert als auf dem Verhandlungswege erzielte Einigungen zum Austausch von Rechten, entstehenden Kosten. Vgl. grundlegend Williamson (1985). 
10 gibt einen Überblick über die verschiedenen Zweige der Neuen Institutionenökonomik und ihren jeweiligen Untersuchungsgegenstand.

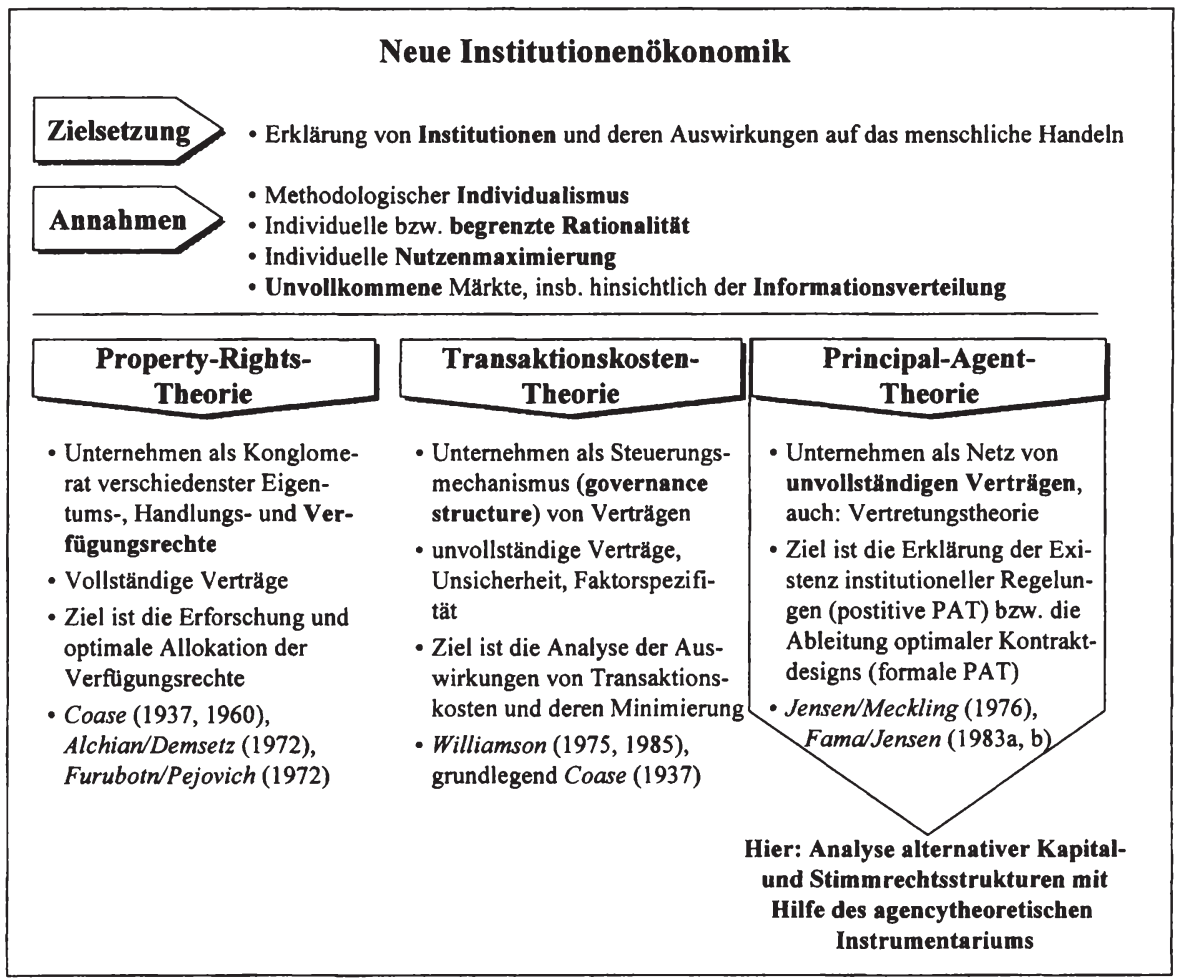

Abb. 10: Neue Institutionenökonomik

Im Vordergrund dieser Arbeit steht die Agency-Theorie, die sich mit der Unternehmung als Netz von (Agency)-Verträgen beschäftigt. ${ }^{384}$ Die Notwendigkeit der Vertragsbeziehungen ergibt sich aus der Delegation von Verfügungsrechten; wie Jensen/Meckling es formulieren: „contractual relations are the essence of the firm“ ${ }^{385}$ Die Agency-Theorie wird nach Jensen (1983) in einen positiven (,posi-

383 Weitere, neben den hier genannten drei Forschungsrichtungen existierende Forschungszweige können nach Meinung von Terberger darunter subsumiert werden, sodass sie hier nicht einzeln aufgeführt werden. Vgl. Terberger (1994), S. 2f. Vgl. auch Noth (1996), S. 118-120. Für eine breitere Aufsplitterung vgl. Richter/Furubotn (1999), S. 35-38; Erlei/Leschke/Sauerland (1999), S. 42-45.

384 Die agency-theoretische Forschung wurde wesentlich geprägt durch die Beiträge von Jensen/Meckling (1976) und Fama/Jensen (1983, 1983a); im Weiteren zu nennen sind die Arbeiten von Baumol (1959), sowie Grossman/Hart (1980).

Jensen/Meckling (1976), S. 310. 
tive theory of agency“) und einen normativen Zweig (,principal-agent literature") unterteilt. ${ }^{386}$ Die positive Agency-Theorie befasst sich im Wesentlichen mit der Erklärung von real existierenden Vertrags- und Auftragsbeziehungen sowie institutionellen Regelungen. ${ }^{387}$ Dabei wird auf explizite, insbesondere mathematisch hergeleitete Gestaltungsempfehlungen in der Regel verzichtet, stattdessen werden empirische Untersuchungen einbezogen. ${ }^{388}$ Der normative Zweig der Agency-Theorie ${ }^{389}$ zielt als formale Theorie auf die Ableitung von Gestaltungsempfehlungen für eine optimale Kontraktgestaltung. ${ }^{390}$

In Bezug auf die Eigentümerstrukturanalyse ermöglichen die Ergebnisse der Agency-Theorie die Analyse der Beziehung zwischen Anteilseignern und Management einerseits und der $z$ wischen verschiedenen Aktionärsgruppen andererseits. Bevor in Unterkapitel III.2 eine Ausdehnung auf Agency-Beziehungen zwischen verschiedenen Aktionärsgruppen erfolgt, wird im Folgenden ein Überblick über die klassische Agency-Theorie gegeben.

\subsubsection{Verfügungsrechtsdelegation als Ursache von Agency-Konflikten}

Ausgangspunkt der verschiedenen Entwicklungen innerhalb der Neuen Institutionenökonomik und damit auch der Agency-Theorie ist die regelmäßig Berle/Means (1932) zugeschriebene Erkenntnis, dass im Rahmen der „modern corporation ${ }^{\text {‘391 }}$ die Unternehmensführung von den Eigentümern (principal) auf angestellte Manager (agent) übertragen wird, die aufgrund von spezifischem Know-how für diese Aufgabe geeignet scheinen. ${ }^{392}$ Diese Form der Unternehmensorganisation hat sich heute für große Unternehmen weltweit durchgesetzt, wenngleich ihre Eignung immer wieder bezweifelt und teilweise ihr Untergang prognostiziert wird. Aus heutiger Sicht haben jedoch weder Thonet/Poensgen (1979) Recht behalten, die managerkontrollierte Unternehmen als „ziemlich kleine Minderheit ${ }^{\star 393}$ in Deutschland ansahen, noch Jensen (1989), der mit der

\footnotetext{
386 Vgl. Jensen (1983), S. 334-336.

387 Vgl. Elschen (1991), S. 1006; Meinhövel (1999), S. 24; Renner (1999), S. 44.

388 Vgl. Nemec (1999), S. 39; Eisenhardt (1989), S. 66f., mit einem Überblick.

389 Zur Principal-Agent-Theorie i.e.S. vgl. Jensen (1983), S. 334; Elschen (1991), S. 1006

390 Vgl. Elschen (1991), S. 1006; Terberger (1994), S. 99f. Vgl. zur normativen PrincipalAgent-Theorie in historischer Reihenfolge Wilson (1969); Berhold (1971); Ross (1973); Harris/Raviv (1978); Holmström (1979); Shavell (1979).

391 Ihr Buchtitel lautet „The Modern Corporation and Private Property”.

392 Vgl. Berle/Means (1932) S. 220f.; Fama/Jensen (1983), S. 308; Grossman/Hart (1986), S. 691.

393 Thonet/Poensgen (1979), S. 26.
} 
„Eclipse of the Public Corporation“ den Untergang der Publikumsgesellschaft prophezeite.

Der Grund für die kritische Haltung vieler Autoren gegenüber der „modernen Publikumsgesellschaft" liegt in den mit der Delegation von Verfügungsrechten einhergehenden Problemen, die den Kern der agency-theoretischen Forschung bilden. ${ }^{394}$ Bereits vor Berle/Means wurde dieses Problem in ähnlicher Form von Adam Smith erkannt, der schon 1776 formulierte: ${ }^{395}$ „The directors of such companies, however, being the managers rather of other people's money than of their own, it cannot well be expected, that they should watch over it with the same anxious vigilance with which the partners in a private copartnery frequently watch over their own." 396

Die Delegation von Verfügungsrechten auf angestellte agents führt zu einer Trennung von Eigentum und Verfügungsmacht (ownership and control), wobei Verfügungsmacht die Entscheidungsgewalt über die Verwendung von Unternehmensressourcen beinhaltet. ${ }^{397}$ Die Übertragung der Verfügungsmacht erfolgt mit Hilfe von Verträgen, die jedoch unvollständig sind und als so genannte „relationale Verträge" Spielraum für Interpretationen bieten. ${ }^{398}$ Die Situation ist gekennzeichnet durch Unsicherheit des principals über die Präferenzordnung des agents ebenso wie über die künftige Umweltentwicklung. ${ }^{399}$ Der principal ist über das Tagesgeschäft nicht ausreichend informiert und es entstehen Informationsasymmetrien hinsichtlich der Eignung, geplanter Aktivitäten und des Anstrengungsniveaus des agents. ${ }^{400}$

394 Vgl. mit einem Überblick über kritische Beiträge Juhnke (1995), S. 61-63.

395 Theoretisch finden sich die 1932 von Berle/Means empirisch untersuchten Unternehmensstrukturen auch bereits in den Arbeiten von Steinitzer (1908); Rathenau (1918) und Veblen (1923). Vgl. Steinitzer (1908), S. 53ff.; Rathenau (1918), S. $141 \mathrm{ff} . ;$ Veblen (1923), S. 50ff. Zu anderen Anfang des 20. Jahrhunderts erschienenen Monografien mit ähnlicher Thematik vgl. Juhnke (1995), S. 63. Smith (1776), S. 741.

Vgl. Jensen/Meckling (1976), S. 308; Stigler/Friedland (1983), S. $247 f$.

Vgl. Macneil (1974), S. 753; Richter (1990), S. 583. Die Unvollständigkeit der Verträge schafft die Voraussetzung für die Realisierung von Spezialisierungsvorteilen innerhalb der Auftragsbeziehung. Vgl. Fama/Jensen (1983a), S. 331; Shleifer/Vishny, (1997), S. 741; Elschen (1991), S. 1004; Richter/Bindseil (1995), S. $137 \mathrm{f}$.

Unterstellt wird eine eingeschränkte Rationalität und Opportunismus des agents. Vgl. Williamson (1985), S. 46f.; Richter (1990), S. $581 \mathrm{f}$.

Man unterscheidet hidden characteristics, information, intention und action, die teilweise vor und teilweise nach Vertragsabschluss von Bedeutung sind. Vgl. Arrow (1985), S. 38; Fama/Jensen (1983), S. 304; Richter/Furubotn (1999), S. 163-171; Hartmann-Wendels (1989), S. 714f.; Spremann (1990), S. 561-586. 
Dieser Informationsvorsprung eröffnet dem Management Handlungsspielräume, im eigenen Interesse nutzenmaximierend zu agieren und die Interessen der Anteilseigner zu vernachlässigen. ${ }^{401}$ Aus Sicht des principals resultieren die Gefahren der adverse selection ${ }^{402}$ (Auswahl des falschen Vertragspartners aufgrund unvollständiger Information), moral hazard ${ }^{403}$ (Eigennutzorientierung des agents in Form von Consumption on the Job oder Drückebergerei nach Vertragsabschluss) und hold up ${ }^{404}$ (opportunistisches Ausnutzen von Vertragslücken nach Vertragsabschluss).

Durch die Ausnutzung speziell nicht-pekuniärer Vergünstigungen seitens des Managements wird der zur Ausschüttung an die Aktionäre zur Verfügung stehende Zahlungsstrom reduziert. ${ }^{405}$ Die principals werden auf diese Gefahr der Wohlfahrtsverschiebung zu ihren Lasten reagieren und versuchen, die Informationsasymmetrien zu reduzieren. In der Folge entstehen Agency-Kosten entweder beim Auftraggeber oder beim Auftragnehmer ${ }^{406}$ Im Einzelnen werden monitoring $\operatorname{costs}^{407}$, bonding $\operatorname{costs}^{408}$ und residual loss ${ }^{409}$ unterschieden. ${ }^{410}$ Die

401 Vgl. Shleifer/Vishny (1997), S. 740f., sowie den Überblick bei Varga von Kibed (2001), S. 60-65. Kritisch zu der Annahme eigennutzorientierter agents Demsetz (1983).

402 Vgl. Matschke (2001); Richter/Furubotn (1999), S. 236-240, sowie grundlegend Akerlof (1970) mit dem „Market for lemons“. Lösungsansätze bieten Spence (1973) und Arrow (1986).

403 Z.B. die Auswahl eines großen Dienstwagens oder der Nutzung des Firmenjets für private Zwecke. Vgl. Jensen/Meckling (1976), S. 308; Holmström (1979); Harris/Raviv (1978); Furubotn/Richter (1995), S. 21; Spremann (1990), S. 571f.

404 Vgl. Klein/Crawford/Alchian (1978); Williamson (1985), S. 48; Furubotn/Richter (1995), S. 631f.; Spremann (1990), S. 568-570.

405 Vgl. Jensen/Meckling (1976), S. 312.

406 Vgl. Jensen/Meckling (1976), S. 308; Richter/Furubotn (1999), S. 166f.; Erlei/Leschke/Sauerland (1999), S. 75; Picot/Dietl/Franck (1997), S. 87. Die Existenz von AgencyKosten konnte durch empirische Untersuchungen bestätigt werden. Vgl. für einen Überblick Shleifer/Vishny (1997), S. 746-748.

407 Kosten des principals aufgrund der Kontrolle und Überwachung des agents; insb. Kosten der Informationsbeschaffung. Vgl. Jensen/Meckling (1976), S. 323.

408 Kosten aufgrund der durch den principal überprüfbaren Einschränkungen der Entscheidungs- und Handlungsspielräume des agents (Selbstbindung); insb. Kosten der Vertragsgestaltung und Opportunitätskosten, da die First-Best-Lösung aufgrund eingeschränkter Flexibilität des agents nicht erreicht wird. Vgl. Jensen/Meckling (1976), S. 325; Noth (1996), S. 127.

409 Verbleibender Nutzenverlust des principals, der trotz der Installation von Kontroll- und Überwachungssystemen dadurch entsteht, dass der agent verbleibende Handlungsspielräume ausnutzt und nicht die für den principal optimale Handlungsalternative wählt. Vgl. Jensen/Meckling (1976), S. 319; Noth (1996), S. 127. 
Summe der Agency-Kosten ergibt sich als Differenz zwischen der in einer Welt ohne Informationsasymmetrien theoretisch möglichen First-Best-Lösung und der realiter bestenfalls erreichbaren Second-Best-Lösung. ${ }^{411}$ Zielsetzung der normativen Agency-Theorie ist die Identifikation eines pareto-optimalen Arrangements, bei dem die Summe der durch die Entscheidungsdelegation entstehenden Nutzenminderungen (gemessen als Opportunitätskosten) und der Kosten zur Verringerung der Agency-Problematik minimal werden. ${ }^{412}$

\subsubsection{Free-Rider-Problematik in Publikumsgesellschaften}

Grundsätzlich hat jeder Aktionär die Möglichkeit der Kontrollausübung auf der Hauptversammlung; ,the right to vote is the right to make all decisions not otherwise provided by contract ${ }^{4413}$. Diese Kontrollausübung mit dem Ziel der Agency-Kosten-Reduzierung liegt prinzipiell im Interesse aller an der Unternehmung beteiligten Aktionäre. Ein wesentliches Problem der Publikumsgesellschaft liegt jedoch darin begründet, dass die Informationskosten des einzelnen Aktionärs, die ihm eine im Sinne der Unternehmenspolitik optimale Entscheidung auf der Hauptversammlung - und somit eine effiziente Kontrolle - ermöglichen, hoch sind. ${ }^{414}$ Neben den Informationskosten entstehen Koordinationskosten, wenn - und das ist Voraussetzung für ein erfolgreiches Abstimmungsergebnis - auch andere Aktionäre für die Unterstützung des Antrags gewonnen werden sollen. Insbesondere für Kleinaktionäre stehen diese Informations- und Koordinationskosten nicht in angemessenem Verhältnis zum damit verbundenen Erfolg, sodass es für sie individuell rational ist, schlecht informiert oder gar nicht abzustimmen. ${ }^{415}$

410 Als Beispiele von Agency-Kosten werden neben der Realisierung nicht-pekuniärer Vergünstigungen durch den agent eine suboptimale Investitionspolitik (Über- bzw. Unterinvestition) und Liquidationsverschleppung genannt. Vgl. Jensen/Meckling (1976), S. 305ff.; Jensen (1986); Wosnitza (1991); Noth (1996), S. 133-139. Zur Kritik am Konzept der Agency-Kosten vgl. Schneider (1989); Meinhövel (1999), S. 50-55.

411 Vgl. Jensen/Meckling (1976), S. 327; Meinhövel (1999), S. 42-44.

412 Vgl. Pratt/Zeckhauser (1985), S. 3; Elschen (1988), S. 250; Picot/Dietl/Franck (1997), S. 83.

413 Easterbrook/Fischel (1983), S. 402.

414 Vgl. Berle/Means (1932), S. 84-89, 121f.; Grossman/Hart (1980), S. 42; Hansmann (1988), S. 275-277, 283; Baums/Schmitz (1998), S. 4f.; Jansch (1999), S. 67. Vgl. zur „Passivity Story“ Black (1990), S. 526-530; Schreyögg/Steinmann (1981), S. 534.

415 Vgl. Marris (1964), S. 18; Großfeld (1968), S. 14; Grossman/Hart (1980), S. 43; Easterbrook/Fischel (1983), S. 402; Shleifer/Vishny (1986), S. 461f.; Fluck (1999), S. 381; Paul (1999), S. 659. 
Entsprechend nehmen viele Kleinaktionäre gar nicht an der Hauptversammlung teil (Absentismus im engeren Sinne), oder sie stimmen den Vorschlägen der Verwaltung unreflektiert zu (Absentismus im weiteren Sinne). ${ }^{416}$ Darüber hinaus fehlt vielen (Klein-)Aktionären regelmäßig die erforderliche Sachkompetenz für die Ausübung von Kontrolle. ${ }^{417}$ Wie Fama/Jensen es formulieren: „When there are many residual claimants, it is costly for all of them to be involved in decision control $[\ldots]$ and most of the diffuse residual claimants are not qualified for roles in the decision process. ${ }^{\prime 418}$

Aktionärskontrolle kommt als öffentliches Gut allen an der Unternehmung beteiligten Aktionären zugute, wohingegen eine Allokation der damit verbundenen Kosten auf alle Aktionäre nicht möglich ist. ${ }^{419}$ Obwohl ein gut informiertes $\mathrm{Ab}$ stimmungsverhalten im Sinne aller Aktionäre wäre, vertraut daher der Einzelne als sog. Free Rider darauf, dass die anderen Aktionäre gut informiert abstimmen und er an dem daraus resultierenden Nutzen partizipieren kann. ${ }^{420}$ In diesem $\mathrm{Zu}$ sammenhang wurde der Begriff der ,rationalen Apathie“ geprägt. ${ }^{421} \mathrm{Da}$ der Aktionär sich von der Ausübung seines Stimmrechts keinen angemessenen Nutzen verspricht, bleibt ihm bei Unzufriedenheit mit der Tätigkeit des Managements und einer Trägheit der anderen Aktionäre die seiner entspricht - nur die Option des Verkaufs. ${ }^{422}$

Im Ergebnis sind somit zwar grundsätzlich alle Aktionäre an der Reduzierung der Agency-Kosten interessiert, die individuelle Einsatzbereitschaft ist für den einzelnen (kleinen) Aktionär indes nicht gegeben. Vor diesem Hintergrund sollen im Folgenden verschiedene Mechanismen zur Reduzierung des principalagent-Konfliktes unter Berücksichtigung alternativer Rahmenbedingungen auf ihre Eignung überprüft werden.

416 Vgl. Jansch (1999), S. 66.

417 Vgl. Witte (1981), S. 733; Iber (1987), S. 69; Jansch (1999), S. 67.

418 Fama/Jensen (1983), S. 309.

419 Vgl. Groves/Ledyard (1977); Grossman/Hart (1980), S. 42; Ruffner (2000), S. 175.

420 Vgl. Easterbrook/Fischel (1983), S. 427f.; Coffee (1990), S. 1532; Rock (1991), S. 453ff.; Roe (1994), S. 6; Ruffner (2000), S. 174-177; Baums/v. Randow (1995), S. 147, basierend auf Olson (1965). Zum Free-Rider-Problem ausführlich auch Grossman/Hart (1980).

421 Vgl. Gordon (1991), S. 355; Ruffner (2000), S. 176 m.w.N.

422 Er wählt die „exit“- anstelle der „voice-Option“. Vgl. Hirschman (1970); Renner (1999), S. 135-141; Nassauer (2000), S. 32f., sowie Kapitel III.1.1.1. 


\subsubsection{Mechanismen zur Reduzierung des principal-agent-Konflikts}

Zielsetzung der verschiedenen im Folgenden aufgezeigten Instrumente ist die Reduzierung delegationsbedingter Agency-Konflikte. Durch Kontroll- und/oder Anreizmechanismen soll eine weitestgehende Interessenkonvergenz zwischen Eigentümern und Managern erzielt werden. ${ }^{423}$ Die verschiedenen Mechanismen können nach marktbezogenen und unternehmensinternen Instrumenten systematisiert werden. Maßnahmen zur Stimmrechtskumulation werden aufgrund der besonderen Bedeutung für das Ziel dieser Arbeit separat betrachtet. ${ }^{424}$

\subsubsection{Marktbezogene Instrumente}

Die Aufgabe von Märkten liegt in der Allokation und Bewertung von Ressourcen. Voraussetzung dafür, dass die gehandelten Ressourcen tatsächlich ihrer effizientesten Verwendung zugeführt werden, ist die korrekte Preisbildung, die nur auf funktionsfähigen Märkten möglich ist. ${ }^{425}$ Vor diesem Hintergrund sind die Mechanismen der marktbezogenen Kontrolle kritisch zu würdigen. Von Bedeutung sind hier neben dem „Markt für Unternehmenskontrolle“ der „Markt für Manager" und der Gütermarkt.

Die Idee des Marktes für Unternehmenskontrolle basiert auf Manne (1965). ${ }^{426}$ Auf einem funktionierenden Kapitalmarkt wird ein Unternehmen, dessen Management aufgrund schlechter Leistungen eine gute Performance des Unternehmens verhindert, zu einem potenziellen Übernahmekandidaten. ${ }^{427}$ Diese Tatsache übt einen disziplinierenden Einfluss auf das Management aus, da mit einer Übernahme die Gefahr eines Arbeitsplatzverlustes verbunden ist. ${ }^{428}$ In diesem Zusammenhang wurde daher auch der Begriff vom „Aktienmarkt als Kontrollmarkt" geprägt, der zu einer Reduzierung der Agency-Kosten beitragen kann. ${ }^{429}$ Jensen/Ruback beschreiben den „market for corporate control as the arena in

423 Vgl. Elschen (1991), S. 210f.; Heinrich (2000). Für einen Überblick über verschiedene Studien vgl. Jensen/Warner (1988).

${ }^{424} \mathrm{Zu}$ alternativen Systematisierungsansätzen von Corporate-Goverance-Maßnahmen vgl. Nemec (1999), S. 99-102; Geldmacher (2000), S. 52-54. Für eine Berücksichtigung der Besonderheiten in Konzernen vgl. Pellens (1994), S. 176-182.

425 Vgl. ausführlich Geldmacher (2000), S. 86-90.

426 Vgl. zudem grundlegend Grossman/Hart (1980); Jensen/Ruback (1983); Scharfstein (1988); Shleifer/Vishny (1988); Franks/Mayer (1996). Einen ausführlichen Überblick geben Flassak (1995); Preuschl (1997).

427 Vgl. Manne (1965), S. 113; Furubotn/Pejovich (1972), S. 1150.

$428 \mathrm{Vgl}$. Wolff (2000), S. 177.

429 Vgl. Hart (1995a), S. 684; Ridder-Aab (1980), S. 104. 
which management teams compete ${ }^{\text {“430 }}$. Die Wirksamkeit dieses Instrumentes ist jedoch an die von Manne beschriebene „hohe Korrelation“ von Managementeffizienz und Marktpreisen gebunden; die Anforderungen an die Kapitalmarkteffizienz sind somit hoch. ${ }^{431}$ Die praktische Bedeutung dieses Marktes war entsprechend im kontinentaleuropäischen Raum und insbesondere in Deutschland in der Vergangenheit eher gering. ${ }^{432}$ Inwieweit das seit 2002 gültige WpÜG zu einer nachhaltigen Belebung des Kontrollmarktes in Deutschland beitragen wird, bleibt abzuwarten. ${ }^{43}$ Die Wirksamkeit des Kontrollmarktes ist Gegenstand zahlreicher empirischer Studien, jedoch ohne eindeutiges Ergebnis hinsichtlich seiner Kontrollfunktion. ${ }^{434}$

Eng mit dem Markt für Unternehmenskontrolle verbunden ist der Markt für Manager, auf dem die Verfügungsrechte am Humankapital der Manager gehandelt werden. ${ }^{435}$ Durch eine erfolgreiche Ausübung seiner Managerfunktionen erwirbt ein Manager Reputation, die seinen Marktwert auf dem unternehmensinternen und -externen Arbeitsmarkt steigert. ${ }^{436}$ Parallel dazu führt die Angst vor einem möglichen Arbeitsplatzverlust zu vermehrten Anstrengungen. ${ }^{437}$ Die Theorie geht davon aus, dass der Markt für Manager in der Lage ist, die sich am Kapitalmarkt niederschlagenden Fähigkeiten des Managers korrekt zu bewerten. ${ }^{438}$ Von einem direkten Niederschlag von Managementleistungen am Kapitalmarkt ist jedoch in der Praxis nur bei Top-Managern auszugehen. ${ }^{439}$ Kündigungsschutzbestimmungen und Wettbewerbsverbote schränken seine Wirksamkeit

430 Jensen/Ruback (1983), S. 6.

431 Vgl. Flassak (1995), S. 149; Wolff (2000), S. 177 sowie bereits Alchian (1984), S. 44 Kritisch auch Grossman/Hart (1980), S. 42f.; Jensen (1993), S. 851f. Zur Kapitalmarkteffizienz vgl. Schremper (2002a), grundlegend Fama $(1970,1991)$.

432 Vgl. Franks/Mayer (1996); Böhmer (2000); Jenkinson/Ljungqvist (2001). Zur Wirksamkeit des Kontrollmarktes vgl. die empirische Analyse von Köke (2002).

433 Vgl. Assmann (2002); Schneider (2002); Schmidt/Prigge (2002).

434 Vgl. exemplarisch Jensen/Ruback (1983); Jarrel/Brickley/Netter (1988); Morck/Shleifer/Vishny (1989); Franks/Mayer (1996); Köke (2000); Franks/Mayer/Renneboog (2001) jeweils m.w.N sowie den Überblick bei Gugler (2001), S. 32ff. und Wolff(2000), S. 182185.

435 Vgl. Fama (1980), S. 297f.; Fama/Jensen (1983); Ridder-Aab (1980), S. 97; Geldmacher (2000), S. 92-95. Für eine informationsökonomische Analyse vgl. Renner (1999), S. 141155.

436 Vgl. Fama (1980), S. 196; Geldmacher (2000), S. 92; Agrawal/Knoeber (1996), S. 377f., sowie ausführlich zum Aufbau von Reputation Gomes (2000), S. 616ff., auch Pellens (1994), S. 179f. m.w.N.

437 Vgl. Fama/Jensen (1983), S. 309; Geldmacher (2000), S. $92 \mathrm{f}$.

438 Vgl. Fama (1980), S. 296.

439 Vgl. Geldmacher (2000), S. 94; Schenk (1997a), S. 190f. 
ebenfalls ein. ${ }^{40}$ Empirische Evidenz zur Wirksamkeit dieses Kontrollmechanismus ist begrenzt, vorhandene Studien stützen jedoch eher die theoretischen Bedenken. ${ }^{441}$

Grundsätzlich kann auch die Konkurrenz auf dem Gütermarkt, in der englischsprachigen Literatur beschrieben als product market competition, zu einer Managementdisziplinierung beitragen. ${ }^{442}$ Auf einem sich im Gleichgewicht befindlichen Gütermarkt sind die Preise ein Datum und die Unternehmen agieren als Mengenanpasser. Unternehmen, die langfristig keinen Gewinn erwirtschaften, scheiden aus dem Markt aus. ${ }^{443}$ Die mit der Realisierung von privaten Vorteilen seitens des Managements verbundene Erhöhung der (Agency-)Kosten kann dazu führen, dass ein Unternehmen nicht mehr kostendeckend arbeitet und damit langfristig von der Insolvenz bedroht ist. Für den Manager ist dieses mit einem Arbeitsplatzverlust verbunden, sodass ein Anreiz besteht, diese Handlungen zu unterlassen. ${ }^{44}$ Darüber hinaus führt ein starker Wettbewerb $\mathrm{zu}$ mehr Markttransparenz, die in Folge den Abschluss Agency-Kosten-minimierender Second-Best-Verträge erleichtert. ${ }^{445}$ Die Wirksamkeit der Gütermarktkontrolle wird aufgrund der relativ abstrakten Bedrohung jedoch als eher gering eingeschätzt. ${ }^{446}$

Im Ergebnis bleibt festzuhalten, dass Voraussetzung für die marktorientierten Kontrollmechanismen die Effizienz der jeweils betrachteten Märkte ist. Diese dürfte in allen drei betrachteten Fällen in Deutschland zumindest eingeschränkt sein, sodass von einer maßgeblichen Minderung der Agency-Kosten aufgrund von Marktdruck nicht auszugehen ist. ${ }^{447}$

440 Kritisch auch Ridder-Aab (1980), S. 98; Geldmacher (2000), S. 93f;; Nemec (1999), S. 104; Nassauer (2000), S. 55.

441 Vgl. Nemec (1999), S. 106; Kaplan (1994), sowie Agrawal/Knoeber (1996), die auch einen Überblick über andere Studien geben.

442 Vgl. Hart (1983); Holmström/Tirole (1989); Hermalin (1992). Einen Überblick geben Januszewski/Köke/Winter (1999), S. 4-6 m.w.N.; vgl. auch Nassauer (2000), S. 53f.; Juhnke (1995), S. 141f.

443 Vgl. Jensen (1986), S. 323; Jensen/Meckling (1976), S. 330; Januszewski/Köke/Winter (1999), S. 4; Geldmacher (2000), S. 91.

444 Der Manager hat Insolvenzkosten zu tragen. Vgl. Geldmacher (2000), S. 61, 91f.; Nemec (1999), S. 110.

445 Vgl. Ridder-Aab (1980), S. 127f;; Nemec (1999), S. 110; Geldmacher (2000), S. 92.

446 Vgl. Nemec (1999), S. 110f.; Nassauer (2000), S. 54, jeweils m.w.N. Vgl. jedoch die empirische Studie von Nickell/Nicolitsas/Dryden (1997).

447 Vgl. mit ähnlichem Fazit Wolff (2000), S. 193; Geldmacher (2000), S. 104; Nemec (1999), S. 104, 108, 110. Zur Bedeutung der Markteffizienz für die Kontrolleffizienz ausführlich auch Renner (1999), S. 68ff. 


\subsubsection{Unternehmensinterne Instrumente}

Neben den marktorientierten bieten sich unternehmensinterne Instrumente zur Reduzierung von Agency-Konflikten an, die möglicherweise insbesondere dann zum Tragen kommen könnten, wenn die Effizienz der verschiedenen Kontrollmärkte nicht in ausreichendem Maße gegeben ist. ${ }^{448} \mathrm{Zu}$ unterscheiden sind hier Anreizsysteme, die Gestaltung der Kapitalstruktur sowie Maßnahmen zur Reduzierung von Informationsasymmetrien. Grundsätzlich ist auch der Aufsichtsrat als Kontrollorgan ein unternehmensinternes Instrument, das hier jedoch zu den Vertretungssystemen gezählt wird.

Nicht über Kontroll- sondern über Motivationsmechanismen arbeiten Anreizsysteme. ${ }^{449}$ Durch eine Kopplung des Gehalts an den Unternehmenserfolg - z.B. durch die Ausgabe von Stock Options oder die Anbindung an wertorientierte Erfolgskennzahlen - soll eine Kongruenz von Individual- und Unternehmenszielen erreicht werden, sodass sich aktionärsschädigendes Verhalten seitens des Managements negativ auf das eigene Einkommen auswirkt. ${ }^{450}$ Ausschlaggebend für die Wirksamkeit dieses Mechanismus ist die Höhe der potenziell zu realisierenden nicht-pekuniären Vergünstigungen des Managements im Verhältnis zu den alternativ realisierbaren Einkommenssteigerungen über die wertorientierten Entlohnungssysteme. ${ }^{451}$ Sofern das Einkommen an kapitalmarktorientierte Größen gekoppelt ist, erfordert die Wirksamkeit zudem hinreichende Kapitalmarkteffizienz, die gewährleistet, dass sich Reichtumsverschiebungen auch im Aktienkurs niederschlagen; aus Sicht des Managers sollte der Grundsatz der "Controllability“ erfüllt sein. ${ }^{452}$ Sinnvoll erscheinen Anreizsysteme zudem nur, wenn die Kosten-Nutzen-Relation gewährleistet ist und die Anreizwirkung so stark ist, dass nicht zusätzlich zu den entstehenden Transaktionskosten wesentliche Kontrollkosten entstehen. Trotz der restriktiv scheinenden Voraussetzungen

448 So stellt Roe zutreffenderweise fest, „there is more than one way [for a governance system] to deal with agency problems". Roe (1993), S. 1929. Vgl. auch Ayres/Cramton (1994), S. 1035.

449 Vgl. Jensen/Murphy (1990), zum Zusammenhang von Corporate Governance und Anreizsystemen ausführlich Suter (2000).

450 Vgl. Nemec (1999), S. 103, sowie Crasselt (2000). Die Wirkung von aktienkursbasierten Anreizmechanismen ist daher eng mit der Funktionsfähigkeit des Kapitalmarktes verbunden. Vgl. Fama (1980), S. 195-197; Larner (1970), S. 33-62. Zu verschiedenen Formen von Anreizsystemen vgl. Geldmacher (2000), S. 56-61, sowie Pellens/Crasselt/Rockholtz (1998); Crasselt (2003); kritisch Kunz/Pfaff (2002).

451 Vgl. Geldmacher (2000), S. 54; Gugler (2001), S. 43.

452 Vgl. Fama (1980), S. 296f.; Ewert/Wagenhofer (2003), S. 433f.; Spremann (1990), S. 581 f.; Nemec (1999), S. 103. 
deuten die empirischen Ergebnisse insgesamt eher auf eine positive Wirkung von erfolgsabhängiger Entlohnung auf die Performance hin. ${ }^{453}$

Als weiterer disziplinierender Effekt wird die Kapitalstruktur des Unternehmens genannt. ${ }^{454}$ Mit der Aufnahme von Krediten ist die vertragliche Verpflichtung, Zins- und Tilgungszahlungen zu leisten, verbunden. ${ }^{455}$ Die Dispositionsfreiheit des Managements über den Cash Flow des Unternehmens wird damit beschränkt, sodass auch die Möglichkeit, Finanzmittel für privaten Konsum abzuzweigen, sinkt: ${ }^{456}$ „Debt creation [...] enables managers to effectively bond their promise to pay out future cash flows “457. Die Nichterfüllung der Zahlungsverpflichtungen gegenüber den Gläubigern hat die Insolvenz des Unternehmens zufolge, die für den Manager mit Kosten in Form von Arbeitsplatz- und Reputationsverlust verbunden ist. ${ }^{458}$ Eine pauschale Beurteilung des disziplinierenden Effektes der Kapitalstruktur ist schwierig, da sie stark abhängig von Branche und Kapitalbedarf des Unternehmens ist. ${ }^{459}$ Zudem können mit einem hohen Gläubigereinfluss für die Anteilseigner auch negative Auswirkungen verbunden sein, wie etwa eine unerwünschte Einflussnahme auf die Investitionspolitik. ${ }^{460}$

453 Vgl. für einen Überblick über verschiedene empirische Studien Nemec (1999), S. 105107; Gugler (2001), S. $43 \mathrm{f}$.

454 Vgl. grundlegend Grossman/Hart (1982); Jensen (1986); Harris/Raviv (1990). Die von Modigliani/Miller $(1958,1963)$ postulierte Unabhängigkeit des Unternehmenswertes von der Kapitalstruktur würde damit nicht gelten.

455 Vgl. Stiglitz (1985), S. $141 \mathrm{f}$.

456 Vgl. Jensen (1986), S. 323f.; Harris/Raviv (1990), S. 322f.; Noth (1996), S. 144-147; Geldmacher (2000), S. 61. Mit der Kreditaufnahme werden regelmäßig so genannte „debt covenants" vereinbart, die den Handlungsspielraum - z.B. durch Vorgabe einer bestimmten Vermögensstruktur oder Mindestrendite - zusätzlich einschränken. Vgl. grundlegend Smith/Warner (1979), sowie erläuternd Shleifer/Vishny (1997), S. 761-766 mit einem Überblick über die relevante Literatur.

457 Jensen (1986), S. 324.

458 Vgl. Grossman/Hart (1982), S. 107f.; Hart (1995a), S. 685f.; Shleifer/Vishny (1997), S. 762; Geldmacher (2000), S. 61; Laux (1996), S. 43f. Eine ähnliche Disziplinierungswirkung kann auch die Ausschüttung von Dividenden haben, auf die hier nicht weiter eingegangen wird. Vgl. jedoch Grossman/Hart (1982); Easterbrook (1984); Megginson (1997); Nemec (1999), S. 118-120; La Porta et al. (1999a); Myers (2000).

459 Vgl. Nemec (1999), S. 133f.; Noth (1996), S. 146f.

460 Gläubiger sind an der Erzielung hoher Renditen nicht interessiert, solange ihre Forderungen befriedigt werden, sodass sie versuchen könnten, eine risikoärmere Investitionspolitik durchzusetzen. Vgl. Geldmacher (2000), S. 62; Noth (1996), S. 147; Nassauer (2000), S. 14-17. Im Ergebnis werden Konflikte zwischen Anteilseignern und Managern substituiert durch Konflikte zwischen Anteilseignern und Gläubigern. Vgl. ausführlich Noth (1996), S. 147-160. 
Entsprechend widersprüchlich sind auch empirische Befunde zu dieser Fragestellung. ${ }^{461}$

Unter die unternehmensinternen Instrumente zur Minderung der Agency-Kosten fallen auch die Maßnahmen vor Vertragsabschluss, die unmittelbar an der Reduzierung von Informationsasymmetrien ansetzen. ${ }^{462}$ Signalling wird durch den agent selbst betrieben, der sein hohes Leistungsvermögen bzw. seine hohe Reputation an den principal signalisiert. ${ }^{463}$ Es kann dann ein wirksames Instrument zur Reduzierung von Informationsasymmetrien sein, wenn die Signalisierung einer hohen Qualität für gute Manager mit geringeren Kosten verbunden ist als für schlechte. Da schlechtere Manager die kostenintensive Signalisierung scheuen werden, entsteht für den principal eine Differenzierungsmöglichkeit und Informationsasymmetrien können abgebaut werden. ${ }^{464}$ Alternativ kann der principal selbst im Vorfeld der Einstellung durch Einholung von Informationen über die Qualität des agents seinen Informationsstand verbessern. Da der uninformierte Verhandlungspartner zuerst aktiv wird, liegt ein so genanntes Screening vor. ${ }^{465}$ Im Rahmen der Self Selection bietet der Auftraggeber dem agent alternative Vertragsvarianten an und zieht aus der Wahl des agents Rückschlüsse auf dessen Leistungsvermögen. ${ }^{466}$

\subsubsection{Stimmrechtskumulation}

Maßnahmen der Stimmrechtskumulation zielen darauf ab, den Anreiz der Aktionäre zum Free Riding beim Monitoring des Managements zu reduzieren. Sie können sowohl unternehmensextern (Vertretungssysteme) als auch unternehmensintern (Eigenkapitalstruktur) stattfinden.

Auf die Minderung des Arbeitsaufwandes, der mit einem informierten Abstimmungsverhalten seitens der Kleinaktionäre verbunden ist, zielen verschiedene Vertretungssysteme $a b .{ }^{467}$ Der Anreiz zum Free Riding sinkt, wenn die Wahrung

461 Einen Überblick gibt Nemec (1999), S. 134-136; Israel (1992).

462 Vgl. Roth (2001); Spremann (1990). Ziel ist die Verhinderung einer adversen Selektion.

463 Vgl. Spence (1973), S. 358f.; Roth (2001), S. 373. Diese Signalisierung erfolgt z.B. durch Zeugnisse, Gütesiegel o.ä.

464 Vgl. Spence (1973), S. 358; Kreps (2000), S. 645-649; Erlei/Leschke/Sauerland (1999), S. 157-162.

465 Vgl. zum Screening Rothschild/Stiglitz (1976); Roth (2001), S. 375-377.

466 Vgl. Roth (2001), S. 375.

467 Vgl. Hart (1995a), S. 682f. 
der eigenen Interessen ohne großen Aufwand auf Vertreter delegiert werden kann. $^{468}$

Das US-amerikanische System des Proxy Voting ebenso wie das bereits in Kapitel II diskutierte deutsche Auftragsstimmrecht (Depotstimmrecht) dienen grundsätzlich diesem Zweck. ${ }^{469}$ Die Vor- und Nachteile dieser, insbesondere den Kreditinstituten weitreichendes Einflusspotenzial gewährenden Regelung, ist Gegenstand zahlreicher theoretischer und empirischer Untersuchungen. ${ }^{40}$ Der Einfluss der Kreditinstitute aus dem Depotstimmrecht ist für die vorliegende Problemstellung immer dann von entscheidender Bedeutung, wenn die Bank gleichzeitig auch als Aktionär fungiert. Sofern das Kreditinstitut zusätzlich Gläubiger und/oder Anteilseigner des Unternehmens ist, ergeben sich ggf. divergierende Interessen, die dazu führen können, dass das Depotstimmrecht nicht im Sinne der vertretenen (Klein-)Aktionäre ausgeübt wird, sondern die Interessen als Kreditgeber im Vordergrund stehen. ${ }^{471}$ Empirische Studien zur Einflussnahme von Kreditinstituten können die vielfach formulierten Bedenken gegenüber der „Macht der Banken“ weder eindeutig bestätigen noch verwerfen. Je nach Untersuchungsdesign ergeben sich widersprüchliche Ergebnisse. ${ }^{472}$

Im Ergebnis erscheint eine Reduzierung der Agency-Kosten aufgrund der Stimmrechtskumulation bei Kreditinstituten immer dann wahrscheinlich, wenn die Interessen der Bank mit den Interessen aller Aktionäre konform gehen. Dies jedoch ist abhängig von der Anreizstruktur, die sich aus Beziehungen jenseits der Stimmrechtsvollmachten als Eigen- und/oder Fremdkapitalgeber ergibt, sodass eine pauschale Aussage unmöglich erscheint. In der Praxis ist die Bedeutung des Depotstimmrechts ohnehin rückläufig, da z.B. Direktbanken diesen

468 Vgl. Paul (1995), S. $161 \mathrm{f}$.

469 Vgl. Latham (1999). Für einen internationalen Überblick Baums (1997); Weikert (2001). Auf das System des so genannten Proxy Voting soll an dieser Stelle jedoch nur verwiesen werden. Die Idee ist, dass einzelne Aktionäre mittels Werbung um die Stimmen der anderen Aktionäre eigene Interessen auch gegen das Management durchsetzen können. Vgl. ausführlich Black (1990), sowie Merkt (1991), S. 372-388; Monks/Minow (1996), S. 143 145; Schmidt (2001), S. 149-152 m.w.N.; kritsch Bebchuk (2003); grundlegend Easterbrook/Fischel (1983).

470 Vgl. für einen Überblick über die zahlreichen kritischen Beiträge Baums/v. Randow (1995); Gottschlich (1996), S. 168-171; Wellkamp (1998), S. 12-14; Geldmacher (2000), S. 231-236; Weikert (2001).

471 Vgl. beispielhaft Adams (1997), S. 23f.; Mülbert (1996a), S. E 1ff.; Schneider/Burgard (1996), S. 1761; Süchting/Paul (1998), S. 130-134; Wellkamp (1998), S. 12-14; Geldmacher (2000), S. 70, 231-236; Nassauer (2000), S. 110f.; Schmidt (2001), S. $75 f$.

472 Einen tabellarischen Überblick über verschiedene Studien zur Einflussnahme von Banken auf Industrieunternehmen gibt Nassauer (2000), S. 116f., sowie Weikert (2001), S. 48-50; Seger (1997). Ausführlich auch Brendel (2001). 
Service nicht anbieten und die zunehmende Zahl internationaler Anleger ihn nicht nutzt. ${ }^{473}$

Als Vertretungssystem kann nicht nur die explizite Delegation des eigenen Stimmrechtes auf der Hauptversammlung gesehen werden, sondern auch die gesetzlich kodifizierte oder satzungsmäßig festgelegte Übertragung bestimmter Kontrollaufgaben an ein separates Organ. ${ }^{474}$ In deutschen Aktiengesellschaften nimmt der bereits an verschiedenen Stellen dieser Arbeit diskutierte Aufsichtsrat Überwachungsaufgaben im Auftrag der Aktionäre wahr. ${ }^{475}$ Als Kontrollorgan ist der Aufsichtsrat - zumindest von seiner theoretischen Konzeption her - grundsätzlich geeignet, private Vorteilsnahme seitens des Managements zu verhindern. In der Praxis erscheint seine Funktionsfähigkeit jedoch vielfach eingeschränkt. ${ }^{476}$ Die Sitzungsfrequenz ist gering und die Anteilseignervertreter werden regelmäßig nur in Form einer Listenwahl bestimmt. ${ }^{477}$ Die Vorschläge für die Liste erstellt der Aufsichtsrat selbst, sodass der einzelne Aktionär weder einen Einfluss auf die Auswahl der Kandidaten hat noch die Bestellung einzelner Aufsichtsratsmitglieder ablehnen kann, ohne die ganze Liste abzulehnen ${ }^{478}$ In der Praxis nehmen zudem in der Regel Großaktionäre und/oder „befreundete“ Unternehmen bzw. Kreditinstitute Aufsichtsratsmandate wahr, die nicht notwendigerweise die Interessen der Kleinaktionäre vertreten. ${ }^{479}$ Gleiches gilt für die Arbeitnehmervertreter im Aufsichtsrat. ${ }^{480}$ Geringe Sitzungshäufigkeiten, mangelndes Engagement und Professionalität der Aufsichtsratsmitglieder können ein effizientes Monitoring verhindern. ${ }^{481}$

473 Vgl. Noack (2002), S. 625; o.V. (2003), S. 19.

474 Teilweise wird auch die Funktion des Abschlussprüfers als Kontrolleur diskutiert, worauf hier verzichtet werden soll. Vgl. jedoch Geldmacher (2000), S. 81-84.

475 Vgl. insbesondere Kapitel II.1.3. Vgl. Moerland (1995), S. 454; Flassak (1995), S. 126131; Ruhwedel (2002), S. 13-16, 50-57; Renner (1999), S. $131 \mathrm{f}$.

476 Vgl. hierzu die empirischen Ergebnisse von Epstein/Ruhwedel (2002), bzw. Ruhwedel/Epstein (2003).

477 Vgl. Epstein/Ruhwedel (2002), S. 14. Vgl. zur Bildung und Zusammensetzung des Aufsichtsrats Ruhwedel (2002), S. 46-48; Martens (2000), S. $19 f$.

478 Vgl. $\S 101$ Abs. 1, 119 Abs. 1 Nr. 1, 124 Abs. 3, 133 Abs. 1, 2 AktG, sowie Ruhwedel (2002), S. 47; Wellkamp (2000), S. 36.

479 Diese personelle Verflechtung großer Konzerne ist neben der Kapitalverflechtung Ausdruck der so genannten „Deutschland AG“. Vgl. Beyer (2002); Jansch (1999), S. 78; Nassauer (2000), S. 113; Wolff (2000), S. 72f.; Aleff/Steden (2001); Hillebrandt (2001). Geldmacher (2000), S. 78, spricht von einem ,systematischen Kontrolldilemma“.

480 Vgl. Niedenhoff (2002), S. $571 \mathrm{f}$.

481 Vgl. Hart (1995a), S. 682; Ruhwedel (2002), S. 136f., 193-196. 
Aus agency-theoretischer Perspektive führt ein separates Kontrollorgan zwar zu einer möglichen Verminderung des Konflikts zwischen Management und Aktionären, es entsteht jedoch eine neue Konfliktebene zwischen Anteilseignern und Aufsichtsrat. Es liegt somit eine zweistufige Agency-Beziehung vor, die Aktionäre sehen sich zusätzlich der Aufgabe „Watching the Watchers" ${ }^{\text {482 }}$ gegenübergestellt. ${ }^{483} \mathrm{Ob}$ der Aufsichtsrat somit ein effizientes Kontrollorgan darstellt, ist schwer allgemeingültig zu beurteilen, da die Institution an sich eine solche zwar grundsätzlich ermöglicht, diese in der Praxis jedoch häufig nicht umgesetzt wird. ${ }^{484}$ Empirische Ergebnisse für das US-Modell deuten eher auf einen positiven Einfluss eines separaten Aufsichtsgremiums hin, die Aussagekraft dieser Studien für die Kontrolleffizienz deutscher Aufsichtsräte ist indes gering. ${ }^{485}$

Neben der Stimmrechtsbündelung kann auch die Gestaltung der Eigenkapitalstruktur zu einer Stimmrechtskumulation und damit - zumindest theoretisch - zu einer Minderung des Agency-Kosten induzierenden Free-Rider-Problems in Publikumsgesellschaften beitragen. Über die Gestaltung der Eigenkapitalstruktur muss den Aktionären ein Anreiz gewährt werden, ihre de jure vorhandenen Kontrollmöglichkeiten auch de facto auszuüben. Nimmt der Aktionär Anstrengungen im Rahmen der Informationsbeschaffung auf sich, so muss er auch einen entsprechenden Nutzen realisieren können, also zumindest Einfluss auf die Entscheidung des Managements nehmen können. Diese Einflussmöglichkeit kann grundsätzlich über die ,normale“ Kapital- und Stimmrechtsbündelung des Großaktionärs erfolgen. Darüber hinaus führt auch die Emission von Vorzugsaktien zu einer Stimmrechtsbündelung, die die Ausübung von Managementkontrolle auch bei kleineren Kapitalanteilen ermöglicht. Theoretisch erfüllen diesen Zweck auch die für börsennotierte Gesellschaften in Deutschland nicht mehr zulässigen Mehrstimmrechtsaktien. ${ }^{486}$ Die ökonomische Bewertung dieser Stimmrechtsbündelungen und die empirische Überprüfung der abgeleiteten Hypothesen hinsichtlich ihrer Auswirkung auf den Unternehmenswert sind Gegenstand der folgenden Kapitel, sodass auf weitere Ausführungen an dieser Stelle verzichtet werden soll. Im Zentrum von Kapitel III.2.2 steht dabei die theore-

482

483

484

So der Buchtitel von Monks/Minow (1996). Ähnlich Black (1992), der titelt: „Agents Watching Agents".

Vgl. Martens (2000), S. 39-41; Ruhwedel (2002), S. 72f.; Nassauer (2000), S. 34f.; Renner (1999), S. 133-135.

Kritisch zur aktuellen Praxis Ruhwedel (2002), S. 193-196; Jansch (1999), S. 78-82; Juhnke (1995), S. 182-188.

Vgl. Nassauer (2000), S. 34f., einen negativen Einfluss finden Franks/Mayer/Renneboog (2001).

Vgl. Hering/Olbrich (2001), S. 20f.; Zöllner/Noack (1991), S. 117; Saenger (1997), S. 1813; Baums/Schmitz (1998), S. 21; Becht/Böhmer (2001), S. 134. 
tische Analyse des Einflusses von Großaktionären, bei denen Kapital- und Stimmrechtsanteile übereinstimmen, Kapitel III.2.3 beleuchtet die Auswirkungen von abweichenden Kapital- und Stimmrechtsanteilen. Teil IV der Arbeit überprüft die Ergebnisse empirisch.

\subsection{Zwischenfazit}

Aufgabe des vorangegangenen Kapitels war die Abgrenzung der Aktionärskontrolle und die Begründung ihrer Notwendigkeit auf Basis agency-theoretischer Überlegungen. Dabei wurden folgende Ergebnisse erzielt:

- Aktionärskontrolle als auf das Management gerichtete Kontrolle der Aktionäre beinhaltet neben einer Ex-post-Kontrolle insbesondere auch die Beeinflussung unternehmerischer Grundsatzentscheidungen. Im Rahmen des Corporate-Governance-Systems kommt der Aktionärskontrolle als Bestandteil sowohl der externen als auch der internen Corporate Governance eine herausragende Bedeutung zu.

- Die Neue Institutionenökonomik bietet einen Ansatzpunkt zur Analyse der Aktionärskontrolle, da sie hinsichtlich ihrer Vorgehensweise (methodologischer Individualismus) und Verhaltensannahmen (begrenzte Rationalität, individuelle Nutzenmaximierung, unvollkommene Märkte, Informationsasymmetrien) in der Realität beobachtbare Vorkommnisse gut abbildet.

- In Publikumsgesellschaften ergibt sich die Notwendigkeit für eine Aktionärskontrolle aus der Trennung von Eigentum und Verfügungsmacht. Für angestellte Manager bestehen Anreize, im Eigeninteresse nutzenmaximierend $\mathrm{zu}$ Lasten der Aktionäre zu agieren, was aufgrund geringer Kontrollanreize von den Kleinaktionären nur begrenzt verhindert wird (Free-Rider-Problem).

- Verschiedene Instrumente zielen auf die Minderung dieser Problematik. Voraussetzung für die Wirksamkeit der marktorientierten Mechanismen sind funktionsfähige Märkte, speziell ein funktionsfähiger Kapitalmarkt. Insbesondere bei eingeschränkter (Kapital-)Markteffizienz spielen unternehmensinterne Mechanismen, wie z.B. Anreizsysteme oder die Gestaltung der Kapitalstruktur eine Rolle. Auch die Stimmrechtskumulation durch das Depotstimmrecht und der Aufsichtsrat können zur Minderung von Agency-Konflikten beitragen. Die vorgestellten Mechanismen scheinen jedoch weder einzeln noch in ihrer Summe geeignet, unmittelbare Aktionärskontrolle vollständig zu substituieren.

Unter welchen Konstellationen Aktionäre Anreize zur Ausübung von Kontrolle haben und welche Auswirkungen diese Kontrolle auf den Unternehmenswert haben kann, wird daher im folgenden Kapitel betrachtet. Dabei stehen insbeson- 
dere mögliche Interessenkonflikte zwischen verschiedenen Aktionärsgruppen im Zentrum der Analyse.

\section{Auswirkung von Eigentümer- und Stimmrechtsstruktur auf die Aktionärskontrolle}

\subsection{Wissenschaftstheoretische Grundlagen}

\subsubsection{Agency-Beziehung zwischen Aktionärsgruppen}

Neben die traditionelle, mit der Beziehung zwischen principal und agent befassten Agency-Theorie ist in den neunziger Jahren ein Forschungsstrang getreten, der das Verhältnis zwischen verschiedenen Aktionärsgruppen analysiert. Dieses Verhältnis wird regelmäßig - in der Regel ohne dieses weiter zu problematisieren - als Agency-Beziehung charakterisiert. ${ }^{487}$ In der Literatur ist die Abgrenzung von Agency-Beziehungen indes nicht unumstritten. Im Rahmen einer weiten Auslegung, die maßgeblich geprägt ist durch die Beiträge von Arrow (1985) und Pratt/Zeckhauser (1985), liegt eine Agency-Beziehung bereits immer dann vor, wenn ,the [agent's] action affects the welfare of both the agent and another person, the principal" 488 bzw. "whenever one individual depends on the action of another" ${ }^{489}$. Halpern (2000) formuliert im Hinblick auf die Beziehung zwischen Klein- und Großaktionären: „This situation [between controlling and noncontrolling shareholders] is identical to the principal-agent problem described by Berle and Means“490. Die Beziehungen zwischen Aktionärsgruppen wären demnach als Agency-Beziehungen zu charakterisieren. ${ }^{491}$ Eine traditionelle, sehr enge Sichtweise definiert Agency-Beziehungen hingegen ausschließlich über das Vorliegen einer Handlungsdelegation. ${ }^{492} \mathrm{Da}$ eine solche zwischen verschiedenen

487 So etwa Shleifer/Vishny (1997), S. 758; Faccio/Lang/Young (2001); La Porta et al. (2002), einen Überblick gibt Holderness (2003); Becht (1997). Vgl. jedoch DeMott (1997); Halpern (2000), S. 31. In der deutschen Diskussion um die Corporate Governance wird die Konfliktebene zwischen Groß- und Kleinaktionären trotz der großen Bedeutung von Blockbildungen bisher noch wenig beachtet. Vgl. Hartmann-Wendels/von Hinten (1989), S. 271, die den Konflikt zwar theoretisch modellieren, ihm jedoch jede praktische Bedeutung absprechen. Arrow (1985), S. 37.

Pratt/Zeckhauser (1985), S. 2.

Halpern (2000), S. 31.

Eine solche weite Sichtweise ist inzwischen vorherrschend. Vgl. Erlei/Leschke/Sauerland (1999), S. 74f.; DeMott (1997), S. 324.

492 Vgl. Ross (1973), S. 134; Eisenhardt (1989), S. 58; Schneider (1995), S. 47f.; Meinhövel (1999), S. 7. 
Aktionärsgruppen in der Regel nicht gegeben ist, läge somit keine AgencyBeziehung im Sinne dieser engen Definition vor.

Für eine Anwendbarkeit agency-theoretischer Argumentationsmuster sprechen unabhängig von alternativen Definitionen - im Wesentlichen zwei Gründe: Zum einen liegt zwar keine formale Delegation der Kontrollfunktion vor; zumindest die nicht abstimmenden (Klein-)Aktionäre delegieren ihre Kontrolle jedoch stillschweigend. ${ }^{493}$ Zum anderen spricht die bereits in Kapitel II.2.2.1 diskutierte Treuepflicht für das Vorliegen einer Agency-Beziehung zumindest in bestimmten Fällen. Eine Treuepflicht gegenüber den Mitaktionären besteht für Aktionäre, die aufgrund ihres Kapital- oder Stimmrechtsanteils einen wesentlichen Einfluss auf die Geschäftspolitik ausüben können. ${ }^{494}$ Sie verpflichtet diese zur Berücksichtigung der Interessen der Mitaktionäre immer dann, wenn einzelne Aktionen des Großaktionärs die Position der Mitaktionäre berühren. ${ }^{495}$ Im Rahmen der klassischen Principal-Agent-Beziehung entstehen Agency-Kosten durch das Ausnutzen nicht vertraglich regulierter Spielräume des agents. Im Fall des Großaktionärs liegt die Gefahr nicht im Ausnutzen von Vertragslücken sondern in der Nichtbeachtung von Pflichten, die aus dem unbestimmten Rechtsbegriff der Treuepflicht resultieren.

Im Ergebnis liegt somit eine Agency-Beziehung im Sinne des weiten Begriffsverständnisses, nicht jedoch nach der engeren Definition vor. Aufgrund der stillschweigenden Delegation von Kontrolle durch die nicht abstimmenden Aktionäre und den aus der Treuepflicht resultierenden besonderen Pflichten der Großaktionäre erscheint eine auf den Grundgedanken der Agency-Theorie basierende Argumentation davon unabhängig plausibel.

\subsubsection{Eigenkapitalstruktur und Unternehmenswert}

Die Ansiedelung des vorliegenden Problemfeldes innerhalb der Neuen Institutionenökonomik beinhaltet gleichzeitig eine Abgrenzung zu den im Zusammenhang mit der Kapitalstruktur vorliegenden Theorien der Neoklassik. Im Rahmen ihrer richtungsweisenden Beiträge von 1958/1963 haben Modigliani/Miller die Unabhängigkeit des Unternehmenswertes von der Kapitalstruktur nachgewiesen.

493 Auch Spremann sieht den Principal-Agent-Begriff unabhängig von einer formalrechtlichen Delegation. Vgl. Spremann (1987), S. 342.

494 Vgl. Raiser (2001), S. 110f.; Schmidt (2002), S. 588f; Wellkamp (1998), S. 18; sowie die Untersuchung von Goergen/Renneboog (2002).

495 Dies kann etwa bei der Ausübung von Stimmrechten oder einer Einflussnahme auf die Verwaltung der Fall sein. Vgl. Wellkamp (1998), S. 18. Bei DeMott (1997), S. 325, heißt es, „A shareholder that exercises control owes fiduciary duties, defined in contextspecific fashion, to the corporation and its noncontrolling sharcholders". 
Die Gültigkeit ihrer Aussagen würde der vorliegenden Untersuchung die Grundlage entziehen, da die Irrelevanz des Verhältnisses von Eigen- und Fremdkapital auch die Irrelevanz der Zusammensetzung des Eigenkapitals beinhaltet. ${ }^{496}$ Verschiedenste Erweiterungen des Grundmodells legen jedoch eine Relevanz der Kapitalstruktur in einer Welt von Steuern, Insolvenz- und Agency-Kosten nahe, sodass unter den hier zugrunde gelegten Annahmen ${ }^{497}$ die Irrelevanzthese keine Gültigkeit hat. ${ }^{498}$

Die Relevanz der Eigentümerstruktur für den Unternehmenswert wird in der Literatur unter dem Stichwort „ownership theory“ seit den 1980er Jahren diskutiert; zu nennen sind hier insbesondere die Arbeiten von Demsetz (1983), Demsetz/Lehn (1985), Shleifer/Vishny (1986) und Wruck (1988). ${ }^{499}$ Von der auch hier gewählten breiten Herangehensweise, die Bedeutung der Eigenkapitalstruktur grundsätzlich zu untersuchen, ist der Forschungszweig abzugrenzen, der sich ausschließlich mit der Wirkung der Kapitalkonzentration in den Händen des Managements (,managerial ownership theory“) auseinandersetzt. ${ }^{500}$ Bereits Jensen/Meckling entwickeln eine „theory of the corporate ownership structure“, im Rahmen derer sie den optimalen Anteilsbesitz des Managers unter bestimmten Prämissen ableiten. ${ }^{501}$ Die Argumentation dieses Forschungsstrangs basiert jedoch nicht auf der Kontrollfunktion des Anteilsbesitzes sondern auf der Anreizwirkung beim Manager selbst. ${ }^{502} \mathrm{Zu}$ nennen sind hier insbesondere die Beiträge von Leland/Pyle (1977), Grossman/Hart (1982), Jensen (1986, 1986a), Harris/Raviv (1988) und Stulz (1988). Beide Forschungsgebiete sind nicht über-

496 Vgl. Jensen/Warner (1988), S. 5, sowie den Beitrag von Langner (2001).

497 Vgl. Kapitel III.1.2.1.1.

498 Vgl. z.B. Paul/Horsch (2002), S. 249-253. Einen Überblick über die verschiedenen Erweiterungen des Modells von Modigliani/Miller gibt Noth (1996), über die älteren Beiträge Jensen/Smith (1984). Vgl. zum Zusammenhang zwischen Kapitalstrukturtheorie und „ownership theory“ die Beiträge von Bessler/Kurth/Thies (2001); Brailsford/Oliver/Pua (2002), sowie Ruffner (2000), S. 537f., zur Einordnung in die betriebswirtschaftliche Theorie auch Mayer (2000).

499 Beeinflusst durch Baumol (1959), Marris (1964) und Williamson (1964), die sich aber nicht explizit der Relevanz von Eigentümerstrukturen widmen.

500 In der Literatur werden diese Forschungsstränge z.T. nicht getrennt. Vgl. z.B. Goergen (1998), S. 12-14. Für eine Abgrenzung der Forschungsgebiete vgl. McConnell/Servaes (1990), S. 596-599; Chirinko et al. (1999), S. 12f.; Belkaoui/Pavlik (1992), S. 344f.; Denis/McConnel (2002).

501 Vgl. Jensen/Meckling (1976), S. 343-351.

502 Im Rahmen der folgenden empirischen Untersuchung wird dieser unterschiedlichen Ausgangslage durch Verwendung einer Dummy-Variablen Rechnung getragen. 
schneidungsfrei, da im Rahmen der ownership theory Mitglieder der Unternehmensleitung als mögliche Eigentümer mit berücksichtigt werden. ${ }^{503}$

Die im Folgenden im Vordergrund stehende Diskussion um die Bedeutung der Stimmrechtsstruktur für den Unternehmenswert wird bis heute wesentlich beeinflusst durch den grundlegenden Beitrag von Easterbrook/Fischel (1983) sowie die Arbeiten von Lease/McConnell/Mikkelson (1983, 1984), Bhagat/Brickley (1984), Grossman/Hart (1988) und Harris/Raviv (1988a). Im Rahmen der folgenden Argumentation wird zunächst von kongruenten Stimmrechts- und Kapitalanteilen bzw. Stimm- und Cash-Flow-Rechten ausgegangen. In Kapitel III.2.3 werden anschließend divergierende Kapital- und Stimmrechtsanteile betrachtet, die in besonderem Maße zu Anreizproblemen im Rahmen der Kontrollausübung führen können.

\subsection{Aktionärskontrolle bei Kongruenz von Stimm- und Cash-Flow- Rechten}

\subsubsection{Theorien zur Anreizwirkung von Blockbildungen}

Eine optimale Allokation der Kontrollrechte ist nach Hartmann-Wendels „dadurch gekennzeichnet, daß die Entscheidungskompetenz jeweils bei demjenigen liegt [...], dessen Individualinteresse mit dem gesellschaftlichen Optimum übereinstimmt. “504 Wie eine solche optimale Verteilung der Kontrollrechte in der Praxis auszugestalten ist, ist weder theoretisch noch empirisch bisher einwandfrei geklärt. Im Folgenden werden daher die verschiedenen Hypothesen zur Wirkung von Blockbildungen zunächst theoretisch hergeleitet und anschließend vor dem Hintergrund des deutschen Regulierungsumfeldes kritisch gewürdigt, um daraus Hypothesen für die eigene empirische Untersuchung abzuleiten.

\subsubsection{Interessenkonvergenzhypothese}

Im Rahmen von Kapitel III.1.2.2 wurde bereits angedeutet, dass Großaktionäre zu einer Minderung von Agency-Kosten durch Ausübung von Kontrolle beitragen können. Die Interessenkonvergenzhypothese setzt an der Reduzierung des Free-Rider-Problems durch Kapitalkumulation an. Für Aktionäre mit einem großen Kapitalanteil stehen Kosten und Nutzen einer intensiven Information in einem angemesseneren Verhältnis als für Kleinaktionäre. ${ }^{505}$ Den hohen Stimmrechtsanteilen stehen in gleicher Höhe Ansprüche an den Cash Flows - also an allen mit dem Kapitalanteil verbundenen Rechten auf Zahlungen aus der Aktie -

\footnotetext{
503 Vgl. Chirinko et al. (1999), S. $12 \mathrm{f}$.

504 Hartmann-Wendels (2001), Sp. 1349.

505 Vgl. Shleifer/Vishny (1997), S. 754; Gugler (2001), S. $13 f$.
} 
gegenüber. Entsprechend ist es für Großaktionäre individuell rational, trotz bestehender Informationskosten Anstrengungen zu betreiben, um die zu Gunsten des Managements bestehende Informationsasymmetrie zu reduzieren und somit Reichtumsverschiebungen zu ihren Lasten zu verhindern. ${ }^{506}$ Ihre Monitoringaktivitäten schlagen sich in einer verbesserten Unternehmensperformance in Form von Kurssteigerungen und Dividendenzahlungen nieder, an der sie in Höhe ihres Kapitalanteils partizipieren. ${ }^{507} \mathrm{Je}$ größer der Anteil des Großaktionärs ist, desto geringer sind somit ceteris paribus die Agency-Kosten, die aus der Handlungsdelegation resultieren, da der Monitoringanreiz linear mit dem Kapitalanteil steigt. ${ }^{508}$ Durch die Kapitalkonzentration und die damit verbundene Einflussmöglichkeit auf das Management wird die von Berle/Means beschriebene Problematik der Separierung zwischen principal und agent aufgeweicht, das FreeRider-Problem verringert sich. ${ }^{509}$ Die Interessenkonvergenzhypothese wird daher teilweise auch als Berle-Means-Hypothese bezeichnet. ${ }^{510} \mathrm{Abb} .11$ veranschaulicht die Anreizstruktur des Aktionärs in Abhängigkeit vom gehaltenen Kapitalanteil (KA):

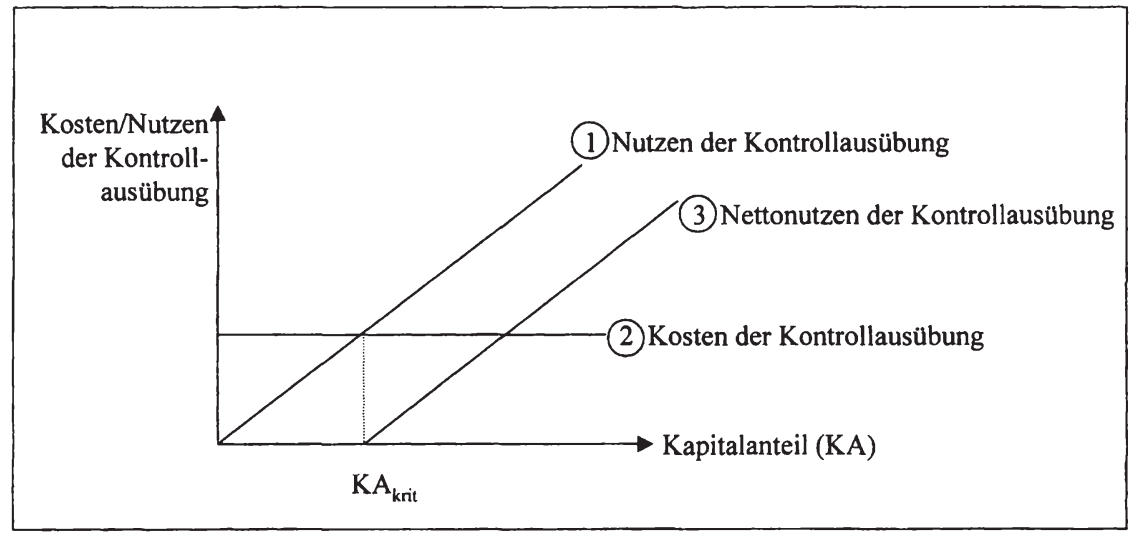

Abb. 11: Kontrollausübung ${ }^{\text {S11 }}$

506 Vgl. Black(1990), S. 575-584; Jensen (1993), S. 867; Ayres/Cramton (1994), S. 1035.

Vgl. Morck/Shleifer/Vishny (1988), S. 293; Roe (1994), S. 6.

508 Vgl. Chirinko et al. (1999), S. 11; Shleifer/Vishny (1997), S. 754-757; Bebchuk (1999), S. 28; Jensen/Meckling (1976), S. 312f., sowie bereits Steinitzer (1908), S. 66ff. Je größer der Kapitalanteil, desto eher kann der Aktionär die externen Effekte durch seine Informationsbemühungen internalisieren, da sie sich in hohem Maße in seinem zu erwartenden Zahlungsstrom niederschlagen. Vgl. Easterbrook/Fischel (1983), S. $402 \mathrm{f}$.

Vgl. Fama/Jensen (1983), S. 322; Morck/Shleifer/Vishny (1988), S. 294; Ayres/Cramton (1994), S. 1041; Shleifer/Vishny (1997), S. 754; Blies (2000), S. 72.

510 Vgl. beispielsweise Gugler (1999), S. 584.

511 In Anlehnung an Geldmacher (2000), S. 65. 
Es gilt die Annahme, dass die für eine sachgerechte Ausübung der Aktionärskontrolle anfallenden (Informationsbeschaffungs-)Kosten grundsätzlich unabhängig von der Höhe des Kapitalanteils sind. ${ }^{512}$ Eine eventuell erleichterte Informationsbeschaffung durch Großaktionäre würde sich in einer fallenden Kostenkurve ausdrücken und an der grundsätzlichen Argumentation nichts ändern. An dem aus der Kontrollausübung entstehenden Nutzen in Form von steigenden Dividenden und Aktienkursen profitiert jeder Aktionär in Abhängigkeit seiner Beteiligungshöhe. Somit lohnt sich die Ausübung von Aktionärskontrolle erst ab einem Kapitalanteil von $\mathrm{KA}_{\text {krit }}$. Der in der Grafik dargestellte Verlauf des Nutzens aus der Kontrollausübung (1) muss realiter nicht zwingend linear sein. Es könnte vielmehr plausibel sein, von einem abnehmenden Grenznutzen auszugehen. Der Einfachheit halber wird hier zunächst von einem linearen Verlauf ausgegangen. ${ }^{513}$ Der Nettonutzen aus der Kontrollausübung (3), der sich nach Abzug der Kontrollkosten des Aktionärs als Saldo aus (1) und (2) ergibt, ist ab $\mathrm{KA}_{\text {krit }}$ positiv.

Wie hoch der kritische Kapitalanteil ist, ab dem sich eine Wahrnehmung von Kontrolle lohnt, kann nicht allgemeingültig theoretisch abgeleitet werden; er ist abhängig von verschiedensten Einflussfaktoren (Kosten der Kontrollausübung, diskretionärer Handlungsspielraum des Managements, Wirksamkeit alternativer, insbesondere marktorientierter Kontrollmechanismen usw.). ${ }^{514}$ Voraussetzung dieser Argumentation ist, dass dem Aktionär durch die Investition in einen groBen Kapitalanteil keine Nachteile aus mangelnder Diversifikation entstehen, die den Nutzen aus der Kontrollausübung überkompensieren. ${ }^{515}$ Probleme entstehen somit insbesondere für Großaktionäre, die nur in ein Unternehmen investiert sind. ${ }^{516}$ Dies sind im Regelfall natürliche Personen, Mitglieder des Managements oder der Gründungsfamilie. Den weitaus größten Teil der Blockaktionäre

512 Von niedrigeren Kosten aufgrund von Spezialisierungsvorteilen (z.B. vorhandenes Know-how eines Kreditinstitutes bei der Bewertung der Ertragslage) wird hier abgesehen. Von alternativ möglichen Kontrollintensitäten soll ebenfalls abstrahiert werden. Sofern der Nutzen der Kontrollausübung abhängig vom Grad der Kontrollintensität ist, ergibt sich die optimale Monitoringintensität dort, wo die Grenzkosten der Kontrollausübung dem Grenznutzen entsprechen. Vgl. Huddart (1993), S. 1407.

513 Vgl. jedoch die Ausführungen in Kapitel III.2.2.1.3.

514 Vgl. Goergen (1998), S. 130.

515 Vgl. Demsetz/Lehn (1985), S. 1158; Zeckhauser/Pound (1990), S. 156, sowie ausführlich Heinrich (2000); Heaney/Holmen (2002).

516 Vgl. Shleifer/Vishny (1997), S. 758; Carlsson (2001), S. 189-191. Für den Fall mangelnder Marktliquidität ergeben sich Einschränkungen für die Argumentation. Maug konstatiert eine positive Korrelation zwischen Monitoringanreizen und Marktliquidität. Aktionäre neigen bei geringer Liquidität zu einer breiteren Streuung ihrer Anteile und nehmen entsprechend weniger Kontrollaufgaben wahr. Vgl. Maug (1998), S. 88. 
am deutschen Kapitalmarkt stellen jedoch Finanzintermediäre und Unternehmen, sodass dieser Problematik in der Regel nur geringe Bedeutung beigemessen wird.

Sofern kein einzelner Großaktionär vorhanden ist, dessen Kapitalanteil groß genug für eine Einflussnahme ist, kann sich dennoch ein Monitoringeffekt ergeben, sofern stattdessen mehrere einzelne Aktionäre vergleichbar große Aktienpakete halten. ${ }^{517}$ Jeder einzelne dieser Aktionäre kann in vergleichbarem Maße erwarten, dass seine Interessen durchgesetzt werden, wenn er über informiertes Wahlverhalten Einfluss auf die Geschäftspolitik nimmt. ${ }^{518}$ Die Voraussetzung hierfür ist jedoch, dass der individuelle Kapitalanteil so groß ist, dass Anreize für eine Kontrollausübung vorhanden sind. Eine Abschwächung des Free-RiderProblems ergibt sich in dieser Konstellation zudem, da ein koordiniertes Handeln der einzelnen Investoren auch bei mehreren Aktionären kostengünstig zu realisieren ist, sofern die Anzahl der Aktionäre überschaubar ist. ${ }^{519}$ Für eine Vielzahl von Kleinaktionären erscheint eine solche Koordination hingegen unrealistisch. $^{520}$

Aufgrund dieser Vorteile einer konzentrierten Aktionärsstruktur wird die Blockbildung in der Literatur teilweise als eigener (immaterieller) Vermögenswert gesehen, der eine überproportionale Rendite erwarten lässt. ${ }^{521}$ Aufgrund idiosynkratischer, also nicht kopierbarer Eigenschaften einzelner Aktionärsgruppen (z.B. das spezifische Know-how eines Großaktionärs aus seiner betrieblichen Tätigkeit) führen bestimmte Aktionärsstrukturen zu einer besseren Performance des Unternehmens. ${ }^{522}$ So hat z.B. ein Großaktionär Anreize, Investitionspläne des Managements durch Ertragsthesaurierung zu unterstützen, da er von den zu erwartenden positiven Renditen in erheblichem Maße profitiert. Kleinaktionäre, die von den Plänen erfahren, könnten hingegen Interesse haben, die Information extern am Kapitalmarkt zu verkaufen, um so ihren individuellen Nutzen zu maximieren. Das Management wird daher solche Pläne nur dann kommunizieren,

517 Dieses gilt auch, wenn der Kapital- bzw. Stimmrechtsanteil jedes einzelnen Aktionärs für eine Beeinflussung des Managements nicht ausreicht.

518 Vgl. Roe (1994), S. 9; Nicodano/Sembenelli (2000), S. 6.

519 Vgl. Belkaoui/Pavlik (1992), S. 345. Für den Einfluss des Koordinationsaufwandes auf die Agency-Kosten vgl. Carney (1987). Vgl. auch die transaktionskostentheoretische Analyse der Aktionärsstruktur von Grossman/Hart (1986); Hansmann (1988).

520 Vgl. bereits Hansmann (1988), S. 277-280.

521 Vgl. Schmid(1996), S. 407-409; Zeckhauser/Pound (1990), S. 165.

522 Die idiosynkratischen Eigenschaften gehen auf bewusste Investitionen und Lernprozesse zurück. Sie sind insofern nicht kopierbar, als dass ihre Adoption durch einen Aktionär anderen Typs dazu führt, dass er der kopierten Aktionärsgruppe zugehörig wird. Vgl. Schmid (1996), S. 407. 
wenn Großaktionäre vorhanden sind, von denen es sich Unterstützung erwartet. Eine konzentrierte Aktionärsstruktur würde, so die Argumentation, damit zu geringeren Informationsasymmetrien führen. ${ }^{523}$ Grundsätzlich basiert die Idee der Aktionärsstruktur als Vermögensgegenstand jedoch immer auf dem Gedanken, dass Aktivitäten des Großaktionärs nicht nur ihm, sondern auch allen anderen Aktionären zugute kommen. Daher wird sie hier unter die Interessenkonvergenzhypothese subsumiert.

Im Ergebnis legt die Interessenkonvergenzhypothese nahe, dass die Kapitalkonzentration bei einem oder mehreren Aktionären aus Sicht aller Aktionäre positiv $\mathrm{zu}$ bewerten ist und $\mathrm{zu}$ einer Minderung der Agency-Kosten zwischen Management und Anteilseignern beiträgt.

\subsubsection{Ausbeutungshypothese}

Die Ausbeutungshypothese ${ }^{524}$ setzt an den Schwächen der Interessenkonvergenzhypothese an, die davon ausgeht, dass der Großaktionär seine Kontrollrechte auch tatsächlich im Interesse aller Aktionäre ausübt. ${ }^{525}$ Durch seinen großen Kapitalanteil hat er jedoch die Möglichkeit, neben oder anstatt der Ausübung von Managementkontrolle Einfluss auf die Geschäftspolitik zu nehmen und hierbei im Eigeninteresse nutzenmaximierend zu agieren. ${ }^{526}$ Er kann auf die mit allen anderen Aktionären zu teilenden Erträge aus der Kontrollausübung verzichten und stattdessen private Vorteile (private benefits) realisieren, die ihm exklusiv zugute kommen. ${ }^{527}$ Private benefits der Kontrolle werden dabei defi-

523 Vgl. Schmid (1996), S. 408.

524 Teilweise auch „opposed-interests hypothesis“ bzw. „entrenchment hypothesis“. Vgl. Chirinko et al. (1999), S. 11; Morck/Shleifer/Vishny (1988), S. 294; Gugler (2001), S. 26, wobei der Begriff der „entrenchment hypothesis“ ursprünglich die private Vorteilsnahme des Managements beschreibt.

525 Vgl. Shleifer/Vishny (1997), S. 758; Bainbridge (1995), S. 716f.; Bebchuk/Zingales (2000), S. 56; Holderness/Sheehan (2000), S. $139 \mathrm{f}$.

526 Vgl. Barclay/Holderness (1989), S. 372; Harris/Raviv (1989), S. 256; Bebchuk (1999), S. 28; Shleifer/Vishny (1997), S. 758; Ang/Cole/Lin (2000), S. 81; Dyck/Zingales (2002), S. 6-8; Erhardt/Nowak (2002), S. 6. Vereinzelt wird der Nutzen aus der Kontrollausübung an sich mit private benefits betitelt. Vgl. Harris/Raviv (1988a), S. $205 \mathrm{f}$.

527 Vgl. bereits Andrews (1965), S. 523-526, grundlegend für die jüngere Literatur Grossman/Hart (1988); Barclay/Holderness (1989). Die Realisierung solcher privaten Vorteile ist von großer praktischer Bedeutung und wird durch empirische Untersuchungen bestätigt. Vgl. Zingales (1994), S. 134-137; Barclay/Holderness (1989), S. 372; Schmid (1997); Barclay/Holderness/Sheehan (2001). Für alternative Ansatzpunkte zur Quantifizierung der private benefits vgl. Lamba/Stapledon (2001), S. 20; Pellens/Hillebrandt (2001), S. 64f.; Dyck/Zingales (2002), S. 8f.; Atanasov (2002); Heaney/Holmen (2002); Dittmann (2003). 
niert als der Wert der Vorteile, die ein Großaktionär aus der von ihm kontrollierten Gesellschaft zu Lasten der anderen Aktionäre ziehen kann. ${ }^{528}$ Die folgende Abb. 12 gibt einen Überblick über die unterschiedlichen Dimensionen der private benefits: ${ }^{.29}$

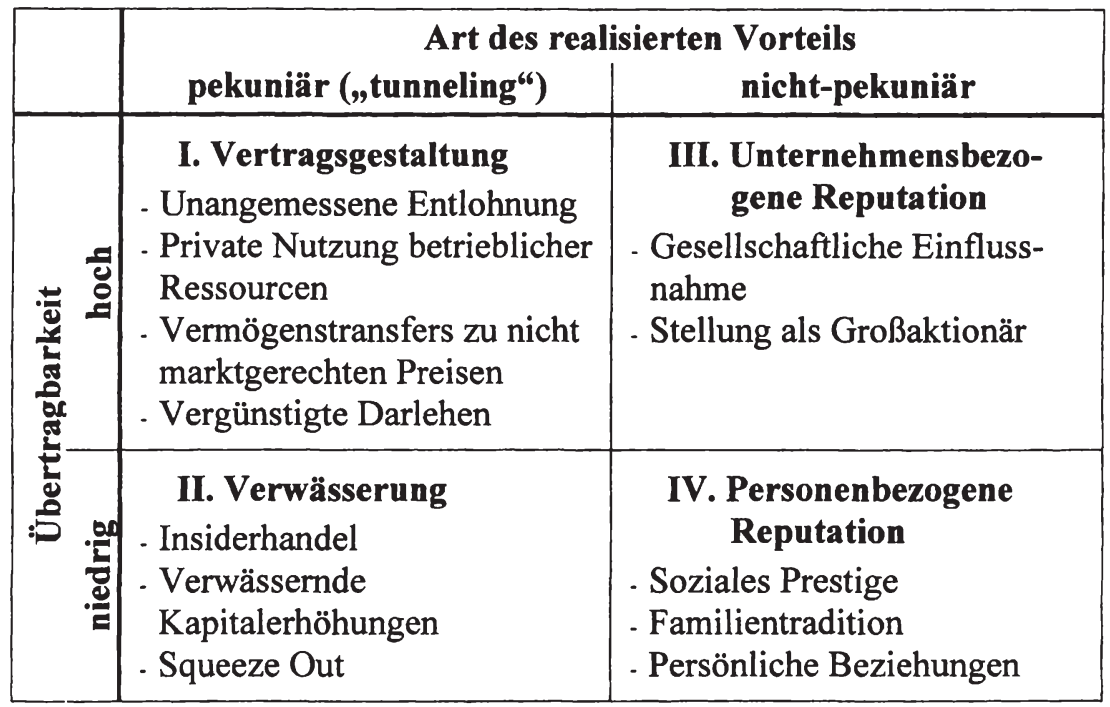

Abb. 12: Dimensionen von private benefits

Die privaten Vorteile können hinsichtlich ihrer Übertragbarkeit differenziert werden. Während bestimmte benefits nur durch einen bestimmten Großaktionär nutzbar sind, gehen andere bei Veräußerung des Aktienpakets auf den neuen Eigentümer über. Beispiele für nicht übertragbare private benefits sind die $\mathrm{Be}-$ einflussung der Vertragsgestaltung bei gegenseitigen Lieferantenverhältnissen oder die Durchsetzung einer risikoaversen Geschäftspolitik im Rahmen der Aufsichtsratstätigkeit durch eine gleichzeitig kreditgebende Bank. ${ }^{530}$ Bei gleichzeitig geschäftsführenden Gesellschaftern sind private benefits in Form von unan-

528 Vgl. ähnlich Nenova (2000), S. 2. Die Realisierung von private benefits führt zu einer Minderung der ausschüttbaren Cash Flows und damit zu einer Reduzierung des Unternehmenswertes aus Sicht aller Eigenkapitalgeber. Der Meinung von Teall, dass die Umverteilung von Cash Flows zu einer privilegierten Gruppe den Unternehmensgesamtwert nicht mindert, kann nicht gefolgt werden, da die potenziell ausschüttbaren Cash Flows den Unternehmenswert determinieren. Die private benefits Einzelner stehen jedoch zur Ausschüttung gerade nicht mehr zur Verfügung. Vgl. Teall (1997), S. $221 \mathrm{f}$.

In Anlehnung an Ehrhardt/Nowak (2002), S. 9.

530 Vgl. bspw. Hart (1995), S. 682f. Für verschiedene Beispiele von "unangemessenen Vertragsbeziehungen" speziell in deutschen Aktiengesellschaften vgl. ausführlich Scheffler (2002), S. 543f.; Barclay/Holderness (1989), S. 374; Johnson et al. (2000). 
gemessen hohen Gehältern von praktischer Bedeutung. ${ }^{531}$ Private benefits können somit sowohl nicht-pekuniärer als auch pekuniärer Natur sein, die Realisierung pekuniärer Vorteile wird auch als ,tunneling“ bezeichnet. ${ }^{532}$

Für Großaktionäre ergibt sich hinsichtlich der private benefits ein Trade-off zwischen einer Minderung des Unternehmenswertes einerseits und der persönlichen Bereicherung andererseits. ${ }^{533} \mathrm{Maßnahmen}$ zur Generierung von private benefits sind aus Sicht des Großaktionärs so lange positiv zu bewerten, wie die hieraus resultierende Wertminderung des Gesamtunternehmens die aus den private benefits zu erzielenden Zahlungsströme nicht überkompensiert. Von einer Wertminderung sind alle Aktionäre entsprechend ihres Anteils betroffen, während die private benefits ausschließlich dem ausbeutenden Aktionär zugute kommen. ${ }^{534}$ Unter Berücksichtigung von private benefits ändert sich somit auch die Anreizstruktur in Abhängigkeit vom Kapitalanteil, wie Abb. 13 zeigt. ${ }^{535}$

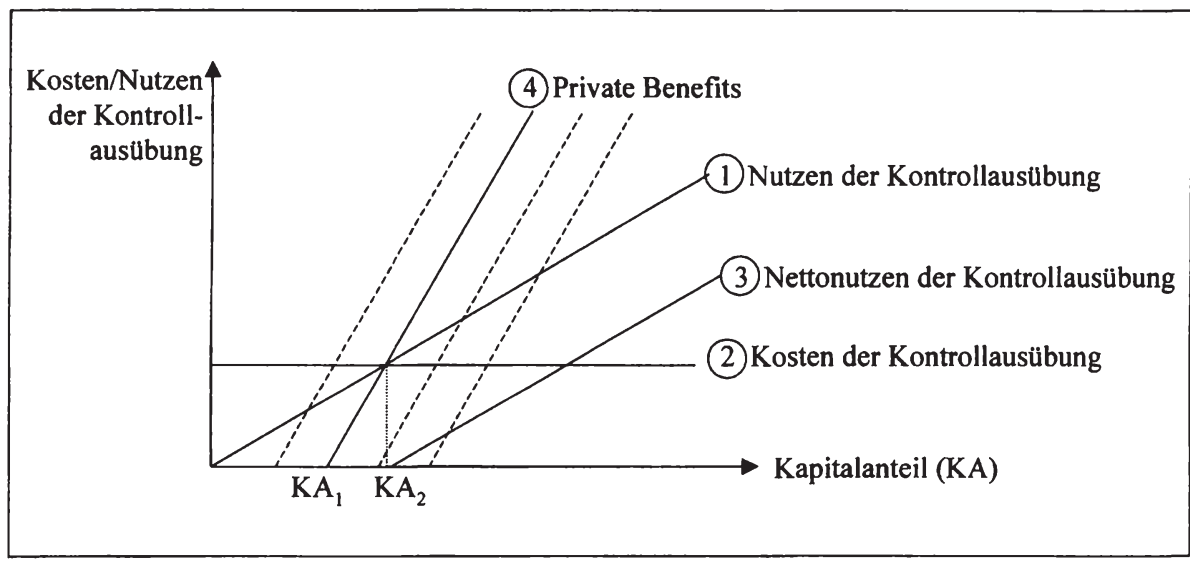

Abb. 13: Kontrollausübung unter Berücksichtigung von private benefits

531 Vgl. Slovin/Sushka (1993), S. 1320; Zingales (1995), S. 1070.

532 Vgl. Johnson et al. (2000), S. 22; Erhardt/Nowak (2002), S. 9. Auch Shleifer/Vishny (1997), S. 758f., differenzieren zwischen direkten monetären private benefits (z.B. Sonderdividenden nur an den Großaktionär) und solchen aus begünstigenden Verträgen. Erstere dürften in Deutschland aufgrund rechtlicher Beschränkungen jedoch nur eine eingeschränkte Rolle spielen. Denkbar ist jedoch eine Beeinflussung der Dividendenpolitik. Vgl. den empirischen Nachweis von DeAngelo/DeAngelo (2000), sowie Short/Zhang/ Keasey (2002).

533 Vgl. Cronqvist/Nilsson (2002), S. 1 m.w.N.

534 Vgl. Becht (1997), S. 24; Claessens et al. (1999), S. 3; Pellens/Hillebrandt (2001), S. 61 f. m.w.N.

535 Vgl. auch Abb. 11 auf Seite 89 dieser Arbeit. 
Ohne Berücksichtigung privater Vorteile wäre für den Aktionär eine Kontrollausübung ab einem Kapitalanteil von $\mathrm{KA}_{2}$ rational, da sein Nutzen größer ist als die Kosten, er einen positiven Nettonutzen (3) realisiert. Ab einem bestimmten Kapitalanteil (hier $\mathrm{KA}_{1}$ ) hat der Aktionär jedoch die Möglichkeit, Einfluss auf das Management im Sinne seiner persönlichen Interessen zu nehmen, da zwischen Managern und Großaktionären ein Abhängigkeitsverhältnis besteht. Mit steigendem Kapitalanteil nimmt die Möglichkeit zur Einflussnahme und damit zur Realisierung von private benefits für den Aktionär zu (4). Im Rahmen der Abbildung kann der Großaktionär - so die Ausbeutungshypothese - ab dem Kapitalanteil $\mathrm{KA}_{1}$ aus der Realisierung von private benefits einen Nutzen ziehen, wohingegen er einen - noch zudem geringeren - Nutzen aus der Kontrollausübung erst ab $\mathrm{KA}_{2}$ realisiert. Da der Nutzen aus den private benefits ihm exklusiv zugute kommt, wohingegen er steigende Gewinne mit anderen Aktionären teilen muss, wird er sich - opportunistisches Verhalten unterstellt - in dieser Situation immer für die Realisierung von private benefits entscheiden. Die Ausbeutungshypothese legt somit nahe, dass Aktionäre, deren Kapitalanteil so groß ist, dass sie Einfluss auf das Management nehmen können, auf die Ausübung von Kontrolle verzichten und stattdessen private benefits realisieren, von denen sie exklusiv profitieren. Je nach Lage der Kurven ergibt sich somit kein oder nur ein sehr begrenzter positiver Effekt durch die Kapitalkumulation, was durch die gestrichelten Linien angedeutet wird. ${ }^{536}$ Es sei noch darauf hingewiesen, dass annahmegemäß keine Kosten der Kontrollausübung anfallen, wenn sich der Großaktionär für die Realisierung der private benefits entscheidet. Die privatebenefits-Kurve ist somit eine Netto-Nutzengerade.

Die Gefahr von Wertminderungen durch Großaktionäre wird durch die Konsequenzen ihrer Aktivitäten auf die anderen Aktionäre zusätzlich verstärkt. Sofern diese die Gefahr der Realisierung von private benefits durch einen Großaktionär antizipieren, könnte dies zu sinkender Investitionsbereitschaft führen. ${ }^{537} \mathrm{Im}$ Extremfall könnte ein Rückzug kleinerer Eigenkapitalgeber aus dem organisierten Kapitalmarkt die Folge sein. ${ }^{538}$ Die Angst vor einer intensiven Überwachung durch den Großaktionär könnte zudem Manager veranlassen, nicht für das Unternehmen tätig zu werden oder von unternehmensspezifischen Investitionen in ihr Humankapital abzusehen. ${ }^{539}$

536 Es ist denkbar, dass die private-benefits-Kurve weiter rechts liegt, sodass sich zumindest für bestimmte Kapitalanteile noch positive Effekte ergeben. Dies wird jedoch von der Ausbeutungshypothese nicht berücksichtigt.

537 Vgl. Shleifer/Vishny (1997), S. 760; Gugler (2001), S. 28f.

538 Vgl. Shleifer/Vishny (1997), S. 760.

539 Vgl. Schmidt (1996), S. 22; Burkart/Gromb/Panunzi (1997), S. 694. 
Im Ergebnis lässt die Ausbeutungshypothese die einseitig positive Wahrnehmung von Großaktionären zweifelhaft erscheinen. Ein Großaktionär, der nicht von anderen Aktionären kontrolliert wird, hat Anreize und Möglichkeiten, im Eigeninteresse nutzenmaximierend zu handeln und damit den Gesamtunternehmenswert zu schmälern. Unter Berücksichtigung des unterstellten opportunistischen Verhaltens der einzelnen Akteure erscheint die Annahme einer solchen Eigennutzorientierung innerhalb der gesetzlichen Rahmenbedingungen - und gegebenenfalls auch darüber hinaus - grundsätzlich plausibel. Die Reduzierung des Agency-Konfliktes zwischen Management und Aktionären geht somit einher mit der Schaffung eines Agency-Konfliktes zwischen Großaktionären und Kleinaktionären.

\subsubsection{Nichtlinearitätshypothese}

Die Nichtlinearitätshypothese stellt eine Kombination von Interessenkonvergenz- und Ausbeutungshypothese dar und berücksichtigt in ihrer Argumentation explizit den Trade-off des Großaktionärs zwischen seinen private benefits und dem Wert seiner Aktien bei alternativen Beteiligungsquoten. ${ }^{540}$ Demnach ist die Kapitalkonzentration bei einzelnen Aktionären nicht grundsätzlich positiv oder negativ zu beurteilen sondern vielmehr abhängig von der Höhe des Kapitalanteils. Zudem wird berücksichtigt, dass die private-benefits-Kurve in der Regel nicht linear verlaufen wird, wie die folgende Abbildung veranschaulicht:

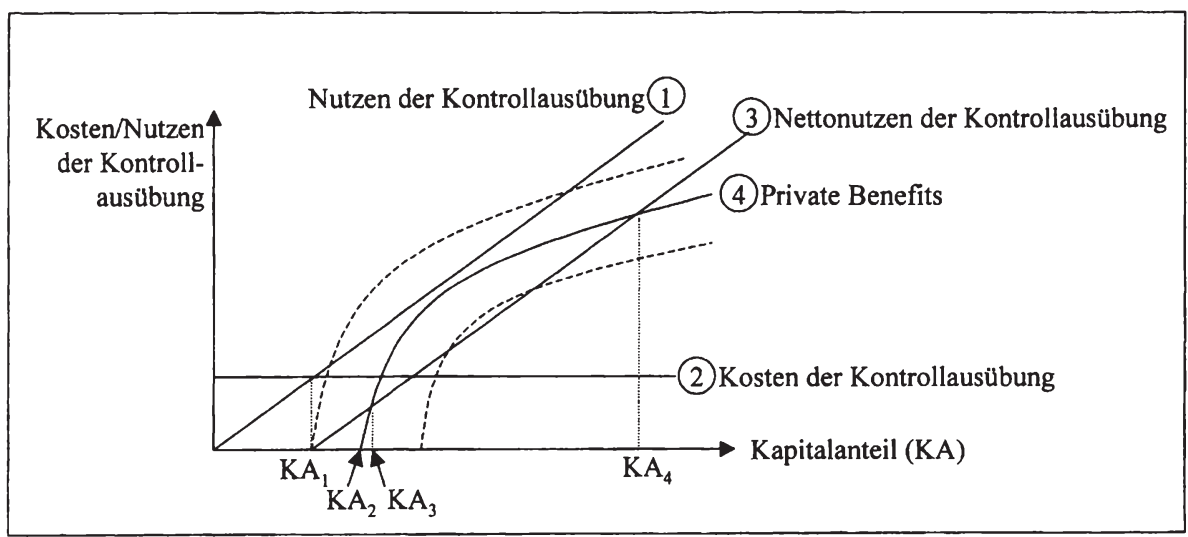

Abb. 14: Kontrollausübung unter Berücksichtigung nichtlinearer private benefits

Nach einem steilen Anstieg flacht die private-benefits-Kurve wieder ab, da ab einem bestimmten Kapitalanteil, der einen maßgeblichen Einfluss auf das Ma-

540 Vgl. in Ansätzen ähnlich Chirinko et al. (1999), S. 12, die eine „Insiderhypothese“ für den Spezialfall von Kapitalbeteiligungen durch Finanzintermediäre formulieren, sowie Claessens et al. (1999), S. 5. 
nagement ermöglicht, größere Kapitalanteile keine zusätzlichen private benefits ermöglichen. Zudem mindern eventuelle Risikoabschläge der sonstigen Aktionäre, die ein Fehlverhalten des Großaktionärs antizipieren, den Unternehmenswert, was den Nettonutzen aus den private benefits ab einem bestimmten Kapitalanteil schmälert und einen nichtlinearen Verlauf der Kurve plausibel erscheinen lässt. Zwischen $\mathrm{KA}_{1}$ und $\mathrm{KA}_{3}$ überwiegt der positive Einfluss des Großaktionärs, da er bereits einen Nutzen aus der Kontrollausübung generieren kann und dieser zudem größer ist als der Nutzen aus den private benefits, die er ab einem Kapitalanteil von $\mathrm{KA}_{2}$ realisieren kann. $\mathrm{Ab}$ einem Kapitalanteil von $\mathrm{KA}_{3}$ hingegen ist der aus den private benefits zu erzielende Cash Flow größer als der aus der Kontrollausübung, sodass sich für Kapitalanteile zwischen $\mathrm{KA}_{3}$ und $\mathrm{KA}_{4}$ ein negativer Einfluss des Großaktionärs für die anderen Aktionäre ergibt. Ab einem Kapitalanteil von $\mathrm{KA}_{4}$ hingegen wäre die Ausübung von Kontrolle wieder sinnvoller: Die private-benefit-induzierte Unternehmenswertminderung trifft in zunehmendem Maße über seinen Kapitalanteil auch den Großaktionär und Antizipationseffekte bei den verbleibenden Kleinaktionären verstärken die Wertminderungen zusätzlich. Verschiebt man die private-benefits-Kurve über $\mathrm{KA}_{1}$ hinaus weiter nach links, wie es durch eine gestrichelte Linie angedeutet ist, ergeben sich im Bereich geringer Kapitalanteile gar keine positiven Effekte aus Blockbildungen; der Nettonutzen aus der Kontrollausübung ist ausschließlich bei sehr großen Blöcken größer als der aus den private benefits. Welche Kapitalanteile in der Praxis mögliche Wendepunkte zwischen einem positiven bzw. negativen Einfluss markieren, ist schwer theoretisch abzuleiten. Denkbar wäre, dass die aktienrechtlich bedeutenden Schwellenwerte eine Rolle spielen könnten.

Ein nichtlinearer Einfluss der Kapitalkonzentration auf den Unternehmenswert lässt sich auch bereits aus dem Beitrag von Fama/Jensen (1983) ableiten. ${ }^{541}$ Aufbauend auf Jensen/Meckling (1976), die den positiven Einfluss der Konzentration des Kapitals hervorheben, weisen Fama/Jensen auf den negativen Einfluss insbesondere größerer Kapitalkonzentrationen hin. ${ }^{542}$ Durch die Bündelung eines großen Teils des Kapitals bei einem Großaktionär bestehe die Gefahr einer Beeinflussung in Richtung einer aus Sicht aller Aktionäre zu risikoaversen Investitionspolitik, da der Großaktionär nicht mehr ausreichend diversifiziert ist

541 Fama/Jensen (1983) argumentieren auf Basis eines Eigentümer-Managers. Die beschriebene Wirkung der Kapitalkonzentration ergibt sich indes analog auch für nicht am Management beteiligte Großaktionäre.

542 Vgl. Fama/Jensen (1983), insbesondere S. 306-309. 
bzw., sofern er gleichzeitig als Manager agiert, seinen Arbeitsplatzverlust befürchtet. $^{543}$

Für den Sonderfall des Anteilsbesitzes von Managern begründet das Modell von Stulz (1988) eine nichtlineare Beziehung zwischen Anteilsquote und Unternehmenswert. Er argumentiert, dass die Wahrscheinlichkeit einer feindlichen Übernahme mit dem Kapitalanteil des Managements sinkt, wohingegen die durch das Management verhandelte Übernahmeprämie steigt. ${ }^{54} \mathrm{Da}$ Manager feindliche Übernahmen aufgrund des damit verbundenen Kontrollverlusts fürchten, wird ein sehr hoher Kapitalanteil dazu führen, dass sie Übernahmen vollständig verhindern. ${ }^{545}$ Sofern sie jedoch gar nicht am Unternehmen beteiligt sind, besteht die Gefahr, dass Übernahmen mit einer geringeren als der eigentlich durchsetzbaren Prämie realisiert werden. ${ }^{546}$ Beides hat negative Auswirkungen auf den Unternehmenswert, sodass das Modell die nichtlineare Beziehung bestätigt. ${ }^{547}$

Im Ergebnis lässt die Nichtlinearitätshypothese somit eine nichtlineare Beziehung zwischen Kapitalanteil des Großaktionärs und Unternehmenswert erwarten. ${ }^{548} \mathrm{Zu}$ erwarten wäre ein positiver Einfluss kleiner und sehr großer Kapitalbündelungen, für Blockbildungen mittlerer Größe würde sich hingegen ein eher negativer Einfluss auf den Unternehmenswert ergeben.

\subsubsection{Sonstige Hypothesen}

Neben den drei für die Argumentation dieser Arbeit zentralen, zuvor diskutierten Hypothesen sind verschiedene andere Erklärungsansätze für die Wirkung von Kapitalblöcken denkbar, die zum Teil mit den obigen Hypothesen eng verwandt sind. ${ }^{549}$ Es sollen im Folgenden jeweils die Kernaussagen der sich teilweise widersprechenden Hypothesen vorgestellt werden, ohne auf die zugrunde liegenden Annahmen, die nicht immer mit den im Rahmen dieser Arbeit getroffenen übereinstimmen, im Detail einzugehen.

\footnotetext{
543 Vgl. zur managerial ownership theory Fama/Jensen (1983), S. 309, sowie Morck/ Shleifer/Vishny (1988), S. 293f.; Börsch-Supan/Köke (2000), S. 10-12.

544 Vgl. Stulz (1988), S. 32f.

545 Vgl. Stulz (1988), S. 26.

546 Vgl. Stulz (1988), S. 26.

547 Vgl. Stulz (1988), S. 35.

548 Verschiedenste empirische Arbeiten deuten auf eine solche nichtlineare Beziehung hin. Vgl. die grundlegende Studie von Morck/Shleifer/Vishny (1988), sowie Chirinko et al. (1999); Himmelberg/Hubbard/Palia (1999); Thomsen/Pedersen (2000); Belkaoui/Pavlik (1992); Alexander/Cohen (1999); Lins (2003).
}

549 Die hier vorgestellten Erklärungsansätze finden sich an verschiedensten Stellen in der Literatur, die gewählten Namen für die Hypothesen sind nicht gängiger Sprachgebrauch 
a) INFORMATIONSEFFIZIENZHYPOTHESE:

Roe argumentiert, dass mangelnde Kapitalmarkteffizienz die direkte Weitergabe von wertrelevanten Informationen an einzelne Großaktionäre erforderlich macht. ${ }^{550}$ Diese seien im Gegensatz zu Kleinaktionären in der Lage, speziell langfristig ausgerichtete Großprojekte fundiert $\mathrm{zu}$ beurteilen und trügen somit zur korrekten Entscheidungsfindung des Managements bei. ${ }^{551}$ Er begründet dies mit der größeren Nähe der Großaktionäre zum Management die es ihnen ermöglicht, aus langfristigen Projekten resultierende strategische Vorteile oder resultierende Handlungsspielräume $\mathrm{zu}$ erkennen und in ihr Bewertungskalkül einfließen zu lassen. Roe geht davon aus, dass der Kapitalmarkt (in Form anonymer Kleinaktionäre) diese Vorteile langfristiger Projekte nicht zu erkennen vermag und stattdessen die Realisierung kurzfristig gewinnbringender Projekte präferiert. ${ }^{552}$ Großaktionäre würden somit zur Unterstützung einer langfristig wertschaffenden Investitionspolitik des Unternehmens beitragen.

b) ANLAGEHORIZONTHYPOTHESE:

Ähnlich argumentiert die Anlagehorizonthypothese, die positive Auswirkungen von Großaktionären auf den Unternehmenswert mit dem in der Regel langfristigen Anlagehorizont dieser Aktionärsgruppe begründet. ${ }^{553} \mathrm{Ay}$ res/Cramton argumentieren, dass Blockaktionäre über Anreize verfügen, langfristige Anreizsysteme für das Management zu implementieren, da sie über die in der Folge realisierbaren Wertsteigerungen selbst von diesen profitieren. ${ }^{554}$ Sie besitzen im Gegensatz zu eher kurzfristig ausgerichteteren Kleinaktionären die Möglichkeit, auch die Einhaltung impliziter Vertragsbe-

550 Vgl. Roe (1994), S. 241f., kritisch Bainbridge (1995), S. 711f. Zur Informationseffizienz des Kapitalmarkts vgl. Fama (1970, 1991), erläuternd Schremper (2002a). Maug weist darauf hin, dass der Informationsvorsprung der Großaktionäre bei diesen zu höheren Erträgen aufgrund der Kenntnis über die Volatilität künftiger Erträge führt, vgl. Maug (1998), S. 88. Fan/Wong (2002) weisen nach, dass der Informationsgehalt der publizierten Ergebnisgrößen in Unternehmen mit konzentrierter Aktionärsstruktur geringer ist. Dies könnte auf exklusive Informationsrechte der Großaktionäre hindeuten.

551 Vgl. Roe (1994), S. 241. Dabei ist jedoch zu berücksichtigen, dass die Informationsvorsprünge nicht nur zu einer wertorientierten Wahrnehmung der Kontrollfunktion genutzt werden können, sondern auch Grundlage für Spekulationsgeschäfte sein können, die die Position der anderen Aktionäre schädigen können. Vgl. Kahn/Winton (1998), die auf den Trade-off zwischen „speculation“ und ,intervention“ hinweisen. Ähnlich auch Maug (1998), S. 89.

552 Vgl. Roe (1994), S. 242. Roe stellt damit die Gültigkeit einer halbstrengen Informationseffizienz des Kapitalmarkts infrage. Vgl. kritisch Bainbridge (1995), S. $711 \mathrm{f}$.

553 Vgl. Ayres/Cramton (1994), S. 1040.

554 Vgl. Ayres/Cramton (1994), S. 1041. 
standteile des Managements zu überwachen, was sich in einer Minderung des principal-agent-Konfliktes niederschlägt. Zudem seien sie aufgrund ihres langfristigen Anlagehorizontes weniger geneigt, auf kurzfristig orientierte feindliche Übernahmeangebote einzugehen. ${ }^{55}$ Sie würden stattdessen Wertsteigerungspotenziale selbst erkennen und durch Ausübung von Kontrolle innerhalb des Unternehmens realisieren.

c) ORgANISATIONSHYPOTHESE:

Ebenfalls von Roe stammt die Hypothese, dass Überkreuzverflechtungen geeignet sind, aus unvollständigen Verträgen resultierendes, opportunistisches Verhalten des Managements zu unterbinden. ${ }^{556}$ Die Idee ist, dass sich im Falle von Managementfehlverhalten verschiedene, jeweils überkreuz beteiligte Aktionäre verbünden und das Management sanktionieren, um so die unternehmerische Effizienz zu steigern. ${ }^{557}$ Die Wirksamkeit wird sich insbesondere innerhalb einer Branchen ergeben, wo die einzelnen Großaktionäre auch untereinander in intensivem Kontakt stehen und ggf. selbst miteinander verflochten sind. Überkreuzverflechtungen fungieren als Mittelweg zwischen einer vollständigen organisationalen Integration der Unternehmen und einer reinen Vertragsbeziehung. ${ }^{558}$ Rückwirkungen auf nicht beteiligte Aktionärsgruppen sowie nicht im Interesse der Aktionärsgesamtheit liegende Eigeninteressen der agierenden Aktionäre werden im Rahmen dieser Hypothese nicht explizit berücksichtigt. ${ }^{559}$

d) SignallinghYPOTHESE:

Eng mit der Interessenkonvergenzhypothese verbunden ist die Signallinghypothese. Leland/Pyle (1977) argumentieren, dass Großaktionäre, die im Rahmen des Börsengangs nur einen Teil des Eigenkapitals veräußern und selbst wesentlich investiert bleiben, damit positive Erwartungen in die zukünftige Performance signalisieren. Goergen (1998), überträgt diese Argumentation auf Kapitalerhöhungen. ${ }^{560}$ Der Argumentation liegt somit erneut der Gedanke zugrunde, dass Großaktionäre über einen Wissensvorsprung hinsichtlich der Beurteilung der wirtschaftlichen Lage verfügen. Da im Rahmen dieser Studie jedoch der langfristige Einfluss von Großaktionären auf die Performance untersucht werden soll, kommt der Signallinghypothe-

\footnotetext{
555 Vgl. Ayres/Cramton (1994), S. $1060 \mathrm{f}$.

556 Vgl. Roe (1994), S. $248 \mathrm{f}$.

557 Vgl. Roe (1994), S. 249.

$558 \mathrm{Vgl}$. Roe (1994), S. 248f.

559 Vgl. jedoch ansatzweise Roe (1994), S. 250.

560 Vgl. Goergen (1998), S. 129.
} 
se, die sich auf den Zeitpunkt um ein Public Offering bezieht, vergleichsweise geringe Bedeutung $\mathrm{zu}^{561}$

e) LIQUIDITÄTSHYPOTHESE:

Die Liquiditätshypothese setzt an den Folgen einer Blockbildung für die Fungibilität der Aktie an, die wiederum Einfluss auf den Aktienkurs hat. Die Kapitalbündelung bei einem oder wenigen Großaktionären, die ihr Paket langfristig halten, führt zu einer Einschränkung der Liquidität der Aktie am Kapitalmarkt, da die Anzahl der frei handelbaren Aktien abnimmt. ${ }^{562}$ Dieses kann von den Marktteilnehmern mit einem Kursabschlag bestraft werden, sodass sich ein negativer Einfluss auf den Unternehmenswert ergibt. ${ }^{563}$

\section{f) KAPITALSTRUKTURHYPOTHESE:}

Die Kapitalstrukturhypothese besagt, dass Kapitalbündelungen bei einem Großaktionär zu einer Erhöhung der Agency-Kosten des Fremdkapitals führen könnte, da die Gläubiger eine Beeinflussung des Managements in Richtung einer risikoreichen Investitionspolitik befürchten. ${ }^{564}$ Im Extremfall würde dies dazu führen, dass die Aktionäre, die letztendlich die AgencyKosten des Fremdkapitals tragen, auf Fremdfinanzierung vollständig verzichten und Wachstumsoptionen verstreichen lassen. ${ }^{565}$ Der Hypothese liegt die auf Jensen/Meckling (1976) zurückgehende Argumentation zugrunde, dass der potenzielle Ertrag aus einer risikoreicheren Investition ausschließlich den Aktionären zu Gute kommt, wohingegen ein eventueller Verlust im Insolvenzfall auch von den Gläubigern getragen wird. Die Kapitalstrukturhypothese stellt einen Gegenpol zur Informationseffizienzhypothese dar, die gerade einen positiven Einfluss von Großaktionären auf die Investitionspolitik unterstellt.

g) ENDOGENITÄTSHYPOTHESE:

Demsetz (1983) argumentiert, dass die Aktionärsstruktur keinen Einfluss auf die Agency-Kosten des Unternehmens hat, die jeweilige Aktionärsstruktur

561 Die Studie von Mikkelson/Partch/Shah (1997) belegt, dass nach dem Börsengang zunächst im Unternehmen verbleibende Großaktionäre ihren Aktienbestand in der Folge kontinuierlich reduzieren. Vor diesem Hintergrund erscheint eine Anwendbarkeit der Signallinghypothese für einen Langfristzeitraum fraglich.

562 Die Argumentation geht zurück auf Holmström/Tirole (1993). Vgl. auch Burkart/Gromb/ Panunzi (1997), S.695; Ragazzi (1981), S. 274; Becht (1999), sowie Ang/Cole/Lin (2000), S. 81.

563 Ausführlich zum Verhältnis von „Liquidity versus Control“ vgl. auch Coffee (1991).

564 Vgl. den Beitrag von Inderst/Müller (1999).

565 Vgl. Inderst/Müller (1999), S. 14. 
sei vielmehr das Ergebnis eines Wettbewerbsprozesses. ${ }^{566}$ Er formuliert „I view the ownership structure of the firm as an endogenous outcome of a maximizing process" ${ }^{\$ 67}$. Die jeweilige Eigentümerstruktur ergibt sich demnach in Abhängigkeit der unternehmensindividuellen (Agency-)Kostenstruktur. ${ }^{568}$ Der Unternehmenswert wird durch ein effizientes Management aller Kosten gesteigert und nicht durch eine Minimierung der AgencyKosten. ${ }^{569}$ Diese sind vielmehr ,normale Kosten“ im Sinne einer nichtpekuniären Entlohnung des Managements. ${ }^{570}$ Die Aktionärsstruktur ergibt sich somit als Konsequenz der nicht-pekuniären Bestandteile der Managemententlohnung. Über alle Unternehmen ergibt sich ein Gleichgewicht das die effiziente Allokation des Kapitals sicherstellt. ${ }^{571}$ Spätere Veröffentlichungen haben die Endogenität der Aktionärsstruktur im Sinne einer umgekehrten Kausalität interpretiert. ${ }^{572}$ Demzufolge führen etwa Großaktionäre nicht zu einer besseren Performance des Unternehmens, die Großaktionäre selbst investieren vielmehr in genau die Unternehmen mit einer guten Performance. Die Gültigkeit der Endogenitätshypothese für den deutschen Kapitalmarkt soll im Rahmen der empirischen Untersuchung überprüft werden. Sie wird daher in Kapitel IV.2.2.1 noch ausführlich diskutiert.

\subsubsection{Relevanz der Identität des Großaktionärs}

Im Rahmen der vorangegangenen Argumentationen wurden Großaktionäre als homogene Gruppe mit einheitlichen Anreizstrukturen betrachtet. Je nach Identität des Großaktionärs können sich jedoch unterschiedliche Motive beim Erwerb großer Beteiligungen ergeben. Entsprechend ist auch die Wahrscheinlichkeit, dass private benefits realisiert werden, nicht immer gleich hoch. Im Rahmen von Kapitel II. 3 wurden bereits verschiedene Typen von Großaktionären charakterisiert. Tab. 6 gibt einen Überblick über die Möglichkeit der Einflussnahme alternativer Aktionärsgruppen sowie die potenziellen Vor- und Nachteile, die daraus für die Gesamtheit der Aktionäre resultieren. Dabei ist jedoch zu berücksichtigen, dass die individuellen Anreize dennoch sehr heterogen ausgeprägt sein

566 Vgl. Demsetz (1983), S. 376, insbesondere Fn. 3. Eine ausführliche Darstellung der Theorie von Demsetz findet sich bei Schmid (1996), S. 404-409.

567 Demsetz (1983), S. 377.

568 Vgl. Demsetz (1983), S. 385.

569 Vgl. Demsetz (1983), S. 384f.

570 Dem Agency-Problem wird damit im Wettbewerbsgleichgewicht keine Relevanz beigemessen. Vgl. auch Demsetz/Lehn (1985), S. 1173-1176.

571 Vgl. Schmid (1996), S. $406 f$.

572 Vgl. Demselz/Villalonga (2001), S. 215f.; Lehmann/Weigand (2000), S. 172-174; Himmelberg/Hubbard/Palia (1999), S. 358-360; Börsch-Supan/Köke (2000), S. 6 f. 
können und die Zuordnung zu den einzelnen Gruppen nicht immer überschneidungsfrei möglich ist. Ausländische Anteilseigner werden nicht als separate Gruppe aufgenommen, da sie als Gruppe zu heterogen sind, um ihnen einheitliche Anreizstrukturen zuzuordnen.

\begin{tabular}{|c|c|c|c|}
\hline $\begin{array}{l}\text { Art des } \\
\text { Aktionärs }\end{array}$ & $\begin{array}{l}\text { Möglichkeit der Ein- } \\
\text { flussnahme über.... }\end{array}$ & $\begin{array}{l}\text { Vorteile aus Sicht aller } \\
\text { Aktionäre }\end{array}$ & $\begin{array}{l}\text { Gefahren aus Sicht } \\
\text { aller Aktionäre } \\
\text { (private benefits) }\end{array}$ \\
\hline $\begin{array}{l}\text { (Gründer-) } \\
\text { Familie }\end{array}$ & $\begin{array}{l}\text { - Aufsichtsratsmandate } \\
\text { - persönliche Beziehun- } \\
\text { gen; (ehemalige) Ab- } \\
\text { hängigkeiten }\end{array}$ & $\begin{array}{l}\text { - Gute Kenntnis der } \\
\text { unternehmerischen } \\
\text { Strukturen (Chan- } \\
\text { cen/Risiken) } \\
\text { - Marktkenntnis } \\
\end{array}$ & $\begin{array}{l}\text { - Nutzung insbesondere } \\
\text { nicht-pekuniärer Ver- } \\
\text { günstigungen } \\
\text { - Ggf. geringe Innova- } \\
\text { tionsbereitsschaft }\end{array}$ \\
\hline $\begin{array}{l}\text { Industrie- } \\
\text { bzw. Dienst- } \\
\text { leistungsun- } \\
\text { ternehmen }\end{array}$ & $\begin{array}{l}\text { - Aufsichtsratsmandate } \\
\text { - direkten Kontakt zum } \\
\text { Management }\end{array}$ & $\begin{array}{l}\text { - Gute Marktkenntnis, } \\
\text { sofern branchenver- } \\
\text { wandt } \\
\text { - Ggf. vertikale Integra- } \\
\text { tion und Transakti- } \\
\text { onskostensenkung }\end{array}$ & $\begin{array}{l}\text { Eigennützige Ver- } \\
\text { tragsgestaltung, sofern } \\
\text { Geschäftsbeziehung }\end{array}$ \\
\hline $\begin{array}{l}\text { Finanzin- } \\
\text { termediäre }\end{array}$ & $\begin{array}{l}\text { - Aufsichtsratsmandate } \\
\text { - direkten Kontakt zum } \\
\text { Management } \\
\text { - gegenseitige Abhän- } \\
\text { gigkeiten } \\
\text { (Überkreuzver- } \\
\text { flechtung) }\end{array}$ & $\begin{array}{l}\text { - Spezialisierungsvortei- } \\
\text { le bei der Bewertung } \\
\text { der VFE sowie ge- } \\
\text { planter Investitionen } \\
\text { und Strategien }\end{array}$ & $\begin{array}{l}\text { - Verquickung unter- } \\
\text { schiedlicher Interessen } \\
\text { (Aktionärs- und Gläu- } \\
\text { bigerstellung, Depot- } \\
\text { stimmrecht) } \\
\text { - Risikoaverse Investiti- } \\
\text { onspolitik }\end{array}$ \\
\hline $\begin{array}{l}\text { Manage- } \\
\text { ment }\end{array}$ & $\begin{array}{l}\text { - Gestaltung der opera- } \\
\text { tiven und strategischen } \\
\text { Entscheidungen }\end{array}$ & $\begin{array}{l}\text { - Anreiz zur Steigerung } \\
\text { des Marktwerts auf- } \\
\text { grund von Interessen- } \\
\text { kongruenz } \\
\text { - Konflikt aus } \\
\text { traditioneller } \\
\text { Principal-Agent- } \\
\text { Beziehung geht zurück }\end{array}$ & $\begin{array}{l}\text { - Nutzung insbesondere } \\
\text { nicht-pekuniärer Ver- } \\
\text { günstigungen } \\
\text { - Großer Kapitalanteil } \\
\text { verhindert effektive } \\
\text { Kontrollausübung } \\
\text { durch andere Aktionä- } \\
\text { re }\end{array}$ \\
\hline $\begin{array}{l}\text { Öffentliche } \\
\text { Haushalte }\end{array}$ & - Aufsichtsratsmandate & $\begin{array}{l}\text { - Sicherstellung einer } \\
\text { gesetzmäßigen Ge- } \\
\text { schäftsführung des } \\
\text { Managements }\end{array}$ & $\begin{array}{l}\text { - i.d.R. hohes Maß an } \\
\text { Regulierung und damit } \\
\text { mangelnder Flexibili- } \\
\text { tät }\end{array}$ \\
\hline
\end{tabular}

Tab. 6: Anreizstrukturen alternativer Großaktionärstypen

Die Übersicht macht deutlich, dass die verschiedenen Großaktionärstypen aus Sicht der Kleinaktionäre in jeweils unterschiedlichem Maße Aktionärskontrolle 
ausüben bzw. private benefits realisieren können. ${ }^{573}$ Dennoch sind auch innerhalb der einzelnen Großaktionärstypen Unterschiede in der Kontrollausübung zu erwarten. Einen wirksamen Beitrag zur Minderung der Agency-Kosten und damit zur Steigerung des Unternehmenswertes wird ein einzelner Großaktionär immer dann leisten können, wenn folgende Kriterien möglichst vollständig erfüllt sind:

- Der Kapitalanteil ist groß genug, um dem Großaktionär einen ausreichenden monetären Anreiz zur Ausübung der Monitoringfunktion zu gewährleisten.

- Verflechtungen aus Lieferungen und Leistungen bzw. sonstigen Vertragsbeziehungen, die Ansatzpunkte zur Realisierung von private benefits bieten, sind gering.

- Der Großaktionär verfügt über entsprechendes Know-how zur Ausübung der Monitoringfunktion.

- Die (persönlichen) Verflechtungen zwischen Management und Großaktionär sind ebenso gering wie Abhängigkeiten etwa aus Überkreuzbeteiligungen.

- Der Großaktionär vertritt keine divergierenden Interessen in der Gesellschaft.

- Die Möglichkeit der persönlichen Vorteilsnahme durch das handelnde Individuum ist gering. ${ }^{574}$

Im Rahmen der Hypothesenbildung wird daher zu überprüfen sein, inwieweit die formulierten Kriterien am deutschen Kapitalmarkt erfüllt sind.

\subsection{Aktionärskontrolle bei fehlender Kongruenz von Stimm- und Cash- Flow-Rechten}

\subsubsection{Theorie zur Anreizwirkung unterproportionaler Cash-Flow-Rechte}

Im Rahmen der vorangegangenen Analyse wurde unterstellt, dass den Stimmrechtsanteilen des Aktionärs, die ihm eine Ausübung von Aktionärskontrolle ermöglichen, in gleichem Maße Kapitalanteile gegenüberstehen und somit eine Kongruenz von Stimm- und Cash-Flow-Rechten besteht. Tatsächlich müssen

573 Hinsichtlich der verschiedenen Anreize vgl. beispielsweise Shleifer/Vishny (1997), S. 771-773; Blies (2000), S. 73f., 100-108; Bessler/Kurth/Thies (2001), S. 233-235; Cronqvist/Nilsson (2002), S. 7f.; Ayres/Cramton (1994), S. 1061-1063; Coffee (1991), S. 1321-1323; Bainbridge (1995), S. 711-728; Ehrhardt/Nowak (2002).

574 Im Vergleich z.B. zu Mitgliedern der Gründerfamilie hat das Management beteiligter Unternehmen i.d.R. keinen persönlichen Vorteil aus einer das beteiligte Unternehmen begünstigenden Vertragsgestaltung, da aus der Ertragssteigerung des beteiligten Unternehmens in der Regel kein individueller Vorteil für den handelnden Akteur resultiert. Entsprechend ist der individuelle Anreiz geringer, private benefits zu realisieren. Vgl. Cronqvist/Nilsson (2002), S. 8. 
diese Rechte jedoch nicht immer übereinstimmen. So führen die Emission von Vorzugsaktien oder Aktien mit Mehrfachstimmrechten und die Bildung von Eigenkapitalpyramiden dazu, dass einzelne Aktionäre über Stimmrechte verfügen, die über ihren Kapitalanteil hinausgehen. ${ }^{575}$

Die oben geschilderte Interessenkonvergenzhypothese geht von einer Senkung der Agency-Kosten durch die Bildung von Stimmrechtsblöcken aus. ${ }^{576} \mathrm{Ihr}$ Grundgedanke ist, dass sich der Großaktionär im Interesse aller Aktionäre als Überwacher des Managements engagiert. Die Anreize für ein effizientes Monitoring resultieren jedoch nicht aus den Kontrollrechten selbst sondern aus den damit einhergehenden Cash-Flow-Ansprüchen. ${ }^{577}$ Gerade diese sind jedoch nicht vorhanden, wenn der Aktionär zwar große Stimmrechtsanteile hält, denen jedoch nicht in gleichem Maße Kapitalanteile gegenüberstehen. ${ }^{578}$ Ein Aktionär mit deutlich unterproportionalen Cash-Flow-Rechten wird sich nicht als aktiver Managementkontrolleur engagieren, obwohl er aufgrund seines Stimmrechtsanteils die Möglichkeit hätte, sofern er alternativ die Möglichkeit hat, private benefits zu realisieren. ${ }^{579}$ Während ihm diese vollständig zugute kommen, profitiert er an den positiven Rückflüssen aus eventuellen Monitoringaktivitäten noch nicht einmal in Höhe seiner Stimmrechte sondern nur in Höhe seines geringeren Kapitalanteils. Sofern der kontrollierende Aktionär über die Stimmrechtsmehrheit verfügt, kann er zudem Übernahmen verhindern; sodass die Funktion des Marktes für Unternehmenskontrolle außer Kraft gesetzt wird. ${ }^{580}$

Der positive Einfluss solcher Stimmrechtsblöcke, die durch eine Abkehr vom Prinzip des „One-Share-One-Vote“ zustande gekommen sind, ist demnach geringer einzuschätzen als der, der sich durch die unmittelbare Kapitalbeteiligung in gleicher Höhe ergibt. ${ }^{581}$ Entsprechend ist die Gefahr der Ausbeutung durch die beherrschenden Aktionäre für Eigenkapitalgeber ohne bzw. mit einge-

575 Vgl. insbesondere die Beiträge von Bianchi/Bianco/Enriques (2001); Bebchuk/Kraakman/Triantis (2000); Claessens et al. (1999); Halpern (2000), S. 32-35; Cronqvist/Nilsson (2002), S. 28; Lemmon/Lins (2003).

576 Wobei Stimmrechtsblöcke hier mit Kapitalblöcken identisch sind. Vgl. Kapitel III.2.2.1.1.

577 Vgl. zur Bedeutung des One-Share-One-Vote-Prinzips insbesondere die grundlegenden Arbeiten von Grossman/Hart (1988), sowie Harris/Raviv (1988a).

578 Vgl. Bebchuk (1999), S. 28f.; Shleifer/Vishny (1997), S. 754; Gerson/Barr (1996), S. 79; Ehrhardt/Nowak (2002a), S. 27.

579 Vgl. Zingales (1994), S. 126f.; Cronqvist/Nilsson (2002), S. 6f.; Bergström/Rydqvist (1990), S. 255f.; Faccio/Lang/Young (2001), S. 56f.

580 Vgl. Halpern (2000), S. 31; Becht (1997), S. $24 f$.

581 Vgl. Becht (1997), S. 24; Berglöf (1997), S. 116; Claessens et al. (1999), S. 3; La Porta et al. (2002). 
schränktem Stimmrecht größer als für Minderheitsaktionäre mit normalem Stimmrecht. ${ }^{582}$ Harris und Raviv prägen in diesem Zusammenhang den Begriff der „cheap votes“, der den Erwerb solcher Unternehmensanteile repräsentiert, die zwar die Ausübung von Kontrolle ermöglichen, jedoch nur unterproportional auf eine Änderung der Cash Flows aufgrund schlechten Managements reagieren und daher potenziellen Erwerbern einen Anreiz zur Minderung des Shareholder Value bieten. ${ }^{583}$

Für die Situation unterproportionaler Cash-Flow-Rechte kann die grafische Argumentation aus den vorangegangenen Kapiteln fortgeführt werden, auf der Abzisse wird nun der Stimmrechtsanteil (StA) abgetragen.

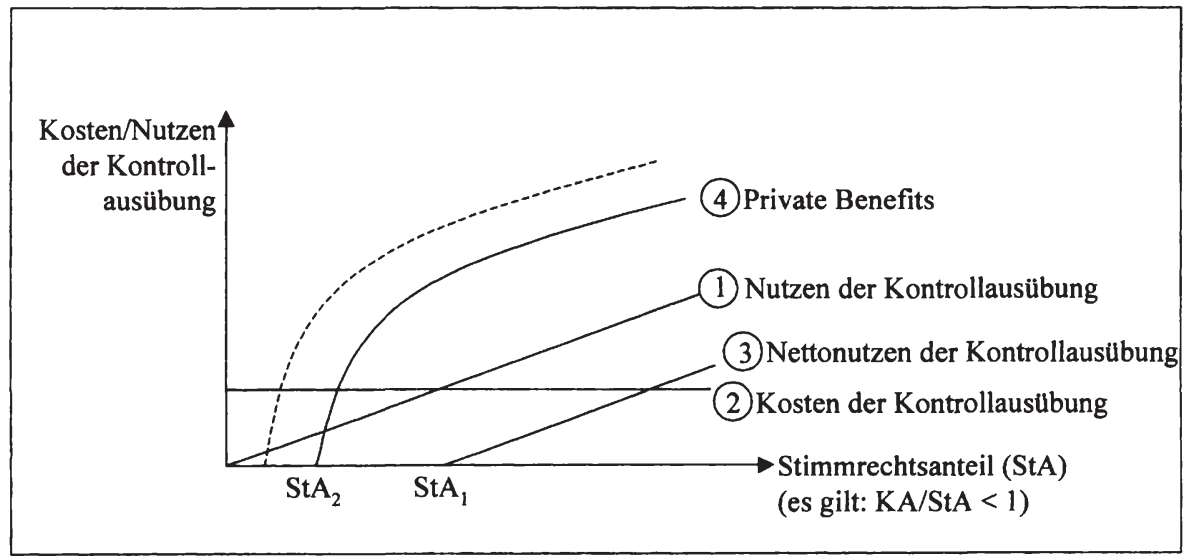

Abb. 15: Kontrollausübung unter Berücksichtigung abweichender Stimmrechte

Aufgrund der unterproportionalen Beteiligung an Dividenden und Kurssteigerungen verläuft die Nutzenkurve die sich aus der Kontrollausübung ergibt flacher als im Ausgangsszenario. Die Kosten der Kontrollausübung sowie der Verlauf der private-benefits-Kurve sind hingegen unverändert. Es gibt daher in dem gewählten Beispiel keinen Stimmrechtsanteil, bei dem es aus Sicht des Großaktionärs sinnvoller ist, Aktionärskontrolle auszuüben anstatt private benefits zu generieren.

Im Ergebnis erscheint somit die Gefahr der Ausbeutung von Minderheitsaktionären um so größer, je kleiner das Verhältnis von Cash-Flow- zu Stimmrechten ist. Um die Relevanz einer solchen fehlenden Kongruenz von Kapital- und

582 Vgl. Shleifer/Vishny (1997), S. 758; Gugler (2001), S. 26-28; Goergen (1998), S. 13; Bebchuk/Kraakman/Triantis (2000), S. 301-305.

583 Vgl. Harris/Raviv (1989), S. 256. Vgl. ebenda, S. 262-267, für den theoretischen Nachweis der Optimalität der One-Share-One-Vote-Struktur, sowie jüngst Maug/Yilmaz (2003). 
Stimmrechtsanteil zu verdeutlichen, wird im Folgenden ein Überblick über die alternativen Ursachen gegeben.

\subsubsection{Ursachen für das Auseinanderfallen von Stimm- und Cash-Flow- Rechten}

Stimmrechts- und Kapitalanteil fallen immer dann auseinander, wenn entweder Aktien nicht mit Stimmrechten ausgestattet sind (Vorzugsaktien), Stimmrechte nur eingeschränkt genutzt werden können (Höchststimmrechte), überproportionale Stimmrechte an eine Aktie gekoppelt sind (Mehrfachstimmrechte) oder durch pyramidenartige Konzernstrukturen über den investierten Kapitalanteil hinaus Stimmrechte genutzt werden können. ${ }^{584}$ Im Folgenden soll dargestellt werden, wie die Abweichung vom Prinzip des „One-Share-One-Vote“ im Einzelfall zustande kommt. Mehrfach- und Höchststimmrechte sollen als grundsätzlich anwendbare Mechanismen zur Trennung von Kapital- und Stimmrechtsanteil ebenfalls knapp berücksichtigt werden, wenngleich sie am deutschen Kapitalmarkt für börsennotierte Aktiengesellschaften nicht mehr zulässig sind.

\subsubsection{Vorzugsaktien}

Vorzugsaktien beinhalten nur einen Teil der typischen Aktionärsrechte, da sie zwar Vermögensrechte, nicht jedoch das Stimmrecht auf der Hauptversammlung verbriefen. Die Ausübung von Aktionärskontrolle ist damit für die Inhaber von Vorzugsaktien regelmäßig nicht möglich. ${ }^{585}$ Aus Sicht eines kontrollierenden Aktionärs ist die Emission von Vorzugsaktien vorteilhaft, da er die Mehrheit der Stimmrechte halten und gleichzeitig dem Unternehmen neues Kapital zuführen kann. ${ }^{586}$ Aus kontrolltheoretischer Sicht ist jedoch entscheidender, dass eine gespaltene Aktionärsstruktur die Ausübung von Kontrolle mit einem unterproportionalen Kapitalanteil ermöglicht. ${ }^{587}$ Die folgende Abb. 16 verdeutlicht das am Beispiel der Fresenius Medical Care AG. Die Fresenius AG hält zwar nur $37,1 \%$ des Eigenkapitals, da jedoch $27 \%$ Vorzugsaktien ohne Stimmrecht aus-

584 Vgl. auch Becht (1997), S. 94-98; Bianchi/Bianco/Enriques (2001); Bebchuk/Kraakman/Triantis (2000); Halpern (2000), S. 32-35; Cronqvist/Nilsson (2002), S. 28.

585 Als Entschädigung für einen Verzicht auf ihr Stimmrecht erhalten die Vorzugsaktionäre in der Regel einen kumulativen Dividendenvorteil. Vgl. zur rechtlichen Ausgestaltung von Vorzugsaktien ausführlich Abschnitt II.2.2.4.2 dieser Arbeit sowie Pellens/Hillebrandt (2001), S. 58f. m.w.N.

586 Vgl. Halpern (2000), S. 34; Smart/Zutter (2000), S. 5.

587 Vgl. Zingales (1994), S. 126; Nicodano/Sembenelli (2000), S. 22; Bergström/Rydqvist (1990), S. 255f. Vgl. zur Wirkung von Vorzugsaktien auf die Anreizstruktur der Stammaktionäre außerdem Zingales (1995); Bebchuk/Kraakman/Triantis (2000), sowie ausführlich Ehrhardt/Nowak (2002). 
stehend sind, verfügt sie mit diesem Kapitalanteil bereits über eine Stimmrechtsmehrheit von $50,8 \%$.

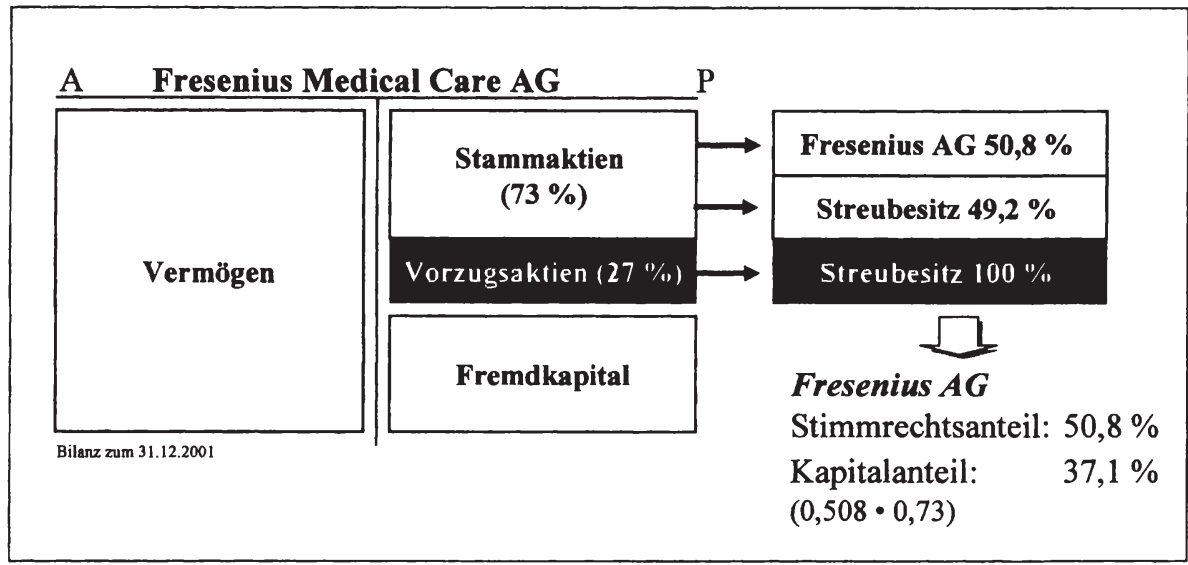

Abb. 16: Wirkung von Vorzugsaktien auf die Aktionärskontrolle ${ }^{588}$

Aus Sicht eines kontrollierenden Aktionärs ist es somit in jedem Fall sinnvoll, an einer gespaltenen Aktionärsstruktur festzuhalten. ${ }^{589}$ Er kann seine privaten Vorteile realisieren, ohne die vollen ökonomischen Konsequenzen seiner unternehmenswertmindernden Handlungen tragen $\mathrm{zu}$ müssen. ${ }^{590}$ Wie groß der ökonomische Wert ist, der dem Stimmrecht beigemessen wird, wird evident, wenn man die unterschiedliche Bewertung von Stamm- und Vorzugsaktien am Kapitalmarkt betrachtet. Der durchschnittliche Kursabschlag der Vorzugs- gegenüber den Stammaktien liegt in Deutschland bei etwa $16 \%{ }^{591}$ Die Marktteilnehmer messen somit offensichtlich dem mit der Stammaktie verbundenen Stimmrecht einen größeren Wert bei als dem mit der Vorzugsaktie verbundenen Dividendenvorteil. ${ }^{592}$ Im Ergebnis kann der positive Effekt aus einer Stimmrechtsbünde-

588 Daten entnommen aus Geschäftsberichten zum 31.12.2001.

589 Vgl. Halpern (2000), S. 32f.; Zingales (1995), S. 1047; Smart/Zutter (2000), S. 24. Entsprechend belegen Ang/Megginson, dass nachdem einmal zwei Aktiengattungen am Markt notieren, in der Regel nur noch Vorzugsaktien emittiert werden. Vgl. Ang/Megginson (1989), S. 303.

590 Vgl. Bebchuk/Zingales (2000), S. 58f.; Muus (1998), S. 2; Bebchuk/Kraakman/Triantis (2000), S. 195f.; Bergström/Rydqvist (1990), S. 255f. Analoge Anreize wie für externe Großaktionäre ergeben sich auch für Manager mit Aktienbesitz. Vgl. grundlegend DeAngelo/DeAngelo (1985).

591 Sample: 55 Nicht-Finanzdienstleister aus dem CDAX, Stichtag 21.7.2002. Vgl. ähnlich Daske/Ehrhardt (2002), S. 17, sowie Hoffmann-Burchardi (1999), S. 3; Doerks (1992). Vgl. außerdem Muus (1998), S. 39; Zingales (1994), S. 126; Chung/Kim (1999).

592 Vgl. zur unterschiedlichen Bewertung verschiedener Aktiengattungen mit einem Überblick über empirische Studien ausführlich Pellens/Hillebrandt (2001), S. 62-64. 
lung im Falle einer gespaltenen Aktionärsstruktur nur sehr begrenzt oder gar nicht zum Tragen kommen, die Gefahr der Ausbeutung von Minderheitsaktionären ist hingegen groß; ,,agency costs are higher for dual-class firms“ ${ }^{\text {“593. Dass }}$ Vorzugsaktien in der Praxis primär von Großaktionären zum Ausbau ihres Einflusses genutzt werden, bestätigt auch die Studie von Becht/Böhmer, die nachweisen, dass Unternehmen, die Vorzugsaktien emittiert haben, eine signifikant größere Blockbildung aufweisen als Unternehmen mit nur stimmberechtigtem Eigenkapital. $^{594}$

Ein grundsätzlich vergleichbarer Effekt wie durch die Emission von Vorzugsaktien ergibt sich in der Rechtsform der $\mathrm{KGaA} .{ }^{595}$ Die Kommanditaktionäre stellen Eigenkapital zur Verfügung, haben jedoch im Vergleich zu Aktionären in Aktiengesellschaften deutlich geringere Einflussmöglichkeiten. So werden die Komplementäre nicht durch den Aufsichtsrat bestellt und abberufen sondern durch die Satzung bestimmt. Beschlüsse der Hauptversammlung bedürfen zudem der Zustimmung der Komplementäre ( $\$ 285$ Abs. 2 AktG). ${ }^{596}$ Der ohnehin schon geringe Einfluss der Kommanditaktionäre kann zusätzlich beschnitten werden, wenn die Aktiengesellschaft der $\mathrm{KGaA}$ zwei Aktiengattungen emittiert und die Vorzugsaktien an die Streubesitzaktionäre ausgegeben werden, während die Stammaktien in den Händen der Komplementäre verbleiben.

\subsubsection{Eigenkapitalpyramiden}

Ein Abweichen von Kontroll- und Cash-Flow-Rechten kann auch ohne bewusste Gestaltung der Beteiligungstitel durch das Unternehmen realisiert werden, indem Eigenkapitalpyramiden gebildet werden. ${ }^{597}$ Durch die Schaffung verschachtelter Konzernstrukturen gelingt es dem an der Spitze der Konzernpyramide stehenden Investor über viele Unternehmen maßgeblichen Einfluss zu erlangen,

593 Jensen/Warner (1988), S. 10.

594 Vgl. Becht/Böhmer (1999), S. 3, sowie Bebchuk (1999), S. 37. Ehrhardt/Nowak (2002) weisen die Nutzung von Vorzugsaktien insbesondere durch Familienunternehmen nach, die sie nutzen, um auch nach dem IPO die Kontrollmehrheit zu halten.

595 Die Rechtsform der KGaA ist geregelt in $§ 278-290$ AktG. Vgl. zum Recht der KGaA Raiser (2001), S. 359-392; Heße/Enders (2001), S. 235; Jansch (1999), S. 54-56, sowie ausführlich Ammenwerth (1997).

596 Vgl. Raiser (2001), S. 375.

597 Zur Pyramidenbildung grundlegend Schierenbeck (1980); Jörs (2002); theoretisch Wolfenzon (1999); empirisch Bianchi/Bianco/Enriques (2001); Bebchuk/Kraakman/Triantis (2000); Becht/Chapelle/Renneboog (2001). 
ohne in jedes einzelne der Unternehmen direkt zu investieren. ${ }^{598}$ Er reduziert somit seine erforderliche Investitionssumme und teilt das Risiko mit den Minderheitsaktionären. ${ }^{599}$ Zudem ermöglicht ihm das so genannte „tunneling“, z.B. durch Gestaltung von Verrechnungspreisen, das Verschieben von Cash Flows aus Unternehmen, in denen er nur geringe Cash-Flow-Rechte hat, in solche, an denen er einen hohen Kapitalanteil hält. ${ }^{600}$ Aus Sicht des kontrollausübenden Aktionärs kann zudem von Vorteil sein, dass seine Beteiligung durch die Zwischenschaltung einer Tochtergesellschaft anderen Namens nicht unmittelbar evident wird. ${ }^{601}$

Das folgende Beispiel zeigt die Wirkung einer Eigenkapitalpyramide. Während die RWE AG an der Leighton Holdings Ltd. indirekt über die Hochtief AG nur $31,2 \%$ des Kapitals hält, hat sie, da sie die Entscheidungen des Hochtief Managements beeinflussen kann, Kontrolle über die Stimmrechtsmehrheit. Siedeln sich unterhalb der Hochtief AG sowie unterhalb der dritten Ebene (Leighton Holdings Ltd.) weitere Tochtergesellschaften an, so ermöglicht die einmalige Mehrheitsbeteiligung der RWE AG an Hochtief die Einflussnahme auf (theoretisch) unbegrenzt viele Gesellschaften ohne weiteren Kapitalzufluss.

Im Rahmen des Beispiels ist eine Beeinflussung der untergeordneten Pyramidenebenen aufgrund des Kapitalanteils von jeweils über $50 \%$ zweifellos durchsetzbar. In der Praxis wird ein solcher aufgrund geringer Hauptversammlungspräsenzen jedoch auch bereits bei geringeren Kapitalanteilen möglich sein, wenngleich dies aus Sicht des kontrollierenden Aktionärs schlecht planbar ist.

598 Neben der Ausübung von Kontrolle ist die Steigerung der Eigenkapitalrendite bzw. die Ausnutzung zusätzlicher Finanzierungsspielräume durch die Steigerung des Konzernverschuldungsgrads häufiges Ziel bei der Bildung pyramidenartiger Konzernstrukturen. Vgl. Schierenbeck (1980), S. 253f.; Pellens (1994), S. 162-167; Schenk (1997a), S. 140-146; Jörs (2002), S. 91.

599 Vgl. Pellens (1994), S. 162; Schenk (1997a), S. 140; Aganin/Volpin (1998), S. 11f.; Wolfenzon (1999), S. 4.

600 Vgl. zum so genannten „tunneling“ Johnson et al. (2000); Bertrand/Mehta/Mullainathan (2002). Der willkürlichen Gestaltung von Verrechnungspreisen sind durch das „Arm's length-Prinzip“ durch den Gesetzgeber jedoch Grenzen gesetzt. Vgl. Treu/Sidler (2000), S. 352.

601 Vgl. bereits Schierenbeck (1980), S. 249, sowie Schenk (1997a), S. 144; Aganin/Volpin (1998), S. 13; Wolfenzon (1999), S. 5. 


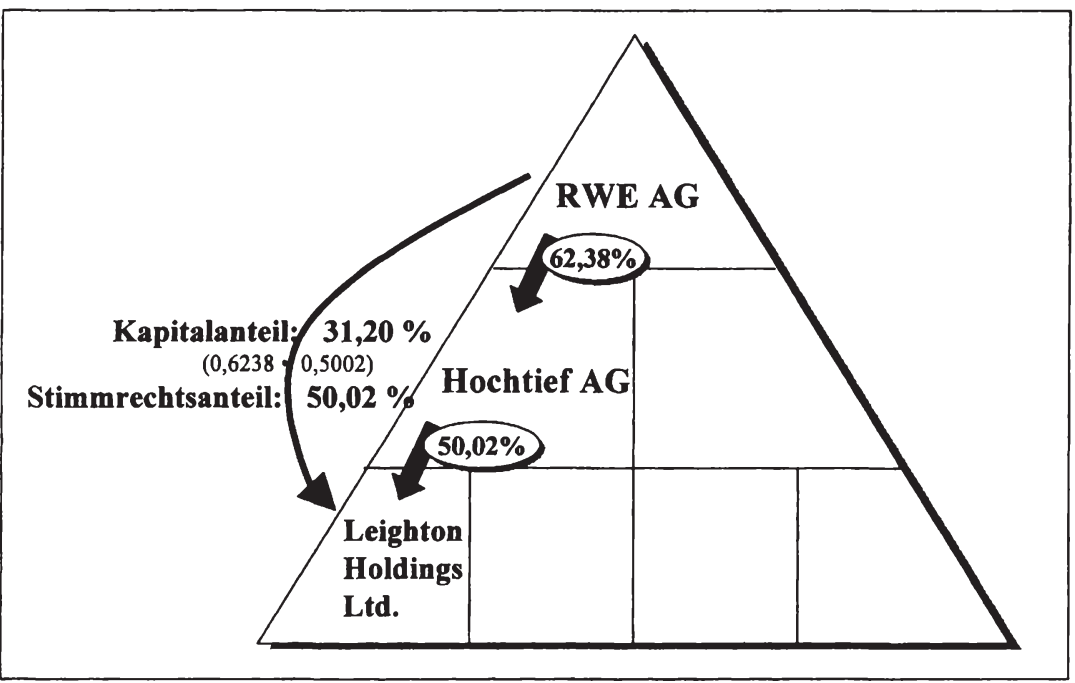

Abb. 17: Eigenkapitalpyramide am Beispiel der RWE $A G^{602}$

Die Auswirkung der Stimmrechtsbündelung durch Pyramidenbildung auf die Monitoringanreize des Kontrolle anstrebenden Aktionärs ist vergleichbar mit der durch Vorzugs- oder Mehrstimmrechtsaktien entstehenden Situation. ${ }^{603}$ Aufgrund nur begrenzt vorhandener finanzieller Anreize ist die Wahrscheinlichkeit, dass der kontrollausübende Aktionär private benefits realisiert, anstatt durch die Ausübung von Managementkontrolle den Unternehmenswert im Interesse aller Aktionäre zu steigern, deutlich größer als in Unternehmen mit kongruenten Stimm- und Cash-Flow-Rechten. ${ }^{604}$ Die negative Auswirkung überproportionaler Stimmrechte auf den Unternehmenswert sollte aufgrund der gegebenen Anreize um so größer sein, je stärker Stimm- und Cash-Flow-Rechte voneinander abweichen. ${ }^{605}$

Konzernpyramiden dominieren ebenso wie Vorzugsaktien in Ländern mit konzentrierten Aktionärsstrukturen, die eher schwach ausgeprägte Aktionärsschutz-

602 Daten entnommen aus Geschäftsberichten zum 31.12.2001.

603 Entsprechend treten sie auch in der Praxis häufig gemeinsam auf. Vgl. Nicodano (1998), S. 1131.

604 Vgl. Aganin/Volpin (1998), S. 2; Wolfenzon (1999), S. 3; Bebchuk/Zingales (2000), S. 56f.; Bebchuk/Kraakman/Triantis (2000); Pellens/Hillebrandt (2001), S. $61 \mathrm{f}$.

Vgl. Nicodano (1998), S. 1118f.; Wolfenzon (1999), S. 3. 
bestimmungen haben. ${ }^{606}$ Die Dominanz von Großaktionären in speziell diesen Ländern wird in der Literatur häufig damit begründet, dass sie die Kontrollfunktion des Marktes für Unternehmenskontrolle substituieren. ${ }^{607}$ Die Tatsache, dass dieses parallel mit der Separation von Stimm- und Cash-Flow-Rechten einhergeht, könnte jedoch eher die Hypothese stützen, dass es Großaktionären in diesen Ländern besonders leicht ist, private benefits zu realisieren.

\subsubsection{Sonstige Ursachen}

Ebenso wie Vorzugsaktien weichen auch Mehrfach- und Höchststimmrechte vom Prinzip des One-Share-One-Vote ab. Höchststimmrechte sind Satzungsregelungen, die bestimmen, dass unabhängig von der Höhe des Kapitalanteils eines Aktionärs Stimmrechte maximal bis zu einem bestimmten Anteil ausgeübt werden dürfen. ${ }^{608}$ Die Festlegung eines Höchststimmrechtes in der Satzung führt dazu, dass selbst Großaktionäre, die aufgrund ihres Kapitalanteils ausreichenden Anreiz zur Ausübung von Managementkontrolle hätten, ihre Kontrollfunktion nicht wirksam ausüben können. Mit der Kodifizierung von Höchststimmrechten in der Satzung wird daher zwar die Generierung von private benefits seitens einzelner Großaktionäre verhindert, gleichzeitig besteht jedoch die Gefahr der Ausbeutung durch ein opportunistisches, nicht mehr $\mathrm{zu}$ kontrollierendes Management. In der Bundesrepublik Deutschland sind Höchststimmrechte seit In-KraftTreten des KonTraG am 1. Mai 1998 auf nicht-börsennotierte Aktiengesellschaften beschränkt. ${ }^{609}$

Mehrfachstimmrechte durchbrechen das Prinzip des One-Share-One-Vote dahingehend, dass eine Aktie mehr als ein Stimmrecht besitzt. ${ }^{610}$ Von ihrer Wirkung her sind Mehrstimmrechtsaktien aus Sicht des Kontrolle anstrebenden Aktionärs vergleichbar mit der Emission von Vorzugsaktien, die ebenfalls zu einer

606 Vgl. La Porta et al. (1999), S. 498-502, den Sammelband von Barca/Becht (2001) mit einem Überblick über Europa sowie den theoretischen Nachweis bei Wolfenzon (1999), S. 3. Die große Bedeutung von abweichenden Stimm- und Cash-Flow-Rechten insbesondere in Ländern mit schwächerem Aktionärsschutz wird durch verschiedene Studien empirisch bestätigt, vgl. Gugler/Stomper/Zechner (2000) für Österreich; Zingales (1994); Aganin/Volpin (1998) für Italien; Lins (2003) für verschiedene Entwicklungsländer; Claessens et al. (1999) für Ostasien; La Porta et al. (2002) für verschiedene Industriestaaten.

607 Vgl. beispielhaft Shleifer/Vishny (1997), S. 769.

608 Vgl. Adams (1990); Zöllner/Noack (1991); Cahn (1997), S. 504-506.

609 Vgl. § 134 Abs. 1 AktG; Baums/Schmitz (1998), S. 21, zur Verbreitung vor der Abschaffung Becht/Böhmer (2001), S. 133f.

610 Vgl. Adams (1990); Kluth (1997); Saenger (1997); Gerster (1997). Mehrstimmrechte dienen von ihrer Intention her der Verhinderung feindlicher Übernahmen. Vgl. Saenger (1997), S. 1813; Hering/Olbrich (2001), S. 20. 
überproportionalen Stimmrechtsbündelung in den Händen der Stammaktionäre führt. ${ }^{611}$ Dementsprechend ergibt sich die bereits diskutierte Gefahr, dass der stimmrechtsdominante Aktionär aufgrund unzureichender Monitoringanreize die Realisierung von private benefits einer Ausübung der Kontrollfunktion vorzieht. ${ }^{612}$ Mehrfachstimmrechte sind seit 1998 in Deutschland ebenfalls nicht mehr zulässig; sie wurden in der Vergangenheit insbesondere von Versorgern genutzt. $^{613}$

Von der Wirkung her vergleichbar mit dem Auseinanderfallen von Stimm- und Cash-Flow-Rechten ist die Schaffung von Überkreuz- bzw. Ringverflechtungen. Sind zwei Unternehmen aneinander unmittelbar (Überkreuzverflechtung) oder mittelbar über Zwischenschaltung weiterer Unternehmen (Ringverflechtung) beteiligt, liegt eine Verflechtung auf horizontaler Ebene vor. ${ }^{614}$ Bei dieser Art von Verflechtung entsprechen sich Kapital- und Stimmrechtsanteil zunächst grundsätzlich. Durch die wechselseitige Beteiligung halten die Gesellschaften jedoch jeweils einen Teil ihres eigenen Kapitals. Durch die gegenseitige Einflussmöglichkeit ist die Wahrscheinlichkeit erhöht, dass keine wirksame Kontrolle ausgeübt wird. ${ }^{615}$ Einschränkend greift jedoch die Regelung des $\S 328$ AktG, die die Ausübung der Stimmrechte auf $25 \%$ beschränkt (Abs. 1) und wechselseitig beteiligte Unternehmen von der Wahl der Anteilseignervertreter in den Aufsichtsrat ausschließt (Abs. 3). Die Bedeutung von wechselseitigen Beteiligungen am deutschen Kapitalmarkt ist weniger groß als oft vermutet. Beyer stellt in seiner Untersuchung deutscher Eigentümerstrukturen fest, dass Überkreuz- und Ringverflechtungen ,nur von einer eng begrenzten Anzahl von Unternehmen geknüpft“ ${ }^{616}$ werden. Es seien lediglich $1,0 \%$ der Unternehmen in

611 Nicodano (1998) belegt, dass verschiedene Instrumente zur Abspaltung der Stimmrechte von den Cash-Flow-Rechten in der Praxis häufig gemeinsam genutzt werden.

$612 \mathrm{Zu}$ Problemen von Mehrstimmrechtsaktien vgl. ausführlich Gerster (1997), S. 35-59.

613 Für die Emission von Mehrstimmrechtsaktien war auch vor dem KonTraG eine Ministererlaubnis erforderlich. Vgl. Hering/Olbrich (2001), S. 20f., für einen historischen Überblick in Deutschland. Vgl. außerdem Zöllner/Noack (1991), S. 117; Saenger (1997), S. 1813; Baums/Schmitz (1998), S. 21; Marsch-Barner (1999); Becht/Böhmer (2001), S. 134. Vereinzelt existieren noch Ausnahmeregelungen, wie etwa das so genannte „VWGesetz", das dem Land Niedersachsen die Kontrolle über die Volkswagen AG garantiert, obwohl das Land nur knapp 20 \% des Aktienkapitals hält. Das jüngste EU-Verbot von so genannten ,goldenen Aktien“ könnte jedoch auch hier zu einer Abschaffung führen. Vgl. o.V. (2002), S. 1.; o.V. (2003b), S. 6.

614 Vgl. Adams (1994), S. 149; Beyer (1998), S. 87. § 19 Abs. 1 AktG definiert die wechselseitige Beteiligung und setzt eine gegenseitige Mindestbeteiligung von $25 \%$ voraus.

615 Vgl. Beyer (1998), S. 86f.; Becht/Böhmer (1999), S. 16; Geldmacher (2000), S. 211; Ritzberger/Shorish (2002), S. 18.

616 Beyer (1998), S. 99, sowie Beyer (1996), S. 90f. 
Überkreuz- und 3,2\% der Unternehmen in Ringverflechtungen eingebunden. Nach den Ergebnissen von Köke sind sogar nur 1,3\% der Unternehmen in eine wechselseitige Beteiligung eingebunden. ${ }^{617}$

\subsubsection{Bedeutung unterproportionaler Cash-Flow-Rechte}

Die vorangegangenen Ausführungen machen deutlich, dass je nach Ausgestaltung der Eigenkapital- und Stimmrechtsstrukturen Blockbildungen einen Beitrag zur Minderung der Agency-Kosten zwischen Management und Anteilseignern leisten können oder aber zur Schaffung neuer Agency-Kosten zwischen Aktionärsgruppen beitragen. Die folgende Abb. 18 gibt einen Überblick über die aus alternativen Strukturmodellen resultierenden Konfliktebenen.

Für den im Rahmen der folgenden empirischen Untersuchung zu betrachtenden deutschen Kapitalmarkt sind die Quadranten I, II und IV grundsätzlich relevant. Da jedoch breit gestreute Unternehmen (Quadrant I) eher selten sind, liegt der Schwerpunkt der Analyse auf Quadrant IV sowie insbesondere auf Quadrant II, da die Auswirkungen von divergierenden Stimm- und Cash-Flow-Rechten auf die Performance für den deutschen Kapitalmarkt bisher nicht untersucht wurde.

617 Vgl. Köke (2001), S. 281. 


\begin{tabular}{|c|c|c|}
\hline & Stimmrechte im Streubesitz & Stimmrechtsbündelung \\
\hline $\begin{array}{c}\text { Kapital } \\
\text { im } \\
\text { Streu- } \\
\text { besitz } \\
\text {. }\end{array}$ & $\begin{array}{l}\text { I } \\
\text { Situation: } \\
\text { - Geringe Blockbildungen } \\
\text { - Funktionsfähige Kapitalmärkte } \\
\text { Vorteile: } \\
\text { - Hohe Liquidität } \\
\text { - Diversifikationsmöglichkeiten } \\
\text { - Aktiver Markt für Unternehmens- } \\
\text { kontrolle möglich } \\
\text { Nachteile: } \\
\text { - Eigentümer-Manager-Konflikt } \\
\text { => kein direktes Monitoring } \\
\text { - Free-Rider-Problem }\end{array}$ & $\begin{array}{l}\text { II } \\
\text { Situation: } \\
\text { - Vorzugsaktien } \\
\text { - Mehrfachstimmrechte } \\
\text { - Eigenkapitalpyramiden } \\
\text { Vorteile: } \\
\text { - Direktes Monitoring möglich } \\
\text { - Hohe Liquidität } \\
\text { - Diversifikationsmöglichkeiten } \\
\\
\text { Nachteile: } \\
\text { - Kontrollanreize aufgrund unterpro- } \\
\text { portionaler Cash-Flow-Rechte sehr } \\
\text { begrenzt } \\
\text { >> Gefahr von private benefits } \\
\text { - Konflikt zwischen kontrollierendem } \\
\text { Aktionär und Minderheitsaktio- } \\
\text { nären }\end{array}$ \\
\hline $\begin{array}{c}\text { Kapital } \\
\text { konzen- } \\
\text { triert }\end{array}$ & $\begin{array}{l}\text { SiI } \\
\text { Situation: } \\
\text { • Höchststimmrechte } \\
\text { Vorteile: } \\
\text { - Schutz der Minderheitsaktionäre } \\
\text { durch Stimmrechtsbeschränkungen } \\
\text { Nachteile: } \\
\text { - Kein Anreiz, zu investieren } \\
\text { - Eigentümer-Manager-Konflikt } \Rightarrow> \\
\text { kein direktes Monitoring } \\
\text { - Geringe Liquidität } \\
\text { - Schlechte Diversifikation } \\
\text { - Schränkt Wirksamkeit des Kon- } \\
\text { trollmarkts ein }\end{array}$ & $\begin{array}{l}\text { IV } \\
\text { Situation: } \\
\text { - Kapital und Stimmrechte bei Groß- } \\
\text { aktionären konzentriert } \\
\text { Vorteile: } \\
\text { - Direktes Monitoring möglich } \\
\text { - Kontrollanreize gegeben } \\
\text { Nachteile: } \\
\text { - Kontrollanreize können durch An- } \\
\text { reiz zur Realisierung von private } \\
\text { benefits überkompensiert werden } \\
\text { - Intensive Kontrolle kann Initiative } \\
\text { des Managements hemmen } \\
\text { - Konflikt zwischen Groß- und } \\
\text { Kleinaktionären } \\
\text { - Geringe Liquidität } \\
\text { - Schlechte Diversifikation } \\
\text { - Schränkt Wirksamkeit des Kon- } \\
\text { trollmarkts ein } \\
\end{array}$ \\
\hline
\end{tabular}

Abb. 18: Ausprägungen von Kapital- und Stimmrechtsstruktur ${ }^{618}$

618 In Anlehnung an Becht (1997), S. 25. Ähnlich auch Gugler (2001), S. 5; Pellens/Hillebrandt (2001), S. 62. 
Im Ergebnis bleibt festzuhalten, dass die zwischen kontrollierenden Aktionären und Minderheitsaktionären bestehenden Agency-Probleme bei abweichenden Stimm- und Cash-Flow-Rechten von besonderer Bedeutung sind. Da die monetären Anreize zur Ausübung der Kontrollfunktion nur noch sehr eingeschränkt vorhanden sind, kommt der Interessenkonvergenzhypothese in diesem Szenario nur geringes Gewicht zu, die Anreize zur Realisierung privater Vorteile nehmen stattdessen zu.

\subsection{Theoretische Modellierung des Zusammenhangs zwischen Eigentii- merstruktur und Unternehmenserfolg}

\subsection{1 Überblick über theoretische Arbeiten zur Eigentümer- und Stimmrechtsstruktur}

Die zuvor verbal bzw. grafisch vorgestellte Argumentation wurde von verschiedenen Autoren durch modelltheoretische Arbeiten untermauert. $\mathrm{Zu}$ unterscheiden sind im Wesentlichen drei verschiedene Theoriestränge: (1) Arbeiten zur Anreizwirkung von Managementbeteiligungen, (2) Arbeiten zur Anreizwirkung von Beteiligungen sonstiger Großaktionäre sowie (3) Arbeiten zur Wirkung divergierender Stimm- und Cash-Flow-Rechte. Abb. 19 gibt einen komprimierten Überblick über die verschiedenen Forschungsrichtungen und ihre Autoren, ${ }^{619}$ Anhang A fasst die modellierten Anreize und die zentralen Ergebnisse der modelltheoretischen Studien in tabellarischer Form zusammen. Bei der hier gewählten überblickartigen Darstellung der verschiedenen Modelle ist zu berücksichtigen, dass die Herangehensweise an die Problemstellung zwischen den einzelnen Autoren teilweise stark divergiert. Verschiedene Arbeiten bilden die Anreize eines Entrepreneurs im Rahmen des IPO mit Hilfe von Zwei-ZeitpunktModellen ab, andere stellen auf die optimale Eigentümerstruktur aus Sicht aller Aktionäre $\mathrm{ab}$ oder modellieren das optimale private-benefit-Niveau aus Sicht des kontrollausübenden Aktionärs. Aufgrund der teilweise sehr unterschiedlichen analytischen Problemlösungsansätze bauen die einzelnen Modelle nur in Einzelfällen aufeinander auf und können nicht eindeutig auf einen gemeinsamen Grundlagenaufsatz zurückgeführt werden. Die Arbeiten hinsichtlich der Anreizwirkung von Managementbeteiligungen sind jedoch wesentlich beeinflusst durch die formale Analyse von Jensen/Meckling (1976); für die Beiträge zur theoretischen Modellierung der Beziehung zwischen einzelnen Aktionärsgruppen hat der Beitrag von Grossman/Hart (1980) zum Free-Rider-Problem ein wichtiges Fundament gelegt.

619 Einzelne Arbeiten werden in Abb. 19 verschiedenen Theoriesträngen zugeordnet, sofern sie entweder nicht eindeutig zuzuordnen sind oder mehrere Aspekte beleuchten. 


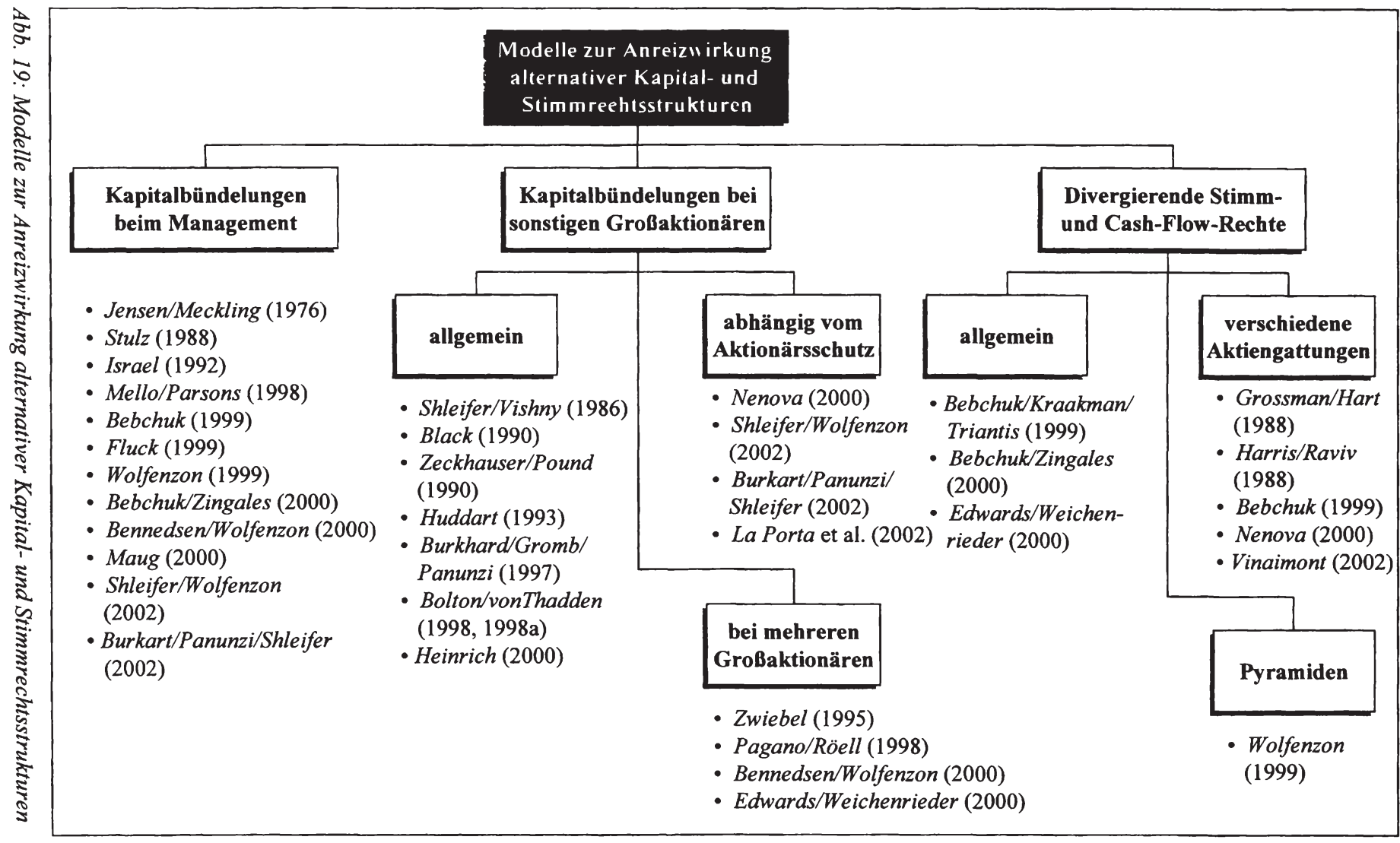


Die Arbeiten zur Anreizwirkung von Kapitalbündelungen beim Management gehen von einer Identität des Großaktionärs und des Managers aus und gehören somit der „managerial ownership theory“ an. Zentrales Thema der Analysen ist die Minderung des principal-agent-Konflikts zwischen Aktionären und Management aufgrund der Anreizwirkung des Managers aus seiner Kapitalbeteiligung. Der Manager sieht sich einem Trade-off zwischen persönlicher Bereicherung und dem reduzierten Cash-Flow-Zufluss aus der Kapitalbeteiligung gegenüber. Zusätzlich wird regelmäßig das Drohpotenzial eines Arbeitsplatzverlustes durch eine Übernahme in Folge übermäßiger Generierung von private benefits in die Modelle einbezogen. Handelnder Akteur vieler Arbeiten dieses Theoriestrangs ist ein Entrepreneur in der Entscheidungssituation, Teile oder sein ganzes Unternehmen im Rahmen eines IPO an weitere Aktionäre zu verkaufen. Beispiele hierfür sind die Arbeiten von Mello/Parsons (1998), Pagano/Röell (1998), Bebchuk (1999), Fluck (1999), Maug (2000) oder jüngst die Arbeiten von Burkart/Panunzi/Shleifer (2002) und Shleifer/Wolfenzon (2002). Die Ergebnisse der Modelle lassen im Regelfall keine eindeutige Aussage über die Vorteilhaftigkeit von Managementbeteiligungen zu, sie zeigen vielmehr UrsacheWirkungs-Beziehungen auf.

Einige der Modelle zur Kapitalbündelung bei externen Großaktionären unterstellen Interessenkonvergenz aller Aktionäre und untersuchen primär die Funktionsfähigkeit des Großaktionärs als Monitor des Managements [so z.B. Shleifer/Vishny (1986), Burkart/Gromb/Panunzi (1997), teilweise unter Berücksichtigung der Auswirkung auf die Liquidität (wie etwa Bolton/von Thadden (1998, 1998a), Heinrich (2000)]. Jüngere Modelle wie etwa das von La Porta et al. (2002) beziehen die Möglichkeit der Realisierung von private benefits durch den Großaktionär mit ein und untersuchen die Gefahr der privaten Vorteilnahme vor dem Hintergrund alternativer Aktionärsschutzbestimmungen [so z.B. Nenova (2000), Shleifer/Wolfenzon (2002), Burkart/Panunzi/Shleifer (2002)]. Zwiebel (1995), Pagano/Röell (1998), Bennedsen/Wolfenzon (2000) und Edwards/Weichenrieder (2000) modellieren die Auswirkungen verschiedener Minderheitsaktionäre mit vergleichbar großen Kapitalanteilen unter Berücksichtigung der gegenseitigen Disziplinierungswirkung.

Aufbauend auf den Arbeiten von Grossman/Hart (1988) und Harris/Raviv (1988) beschäftigen sich verschiedene modelltheoretische Ansätze mit den Auswirkungen divergierender Stimm- und Cash-Flow-Rechte. Neben den allgemeinen Arbeiten von Bebchuk/Kraakman/Triantis (2000), Bebchuk/Zingales (2000) und Edwars/Weichenrieder (2000) spezialisieren sich einzelne Autoren auf multiple Aktiengattungen [Bebchuk (1999), Nenova (2000)] oder Eigenkapitalpyramiden [Wolfenzon (1999)]. Die verschiedenen Modelle weisen überein- 
stimmend eine aus Sicht aller Aktionäre negative Wirkung unterproportionaler Cash-Flow-Rechte nach.

\subsubsection{Eigenes Modell}

Um die grundlegende Vorgehensweise einer modelltheoretischen Analyse zu verdeutlichen, wird im Folgenden ein Modell hergeleitet, ${ }^{620}$ das die Auswirkungen von Kapital- und Stimmrechtskonzentrationen auf die Anreize des kontrollausübenden Aktionärs in Abhängigkeit von seinem Kapital- bzw. Stimmrechtsanteil modelliert. Zielsetzung ist es, exemplarisch zu erläutern, welche Art von Aussagen mit Hilfe einer modelltheoretischen Analyse getroffen werden können und wo ihre Grenzen liegen.

Der Aktionär verfügt über einen Anteil $c$ am Eigenkapital der Gesellschaft bei einem Anteil $s$ an den Stimmrechten. Dabei gilt, dass der Stimmrechtsanteil nicht kleiner ist als der Cash-Flow-Anteil ( $s \geq c$ ) und ausreichend groß, um Einfluss auf die Aktivitäten des Managements zu nehmen. Die Variable $s$ bildet dabei sowohl Stimmrechte ab, denen in gleicher Höhe Cash-Flow-Rechte gegenüber stehen als auch solche, die aus stimmrechtsbevorzugten Aktien oder Konzernpyramiden resultieren, sodass die Anreizwirkung unterproportionaler CashFlow-Rechte dargestellt werden kann. Die aus der Geschäftstätigkeit des Unternehmens resultierenden Cash Flows $C F$ werden in Abhängigkeit vom Anteil am Eigenkapital zwischen den Aktionären aufgeteilt, sodass dem betrachteten kontrollausübenden Aktionär grundsätzlich ein Cash-Flow-Anteil in Höhe von $c \cdot C F$ zukommt. Zusätzlich hat dieser Aktionär aufgrund seiner Position jedoch die Möglichkeit, private benefits zu realisieren, die die ausschüttbaren Cash Flows um den Anteil $p \cdot C F$ mindern. Entsprechend wird der an alle Aktionäre ausschüttbare Cash Flow gemindert und beträgt nur noch $(1-p) \cdot C F$, wovon ein Anteil in Höhe von $c \cdot(1-p) \cdot C F$ an den kontrollausübenden Aktionär geht. Durch die Realisierung von private benefits durch den Großaktionär entstehen zudem Kosten, sodass ein Teil der Cash Flows vollständig verloren geht. ${ }^{621}$ Die Höhe der Kosten zur Realisierung von private benefits ist abhängig vom Umfang der private benefits, die der Großaktionär realisieren will und von seinem (ggf. überproportionalen) Stimmrechtsanteil, sodass gilt $k(s, p)$. Die Funktion $k(s, p)$ hat dabei folgende Eigenschaften:

Das Modell ist vom formalen Ansatz her vergleichbar mit dem von La Porta et al. (2002), S. 1150-1153, die jedoch den Einfluss von Aktionärsschutzbestimmungen auf den Anreiz zur Generierung von private benefits modellieren.

621

Denkbar sind hier Kosten aufgrund von Informationsbeschaffungsaktivitäten des Großaktionärs, Nutzung betrieblicher Ressourcen, Bestechung o.ä. 
$k(s, 0)=0, \quad k_{p} \geq 0, \quad k_{s} \leq 0, \quad k_{p p}>0, \quad k_{s p} \leq 0$.

Demzufolge entstehen keine Kosten aus der Generierung von private benefits wenn keine Eigennutzorientierung des kontrollausübenden Aktionärs vorliegt, somit $p=0$ ist. Aus der zweiten und dritten Annahme folgt, dass die Gesamtkosten der Eigennutzorientierung bei steigendem private-benefit-Anteil nicht kleiner und bei steigendem Stimmrechtsanteil nicht größer werden. Der Grundgedanke ist, dass die Realisierung höherer private benefits auch zu höheren Kosten führt, wohingegen ein höherer Stimmrechtsanteil zu einer gesteigerten Einflussnahmemöglichkeit führt, die eine private Vorteilsnahme leichter und zu geringeren Kosten ermöglicht. ${ }^{622}$ Die beiden letzten Annahmen betreffen die marginalen Kosten der Eigennutzorientierung des Großaktionärs. Diese steigen mit zunehmendem Anteil private benefits an und sind nicht-positiv hinsichtlich eines steigenden Stimmrechtsanteils. Die Grenzkosten der Realisierung von private benefits sind somit um so größer, je mehr private benefits dem Unternehmen bereits entzogen worden sind und um so kleiner, je größer das vorhandene Einflusspotenzial aus dem Stimmrechtsanteil ist.

Aus Sicht des Aktionärs, der seinen optimalen private-benefit-Anteil $p$ plant, ergibt sich somit folgende zu maximierende Nutzenfunktion:

$U=c \cdot(1-p) \cdot C F+p \cdot C F-k(s, p) \cdot C F$

Der erste Term spiegelt den Anteil des Großaktionärs am Cash Flow des Unternehmens wider, nachdem dieser bereits um die private benefits dezimiert wurde. Der zweite Term drückt den Cash-Flow-Anteil aus, den der kontrollausübende Aktionär aufgrund seiner privaten Vorteilsnahme exklusiv vereinnahmt und der letzte Term stellt die Kosten der private benefits dar, wobei vereinfachend angenommen wird, dass der Großaktionär die aufgrund seiner privaten Vorteilsnahme entstehenden Kosten vollständig trägt. ${ }^{623}$ Eine Betrachtung der Gleichung zeigt deutlich die unterschiedliche Anreizwirkung von Cash-Flow- und Stimmrechten. Der erste Term, der Anreiz bietet, die Realisierung von private benefits zu unterlassen, fällt um so kleiner aus, je kleiner der Cash-Flow-Anteil ist. Der letzte Term hingegen, der ebenfalls die private Vorteilsnahme verhindern kann, fällt um so kleiner aus, je größer die Stimmrechte sind (da gilt $k_{s} \leq 0$ ). Aus Sicht des Nutzen maximierenden Großaktionärs ergibt sich somit ein Anreiz zur

622 Die Effekte werden als nicht-negativ bzw. nicht-positiv formuliert, da denkbar ist, dass auf einem bestimmten Niveau die Änderung von private-benefit-Ausmaß bzw. Stimmrechtsanteil keine Auswirkungen auf die Kosten der Eigennutzorientierung mehr hat. Vgl. auch Edwards/Weichenrieder (2000), S. 10. 
Generierung von private benefits insbesondere dann, wenn die Cash-FlowRechte $c$ im Verhältnis zu den Stimmrechten $s$ sehr klein sind.

Da das optimale private-benefit-Niveau $p$ in Prozent unabhängig von der absoluten Höhe des Cash Flows $C F$ ist, kann die zu maximierende Gleichung wie folgt vereinfacht werden:

$U=c \cdot(1-p)+p-k(s, p)$.

Die erste Ableitung nach $p$ liefert

$U_{p}=-c+1-k_{p}(s, p)=0$.

Für die Gewinnung von ökonomischen Aussagen hinsichtlich der Wirkung alternativer Kapital- und Stimmrechtsanteile auf den Anreiz zur Generierung von private benefits wird die erste Ableitung zunächst zum Kapitalanteil $c$ weiter differenziert, sodass gilt:

$-1-k_{p p}\left(s, p^{*}\right) \frac{d p^{*}}{d c}=0$

Unter Berücksichtigung der unter (III 1.) getroffenen Annahmen hinsichtlich der Kostenfunktion $k(s, p)$ gilt somit:

$\frac{d p^{*}}{d c}=-\frac{1}{k_{p p}\left(s, p^{*}\right)}<0$

Damit gilt, dass die Generierung von private benefits um so geringer ausfällt, je größer der Cash-Flow-Anteil des Großaktionärs ist.

Für die weitere Differenzierung der ersten Ableitung aus (III 4.) zum Stimmrechtsanteil $s$ gilt:

$k_{s p}(s, p)+k_{p p}(s, p) \frac{d p^{*}}{d s}=0$,

sodass sich unter Berücksichtigung der getroffenen Annahmen aus (III 1.) nach Umformung ergibt:

$\frac{d p^{*}}{d s}=-\frac{k_{s p}(s, p)}{k_{p p}(s, p)}>0$.

623 Diese Annahme hat keinen Einfluss auf den Aussagegehalt des Modells. Vgl. La Porta et al. (2002), S. 1151. 
Der Großaktionär wird somit um so mehr private benefits für sich vereinnahmen, je größer sein Stimmrechtsanteil und damit seine Einflussmöglichkeit ist.

Die Ergebnisse des Modells stützen somit - unter den getroffenen Annahmen die Aussagen der in den vorangegangenen Abschnitten verbal formulierten Hypothesen. Während größere Kapitalanteile den Anreiz zur Realisierung von private benefits mindern, führt eine alleinige Erhöhung des Stimmrechtsanteils zu einem gesteigerten Anreiz, private Vorteile zu Lasten des insgesamt entziehbaren Cash Flows in Anspruch zu nehmen.

Analog zu den hier abgebildeten Einflussfaktoren können weitere hinzugefügt werden, wie etwa das Vorhandensein eines weiteren Großaktionärs. Da die Argumentationsweise sich von der hier dargestellten jedoch nicht unterscheidet, wird auf eine Darstellung solcher Erweiterungen hier verzichtet. Edwards/Weichenrieder (2000) weisen mit ihrem Modell nach, dass ein zweiter Großaktionär die Kosten der Generierung von private benefits steigert und somit das optimale private-benefit-Niveau aus Sicht des ausbeutenden Aktionärs sinkt. ${ }^{624}$ Auch die Darstellung eines nichtlinearen Einflusses alternativer Kapital- oder Stimmrechtsanteile ist grundsätzlich denkbar, sie würde jedoch ein deutlich komplexeres Modell erfordern.

\subsubsection{Kritische Würdigung}

Theoretische, insbesondere modellgestützte Argumentationen können unter bestimmten Prämissen die grundlegenden Anreize der handelnden Akteure präzise abbilden. Kritisch anzumerken ist jedoch, dass die Modellergebnisse stark durch die gesetzten Annahmen determiniert werden. Andere Annahmen im obigen Modell hinsichtlich der relevanten Einflussfaktoren würden zu gegebenenfalls anderen Ergebnissen führen. Um verallgemeinerbare Ergebnisse für die Anreizstrukturen auf dem hier zu untersuchenden deutschen Kapitalmarkt abzuleiten, wäre es somit erforderlich, die Nutzenfunktionen und Handlungsparameter der Akteure im Detail zu kennen. Da diese jedoch realiter in der Regel nicht bekannt sind, liegt der Nutzen modelltheoretischer Darstellungen eher in der Modellierung fundamentaler Zusammenhänge: Aufgezeigt werden etwa grundsätzliche Beziehungen wie „Ein steigender Cash-Flow-Anteil reduziert den Anreiz zur Generierung von private benefits“ oder „Überproportionale Stimmrechte senken die Kosten der privaten Vorteilsnahme". Der genaue Verlauf einer Anreizstrukturen abbildenden Funktion kann jedoch mit Hilfe von Modellen in der Regel

$624 \mathrm{Vgl}$. Edwards/Weichenrieder (2000), S. 9-12. 
nicht abgebildet werden. ${ }^{625}$ So stellen Jensen/Meckling im Rahmen ihres Modells zum optimalen Anteilsbesitz von Managern fest, dass „the shape of these functions is a question of fact and can only be settled by empirical evidence ${ }^{\text {(6626. }}$.

Problematisch erscheint eine abschließende Beurteilung der Wirkung eines Einflussfaktors auf Basis einer theoretischen Analyse insbesondere in den Fällen, in denen ein bestimmter Einflussfaktor gegenläufige Wirkungen entfalten kann. Dies ist bei dem hier betrachteten ökonomischen Sachverhalt der Anreizstruktur von Großaktionären der Fall. Cash-Flow-Rechte begründen zwar prinzipiell eine Interessenkonvergenz, ermöglichen jedoch, sofern sie gleichzeitig mit Stimmrechten einhergehen, darüber hinaus die Ausbeutung von Kleinaktionären. Theoretische Modelle können hier zwar einen Trade-off aufzeigen, welcher Einfluss im Endeffekt dominiert, ist jedoch schwer allgemeingültig zu formulieren. Insbesondere ist die Prognose bestimmter Kapitalanteile, ab denen ein positiver oder negativer Einfluss überwiegt, nicht möglich. Um die Komplexität des Modells in einem vertretbaren Rahmen zu halten, umfassen die einzelnen Modelle zudem jeweils nur eine begrenzte Anzahl Einflussfaktoren, die die Realität somit nur unvollständig abbilden. Um Aussagen über die Vorteilhaftigkeit konkreter Aktionärsstrukturen treffen zu können, erscheint das alleinige Abstellen auf theoretische Modelle somit trotz ihres hohen Erklärungsgehaltes im Einzelfall begrenzt geeignet. Zusätzlichen Erkenntnisgewinn bieten hier empirische Untersuchungen, die zumindest für die Sampleunternehmen des untersuchten Kapitalmarktes und untersuchten Zeitraumes eine Bestätigung oder Verwerfung der theoretisch abgeleiteten Hypothesen erlauben und diese zusätzlich präzisieren.

\subsection{Hypothesenbildung}

Auf Basis der vorangegangenen Überlegungen sollen im Folgenden Hypothesen für die eigene empirische Untersuchung abgeleitet werden, um einen Beitrag zum weiteren Verständnis des Zusammenhangs zwischen Aktionärsstruktur und Unternehmenswert am deutschen Kapitalmarkt zu leisten. Dafür werden die verschiedenen zuvor präsentierten Ansätze vor dem Hintergrund des regulatorischen Umfelds in Deutschland kritisch gewürdigt. ${ }^{627}$ Dabei sollen zunächst erwartete Beziehungen grundsätzlicherer Natur formuliert werden. Eine Präzisierung der Hypothesen mit geeigneten Proxy-Größen erfolgt im folgenden empirischen Teil dieser Arbeit.

\footnotetext{
625 Vgl. Goergen (1998), S. 130.

626 Jensen/Meckling (1976), S. 346.

627 Vgl. zur Relevanz der Rahmenbedingungen für die Auswirkung alternativer Aktionärsstrukturen auf den Unternehmenswert auch Schmid (1996), S. 411.
} 


\subsubsection{Hypothesen zum Kapital- bzw. Stimmrechtsanteil des Großaktionärs}

Mit der Interessenkonvergenz- und der Ausbeutungshypothese liegen zwei konfliktäre Theorien zur Wirkung von großen Kapital- bzw. Stimmrechtsblöcken vor. Welcher im Einzelfall mehr Gewicht zukommt, ist schwierig allgemeingültig zu formulieren. Es gilt jedoch, dass der positive Effekt aus der Kontrollfunktion von Großaktionären insbesondere dann zum Tragen kommen wird, wenn andere Mechanismen zur Reduzierung der Agency-Kosten nicht greifen. ${ }^{628}$ Von Bedeutung sind hier insbesondere die marktorientierten Instrumente. ${ }^{629}$ So weist Maug nach, dass die Wirksamkeit von Großaktionären als Kontrolleur des Managements insbesondere für weniger liquide Kapitalmärkte gegeben ist, auf denen der Markt für Unternehmenskontrolle seine Funktion nur begrenzt wahrnehmen kann. ${ }^{630}$ Diese modelltheoretische Analyse korrespondiert mit der Beobachtung, dass Großaktionäre insbesondere in Ländern mit weniger gut entwickelten Kapitalmärkten von großer Bedeutung sind. ${ }^{631}$ Andere Studien zeigen jedoch, dass die Wahrscheinlichkeit, dass ein Großaktionär private benefits realisiert um so größer ist, je geringer der institutionelle Aktionärsschutz ist. ${ }^{632}$ Übereinstimmend damit weisen La Porta et al. nach, dass Großaktionäre insbesondere in Volkswirtschaften vorherrschen, in denen der Aktionärsschutz eher schwach ausgeprägt ist. ${ }^{63}$ Voraussetzung für die Ausübung von Aktionärskontrolle ist jedoch, dass die Aktionärsschutzbestimmungen zumindest so weit ausgeprägt sind, dass der Großaktionär seine Rechte auch wahrnehmen kann. So formulieren Shleifer/Vishny: "The effectiveness of large shareholders is intimately tied to their ability to defend their rights"634.

Für den deutschen Kapitalmarkt bedeuten diese Ergebnisse folgendes: Die Funktionsfähigkeit des deutschen Kapitalmarktes entwickelt sich in den letzten Jahren erst langsam; im Vergleich insbesondere zum großen US-amerikanischen

628 Vgl. Maug (1998), S. 89.

629 Vgl. zur Abgrenzung der marktorientierten Instrumente Kapitel III.1.2.2.1

630 Vgl. Maug (1998), S. 83-87, sowie bereits Holl (1977). Hansmann widerspricht dem Zusammenhang zwischen Kapitalkonzentration und Funktionsfähigkeit des Markts für Unternehmenskontrolle mit der Begründung, dass die USA seit jeher streubesitzdominiert gewesen sei, der Markt für Unternehmenskontrolle sich jedoch erst in den sechziger Jahren gebildet habe. Vgl. Hansmann (1988), S. 283.

631 Vgl. die umfassende Studie von La Porta et al. (1999), zudem Lins (2003); Maug (2002).

632 Vgl. Roe (2000), S. 539; Cronqvist/Nilsson (2002), S. 6; Mayer (2000), S. 9, sowie den empirischen Nachweis bei Nenova (2000); Dyck/Zingales (2002); Klapper/Love (2002); Doidge (2003).

633 Vgl. La Porta et al. (1998), S. 1113

634 Shleifer/Vishny (1997), S. 755. 
Markt ist die Börsenkapitalisierung nach wie vor gering. ${ }^{635}$ Der Markt für Unternehmenskontrolle nahm - zumindest für den im Rahmen dieser Arbeit zu betrachteten Zeitraum von 1997 bis 2000 - am organisierten Kapitalmarkt eine Kontrollfunktion praktisch nicht wahr. ${ }^{636}$ Ähnliches gilt für den so genannten Markt für Manager. ${ }^{637}$ Aufgrund der eingeschränkten Wirksamkeit marktorientierter Mechanismen zur Reduzierung von Agency-Konflikten könnte daher der Kontrollfunktion von Großaktionären in Deutschland ein besonderes Gewicht zukommen; ein positiver Einfluss auf den Unternehmenswert wäre zu erwarten. Die Qualität des institutionellen Aktionärsschutzes, die die Möglichkeit zur Realisierung von private benefits determiniert, liegt jedoch in Deutschland nur im internationalen Mittelfeld. ${ }^{638}$ Es wäre daher damit zu rechnen, dass es dominanten Großaktionären zumindest in wahrnehmbarem Maß gelingt, private Vorteile aus ihrer Aktionärsrolle zu ziehen und somit einen negativen Einfluss auf den Unternehmenswert auszuüben. Eine eindeutige Überlegenheit der Interessenkonvergenz- oder der Ausbeutungshypothese ergibt sich somit auch unter Berücksichtigung des Kapitalmarktumfeldes nicht.

Von den verschiedenen sonstigen Hypothesen zur Wirkung von Kapital- bzw. Stimmrechtsblöcken, die im Rahmen von Kapitel III.2.2.1.4 vorgestellt wurden, lassen die Anlagehorizont-, Informationseffizienz-, Organisations- und Signallinghypothese einen eher positiven Einfluss erwarten, die Liquiditäts- und die Kapitalstrukturhypothese stützen einen negativen und die Endogenitätshypothese gar keinen Einfluss auf den Unternehmenswert. ${ }^{639}$ Empirische Studien zur Auswirkung von Blockbildungen auf verschiedenen internationalen Kapitalmärkten kommen ebenfalls zu unterschiedlichen Ergebnissen, wenn auch mit

635 Die Börsenkapitalisierung betrug zum Ende des Untersuchungszeitraums (31.12.2000) in Deutschland lediglich $67,8 \%$ des Bruttoinlandsproduktes, in den USA hingegen $181 \%$. Vgl. DAI (2002), S. 05-1, 05-3.

636 Vgl. Franks/Mayer (1996); Böhmer (2000); Jenkinson/Ljungqvist (2001), sowie die Ausführungen in Kapitel III.1.2.2.1.

637 Vgl. Fama (1980), S. 297f.; Fama/Jensen (1983); Ridder-Aab (1980), S. 97; Renner (1999), S. 141-155; Geldmacher (2000), S. 92-95.

638 Vgl. La Porta et al. (1998), S. 1113; Apcims (2002). Auf eine hohe Bedeutung privater Kontrollrenten am deutschen Kapitalmarkt deuten auch die empirischen Ergebnisse von Ehrhardt/Nowak (2002a) hin.

639 Die Aussagekraft der Informationseffizienzhypothese erscheint unter Berücksichtigung der deutschen Kapitalmarktverhältnisse eher gering, da keine regelmäßigen Kontakte zwischen Groß- und Kleinaktionären bestehen. Denkbar wäre eine von der Hypothese unterstellte Informationsweitergabe allenfalls bei Finanzintermediären, wenn diese die im Rahmen ihrer Funktion als Großaktionär erlangten Informationen in ihre Investmentempfehlungen einarbeiten. 
einer Tendenz zu einem eher positiven Einfluss. ${ }^{640}$ Ein solcher wird insbesondere in den Studien nachgewiesen, die den Einfluss von Großaktionären auf großen, funktionsfähigen Kapitalmärkten untersuchen, ein negativer Einfluss ergibt sich in verschiedenen Studien für Entwicklungs- oder Schwellenländer. ${ }^{641}$

Eine eindeutige Prognose hinsichtlich der Auswirkung von Kapital- bzw. Stimmrechtsbündelung bei Großaktionären auf den Unternehmenserfolg gelingt somit auch unter Berücksichtigung bisheriger empirischer Ergebnisse nicht. Die entsprechende Hypothese hinsichtlich des Einflusses von Stimmrechtsbündelungen soll daher offen formuliert werden: ${ }^{642}$

Hla: Zwischen Stimmrechtsbündelungen bei Großaktionären und Unternehmenserfolg besteht ein Zusammenhang.

Entsprechend ist auch für Kapitalbündelungen ein Zusammenhang zu erwarten. Sollte sich ein negativer Zusammenhang zwischen Stimmrechtsbündelungen und Unternehmenserfolg ergeben, so wäre zu erwarten, dass dieser für Kapitalbündelungen weniger signifikant ausfällt; ein positiver Zusammenhang wäre entsprechend stärker zu erwarten als der unter H1a formulierte. Dies wäre zu erwarten, da mit Kapitalbündelungen in stärkerem Maße positiv wirkende Kontrollanreize verbunden sind als mit (reinen) Stimmrechtsbündelungen. Ein negativer Zusammenhang sollte somit abgeschwächt, ein positiver verstärkt werden.

H1b: Zwischen Kapitalbündelungen bei Großaktionären und Unternehmenserfolg besteht ein Zusammenhang.

Unter Berücksichtigung der Argumentation der Nichtlinearitätshypothese könnte erwartet werden, dass nicht für alle Anteilsquoten eine einheitliche Aussage getroffen werden kann, da je nach Kapitalanteil der Kontrollanreiz oder der Ausbeutungsanreiz überwiegt. Gemäß der vorliegenden Theorie wäre davon auszugehen, dass ein nichtlinearer Zusammenhang besteht und sich ein positiver Einfluss des Großaktionärs erst dann ergibt, wenn die Höhe des Kapitalanteils einen ausreichend großen Anreiz zur Ausübung von Kontrolle gewährleistet. Verschiedene empirische Untersuchungen haben einen solchen Zusammenhang für andere Kapitalmärkte bereits bestätigt, der sowohl für die Kapital- als auch für

\footnotetext{
640 Vgl. die ausführliche Auswertung bereits vorhandener empirischer Studien in Kapitel IV.1 sowie den tabellarischen Überblick in Anhang B.

641 Vgl. z.B. die Studien von Gugler (1999); Lins (2003); La Porta et al. (2002).

${ }^{642}$ Vgl. auch Goergen (1998), S. 130.
} 
die Stimmrechtsanteile zu erwarten ist, sodass die Hypothesen 1c und 1d für den deutschen Kapitalmarkt wie folgt formuliert werden: ${ }^{643}$

H1c: Zwischen Stimmrechtsbündelungen bei Großaktionären und Unternehmenserfolg besteht ein nichtlinearer Zusammenhang.

H1d: Zwischen Kapitalbündelungen bei Großaktionären und Unternehmenserfolg besteht ein nichtlinearer Zusammenhang.

\subsubsection{Hypothesen zu unterproportionalen Cash-Flow-Rechten}

Unterproportionale Cash-Flow-Rechte entstehen in Deutschland durch die Emission von Vorzugsaktien und die Bildung von Eigenkapitalpyramiden. Höchstund Mehrfachstimmrechte lagen in den letzten Jahren nur noch in Einzelfällen aufgrund von Bestandsschutzregelungen vor. Aufgrund der oben ausführlich diskutierten mangelhaften Anreize, Kontrollrechte, die nicht von Cash-FlowRechten begleitet werden, im Sinne aller Aktionäre auszuüben, wäre eine negative Auswirkung auf den Unternehmenswert zu erwarten.

Empirische Untersuchungen zu dem vorliegenden Problem sind erst in jüngerer Zeit entstanden und untersuchen primär wenig entwickelte Kapitalmärkte. Die empirische Evidenz bestätigt überwiegend den auf Basis der theoretischen Argumentation zu vermutenden negativen Einfluss unterproportionaler Cash-FlowRechte auf den Unternehmenswert. ${ }^{644}$ Im Vergleich etwa zu Entwicklungs- oder Schwellenländern ist die Divergenz zwischen Stimm- und Cash-Flow-Rechten in Deutschland eher klein, gegenüber anderen Industrienationen, hier insbesondere etwa im Vergleich zu den USA, jedoch groß. ${ }^{645}$ Insgesamt könnte daher ein negativer Einfluss erwartet werden, sodass Hypothese 2a lautet:

H2a: Stimmrechtsbündelungen, die nicht von entsprechenden Cash-Flow-Bündelungen begleitet werden, haben einen negativen Einfluss auf den Unternehmenserfolg.

643 Vgl. Morck/Shleifer/Vishny (1988); Chirinko et al. (1999); Himmelberg/Hubbard/Palia (1999); Holderness et al. (1999); Thomsen/Pedersen (2000); Belkaoui/Pavlik (1992); Alexander/Cohen (1999); Lins (2003).

644 Vgl. z.B. die Studien von Claessens et al. (1999); Edwards/Weichenrieder (2000); Gugler et al. (2002); La Porta et al. (2002); Lins (2003); Volpin (2002); Lemmon/Lins (2003). Keinen Einfluss abweichender Stimm- und Cash-Flow-Rechte finden Wiwattanakantang (2001), sowie Cronqvist/Nilsson (2002).

Vgl. die jüngste Auswertung von La Porta et al. (2002), nach der die Differenz zwischen Stimm- und Cash-Flow-Rechten in Deutschland bei 0,07 liegt, in den USA nur bei 0,01. Vgl. La Porta et al. (2002), S. 1168. Deutschland liegt jedoch unter dem Durchschnitt von 0,10 der 27 untersuchten Nationen. 
In diesem Zusammenhang bietet sich außerdem an, zu untersuchen, wie der Kapitalmarkt die beiden wesentlichen Instrumente zur Schaffung divergierender Stimm- und Cash-Flow-Rechte wahrnimmt. In Anbetracht der anhaltend kritischen Diskussion um die so genannte „Deutschland $A^{\prime}$ “ könnte vermutet werden, dass unabhängig vom Ausmaß der Pyramidenbildung verschachtelte Konzernstrukturen vom Kapitalmarkt negativ wahrgenommen werden und somit $\mathrm{zu}$ einer Minderbewertung führen: ${ }^{646}$

$H 2 b$ : Die Einbindung eines Unternehmens in eine Konzernpyramide hat einen negativen Einfluss auf den Unternehmenserfolg.

Mit einer entsprechenden Hypothese soll außerdem die Beurteilung von Vorzugsaktien durch den Kapitalmarkt überprüft werden. Aufgrund der unterproportionalen Kapitalanteile der (großen) Stammaktionäre ergeben sich nur geringe Anreize zur Ausübung von Kontrolle, sodass ein negativer Einfluss auf den Unternehmenswert aufgrund eines gespaltenen Eigenkapitals zu erwarten wäre: ${ }^{647}$

H2c: Unternehmen mit Stamm- und Vorzugsaktien weisen einen geringeren Unternehmenserfolg auf als solche, die nur Stammaktien haben.

\subsubsection{Hypothese zu konkurrierenden Minderheitsaktionären}

Verfügt ein Aktionär über einen ausreichenden Stimmrechtsanteil, so kann er innerhalb eines bestimmten Rahmens private benefits realisieren. Voraussetzung hierfür ist jedoch, dass kein anderer Aktionär vorhanden ist, dessen Einfluss seinerseits so groß ist, dass er eine solche private Vorteilsnahme verhindern kann. Haben somit zwei oder mehr Aktionäre einen vergleichbar großen Stimmrechtsanteil, so können sie sich gegenseitig an der Eigennutzorientierung hindern. Sofern die Alternative, private Vorteile zu realisieren, den Minderheitsaktionären jeweils verschlossen ist, könnte erwartet werden, dass sie die zweite Möglichkeit wählen, Einfluss auf ihre persönlichen Cash Flows zu nehmen: die Beteiligung am Monitoring des Managements. ${ }^{648}$ Voraussetzung dafür ist jedoch, dass die

646 Vgl. Adams (1994), jüngst Aleff/Steden (2001), sowie Hillebrandt (2001) mit einem Überblick über verschiedenste kritische Literaturbeiträge.

647 Vgl. für eine kritische Bewertung von Vorzugsaktien z.B. Siebel (1997); Mildenberger (2002), sowie Pellens/Hillebrandt (2000) m.w.N.

648 Vgl. auch die theoretische Analyse von Bennedsen/Wolfenzon (2000), sowie Edwards/ Weichenrieder (2000). Einen Überblick geben Gutiérrez/Tribo (2002). 
Minderheitsaktionäre keine Koalition bilden und die realisierten private benefits unter sich aufteilen. ${ }^{649}$

Die Präsenz mehrerer vergleichbar großer Aktionäre wurde bisher nur in wenigen Studien untersucht. ${ }^{650}$ Deren Ergebnisse legen jedoch ebenso wie die theoretische Argumentation einen positiven Einfluss der gegenseitigen Kontrolle von Minderheitsaktionären nahe, sodass Hypothese 3 lautet:

H3: Die Präsenz mehrerer großer Aktionäre, von denen keiner eine Stimmrechtsmehrheit hält, hat einen positiven Einfluss auf den Unternehmenserfolg.

\subsubsection{Hypothesen zur Identität des Großaktionärs}

In Kapitel III.2.2.2 wurden Vor- und Nachteile unterschiedlicher Aktionärstypen herausgearbeitet und Erfolgsfaktoren für eine aus Sicht aller Aktionäre positive Einflussnahme des Aktionärs formuliert. ${ }^{651}$ Dabei wurde zwischen folgenden Aktionärstypen differenziert: Familien, Industrie- bzw. Dienstleistungsunternehmen, Kreditinstituten, Fondsgesellschaften/Versicherungen, Management, öffentlichen Haushalten und Ausländern.

Familien als Großaktionäre sind häufig (Erben der) Firmengründer. Sie haben aufgrund ihrer langfristigen Beziehung zur Gesellschaft daher in der Regel gute Kenntnisse über das Unternehmen. Ihre Gelegenheit zur Realisierung von privaten Vorteilen ist jedoch aufgrund persönlicher Beziehungen häufig ausgeprägt und die wirtschaftswissenschaftliche Befähigung zur Abschätzung zukünftiger Chancen und Risiken nicht zwingend gegeben. Da zudem vorliegende empirische Ergebnisse auf einen eher negativen Einfluss hindeuten, wird Hypothese $4 \mathrm{a}$ wie folgt formuliert: ${ }^{652}$

H4a: Ein Großaktionär in Form eines Familienmitglieds hat einen negativen Einfluss auf den Unternehmenserfolg.

649 Eine Koalitionsbildung unterstellt das Modell von Zwiebel (1995), die empirischen Ergebnisse von Maury/Pajuste unterstützen dieses. Vgl. Maury/Pajuste (2002), S. 24.

650 Vgl. z.B. Zingales (1994), S. 127; Lehmann/Weigand (2000), S. 185; Boehmer (2000); Edwards/Weichenrieder (2000); Gutiérrez/Tribo (2002); Maury/Pajuste (2002); CrespiCladera/Renneboog (2003).

651 Vgl. für Erfolgsfaktoren von effizientem Monitoring durch Großaktionäre auch Ayres/ Cramton (1994), S. 1061-1063.

652 Vgl. z.B. Cronqvist/Nilsson (2002); Ehrhardt/Nowak (2002, 2002a), sowie Anderson/ Mansi/Reeb (2003), die eine Interessenkonvergenz zwischen Familienmitgliedern und Gläubigern nachweisen. Anders jedoch jüngst Anderson/Reeb (2003). 
Die Prognose der Auswirkung größerer Managementbeteiligungen ist ebenfalls sehr komplex. Zwar wurden bereits zahlreiche Studien zu ihren Vor- und Nachteilen angefertigt, bis heute jedoch ohne eindeutiges Ergebnis. Der positive Einfluss ergibt sich aus einer Reduzierung des traditionellen Principal-AgentProblems, indem der Manager durch seine Beteiligung Anreize erhält, sich im Sinne aller Aktionäre zu verhalten. ${ }^{653}$ Größere Beteiligungen geben ihm jedoch eine nahezu unbeschränkte Macht, da er sich in seiner Managementfunktion selbst kontrolliert. Entsprechend wäre es auch hier plausibel, von einem nichtlinearen Einfluss auszugehen. Da ein solcher in einer Dummy-Variablen jedoch nicht abgebildet werden kann, wird eine offene Hypothese formuliert:

\section{H4b: Kapitalblöcke in den Händen des Managements haben einen Einfluss auf} den Unternehmenserfolg.

Die sonstigen natürlichen Personen umfassen diejenigen Personen, die nicht dem Management oder der Gründungsfamilie zugeordnet werden können. Bei natürlichen Personen ist nicht davon auszugehen, dass sie besondere Spezialisierungsvorteile für die Ausübung von Aktionärskontrolle besitzen. Für einen positiven Einfluss spricht jedoch, dass natürliche Personen in der Regel nicht über so viel Kapital verfügen, das ihnen eine Beteiligung in großem Umfang an verschiedenen (größeren) Gesellschaften ermöglichen würde. Sie sind somit in besonderem Maße dem unsystematischen Risiko einer Einzelinvestition ausgesetzt, sodass sie einen besonderen Anreiz haben, Kontrolle auszuüben. Die Hypothese wird daher positiv formuliert:

H4c: Kapitalblöcke in den Händen von natürlichen Personen haben einen positiven Einfluss auf den Unternehmenserfolg.

Hinsichtlich der Hypothesen 4a bis 4c ist kritisch anzumerken, dass die Zuordnung der Aktionäre zu den einzelnen Gruppen nicht überschneidungsfrei ist. Mitglieder des Managements sind ebenso wie Familienmitglieder natürliche Personen. Hier könnten mögliche Fehler bei der Zuordnung eine Verzerrung der Ergebnisse bedingen.

Industrie- und Dienstleistungsunternehmen erwerben Beteiligungen an anderen Aktiengesellschaften häufig aus strategischen Überlegungen an branchenverwandten Unternehmen. Durch die vergleichsweise große inhaltliche Nähe könnten die hier unter Industrieunternehmen zusammengefassten Gesellschaften über mehr relevante Kenntnisse zur Ausübung von Kontrolle verfügen als andere Aktionäre. Demnach wäre ein eher positiver Einfluss zu erwarten, sodass Hypothese $4 \mathrm{~d}$ wie folgt formuliert wird:

653 Vgl. beispielhaft Core/Larcker (2002). 
H4d: Ein Großaktionär in Form eines Industrieunternehmens hat einen positiven Einfluss auf den Unternehmenserfolg.

Zunehmende Allfinanzbestrebungen und starke Verflechtungen der Banken und Versicherungen untereinander führen dazu, dass die Abgrenzungen zwischen den verschiedenen Finanzintermediären immer stärker verwischen und eine eindeutige Zuordnung zu den einzelnen Gruppen schwierig ist. Es soll daher eine gemeinsame Hypothese für alle Finanzintermediäre formuliert werden. ${ }^{654}$ Die divergierenden Anreize von Kreditinstituten aus ihrer Funktion als Kreditgeber, Depotstimmrechtsverwalter und Aktionär wurde an verschiedenen Stellen bereits angesprochen. Da Kreditinstitute, die als Großaktionär in einem Unternehmen involviert sind, in der Regel auch eine kreditgebende Funktion haben, ist der Anreiz zur Einflussnahme im Sinne des Kreditengagements und nicht im Sinne aller Aktionäre besonders groß. ${ }^{655}$ Es wäre demnach ein negativer Einfluss aufgrund von Unterinvestition zu erwarten. Für Versicherungen und Fondsgesellschaften könnte hingegen ein positiver Einfluss erwartet werden. ${ }^{656} \mathrm{Da}$ gerade Fondsgesellschaften jedoch ihr Stimmrecht häufig an die Depotbanken delegieren, könnte auch hier der negative Einfluss überwiegen. Hypothese $4 \mathrm{e}$ lautet daher:

H4e: Ein Großaktionär in Form eines Finanzintermediärs hat einen negativen Einfluss auf den Unternehmenserfolg.

Die Formulierung einer Hypothese für ausländische Großaktionäre ist schwierig, da diese Gruppe in sich heterogen ist und sich aus den verschiedenen anderen Gruppen zusammensetzt. Berücksichtigt man jedoch, dass ausländische Aktionäre ihr Stimmrecht auf der Hauptversammlung nur sehr selten ausüben, ${ }^{657}$ so könnte man davon ausgehen, dass die Nichtwahrnehmung von Kontrolle durch Ausländer das Management zu diskretionären Handlungen verleitet. Die Hypothese soll daher lauten:

654 Vgl. Corsten (1999); Dinauer (2001), zum Konzentrationsprozess am europäischen Bankenmarkt Paul (2001).

655 Da die empirischen Ergebnisse zum Einfluss von Kreditinstituten in ihrer Rolle als Aktionär sehr heterogen sind, wird auf eine Einbeziehung im Rahmen der Hypothesenbildung verzichtet. Vgl. jedoch den Überblick in Anhang B.3.

656 Vgl. Nickell et al. (1997); Thomsen/Pedersen (2000); Woidtke (2002); Bassen (2002a), sowie die umfangreiche theoretische Analyse von Reinholz (1997). Vgl. auch für den Spezialfall von Venture-Capital-Gesellschaften Bessler/Kurth/Thies (2001), S. 233f., sowie Cotter/Peck (2001) für LBO-Gesellschaften. Die Studie von Bassen (2002) zeigt, dass institutionelle Investoren auch am deutschen Kapitalmarkt Einfluss ausüben.

657 Vgl. Hasselbach/Schumacher (2000), S. 259; Spindler (2000), S. 421f., $440 f$. 
H4f: Kapitalblöcke in den Händen von Ausländern haben einen negativen Einfluss auf den Unternehmenserfolg.

Für Beteiligungen öffentlicher Haushalte wird ebenfalls ein negativer Einfluss auf den Unternehmenserfolg erwartet. Hierfür spricht zum einen eine potenziell geringe Sachkompetenz zur Ausübung der Kontrollfunktion; ${ }^{658}$ darüber hinaus kann vermutet werden, dass die im öffentlichen Auftrag Handelnden verschiedenste Interessen zu wahren haben, die nicht immer im Einklang mit den Aktionärsinteressen stehen werden. Konfliktpotenziale bergen sich etwa bei der Standortpolitik oder in Fragen der Arbeitsplatzsicherung.

H4g: Kapitalblöcke in den Händen öffentlicher Haushalte haben einen negativen Einfluss auf den Unternehmenserfolg.

658 Vgl. zum Einfluss des Staates als Aktionär La Porta et al. (2002a), Sun/Tong/Tong (2002). 


\section{Empirische Untersuchung zum Zusammenhang zwi- schen Eigentümer- bzw. Stimmrechtsstruktur und Un- ternehmenserfolg}

\section{Stand der empirischen Forschung}

\subsubsection{Studien für internationale Kapitalmärkte}

Auf internationaler Ebene wurden bereits vielfältige Untersuchungen über die Wirkung alternativer Eigentümer- und Stimmrechtsstrukturen auf die Performance durchgeführt. ${ }^{659}$ Insbesondere bei den älteren Untersuchungen stehen dabei die anglo-amerikanischen Kapitalmärkte im Vordergrund, für die bereits seit langem umfangreiche Informationen über die Aktionärsstrukturen börsennotierter Aktiengesellschaften vorliegen. Die Studien erklären in der Regel mit Hilfe multivariater Regressionsanalysen die Performance eines Unternehmens (in älteren Studien häufig gemessen durch buchwertbezogene Rentabilitätskennziffern, in jüngeren Beiträgen durch Marktwert/Buchwert-Verhältnisse) durch eine oder mehrere erklärende Variablen zur Kapital- und/oder Stimmrechtsstruktur sowie verschiedene Kontrollvariablen. Vereinzelt wird auch die Überrendite eines Unternehmens nach dem IPO in Abhängigkeit von der Aktionärsstruktur ermittelt oder die Auswirkung eines Eigentümerwechsels mit Hilfe einer Event-Study untersucht. ${ }^{660}$ Erst in den letzten Jahren haben vereinzelt Studien nicht nur Kapital- oder Stimmrechte isoliert betrachtet, sondern differenziert die Auswirkungen einer fehlenden Kongruenz analysiert. ${ }^{661}$

659 Der Begriff Performance bzw. Unternehmenserfolg soll in diesem Zusammenhang als Oberbegriff für verschiedene Variablen dienen, die in empirischen Studien eingesetzt werden, um einen Einfluss auf den Unternehmenswert zu approximieren. Denkbar sind hier Rentabilitätskennziffern, Aktienrenditen, Marktwert/Buchwert-Verhältnisse u.ä., gelegentlich werden auch eher indirekte Indikatoren untersucht wie z.B. die Anzahl der Vorstandswechsel oder die leistungswirtschaftliche Profitabilität.

660 So z.B. die Studien von Mikkelson et al. (1997); Goergen (1998) als Beispiel für IPOStudien; Duggal/Millar (1999), sowie Boehmer (2000) für Event-Studies. Zum Verfahren der Event-Study vgl. Kothari (2001), S. 116f., 186-189; ausführlich Schremper (2002), S. 123-171 m.w.N.; für die Verbreitung der Methodik waren insb. die richtungsweisenden Beiträge von Ball/Brown (1968) und Beaver (1968) ursächlich.

661 Vgl. insb. die Arbeiten von La Porta et al. (2002); Lins (2003); Volpin (2002); Cronqvist/Nilsson (2002); Wiwattanakantang (2001); Claessens et al. (1999). 
Anhang B.1 fasst die zentralen Ergebnisse sowie die untersuchten Zusammenhänge von 77 internationalen empirischen Studien tabellarisch zusammen. ${ }^{662}$ Die Ergebnisse sind insgesamt sehr heterogen. Weder grundsätzlich noch für einzelne Kapitalmärkte ergibt sich ein eindeutig positiver oder eindeutig negativer Einfluss von Kapitalbündelungen. Die folgenden beiden Tabellen geben einen Kurzüberblick, welche Tendenzaussage den jeweiligen Studien zugeschrieben werden kann. ${ }^{663}$ Tab. 7 fasst die in jüngerer Zeit vermehrt entstandenen internationalen Vergleichsstudien zusammen, die den Aktionärsstruktur-PerformanceZusammenhang auf verschiedenen Kapitalmärkten parallel betrachten, um so einen Rückschluss auf die Wirkung von Blockbildungen in alternativen Corporate-Governance-Systemen zu ermöglichen.

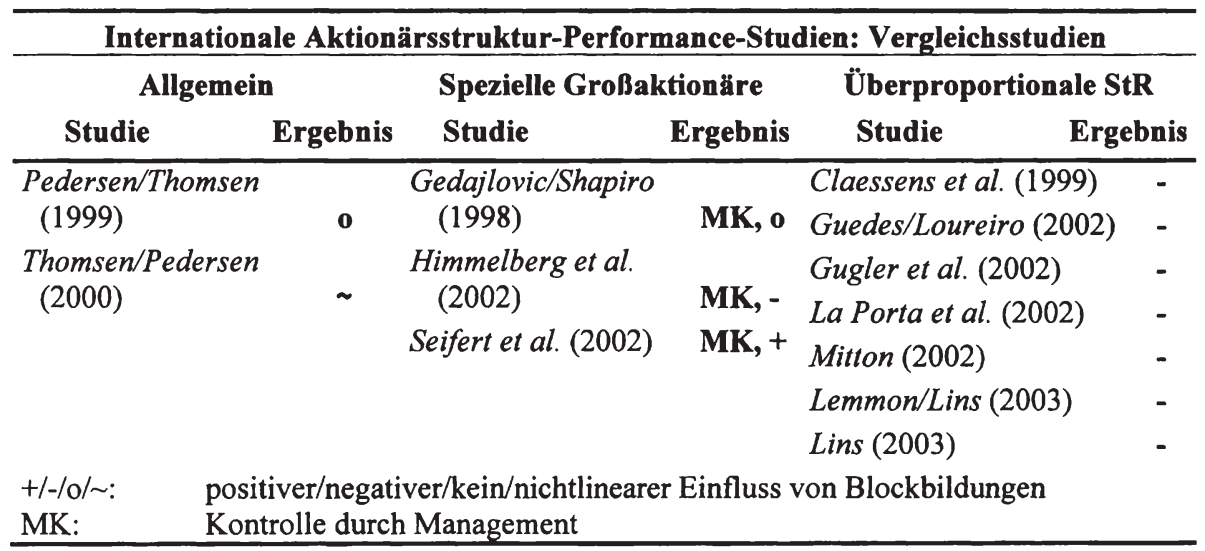

Tab. 7: Internationale Aktionärsstruktur-Performance-Studien: Vergleichsstudien

Tab. 8 beleuchtet die Regressionsanalysen, die sich auf einen Kapitalmarkt beziehen, die also die Auswirkung der Aktionärsstruktur unter gegebenen Rahmenbedingungen analysieren. Die Studien werden jeweils systematisiert nach Arbeiten, die die Performancewirkung der Aktionärsstruktur allgemein betrachten, nach solchen, die sich auf die Wirkung spezieller Großaktionäre beziehen und nach Studien, die die Wirkung divergierender Stimm- und Cash-Flow-

662 Für einen Überblick über Studien des deutschen Kapitalmarktes vgl. Abschnitt IIV.1.2. Einen Überblick über internationale Studien geben auch Short (1994); Goergen (1998), S. 14-22; Gugler (2001), S. 15-20. Eine grafische Darstellung der Ergebnisse von sieben Studien des US-Marktes findet sich bei Demsetz/Villalonga (2001).

663 Studien mit nicht klar zuzuordnenden Ergebnissen oder deutlich abweichenden Untersuchungsmethoden sind in den folgenden Tabellen nicht enthalten, werden jedoch in Anhang B.1 aufgeführt. Neben den hier aufgeführten Studien enthält Anhang B.1 zudem einzelne deskriptive Studien, die für das Verständnis von Aktionärsstrukturen von grundsätzlicher Bedeutung waren, begonnen mit der Arbeit von Berle/Means (1932). 
Rechte analysieren. Dabei wird jeweils auf das zentrale Ergebnis abgestellt; ${ }^{664}$ auf die Methodik einzelner, mit dieser Untersuchung vergleichbarer Studien, wird an späterer Stelle eingegangen.

\begin{tabular}{|c|c|c|c|c|c|}
\hline \multicolumn{6}{|c|}{$\begin{array}{c}\text { Internationale Aktionärsstruktur-Performance-Studien: } \\
\text { Studien für einen Kapitalmarkt }\end{array}$} \\
\hline \multicolumn{2}{|l|}{ Allgemein } & \multicolumn{2}{|c|}{ Spezielle Großaktionäre } & \multicolumn{2}{|c|}{ Überproportionale StR } \\
\hline Studie & Ergebnis & Studie & Ergebnis & Studie & Ergebnis \\
\hline Kamerschen (1968) & $\mathbf{0}$ & Mc Eachern (1975) & MK, + & Leech/Leahy (1991) & - \\
\hline Monsen et al. (1968) & + & Jacqumin/de Ghel- & & Wiwattanakantang & \\
\hline Larner (1970) & + & linck (1980) & FK, 0 & $(2001)$ & $\mathbf{0}$ \\
\hline Radice (1971) & + & Kim et al. (1988) & MK, + & Cronqvist/Nilsson & \\
\hline Elliott (1972) & $\mathbf{0}$ & Morck et al. (1988) & MK, & (2002) & $\mathbf{o}$ \\
\hline Boudreaux (1973) & + & McConnell/Servaes & $\mathbf{M K}, \sim$ & Volpin (2002) & - \\
\hline Palmer (1973) & $\mathbf{0}$ & $(1990)$ & IIK, + & Joh (2003) & - \\
\hline Holl (1975) & $\mathbf{0}$ & $\begin{array}{l}\text { Chaganti/Damanpour } \\
\text { (1991) }\end{array}$ & IIK, $\mathbf{0}$ & & \\
\hline Ware (1975) & - & Hermalin/Weisbach & & & \\
\hline Round (1976) & o & (1991) & MK, & & \\
\hline Holl (1977) & + & Oswald/Jahera & & & \\
\hline Steer/Cable (1978) & + & (1991) & MK, + & & \\
\hline Bothwell (1980) & + & Belkaoui/Pavlik & & & \\
\hline Levin/Levin (1982) & + & (1992) & MK, & & \\
\hline Demsetz/Lehn (1985) & o & Lichtenberg/Pushner & $r$ IIK, + & & \\
\hline Lloyd et al. (1986) & o & (1994) & FK, + & & \\
\hline $\begin{array}{l}\text { Holderness/Sheehan } \\
\text { (1988) }\end{array}$ & o & $\begin{array}{l}\text { Agrawal/Knoeber } \\
\text { (1996) }\end{array}$ & $\mathbf{M K}+$ & & \\
\hline Cosh/Hughes (1989) & + & Górriz/Fumás (1996) & ) FK, + & & \\
\hline Murali/Welch (1989) & $\mathbf{0}$ & Kole (1996) & MK, - & & \\
\hline $\begin{array}{l}\text { Zeckhauser/Pound } \\
\text { (1990) }\end{array}$ & o & $\begin{array}{l}\text { Loderer/Martin } \\
\text { (1997) }\end{array}$ & MK, o & & \\
\hline Prowse (1992) & o & $\begin{array}{l}\text { Mikkelson et al. } \\
\quad(1997)\end{array}$ & MK, $\mathbf{0}$ & & \\
\hline $\begin{array}{l}\text { Gugler (1999) } \\
\text { Himmelberg et al. }\end{array}$ & - & Nickell et al. (1997) & IIK, + & & \\
\hline$(1999)$ & $\sim$ & Cole/Mehran (1998) & $\mathbf{M K},+$ & & \\
\hline Bohren/Odegaard & & Cho (1998) & MK, + & & \\
\hline$(2001)$ & $\sim$ & Li/Simerly (1998) & MK, + & & \\
\hline Demsetz/Villalonga & & Chirinko et al. (1999) & 9) IIK, & & \\
\hline (2001) & $\mathbf{o}$ & Duggal/Millar (1999) & 9) IIK, o & & \\
\hline
\end{tabular}

664 Ein „o“ besagt etwa, dass zwischen Blockbildung und Performance kein Zusammenhang nachgewiesen wurde, „MK, +“ bei „Speziellen Großaktionären“ besagt, dass Anteilsbesitz beim Management einen positiven Einfluss ausübt. 


\begin{tabular}{lcccc}
\hline \multicolumn{5}{c}{ Internationale Aktionärsstruktur-Performance-Studien: } \\
Studien für einen Kapitalmarkt
\end{tabular}

Tab. 8: Internationale Aktionärsstruktur-Performance-Studien: Ein Kapitalmarkt

Bei der Bewertung der Ergebnisse ist zu berücksichtigen, dass die hier betrachteten Performancestudien an verschiedensten Kapitalmärkten über einen sehr langen Zeitraum entstanden sind, ${ }^{665}$ in dem insbesondere die ökonometrischen Verfahren zur Untersuchung multivariater Zusammenhänge deutlich weiterentwickelt wurden. Auch die unterschiedliche Samplegröße, andere einbezogene Variablen und Untersuchungszeiträume schränken die Vergleichbarkeit erheblich ein.

Auf Basis einer rein quantitativen Analyse überwiegt die Anzahl der Untersuchungen, die keinen Einfluss der Aktionärsstruktur auf die Performance nachweisen können. Bei den Studien, die einen signifikanten Zusammenhang sehen, besteht ein Überhang derer, die einen positiven Einfluss konstatieren. Ein solch positiver Einfluss wird dabei insbesondere von den Studien nachgewiesen, die in Ländern mit kapitalmarktorientierten Corporate-Governance-Systemen durchgeführt wurden ${ }^{666}$ Speziell für die USA weisen verschiedene Studien einen positiven Einfluss von Stimmrechtsbündelungen nach. Studien in Ländern mit netzwerkorientierten Corporate-Governance-Systemen können hingegen häufig keinen Einfluss nachweisen oder die Ergebnisse deuten auf einen negativen Einfluss von Blockbildung hin. Verschiedene der jüngeren Studien beziehen auch nichtlineare Beziehungen in die Analyse mit ein. Interessant ist, dass die vereinzelten Studien, die eine Differenzierung zwischen Cash-Flow- und Stimmrech-

665 Cronqvist/Nilsson (2002), S. 23, erläutern die Bedeutung des untersuchten Kapitalmarkts für das Ergebnis der Untersuchung.

666 Vgl. auch Gedajlovic/Shapiro (1998), S. 534. 
ten vornehmen, fast alle einen negativen Einfluss überproportionaler Stimmrechtsbündelungen auf die Performance konstatieren. Betrachtet man die Ergebnisse im Zeitablauf, so fällt auf, dass die eindeutig positive Wahrnehmung von Blockbildungen insbesondere bei älteren Studien zu verzeichnen ist, wohingegen die jüngeren Ergebnisse ambivalenter sind. Unklar ist jedoch, ob dieser Entwicklung tatsächlich ökonomische Veränderungen zugrunde liegen oder ob sie primär auf eine Weiterentwicklung der statistischen Verfahren zurückzuführen sein könnte.

\subsection{Studien für den deutschen Kapitalmarkt}

\subsubsection{Ausgangssituation}

Da die zuvor dargestellten Ergebnisse primär auf Kapitalmärkten erzielt wurden, die mit dem deutschen nur eingeschränkt vergleichbar sind, soll im Folgenden der Stand der Forschung über Eigentümer- und Stimmrechtsstrukturen am deutschen Kapitalmarkt vorgestellt werden. Studien auf Basis der Eigentümerstrukturdaten deutscher Unternehmen haben mit einer im internationalen Vergleich mangelhaften Datenqualität umzugehen. Dies gilt insbesondere dann, wenn sie nicht ausschließlich auf tagesaktuellen Daten basieren. Bereits im Rahmen von Kapitel II.3.5 wurde auf die geringe Transparenz hingewiesen, die lange Jahre hinsichtlich der Eigentümer- und Stimmrechtsstrukturen deutscher Gesellschaften bestand ${ }^{667}$ Erst seit der Einführung der $\S \S 21-25$ WpHG in 1995 liegen zumindest für die im amtlichen Handel notierten Aktiengesellschaften verlässliche Informationen vor - wenngleich nach wie vor keine explizite Differenzierung zwischen Kapital- und Stimmrechtsanteilen erfolgt und eine WpHG-Meldung nur bei Unter- oder Überschreiten der Meldeschwellen erfolgt. ${ }^{668}$ Es existiert somit keine umfassende, öffentlich zugängliche Datenbank, die einen Überblick über aktuelle und vergangene Stimmrechtsstrukturen deutscher Unternehmen gibt. Auch die individuelle Recherche für jedes Sampleunternehmen ist nur begrenzt erfolgversprechend, da bei den weit verbreiteten Inhaberaktien häufig selbst innerhalb eines Unternehmens keine Transparenz über die Anteilseignerstruktur herrscht. Sofern diese Kenntnis über die aktuelle Anteilseignerstruktur vorhanden ist, besteht häufig Unkenntnis über die Struktur der vergangenen Jahre oder es besteht unternehmensseitig keine Auskunftsbereitschaft. Entsprechend ist die Anzahl der untersuchten Unternehmen gerade bei den Studien, die ältere

667 Vgl. zu den Mängeln verschiedener Informationsquellen ausführlich Becht/Böhmer (1999).

668 Dem BAFin (vormals BAWe) werden nur Stimmrechtsanteile gemeldet. Seit dem 1.4.2002 betrifft die Meldepflicht alle in einem organisierten Markt notierten Aktiengesellschaften. 
Jahrgänge einbeziehen oder zwischen Stimm- und Cash-Flow-Rechten differenzieren, in der Regel deutlich kleiner als in Ländern, in denen aus einer öffentlich zugänglichen Datenbank die Eignerstruktur aller börsennotierten Unternehmen erhoben werden kann. Dennoch liegen auch für den deutschen Kapitalmarkt verschiedene Studien vor. Im Folgenden soll differenziert werden nach deskriptiven Studien, die die reine Erhebung von Anteilseignerstrukturen zum Ziel haben und Performancestudien, die die Verbindung zum Unternehmenswert herstellen und somit Vorläuferstudien der hier durchzuführenden Untersuchung sind. Neben den Value-Relevance-Studies soll hier den Event-Studies ein eigener Abschnitt gewidmet werden.

\subsubsection{Deskriptive Studien}

Nachdem in den USA die Diskussion über Vor- und Nachteile von Aktiengesellschaften mit breit gestreutem Kapital spätestens seit Berle/Means (1932) mit anhaltender Intensität geführt wird, war dieses in Deutschland - möglicherweise wegen der deutlich geringeren Bedeutung dieser Rechtsform - erst viel später ein Thema. Die vermutlich erste empirische Untersuchung stammt von Werth (1960), der im Rahmen seiner Befragung zum Zusammenspiel von Vorstand und Aufsichtsrat auch Daten zur Anteilseignerstruktur erhebt. ${ }^{669}$ Die folgende Tabelle gibt einen Überblick über Untersuchungsgegenstand, Methodik und zentrale Ergebnisse der Werth-Studie sowie späterer deskriptiver Untersuchungen zur Aktionärsstruktur: ${ }^{670}$

\begin{tabular}{|c|c|c|}
\hline $\begin{array}{l}\text { Autor } \\
\text { (Jahr) }\end{array}$ & $\begin{array}{l}\text { Gegenstand und } \\
\text { Methodik }\end{array}$ & Zentrale Ergebnisse \\
\hline Werth (1960) & $\begin{array}{l}\text { Befragung von } 136 \text { börsen- } \\
\text { notierten AG zum Zusam- } \\
\text { menspiel von Vorstand und } \\
\text { Aufsichtsrat, darin Erhe- } \\
\text { bung von Daten zur An- } \\
\text { teilseignerstruktur (Rück- } \\
\text { laufquote } 16,6 \% \text { ) }\end{array}$ & $\begin{array}{l}\text { - } 70 \% \text { der Gesellschaften mind. ,überwie- } \\
\text { gend“ in den Händen von Großaktionären } \\
\text { - } 66,2 \% \text { im Streubesitz (Ergebnisse wider- } \\
\text { sprechen sich teilweise) } \\
\text { - Großaktionäre üben Einfluss insb. über Or- } \\
\text { ganmitgliedschaften aus }{ }^{671}\end{array}$ \\
\hline
\end{tabular}

669 Werth verweist zudem auf ältere Daten des Statistischen Bundesamtes von 1958 hinsichtlich der Identität des Großaktionärs. Die dort gewählte Einteilung ist jedoch so unpräzise, dass sie hier nicht weiter betrachtet wird. Vgl. Werth (1960), S. 54.

670 Auf die Darstellung der regelmäßig erstellten Monopolkommission-Gutachten wird verzichtet. Für einen Überblick über thematisch verwandte Studien beispielsweise zur Aufsichtsratsbesetzung durch Aktionäre vgl. Böhmer (2001).

671 Nur drei der befragten Gesellschaften gaben an, dass der Großaktionär ohne Organmitglied zu sein, Einfluss auf die Geschäftspolitik nimmt. Auffällig ist jedoch, dass die (Groß-)aktionäre von 106 bzw. 23 der befragten 136 Gesellschaften ein Aufsichtsratsbzw. Vorstandsmandat bekleiden. Vgl. Werth (1960), S. 56f. 


\begin{tabular}{|c|c|c|}
\hline $\begin{array}{l}\text { Autor } \\
\text { (Jahr) }\end{array}$ & $\begin{array}{l}\text { Gegenstand und } \\
\text { Methodik }\end{array}$ & Zentrale Ergebnisse \\
\hline $\begin{array}{l}\text { Berndsen } \\
\text { (1961) }\end{array}$ & $\begin{array}{l}\text { Analyse der Identität des } \\
\text { Großaktionärs von } 2.533 \\
\text { AG }\end{array}$ & $\begin{array}{l}\text { - } 31 \% \text { sonstige Unternehmen } \\
\text { - } 14 \% \text { öffentliche Hand } \\
\text { - } 13 \% \text { Ausländer } \\
\text { - } 7 \% \text { Familien und natürl. Personen } \\
\text { - } 34 \% \text { nicht identifizierbar bzw. Streubesitz }\end{array}$ \\
\hline $\begin{array}{l}\text { Cassier } \\
(1962)\end{array}$ & $\begin{array}{l}\text { Analyse der Kapitalstruktu- } \\
\text { ren von } 136 \text { Großunter- } \\
\text { nehmen mit Hilfe öffentlich } \\
\text { verfügbarer Aktienführer }\end{array}$ & $\begin{array}{l}\text { - } 39 \% \text { sind konzernverbunden } \\
\text { - } 22 \% \text { im Streubesitz } \\
\text { - } 29 \% \text { haben Großaktionär (primär Privatper- } \\
\text { sonen, öffentliche Hand oder Familie, gerin- } \\
\text { ge Bedeutung von Banken) }\end{array}$ \\
\hline $\begin{array}{l}\text { Gefromm } \\
\text { (1965) }\end{array}$ & $\begin{array}{l}\text { Analyse der Identität des } \\
\text { Großaktionärs von } 2.533 \\
\text { AG; Untersuchungsaufbau } \\
\text { analog Berndsen (1961) }\end{array}$ & $\begin{array}{l}\text { - } 35 \% \text { sonstige Unternehmen } \\
\text { - } 14 \% \text { öffentliche Hand } \\
\text { - } 15 \% \text { Ausländer } \\
\text { - } 6 \% \text { Familien und natürl. Personen } \\
\text { - } 29 \% \text { nicht identifizierbar/Streubesitz } \\
\end{array}$ \\
\hline $\begin{array}{l}\text { Pross } \\
(1965)\end{array}$ & $\begin{array}{l}\text { Kontrollsituation der } 110 \\
\text { umsatzgrößten deutschen } \\
\text { Unternehmen }\end{array}$ & $\begin{array}{l}\text { - } 5 \% \text { vollständig eigentümerkontrolliert } \\
\text { - } 55 \% \text { unter Mehrheitsbesitz } \\
\text { - } 19 \% \text { Kontrolle durch mehrere Minderheits- } \\
\text { aktionäre } \\
\text { - } 20 \% \text { im Streubesitz }\end{array}$ \\
\hline $\begin{array}{l}\text { Hansen } \\
\text { (1976) }\end{array}$ & 865 Industrie- $A G$ & $\begin{array}{l}\text { - } 89 \% \text { haben Großaktionär }>40 \% \text { bei maß- } \\
\text { geblichem Einfluss bzw. }>50 \%{ }^{673} \\
\text { - } 8 \% \text { (Schachtel-)beteiligung }>25 \% \\
\text { - } 1 \% \text { im Streubesitz }\end{array}$ \\
\hline $\begin{array}{l}\text { Thonet/Poens- } \\
\text { gen (1979) }\end{array}$ & $\begin{array}{l}\text { Analyse von ca. } 300 \text { bör- } \\
\text { sennotierten AG für } 1961 \text {, } \\
1966 \text { und } 1970 \text { mit Hilfe } \\
\text { öffentlich verfügbarer Ak- } \\
\text { tienführer }\end{array}$ & $\begin{array}{l}\text { - Zwischen } 5 \% \text { (1970) und } 7 \%(1961) \text { im } \\
\text { Streubesitz } \\
\text { - Zwischen } 16 \% \text { (1970) und } 24 \% \text { (1961) ei- } \\
\text { gentümerkontrolliert }\end{array}$ \\
\hline $\begin{array}{l}\text { Vogel } \\
(1980)\end{array}$ & $\begin{array}{l}\text { Befragung von knapp } 300 \\
\text { Vorstands- oder Aufsichts- } \\
\text { ratsmitgliedern in mittel- } \\
\text { großen AG }\end{array}$ & $\begin{array}{l}\text { - } 76 \% \text { haben Mehrheitsaktionär mit }>75 \% \\
\text { des Kapitals } 675 \\
\text { - } 14 \% \text { mit }<50 \% \text { im Streubesitz, sonst Groß- } \\
\text { aktionär } \\
\text { - } 10 \% \text { mit }>50 \% \text { im Streubesitz }\end{array}$ \\
\hline
\end{tabular}

672 Zugrunde liegen Daten von 1959. Diese sind mit den von Werth (1960) untersuchten nicht identisch. Er nutzt insb. die Hoppenstedt- und Hypobank-Führer.

673 Insb. natürliche Personen und Familien (26\%), öffentliche Hand (16\%), Ausländer (13\%), Unternehmen (21\%) und Banken (7\%). Vgl. Hansen (1976), S. $296 f$.

674 Wer gehört zu wem?-Führer der Commerzbank.

$67527 \%$ Familie bzw. natürliche Person, $31 \%$ Konzernobergesellschaft, $18 \%$ zwei oder mehr Großaktionäre. Vgl. Vogel (1980), S. 74. 


\begin{tabular}{|c|c|c|}
\hline $\begin{array}{l}\text { Autor } \\
\text { (Jahr) }\end{array}$ & $\begin{array}{l}\text { Gegenstand und } \\
\text { Methodik }\end{array}$ & Zentrale Ergebnisse \\
\hline $\begin{array}{l}\text { Schreyögg/ } \\
\text { Steinmann } \\
(1981)^{676}\end{array}$ & $\begin{array}{l}\text { Analyse der } 300 \text { größten } \\
\text { deutschen Unternehmen in } \\
1972 \text { mit Hilfe öffentlich } \\
\text { verfügbarer Aktienführer }^{677}\end{array}$ & $\begin{array}{l}\text { - } 37 \% \text { rein eigentümerkontrolliert } \\
\text { - } 19 \% \text { unter Mehrheitsbesitz } \\
\text { - } 19 \% \text { Kontrolle durch mehrere Minderheits- } \\
\text { aktionäre } \\
\text { - } 25 \% \text { im Streubesitz } \\
\text { - In der ,zweiten Stufe“ sind } 35 \% \text { eigentümer- } \\
\text { und } 65 \% \text { managerkontrolliert }\end{array}$ \\
\hline $\begin{array}{l}\text { Mehrfeld } \\
\text { (1984) }\end{array}$ & $\begin{array}{l}\text { Analyse von ca. } 1.000 \mathrm{AG} \\
\text { des verarbeitenden Gewer- } \\
\text { bes an vier Stichtagen von } \\
1961-1980 \text { mit Hilfe öf- } \\
\text { fentlich verfügbarer Akti- } \\
\text { enführer }{ }^{678}\end{array}$ & $\begin{array}{l}\text { - Bedeutung von Holdinggesellschaften nimmt } \\
\text { im Zeitablauf zu, Eigentum von natürlichen } \\
\text { Personen geht zurück } \\
\text { - Kreditinstitute gehen insb. indirekte Beteili- } \\
\text { gungen ein } \\
\text { - Streubesitz relativ konstant über die Zeit }\end{array}$ \\
\hline $\begin{array}{l}\text { Iber (1985, } \\
1987)\end{array}$ & $\begin{array}{l}\text { Analyse von ca. } 350 \text { AG in } \\
\text { den Jahren } 1963,1973 \text {, } \\
1983 \text { mit Hilfe öffentlich } \\
\text { verfügbarer Aktienführer }\end{array}$ & $\begin{array}{l}\text { - Bedeutung von Unternehmen als Aktionär } \\
\text { nimmt zu, Eigentum von natürlichen Perso- } \\
\text { nen geht zurück } \\
\text { - Großaktionäre und ausländische Aktionäre } \\
\text { gewinnen an Bedeutung } \\
\text { - Stellung von Kleinaktionären im Zeitablauf } \\
\text { geschwächt }\end{array}$ \\
\hline Beyer (1998) & $\begin{array}{l}\text { Analyse von } 694 \text { Unter- } \\
\text { nehmen } 1992 \text { mit Hilfe } \\
\text { öffentlich verfügbarer Ak- } \\
\text { tienführer }^{680}\end{array}$ & $\begin{array}{l}\text { - } 36 \% \text { unter Mehrheitsbesitz }>75 \% \\
\text { - } 13 \% \text { unter Mehrheitsbesitz }>50 \% \\
\text { - } 40 \% \text { Kontrolle durch Minderheitsaktionär(e) } \\
>5 \% \\
\text { - } 11 \% \text { im Streubesitz } \\
\text { - Große Verflechtungen der Unternehmen }\end{array}$ \\
\hline $\begin{array}{l}\text { Becht/Böhmer } \\
(2001,2001 \mathrm{a})\end{array}$ & $\begin{array}{l}\text { Analyse der Kapital- und } \\
\text { Stimmrechtsstrukturen der } \\
\text { DAX-Unt. sowie der } \\
\text { Stimmrechtsstrukturen von } \\
430 \text { Nicht-DAX-Unt. per } \\
1996 \text { (BAWe-Daten) }\end{array}$ & $\begin{array}{l}\text { - Unternehmen mit } 2 \text { Aktienklassen sind stär- } \\
\text { ker konzentriert, nur } 2 \text { DAX-Unternehmen in } \\
\text { echtem Streubesitz } \\
\text { - Hohe Stimmrechtskonzentration bei den } \\
\text { Nicht-DAX-Unternehmen, mehr als } 50 \% \\
\text { haben Mehrheitsaktionär }\end{array}$ \\
\hline
\end{tabular}

${ }^{676} \mathrm{Zu}$ der Studie von Schreyögg/Steinmann ist kritisch anzumerken, dass sie Unternehmen, deren beherrschende Muttergesellschaft eine Publikumsgesellschaft ist, als managerkontrolliert betrachten. Diese Klassifikation erscheint jedoch verfehlt, da die Kleinaktionäre von Publikumsgesellschaften ihre Stimmrechte gerade nicht ausüben. Selbst wenn sie dieses täten, könnten sie keinen Einfluss auf die Geschäftspolitik von Tochterunternehmen ausüben. Vgl. Schreyögg/Steinmann (1981), S. 542f.

677 Wer gehört zu wem?-Führer der Commerzbank sowie der Hypobank-Führer.

$678 \mathrm{Vgl}$. zu den diversen eingesetzten Quellen Mehrfeld (1984), S. 110f.

679 Vgl. zu den diversen eingesetzten Quellen Iber (1985), S. 1110.

$680 \mathrm{Vgl}$. zu den diversen eingesetzten Quellen Beyer (1998), S. 26.

681 Ähnlich auch die Ergebnisse der vergleichbaren, internationalen Studie von van der Elst (2000). 


\begin{tabular}{|c|c|c|}
\hline $\begin{array}{l}\text { Autor } \\
\text { (Jahr) }\end{array}$ & $\begin{array}{l}\text { Gegenstand und } \\
\text { Methodik }\end{array}$ & Zentrale Ergebnisse \\
\hline $\begin{array}{l}\text { Köke } \\
(2001)\end{array}$ & $\begin{array}{l}\text { Analyse der Eignerstruktu- } \\
\text { ren von ca. } 1.000 \text { Kapital- } \\
\text { gesellschaften von 1993- } \\
\text { 1997, Identifikation des } \\
\text { finalen Eigners von Pyra- } \\
\text { miden (Hoppenstedt-Daten) }\end{array}$ & $\begin{array}{l}\text { - Hoher, zunehmender Konzentrationsgrad } \\
\text { Diskrepanz zwischen Stimm- und CF- } \\
\text { Rechten bei } 25 \% \text { der Unternehmen, jedoch } \\
\text { nur in geringem Umfang } \\
\text { - Überkreuzverflechtungen haben nur bei Fi- } \\
\text { nanzintermediären große Bedeutung }\end{array}$ \\
\hline Wójcik(2001) & $\begin{array}{l}\text { Analyse der Stimmrechts- } \\
\text { strukturen von ca. } 450 \text { bör- } \\
\text { sennotierten AG per } 1997 \\
\text { und } 2001 \text { (BAWe-Daten) }\end{array}$ & $\begin{array}{l}\text { - Konzentration im Zeitablauf rückläufig, da } \\
\text { mehr breit gestreute Unternehmen an die } \\
\text { Börse gegangen sind } \\
\text { - Stimmrechtsanteile von Banken rückläufig } \\
\text { - Hohe Konzentration insb. bei DAX-Unt. }\end{array}$ \\
\hline
\end{tabular}

Tab. 9: Deskriptive Studien zur Aktionärsstruktur in Deutschland

Die Ergebnisse der verschiedenen Studien weisen auch bei den Untersuchungen, die innerhalb eines vergleichbaren Zeitfensters entstanden sind, große Divergenzen auf. Diese sind primär auf die unterschiedlichen Datensätze zurückzuführen, die teilweise nur börsennotierte Aktiengesellschaften, teilweise auch nicht börsennotierte Kapitalgesellschaften und Personengesellschaften beinhalten. Zudem dominiert bei den älteren Studien die Identifikation der Eigentümer mittels individueller Recherche für jedes einzelne Unternehmen; bei mangelnder Datenverfügbarkeit fallen somit Unternehmen aus der Stichprobe heraus. Die jüngeren Studien von Wójcik (2001) und Becht/Böhmer (2001, 2001a) stützen sich auf die Stimmrechtsdatenbank des Bundesaufsichtsamts für den Wertpapierhandel, sodass sie entsprechend größere Datenmengen ohne Individualrecherche auswerten können. Der Nachteil ist jedoch, dass sie auf die Analyse von Stimmrechten beschränkt bleiben und freiwillige Angaben der Unternehmen zu Aktionären, die Anteile unterhalb der kritischen Meldeschwellen halten, unberücksichtigt bleiben.

Übereinstimmend konstatieren die Studien jedoch eine im internationalen Vergleich geringe Bedeutung des Streubesitzes. ${ }^{62}$ Die klassische „Berle/MeansUnternehmung" ist in Deutschland offensichtlich eine Randerscheinung. Eine vorsichtige Betrachtung der Entwicklungen im Zeitablauf unter Berücksichtigung der längerfristig angelegten Studien von Thonet/Poensgen (1979), Mehrfeld (1984) und Iber (1985, 1987), sowie der die jüngere Vergangenheit abdeckenden Studie von Köke (2001) zeigt zudem einen Bedeutungsgewinn von Großaktionären zu Lasten des Streubesitzes. Dabei überrascht insbesondere die Untersuchung von Köke (2001), da sie einen Zeitraum abdeckt (1993 - 1997),

682 Für internationale Vergleichszahlen vgl. die verschiedenen im vorigen Abschnitt zitierten internationalen Studien. 
der durch einen Bedeutungsgewinn des institutionalisierten Kapitalmarktes und durch ein stärkeres Interesse auch kleinerer Anleger an der Aktienanlage gekennzeichnet war. ${ }^{683}$ Hier hätte eine Entwicklung zu mehr Streubesitz anstelle starker Konzentrationstendenzen erwartet werden können. Zu erklären sein könnte dieses Phänomen mit der zugrunde liegenden Datenbasis, die zu einem großen Teil GmbHs beinhaltet, die im Zuge der fortschreitenden Konzentration einzelner Wirtschaftsbereiche vermehrt aufgekauft worden sind. Notwendig wäre hier eine Untersuchung der jüngeren Vergangenheit, die insbesondere die börsennotierten Unternehmen abdeckt.

Im Ergebnis kann festgehalten werden, dass die vorhandenen deskriptiven Studien des deutschen Kapitalmarkts auf eine hohe Bedeutung von Großaktionären bei im internationalen Vergleich geringem Streubesitz hindeuten. Dies impliziert, dass der Konflikt zwischen Groß- und Kleinaktionären von besonderer Relevanz sein könnte, wohingegen dem klassischen Konflikt zwischen Anteilseignern und Management eine geringere Bedeutung zukommen könnte, als an anderen Kapitalmärkten.

Informationen über die Divergenz zwischen Kapital- und Stimmrechtsanteilen sind rar, lediglich die Untersuchung von Becht/Böhmer (2001) unterscheidet hier überhaupt, wenngleich sie nur die DAX30-Unternehmen betrachtet. Hier besteht somit, neben einer Auswertung insbesondere jüngerer Daten, im deskriptiven Bereich noch erheblicher Forschungsbedarf.

\subsubsection{Performancestudien}

Die Arbeit von Kretschmann (1976) trägt den Titel „Der Einfluss der Aktionärsstruktur auf die Kursbildung" und ist wohl die erste Performancestudie am deutschen Kapitalmarkt. Es werden jedoch noch keine statistischen Verfahren eingesetzt, vielmehr wird fallstudienartig die Kursentwicklung von Unternehmen aus fünf verschiedenen Branchen in Abhängigkeit von der Aktionärsstruktur untersucht. Die Ergebnisse lassen jedoch keine Verallgemeinerung zu und differenzieren primär nach verschiedenen Arten von Kleinaktionären, sodass auf die Arbeit an dieser Stelle nur verwiesen werden soll. Andere Studien stellen den Zusammenhang zur Performance mit Hilfe von einfachen Mittelwertvergleichen ${ }^{684}$

683 Vgl. Titzrath (1995), S. 134; Drobetz/Schillhofer (2003), S. 20. Massiv zugenommen hat das Interesse von Kleinaktionären jedoch erst mit dem Börsengang der Deutschen Telekom AG im November 1996, der auf die Ergebnisse von Köke somit keinen maßgeblichen Einfluss mehr gehabt haben dürfte.

684 Vgl. Bühner (1984); Perlitz/Seger (1994); Chirinko/Elston (1996, 1996a). 
oder Korrelationsanalysen ${ }^{685}$ her, auf die aufgrund teilweise geringer statistischer Fundierung der Ergebnisse ebenfalls nur verwiesen werden soll.

\subsubsection{Regressionsanalysen zur Performance}

Zur Darstellung komplexerer Zusammenhänge zwischen verschiedenen beobachtbaren Variablen, zwischen denen eine Kausalität vermutet wird, bietet sich die Regressionsanalyse an. Studien, die den Einfluss ökonomischer Variablen auf den Unternehmenserfolg mit Hilfe einer solche Regressionsanalyse abschätzen, werden als „Value-Relevance-Studies“ bezeichnet. ${ }^{686}$ Sie werden regelmäßig auch zur Analyse des Einflusses der Aktionärsstruktur auf die Performance herangezogen. Dabei ist zu unterscheiden zwischen Arbeiten, die auf den Einfluss von Blockbildungen grundsätzlich abstellen und Studien, die die Auswirkung einer speziellen Aktionärsgruppe untersuchen. Im Zentrum der Studien, die sich mit der Auswirkung einer spezifischen Großaktionärsgruppe beschäftigen, steht in Deutschland fast ausschließlich der Einfluss von Kreditinstituten. Die Extrahierung der Wirkung des Kontrollpotenzials von Kreditinstituten, das aus eigenen Kapitalbeteiligungen resultiert, ist aus diesen Studien jedoch häufig schwierig, da viele der Arbeiten zusätzlich die Depotstimmrechte oder die Einflussnahme über Aufsichtsratsmandate berücksichtigen. Es sei daher auf die in Anhang B.3 ausgewiesenen zentralen Ergebnisse dieser Studien sowie ihre Methodik an dieser Stelle nur verwiesen.

Anhang B.2 gibt einen Überblick über allgemein ausgerichtete Arbeiten zum Aktionärsstruktur-Performance-Zusammenhang, die hinsichtlich Zielsetzung und Methodik mit der hier vorliegenden Arbeit grundsätzlich vergleichbar sind. Hier ist zu unterscheiden zwischen Studien, für die die Aktionärsstruktur expliziter Untersuchungsgegenstand ist und solchen, die sie als erklärende Variable berücksichtigen, in deren Fokus jedoch ein anderer Zusammenhang steht. ${ }^{687} \mathrm{Im}$ Folgenden sollen die Ergebnisse der Studien besprochen werden, die sich mit der Fragestellung der Aktionärsstruktur explizit auseinandergesetzt haben. Für die Studien, die den Einfluss der Aktionärsstruktur zwar miterheben, deren For-

685 Vgl. z.B. Witte (1981).

686 Vgl. zur Systematik von Value-Relevance-Studies Holthausen/Watts (2001), S. 5 f.

687 So analysiert Nowak (1997) primär die Auswirkung der Forschungsintensität auf die Performance, berücksichtigt jedoch als Kontrollvariable die Eigentümerstruktur in Form einer Dummy-Variablen. Lipka (1995) stellt auf die Trennung von Eigentum und Kontrolle in der Theorie der Unternehmung ab, Schmid/Seger (1998), Edwards/Nibler (2000) sowie Gorton/Schmid (2002) analysieren den Einfluss der Mitbestimmung und Wolf (1999) untersucht die Auswirkung alternativer Agency-Probleme auf den Unternehmenserfolg. 
schungsschwerpunkt jedoch auf anderen Themen liegt, sei auf Anhang B.2 verwiesen.

Die älteste Studie zur Aktionärsstruktur ist die von Thonet (1977) bzw. Thonet/Poensgen (1979), ${ }^{68}$ die für das oben beschriebene Sample ${ }^{689}$ einen negativen Einfluss von Stimmrechtskonzentrationen auf die Eigenkapitalrendite deutscher Unternehmen ermittelt haben, jedoch einen positiven Einfluss auf das Marktwert/Buchwert-Verhältnis. ${ }^{690}$ Als erklärende Variable im Rahmen ihrer Regressionsanalyse verwenden die Autoren eine Dummy-Variable (eigentümerversus managerkontrolliert). ${ }^{691}$

Die Studie von Gedajlovic/Shapiro (1998) betrachtet den deutschen Kapitalmarkt im Vergleich zu den USA, Großbritannien, Kanada und Frankreich. Berücksichtigt wird die Aktionärsstruktur von 99 deutschen Unternehmen im Jahr 1991. In ihrer multivariaten Regressionsanalyse für das deutsche Sample stellen sie einen nichtlinearen Zusammenhang zwischen dem Kapitalanteil des größten Aktionärs und der Gesamtkapitalrendite ${ }^{692}$ fest. $^{693}$ Sie finden bis zu einem Kapitalanteil von $70 \%$ einen signifikant negativen Einfluss von Blockbildungen, der dann jedoch signifikant positiv wird. Die Ergebnisse legen damit einen nichtlinearen Zusammenhang nahe, der hinsichtlich seines Verlaufs für mittlere und große Kapitalbeteiligungen der im theoretischen Teil formulierten Nichtlinearitätshypothese entspricht. Der positive Einfluss kleinerer Kapitalbündelungen wird hingegen nicht bestätigt. Die Studie von Gedajlovic/Shapiro ist für den deutschen Kapitalmarkt die erste, die die Höhe des Kapitalanteils des größten Aktionärs als erklärende Variable heranzieht, sodass ihr eine besondere Bedeutung zukommt. Kritisch anzumerken ist jedoch die eher geringe Samplegröße und die Beschränkung der Analyse auf ein Jahr.

Vom Ansatz her ähnlich ist die Untersuchung von Seifert/Gonenc/Wright (2002), die mit Deutschland, USA, Großbritannien und Japan ebenfalls vier Kapitalmärkte für ein Jahr (1999) parallel untersucht. Die Autoren stellen einen linearen, positiven Zusammenhang zwischen Stimmrechtsanteil des Managements und Performance für den deutschen Kapitalmarkt fest. Für Stimmrechtsbündelungen anderer Großaktionäre erzielen sie jedoch keine Ergebnisse. Die

\footnotetext{
688 Die Studien unterscheiden sich nur hinsichtlich der Stichprobe leicht.

689 Vgl. Abschnitt IIV.1.2.2.

690 Kontrollvariablen: Unternehmensgröße, Marktanteil.

691 Eigentümerkontrolliert bei Kapitalanteil $\geq 25 \%$. Kontrollvariablen: Unternehmensgröße, Marktanteil.

692 Definiert als net income/total assets. Vgl. Gedajlovic/Shapiro (1998), S. 544

$693 \mathrm{Vgl}$. Gedajlovic/Shapiro (1998), S. 546f.
} 
Ergebnisse sinnvoll einzuschätzen erscheint schwierig, da weder über die eingesetzten ökonometrischen Verfahren noch über das zugrunde liegende Sample aussagekräftige Informationen vorliegen.

Die beiden jüngeren, explizit den deutschen Kapitalmarkt betrachtenden Studien stammen von Lehmann/Weigand und Edwards/Weichenrieder, jeweils aus dem Jahr 2000. Lehmann/Weigand analysieren 361 deutsche Industrieunternehmen (AG und $\mathrm{GmbH}$ ) für den Zeitraum 1991-1996 (Panel-Studie) ${ }^{694}$ mittels einer multivariaten Regressionsanalyse unter Berücksichtigung von Instrumentenschätzern bzw. Fixed Effects. ${ }^{695}$ Ihre Studie ist nicht als reine Eigentümerstruktur-Studie konzipiert, ${ }^{696}$ sie beinhaltet verschiedene weitere Aspekte der Corporate Governance wie die Repräsentanz von Großaktionären in Vorstand oder Aufsichtsrat. Betrachtet wird ausschließlich das stimmberechtigte Eigenkapital, es erfolgt somit keine Differenzierung der Auswirkungen von Stimmrechts- und Cash-Flow-Bündelungen. Als erklärende Eigentümerstruktur-Variable ziehen die Autoren den Stimmrechtsanteil des größten Aktionärs $(\geq 5 \%)$ und einen Herfindahl-Index ${ }^{697}$ heran, die Identität des Aktionärs wird als Dummy-Variable abgebildet. ${ }^{698}$ Als zu erklärende Performancevariablen werden auf Basis der Einzelabschlussdaten kalkulierte operative Gesamt- und Eigenkapitalrenditen verwandt. Lehmann/Weigand finden einen negativen Einfluss von Stimmrechtsbündelungen bei Großaktionären, der bei nicht börsennotierten Unternehmen besonders ausgeprägt ist. Kontrollblöcke speziell bei institutionellen Investoren haben hingegen einen positiven Einfluss. Der Studie kommt insbesondere aufgrund der ausgereiften statistischen Durchführung ein hoher Erklärungsgehalt für den deutschen Kapitalmarkt zu. Aus ökonomischer Sicht ist jedoch die Verwendung von buchwertbezogenen Einzelabschlussdaten als Performancevariablen kritisch zu bewerten. Aus Aktionärssicht kommt dem Einzelabschluss des

694 Panel-Studien betrachten Datenreihen mehrerer Unternehmen über einen Zeitraum von mehreren Jahren, sie kombinieren somit Längsschnitt- und Querschnittsanalyse.

Vgl. zu den Verfahren ausführlich Kapitel IIV.2.2.

${ }^{696}$ Der Titel der Studie lautet „Does the Governed Corporation Perform Better?“. In einer weiteren Studie verändern sie ihr Forschungsdesign durch Verwendung eines „efficiency score" als erklärende Variable. Da dieses eine isolierte Identifizierung des Einflusses der Anteilseignerstruktur unmöglich macht, wird auf die Studie hier nicht weiter eingegangen. Vgl. Lehmann/Warning/Weigand (2002).

Der Herfindahl-Index wird als Summe der quadrierten Stimmrechtsanteile der Aktionäre berechnet, wobei die Kleinaktionäre einmal als ein Block und einmal mit einem unterstellten Stimmrechtsanteil von jeweils $1 \%$ in die Kalkulation eingehen. Vgl. Lehmann/Weigand (2000), S. 168.

698 Kontrollvariablen: Börsennotierung, Unternehmensgröße, Wachstum, Kapitalstruktur, Branche, Wettbewerbsintensität. Die Stimmrechtsdaten entstammen aus Hoppenstedt's Börsenführer, dem Hypobank- und dem Commerzbank-Führer. 
Mutterunternehmens nur eine sehr begrenzte Aussagekraft über die RenditeRisiko-Position des Konzerns zu. ${ }^{699}$ Hier wäre eine Verwendung von Konzernabschlussdaten bzw. bei den börsennotierten Unternehmen zusätzlich von marktbezogenen Daten sinnvoll gewesen. Zudem liefert die Untersuchung aufgrund ihrer Beschränkung auf Stimmrechtsanteile keinen Aufschluss über die Auswirkungen abweichender Stimm- und Cash-Flow-Rechte und eine eventuelle Nichtlinearität der Beziehung zwischen Stimmrechtsstruktur und Performance wird nicht berücksichtigt.

Die Arbeit von Edwards/Weichenrieder (2000) betrachtet hingegen Cash-Flowund Stimmrechte separat. Die Datenbasis beinhaltet jedoch nur 97 Industrieunternehmen zu einem Stichtag (1991), sodass der Aussagegehalt geringer einzuschätzen ist als bei einer Panel-Studie über mehrere Jahre. Als erklärende Variable verwenden die Autoren den Cash-Flow- bzw. Stimmrechtsanteil des größten und des zweitgrößten Aktionärs. ${ }^{700}$ Die abhängige Variable ist das Marktwert/Buchwert-Verhältnis. ${ }^{701}$ Die Studie deutet auf einen positiven Einfluss von Großaktionären auf die Performance hin, der jedoch negativ wird, sofern Stimmund Cash-Flow-Rechte auseinanderfallen. Die Existenz eines zweiten großen Aktionärs wirkt sich ebenfalls positiv aus. Edwards/Weichenrieder betrachten in ihrer Studie nur Unternehmen, deren Eigentümerstruktur über längere Zeit unverändert war, um eine Beeinflussung der Ergebnisse durch eine eventuelle Endogenität der abhängigen Variablen zu vermeiden. ${ }^{702}$ Dieses Verfahren erscheint jedoch problematisch, da es die Gefahr eines „Sample Selection Bias“ birgt und damit die Allgemeingültigkeit der Ergebnisse fraglich ist. ${ }^{703}$ Ein Sample Selection Bias liegt vor, wenn die Auswahl der in der Untersuchung enthaltenen Unternehmen nicht mehr zufällig erfolgt. Es könnte eine Kausalität dahingehend bestehen, dass gerade die langfristig orientierten Großaktionäre eine Kontrollfunktion wahrnehmen und so zwischen Unternehmensauswahl und Regressionsergebnis ein Zusammenhang besteht.

699 Vgl. ausführlich Pellens (1989), S. 49f. m.w.N. sowie S. 202-236; Schulte (1996), S. 258f., sowie Pellens (1994), S. 144f.; Sürken (1999), S. 17-19.

700 Als Stimmrechte werden die tatsächlich ausgeübten Stimmrechte auf der Hauptversammlung gewertet. Vgl. Edwards/Weichenrieder (2000), S. 14f.

701 Kontrollvariablen: Fremdkapitalquote, Betafaktor, Branche.

$702 \mathrm{Vgl}$. Edwards/Weichenrieder (2000), S. 20, 24f. zu einem hierzu durchgeführten Test mit Hilfe von Instrumentenschätzern. Zum Problem der Variablenendogenität vgl. ausführlich den folgenden Abschnitt IIV.2.2.1.

703 Vgl. ausführlich Börsch-Supan/Köke (2000), S. 17f., sowie Schremper (2002), S. 207209 m.w.N. 
Die jüngst erschienene Studie von Clark/Wójcik (2003) betrachtet den Einfluss von Stimmrechtsbündelungen auf die Aktienrendite. Die Autoren stellen einen negativen Zusammenhang fest.

Verschiedene weitere Studien betrachten den Einfluss von Eigentümer- und Stimmrechtsstrukturen auf die Performance nicht unmittelbar, sondern verwenden abhängige Variablen, die einen indirekten Schluss auf den Unternehmenserfolg zulassen. So wird der Einfluss der Aktionärsstruktur auf das Investitionsverhalten ${ }^{704}$ Produktivitätswachstum, ${ }^{705}$ Anzahl Vorstandswechsel ${ }^{706}$, Aktienliquidität ${ }^{707}$ und die Liquiditätslage des Unternehmens ${ }^{708}$ analysiert. Einen Überblick über die Ergebnisse gibt Anhang B.4.

\subsubsection{Event-Studies und Long-Run-Performance-Studies}

Neben den Value-Relevance-Studies werden Event-Studies und Long-Run-Performance-Studies herangezogen, um den Einfluss der Aktionärsstruktur auf den kapitalmarktbezogenen Unternehmenserfolg zu untersuchen. ${ }^{709}$ Im Rahmen der Eigentümerstrukturanalyse bietet sich als Ereignistag im Rahmen solcher Studien der Zeitpunkt eines Eigentümerwechsels an. Goergen (1998) untersucht daher die Eigentümerstrukturen vor und nach dem Börsengang für 62 deutsche IPOs von 1981-1988. ${ }^{710}$ Er kann jedoch keinen Einfluss des Anteils, den der Alteigentümer auch nach dem IPO behält, auf die Performance feststellen. Thies (2000) betrachtet im Rahmen seiner Long-Run-Performance-Study die langfristige Performance von 218 Börsengängen und 1.180 Kapitalerhöhungen im Zeitraum von 1974-1995. ${ }^{711} \mathrm{Er}$ stellt fest, dass die langfristige Performance von Unternehmen mit Großaktionären signifikant schlechter ist als die anderer Gesellschaften. ${ }^{712}$

Boehmer (2000) stellt hingegen auf die abnormalen Renditen bei Ankündigung eines Eigentümerwechsels im Rahmen einer Übernahme ab. ${ }^{713}$ Der Untersu-

\footnotetext{
704 Vgl. Elston (1993); Ossadnik/Dorenkamp (1999).

705 Vgl. Januszewski et al. (1999); Köke (2002), S. 109-128; Köke/Renneboog (2003).

706 Vgl. Franks/Mayer (1997/2001).

707 Vgl. Becht (1999).

708 Vgl. Weigand/Audretsch (1999); Haid/Weigand (2001).

709 Vgl. Brown (2001), S. 27f.; Schremper (2002), S. 123-171 m.w.N.

710 Vgl. Goergen (1998), S. 128.

711 Auf den Erfolg von Kapitalerhöhungen stellen auch die Arbeiten von Padberg (1995), Ljungqvist (1996) und Bessler/Kaen/Sherman (1998) ab, die jedoch den Einfluss der Aktionärsstruktur jeweils nur am Rande betrachten.

712 Vgl. Thies (2000), S. 440.

713 Vgl. Boehmer (2000), S. 117.
} 
chung liegen 715 Übernahmen durch 127 börsennotierte Unternehmen im Zeitraum von 1984 bis 1995 zugrunde. ${ }^{714}$ Das Vorhandensein eines Großaktionärs beim bietenden Unternehmen hat jedoch keinen positiven Einfluss auf die Übernahmeprämie, sodass nicht auf bessere Akquisitionsentscheidungen in großaktionärskontrollierten Unternehmen geschlossen werden kann. Kreditinstitute als Anteilseigner entwickeln dann eine positive Wirkung, wenn ein weiterer großer Aktionär vorhanden ist. Neben der Studie von Boehmer existieren verschiedene ältere Arbeiten, die die Relevanz der Aktionärsstruktur durch Analyse von Übernahmen untersuchen, auf die an dieser Stelle nur verwiesen werden soll. ${ }^{715}$

Dilger/Frick (2000) ${ }^{716}$ untersuchen die Kapitalmarktreaktionen auf Veröffentlichungen von Veränderungen der Stimmrechtsverteilung. ${ }^{717}$ Sie verwenden dabei die dem Bundesaufsichtsamt für den Wertpapierhandel gemeldeten Über- oder Unterschreitungen der relevanten Stimmrechtsgrenzen im Zeitraum vom 1995 bis 1996 . $^{718}$ Eine Kapitalmarktreaktion auf die Veröffentlichung können die Autoren jedoch weder mit Hilfe von Varianzanalysen noch mit Regressionsschätzungen nachweisen. Ein möglicher Grund könnte der bereits im Rahmen der theoretischen Analyse kritisierte lange Zeitraum sein, den eine solche WpHGMeldung im Extremfall benötigt, bis sie an den Kapitalmarkt kommuniziert wird.

Einen ähnlichen Untersuchungsaufbau verwendet Bott (2002), die ebenfalls die Kapitalmarktreaktionen auf WpHG-Meldungen untersucht. Sie analysiert die Kursreaktionen auf WpHG-Meldungen zu Änderungen des Stimmrechtsanteils von 117 Unternehmen im Zeitraum von September 1997 bis Januar 1999. Die erwartete positive Kursreaktion auf die Erhöhung von Stimmrechtsanteilen tritt nicht ein, nach der Veröffentlichung sind nur noch überwiegend nicht signifikante Restkurseffekte zu messen. Bezieht man den Zeitraum vor der Veröffentlichung mit ein, ergeben sich eher negative Kursreaktionen. Die erzielten Ergebnisse sind indes nur teilweise robust in Bezug auf die eingesetzten Verfahren.

Hinsichtlich des von Dilger/Frick (2000) und Bott (2002) angewandten Verfahrens sind folgende kritische Anmerkungen zu machen: Die Untersuchung der Kapitalmarktrelevanz der Aktionärsstruktur mittels einer Ereignisstudie ist

714 Er betrachtet nicht nur börsennotierte Unternehmen.

715 Vgl. Blättchen (1981); Bühner (1990, 1992); Grandjean (1992); Apenbrink (1993); Gerke/Garz/Oerke (1995); Böhmer/Löffler (1999); Eckardt (1999); Scheller (1999), sowie den Überblick bei Bott (2002), S. 95-98.

716 Vgl. ebenso Frick (1999).

717 Vgl. Dilger/Frick (2000), S. 18.

718 Das Sample beinhaltet 485 Veröffentlichungen. Vgl. zu den WpHG-Meldepflichten an das BAFin ausführlich Kapitel II.3.5. 
grundsätzlich nur dann sinnvoll, wenn der Ereigniszeitpunkt plausibel ermittelt werden kann. Gerade das ist jedoch in Anbetracht des langen Zeitraums zwischen Veränderung der Aktionärsstruktur und Kenntniserlangung durch den Kapitalmarkt (bis zu 16 Tage) schwierig. Die Wahrscheinlichkeit, dass verschiedene Kapitalmarktteilnehmer bereits vor der Veröffentlichung Kenntnis von der Stimmrechtsstrukturveränderung erlangen, ist hoch. Zudem führt eine weitere Akkumulation von Kapital durch den neuen Großaktionär auch nach Überschreiten der Meldegrenze aufgrund einer Verknappung des Angebots an Aktien zu Kurssteigerungen. ${ }^{719}$ Diese Kurssteigerungen könnten dann jedoch auf eine erhöhte Nachfrage durch den Großaktionär zurückzuführen sein und nicht auf eine positive Wahrnehmung des Kontrollerwerbs durch den Kapitalmarkt.

\subsection{Zwischenfazit}

Im Ergebnis kann somit festgehalten werden, dass bisher keine Studie für den deutschen Kapitalmarkt vorliegt, die im Rahmen einer Panel-Analyse die Auswirkungen divergierender Stimm- und Cash-Flow-Rechte auf den Unternehmenswert untersucht. ${ }^{720}$ Die beiden am engsten verwandten Studien von Lehmann/Weigand (2000) sowie Edwards/Weichenrieder (2000) differenzieren entweder nicht nach Stimm- und Cash-Flow-Rechten oder verwenden keine Panel-Daten. Die Studie von Edwards/Weichenrieder unterscheidet sich von dem hier zu wählenden Ansatz zudem dahingehend, dass sie nicht die Stimmrechtsanteile sondern die tatsächlich ausgeübten Stimmrechte betrachtet. ${ }^{721}$ Die verwandten Datensätze beziehen sich darüber hinaus auf die Jahre 1992-1996 bzw. 1991, sodass eine Analyse von jüngeren Daten, gerade vor dem Hintergrund der in den vergangenen Jahren $\mathrm{zu}$ beobachtenden Bedeutungszunahme des deutschen Aktienmarktes, einen zusätzlichen Erkenntnisfortschritt verspricht.

Im Folgenden wird eine eigene empirische Untersuchung durchgeführt, die eine deskriptive Analyse der Eigentümer- und Stimmrechtsstrukturen deutscher börsennotierter Aktiengesellschaften von 1997 - 2000 sowie eine Analyse des Zusammenhangs mit dem Unternehmenserfolg umfasst. Zunächst soll in Kapitel IV.2 ein Überblick über die einzusetzenden statistischen Verfahren gegeben werden. Dabei wird ein besonderes Augenmerk auf die spezifischen Probleme

719 Eine solche Situation ergibt sich z.B., wenn der neue Großaktionär bei Erwerb von $5 \%$ seine Meldepflicht erfüllt, aber weiter als Käufer am Markt auftritt, da er einen höheren Stimmrechtsanteil erwerben möchte. Ein Beispiel ist hier der Erwerb von CommerzbankAktien durch die Cobra Beteiligungsgesellschaft im Jahr 2000.

720 Auch auf internationaler Ebene untersuchen nur vereinzelt Studien speziell abweichende Kontroll- und Cash-Flow-Rechte unter Verwendung von Panel-Daten. Vgl. Claessens et al. (1999), S. 5.

721 Vgl. Edwards/Weichenrieder (2000), S. $14 \mathrm{f}$. 
einer solchen Untersuchung gelegt und die Datenbasis vorgestellt. Anschließend erfolgt in Kapitel IV.3 die deskriptive Analyse der Datenbasis, darauf aufbauend werden die Regressionsergebnisse dargestellt und interpretiert. Dabei sollen jeweils die Eigentümer- und Stimmrechtsstrukturen unter besonderer Berücksichtigung abweichender Stimm- und Cash-Flow-Rechte betrachtet werden.

\section{Grundlagen der empirischen Untersuchung}

\subsection{Multivariate Regressionsanalyse}

\subsection{1 Überblick über das Verfahren}

Zielsetzung der vorliegenden Untersuchung ist es, die Auswirkung der Eigenkapital- und Stimmrechtsstrukturen auf die Performance deutscher Aktiengesellschaften zu erklären. Die multivariate Regressionsanalyse überprüft, ob zwischen einer abhängigen bzw. erklärten Variablen (Regressand) und mehreren erklärenden Variablen (Regressoren) ein Zusammenhang besteht. ${ }^{722}$ Sie ermöglicht dabei nicht nur die Aufdeckung von Korrelationen, sondern gibt vielmehr Auskunft über Stärke und Richtung des Zusammenhangs. ${ }^{723}$ Voraussetzung für unverzerrte Schätzergebnisse ist die korrekte Spezifikation des zugrunde liegenden Modells unter Berücksichtigung des gegebenen Datenmaterials und des Analyseziels. ${ }^{724}$ Im Folgenden werden daher zunächst die Verfahrensgrundlagen dargestellt, um anschließend auf die Besonderheiten einzugehen, die sich bei der Analyse des Zusammenhangs von Anteilseignerstrukturen und Performance ergeben. ${ }^{725}$ In ihrer einfachsten, linearen Form ist die Regressionsgleichung wie folgt spezifiziert:

$$
y_{i}=\alpha+\beta_{1} x_{1 i}+\beta_{2} x_{2 i}+\ldots+\beta_{k} x_{k i}+u_{i}
$$

mit $y_{i}=$ Wert der zu erklärenden Größe (Regressand) des Objekts i

$\mathbf{x}_{\mathrm{ji}}=$ Wert der j-ten erklärenden Größe (Regressor) des Objekts $\mathrm{i}$

$\alpha=$ Regressionskonstante

$\beta_{\mathrm{j}}=$ Regressionskoeffizient (Parameter) der j-ten erklärenden Größe

$u_{i}=$ Wert der Störvariablen (Residuum) des Objekts i.

722 Vgl. zahlreiche Lehrbuchdarstellungen etwa bei Greene (2003), S. 7ff.; Kennedy (1998), S. 42ff.; Poddig et al. (2000), S. 204ff.; Gujarati (2003), S. 41 ff.; Fahrmeir et al. (1996), S. 478ff.; Backhaus et al. (2000), S. 2ff.; Winker (1997), S. $130 \mathrm{ff}$.

723 Vgl. Albrecht (1984), S. 213.

724 Vgl. Kennedy (1998), S. 42.

725 Vgl. zur Bedeutung von Modellanpassungen in Abhängigkeit von der spezifischen Analysesituation Kennedy (1998), S. 42f. 
Im Rahmen der vorliegenden Problemstellung spiegelt $y_{i}$ die Performance des Unternehmens wider, die verschiedenen $x_{j i}$ werden durch die erklärenden Aktionärsstrukturvariablen sowie verschiedene Kontrollvariablen gebildet. Die Regressoren können dabei metrisch oder kategorial skaliert sein. ${ }^{726}$ Der Koeffizient $\beta_{j}$ misst die Veränderung von $y$, die sich aus einer Veränderung von $x_{j}$ um eine Einheit ergibt. Die erklärenden Variablen sowie die Konstante $\alpha$ stellen die systematische Komponente des Modells dar, der Störterm $u_{i}$ die unsystematische. ${ }^{727}$ Der Störterm ist dabei die Zufallsvariable der beobachteten Werte der Störkomponente; er subsumiert alle Einflüsse, die durch die erklärenden Regressoren nicht abgebildet werden. ${ }^{728}$ Die Regressionskoeffizienten $\beta_{j}$ werden nach der sogenannten Methode der kleinsten Quadrate (OLS, Ordinary Least Squares) ermittelt, bei der die Summe der Quadrate der Residuen minimiert wird. ${ }^{729}$ Die Residuen sind die Abweichungen der mit Hilfe der Regressionsfunktion geschätzten Werte von den tatsächlich beobachteten Werten. ${ }^{730}$ Es wird somit eine Funktion gesucht, die einen möglichst großen Teil dieser Abweichungen erklärt und die Residuen minimiert. ${ }^{731}$

\subsubsection{Bewertung der Schätzgüte}

Aus den beobachteten Werten wird eine Regressionsgleichung ermittelt, die den Zusammenhang zwischen der zu erklärenden Variablen und der unabhängigen Variablen möglichst gut beschreibt. Diese Gleichung gibt Hinweise auf Stärke und Richtung des beobachteten Zusammenhangs, sie sagt jedoch für sich genommen nichts darüber aus, wie signifikant bzw. wie effizient die Schätzung gewesen ist. Erforderlich sind demnach Instrumente, mit denen die Schätzgüte bewertet werden kann; mit denen somit zu analysieren ist, wie gut sich die ge-

726 Im Falle einer kategorialen Zuordnung liegt eine „Dummy-Variable“ vor, die bei Zugehörigkeit des Objekts zur untersuchten Kategorie (z.B. Unternehmen hat Vorzugsaktien emittiert) gleich eins, sonst gleich null gesetzt wird. Vgl. Fahrmeir et al. (1996), S. 94, ausführlich Greene (2003), S. 116-122; Kennedy (1998), S. 221-232.

727 Vgl. Poddig et al. (2000), S. 204f.; Albrecht (1984), S. 214.

728 Vgl. Greene (2003), S. 7f.; Albrecht (1984), S. 214; Gujarati (2003), S. 45-47. Es wird unterstellt, dass die $u_{i}$ unabhängig verteilte Zufallsgrößen sind, deren Mittelwert null ist und die eine einheitliche Varianz aufweisen. Vgl. Chatterjee/Price (1995), S. 3.

729 Vgl. Chatterjee/Price (1995), S. 4f.; Gujarati (2003), S. 58-65; Poddig et al. (2000), S. 211-221.

730 Vgl. Albrecht (1984), S. 214; Backhaus et al. (2000), S. $12 \mathrm{f}$.

731 Vgl. Backhaus et al. (2000), S. 15. Für die Herleitung der Parameter vgl. Albrecht (1984), S. 218-223; Chatterjee/Price (1995), S. 4-6; Backhaus et al. (2000), S. $15 \mathrm{f}$. 
schätzte Gerade den beobachteten Werten anpasst und wie hoch ihre Schwankungen um ihren Mittelwert sind. ${ }^{732}$

Das lineare Bestimmtheitsmaß $r^{2}$ gibt an, wie gut die Regressionsfunktion die abhängige Variable erklärt. Ein $r^{2}$ von $30 \%$ zeigt z.B., dass die Variabilität der Performance zu $30 \%$ durch die in die Regressionsanalyse einbezogenen Variablen erklärt werden kann. Die Güte der Regression ist somit um so besser, je höher das $r^{2}$ ist. $r^{2}$ beschreibt das Verhältnis der durch die Regressoren $x_{j}$ erklärten Streuung zur Gesamtstreuung von y: ${ }^{733}$

$$
r^{2}=1-\frac{\sum\left(\hat{y}_{i}-\bar{y}_{i}\right)^{2}}{\sum\left(y_{i}-\bar{y}_{i}\right)^{2}}
$$

Das $r^{2}$ ist ceteris paribus um so größer, je mehr erklärende Regressoren in die Regression einbezogen werden, da jede zusätzliche Variable einen potenziellen Erklärungsgehalt aufweist. Dies gilt auch für ökonomisch irrelevante Regressoren. Als Maß für die Schätzgüte einer multivariaten Regression erscheint das unkorrigierte $r^{2}$ daher begrenzt geeignet. ${ }^{734}$ Stattdessen sollte hier das korrigierte bzw. adjusted $r^{2}$ (adj. $r^{2}$ ) verwandt werden. ${ }^{735}$ Das adj. $r^{2}$ vermindert das einfache $\mathrm{r}^{2}$ um eine Korrekturgröße, die um so größer ist, je größer die Zahl der Regressoren und je kleiner die Anzahl der Freiheitsgrade ist. ${ }^{736}$ Adj. $r^{2}$ ist Ausdruck des Anteils der erklärten Varianz und ist definiert als

$$
\operatorname{adj} \cdot r^{2}=r^{2}-\frac{J \cdot\left(1-r^{2}\right)}{I-J-1}
$$

$$
\begin{array}{ll}
\text { mit } \quad \text { I } & =\text { Zahl der Beobachtungswerte/Objekte } \\
\text { J } & =\text { Zahl der Regressoren und } \\
\text { I-J-1 } & =\text { Zahl der Freiheitsgrade. }
\end{array}
$$

Die Performance von Unternehmen wird in der Praxis durch eine Vielzahl von Faktoren beeinflusst, von denen nur ein Bruchteil im Rahmen der Regressionsanalyse abgebildet wird. Das $\mathrm{r}^{2}$ bewegt sich daher bei Value-Relevance-Studies in der Regel deutlich unterhalb von $50 \%$.

732 Vgl. Gujarati (2003), S. 81f.; Albrecht (1984), S. 219.

$733 \bar{y}$ ist der Mittelwert der geschätzten $\hat{y}$-Werte. Vgl. Chatterjee/Price (1995), S. 7; Greene (2003), S. 31-38; Backhaus et al. (2000), S. 22; Poddig et al. (2000), S. 204; Fahrmeir et al. (1996), S. 108f.

734 Vgl. Gujarati (2003), S. 217; Backhaus et al. (2000), S. 24.

735 Vgl. Greene (2003), S. 34f.; Backhaus et al. (2000), S. 24.

736 Adj. $\mathrm{r}^{2}$ kann somit durch die Hinzunahme weiterer Erklärender auch sinken. Vgl. Backhaus et al. (2000), S. 24; Gujarati (2003), S. 218f.; Greene (2003), S. 35. 
Als $\mathrm{Ma} ß$ zur Überprüfung der Qualität der gesamten Regressionsgleichung testet der F-Test die Signifikanz des Bestimmtheitsmaßes. ${ }^{737}$ Getestet wird die Nullhypothese, dass zwischen der abhängigen und den unabhängigen Variablen kein Zusammenhang besteht, die Koeffizienten also null sind. ${ }^{738}$ Die Hypothese wird abgelehnt, wenn der F-Wert den kritischen Wert übersteigt. Dann ist davon auszugehen, dass wenigstens einer der Regressoren einen Einfluss auf den Regressand hat. ${ }^{739}$ Hinsichtlich der Schätzgüte gilt somit, dass ein großer F-Wert auf einen hohen Erklärungsgehalt der Funktion hindeutet. Die F-Statistik wird wie folgt ermittelt: ${ }^{70}$

$$
F=\frac{\sum_{i=1}^{l}\left(\hat{y}_{i}-\bar{y}\right)^{2} / J}{\sum_{i=1}^{I}\left(\hat{y}_{i}-\bar{y}\right)^{2} /(I-J-1)}
$$

Interessanter für die Interpretation ist im Hinblick auf die zugrunde liegende Fragestellung jedoch speziell der Erklärungsgehalt der Eigentümerstrukturvariablen. Der Erklärungsgehalt der einzelnen Regressionskoeffizienten kann durch den t-Test beurteilt werden: Die Nullhypothese $\beta_{j}=0$ sagt aus, dass der j-te Regressor keinen Einfluss auf den Regressanden hat. ${ }^{71}$ Sie wird verworfen, wenn der absolute Betrag von $t$ den kritischen Wert übersteigt. ${ }^{742}$ Die Prüfgrößte

737 Auch: „Goodness of fit-Test“. Der F-Test berücksichtigt neben der Streuungszerlegung zusätzlich auch die Stichprobengröße. So wird ein möglicherweise sehr hohes $\mathrm{r}^{2}$, das aufgrund sehr weniger Beobachtungswerte zustande kommt, relativiert. Vgl. Greene (2003), S. 54f.; Backhaus et al. (2000), S. 25; Fahrmeir et al. (1996), S. 109f.

738 Vgl. Backhaus et al. (2000), S. 25f. Die F-Statistik wird dabei bestimmt als Verhältnis der jeweils durch die Zahl ihrer Freiheitsgrade dividierten erklärten und nicht-erklärten Streuung. Vgl. Backhaus et al. (2000), S. 26; Brannath/Futschik (2001), S. 207.

739 Der kritische Wert ergibt sich durch die Vorgabe eines Signifikanzniveaus. Wird etwa eine Irrtumswahrscheinlichkeit von $5 \%$ akzeptiert, so kann mit einer Wahrscheinlichkeit von $95 \%$ davon ausgegangen werden, dass, wenn der Test zu einer Annahme der Nullhypothese führt, kein Zusammenhang besteht. Vgl. Backhaus et al. (2000), S. 26f.; Poddig et al. (2000), S. 279; Greene (2003), S. 54.

740 I beschreibt die Größe des Stichprobenumfangs, J die Zahl der Regressoren.

741 Es liegt somit ein zweiseitiger t-Test vor. Vgl. zum t-Test Chatterjee/Price (1995), S. 7; Greene (2003), S. 50-52; Brannath/Futschik (2001), S. 207; Fahrmeir et al. (1996), S. 110-112, ausführlich auch Poddig et al. (2000), S. 279-288.

742 Der kritische t-Wert für eine theoretisch unendlich große Stichprobe liegt für $\alpha=0,05$ bei $|1,96|$. Der durch Statistikprogramme ausgewiesene $\mathrm{p}$-Wert gibt die Irrtumswahrscheinlichkeit an, mit der man sich aufgrund des ermittelten $\mathrm{t}$-Wertes für $\mathrm{H}_{1}$ entscheidet, obwohl $\mathrm{H}_{0}$ korrekt gewesen wäre. Ist der $\mathrm{p}$-Wert größer als $\alpha$, so wird $\mathrm{H}_{0}$ beibehalten. Vgl. Poddig et al. (2000), S. 286; Fahrmeir et al. (1996), S. 110. 
$\mathrm{t}_{\mathrm{j}}$ ist eine Student- bzw. t-verteilte Variable mit (n-k) Freiheitsgraden und wird wie folgt ermittelt: $:^{733}$

$t_{j}=\frac{\hat{\beta}_{j}-\beta_{j}}{s_{\hat{\beta}_{j}}}$

mit $\quad \hat{\beta}_{j} \quad=$ Regressionskoeffizient des j-ten Regressors

$\beta_{j} \quad=$ wahrer Regressionskoeffizient (unbekannt)

$s_{\hat{\beta},} \quad=$ Standardfehler des Regressionskoeffizienten des j-ten Regressors

\subsection{3 Überprüfung der Regressionsvoraussetzungen}

Die mit Hilfe von Bestimmtheitsmaß und verschiedenen Tests erzielten Aussagen besitzen jedoch nur dann Gültigkeit, wenn die verschiedenen Annahmen der OLS-Methode nicht verletzt wurden. Kennedy (1998) formuliert fünf Voraussetzungen, die für eine Anwendung erfüllt sein müssen, über die Tab. 10 einen Überblick gibt. ${ }^{744}$ Im Folgenden sollen die verschiedenen Annahmen überblickartig diskutiert werden, bevor in Kapitel IV.2.2 auf Spezialprobleme eingegangen wird, die die Analyse von Eigentümerstruktur und Performance betreffen.

\begin{tabular}{|c|c|c|c|}
\hline Annahme & Formale Darstellung & Verletzung durch & Folge \\
\hline $\begin{array}{l}\text { (1) Abhängige Varia- } \\
\text { ble kann als Linear- } \\
\text { funktion von Re- } \\
\text { gressoren und Stör- } \\
\text { term modelliert wer- } \\
\text { den }\end{array}$ & $\begin{array}{l}y_{i}=\alpha+\beta_{I} x_{i}+u_{i} \\
\text { für } \mathrm{i}=1, \ldots, \mathrm{I}\end{array}$ & $\begin{array}{l}\text { Fehlerhafte Regresso- } \\
\text { ren, Nichtlinearität, } \\
\text { nicht konstante Para- } \\
\text { meter }\end{array}$ & $\begin{array}{l}\text { Verzerrung der } \\
\text { Schätzwerte }\end{array}$ \\
\hline $\begin{array}{l}\text { (2) Erwartungswert } \\
\text { des Störterms ist null } \\
\text { (Vollständigkeit des } \\
\text { Modells) }\end{array}$ & $\begin{array}{l}E\left(u_{i}\right)=0 \\
\text { für alle i }\end{array}$ & $\begin{array}{l}\text { Unvollständiges Mo- } \\
\text { dell }\end{array}$ & $\begin{array}{l}\text { Verzerrung der } \\
\text { Schätzwerte }\end{array}$ \\
\hline $\begin{array}{l}\text { (3) Störterme haben } \\
\text { eine konstante Vari- } \\
\text { anz (Homoskedasti- } \\
\text { zität) und sind nicht } \\
\text { miteinander korre- } \\
\text { liert }\end{array}$ & $\operatorname{Var}\left(u_{i}\right)=\sigma^{2}$ & $\begin{array}{l}\text { Heteroskedastizität, } \\
\text { Autokorrelation }\end{array}$ & $\begin{array}{l}\text { Ineffizienz der Schät- } \\
\text { zung }\end{array}$ \\
\hline
\end{tabular}

743 Vgl. Greene (2003), S. 50f.; Backhaus et al. (2000), S. 29.

744 Vgl. Kennedy (1998), S. 43-45, ähnlich Backhaus et al. (2000), S. 33. Die Erfüllung ist Voraussetzung dafür, dass die Methode der kleinsten Quadrate effiziente Schätzwerte (best linear unbiased estimators, BLUE) liefert. Vgl. Greene (2003), S. 56f.; Poddig et al. (2000), S. 230f.; Fahrmeir et al. (1996), S. 99f.; Backhaus et al. (2000), S. 33. 


\begin{tabular}{llll}
\hline Annahme & Formale Darstellung & Verletzung durch & Folge \\
\hline $\begin{array}{l}\text { (4) Erklärende Vari- } \\
\text { ablen sind determini- } \\
\text { stische Größen }\end{array}$ & $\begin{array}{l}\text { Elemente der Daten- } \\
\text { matrix X sind feste } \\
\text { Größen }\end{array}$ & $\begin{array}{l}\text { Abhängigkeiten zwi- } \\
\text { schen Regressoren } \\
\text { und Residuen (Endo- } \\
\text { genität) }\end{array}$ & $\begin{array}{l}\text { Verzerrung der } \\
\text { Schätzwerte }\end{array}$ \\
$\begin{array}{l}\text { (5) Keine lineare Ab- } \\
\text { hängigkeit zwischen } \\
\text { den Regressoren; }\end{array}$ & $\sum_{i=1}^{I}\left(x_{i}-\bar{x}\right)^{2} \neq 0$ & $\begin{array}{l}\text { Perfekte Multi- } \\
\text { kollinearität }\end{array}$ & $\begin{array}{l}\text { Schätzung nicht } \\
\text { durchführbar }\end{array}$ \\
$\begin{array}{l}\text { Anzahl Beobachtun- } \\
\text { gen } \geq \text { Anzahl Re- } \\
\text { gressoren }\end{array}$ & & & \\
\hline
\end{tabular}

Tab. 10: Regressionsvoraussetzungen

\section{(1) LINEARITÄT DES MODELLS}

Die Annahme erfordert, dass das Modell in seinen Parametern konstant linear ist (korrekte Modellspezifikation). ${ }^{745}$ Sie wird verletzt durch (1) eine falsche Variablenauswahl, (2) Schwankungen in den Parametern oder (3) eine nichtlineare funktionale Form der Gleichung. Eine falsche Variablenauswahl liegt vor, wenn Variablen mit einem signifikanten Erklärungsgehalt nicht in die Regression einbezogen werden. ${ }^{746}$ Des weiteren müssen die Regressionskoeffizienten sowohl über die Zeit als auch über die verschiedenen Objekte konstant sein. ${ }^{747}$ Wenn der $\mathrm{zu}$ beschreibende Zusammenhang nicht linear ist, sind verzerrte Parameterschätzwerte die Folge, die sich auch bei zunehmendem Stichprobenumfang nicht mehr an die wahren Werte annähern. ${ }^{74}$ Problematisch ist eine nichtlineare Beziehung zwischen den Variablen, wenn sie nicht entdeckt und bei der Formulierung des Modells nicht berücksichtigt wird. ${ }^{749}$ Sofern also der ökonomische Zusammenhang Anlass gibt zu vermuten, dass die zu erklärende Beziehung nichtlinearer - z.B. quadratischer - Natur ist, so sollte in das Modell der linearen

745 Eine Linearität ist nur in den Parametern, nicht jedoch in den Variablen erforderlich. Vgl. Kennedy (1998), S. 94-108.

746 Vgl. zu den Folgen für die Effizienz der Schätzung ausführlich Kennedy (1998), S. $94 f$.

747 Sofern das ökonomische Umfeld nicht durch Strukturbrüche oder erhebliche Divergenzen im Unternehmensumfeld gekennzeichnet ist, kann von einer Konstanz der Parameter grundsätzlich ausgegangen werden. Vgl. Kennedy (1998), S. 99, 101.

748 Vgl. Backhaus et al. (2000), S. 34. Zu den Voraussetzungen der Unverzerrtheit bzw. Erwartungstreue der Schätzwerte vgl. Poddig et al. (2000), S. $231 \mathrm{f}$.

749 Vgl. Assenmacher (2002), S. 101f.; Sieber (1985), S. 516f.; Backhaus et al. (2000), S. 34. Das Vorliegen eines nichtlinearen Zusammenhangs und/oder unkorrekter Variablen kann z.B. mit Hilfe des RESET überprüft werden. Vgl. zu weiteren Verfahren Kennedy (1998), S. 98 . 
Mehrfachregression das Quadrat der unabhängigen Variablen als zusätzlicher Regressor mit aufgenommen werden. ${ }^{750}$

\section{(2) ERWARTUNGSWERT DER STÖRTERME GLEICH NULL}

Der Erwartungswert der Störterme ist immer dann gleich null, wenn die Störvariable $u_{i}$ nur zufällige Schwankungen beinhaltet, also das Regressionsmodell alle relevanten Einflussgrößen der abhängigen Variablen berücksichtigt (Vollständigkeit des Modells). ${ }^{751}$ Unterschieden wird „underfitting“ und „overfitting“ des Modells, also die Berücksichtigung von zu wenigen oder zu vielen Regressoren. Da die Verletzung dieser Modellannahme jedoch in der Regel nur zu einer Verzerrung des Schätzwertes für die Regressionskonstante und nicht zu verzerrten Schätzern für die Regressionskoeffizienten führt, ist sie im Vergleich als weniger gravierend einzuschätzen. ${ }^{752}$

\section{(3) HOMOSKEDASTIZITÄT UND FEHLENDE AUTORKORRELATION}

Heteroskedastizität und Autokorrelation der Störterme haben beide eine Ineffizienz der Schätzung zur Folge. ${ }^{753}$ Heteroskedastizität liegt vor, wenn die Störterme einzelner Beobachtungen nicht alle die gleiche Varianz aufweisen, also die Streuung der Residuen der geschätzten Variablen nicht konstant ist. Die Folge sind verzerrte Standardfehler. ${ }^{754}$ Heteroskedastizität liegt häufig in der Form vor, dass die Größe der Schätzfehler von der Größe der abhängigen Variablen abhängt. ${ }^{755}$ Sie kann entweder über eine visuelle Analyse der Residuen sowie formal über verschiedene Tests überprüft werden. ${ }^{756}$ Zur Behandlung bietet sich eine Transformation der abhängigen Variablen an. ${ }^{757}$ Alternativ können die Standardfehler mit Hilfe spezieller Verfahren geschätzt werden, die den Einfluss

750 Vgl. Brannath/Futschik (2001), S. 219. Die quadratische Erklärende $x^{2}$ wird dann transformiert in eine lineare Erklärende z. Eine solche Transformation ist immer dann möglich, wenn das Modell zwar nichtlinear in seinen Variablen, aber linear in den Parametern ist. Vgl. Kennedy (1998), S. 97.

751 Vgl. Backhaus et al. (2000), S. 37f.; Kennedy (1998), S. 113-115.

752 Vgl. Gujarati (2003), S. 337f.; Kennedy (1998), S. 113.

753 Vgl. Kennedy (1998), S. 116-126.

754 Die Folge sind verzerrte Testergebnisse. Die Koeffizienten selbst werden nicht verzerrt. Vgl. Chatterjee/Price (1995), S. 127; Kennedy (1998), S. 119-121; Backhaus et al. (2000), S. 38; Winker (1997), S. 159, 161; Assenmacher (2002), S. 180.

755 Dies ist häufig der Fall bei sehr langen, trendabhängigen Zeitreihen oder reinen Querschnittsanalysen. Vgl. Assenmacher (2002), S. 180; Kennedy (1998), S. 123.

$756 \mathrm{Zu}$ den bekanntesten Verfahren zählen der White-Test, Breusch-Pagan-Test oder Goldfeld-Quandt-Test. Vgl. Kennedy (1998), S. 120f.; Assenmacher (2002), S. 187-190; Winker (1997), S. 162. Vgl. Backhaus et al. (2000), S. 38f.

757 Vgl. Backhaus et al. (2000), S. 39, ausführlich Assenmacher (2002), S. 182-187. Zur Variablentransformation vgl. Chatterjee/Price (1995), S. 32-36. 
von Heteroskedastizität eliminieren (z.B. nach White oder Newey-West) ${ }^{758} \mathrm{Da}$ in der vorliegenden Studie eine große Anzahl von Unternehmen über eine begrenzte Anzahl von Jahren beobachtet werden, stellt Heteroskedastizität ein potenzielles Problem dar, das entsprechend zu berücksichtigen sein wird. ${ }^{759}$

Autokorrelation liegt vor, wenn die Störterme miteinander korreliert sind, also die Residuen nicht unabhängig voneinander sind. ${ }^{760}$ Sie stellt insbesondere bei der Analyse von Zeitreihen ein Problem dar, da aufeinanderfolgende Residuen häufig positiv korreliert sind. ${ }^{761}$ Autokorrelation führt zwar nicht zu verzerrten Schätzern, die Ergebnisse sind jedoch nicht effizient, also nicht varianzminimal. ${ }^{762}$ Die Überprüfung auf Autokorrelation erfolgt z.B. anhand von optischen Merkmalen, mit Hilfe des verbreiteten Durbin-Watson-Tests oder des an weniger restriktive Voraussetzungen gebundenen Breusch-Godfrey-Tests. ${ }^{763}$ Zur Anwendung kommen zudem Schätzverfahren, wie das von Newey-West, die auch bei Vorliegen von Autokorrelation robuste Ergebnisse liefern. ${ }^{764}$

\section{(4) ERKLÄRENDE VARIABLEN SIND DETERMINISTISCH}

Diese Annahme besagt, dass die Regressoren in verschiedenen Stichproben der Grundgesamtheit immer konstant sind, d.h. nicht selbst stochastische Zufallsvariablen sind und zwischen ihnen und den Residuen keine Abhängigkeit vorliegt. ${ }^{765}$ Folge von nicht konstanten Regressoren sind verzerrte Regressionskoeffizienten, die je nach Art der Korrelation den Zusammenhang zwischen abhängiger und unabhängiger Variable über- oder unterschätzen. ${ }^{766}$ Die Annahme ist immer dann verletzt, wenn die Kausalität zwischen abhängiger und unabhängi-

758 Vgl. White (1980); Greene (2003), S. 198-201; Kennedy (1998), S. 121, 134.

759 Vgl. Gedajlovic/Shapiro (1998), S. 544.

760 Vgl. Chatterjee/Price (1995), S. 157-181; Assenmacher (2002), S. $163 \mathrm{f}$.

761 Die Abweichungen von der Funktionsgleichung sind nicht mehr zufällig sondern abhängig von denen der vorangegangenen Beobachtungswerte. Vgl. Kennedy (1998), S. 122f.; Backhaus et al. (2000), S. 39; Chatterjee/Price (1995), S. 157.

762 Der Standardfehler wird bei Autokorrelation verzerrt geschätzt. Vgl. Chatterjee/Price (1995), S. 157f.; Backhaus et al. (2000), S. 39.

763 Vgl. Chatterjee/Price (1995), S. 162; Backhaus et al. (2000), S. 41. Zu grafischen Verfahren vgl. Gujarati (2003), S. 462-474. Zum Breusch-Godfrey-Test vgl. Kennedy (1998), S. 130; Gujarati (2003), S. 487f.

764 Der Newey-West-Schätzer ist robust sowohl gegen Heteroskedastizität als auch gegen Autokorrelation. Vgl. Gujarati (2003), S. 484f.

765 Vgl. Kennedy (1998), S. 137-146; Chatterjee/Price (1995), S. 120-124. Ist die Annahme verletzt, so gilt die Voraussetzung der Unkorreliertheit von Regressor und Störterm $\operatorname{cov}\left[x_{i}, \varepsilon_{i}\right]=0$ nicht mehr. Ausgelöst werden kann dies z.B. durch Messfehler bei der Variablenerhebung oder Autoregressivität. Vgl. Kennedy (1998), S. 137.

766 Vgl. Kennedy (1998), S. 138; Gujarati (2003), S. $715 f$. 
ger Variable nicht eindeutig ist, die beiden Variablen sind dann endogen. ${ }^{767}$ Ihre Erfüllung kann z.B. mit einem Hausman-Test überprüft werden. ${ }^{768}$ Sofern endogene Variablen vorliegen, sind spezielle Schätzverfahren erforderlich. Die gegenseitige Abhängigkeit kann z.B. durch die Nutzung von Instrumentalvariablen $^{769}$ im Rahmen von simultanen Gleichungssystemen berücksichtigt werden. ${ }^{770}$ Aufgrund der besonderen Bedeutung für diese Untersuchung wird das Problem endogener Variablen im Folgekapitel noch ausführlich betrachtet.

\section{(5) KEINE PERFEKTE MULTIKOLLINEARITÄT}

Diese Annahme besagt, dass die Regressoren nicht exakt linear abhängig sein dürfen, dass es also nicht möglich sein darf, eine erklärende Variable als lineare Funktion der übrigen erklärenden darzustellen. ${ }^{771}$ Zudem muss die Anzahl der Beobachtungswerte mindestens ebenso groß sein wie die Anzahl der Regressoren. ${ }^{772}$ Entscheidend ist, dass keine perfekte Multikollinearität der Regressoren vorliegt, also z.B. bei Dummy-Variablen, die sich zu 1 aufaddieren. ${ }^{773}$ Ein bestimmtes $\mathrm{Ma} 3$ an Korrelation zwischen den erklärenden Variablen ist in der Praxis fast immer gegeben und stellt für das Regressionsmodell noch keine Gefahr dar. ${ }^{774}$ Je größer sie jedoch ausfällt, desto größer werden die Standardfehler der Regressionskoeffizienten, was zu ineffizienten Parameter-Schätzwerten führt. ${ }^{775}$ Zur Aufdeckung von Multikollinearität können die Korrelationsmatrizen der Regressoren genutzt werden; hohe Korrelationskoeffizienten zwischen den Parametern deuten auf Multikollinearität hin. Ein weiterer Hinweis ergibt sich, wenn die Hinzunahme bzw. das Weglassen eines Regressors die Ergebnisse stark beeinflusst oder die erklärenden Variablen ökonomisch unplausible

767 Vgl. Gujarati (2003), S. $715 \mathrm{f}$.

768 Vgl. Hausman (1978); Greene (2003), S. 301-303; Kennedy (1998), S. 139; Gujarati (2003), S. 754f., sowie Kapitel IV.2.2.1.1.

769 Vgl. Kennedy (1998), S. 139; Greene (2003), S. 397f., ausführlich Assenmacher (2002), S. 318-324.

770 Gängig im Rahmen von Eigentümerstrukturanalysen ist hier z.B. die Two-Stage-LeastSquares-Methode. Vgl. Gujarati (2003), S. 762-779; Greene (2003), S. 378-400; Kennedy (1998), S. 157-162; Assenmacher (2002), S. 327-335.

771 Vgl. Greene (2003), S. 56-59; Backhaus et al. (2000), S. 41.

772 Ein Problem ergibt sich, wenn die Stichprobengröße und damit die Anzahl Freiheitsgrade zu gering ist. Vgl. Gujarati (2003), S. 342; Kennedy (1998), S. 183, 189.

773 Liegt exakte Multikollinearität vor, so kann der Regressionskoeffizient mathematisch nicht mehr bestimmt werden. Vgl. Kennedy (1998), S. 183; Winker (1997), S. 155.

774 Vgl. Gujarati (2003), S. 343; Backhaus et al. (2000), S. 41f.; Winker (1997), S. 155.

775 Vgl. Kennedy (1998), S. 184f. Die Folge von Multikollinearität kann sein, dass das $\mathrm{r}^{2}$ signifikant ist, obwohl alle Regressionskoeffizienten nicht signifikant sind. 
Vorzeichen aufweisen. ${ }^{776}$ Zur Behandlung der Multikollinearität bietet sich primär die Eliminierung von unabhängigen Variablen aus der Regressionsgleichung an. Dies ist jedoch problematisch, wenn diesen ökonomisch ein potenziell hoher Erklärungsgehalt zukommt. Alternativ bieten sich die Vergrößerung der Stichprobe oder eine Variablentransformation an. ${ }^{777}$

\subsection{Berücksichtigung besonderer ökonometrischer Probleme bei der Analyse von Eigentümerstrukturen}

Im Folgenden soll analysiert werden, welche der geschilderten Problemfelder bei Eigentümerstrukturstudien von besonderer Bedeutung sind. Die bisher wenig eindeutigen Ergebnisse empirischer Studien (vgl. Kapitel IV.1) haben dazu geführt, dass jüngere Veröffentlichungen verzerrenden Einflussfaktoren besondere Aufmerksamkeit widmen und mit Hilfe neuerer ökonometrischer Verfahren versuchen, diese weitestgehend zu vermeiden.

\subsubsection{Endogenität der abhängigen Variablen}

\subsubsection{Problem}

Im Rahmen der theoretischen Ausführungen in Teil III wurde davon ausgegangen, dass die Eigentümerstruktur einen Einfluss auf die Performance ausübt. ${ }^{778}$ Voraussetzung für eine solche Beziehung ist, dass die Aktionärsstrukturvariable tatsächlich exogen ist, also unabhängig von der zu erklärenden Größe. ${ }^{779}$ Sofern diese Unabhängigkeit nicht gewährleistet ist, liegt Endogenität der abhängigen Variablen vor, was $\mathrm{zu}$ einer Verzerrung der Regressionsergebnisse führen

776 Vgl. Greene (2003), S. 56f.; Kennedy (1998), S. 186f.; Gujarati (2003), S. 359-363. Als Daumenregel gilt, dass die Multikollinearität solange kein problematisches Ausmaß annimmt, wie das $\mathrm{r}^{2}$ der Regression größer ist als die $\mathrm{r}^{2}$ der unabhängigen Variablen, regressiert auf den Satz der anderen unabhängigen Variablen. Auch hohe t-Werte $(>2)$ sprechen gegen Multikollinearität. Vgl. Kennedy (1998), S. 187.

777 Vgl. Kennedy (1998), S. 188f.; Gujarati (2003), S. 363-369.

778 Vgl. Abschnitt III.2.2.

779 Diese Unabhängigkeit wurde durch die vielbeachtete Studie von Demsetz/Lehn (1985) erstmals infrage gestellt. 
kann. ${ }^{780}$ Im Rahmen der Analyse von Eigentümerstrukturen sind zwei Fälle von Endogenität zu unterscheiden: ${ }^{781}$

Umgekehrte Kausalität (,structural reverse causality“) liegt vor, wenn das Vorhandensein von Großaktionären nicht die Ursache einer besseren Performance ist, sondern vielmehr Großaktionäre speziell in die Unternehmen investieren, von denen sie eine Outperformance des Marktes erwarten. ${ }^{782}$ Der Zugang zu nicht öffentlich verfügbaren Informationen könnte ihnen eine Vorabidentifikation guter Unternehmen ermöglichen, sofern der Kapitalmarkt nur schwach informationseffizient ist. ${ }^{783}$ Geht in die Regressionsgleichung die Performancevariable als abhängige und die Eigentümerstruktur als unabhängige Variable ein, so bildet dies den ökonomischen Sachverhalt möglicherweise falsch ab.

Probleme ergeben sich zudem, wenn bestimmte Variablen, die sowohl die Eigentümerstruktur als auch die Performance simultan beeinflussen können, nicht beobachtbar sind und somit nicht als Kontrollvariable in die Regression aufgenommen werden können („unobserved firm characteristics“). ${ }^{784}$ Es liegt dann eine unechte Korrelation (,spurious correlation“) vor. Sofern z.B. ein Management in hohem Maße externen Kontrollmechanismen über den Güter- oder Kapitalmarkt unterliegt, sind Beteiligungen von Großaktionären unter Kontrollgesichtspunkten weniger erforderlich. Potenzielle Großaktionäre hätten nur geringe Anreize zu investieren, da sie durch Ausübung von Kontrolle nur geringe oder keine Verbesserungen der Profitabilität erzielen könnten. Übt nun der Wettbewerb auf dem Gütermarkt einen positiven Einfluss auf die Performance eines breit gestreuten Unternehmens aus, so könnte dieses fälschlicherweise auf die nur geringe Beteiligung von Großaktionären zurückgeführt werden. ${ }^{785}$ Tatsächlich ist die positive Performanceentwicklung jedoch durch exogene Faktoren bedingt, die in der Regressionsgleichung nicht berücksichtigt werden. ${ }^{786}$

780 Die vierte Annahme ist verletzt, die Regressoren sind nicht deterministisch. Vgl. Kennedy (1998), S. 157; Greene (2003), S. 381f.; Assenmacher (2002), S. $262 \mathrm{f}$.

781 Vgl. die ausführliche Darstellung bei Börsch-Supan/Köke (2002), S. 297-305, sowie annähernd inhaltsgleich Köke (2002), S. 12-36. Vgl. außerdem Coles et al. (2002), sowie zur Abgrenzung der beiden Varianten der Endogenität Himmelberg/Hubbard/Palia (1999), S. 356.

782 Vgl. Börsch-Supan/Köke (2002), S. 297; Berglöf (1997), S. 112; Loderer/Martin (1997), S. 235-238; Rajan/Zingales (1998), S. 584; Bohren/Odegaard (2001), S. 8; Woidtke (2002), S. 107; Lins (2003), S. 177f.

783 Vgl. grundlegend Fama (1970). Empirische Ergebnisse legen eine schwache bis halbstrenge Informationseffizienz des deutschen Kapitalmarkts nahe. Vgl. Holzer (2001).

784 Vgl. Himmelberg/Hubbard/Palia (1999), S. 357f.; Börsch-Supan/Köke (2002), S. 297f.; Loderer/Martin (1997), S. 234; Bhagat/Jefferis (2002), S. 37f.; Coles et al. (2002), S. 20.

785 Vgl. Bohren/Odegaard (2001), S. 2f., 7f.

786 Vgl. ähnlich Himmelberg/Hubbard/Palia (1999), S. 357f. 
Zwischen unabhängiger und abhängiger Variable wird dann eine nicht vorhandene Kausalität ausgewiesen, es liegt ein „Scheinzusammenhang“ vor. ${ }^{787}$

In beiden Fällen sind Eigentümerstruktur und Performance nicht unabhängig voneinander, die Eigentümerstruktur ist endogen. Im Ergebnis bedeutet dies, dass der Einfluss der Eigentümerstruktur auf die abhängige Performancevariable nicht mehr extrahiert werden kann, die Schätzungen für den Regressionskoeffizienten werden verzerrt und sind nicht mehr konsistent. ${ }^{788}$ Das Vorliegen von Endogenität muss somit im Untersuchungsdesign berücksichtigt werden. Hier bieten sich verschiedene Ansatzpunkte, die im folgenden Kapitel diskutiert werden.

Zunächst muss jedoch überprüft werden, ob Endogenität vorliegt. Hier wird neben dem Granger-Kausalitätstest ${ }^{789}$ häufig ein Hausman-Test eingesetzt. ${ }^{790} \mathrm{Ge}$ testet wird die Nullhypothese, dass zwischen den erklärenden Variablen und den Störtermen keine Korrelation besteht. ${ }^{791}$ Dabei werden die Schätzergebnisse alternativer Verfahren miteinander verglichen. So wird die Regressionsgleichung zunächst mittels einer einfachen OLS-Schätzung regressiert, die eine potenzielle Endogenität nicht berücksichtigt. Anschließend erfolgt eine Regression mit einem die Endogenität berücksichtigenden Verfahren. Die Nullhypothese, dass keine Korrelation und damit Endogenität vorliegt, wird bestätigt, wenn beide Verfahren zu ähnlichen Ergebnissen führen. ${ }^{792}$ In einer anderen Version des Hausman-Tests werden zwei simultane Gleichungen mit endogenen und exogenen Variablen zugrunde gelegt. ${ }^{793}$ Der Störterm, der sich aus der Schätzung der einen Gleichung ergibt, wird als Regressor in die andere einbezogen. Sofern der Koeffizient nicht signifikant von null verschieden ist, liegt keine Korrelation vor. $^{794}$

787 Vgl. Börsch-Supan/Köke (2000), S. 297f.; Himmelberg/Hubbard/Palia (1999), S. 358; Bhagat/Jefferis (2002), S. 37; Poddig et al. (2000), S. 341-344.

788 Vgl. Loderer/Martin (1997), S. 235. Für den formalen Beweis vgl. Börsch-Supan/Köke (2002), S. 298.

789 Vgl. Granger (1969), erläuternd Eckey/Kosfeld/Dreger (2001), S. 362-365; Köke (2002), S. 15; Greene (2003), S. 592f.

790 Vgl. Gujarati (2003), S. 754f.; Kennedy (1998), S. 174; Himmelberg/Hubbard/Palia (1999), S. 373; Alecke (1997), S. 109-111; Cronqvist/Nilsson (2002), S. 17; Hermalin/Weisbach (1991), S. 107.

$791 \mathrm{Vgl}$ Kennedy (1998), S. 138f.

792 Vgl. Kennedy (1998), S. 138f., 150f., $174 \mathrm{f}$.

793 Vgl. Cronquist/Nilsson (2002), S. 18; Gujarati (2003), S. 754

794 Diese Variante findet sich in der Literatur auch unter dem Namen Durbin-Wu-HausmanTest. Vgl. Davidson/MacKinnon (1993), S. 237-242. 


\subsubsection{Lösungsansätze}

\subsection{Auswahl des Regressionsmodells}

Eingesetzt werden können z.B. simultane Gleichungssysteme, die durch Schätzung einer zusätzlichen Regression die Möglichkeit einer umgekehrten Kausalität explizit berücksichtigen. Die ursprünglich unabhängige Variable wird in der zweiten Gleichung zur abhängigen Variablen und erklärt durch den Regressanden der ersten Gleichung. ${ }^{795}$ Voraussetzung ist, dass die Kontrollvariablen tatsächlich exogen sind, sonst wäre eine weitere Gleichung mit der endogenen Kontrollvariablen als Regressand erforderlich. ${ }^{796}$ Für die im Rahmen dieser Untersuchung interessierende Beziehung zwischen Marktwert/Buchwert-Verhältnis (MWBW) und dem Kapitalanteil des größten direkt beteiligten Aktionärs (StA1) ergäbe sich, ergänzt um verschiedene Kontrollvariablen (KV), folgendes beispielhaftes Gleichungssystem: ${ }^{797}$

$$
\begin{aligned}
& M W B W_{l i}=\beta_{10}+\beta_{I I} S t A I_{2 i}+\sum_{k=1}^{K} \beta_{l k} K V_{k i}+u_{l i} \\
& S t A I_{2 i}=\beta_{20}+\beta_{21} M W B W_{l i}+\sum_{k=1}^{K} \beta_{2 k} K V_{k i}+u_{2 i}
\end{aligned}
$$

Simultane Gleichungssysteme liegen der Instrumentalvariablenmethode (IVMethode) sowie der zweistufigen Kleinste-Quadrate-Methode zugrunde, die im Rahmen von Eigentümerstrukturstudien häufig zur Anwendung kommen ${ }^{798}$ Bei der IV-Methode bzw. „instrumental-variables-technique“ wird dem Endogenitätsproblem begegnet, indem die endogenen Variablen durch exogene ersetzt werden. Dies geschieht derart, dass für den endogenen Regressor eine oder mehrere Instrumentalvariablen gesucht werden, die als neue unabhängige Variablen in die Regression aufgenommen werden. ${ }^{799}$ Diese neuen Variablen sollten möglichst stark mit der zu ersetzenden endogenen Variablen korreliert sein, jedoch nicht mit den Störvariablen. ${ }^{800}$

\footnotetext{
795 Vgl. Gujarati (2003), S. 718f.; Kennedy (1998), S. 157; Coles et al. (2002), S. 27-31.

796 Vgl. Loderer/Martin (1997), S. 236.

797 Vgl. Gujarati (2003), S. 770f., sowie die Umsetzungen bei Loderer/Martin (1997), S. 236; Cho (1998), S. 114; Demsetz/Villalonga (2001), S. 218-220.

$798 \mathrm{Zu}$ weiteren Methoden vgl. Kennedy (1998), S. 163-166; Gujarati (2003), S. 763-770; Assenmacher (2002), S. 312-318, sowie Greene (2003), S. 396-411.

799 Vgl. Gujarati (2003), S. 678f.; Assenmacher (2002), S. 318; Greene (2003), S. 74-80.

800 Vgl. Kennedy (1998), S. 139; Greene (2003), S. 86, ausführlich Assenmacher (2002), S. 318-324.
} 
Die Schwierigkeit dieses Ansatzes liegt darin, Instrumentalvariablen zu finden, die hinsichtlich ihres ökonomischen Erklärungsgehalts geeignet sind, als Substitut für die endogene Variable zu dienen, ohne gleichzeitig auch den Regressanden zu beeinflussen. ${ }^{801}$ Gut geeignet sind die exogene Variablen des simultanen Gleichungssystems ${ }^{802}$ sowie verzögerte Werte („lagged values“) des endogenen Regressors. ${ }^{803}$ Die Aktionärsstruktur des Jahres 1 wird in der Regel mit der des Jahres 0 korreliert sein, ohne jedoch mit den Störtermen korreliert zu sein. ${ }^{804}$ Verschiedene Vergleichsstudien haben gezeigt, dass die Verwendung von Instrumentenschätzern den Erklärungsgehalt von Eigentümer-PerformanceStudien signifikant erhöhen kann. ${ }^{805}$ Voraussetzung für konsistente Ergebnisse ist jedoch, dass der Zusammenhang zwischen der zu erklärenden Performancevariablen und der endogenen Eigentümerstrukturvariablen zwischen den untersuchten Unternehmen nicht zu stark variiert. ${ }^{806}$ Zudem ist die Qualität der Ergebnisse in hohem Maße abhängig von der Auswahl der Instrumentalvariablen. $^{807}$

Die Zweistufige Kleinste-Quadrate-Methode („Two-Stage-Least-Squares“ oder „2SLS“) kann grundsätzlich als Unterform der IV-Methode interpretiert werden. ${ }^{808}$ Es werden zwei Gleichungen geschätzt, wobei in jede Gleichung mindestens eine Instrumentalvariable integriert wird, die nicht Bestandteil der anderen Gleichung ist. ${ }^{809}$ Die Auswahl der Instrumentalvariablen geschieht bei der 2SLS-Methode nicht ausschließlich auf Basis von ökonomischem Sachverstand, vielmehr wird die am besten geeignete Variable mittels ökonometrischer Ver-

801 Vgl. Heckman (1997), S. 442; Gujarati (2003), S. 679; Kennedy (1998), S. 164.

802 Diese sind mit den endogenen Variablen in der Regel korreliert, jedoch nicht mit den Störtermen. Vgl. Kennedy (1998), S. 164.

803 Dabei wird unterstellt, dass die Störterme nicht autokorreliert sind. Vgl. Greene (2003), S. 80; Börsch-Supan/Köke (2002), S. 302; Kennedy (1998), S. 142, 169, der weitere Vorschläge für die Bildung von Instrumentalvariablen macht. Diese „lagged values" werden auch als ,predetermined variables" bezeichnet.

804 Es gilt daher die Annahme, dass Regressor und Störterm unkorreliert sind, also gilt: $\operatorname{cov}\left[x_{i}, u_{i}\right]=0$.

805 Vgl. den Überblick von Zhou (2001).

806 Vgl. Heckman (1997), der die IV-Methode kritisch hinterfragt. Nachteil der IV-Methode ist die große Varianz-Kovarianz-Matrix und die erhöhte Gefahr von Multikollinearität. Vgl. Kennedy (1998), S. 139; Greene (2003), S. 80; Gujarati (2003), S. 678.

807 Alternative Instrumentalvariablen können zu unterschiedlichen Ergebnissen führen. Vgl. Bohren/Odegaard (2001), S. 33.

808 Vgl. Greene (2003), S. 79; Kennedy (1998), S. 165; Gujarati (2003), S. 770-775; Assenmacher (2002), S. 327-335.

809 Vgl. Woidtke (2002), S. 108; Lins (2003), S. 178. 
fahren bewusst herausgefiltert. ${ }^{810}$ Dazu werden die endogenen erklärenden Variablen auf alle exogenen Regressoren des simultanen Gleichungssystems regressiert (Schritt 1): $:^{811}$

$$
M W B W_{l i}=\hat{\delta}_{0}+\sum_{k=1}^{K} \hat{\delta}_{k} K V_{k i}+\hat{u}_{i}
$$

Aus der so geschätzten Gleichung ergibt sich $M \hat{W} B W_{l i}$ als Schätzwert für den Mittelwert der Marktwert/Buchwert-Verhältnisse in Abhängigkeit der exogenen Kontrollvariablen. $\hat{\delta}$ sind die Koeffizienten der auf diese Weise reduzierten Schätzung, die als Linearkombinationen der Koeffizienten beider Gleichungssysteme ermittelt werden. ${ }^{812}$ Es gilt: ${ }^{813}$

$$
M \hat{W} B W_{l i}=\hat{\delta}_{0}+\sum_{k=1}^{K} \hat{\delta}_{k} K V_{k i}
$$

$M W B W_{1 i}$ kann ausgedrückt werden als:

$$
M W B W_{l i}=M \hat{W} B W_{l i}+\hat{u}_{i}
$$

Die nicht stochastische Variable $M W B W_{l}$ wird als Linearkombination der nichtstochastischen Kontrollvariablen und eines Störterms dargestellt. Diese beiden Komponenten sind unkorreliert, so dass die Voraussetzung der nicht stochastischen Regressoren wieder erfüllt ist. ${ }^{814}$ Die so geschätzten Werte der endogenen Variablen werden in Schritt 2 als Instrumentalvariablen für die endogenen Regressoren in die Regression aufgenommen. ${ }^{815}$ Die zweite Gleichung kann entsprechend formuliert werden als

810 Vgl. Kennedy (1998), S. 165; Greene (2003), S. 398-400; Assenmacher (2002), S. 329.

811 Durch diesen Schritt wird die Korrelation zwischen Regressor und Störterm beseitigt Vgl. Gujarati (2003), S. 771. Entscheidend ist, dass auch auf die Kontrollvariablen der zweiten Gleichung regressiert wird. Vgl. Gujarati (2003), S. 773.

812 Zur formalen Herleitung vgl. Gujarati (2003), S. 742.

813 Vgl. Gujarati (2003), S. 771.

814 Für den Nachweis der Unkorreliertheit vgl. Gujarati (2003), S. 773.

815 Alternativ können die ermittelten Schätzwerte sowie die exogenen Variablen als Regressoren im Rahmen einer normalen OLS-Schätzung dienen. Vgl. Kennedy (1998), S. 165 $\mathrm{Zu}$ einer formalen Darstellung der beiden Schritte vgl. Greene (2003), S. 398-400; Gujarati (2003), S. 771. 


$$
\begin{aligned}
S t A 1_{2 i} & =\beta_{20}+\beta_{2 I}\left(M \hat{W} B W_{l i}+\hat{u}_{i}\right)+\sum_{k=1}^{K} \beta_{2 k} K V_{k i}+u_{2 i} \\
& =\beta_{20}+\beta_{2 I} M \hat{W} B W_{l i}+\sum_{k=1}^{K} \beta_{2 k} K V_{k i}+u_{2 i}+\beta_{2 I} \hat{u}_{i} \\
& =\beta_{20}+\beta_{2 I} M \hat{W} B W_{l i}+\sum_{k=1}^{K} \beta_{2 k} K V_{k i}+u^{*}{ }_{i}
\end{aligned}
$$

mit $u^{*}=u_{2 i}+\beta_{2 l} \hat{u}_{i}^{816}$

Obwohl die Gleichung der Ausgangsgleichung sehr ähnlich sieht, ist $M \hat{W} B W_{1 i}$ mit $u^{*}{ }_{i}$ bei ausreichender Samplegröße nicht korreliert, wohingegen $M W B W_{1}$ mit den Störtermen korreliert war. ${ }^{817}$ Das Ergebnis sind somit konsistente Schätzwerte. Vorteil der 2SLS-Methode ist ihre vergleichsweise große Robustheit in Bezug auf Annahmenverletzungen wie Multikollinearität sowie Fehlern in der Variablenspezifikation. ${ }^{818}$

\subsection{Verwendung von Panel-Daten}

Neben der Auswahl eines geeigneten Regressionsmodells kommt der Art der Datenverarbeitung eine entscheidende Bedeutung zu. Wird der Zusammenhang zwischen Eigentümerstruktur und Performance über mehrere Jahre beobachtet, so können die resultierenden Beobachtungen entweder als Querschnitts- oder als Panel-Studie analysiert werden. Die Querschnittsanalyse fasst alle zu verschiedenen Zeitpunkten beobachteten Werte eines Merkmalsträgers in einem Datenpool zusammen. Panel-Studien erfassen hingegen die komplexe Datenstruktur vollständig, indem sie die $\mathrm{i}=1,2, \ldots, \mathrm{N}$ Unternehmen des Datensatzes $\mathrm{zu} t=1$, 2 ,..., T Zeitpunkten im Rahmen einer matrixartigen Struktur erfassen. ${ }^{819}$ Die Information, dass die Unternehmen mehrfach zu verschiedenen Zeitpunkten im Sample enthalten sind, wird somit nicht verschüttet sondern explizit berücksichtigt. $^{820}$ Studien mit Panel-Daten führen aufgrund der erhöhten Anzahl von Freiheitsgraden im Vergleich zur Querschnittsanalyse zu einer erhöhten Effizienz

816 Vgl. Gujarati (2003), S. 772.

817 Vgl. Gujarati (2003), S. 772.

818 Vgl. Kennedy (1998), S. 165; Assenmacher (2002), S. 327. Eng verwandt ist die General Method of Moments (GMM). Vgl. Qian/Schmidt (1999); Greene (2003), S. 400f; Börsch-Supan/Köke (2000), S. 9. Die GMM wird z.B. in den Studien von Nickell et al. (1997) und Januszewski et al. (1999) eingesetzt.

819 Vgl. Hsiao (1986), S. 1-5; Baltagi (2001), S. 1-5; Thome (1992), S. 82-85; Alecke (1997), S. 88; Börsch-Supan/Köke (2002), S. 299f.; Greene (2003), S. 283-286; Engel/Reinecke (1994), S. 1-13.

820 Vgl. zu den Vorteilen von Panel-Daten ausführlich Baltagi (2001), S. 5-7. 
der Schätzung. ${ }^{821}$ Darüber hinaus vermindert sich die Gefahr von Multikollinearität. $^{822}$

Panel-Daten ermöglichen zudem die Verwendung von Fixed-Effects-Modellen, die im Rahmen von Eigentümerstruktur-Analysen häufig zur Anwendung kommen. ${ }^{823}$ Diese Modelle ermöglichen eine Präzisierung der Regression durch eine weitergehende Analyse des Störterms. ${ }^{824}$ Die in das Regressionsmodell aufgenommenen Kontrollvariablen erklären naturgemäß immer nur einen Teil der unternehmensindividuellen Performance. Verschiedene Effekte sind entweder nicht beobachtbar oder können aufgrund von Datenmängeln nicht in das Modell aufgenommen werden. Durch die Verwendung von Panel-Daten wird es möglich, den Effekt von nicht beobachtbaren, aber zeitlich nicht variierenden, unternehmensspezifischen Einflussfaktoren („unobservable firm heterogeneity") zu identifizieren und auszuschalten. ${ }^{825}$ Der Bestandteil des Residuums, der auf unternehmensspezifische Besonderheiten zurückzuführen ist, wird als „FixedEffects-Variable“ separat ausgewiesen. Der Störterm kann somit aufgeteilt werden in einen klassischen „White-Noise-Störterm“ und in Effekte in Abhängigkeit von den nicht beobachtbaren Unternehmenscharakteristika (,between firm variation“) ${ }^{826}$ Zurück bleibt nur die Streuung in der Eigentümerstruktur-Performance-Beziehung innerhalb des Unternehmens über die Zeit (,within firm variation"), die als erklärende Variable fungiert. ${ }^{827}$ Formal ergibt sich für den Störterm damit $u_{i t}=a_{i}+\varepsilon_{i t}$, wobei $a_{i}$ die über die Zeit konstanten, unternehmensspezifischen Effekte abbildet und der White-Noise-Störterm $\varepsilon_{i t}$ die restlichen

821 Vgl. Hsiao (1986), S. 2; Baltagi (2001), S. 6.

822 Vgl. Alecke (1997), S. 88; Hsiao (1986), S. 2; Baltagi (2001), S. 6; Börsch-Supan/Köke (2002), S. 301; Arminger/Müller (1990), S. 1-5.

823 Auch: Fixed-Firm-Effects-Modelle.

824 Vgl. Kruiniger (2002); Greene (2003), S. 287-293; Albrecht (1984), S. 214; Gujarati (2003), S. 45-47; Chatterjee/Price (1995), S. 3; Coles et al. (2002), S. $24 \mathrm{f}$.

825 Vgl. Baltagi (2001), S. 5, 11; Arminger/Müller (1990), S. 3f.; Himmelberg/Hubbard/Palia (1999), S. 357.

826 Vgl. Lehmann/Weigand (2000), S. 172-174; Himmelberg/Hubbard/Palia (1999), S. 358360; Börsch-Supan/Köke (2002), S. 301; Baltagi (2001), S. 6, 12-15; Arminger/Müller (1990), S. 4.

827 Vgl. Lehmann/Weigand (2000), S. 174. Analog können Effekte eliminiert werden, die alle Unternehmen gleichermaßen betreffen und auf Änderungen im Zeitablauf - in der Regel in Folge eines Strukturbruchs - zurückzuführen sind. Darauf wird hier verzichtet, da während des zu betrachtenden Zeitraums keine Strukturbrüche vorlagen. Vgl. jedoch Lehmann/Weigand (2000), S. 172, 174; Alecke (1997), S. $98 f$. 
nicht erklärten, über Zeit und Unternehmen variierenden Einflussfaktoren aufnimmt. ${ }^{828}$

Da die unternehmensspezifischen Effekte nicht beobachtbar sind, ist es nicht möglich, sie als Parameter $\beta_{k i} a_{i}$ zu schätzen. Sie gehen stattdessen als Regressionskonstante in das Modell ein; die Konstante $\alpha$ entfällt. ${ }^{829}$ Die Abbildung erfolgt mit Hilfe von Dummy-Variablen, die immer dann gleich eins sind, wenn für das betrachtete Unternehmen gilt $j=i .{ }^{830}$ Sie wird für alle anderen Unternehmen $i$ gleich null gesetzt, während für das betrachtete Unternehmen alle anderen Dummies gleich null sind. ${ }^{831}$ Es ergibt sich somit für das bereits aus Kapitel IV.2.1.1 bekannte Regressionsmodell:

$y_{i t}=\sum_{j=I}^{J} \beta_{l, j} D_{j t}+\sum_{k=2}^{K} \beta_{k} x_{k, i t}+\varepsilon_{i t}$

Insbesondere bei großen Stichproben kann dieses Verfahren aufgrund der großen Variablenanzahl zu numerischen Problemen in der Umsetzung führen. ${ }^{832}$ Hier bietet sich die sogenannte Durchschnittsmethode an, im Rahmen derer von jeder Variablen der Regressionsgleichung ihr unternehmensbezogener temporärer Durchschnittswert subtrahiert wird. Da $D_{j t}$ für $(j=i)$ jederzeit gleich eins ist, gilt $D_{j t}=\bar{D}_{j t}$ und der Term entfällt. Erneut ohne die Konstante $\alpha$ ergibt sich als zu schätzende Regressionsgleichung: ${ }^{833}$

$y_{i t}-\bar{y}_{i t}=\sum_{k=2}^{K} \beta_{k}\left(x_{k, i t}-\bar{x}_{k, i}\right)+\left(\varepsilon_{i t}-\bar{\varepsilon}_{i}\right)$

Wird für diese Gleichung eine Schätzung durchgeführt, so entspricht die Schätzung des Parametervektors $\beta$ der Schätzung der Regressionsgewichte, die sich

828 Vgl. Himmelberg/Hubbard/Palia (1999), S. 356; Börsch-Supan/Köke (2002), S. 301. Von einer solchen Konstanz kann immer dann nicht ausgegangen werden, wenn während des Untersuchungszeitraums exogene Schocks (z.B. Kriegszustand) wirksam geworden sind und daher Strukturbrüche vorliegen. Vgl. Assenmacher (2002), S. 53.

Vgl. Alecke (1997), S. 99; Baltagi (2001), S. 12f.

830 Least Squares Dummy Variable (LSDV)-Modell. Vgl. Greene (2003), S. 287f.; Alecke (1997), S. 99f.; Cronqvist/Nilsson (2002), S. 16.

831 Vgl. Alecke (1997), S. 99f.

832 Die stark zunehmende Anzahl von Variablen geht zudem mit einem Verlust an Freiheitsgraden einher. Vgl. Baltagi (2001), S. 14; Alecke (1997), S. 100.

833 Vgl. Baltagi (2001), S. 13; Alecke (1997), S. 101; Börsch-Supan/Köke (2002), S. 302; Cronqvist/Nilsson (2002), S. 9, 16. 
unter Nutzung der Dummy-Variablen ergeben hätte. ${ }^{834}$ Durch diese Vorgehensweise werden die Schwankungen zwischen den Unternehmen eliminiert, sodass lediglich die unternehmensindividuelle Schwankung („within“) regressiert wird. $^{835}$ Die Regressionsgewichte selbst werden anschließend über folgende Formel geschätzt: ${ }^{836}$

$\beta_{l i}=\bar{y}_{i}-\sum_{k=2}^{K} \beta_{k} \bar{x}_{k, i}$

Diese getrennte Schätzung von Regressionskonstanten und -gewichten empfiehlt sich immer dann, wenn die Zahl der einbezogenen Objekte groß ist.

Im Ergebnis ist die Verwendung von Panel-Daten für die Analyse matrizenartiger Datenstrukturen der Querschnittsanalyse klar überlegen; die „spurious correlation" kann so beseitigt werden. ${ }^{837}$ Verzerrte Schätzergebnisse werden vermieden und das $\mathrm{r}^{2}$ steigt im Vergleich zur Querschnittsanalyse in der Regel an. ${ }^{838}$ Nachteil speziell des Fixed-Effects-Verfahrens ist jedoch, dass sich die Varianz des Schätzers erhöht. ${ }^{839}$ Konsistente und unverzerrte Ergebnisse ergeben sich zudem nur dann, wenn die unternehmensspezifischen Effekte über die Zeit konstant sind. ${ }^{840}$ Darüber hinaus erklärt die Schätzung von Fixed-Effects-Modellen nicht, wie unternehmensindividuelle Unterschiede in der Performance zustande kommen. ${ }^{841}$ Eine Interpretation der Auswirkungen unterschiedlicher Eigentümerstrukturen ist nur über die Analyse der „within-Schätzwerte“ möglich. ${ }^{842}$ Durch die Beschränkung auf die „within variations“ wird zwar die Schätzgenau-

834 Vgl. Alecke (1997), S. 101.

835 Der erzielte Schätzwert für $\hat{\beta}$ wird auch als „Within-Schătzwert“ oder „Fixed-EffectsSchätzwert" bezeichnet. Vgl. Börsch-Supan/Köke (2002), S. 302.

836 Vgl. Alecke (1997), S. 101.

837 So heißt es bei Börsch-Supan/Köke (2002), S. 300, „panel data are extremely important in getting rid of this second cause of endogeneity" bzw. "only panel data allow to fully capture the dynamic interactions of firm-specific variables".

838 Vgl. auch Lins (2003); Börsch-Supan/Köke (2002), S. 300.

839 Vgl. Arminger/Müller (1990), S. 4.

840 Vgl. Himmelberg/Hubbard/Palia (1999), S. 357f.; Arminger/Müller (1990), S. 5. Es sollten daher alle firmenspezifischen Variablen im Panel-Format vorliegen, nicht nur die Eigentümerstrukturvariablen. Vgl. Börsch-Supan/Köke (2002), S. 303.

841 Vgl. Börsch-Supan/Köke (2002), S. 303. Zu den Grenzen von Panel-Daten vgl. Baltagi (2001), S. 7-9. Alternativ können auch sogenannte Random-Effects-Modelle herangezogen werden, die sich primär für die Analyse von Stichproben aus großen Grundgesamtheiten eignen. Vgl. Baltagi (2001), S. 15; Judge et al. (1985), S. 527; Kennedy (1998), S. 227. Bei Unsicherheit über das korrekte Verfahren kann ein Hausman-Test herangezogen werden. Vgl. Greene (2003), S. 301f.; Alecke (1997), S. 109-111.

842 Vgl. Börsch-Supan/Köke (2002), S. 303. 
igkeit erhöht, jedoch um den Preis verschütteter Informationen. ${ }^{843}$ Die Eignung von Fixed-Effects-Modellen für die hier vorliegende Untersuchung könnte demnach begrenzt sein, wenn die Variation der Eigentümerstrukturen über die Zeit gering ist. ${ }^{844}$

\subsubsection{Fehlende bzw. falsch spezifizierte Variablen}

Die Berücksichtigung möglichst aller relevanten Einflussfaktoren ist Voraussetzung für unverzerrte Schätzergebnisse. ${ }^{845}$ Diese Forderung ist jedoch aufgrund verschiedener Restriktionen nicht uneingeschränkt erfüllbar. ${ }^{846}$ Mangelnde Datenverfügbarkeit schränkt die vollständige Abbildung der Einflussfaktoren ein und die Hinzunahme weiterer Regressoren kann zu einer Verminderung des adj. $\mathrm{r}^{2}$ führen. Die möglichst vollständige Abbildung der Determinanten der Performance ist somit abzuwägen gegen die damit potenziell einhergehende Verminderung der Schätzgüte. Welche potenziell relevanten Einflussfaktoren in einer unvollständigen Regressionsgleichung fehlen, ist mit Hilfe ökonometrischer Tests nicht feststellbar. ${ }^{847}$ Daher ist die ökonomische Plausibilisierung der Variablenauswahl von entscheidender Bedeutung. Neben der ausreichenden Anzahl der Variablen ist deren Dimension ausschlaggebend. Wird fälschlicherweise ein linearer Zusammenhang unterstellt, obwohl tatsächlich ein nichtlinearer vorliegt, sind die Ergebnisse wertlos. Die theoretischen Ausführungen zur Nichtlinearitätshypothese haben deutlich gemacht, dass zwischen Cash-Flow-Steigerungen durch Monitoring und der Realisierung von private benefits ein Trade-off besteht, der einen nichtlinearen Zusammenhang zwischen Kapitalkonzentration und Performance nahe legt. ${ }^{848}$ Im Rahmen der Analyse sollten daher die Variablen zur Eigentümerstruktur in linearer und in nichtlinearer Form in die Regression eingehen. ${ }^{849}$ Wenn der nichtlineare Term unberücksichtigt gelassen wird,

843 Vgl. Zhou (2001), S. 560f. Auch Hermalin/Weisbach (1991), S. 107, argumentieren: „This approach [firm-specific dummy variables], however, would eliminate all betweenfirm variation from the data. Since we believe that the primary force driving our results is between-firm variation, we do not adopt this approach."

844 In der Studie von Himmelberg/Hubbard/Palia (1999) werden die signifikanten Ergebnisse aus der Querschnittsstudie nach Anwendung eines Fixed-Effects-Modells insignifikant. Ähnliches trifft auch für die Studie von Bohren/Odegaard (2001) zu.

845 Vgl. Coles et al. (2002), S. $22 f$.

846 Vgl. Börsch-Supan/Köke (2002), S. $311 \mathrm{f}$.

847 Vgl. Börsch-Supan/Köke (2002), S. 315.

848 Vgl. auch Börsch-Supan/Köke (2002), S. 312.

849 Vgl. Brannath/Futschik (2001), S. 219; Bohren/Odegaard (2001), S. 19. 
obwohl realiter eine solche Beziehung vorliegt, wird der Koeffizient der linearen Variablen unterschätzt. ${ }^{850}$

\subsubsection{Untersuchungssample}

Valide Ergebnisse ökonometrischer Analysen sind immer dann zu erzielen, wenn entweder alle von dem zu untersuchenden Problem betroffenen Merkmalsträger (Unternehmen) in die Untersuchung einbezogen werden (Vollerhebung) oder eine repräsentative Stichprobe zugrunde liegt. Aufgrund der vereinfachten Datenbeschaffung analysieren viele der vorhandenen empirischen Studien jedoch ausschließlich die größten Gesellschaften des jeweiligen Kapitalmarktes. ${ }^{851}$ Diese Vorgehensweise beinhaltet die Gefahr eines Sample Selection Bias, also einer nicht zufälligen Auswahl der Sample-Unternehmen, sodass die erzielten Ergebnisse nicht für alle Unternehmen verallgemeinerbar sind. ${ }^{852}$ Um verallgemeinerbare Aussagen für alle Unternehmen des untersuchten Kapitalmarktes treffen zu können, sollte somit - sofern eine Vollerhebung nicht möglich ist eine Zufallsstichprobe gezogen werden. ${ }^{853}$

Die große Mehrzahl der Eigentümerstruktur-Performance-Studien beschränkt sich auf börsennotierte Unternehmen. ${ }^{854}$ Grundsätzlich ist es wünschenswert, auch nicht-börsennotierte Unternehmen einzubeziehen. ${ }^{855}$ So ist es denkbar, dass börsennotierte Unternehmen über bestimmte, die Performance determinierende Unternehmenscharakteristika verfügen; die Stichprobe wäre damit verzerrt. ${ }^{856}$ Mit der Hinzunahme nicht-börsennotierter Gesellschaften sind indes auch Nachteile verbunden. So stehen für diese Unternehmen sowohl für die abhängige Variable als auch für die Kontrollvariablen keine kapitalmarktbasierten Daten zur Verfügung, sodass ausschließlich jahresabschlussbasierte Performancekennziffern herangezogen werden können. ${ }^{857}$ Diese werden beeinflusst durch den Rechnungslegungsstandard, Wahlrechtsausübungen und Sachverhaltsgestaltun-

850 Vgl. Börsch-Supan/Köke (2002), S. 313. Alternativ können auch sogenannte schrittweise Regressionen durchgeführt werden. Vgl. Morck/Shleifer/Vishny (1988); Hermalin/Weisbach (1991); Cho (1998). Diese Vorgehensweise erscheint jedoch problematisch, da die „Wendepunkte“ in der nichtlinearen Beziehung vom Anwender exogen vorgegeben werden. Vgl. ebenfalls kritisch Börsch-Supan/Köke (2002), S. 313.

851 Vgl. Börsch-Supan/Köke (2002), S. 306f.; Bohren/Odegaard (2001), S. 10.

852 Vgl. Bohren/Odegaard (2001), S. 10; Lins (2003), S. 163.

853 Vgl. Börsch-Supan/Köke (2002), S. 305.

854 Vgl. jedoch Lehmann/Weigand (2000), sowie den Überblick bei Börsch-Supan/Köke (2002), S. 307.

$855 \mathrm{Vgl}$. Lehmann/Weigand (2000), S. 165.

856 Vgl. Pagano/Röell (1998), S. 190f.; Börsch-Supan/Köke (2002), S. 308.

857 Vgl. Köke (2001), S. 271. 
gen. ${ }^{858}$ Zudem sind sie als vergangenheitsbezogene Kennziffern nicht in der Lage, zukunftsbezogene Erwartungen der Kapitalmarktteilnehmer abzubilden. ${ }^{859}$ Sofern die Gefahr eines Sample Selection Bias besteht, kann mit Hilfe des zweistufigen Schätzverfahrens von Heckman (1979) die Repräsentativität der Stichprobe getestet und im Rahmen der Regression berücksichtigt werden. ${ }^{860}$

\subsubsection{Messfehler}

Für die Qualität der Untersuchungsergebnisse ist die Qualität der Inputvariablen von entscheidender Bedeutung. Es sollten nur solche Variablen einbezogen werden, bei denen aufgrund ökonomischer Überlegungen ein hoher Erklärungsgehalt vermutet wird und die unabhängig von der zu erklärenden Variablen sind. ${ }^{861}$ Messfehler bei der Bestimmung der abhängigen Variablen führen zwar nicht zu einer Verzerrung der Schätzwerte, die unerklärten Schwankungen schlagen sich jedoch im Störterm nieder und mindern die Signifikanz der Schätzergebnisse. ${ }^{862}$ Werden hingegen die Regressoren fehlerhaft ermittelt, sind verzerrte und inkonsistente Koeffizienten die Folge. ${ }^{863}$

Um Verzerrungen durch eine falsche Variablenauswahl bzw. fehlerhafte Variablen $\mathrm{zu}$ verhindern, sollten die erzielten Ergebnisse mit Hilfe von Stabilitätstests überprüft werden. So erscheint es sinnvoll, die mit einer marktorientierten Performancekennzahl als abhängiger Variable erzielten Ergebnisse mit Hilfe einer buchwertbezogenen Kennziffer auf Robustheit zu überprüfen. ${ }^{864}$ Auch die Kontrollvariablen können durch Verwendung verwandter Variablen einer Sensitivitätsanalyse unterzogen werden. Werden Informationen nicht mittels individueller Recherche sondern aus kommerziellen Datenbanken ermittelt, so sollten Plausibilitätschecks durchgeführt werden, um die Qualität der Daten sicherzustellen. $^{865}$

858 Vgl. White/Sondhi/Fried (1997), S. 142-144; Küting/Harth/Leinen (2001), S. 861.

859 Vgl. Demsetz/Villalonga (2001), S. 213; Börsch-Supan/Köke (2002), S. 318f.; Wiwattanakantang (2001), S. 333f.

860 Vgl. zum Heckman-Test Heckman (1979); Börsch-Supan/Köke (2002), S. 310f.; Greene (2003), S. 780-790, sowie Schremper (2002), S. 207-209 m.w.N.

861 Vgl. zur „Endogenität“" bereits Abschnitt IV.2.2.1.

862 Vgl. Börsch-Supan/Köke (2002), S. 317.

863 Vgl. Börsch-Supan/Köke (2002), S. 317.

864 Vgl. Börsch-Supan/Köke (2002), S. 319.

${ }^{865}$ Die Datenqualität ist in einigen der kommerziell verfügbaren Datenbanken sehr schlecht. Vgl. Kammerath (2000), S. 19f.; Wiwattanakanntang (2001), S. 326. 


\subsubsection{Berücksichtigung der ökonometrischen Problemfelder in vorhande- nen Studien}

Von den verschiedenen, in Anhang B aufgeführten Studien wird im Folgenden der Untersuchungsaufbau der Studien näher betrachtet, die hinsichtlich der eingesetzten ökonometrischen Verfahren den im Vorfeld vorgestellten besonderen Problemen Rechnung tragen. ${ }^{866}$ Das Problem der Endogenität der Aktionärsstruktur wird auch in den jüngeren Studien noch nicht standardmäßig berücksichtigt. ${ }^{867}$ Die folgende Abbildung gibt einen Überblick über die eingesetzten Verfahren zur Behandlung des Endogenitätsproblems. Die im Rahmen der jeweiligen Studie eingesetzten Verfahren sind mit einem $\mathrm{x}$ markiert. Werden bestimmte Verfahren im Rahmen von Robustheitstests eingesetzt, ohne dass die Regressionsergebnisse im Detail ausgewiesen werden, so wird das Verfahren mit (x) markiert. ${ }^{868}$

\begin{tabular}{|c|c|c|c|c|c|c|c|}
\hline & \multicolumn{2}{|c|}{ Datenstruktur } & \multicolumn{3}{|c|}{ Regressionsmodell } & \multicolumn{2}{|c|}{ Sample } \\
\hline & $\begin{array}{c}\text { Quer- } \\
\text { schnitt }\end{array}$ & Panel & IV & $\begin{array}{c}\text { Fixed } \\
\text { Effects } \\
\end{array}$ & 2SLS & $\begin{array}{c}\text { börsen- } \\
\text { notiert }\end{array}$ & $\begin{array}{c}\text { auch } \\
\text { andere }\end{array}$ \\
\hline $\begin{array}{l}\text { Agrawal/Knoeber } \\
\text { (1996) }\end{array}$ & $\mathrm{x}$ & & & & $\mathrm{x}$ & $\mathrm{x}$ & \\
\hline $\begin{array}{l}\text { Hermalin/Weisbach } \\
\text { (1996) }\end{array}$ & & $\mathbf{x}$ & $x^{869}$ & & & $\mathrm{x}$ & \\
\hline $\begin{array}{l}\text { Loderer/Martin } \\
\text { (1997) }\end{array}$ & $x$ & & & & $\mathrm{x}$ & $\mathbf{x}$ & \\
\hline Cho $(1998)^{870}$ & $x$ & & & & $\mathbf{x}$ & $\mathbf{x}$ & \\
\hline $\begin{array}{l}\text { Himmelberg/Hub- } \\
\text { bard/Palia (1999) }\end{array}$ & & $\mathrm{x}$ & $\mathbf{x}$ & $\mathrm{x}$ & & $x$ & \\
\hline $\begin{array}{l}\text { Edwards/Weichen- } \\
\text { rieder }(2000)\end{array}$ & $\mathrm{x}$ & & $(x)^{871}$ & & & $\mathrm{x}$ & \\
\hline
\end{tabular}

${ }^{866}$ Hier insb. dem Problem der Endogenität.

867 In älteren Studien wird die Endogenität zwar teilweise diskutiert, jedoch in der Regel nicht berücksichtigt. Dies gilt auch für die viel zitierten Studien von Morck/Shleifer/Vishny (1988) und Demsetz/Lehn (1985) sowie verschiedenste Studien aus den neunziger Jahren. Vgl. hierzu kritisch Börsch-Supan/Köke (2002), S. 299f.

$868 \mathrm{Zu}$ Details der Studien vgl. Anhang B.1. Auch andere Studien thematisieren das Endogenitätsproblem, klassifizieren es jedoch entweder als nicht relevant oder behandeln es mit ungeeigneten bzw. hier nicht relevanten Methoden. Vgl. McConnell/Servaes (1990); Kole (1996); Wiwattanakantang (2001).

869 Als Instrumentalvariablen dienen die "lagged values" der Eigentümerstrukturvariablen. Vgl. Hermalin/Weisbach (1991), S. 106; Hermalin/Weisbach (1988).

870 Cho verwendet den „lagged value“ des Verschuldungsgrads als Instrumentalvariable. Die im Fokus des Interesses stehende Eigentümerstruktur wird jedoch nicht über Instrumente abgebildet. Vgl. Cho (1998), S. 115. 


\begin{tabular}{|c|c|c|c|c|c|c|c|}
\hline & \multicolumn{2}{|c|}{ Datenstruktur } & \multicolumn{3}{|c|}{ Regressionsmodell } & \multicolumn{2}{|c|}{ Sample } \\
\hline & $\begin{array}{c}\text { Quer- } \\
\text { schnitt }\end{array}$ & Panel & IV & $\begin{array}{c}\text { Fixed } \\
\text { Effects } \\
\end{array}$ & 2SLS & $\begin{array}{c}\text { börsen- } \\
\text { notiert }\end{array}$ & $\begin{array}{c}\text { auch } \\
\text { andere }\end{array}$ \\
\hline $\begin{array}{l}\text { Lehmann/Weigand } \\
(2000)\end{array}$ & & $\mathrm{x}$ & $\mathbf{x}$ & $\mathrm{x}$ & & $x$ & $\mathrm{x}$ \\
\hline $\begin{array}{l}\text { Bohren/Odegaard } \\
\text { (2001) }\end{array}$ & $\mathbf{x}$ & & $x^{872}$ & $(x)^{873}$ & $x^{874}$ & $x$ & \\
\hline $\begin{array}{l}\text { Demsetz/Villalonga } \\
(2001)\end{array}$ & $\mathrm{x}$ & & & & $\mathbf{x}$ & $\mathrm{x}$ & \\
\hline Woidtke (2002) & $\mathrm{x}$ & & $x^{875}$ & $(x)$ & $\mathrm{x}$ & $x$ & \\
\hline $\begin{array}{l}\text { Cronqvist/Nilsson } \\
(2002)\end{array}$ & & $\mathrm{x}$ & $\mathrm{x}$ & $\mathrm{x}$ & & $\mathrm{x}$ & \\
\hline Lins (2003) & $\mathbf{x}$ & & & $\mathbf{x}$ & $\mathrm{x}$ & $\mathrm{x}$ & \\
\hline
\end{tabular}

Abb. 20: Forschungsdesign bestehender Studien

Die Auswertung macht deutlich, dass nur ein geringer Teil der Studien, die das Problem der Endogenität adressieren, auch die vorhandenen Instrumente zur Behandlung ausnutzt. So verwenden nur wenige Autoren Panel-Daten, obwohl vielen der Querschnitts-Untersuchungen Daten aus mehreren Jahren zugrunde liegen. Bei den alternativen Regressionsmodellen, die trotz endogener Regressoren valide Ergebnisse erzielen können, ist hingegen kein klar dominantes Verfahren erkennbar. Einige Untersuchungen führen im Rahmen von Robustheitstests verschiedene Verfahren parallel durch. ${ }^{876}$ Lehmann/Weigand (2000) finden mit dem Modell, das die unternehmensspezifischen Effekte (fixed effects) expli-

871 Im Rahmen eines Stabilitätstests werden für eine vereinfachte Gleichung exogene, mit den Eigentümerstrukturvariablen korrelierte Variablen als Instrumente herangezogen. Vgl. Edwards/Weichenrieder (2000), S. 25. Sie finden jedoch keine signifikante Änderung der Ergebnisse.

872 Als Instrumente werden die Größe des Boards und die Aktienkursvolatilität als exogene Variablen herangezogen. Vgl. Bohren/Odegaard (2001), S. 32.

873 Als Robustheitstest wird zudem eine GMM-Regression durchgeführt. Vgl. Bohren/Odegaard (2001), S. 28.

874 Bohren/Odegaard (2001) machen keine Angaben welches simultane Gleichungssystem sie verwenden. Sie werden hier unter die 2SLS-Methode subsumiert.

875 Als Instrumentalvariablen werden exogene Variablen genutzt, die keinen Einfluss auf die anderen Regressoren ausüben. Vgl. Woidtke (2002), S. 107.

876 So werden häufig im Rahmen eines mehrstufigen Verfahrens zunächst univariate und multivariate OLS-Schätzungen durchgeführt und anschließend für die zentralen Variablen weitergehende Verfahren eingesetzt. Vgl. etwa Bohren/Odegaard (2001). 
zit berücksichtigt, den höchsten Erklärungsgehalt gemessen durch das $\mathrm{r}^{2} .^{877}$ Hermalin/Weisbach (1991) ermitteln signifikantere Ergebnisse durch die Verwendung von Instrumentalvariablen im Rahmen einer Panel-Studie im Vergleich zur klassischen OLS-Schätzung mit gepoolten Daten. ${ }^{878}$

\subsection{Forschungsdesign der eigenen empirischen Untersuchung}

\subsubsection{Auswahl der Variablen}

\subsubsection{Abhängige Variable}

Bevor die Ergebnisse der empirischen Untersuchung vorgestellt werden, soll im Folgenden die Auswahl der Variablen und des Regressionsmodells diskutiert werden. Dabei wird ein besonderes Augenmerk auf die im vorangegangenen Kapitel angesprochenen Problemfelder gelegt.

Gegenstand der folgenden Analyse sind die Auswirkungen alternativer Eigentümer- und Stimmrechtsstrukturen auf den Unternehmenswert. Der Unternehmenswert selbst kann als Marktwert des Eigenkapitals - hinreichende Kapitalmarkteffizienz unterstellt - über den Börsenkurs der Aktie approximiert werden. ${ }^{879} \mathrm{Da}$ der Unternehmenswert maßgeblich von der Unternehmensgröße abhängig ist, ist er als zu erklärende Variable jedoch nicht geeignet. In der Literatur haben sich daher verschiedene, größenunabhängige Ersatzkriterien herausgebildet, um einen Einfluss auf den Unternehmenswert abzubilden.

Am häufigsten wird „Tobin's $Q^{“}$ - bzw. eine Approximation desselben - als zu erklärende Variable eingesetzt. ${ }^{800}$ Tobin's Q ist definiert als: ${ }^{881}$

$Q=\frac{\text { Marktwert des Unternehmens }}{\text { Reproduktionskosten der Vermögensgegenstände }}$

877 „By far the highest explanatory power is achieved by including fixed individual firm effects." Lehmann/Weigand (2000), S. 181.

878 Vgl. Hermalin/Weisbach (1991), S. 106, 109.

879 Vgl. Lindenberg/Ross (1981).

${ }^{880}$ Zum Informationsgehalt des Buchwert/Marktwert-Verhältnisses vgl. Garza-Gómez (2001).

881 Tobin (1968) entwickelte das Q ursprünglich zur Erklärung des gesamtwirtschaftlichen Investitionsverhaltens definiert als Renditedifferenzial der internen Verzinsung einer Investition im Verhältnis zu den Finanzierungskosten. Es wurde dann entsprechend der hier vorliegenden Argumentation betriebswirtschaftlich interpretiert. Vgl. grundlegend Lindenberg/Ross (1981), sowie Koch (2001), S. 583; Gehrke (1994), S. 20. 
Der Marktwert bringt die Bewertung des Unternehmens am Kapitalmarkt zum Ausdruck. Er wird den Reproduktions- bzw. Wiederbeschaffungskosten der Vermögensgegenstände des Unternehmens gegenübergestellt und ist wie folgt zu interpretieren: ${ }^{882}$ Bei einem $\mathrm{Q}<1$ versieht der Markt die in das Unternehmen investierten Beträge mit einem Abschlag, die Marktteilnehmer erwarten, dass das Unternehmen nicht in der Lage ist, die geforderte Rendite zu erwirtschaften und Unternehmenswert vernichtet. Ein $\mathrm{Q}>1$ drückt hingegen die Bereitschaft der Investoren aus, einen Aufpreis auf den Buchwert des Eigenkapitals zu akzeptieren. Die Zahlung eines Goodwills wird durch Wettbewerbsvorteile, nicht bilanzierte immaterielle Vermögensgegenstände, gute Wachstumserwartungen o.a. gerechtfertigt. ${ }^{883}$ Als marktbezogene Größe bildet $\mathrm{Q}$ nicht nur vorhandene, sich bereits in den Buchwerten widerspiegelnde Vorteilsnahmen des Großaktionärs $\mathrm{ab}$, sondern darüber hinaus den künftig erwarteten Einfluss. ${ }^{\mathbf{8 8 4}}$

In der Praxis sind die Wiederbeschaffungskosten der Vermögensgegenstände für Unternehmensexterne nicht ermittelbar. Es hat sich daher in verschiedensten empirischen Studien eine Approximation von $Q$ durchgesetzt, die anstelle der Wiederbeschaffungskosten den bilanziellen Buchwert der Vermögensgegenstände verwendet und den Marktwert des Fremdkapitals durch den Buchwert annähert. ${ }^{885}$ Dieser Vorgehensweise soll auch hier gefolgt werden, sodass für das Marktwert/Buchwert-Verhältnis (MWBW) gilt: ${ }^{886}$

$M W B W=\frac{\text { Marktwert des Eigenkapitals }+ \text { Buchwert des Fremdkapitals }}{\text { Buchwert der Vermögensgegenstände }}$ (IV 16.)

Alternativ zu Tobin's $Q$ bzw. einem näherungsweise ermittelten Marktwert/Buchwert-Verhältnis werden in verschiedenen empirischen Studien buchwertbezogene Rentabilitätskennziffern als Performancemaßstab eingesetzt. Sie sind jedoch in stärkerem Maße abhängig vom verwendeten Rechnungslegungsstandard, bilanzpolitischen Maßnahmen und Sachverhaltsgestaltung. ${ }^{87}$ Darüber

882 Vgl. Koch (2001), S. 583f.

883 Vgl. Cronqvist/Nilsson (2002), S. 9. Ein Q $=1$ wird sich in einem kompetitiven Umfeld als langfristiger Gleichgewichtszustand ergeben. Vgl. Koch (2001), S. 583f.

884 Vgl. Demsetz/Villalonga (2001), S. 213; Wiwattanakantang (2001), S. 334; Cronqvist/ Nilsson (2002), S. 9.

885 Dies gilt auch für die verschiedenen, in Abschnitt IV.1 dargestellten Performancestudien, vgl. jüngst La Porta et al. (2002), S. 1159. Es ergeben sich keine wesentlichen Unterschiede durch die Verwendung eines approximierten Werts für Tobin's Q. Vgl. erläuternd Cronqvist/Nilsson (2002), S. 9f. m.w.N.

${ }^{886}$ Zur Bestimmung der Eigenkapitalmarktwerte vgl. Kapitel IV.2.3.3.3.

887 Vgl. White/Sondhi/Fried (1997), S. 142-144; Wiwattanakantang (2001), S. $333 f$. 
hinaus sind rein vergangenheitsbezogene Maßgrößen nicht in der Lage, die durch den Markt erwartete, zukünftige Einflussnahme durch den Großaktionär abzubilden. ${ }^{888}$ Sie bilden statt dessen die in der Vergangenheit realisierte Einflussnahme ab. Grundsätzlich besteht daher - trotz der Probleme, die mit jahresabschlussbezogenen Kennzahlen verbunden sind - die Chance eines zusätzlichen Erkenntnisgewinns, sodass zusätzlich zum Marktwert/Buchwert-Verhältnis die Ergebnisse mit einer Eigenkapitalrendite

$$
E K R=\frac{\text { Jahresüberschuss }(J U ̈) \text { vor Anteilen Dritter }}{\text { Eigenkapital inkl. Anteile Dritter }}
$$

und einer Gesamtkapitalrendite

$$
G K R=\frac{J \ddot{U} \text { vor Anteilen Dritter }+ \text { Fremdkapitalzinsen }}{\text { Gesamtkapital }}
$$

auf Stabilität überprüft werden sollen. ${ }^{889}$ Die Daten werden jeweils aus dem Konzernabschluss entnommen, der die Informationsfunktion aus Sicht der Kapitalgeber besser erfüllt als der Einzelabschluss. ${ }^{890} \mathrm{Da}$ im Rahmen der vorliegenden Analyse die Rentabilität des Konzerns unabhängig von der Gesellschafterstruktur zugrunde gelegt werden soll, werden die Minderheitsaktionäre im Sinne der Einheitstheorie als Eigenkapitalgeber betrachtet und ihre Anteile am Eigenkapital und am Jahresüberschuss voll berücksichtigt. ${ }^{891}$

Fraglich ist, welcher Zeitpunkt für die Erhebung der markt- und buchwertbezogenen Daten zugrunde gelegt werden soll. Die Daten zur Eigentümerstruktur wurden jeweils zum Jahresende erhoben. Da die Einflussnahme eines Großaktionärs nicht unmittelbar nach Erwerb seiner Anteile erfolgen muss, werden sie sich auch im Jahresabschluss erst mit zeitlicher Verzögerung niederschlagen. Es erscheint daher sinnvoll, die jahresabschlussbezogenen Variablen mit zeitlicher Verzögerung zu berücksichtigen. ${ }^{892}$ So werden die erklärenden Variablen eines

888 Vgl. Claessens et al. (1999), S. 22; Demsetz/Villalonga (2001), S. 213.

889 Vgl. zu den Vorteilen buchwertbezogener Kennziffern Demsetz/Villalonga (2001), S. 213.

890 Vgl. zur Unzulänglichkeit des Einzelabschlusses als Informationsgrundlage Pellens (1989), S. 49f., 202-236; Schulte (1996), S. 258f.; Sürken (1999), S. 17-19.

891 Vgl. Baetge/Kirsch/Thiele (2002), S. 9. Vgl. zu den Theorien der Konzernrechnungslegung außerdem Pellens (2001), S. 281-283, sowie ausführlich Sürken (1999), S. 103-114 m.w.N. Auch im Rahmen des Marktwert/Buchwert-Verhältnisses gilt die Annahme, dass die Marktkapitalisierung den Marktwert aus Sicht aller Eigenkapitalgeber abbildet, die Anteile Dritter werden somit nicht hinzuaddiert. Der Einfluss dieser Vorgehensweise wird im Rahmen von Stabilitätstests zu überprüfen sein.

892 Vgl. Short/Keasey (1999), S. 89; Cronqvist/Nilsson (2002), S. 19. 
Stichtags auf buchwertbezogene Performancevariablen (EKR, GKR) des Folgejahres regressiert. Die Marktkapitalisierung im Rahmen des Marktwert/Buchwert-Verhältnisses wird jedoch zum gleichen Stichtag wie die Eigentümerstrukturvariablen erhoben, da sich der erwartete Einfluss einer Aktionärsstruktur hinreichende Kapitalmarkteffizienz vorausgesetzt - unmittelbar im Kurs niederschlägt. Um eine in sich kongruente Kennzahl zu ermitteln, werden die Buchwerte von Eigen- und Fremdkapital für das Marktwert/Buchwert-Verhältnis zum gleichen Stichtag erhoben wie die Marktkapitalisierung.

\subsubsection{Variablen zur Eigentümer- und Stimmrechtsstruktur}

\subsection{Variablen zur Eigentümerstruktur}

Die Daten zur Eigentümer- und Stimmrechtsstruktur nehmen im Rahmen der Regressionsanalyse die Funktion der erklärenden Variablen ein. Ihre genaue Spezifizierung ist daher von entscheidender Bedeutung. In der Literatur wird die Einflussmöglichkeit von Großaktionären auch innerhalb einzelner Studien in der Regel mittels verschiedener Variablen abgebildet.

Als wichtiges Indiz für die Erklärung des Einflusspotenzials großer Aktionäre ist zunächst der Kapitalanteil dieser Aktionäre heranzuziehen. Je größer der Kapitalanteil eines Aktionärs ist, desto größer ist in der Regel auch seine Möglichkeit, entweder das Management zu kontrollieren oder aber im eigenen Interesse nutzenmaximierend $\mathrm{zu}$ agieren. Zur Abbildung der Anteilseignerkonzentration bieten sich verschiedene Variablen an:

\section{KAPITALANTEIL DES GRÖßTEN DIREKT BETEILIGTEN AKTIONÄRS (KAD1)}

Der Kapitalanteil des größten direkt beteiligten Aktionärs wird als erklärende Variable in kardinal skalierter Form (Kapitalanteil in Prozent) einbezogen. Teilweise wird zur Abbildung des Einflusspotenzials des Großaktionärs nicht der direkte Kapitalanteil als kardinal skalierte Variable genutzt, sondern es werden drei bis vier Kontrollkategorien gebildet, in die der entsprechende Aktionär einsortiert wird. ${ }^{893}$ Die Abbildung im Rahmen der Regression erfolgt dann mit Hilfe von Dummy-Variablen. ${ }^{894} \mathrm{Da}$ auf diesem Wege jedoch vorhandene Informationen nicht genutzt werden, soll auf dieses Verfahren zunächst nicht zurückgegriffen werden und stattdessen der Kapitalanteil kardinal skaliert einbezogen wer-

${ }^{893}$ Etwa $0 \% \leq \mathrm{KAD} 1<25 \%, 25 \% \leq \mathrm{KAD} 1<50 \%$, $50 \% \leq \mathrm{KAD} 1<75 \%$ und $\mathrm{KAD} 1 \geq$ 75 \%. Vgl. Palia/Lichtenberg (1999); Himmelberg et al. (1999); Boehmer (2000).

894 So argumentieren Lamba/Stapledon, dass ,the theory does not predict that the largest shareholder's percentage stake will be greater the higher the level of private benefits". Vgl. Lamba/Stapledon (2001), S. 14. Vgl. auch Wiwattanakantang (2001), S. 349. 
den. Sofern Kausalitäten zwischen der Höhe des Kapitalanteils und der Performance auch innerhalb einer Klasse theoretisch bestehen können, soll nicht durch das Design der Regression verhindert werden, dass sie ihren Erklärungsgehalt entfalten können.

\section{SUMMIERTER KAPITALANTEIL MEHRERER GROBAKTIONÄRE (SKAD)}

Neben dem Anteil des größten Aktionärs werden die Kapitalanteile dreier weiterer Großaktionäre - sofern vorhanden - einbezogen, da die Existenz weiterer Anteilseigner mit maßgeblichem Kapitalanteil Einfluss auf die Aktivitäten des größten Aktionärs ausüben kann. Um die Beeinflussung durch große Aktionäre insgesamt abzubilden, fasst die Variable SKAD2 (SKAD3, SKAD4) die Summe der Kapitalanteile der zwei (drei, vier) größten direkt beteiligten Aktionäre zusammen.

Zur Abbildung einer eventuellen Nichtlinearität der Beziehung zwischen Anteilseignerstruktur und Performance werden neben den linearen Variablen zum Kapitalanteil die erklärenden Größen auch in quadratischer Form in die Regression einbezogen. ${ }^{895}$

\section{HERFINDAHL-INDEX $(\mathrm{H})$}

Eine weitere Kennzahl zur Abbildung der Anteilseigner-Konzentration ist der sogenannte Herfindahl-Index, der ursprünglich zur Beurteilung der Konzentration auf Gütermärkten entwickelt wurde. ${ }^{896}$ Der Herfindahl-Index $(\mathrm{H})$ bildet den Konzentrationsgrad der gesamten Aktionärsstruktur ab und ist definiert als die Summe der quadrierten Anteile der einzelnen Aktionäre:

$$
H=\sum_{i=1}^{I} K A D_{i}{ }^{2}
$$

Die Kennziffer bietet den Vorteil, dass sie einer asymmetrischen Verteilung der Kapitalanteile Rechnung trägt. ${ }^{897}$ Sie nimmt den Wert null an, wenn das Unternehmen eine theoretisch unendlich große Anzahl kleiner Aktionäre hat und den Wert eins, wenn das Unternehmen vollständig in einer Hand liegt. Der Herfindahl-Index wird in verschiedensten empirischen Studien angewandt, wenngleich in teilweise unterschiedlicher Interpretation. ${ }^{898}$ Anstelle der direkt gehaltenen Kapitalanteile können auch die Stimmrechtsanteile oder die durch das Pyrami-

\footnotetext{
895 Vgl. Bohren/Odegaard (2001), S. 19.

896 Oft auch Hirschman-Herfindahl-Index. Vgl. grundlegend Adelman (1969); Hannah/Kay (1977).

897 Vgl. Lehmann/Weigand (2000), S. 168

898 Vgl. die beiden unterschiedlichen Varianten bei Lehmann/Weigand (2000), S. 168, Fn. 24; Köke (2001), S. 272.
} 
denmutterunternehmen indirekt gehaltenen Anteile für die Indexberechnung zugrunde gelegt werden. ${ }^{899}$

Von entscheidender Bedeutung ist die Auswahl der geeigneten Inputparameter für den Herfindahl-Index. Wenn - wie im Rahmen der vorliegenden Analyse eine Differenzierung zwischen Kapital- und Stimmrechten vorgenommen wird und Aktionäre auf unterschiedlichen Ebenen der Konzernpyramide Berücksichtigung finden, lassen sich verschiedenste Indizes konstruieren. ${ }^{900}$ Für die konkrete Bestimmung wird hier angenommen, dass der Anteil der Kleinaktionäre jeweils maximal ein Prozent beträgt. ${ }^{901}$ Halten beispielsweise ein Großaktionär A $47 \%$, ein Großaktionär B 36,5\% des Kapitals und der Rest ist im Streubesitz, so ergibt sich: ${ }^{902}$

$H=0,47^{2}+0,365^{2}+16 \cdot 0,01^{2}+0,005^{2}=0,356$

Kritisch ist anzumerken, dass der Index die sich aus der Anteilseignerstruktur ergebenden Machtstrukturen nicht immer vollständig präzise abbildet. So führt ein zusätzlicher großer Aktionär nicht notwendigerweise zu einer verbesserten Kontrolle des größten Aktionärs, wenn der bereits durch einen anderen Großaktionär kontrolliert wird. ${ }^{903}$ Gleichzeitig hindert ein zweiter großer Aktionär den größten Aktionär nicht an seiner Kontrollausübung, wenn der größte Aktionär die Stimmrechtsmehrheit hält oder die beiden Großaktionäre eine Koalition bilden. Problematisch ist außerdem, dass die Anteilseignerstrukturen nie vollständig vorliegen, sondern stattdessen die Informationen auf verschiedene Großaktionäre begrenzt sind. Dementsprechend kann der Herfindahl-Index nur unvollständig bestimmt werden bzw. die Anteile der Kleinaktionäre müssen geschätzt werden. ${ }^{904}$ Daher soll er hier nur neben verschiedenen weiteren Kennzahlen zur Erklärung der Performance herangezogen werden.

899 Vgl. etwa bereits Demsetz/Lehn (1985), S. 1163, sowie Lehmann/Weigand (2000), S. 168.

900 Gleiches gilt für den sogenannten Shapley-Value, der vereinzelt in Studien herangezogen wird und Kontrollausübung auf Basis spieltheoretischer Modelle abbildet. Aufgrund seiner Komplexität ist er jedoch für die hier vorliegende Samplegröße und Datenbasis mit diversen Konzernpyramiden nicht geeignet. Vgl. jedoch Cubbin/Leech (1983); Zwiebel (1995); Goergen/Renneboog (2001); Guedes/Loueiro (2002).

901 Vgl. ebenso Lehmann/Weigand (2000), S. 168.

902 Eine weitere Zersplitterung der Kleinaktionärsanteile ändert den Wert des HerfindahlIndex nur noch marginal. Wird alternativ ein Kapitalanteil der Kleinaktionäre von 0,1 \% unterstellt, so ergibt sich $\mathrm{H}=0,354$.

903 Zudem wird im Falle unvollständiger Daten der Streubesitz nicht exakt abgebildet. Vgl. auch die Beispiele bei Crama et al. (2000), S. 23.

904 Vgl. Leech/Leahy (1991), S. $1419 f$. 


\section{IDENTITÄT DER ANTEILSEIGNER}

Die Identität der Anteilseigner wird mit Hilfe von Dummy-Variablen abgebildet. Dabei wird zwischen Ausländern (A), Mitgliedern der Gründerfamilie (F), Finanzintermediären (FI), Mitgliedern von Vorstand oder Aufsichtsrat (M), öffentlicher Hand (Ö) sowie Industrie- und Dienstleistungsunternehmen (I) unterschieden. Im Fall von Konzernpyramiden wird die Identität des Pyramidenmutterunternehmens erfasst. Dem liegt die Annahme zugrunde, dass die Art des Einflusses, den ein Großaktionär ausübt, durch die Identität des Einfluss ausübenden Unternehmens an der Spitze der Konzernpyramide determiniert wird. Bei der Zuordnung der Aktionäre zu den einzelnen Gruppen ist kritisch anzumerken, dass diese nicht immer überschneidungsfrei erfolgen kann. Dies gilt insbesondere für die natürlichen Personen, die grundsätzlich Mitglieder des Managements sowie Familienmitglieder mit beinhaltet. Hinter Ausländern verbergen sich wiederum die verschiedenen anderen Kategorien. Die hier vorliegende Abgrenzung wird dennoch gewählt, da sie in dieser Form auch den meisten anderen Studien zugrunde liegt, und so eine Vergleichbarkeit der Ergebnisse gewährleistet wird. Die erzielten Ergebnisse werden jedoch kritisch zu hinterfragen sein.

\subsection{Variablen zur Stimmrechtsstruktur}

In vielen Fällen entsprechen sich Stimmrechts- und Kapitalanteil eines Aktionärs. Abweichungen ergeben sich aufgrund von Vorzugsaktien, Mehrstimmrechtsaktien oder Höchststimmrechten. ${ }^{905}$ Darüber hinaus führen Pyramiden da$\mathrm{zu}$, dass der an der Spitze der Konzernpyramide stehende Aktionär einen bestimmten Stimmrechtsanteil bei einem deutlich kleineren Kapitalanteil inne hat. Im Einzelnen werden folgende Variablen definiert:

\section{STIMMRECHTSANTEIL (STA)}

Die als Variable StA erfassten Stimmrechte bilden die Stimmrechte des in der letzten Stufe kontrollierenden Aktionärs ab. Der Stimmrechtsanteil wird für den Aktionär mit dem größten Stimmrechtsanteil (StA1) ausgewiesen sowie für die Aktionäre mit den zweit-, dritt- bzw. viertgrößten Anteilen (StA2, StA3, StA4).

Die Stimmrechtsanteile entsprechen, sofern das Prinzip des One-Share-OneVote gilt und der ultimativ kontrollierende Aktionär nicht selbst direkt beteiligt ist, dem Kapitalanteil KAD des direkt beteiligten Aktionärs. Sofern zusätzlich Vorzugsaktien emittiert sind oder Mehrfachstimmrechte gelten, ist er größer als KAD. Eine Abweichung von der Variable KA (Kapitalanteil des Pyramidenmut-

905 Während Vorzugsaktien im gesamten Untersuchungszeitraum von Bedeutung sind, kommen Mehrfach- und Höchststimmrechte nur in Einzelfällen im Jahr 1997 vor. 
terunternehmens) liegt immer dann vor, wenn die Pyramide durch Beteiligungen unter $100 \%$ entstanden ist. ${ }^{906}$

\section{PYRAMIDEN}

Die grundsätzliche Funktionsweise einer Konzernpyramide (PY) wurde bereits im Rahmen von Kapitel II.2.3.2 erläutert. Für die empirische Untersuchung ist jedoch festzulegen, ab welchen Beteiligungshöhen im Einzelfall von einer Pyramide ausgegangen wird. Sie liegt unstrittig immer dann vor, wenn das Mutterunternehmen an seinem Tochterunternehmen die Mehrheit der Stimmrechte hält und dieses Tochterunternehmen seinerseits an einem anderen „Enkelunternehmen" die Stimmrechtsmehrheit innehat. ${ }^{907}$ Die Kapitalanteile des Mutterunternehmens am Enkelunternehmen werden durch Multiplikation der Kapitalbeteiligungen von Mutter und Tochter ermittelt. ${ }^{908}$ Hält etwa die Mutter 50,1\% des Kapitals der Tochter und die Tochter 50,1\% am Enkelunternehmen, so ist die Mutter am Enkel beteiligt mit 50,1\%.50,1\%=25,1\%, beherrscht jedoch $50,1 \%$ der Stimmrechte. Dieser Fall würde wie folgt erfasst:

- Kapitalanteil des Pyramiden-MU (KA): $:^{909}$

$25,1 \%$

- davon direkt gehaltener Kapitalanteil:

$0 \%$

- davon indirekt gehaltener Kapitalanteil: ${ }^{910}$

$25,1 \%$

- Stimmrechtsanteil (StA):

$50,1 \%$

- Ebenen der Konzernpyramide:

2

- Kapitalanteil des direkt beteiligten Aktionärs (KAD): 50,1\%

Sofern das Pyramiden-Mutterunternehmen zusätzlich zu seinem indirekt gehaltenen Anteil auch direkt am Kapital des Enkelunternehmens beteiligt wäre, würde dieses im Kapitalanteil ebenfalls erfasst und als „Davon-Größe“ zusätzlich ausgewiesen.

906 Vgl. hierzu auch bereits das Beispiel in Kapitel III.2.3.2.2.

907 Vgl. auch Wiwattanakantang (2001), S. 336f.; Kammerath (2000), S. 15.

908 Die Kapitalbeteiligung des Pyramiden-Mutterunternehmens ergibt sich mathematisch durch Inversion der Matrix der direkten Beteiligungsquoten. Vgl. Kammerath (2000), S. 16, für eine formale Darstellung, sowie Claessens et al. (1999), S. 11.

909 Der über direkte und indirekte Beteiligungen gehaltene Kapitalanteil des PyramidenMutterunternehmens wird in der Literatur teilweise als „kumulierte“ bzw. „konsolidierte“ Quote“ bzw. als „integrated ownership" bezeichnet. Vgl. Kammerath (2000), S. 16 m.w.N.

910 Der indirekt gehaltene Kapitalanteil des Pyramiden-Mutterunternehmens wird in der Literatur teilweise als „durchgerechnete Quote“, „mehrstufiger Beteiligungsprozentsatz" oder „mittelbare Kapitalbeteiligungsquote“ bezeichnet. Vgl. Kammerath (2000), S. 16 m.w.N. 
Bei einem Stimmrechtsanteil von über $50 \%$ ist von einer möglichen Beherrschung des Tochterunternehmens und des möglichen Durchgriffs auf die Enkelgesellschaft zweifelsfrei auszugehen. ${ }^{911}$ Fraglich ist jedoch, ob auch in Fällen, in denen das Mutterunternehmen weniger als $50 \%$ an der Tochter hält, eine so maßgebliche Einflussnahme vorliegen kann, dass dem Mutterunternehmen die Stimmrechte der Tochter zuzurechnen sind. Dies erscheint unter Berücksichtigung der geringen Hauptversammlungspräsenzen, die eine faktische Beherrschung bereits bei Stimmrechtsanteilen deutlich unter $50 \%$ ermöglichen, sinnvoll. Faccio/Lang (2002) gehen bereits bei einer Beteiligung von jeweils über $5 \%$ vom Vorliegen einer Kontrollkette aus. ${ }^{912}$ Dies erscheint jedoch vor dem Hintergrund deutscher Verhältnisse nicht angemessen, da viele Aktiengesellschaften mehrere Aktionäre mit Stimmrechtsanteilen über $5 \%$ haben. Als mögliche Grenze könnten die gesellschafts- und kapitalmarktrechtlich bedeutsamen Beteiligungshöhen von $20 \%$ (Vermutung eines maßgeblichen Einfluss gemäß $\S$ 271 Abs. 1 HGB) bzw. $25 \%$ (Sperrminorität auf der Hauptversammlung gemäß $\S 179$ AktG) herangezogen werden. ${ }^{913}$

Im Rahmen dieser Untersuchung wird die vergleichsweise konservative Grenze von $30 \%$ der Stimmrechte gewählt, ab der eine Beherrschungsmöglichkeit angenommen wird. Dies erscheint unter Berücksichtigung der durchschnittlichen Hauptversammlungspräsenzen von etwa $50 \%$ des stimmberechtigten Kapitals plausibel. ${ }^{914}$ Dafür spricht auch, dass sich im Rahmen des Gesetzgebungsverfahrens zum WpÜG im Jahre $200130 \%$ als Kapitalanteil durchgesetzt hat, ab dem ein Pflichtangebot zu machen ist. ${ }^{915}$ Diese Grenze, ab der eine Pyramide angenommen wird, wird jedoch insofern eingeschränkt, als dass von einer Beherrschung immer dann nicht ausgegangen wird, wenn der Stimmrechtsanteil eines anderen Aktionärs $75 \%$ der Stimmrechte des größten Aktionärs beträgt bzw. dieser zweitgrößte Aktionär eine Sperrminorität von $25 \%$ plus einer Aktie hält. Dieser zweite Aktionär könnte die Beherrschung durch die Bildung von Koalitionen mit weiteren Minderheitsaktionären gegebenenfalls verhindern. Die fol-

911 Vgl. Kammerath (2000), S. 17.

912 Vgl. Faccio/Lang (2002), S. 372. La Porta et al. (1999) legen die Grenze auf $20 \%$. Vgl. S. 476f. Zur Definition von Kontrollketten vgl. auch Wiwattanakantang (2001), S. 336f., sowie ausführlich Kammerath (2000).

913 Diese Grenze wird auch von verschiedenen anderen Studien gewählt. Vgl. z.B. Cronqvist/Nilsson (2002).

914 Im Jahr 2000 betrug die Hauptversammlungspräsenz bei den DAX-Unternehmen nur 54\%. Vgl. DSW (2000). Vgl. auch Kammerath (2000), S. 18.

915 So heißt es in $\S 29$ Abs. 4: „Kontrolle ist das Halten von mindestens 30 Prozent der Stimmrechte an der Zielgesellschaft.“ Es wird darauf hingewiesen, dass „diese Grenze [...] den Präsenzen in den Hauptversammlungen deutscher Unternehmen Rechnung [trägt]“. Vgl. Gesetzentwurf WpÜG (2001), S. 2; Cahn/Senger (2002), S. 285. 
gende Abbildung verdeutlicht die Vorgehensweise bei der Überprüfung einer Konzernpyramide.

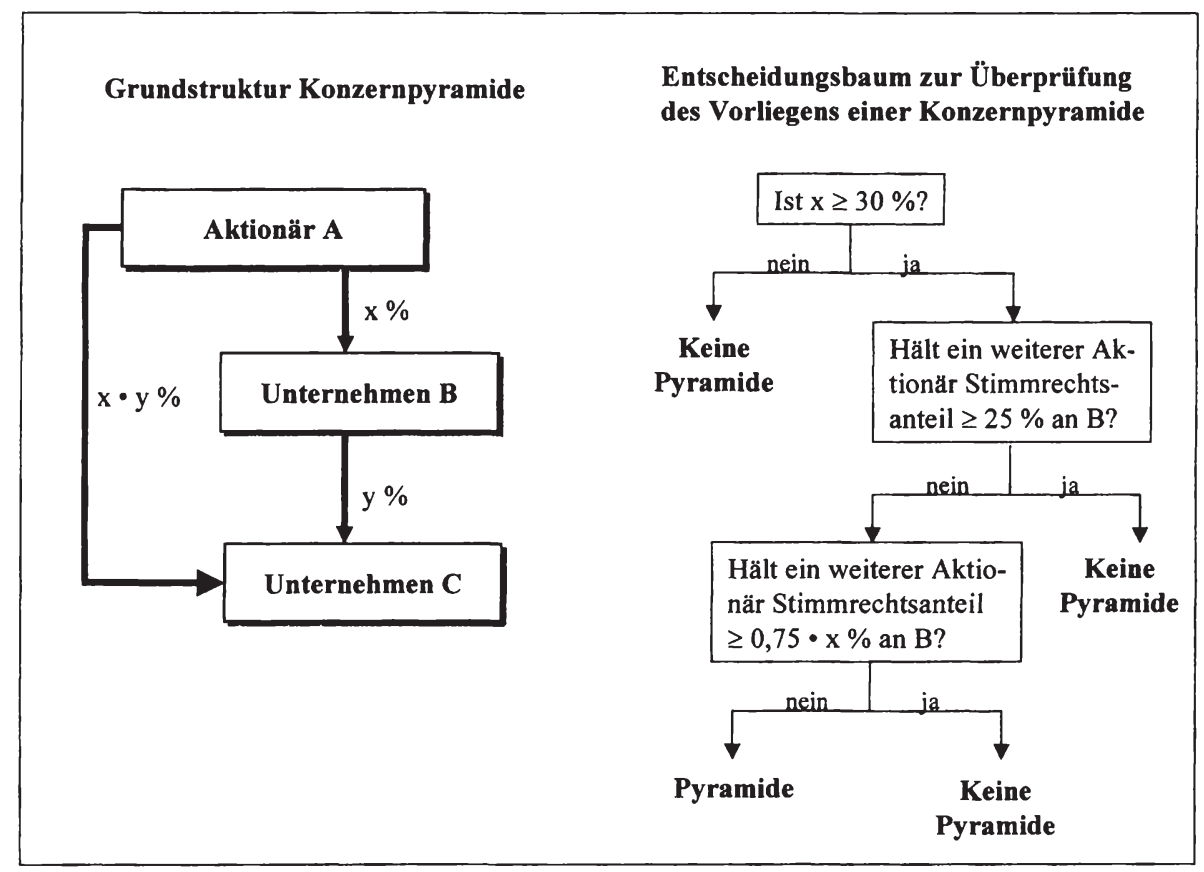

Abb. 21: Entscheidungsbaum Konzernpyramide

In den Fällen, in denen z.B. ein Aktionär A1 einen Stimmrechtsanteil von $30 \%$ und ein Aktionär A2 einen Anteil $>22,5 \%$ an der eine Beteiligung an $\mathrm{C}$ haltenden Gesellschaft B hält, wird somit keine Konzernpyramide ausgewiesen, sondern $\mathrm{B}$ als Einzelaktionär von $\mathrm{C}$ gewertet. Insgesamt wird somit eine konservative Herangehensweise gewählt, die die Bedeutung von Konzernpyramiden eher unterschätzen dürfte. ${ }^{916}$ Dies wird auch dadurch hervorgerufen, dass im Rahmen der Datenerhebung insbesondere bei ausländischen Mutterunternehmen davon auszugehen ist, dass die Kontrollkette nicht immer bis in die letzte Stufe zurückverfolgt werden konnte.

\section{SONSTIGE VARIABLEN}

Die rein numerischen Variablen zum Stimmrechtsanteil werden durch folgende Dummy-Variablen ergänzt: GA2 ist gleich eins, wenn neben dem größten Aktionär noch ein weiterer Großaktionär Stimmrechtsanteile hält, die entweder min-

916 Vgl. auch Ritzberger/Shorish (2002), die zeigen, dass das tatsächliche Kontrollpotenzial des ultimativen Aktionärs unter Nutzung von Pyramiden regelmäßig größer ist, als auf den ersten Blick erkennbar. 
destens drei Viertel so groß sind wie die Stimmrechtsanteile des größten Aktionärs oder mindestens die Sperrminorität von $25 \%$ plus einer Aktie erreichen. Die Dummy-Variablen StA25, StA50 bzw. StA75 sind gleich eins, wenn das Unternehmen einen Aktionär mit über $25 \%, 50 \%$ bzw. $75 \%$ der Stimmrechte aufweist. Die Variable AA5 gibt an, wie groß die Anzahl der Aktionäre mit einem Stimmrechtsanteil über $5 \%$ in dem Unternehmen ist. ${ }^{917}$

\subsection{Variablen zur Diskrepanz zwischen Kapital- und Stimmrechtsanteil}

Zentraler Bestandteil der Untersuchung ist die Analyse der Auswirkungen abweichender Cash-Flow- und Stimmrechte. Daher müssen Maßgrößen in die Analyse einbezogen werden, die das Vorhandensein und die Intensität von Vorzugsaktien, Pyramiden und vergleichbaren Mechanismen abbildbar machen. Die einfachste Variante sind hier Dummy-Variablen, die in der Literatur regelmäßig zur Berücksichtigung von Pyramidenbildungen sowie Abweichungen vom Prinzip des One-Share-One-Vote eingesetzt werden. ${ }^{918}$ Die Existenz einer Kontrollpyramide wird im Rahmen dieser Untersuchung durch die Dummy-Variable PY abgebildet. Unternehmen, die vom Prinzip des One-Share-One-Vote abweichen, werden mit der Dummy-Variablen VA gekennzeichnet. Die Variable ABW fasst Abweichungen zwischen Kapital- und Stimmrechtsanteilen durch Vorzugsaktien und Pyramiden in einer Dummy-Variablen zusammen.

Dummy-Variablen trennen Unternehmen ausschließlich nach dem Vorhandensein eines bestimmten Merkmals. Sie sind daher nicht in der Lage, Informationen über die Stärke der Ausprägung eines Merkmals zu liefern. Es ist jedoch plausibel anzunehmen, dass sich die Wirkungen abweichender Stimm- und Cash-Flow-Rechte in einem Unternehmen, das die maximal zulässige Anzahl von $50 \%$ Vorzugsaktien emittiert hat, stärker bemerkbar machen wird als in einem mit nur $5 \%$ Vorzugsaktien. Daher wird mit der Variable Excess Votes (EV) zusätzlich eine kardinal skalierte Erklärende zur Abbildung divergierender Stimm- und Cash-Flow-Rechte gebildet: ${ }^{919}$

$$
E V=\left(\frac{S t A}{K A}-1\right) \cdot 100 \text {. }
$$

\footnotetext{
917 Für viele Unternehmen werden überhaupt nur Aktionäre mit einem Stimmrechtsanteil von über $5 \%$ erfasst. Aufgrund verschiedener aktienrechtlich bedeutsamer Regelungen, die an eine Stimmrechtsquote von $5 \%$ geknüpft sind, kommt dieser Grenze eine besondere Bedeutung zu. Vgl. Witt (1998), S. 174, Fn. 34; Wolff (2000), S. 4.

918 Vgl. etwa Franks/Mayer (1996); Wiwattanakantang (2001), S. 337, 352.

919 Vgl. Cronqvist/Nilsson (2002), S. 17; Claessens et al. (1999); Bianchi et al. (2001).
} 
Die Excess Votes geben damit den Prozentsatz an, um den der Stimmrechtsanteil eines Aktionärs den Kapitalanteil übersteigt. ${ }^{920}$ Die Variable ist gleich null, sofern weder eine Pyramidenbildung noch ein Abweichen vom Prinzip des OneShare-One-Vote vorliegt. Der Vorteil der Kennziffer liegt darin, dass sie die Auswirkungen der von ihrer ökonomischen Wirkung her vergleichbaren Instrumente zur Bildung abweichender Stimm- und Cash-Flow-Rechte in einer einzigen Variablen abbildet.

\subsection{Zusammenfassung der Variablen zur Eigentümer- und Stimmrechts- struktur}

Die folgende Tabelle gibt einen Überblick über die verschiedenen Variablen zur Abbildung der Eigentümer- und Stimmrechtsstruktur. Die Ausprägungen der verschiedenen Variablen für das vorliegende Datensample finden sich im Rahmen der deskriptiven Analyse in Kapitel IV.3.1.

Variable Beschreibung

Erklärende Variablen zur Eigentümerstruktur

KADi Kapitalanteil des i-ten direkt beteiligten Aktionärs

SKADi Summe der Kapitalanteile der i größten direkt beteiligten Aktionäre, es gilt:

$$
S K A D i=\sum_{i=1}^{I} K A D i
$$

KAi Kapitalanteil des größten Aktionärs an der Spitze der Konzernpyramide; es gilt:

$$
K A i=\prod_{i=1}^{I} p_{i}
$$

mit $p_{i}=$ auf der jeweiligen Pyramidenebene direkt gehaltener Kapitalanteil. Bei einem Stimmrechtsanteil $>30 \%$ auf jeder Ebene wird von einer Kontrollausübung durch Pyramidenbildung ausgegangen, sofern nicht neben dem Aktionär mit den meisten Stimmrechten ein weiterer Aktionär mindestens $3 / 4$ der Stimmrechte des größten Aktionärs oder einen Stimmrechtsanteil von mindestens $25 \%$ plus einer Aktie hält. Sofern keine Pyramidenbildung vorliegt gilt $\mathrm{KADi}=\mathrm{KAi}$

920 Ähnliche Variablen werden auch vorgeschlagen von Becht (1997), S. $97 \mathrm{f}$. 


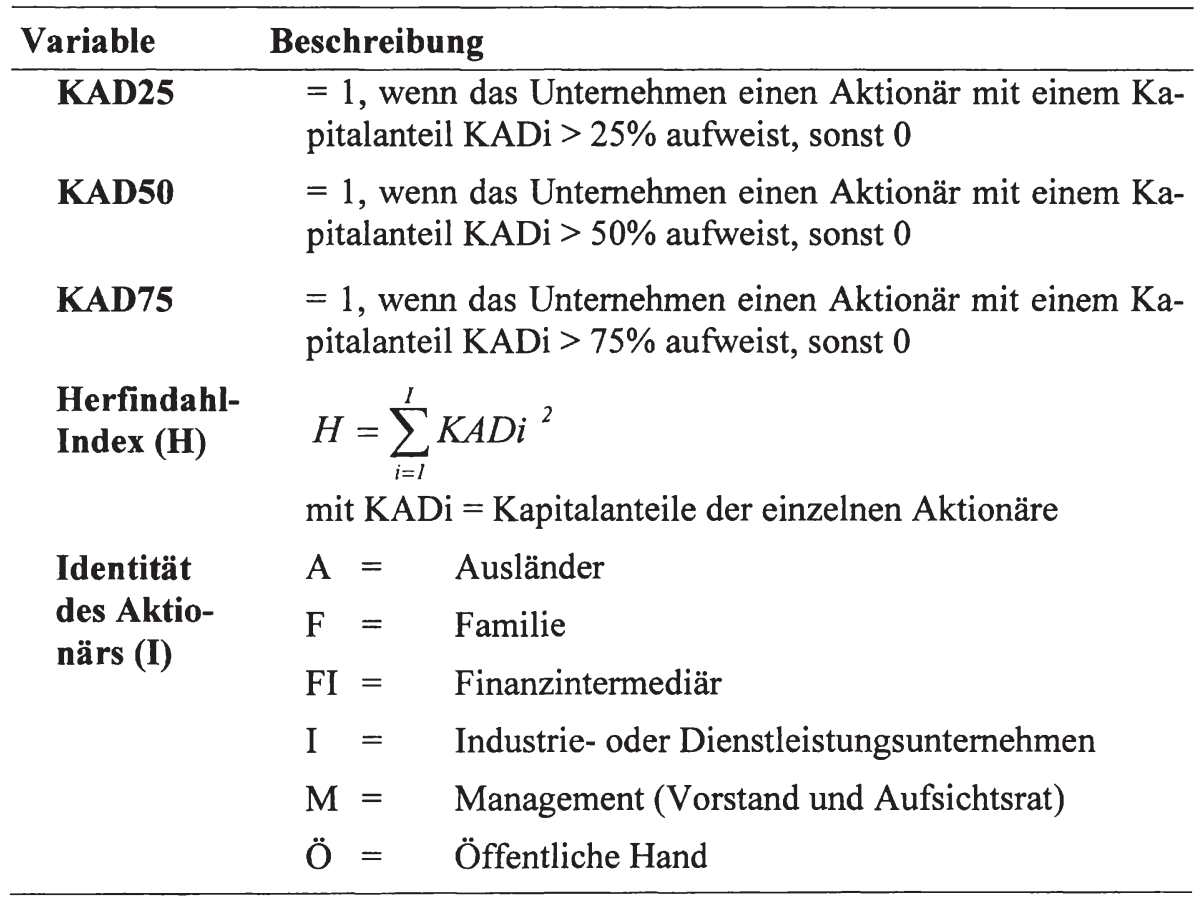

\section{Erklärende Variablen zur Stimmrechtsstruktur}

GA2 = 1, wenn neben dem Aktionär mit den meisten Stimmrechten ein weiterer Aktionär mindestens $3 / 4$ der Stimmrechte des größten Aktionärs oder einen Stimmrechtsanteil von mindestens $25 \%$ plus einer Aktie hält, sonst 0
AA5
Anzahl Aktionäre mit StAi $>5 \%$

StAi

SStAi

Durch die Pyramidenmutter kontrollierter Stimmrechtsanteil. Entspricht in der Regel dem Stimmrechtsanteil des iten direkt beteiligten Aktionärs ${ }^{921}$

SStAi

Summe der Stimmrechtsanteile der i größten direkt beteiligten Aktionäre, es gilt:

$$
S S t A i=\sum_{i=1}^{I} S t A i
$$

StA25 $=1$, wenn das Unternehmen einen Aktionär mit einem Stimmrechtsanteil StAi $>25 \%$ aufweist, sonst 0

921 Abweichungen von KAi ergeben sich durch Vorzugsaktien, Pyramiden, Mehrheitsstimmrechte oder Stimmrechtsbeschränkungen. Sofern die Pyramidenmutter zusätzlich selbst Anteile hält, kann StAi größer sein als der Stimmrechtsanteil des größten direkt beteiligten Aktionärs. 


\begin{tabular}{cl}
\hline Variable & Beschreibung \\
\hline StA50 & $=1$, wenn das Unternehmen einen Aktionär mit einem \\
& Stimmrechtsanteil $\mathrm{StAi}>50 \%$ aufweist, sonst 0 \\
StA75 & $=1$, wenn das Unternehmen einen Aktionär mit einem \\
& Stimmrechtsanteil StAi $>75 \%$ aufweist, sonst 0 \\
\hline
\end{tabular}

Erklärende Variablen zu abweichenden Stimmrechts- und Kapitalanteilen

EV

Excess Votes: Prozentsatz, um den der Stimmrechtsanteil des größten Aktionärs den Kapitalanteil übersteigt; es gilt: $E V=\left(\frac{S t A l}{K A 1}-1\right) \cdot 100$

Variable ist $=0$, sofern weder eine Pyramidenbildung noch ein Abweichen vom Prinzip des One-Share-One-Vote vorliegt ${ }^{922}$

PY $=1$, sofern eine Kontrollkette von mindestens drei Unternehmen vorliegt, bei der das übergeordnete Unternehmen am untergeordneten jeweils zu mindestens $30 \%$ beteiligt ist und gilt, dass nicht neben dem Aktionär mit den meisten Stimmrechten ein weiterer Aktionär mindestens $3 / 4$ der Stimmrechte des größten Aktionärs oder einen Stimmrechtsanteil von mindestens $25 \%$ plus eine Aktie hält; sonst 0

VA $=1$, sofern das Unternehmen mehr als eine Aktiengattung emittiert hat, sonst 0

ABW $=1$, sofern gilt, dass $\mathrm{PY}=1$ oder $\mathrm{VA}=1$

Tab. 11: Variablen zur Eigentümer- und Stimmrechtsstruktur

\subsubsection{Kontrollvariablen}

Zielsetzung der Kontrollvariablen ist es, beobachtbare Unternehmenscharakteristika, die neben der Eigentümerstruktur Einfluss auf die Performance haben (könnten), in die Regression mit aufzunehmen. Dadurch wird eine Verzerrung der Regressionsergebnisse vermieden und der Erklärungsgehalt der Regression erhöht. ${ }^{923}$ Die in vorhandenen empirischen Studien eingesetzten Kontrollvariablen sind im Wesentlichen standardisiert. ${ }^{924}$ Insbesondere Unternehmensgröße

\footnotetext{
922 Vgl. Cronquist/Nilsson (2002), S. 17.

923 Vgl. Short/Keasey (1999), S. 92; Lehmann/Weigand (2000), S. 173.

924 Vgl. hierzu die Angaben in Anhang B.
} 
und Branche werden in fast allen Studien kontrolliert. Darüber hinaus sind Variablen zur Kontrolle der Finanzierungsstruktur, der Anlagenintensität und des Wachstums verbreitet; teilweise werden darüber hinaus Forschungsintensität, Investitionen und Risiko einbezogen. Die Variablen sind jedoch teilweise redundant. Die hier vorgenommene Auswahl basiert auf Ergebnissen primär jüngerer empirischer Studien und ist darüber hinaus durch die Datenverfügbarkeit determiniert.

Die Branchenzugehörigkeit eines Unternehmens wird regelmäßig als Kontrollvariable eingesetzt, da Unternehmen einer Branche in der Regel einem ähnlichen Rendite-Risiko-Profil ausgesetzt sind. Darüber hinaus sind sie in vergleichbarem Maße konjunkturellen Schwankungen unterworfen, die wiederum einen starken Einfluss auf die Performance ausüben. Hinsichtlich der Brancheneinteilung wird auf die Systematisierung der Deutschen Börse AG zurückgegriffen, der ohne Berücksichtigung der Finanzdienstleister die folgenden 16 Sektoren zugrunde liegen: $:^{925}$

\section{Brancheneinteilung der Deutsche Börse AG}

\begin{tabular}{llll}
\hline Automobile & Consumer-cyclical & Media & Technology \\
Basic Resources & Food \& Beverages & Pharma \& Health & Telecommunications \\
Chemicals & Industrials & Retail & Transport \& Logistics \\
Construction & Machinery & Software & Utilities \\
\hline
\end{tabular}

Tab. 12: Brancheneinteilung

Unternehmen einer Branche agieren hinsichtlich Chancen und Risiken in vergleichbaren Wettbewerbsumfeldern. Dementsprechend erscheint die in einzelnen Studien vorgenommene zusätzliche Erfassung der Produktmarktkompetitivität $^{926}$ und des Risikos ${ }^{927}$ redundant, so dass hier zunächst darauf verzichtet werden soll. ${ }^{928}$

Neben der Branche wird die Größe eines Unternehmens regelmäßig als Variable herangezogen, um den sogenannten Size-Effekt zu kontrollieren. Zahlreiche empirische Studien haben nachgewiesen, dass die Performance von kleinen Unternehmen signifikant von der größerer Unternehmen differiert. ${ }^{929}$ Größe und

$925 \mathrm{Vgl}$. zum Ausschluss der Finanzdienstleister das folgende Kapitel IV.2.3.3.1.

926 Vgl. etwa Nickell et al. (1997); Januszewski et al. (1999); Lehmann/Weigand (2000).

927 Vgl. Himmelberg et al. (1999); Pedersen/Thomsen (1999); Bohren/Odegaard (2001); Demsetz/Villalonga (2001).

928 Vgl. jedoch Kapitel IIV.3.2.4.1.

929 Vgl. bereits Banz (1981), sowie Aussenegg/Grünbichler (1999), S. 636-640, mit einem Überblick über empirische Untersuchungen. 
Richtung des Size-Effekts sind abhängig vom beobachteten Kapitalmarkt und dem zugrunde liegenden Untersuchungszeitraum. ${ }^{930}$ Ursache eines positiven Einflusses der Größe auf die Performance könnten economies of scale sein, ${ }^{931}$ Ineffizienzen in großen organisatorischen Einheiten könnten für einen negativen Einfluss sprechen. ${ }^{932}$ Als Proxy für die Unternehmensgröße bieten sich Umsatz, Bilanzsumme und Marktkapitalisierung an. Da die Bilanzsumme in Abhängigkeit von der Branche stark schwanken kann und die Marktkapitalisierung bereits im Rahmen des zu erklärenden Marktwert/Buchwert-Verhältnisses Verwendung findet, ${ }^{933}$ wird hier auf den logarithmierten Umsatz als Kontrollvariable für die Unternehmensgröße abgestellt. ${ }^{934}$ Auf die Formulierung einer Hypothese für die erwartete Richtung des Zusammenhangs zwischen Unternehmensgröße und Erfolg wird verzichtet, da weder die ökonomische Theorie noch die empirischen Ergebnisse zum Size-Effekt eine eindeutige Prognose ermöglichen. ${ }^{935}$

Grundsätzlich erscheint es sinnvoll, die Bedeutung immaterieller Vermögenswerte - die nur teilweise bilanziell abgebildet werden - als Kontrollvariable mit aufzunehmen. ${ }^{936}$ Sofern ein großes Maß an immateriellen Vermögenswerten auf hohe zukünftige Cash Flows hindeutet, wäre ein positives Vorzeichen zu erwarten. ${ }^{937}$ Als Proxy für immaterielle Werte verwenden US-amerikanische Studien in der Regel die F\&E-Aufwendungen. ${ }^{938}$ Nach HGB ist deren Angabe in quantitativer Form im F\&E-Bericht nach $\S 315$ Abs. 2 S. $3^{939}$ jedoch nicht erforderlich, sodass ihre Verwendung als Kontrollvariable ausscheidet. Gleiches gilt für

930 Vgl. Reinganum (1992), S. 58; Aussenegg/Grünbichler (1999), S. 636f.; Brown (2001), S. $105 f$.

931 Vgl. Short/Keasey (1999), S. 92.

932 Vgl. Lehmann/Weigand (2000), S. 173; Seifert/Gonenc/Wright (2002), S. 13.

933 Die gleichzeitige Berücksichtigung auf beiden Seiten der Regressionsgleichung birgt die Gefahr der spurious correlation der Variablen. Vgl. Loderer/Martin (1997), S. 234, sowie zur unechten Korrelation ausführlich Kapitel IV.2.2.1.

934 Die logarithmische Transformation einer Variablen bietet sich an, wenn die zu analysierende Variable eine relativ zum Mittelwert große Standardabweichung aufweist. Die Logarithmierung verringert die Streuung und die Asymmetrie, sodass sich bessere Schätzergebnisse erzielen lassen. Vgl. Chatterjee/Price (1995), S. 53f. Vgl. ebenso Wiwattanakantang (2001); Demsetz/Villalonga (2001); Himmelberg et al. (2002); Volpin (2002); La Porta et al. (2002); Lins (2003).

935 Vgl. für einen Überblick Brown (2001), S. 105-107. Vgl. zum Size-Effekt am deutschen Aktienmarkt Beiker (1993); Stehle (1997).

936 Vgl. Demsetz/Villalonga (2001), S. 221.

937 Vgl. Seifert/Gonenc/Wright (2002), S. 13.

938 Vgl. Demsetz/Villalonga (2001), S. 219; Kole (1996), S. 122-125.

939 Bzw. § 289 Abs. 2 S. 3 HGB für den Einzelabschluss. 
Werbeausgaben, die vereinzelt herangezogen werden. ${ }^{940}$ Stattdessen werden hier die bilanzierten immateriellen Vermögensgegenstände in Prozent der Bilanzsumme (IVG) als Hilfsgröße für die Gesamtheit der intangiblen Werte herangezogen. Die Eignung dieser Größe als Proxy für das immaterielle Kapital einer Gesellschaft wird jedoch durch unterschiedliche Rechnungslegungsstandards eingeschränkt. Unterschiedliche Ansatzkriterien für immaterielle Vermögensgegenstände können hier ebenso zu Verzerrungen führen wie alternative Verfahren der Goodwillbehandlung. ${ }^{941}$ Fraglich ist zudem, inwieweit ein großer Anteil bilanzierter immaterieller Werte als Proxy für die nicht bilanzierten geeignet ist. Da jedoch keine alternative Möglichkeit zur Berücksichtigung zur Verfügung steht, sollen die immateriellen Vermögenswerte als Kontrollvariable zunächst aufgenommen werden. Sie werden hinsichtlich ihres Erklärungsgehalts jedoch kritisch zu hinterfragen sein.

Zusätzlich soll die Anlagenintensität (AI) als Kontrollvariable berücksichtigt werden, die ebenfalls Aufschluss über die Vermögensstruktur gibt. Die Anlagenintensität des Unternehmens kann als Maßgröße für die unternehmerische Flexibilität bzw. ein eventuelles Überinvestitionsniveau herangezogen werden. ${ }^{942}$ Unternehmen mit einer hohen Anlagenintensität können weniger kurzfristig auf Absatzschwankungen reagieren, was sich negativ auf die Performance auswirken kann. Demnach wäre ein negatives Vorzeichen der Proxy-Größe zu erwarten. Da eine hohe Anlagenintensität jedoch alternativ auf hohe Markteintrittsbarrieren hindeuten könnte, soll auf die Formulierung einer Hypothese verzichtet werden. ${ }^{943}$ Die Variable AI wird als Anlagevermögen in Prozent der Bilanzsumme definiert. ${ }^{944}$

Des weiteren soll die Kapitalstruktur als Kontrollvariable berücksichtigt werden. Die buchwertbezogene Eigenkapitalrendite wird maßgeblich durch die Finanzierungsstruktur des Unternehmens determiniert, sodass eine Nichtberücksichtigung der Verschuldung die Ergebnisse verzerren würde. Auf Basis der neoklassischen Kapitalstrukturtheorie wäre ein Einfluss auf den Unternehmenserfolg nicht $\mathrm{zu}$ erwarten. ${ }^{945} \mathrm{Da}$ jedoch die umfangreichen Annahmen in praxi nicht er-

940 Vgl. z.B. Morck et al. (1988); Murali/Welch (1989); Agrawal/Knoeber (1996); Demsetz/Villalonga (2001); Woidtke (2002).

941 Vgl. zur Bilanzierung immaterieller Vermögensgegenstände nach IAS, US-GAAP und HGB Alexander/Archer (2001), S. 21.01-21.18; Delaney et al. (2001), S. 377-392; Pellens (2001), S. 175-184, 454-461; Sellhorn (2000); Pellens/Fülbier (2000); Pellens/Fülbier/Sellhorn (2001).

942 Vgl. Lehmann/Warning/Weigand (2002), S. 9; Lehmann/Weigand (2000), S. 173.

$943 \mathrm{Vgl.} \mathrm{Lehmann/Weigand} \mathrm{(2000),} \mathrm{S.} 173$.

944 Vgl. Himmelberg et al. (1999); Pedersen/Thomsen (1999); Cronqvist/Nilsson (2002).

945 Vgl. grundlegend Modigliani/Miller $(1958,1963)$. 
füllt sind, ist die Höhe der Verschuldung entgegen den Modigliani-MillerThesen nicht irrelevant. ${ }^{946}$ Eine hohe Verschuldung bedingt - ausreichende Solvabilität vorausgesetzt - eine hohe Eigenkapitalrendite bei steigendem Risiko. Die umfangreiche empirische Forschung zur Kapitalstruktur zeigt, dass dieses höhere Risiko vom Kapitalmarkt mit niedrigeren Marktwert/Buchwert-Verhältnissen bestraft wird. ${ }^{947}$ Es wäre demnach ein negatives Vorzeichen der Kapitalstrukturvariable in den Regressionen unter Verwendung der marktorientierten Performancekennziffer zu erwarten. Als Proxy stehen verschiedene Variablen wie Verschuldungsgrad, Eigen- oder Fremdkapitalquote zur Auswahl, die von ihrer Aussage her vergleichbar sind. Im Rahmen dieser Untersuchung soll der Verschuldungsgrad (VG) definiert als Quotient von Fremdkapital und Eigenkapital, jeweils zu Buchwerten, herangezogen werden. ${ }^{948}$ Die Anteile von Minderheitsgesellschaftern werden auch hier zum Eigenkapital gezählt.

Darüber hinaus wird ein Proxy für die Wachstumsintensität des Unternehmens herangezogen. Gewählt wird das prozentuale jährliche Wachstum des Umsatzes (W). Die ökonomische Theorie lässt hier, ebenso wie bisherige empirische Ergebnisse, ein positives Vorzeichen der Variablen erwarten. ${ }^{949}$ Wachstumsintensive Unternehmen erwirtschaften aufgrund realisierter economies of scale eine bessere Performance als schrumpfende Unternehmen, deren Rentabilität aufgrund von Fixkostenremanenz häufig zurückgeht.

Schließlich wird eine Kontrollvariable zur Abbildung des genutzten Rechnungslegungsstandards in Form einer Dummy-Variablen für die Anwendung von IAS oder US-GAAP herangezogen (IASUSG). Die Nutzung internationaler Rechnungslegungsstandards führt $\mathrm{zu}$ einer marktwertnäheren Bilanzierung. ${ }^{950}$ Es könnte daher vermutet werden, dass diese Unternehmen ein niedrigeres Markt-

946 Vgl. erläuternd zum Annahmenrahmen der neoklassischen Kapitalstrukturtheorie und zur Erfüllung derselben in der Praxis Noth (1996), S. 84-114; Uhrig-Homburg (2001), S. 187-194.

947 Vgl. Schneider (1991), S. 221f.; Lehmann/Weigand (2000), S. 173; Seifert/Gonenc/ Wright (2002), S. 13. Zu einem Überblick empirischer Arbeiten, die den Einfluss des Insolvenzrisikos auf die Kapitalstruktur untersuchen vgl. Noth (1996), S. 113f. Ein höherer Verschuldungsgrad geht mit einer erhöhten Insolvenzwahrscheinlichkeit einher. Vgl. Uhrig-Homburg (2001), S. 28-31; grundlegend Altman (1968).

948 Vgl. auch Lehmann/Weigand (2000); Morck et al. (2000); Bohren/Odegaard (2001); Guedes/Loureiro (2002); Seifert et al. (2002).

949 Vgl. Gedajlovic/Shapiro (1998); Short/Keasey (1999), S. 92; Wiwattanakantang (2001); La Porta et al. (2002).

950 Vgl. Pellens/Fülbier (2000a), S. 584; Ballwieser (2001), S. 649; Kahle (2002), S. 99. Ausführlich zu zahlreichen Fällen der Fair-Value-Bilanzierung nach IAS vgl. Mujkanovic (2002), S. 136-181. 
wert/Buchwert-Verhältnis aufweisen (negatives Vorzeichen). Für die jahresabschlussbasierten Rentabilitätskennzahlen ist die Prognose schwieriger. Aufgrund des tendenziell früheren Erfolgsausweises nach IAS und US-GAAP könnte ein positiver Einfluss auf die Renditen erwartet werden. Dieser gleicht sich jedoch über die Jahre aus. Zudem führt die marktwertnähere Bilanzierung zu einer größeren Kapitalbasis, was die Renditen negativ beeinflussen dürfte. ${ }^{951}$ Von der Bildung einer Hypothese wird für die Eigen- und Gesamtkapitalrendite daher abgesehen.

Die folgende Tabelle fasst die verschiedenen Kontrollvariablen noch einmal zusammen:

\begin{tabular}{|c|c|}
\hline Variable & Beschreibung \\
\hline \multicolumn{2}{|l|}{ Kontrollvariablen } \\
\hline $\begin{array}{l}\text { Unternehmens- } \\
\text { größe (U) }\end{array}$ & $U=\ln U m s a t z$ \\
\hline Immaterielle & $I V G=\frac{\text { Immaterielle Vermögensgegenstände }}{}$ \\
\hline Werte (IVG) & Bilanzsumme \\
\hline Finanzierungs- & \multirow{2}{*}{$V G=\frac{\text { Fremdkapitalbuchwert }}{\text { Eigenkapitalbuchwert }}$} \\
\hline struktur (VG) & \\
\hline Anlagenintensität & $A I=\frac{\text { Anlagevermögen }}{}$ \\
\hline (AI) & 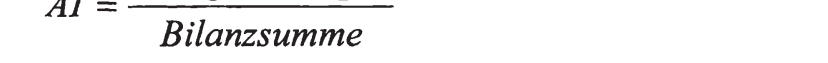 \\
\hline Wachstum (W) & \\
\hline & \\
\hline IASUSG & $\begin{array}{l}=1, \text { wenn Unternehmen nach IAS oder US-GAAP bi- } \\
\text { lanziert, sonst } 0\end{array}$ \\
\hline \multirow[t]{7}{*}{ Branche (B) } & Mach = Machinery \\
\hline & $=$ Construction \\
\hline & $=$ Retail \\
\hline & $=$ Technolgy \\
\hline & $=$ Industrials \\
\hline & ConCy = Consumer-cyclical \\
\hline & FoBe $\quad=$ Food \& Beverages \\
\hline
\end{tabular}

951 Diese Argumentation gilt zumindest für Börsenjahre, in denen die durchschnittlichen Marktwerte über den Buchwerten liegen. Dies war für den vorliegenden Untersuchungszeitraum der Fall. 


\begin{tabular}{ll}
\hline Variable & Beschreibung \\
\hline Auto & $=$ Automobile, Transport \& Logistics \\
PhHe & $=$ Pharma \& Health Care \\
BaRe & $=$ Basic Resources \\
Util & $=$ Utilities \\
Chem & $=$ Chemicals \\
SoTeMe & $=$ Software, Technology, Media \\
\hline
\end{tabular}

Tab. 13: Kontrollvariablen

\subsubsection{Regressionsmodell}

Aus den verschiedenen Variablen wird zunächst folgendes grundlegendes PanelRegressionsmodell gebildet:

$$
\begin{aligned}
M W B W_{i t} & =\alpha+\beta_{I} S t A 1_{i t}+\beta_{2} U_{i t}+\beta_{3} I V G_{i t}+\beta_{4} V G_{i t}+\beta_{5} A I_{i t}+\beta_{6} W_{i t} \\
& +\beta_{7} \text { IASUSG }_{i t}+\sum_{j=1}^{J} \beta_{j 8} \text { Branche }_{j i}+\sum_{m=1}^{M} \beta_{m 9} \text { Identität }_{m i t}+u_{i t}
\end{aligned}
$$

Mit StAl (Stimmrechtsanteil des größten direkt beteiligten Aktionärs) wird hier beispielhaft eine erklärende Eigentümerstrukturvariable in die Regression aufgenommen. Sie wird in weiteren Regressionsmodellen durch alternative Variablen zur Kapital- bzw. Stimmrechtsstruktur und zu Abweichungen zwischen Kapital- und Stimmrechtsstruktur ersetzt bzw. ergänzt. Der Laufindex i = 1, .., 238 dient zur Identifikation der 238 einbezogenen Unternehmen, $t=1997, \ldots, 2000$ beschreibt die vier zugrunde liegenden Untersuchungszeitpunkte. Der Aus$\operatorname{druck} \sum_{m=1}^{M} \beta_{m 9} I_{\text {dentität }}$ mit repräsentiert die über sechs verschiedenen DummyVariablen $(\mathrm{m}=1, \ldots, 6)$ abgebildete Identität des Großaktionärs, der Term $\sum_{j=1}^{J} \beta_{j 8}$ Branche $_{j i}$ bildet analog die dreizehn verschiedenen Branchen ab, die für die einzelnen Unternehmen über die Jahre konstant ist. ${ }^{952}$ Des weiteren werden die in Abschnitt IV.2.3.1.3 erläuterten Kontrollvariablen als Regressoren aufgenommen.

952 Durch die Verwendung von Laufindizes wird in der formalen Darstellung die Übersichtlichkeit erhöht, da alternativ sechs bzw. dreizehn Dummy-Variablen integriert werden müssten. Vgl. ebenso Lehmann/Weigand (2000), S. 171. 


\subsubsection{Datenbasis}

\subsubsection{Sampleauswahl}

Die vorliegende Untersuchung betrachtet börsennotierte Unternehmen, da für diese aussagekräftigere Performancevariablen generiert werden können, als für nicht börsennotierte Gesellschaften. Zudem ist in börsennotierten Aktiengesellschaften, in denen zumindest ein Teil der Aktien breit gestreut ist, sowohl der klassische principal-agent-Konflikt als auch der Konflikt zwischen verschiedenen Anteilseignergruppen von größerer Bedeutung als in solchen Gesellschaften mit begrenzter Aktionärsstruktur und häufig engem Kontakt der Aktionäre zum Management. ${ }^{953}$

Um die bereits diskutierte Gefahr eines Sample Selection Bias ${ }^{954}$ zu vermeiden sind Grundlage dieser Untersuchung alle deutschen Unternehmen, die während des gesamten Untersuchungszeitraums (1997 - 2000) Bestandteil des CDAX waren, also an der Frankfurter Wertpapierbörse seit dem 1.1.1997 ununterbrochen im Amtlichen Handel oder Geregelten Markt notiert wurden. ${ }^{955}$ Es wird eine Beschränkung auf Amtlichen Handel und Geregelten Markt vorgenommen, da die im Freiverkehr notierten Gesellschaften geringeren Publizitätsanforderungen unterliegen und ihre Aktien häufig illiquide sind, sodass sich Verzerrungen ergeben könnten.

Da Finanzintermediäre hinsichtlich ihrer Bilanzstrukturen von Industrieunternehmen stark divergieren, besteht die Gefahr einer Verzerrung der abhängigen Performancevariablen. Marktwert/Buchwert-Verhältnisse beruhen ebenso wie Kapitalrentabilitäten zumindest teilweise auf bilanziellen Größen, sodass insbesondere die unterschiedlichen Eigenkapitalstrukturen eine Vergleichbarkeit erschweren. Da dieses durch die Verwendung von Kontrollvariablen nur begrenzt geheilt werden kann, werden Banken, Versicherungen und sonstige Finanzdienstleister von der vorliegenden Studie ausgeschlossen. Dieses entspricht der

953 Vgl. Köke (2001), S. 271.

954 In vielen Studien werden nur die größten Unternehmen eines Kapitalmarktes einbezogen, was dazu führt, dass die erzielten Ergebnisse nicht mehr für alle börsennotierten Unternehmen verallgemeinerbar sind. Vgl. Bohren/Odegaard (2001), S. 10.

955 Vgl. zur Zusammensetzung des CDAX Deutsche Börse (2002). Durch die Festsetzung des Startzeitpunktes auf den 1.1.1997 sind von den Unternehmen des Neuen Marktes nur diejenigen Bestandteil des Samples, die bereits vor 1997 in einem anderen Index gelistet waren. 
Vorgehensweise zahlreicher internationaler Arbeiten, sodass die erzielten Ergebnisse einen größeren international vergleichbaren Aussagegehalt haben. ${ }^{956}$

Das Ausgangssample der im Untersuchungszeitraum ununterbrochen im CDAX notierten Nicht-Finanzintermediäre umfasst 272 Unternehmen. ${ }^{957}$ Dieses Sample wurde zunächst um 14 Unternehmen bereinigt, die vor Beginn oder während des Untersuchungszeitraums insolvent wurden. Weitere drei Unternehmen haben von den Befreiungsregelungen nach § 292a HGB oder § 293 HGB Gebrauch gemacht und keinen Konzernabschluss erstellt, sodass sie ebenfalls aus dem Sample eliminiert wurden. Somit verbleiben 255 Nicht-Finanzdienstleister, die während des gesamten Untersuchungszeitraums im CDAX notiert waren, nicht insolvent geworden sind und die einen Konzernabschluss aufgestellt haben. Von diesen 255 Unternehmen mussten 17 aufgrund von Datenmängeln eliminiert werden: Für drei Unternehmen waren die Kontrollvariablen nicht in vollem Umfang zu erheben. Für 14 Unternehmen konnten trotz intensiver Recherche die Eigentumsverhältnisse nicht bzw. nur für einzelne Jahre geklärt werden. Der Anteil der aufgrund fehlender Eigentümerstrukturdaten eliminierten Gesellschaften ist mit 5,5\% jedoch gering, sodass das Sample einer Vollerhebung der im entsprechenden Zeitraum im CDAX notierten deutschen Industrieunternehmen sehr nahe kommt und von einer Verzerrung der Ergebnisse durch einen Sample Selection Bias nicht auszugehen ist. Im Ergebnis gehen somit 238 Unternehmen und 952 Beobachtungen in die Analyse ein.

Die folgende Abbildung fasst die Vorgehensweise bei der Sampleauswahl noch einmal zusammen.

956 Insb. die abhängige Variable Tobin's Q bzw. Marktwert/Buchwert-Verhältnis ist zwischen Finanzintermediären und Nicht-Finanzdienstleistern schlecht vergleichbar. Vgl. Lins (2003), S. 163. Vgl. zu Studien, die ebenfalls Finanzintermediäre von der Untersuchung ausschließen etwa Gugler (1999); Pedersen/Thomsen (1999); Guedes/Loureiro (2002); Onishi/Chujo (2002); Volpin (2002). Die Beschränkung auf Industrieunternehmen erhöht insb. die Vergleichbarkeit der Ergebnisse mit denen bereits vorliegender Studien für den deutschen Kapitalmarkt; Lehmann/Weigand (2000) sowie Edwards/Weichenrieder (2000) analysieren ausschließlich Industrieunternehmen.

957 Das Ausgangssample wurde wie folgt ermittelt: Von den am 10. Juli 2002744 im CDAX notierten Unternehmen wurden zunächst 102 Finanzintermediäre (Versicherungen, Banken, Finanzdienstleister) eliminiert. Anschließend wurde für die verbleibenden Unternehmen mit Hilfe von Datastream die Aufnahme der Börsennotierung überprüft und die 370 Neuemissionen seit Anfang 1997 wurden ebenfalls aus dem Sample ausgeschlossen. 


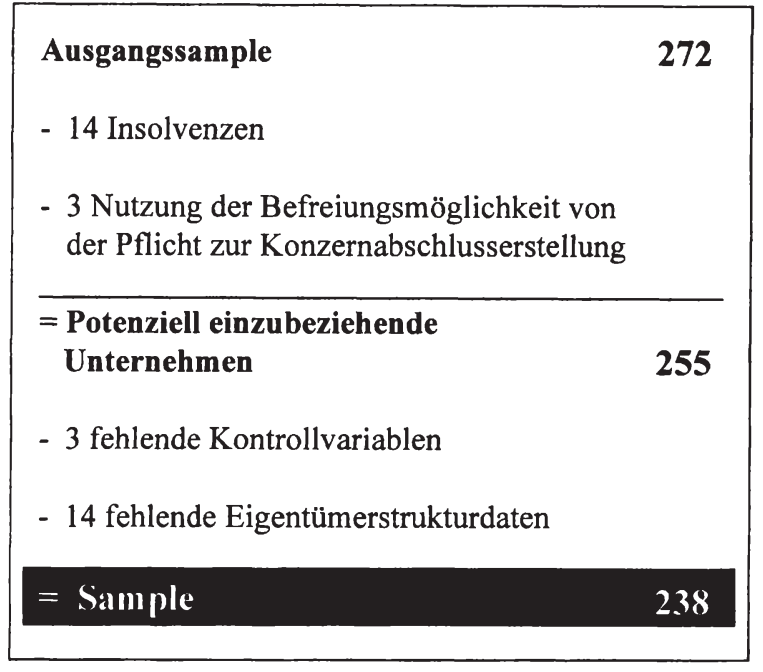

Abb. 22: Sampleauswahl

Die jahresabschlussbezogenen Daten basieren auf den Geschäftsberichten der Jahre 1997 - 2001, die Anteilseignerstrukturen wurden per Ende 1997 - 2000 erhoben.

\subsubsection{Daten zur Eigentümer- und Stimmrechtsstruktur}

Da in Deutschland keine in einer Datenbank aggregierten Informationen über Eigentümer- und Stimmrechtsstrukturen vorliegen, wurden die Daten unter Rückgriff auf verschiedene Quellen wie folgt für jedes Unternehmen individuell erhoben:

Zunächst wurden die durch die Commerzbank AG herausgegebenen „Wer gehört zu wem?" Analyse-CD-Roms ausgewertet. ${ }^{958}$ Für etwa 100 der im Ausgangssample enthaltenen Unternehmen konnten auf diesem Wege nicht für alle vier Jahre Informationen über die Eigentümerstruktur gefunden werden. Einzelne Angaben erschienen zudem unplausibel. ${ }^{959}$ Im Anschluss wurde daher eine unternehmensindividuelle Plausibilisierung unlogischer Angaben und manuelle Ergänzungen wie folgt durchgeführt:

- Die Informationen wurden mit der Hoppenstedt-Konzernstrukturdatenbank abgeglichen, vereinzelt konnten auf diese Weise verbliebene Lücken in der Eigentümerstruktur geschlossen bzw. Daten plausibilisiert werden.

958 Es wurden die Ausgaben 2. Halbjahr 1997, 1998, 1999 sowie 2000/2001 genutzt.

959 So ließen einzelne Eintragungen auf den CD-Roms auf Zahlendreher oder verrutschte Kommastellen schließen. 
- In Einzelfällen wurden größere Überkreuzverflechtungen eliminiert, sodass nur der „Netto-Anteilsbesitz“ berücksichtigt wird. ${ }^{960}$ Grundsätzlich können Stimmrechte jedoch auch innerhalb von Überkreuzverflechtungen ausgeübt werden, sodass eine vollständige Elimination nicht sinnvoll erscheint. Eine Beschränkung ergibt sich nur aus $\S 328 \mathrm{AktG}$, der eine Ausübung der Stimmrechte innerhalb von Überkreuzverflechtungen, die über $25 \%$ hinausgehen, untersagt und die Ausübung des Stimmrechts bei der Wahl der Aufsichtsratsmitglieder verbietet. ${ }^{961}$

- Wenn für Unternehmen mit Vorzugsaktien nur Stimmrechtsanteile berichtet wurden, wurden die gehaltenen Kapitalanteile durch Rückgriff auf die Geschäftsberichte ermittelt. Es wurde in diesen Fällen davon ausgegangen, dass der Großaktionär Stammaktien hält und durch Multiplikation des Stimmrechtsanteils mit dem Anteil Stammaktien auf den Kapitalanteil geschlossen.

- Für einzelne Unternehmen wurden Angaben zur Aktionärsstruktur in den Geschäftsberichten gefunden. Sofern z.B. von 1997 - 1999 eine andere Aktiengesellschaft als großer Aktionär ausgewiesen wurde und die Information für das Jahr 2000 fehlte, wurden die Angaben zu den Beteiligungsverhältnissen im Geschäftsbericht des Mutterunternehmens überprüft. Sofern im 2000er Geschäftsbericht des Mutterunternehmens das Tochterunternehmen noch als Beteiligung geführt wurde, konnten so die vorhandenen Daten ergänzt werden.

- Bei einigen Unternehmen lagen Informationen nur für einzelne oder mehrere Jahre aus dem Zeitraum 1997 - 1999 vor, nicht jedoch über jüngere Daten. Hier wurde die aktuelle Anteilseignerstruktur über die Homepage der Deutschen Börse AG recherchiert. Sofern sie der alten Aktionärsstruktur entsprach, wurden die Lücken unter der Annahme gefüllt, dass sich auch in den dazwischen liegenden Jahren keine Veränderung ergeben hat.

- Durch Recherchen über Internet-Suchmaschinen konnten zudem zahlreiche Umfirmierungen identifiziert werden, sodass für verschiedene Unternehmen auch die früheren Jahre recherchierbar wurden.

- Gesellschaften, für die auf diesem Wege keine vollständigen Angaben erzielt werden konnten, wurden über die Investor-Relations-Abteilungen telefonisch

\footnotetext{
960 Vgl. zur Elimination von Überkreuzverflechtungen Becht (1997), S. 70f.; Wiwattanakantang (2001), S. 337-339; Aleff/Steden (2001), S. 667f. Zur geringen Bedeutung dieser Verflechtungsform am deutschen Kapitalmarkt vgl. Abschnitt III.2.3.2.

961 Vgl. auch Wenger/Kaserer (1998), S. 58f.
} 
oder via Email kontaktiert und um Auskunft zu ihrer Aktionärsstruktur gebeten.

Neben der Ergänzung von fehlenden Daten erfolgten folgende Schritte zur weiteren Präzisierung der Daten:

- Anteilseigner vieler Unternehmen sind Beteiligungsgesellschaften, die wiederum Tochterunternehmen großer Konzerne sind. Sofern der Name eines beteiligten Unternehmens auf eine solche Identität schließen ließ, wurde über das Internet das dahinterstehende Mutterunternehmen identifiziert. Entsprechend wurde auch verfahren, wenn der Name auf ein ausländisches Mutterunternehmen schließen ließ. ${ }^{962}$ Auf diese Weise konnten erheblich mehr Konzernpyramiden identifiziert werden als in den verschiedenen Aktienführern enthalten waren. Dennoch ist davon auszugehen, dass die vorliegenden Daten den Grad der Verflechtung eher unter- als überschätzen. Gerade bei ausländischen Mutterunternehmen werden die dahinterstehenden Anteilseigner in der Regel nicht weiter analysiert.

- Sofern der Anteilseigner eine natürliche Person war, wurde ebenfalls mit Hilfe gängiger Internet-Suchmaschinen soweit möglich identifiziert, ob die entsprechende Person Mitglied von Vorstand oder Aufsichtsrat des Unternehmens ist bzw. ob es sich um ein Mitglied der Gründerfamilie handelt. Die Identitäten der Aktionäre wurden jeweils mit erfasst.

\subsubsection{Jahresabschluss- und Kapitalmarktdaten}

Die Kontrollvariablen basieren ebenso wie die abhängigen Variablen überwiegend auf Bilanz- und GuV-Daten. Diese wurden in einem ersten Schritt aus der Datastream-Datenbank entnommen, die ihrerseits zum größten Teil auf der Hoppenstedt-Bilanzdatenbank aufbaut. Da die dort enthaltenen Daten jedoch unvollständig und in Einzelfällen unplausibel sind, wurden die Ergebnisse manuell ergänzt und stichprobenartig überprüft. Eine solche Überprüfung erfolgte insbesondere in den Fällen, in denen während des Untersuchungszeitraums ein Rechnungslegungswechsel stattgefunden hat. Eine manuelle Ergänzung der Daten war etwa für jedes dritte Unternehmen erforderlich.

Die Kapitalmarktdaten stammen ebenfalls aus Datastream, benötigt wurde hier insbesondere die Marktkapitalisierung des Unternehmens. Der Marktwert des

962 Vgl. hierzu Becht (1997), S. $91 \mathrm{f}$. 
Eigenkapitals wird dabei als Summe der Marktwerte aller Aktien kalkuliert. ${ }^{963}$ Für Unternehmen mit gespaltenem Eigenkapital werden die Marktwerte von Stamm- und Vorzugsaktien addiert. Problematisch ist die Bestimmung des Marktwerts des Eigenkapitals für die Unternehmen, bei denen nur die Vorzugsaktien börsennotiert sind und somit ein Marktwert der Stammaktien nicht unmittelbar feststellbar ist. Dies war bei 18 Sampleunternehmen der Fall. Um den Wert der Stammaktien näherungsweise zu ermitteln, wurde daher für alle Unternehmen mit gespaltenem Eigenkapital, deren Stamm- und Vorzugsaktien an der Börse notieren, der durchschnittliche Kursaufschlag der Stammaktien auf den Wert der Vorzugsaktie ermittelt. ${ }^{964}$ Er betrug im Juli 2002 für die SampleUnternehmen 16,2 \%, ${ }^{965}$ was in etwa dem langjährigen Durchschnitt entspricht, den Daske/Ehrhardt (2002) für den deutschen Kapitalmarkt ermitteln. ${ }^{966}$ Die Anzahl der nicht börsennotierten Stammaktien wurde aus den Geschäftsberichten der Gesellschaften erhoben. Die Aktienanzahl wurde anschließend mit dem fiktiven Kurs der Stammaktien multipliziert, der sich aus dem Kurs der Vorzugsaktie zuzüglich des marktüblichen Aufschlags von 16,2\% ergibt. Dieses Verfahren kann den tatsächlichen Marktwert dieser Unternehmen zwar nur approximieren. Es erscheint jedoch plausibler, den Marktwert aller Aktien auf diese Weise anzunähern, als nur den Marktwert der börsennotierten Aktien zu berücksichtigen. Letzteres würde zu einer Verzerrung der Marktwert/BuchwertVerhältnisse führen, da in die Marktkapitalisierung nur ein Teil der Aktien einfließt, in den Buchwert jedoch alle Aktien. Alternativ könnte das sich nur auf die Vorzugsaktien beziehende Marktwert/Buchwert-Verhältnis ${ }^{967}$ berücksichtigt werden. Dieses ist jedoch systematisch niedriger als bei anderen Unternehmen: Im Durchschnitt der 18 Unternehmen, die nur Vorzugsaktien notiert haben, beträgt es über vier Jahre $\mathrm{MWBW}=0,68$; der Durchschnitt aller Unternehmen liegt bei MWBW = 1,46. Nutzt man jedoch die hier vorgeschlagene Approximation des Marktwertes, ergibt sich für die 18 Unternehmen im Durchschnitt

963 Die Kapitalmarktdaten wurden in Form von Tagesschlusskursen an der Frankfurter Wertpapierbörse aus der Datastream-Datenbank von Thomson Financial Ltd. entnommen.

964 Diese Vorgehensweise bündelt die Einflüsse, die die Stimmrechtsprämie sowie eventuelle Liquiditätsunterschiede der Aktiengattungen und Dividendenvorzüge der Vorzugsaktien ausüben.

965 Die durchschnittlichen Kursaufschläge wurden als arithmetisches Mittel der Auf- bzw. Abschläge der 55 relevanten Sample-Unternehmen zum Stichtag 21.7.2002 bestimmt.

966 Für 101 Gesellschaften ermitteln sie über den Zeitraum von 1956 - 1998 einen durchschnittlichen Kursaufschlag der Stammaktien von 17,2\%. Vgl. Daske/Ehrhardt (2002), S. 17.

967 Definiert als $\frac{\text { Marktwert der VA+Buchwert des } F K \cdot \text { Anteil } V A \text { am } E K \text { in \% }}{\text { Buchwert der Vermögensgegenstände } \text { Anteil VA am } E K \text { in } \%}$. 
MWBW $=1,42$. Eine Verwendung des approximierten Marktwert/BuchwertVerhältnisses erscheint somit dann sinnvoll, wenn nicht davon ausgegangen werden muss, dass sich die Unternehmen, die nur Vorzugsaktien emittiert haben, systematisch von anderen Unternehmen unterscheiden. Zum Vergleich wird daher das durchschnittliche MWBW der Unternehmen ermittelt, die ebenfalls zwei Aktiengattungen aufweisen, bei denen jedoch beide Gattungen notiert sind. Diese Unternehmen, die mit der Gruppe der 18 Unternehmen grundsätzlich vergleichbar sein könnte, weisen ein durchschnittliches MWBW von 1,65 auf. Die Verwendung der Approximationsregel zur Bestimmung des MWBW scheint somit unter Berücksichtigung vergleichbarer Unternehmen zumindest nicht zu einer Überschätzung der Marktbewertung zu führen. Von einer systematischen Verzerrung der Ergebnisse durch das angewandte Verfahren scheint daher zunächst nicht auszugehen zu sein, zumal es nur für 18 von 238 Unternehmen angewandt wurde. Hierzu sollen an späterer Stelle Stabilitätstests durchgeführt werden.

Abgesehen von den Eigentümerstrukturvariablen greifen alle Variablen zumindest teilweise auch auf jahresabschlussbezogene Größen zurück. Die Variablen sind damit den üblichen Schwächen wie Stichtagsbezogenheit, Anfälligkeit für Sachverhaltsgestaltung und Wahlrechtsausübung ausgesetzt. ${ }^{968}$ Verzerrungen durch unterschiedliche Rechnungslegungsstandards stellen eine zusätzliche Gefahr dar. Da diese jedoch zu Beginn des Untersuchungszeitraums noch nicht verbreitet waren und auch im Jahr 2000 primär die Großkonzerne die Befreiungsmöglichkeiten des $\S 292$ a HGB nutzten, sollte sich hieraus keine grundsätzliche Ablehnung der Methodik ergeben. ${ }^{969}$ Ein eventueller Einfluss des Rechnungslegungsstandards wird im Rahmen der folgenden Untersuchung durch Kontrollvariablen zu überprüfen sein. Insgesamt erscheinen die Schwächen in der Datenbasis somit nicht größer als bei vergleichbaren Studien. Vielmehr sollten durch den großen Anteil individueller Recherchen die mit standardisierten Datenbankrecherchen verbundenen Qualitätsmängel vergleichsweise gering sein.

968 Vgl. kritisch Wiwattanakantang (2001), S. 333f.; Claessens et al. (1999), S. 22; Demsetz/Villalonga (2001), S. 213, sowie die Diskussion im vorangegangenen Abschnitt.

969 Von den Sample-Unternehmen haben 10,5\% ihren Jahresabschluss 2000 nach IAS erstellt, $7,1 \%$ nach US-GAAP. Die Anteile in den Vorjahren sind deutlich geringer. 


\section{Ergebnisse der empirischen Untersuchung}

\subsection{Eigentümer- und Stimmrechtsstrukturen am deutschen Kapitalmarkt}

Bevor in Kapitel IV.3.2 der Zusammenhang zwischen Eigentümer- bzw. Stimmrechtsstruktur und Unternehmenserfolg untersucht wird, werden im Folgenden die Sampleunternehmen einer deskriptiven Analyse unterzogen. Die Untersuchung gibt detaillierten Aufschluss über die am deutschen Kapitalmarkt in der jüngeren Vergangenheit bestehenden Eigentümer- und Stimmrechtsstrukturen und trägt so zur Behebung des identifizierten Forschungsdefizits bei.

\subsubsection{Allgemeine Unternehmenscharakteristika}

Das Sample umfasst mit 238 im CDAX notierten Aktiengesellschaften eine insbesondere hinsichtlich ihrer Größe sehr heterogene Gruppe von Unternehmen. So variiert die Marktkapitalisierung der einbezogenen Unternehmen per 31.12.2000 zwischen 0,53 Mio. $€$ und 81.017 Mio. $€$. Die starke Heterogenität wird auch durch die große Standardabweichung von 9.066 Mio. $€$ deutlich. Die Verzerrungen werden insbesondere durch den Einfluss weniger großer DAXWerte hervorgerufen. Dies verdeutlicht auch das mit 2.414 Mio. $€$ im Vergleich zum Median (167 Mio. $€$ ) große arithmetische Mittel der Marktkapitalisierung. Ein vergleichbares Bild ergibt sich auch bei Betrachtung des Umsatzes und der Bilanzsumme. Um eine verbesserte Transparenz über die Verteilungsstruktur zu erhalten, werden daher in der folgenden Tabelle, die neben der Marktkapitalisie-

rung auch Performance- und Jahresabschlussdaten per 31.12.2000 $0^{970}$ enthält, jeweils zusätzlich das erste und dritte Quartil ausgewiesen. ${ }^{971}$

\begin{tabular}{lrrrrr}
\hline & Ar. Mittel & Std.abw. & 1. Quartil & Median & 3. Quartil \\
\hline Marktkapitalisierung (Mio. $\epsilon$ ) & 2.414 & 9.066 & 43 & 167 & 786 \\
\hline Performancedaten & & & & & \\
MWBW & 1,37 & 0,96 & 0,97 & 1,12 & 1,44 \\
EKR (\%) & 1,83 & 29,92 & 0,35 & 6,74 & 15,59 \\
GKR (\%) & 3,64 & 5,83 & 1,25 & 3,86 & 6,71 \\
\hline
\end{tabular}

970 Die entsprechenden Auswertungen für die Jahre 1997 - 1999 finden sich in Anhang C (Tab. A 1 - A 3). Die Eigen- und Gesamtkapitalrentabilitäten wurden um Ausreißer bereinigt, da sich insb. bei der Eigenkapitalrendite für Unternehmen mit sehr geringem Eigenkapital Extremwerte ergeben, die die Gesamtaussage verzerren. Dabei wurden die oberen und die unteren $5 \%$ unberücksichtigt gelassen. Vgl. ebenso La Porta et al. (2002), S.1159; Lins (2003), S. 163.

971 Das 1. (3.) Quartil gibt den Wert an, unter dem 1/4 (3/4) aller Datenwerte liegen. 
Ar. Mittel Std.abw. 1. Quartil Median 3. Quartil

\begin{tabular}{lrrrrr}
\hline Jahresabschlussdaten & & & & & \\
Umsatz (Mio. $\boldsymbol{~ C ) ~}$ & 3.318 & 9.783 & 148 & 446 & 1.996 \\
Bilanzsumme (Mio. $\epsilon)$ & 3.620 & 12.700 & 118 & 368 & 1.468 \\
$I V G(\%)$ & 7,01 & 9,89 & 0,73 & 2,49 & 8,94 \\
$V G$ & 3,12 & 4,25 & 1,25 & 2,09 & 3,53 \\
$A I(\%)$ & 44,63 & 27,62 & 28,74 & 41,01 & 56,57 \\
$W(\%)$ & 8,97 & 36,31 & $-2,57$ & 8,98 & 19,39 \\
\hline
\end{tabular}

Tab. 14: Allgemeine Unternehmenscharakteristika der Sampleunternehmen, $2000^{972}$

Eine Analyse der Rentabilitätskennziffern von 1997 - 2000 bzw. 2001 deutet auf eine deutlich zurückgehende Ertragskraft der Unternehmen zum Ende des Untersuchungszeitraums hin, die im Jahr 2000 begleitet wird von einer geringeren Bewertung der Unternehmen durch den Kapitalmarkt; sowohl Marktkapitalisierung als auch das Marktwert/Buchwert-Verhältnis gehen zurück.

Bei der Betrachtung der Branchenverteilung der Sampleunternehmen ist eine Dominanz der „klassischen“ Branchen festzustellen:

\begin{tabular}{lrrl}
\hline \multicolumn{1}{c}{ Branche } & \multicolumn{3}{c}{ Anteil im Sample } \\
absolut & in \% & Kürzel \\
\hline Machinery & 30 & $12,6 \%$ & Mach \\
Construction & 29 & $12,2 \%$ & Con \\
Retail & 25 & $10,5 \%$ & Ret \\
Technology & 23 & $9,7 \%$ & Tech \\
Industrials & 22 & $9,2 \%$ & Ind \\
Consumer-cyclical & 19 & $8,0 \%$ & ConCy \\
Food \& Beverages & 18 & $7,6 \%$ & FoBe \\
Automobile & 16 & $6,7 \%$ & Auto \\
Pharma \& Health & 14 & $5,9 \%$ & PhHe \\
Basic Resources & 12 & $5,0 \%$ & BaRe \\
Utilities & 11 & $4,6 \%$ & Util \\
Chemicals & 8 & $3,4 \%$ & Chem \\
Transport \& Logistics & 6 & $2,5 \%$ & Auto \\
Software & 2 & $0,8 \%$ & SoTeMe
\end{tabular}

972 Die ausgewiesenen Eigen- und Gesamtkapitalrenditen beziehen sich auf das Jahr 2001. In der Tabelle sind somit jeweils die abhängigen Variablen bzw. Kontrollvariablen dargestellt, die auch in die Regression als ein Datensatz eingehen. Vgl. zur Verwendung von verzögerten jahresabschlussbasierten Regressanden Kapitel IV.2.3.1.1. 


\begin{tabular}{lrrl}
\hline \multicolumn{1}{c}{ Branche } & Absolut & in \% & Kürzel \\
\hline Telecommunications & 2 & $0,8 \%$ & SoTeMe \\
Media & 1 & $0,4 \%$ & SoTeMe \\
\hline \multicolumn{4}{c}{} \\
\hline
\end{tabular}

Tab. 15: Branchenverteilung der Sampleunternehmen in Prozent

Da die Untersuchung ausschließlich Unternehmen betrachtet, die bereits seit 1997 im CDAX gelistet sind, sind die Branchen der sogenannten „New Economy" nur schwach vertreten. Um eine ausreichende Samplegröße je Branche sicherzustellen, werden daher für die folgende Analyse die Branchen Software, Telecommunications und Media zu einem Sektor zusammengefasst. Sie umfassen alle Unternehmen aus Bereichen der sogenannten "New Economy“ die in vergleichbarem Maße zyklischen Schwankungen unterworfen sind. Die Unternehmen aus dem Bereich Transport \& Logistics werden dem vertikal eng verwandten Sektor Automobile zugeschlagen, sodass insgesamt zwischen dreizehn Branchen differenziert wird. ${ }^{973}$

\subsubsection{Eigentümerstrukturen}

Bei der Analyse der Eigentümerstruktur der Sampleunternehmen wird der Frage nachgegangen, ob die deutschen Aktiengesellschaften tatsächlich so stark durch Großaktionäre dominiert sind, wie häufig behauptet wird, und wie ältere empirische Untersuchungen nahe legen. Betrachtet werden daher zunächst die Kapitalanteile der großen Aktionäre. Darüber hinaus soll die Identität der Aktionäre deutscher Aktiengesellschaften beleuchtet werden. Hier ist insbesondere die Rolle von Kreditinstituten und Ausländern von Interesse. Letzteren wird ein zunehmender Einfluss auf deutsche Unternehmen nachgesagt und Banken stehen seit jeher mit ihren Kapitalbeteiligungen im Blickfeld und in der Kritik der Öffentlichkeit. Die folgende Tabelle gibt zunächst einen Überblick über die Kapitalanteile der vier größten direkt beteiligten Aktionäre (KAD1-4) und den Kapitalanteil des größten Aktionärs an der Spitze der Konzernpyramide des direkt

973 Da alle 238 Unternehmen viermal im Datensatz enthalten sind, ist so für fast alle Branchen eine Häufigkeit von über 30 Beobachtungen gewährleistet, die Branche SoTeMe ist 20 mal vertreten. Insgesamt sind die Gruppen somit groß genug, um daraus statistisch signifikante Aussagen ableiten zu können. Vgl. zur Bedeutung des zentralen Grenzwertsatzes Bleymüller/Gehlert/Gülicher (2002), S. 78. 
beteiligten Aktionärs (KA1-4, Werte in Klammern). ${ }^{974}$ Eine Abweichung ergibt sich somit immer dann, wenn der Aktionär seinen Anteil nicht direkt, sondern über ein Tochterunternehmen mit einer Beteiligung von mindestens $30 \%$ hält.

\begin{tabular}{crrrrr}
\hline In \% & Ar. Mittel & Std.abw. & 1. Quartil & Median & 3. Quartil \\
\hline $\boldsymbol{K} \boldsymbol{A D 1}(\boldsymbol{K} \boldsymbol{A} \boldsymbol{1})$ & & & & & \\
1997 & $47,7(44,7)$ & $27,9(27,9)$ & $25,0(22,3)$ & $49,7(40,0)$ & $70,5(63,2)$ \\
1998 & $47,3(44,6)$ & $28,1(27,5)$ & $25,0(22,9)$ & $49,9(42,0)$ & $69,0(61,4)$ \\
1999 & $49,8(46,2)$ & $28,7(28,6)$ & $25,8(23,9)$ & $50,0(42,0)$ & $74,6(67,8)$ \\
2000 & $51,6(47,8)$ & $29,4(29,0)$ & $27,0(25,1)$ & $50,0(43,7)$ & $75,6(73,1)$ \\
\hline $\boldsymbol{K} \boldsymbol{A D 2}(\boldsymbol{K A})$ & & & & & \\
1997 & $15,7(14,2)$ & $11,8(9,9)$ & $7,8(7,5)$ & $13,6(11,3)$ & $22,6(19,6)$ \\
1998 & $16,2(14,6)$ & $12,0(10,2)$ & $7,8(7,4)$ & $13,8(11,8)$ & $24,4(20,2)$ \\
1999 & $16,5(14,8)$ & $12,7(10,3)$ & $7,6(7,4)$ & $13,9(12,8)$ & $24,8(19,5)$ \\
2000 & $16,8(15,8)$ & $11,2(11,1)$ & $9,0(7,7)$ & $14,0(13,6)$ & $25,0(21,9)$ \\
\hline $\boldsymbol{K A D 3}(\boldsymbol{K} \boldsymbol{A 3})$ & & & & & \\
1997 & $9,6(7,9)$ & $5,4(6,5)$ & $5,5(2,7)$ & $9,4(7,6)$ & $11,3(10,7)$ \\
1998 & $9,5(8,9)$ & $5,1(7,1)$ & $5,6(5,0)$ & $8,1(7,9)$ & $12,5(12,2)$ \\
1999 & $9,8(9,2)$ & $5,2(7,0)$ & $6,1(5,0)$ & $10,0(8,4)$ & $12,4(12,4)$ \\
2000 & $9,1(7,8)$ & $6,3(7,1)$ & $5,0(3,4)$ & $7,8(6,5)$ & $11,2(10,0)$ \\
\hline $\boldsymbol{K} \boldsymbol{A D 4}(\boldsymbol{K} \boldsymbol{A 4})$ & & & & \\
1997 & $6,7(6,2)$ & $3,8(4,4)$ & $4,2(3,7)$ & $5,5(5,5)$ & $8,8(8,8)$ \\
1998 & $7,5(7,2)$ & $4,6(4,2)$ & $3,9(3,8)$ & $6,4(6,4)$ & $10,1(10,1)$ \\
1999 & $7,0(6,1)$ & $3,5(4,3)$ & $5,0(3,7)$ & $5,8(5,6)$ & $9,1(8,8)$ \\
2000 & $6,9(5,5)$ & $3,4(4,5)$ & $5,0(2,1)$ & $6,1(5,1)$ & $8,5(8,0)$ \\
\hline
\end{tabular}

Tab. 16: Kapitalstruktur der Sampleunternehmen

Im Jahr 2000 betrug der durchschnittliche direkt gehaltene Kapitalanteil des größten Aktionärs (KAD1) der hier betrachteten Aktiengesellschaften 51,6\%, der Median lag bei 50,0\%. Der durchschnittliche Anteil des zweitgrößten Aktionärs belief sich auf 16,8 \% (Median 14,0\%). Die durch vorangegangene empirische Untersuchungen gestützte These einer hohen Kapitalkonzentration deutscher Aktiengesellschaften kann somit auf Basis des hier vorliegenden, jüngeren Datensatzes bestätigt werden. Eine Betrachtung im Zeitablauf deutet auf eine leichte Zunahme der Kapitalkonzentration des größten und des zweitgrößten Aktionärs hin. Das arithmetische Mittel der direkt gehaltenen Kapitalanteile des größten Aktionärs ist von 47,7\% in 1997 auf 51,6\% in 2000 angestiegen. Die

974 Hinsichtlich der Definition der Konzentrationsmaße wird auf Kapitel IV.2.3.1.2.1 verwiesen. KA1-4 umfasst sowohl direkte als auch indirekte Beteiligungen des Aktionärs an der Spitze der Konzernpyramide; der Einfluss von Vorzugsaktien ist hier noch nicht berücksichtigt. Die Kennzahl KA erlaubt somit noch keine unmittelbaren Aussagen über die Divergenz von Kapital- und Stimmrechten. 
Unterschiede sind jedoch statistisch nicht signifikant, verschiedene Mittelwerttests lassen eine Ablehnung der Nullhypothese gleicher Mittelwerte nicht zu. ${ }^{975}$

Die folgende Tabelle gibt einen Überblick über die kumulierten direkt gehaltenen Kapitalanteile der zwei (drei, vier) größten Aktionäre (SKAD2-4).

\begin{tabular}{rrrrrr}
\hline In \% & Ar. Mittel & Std.abw. & 1. Quartil & Median & 3. Quartil \\
\hline SKAD2 & & & & & \\
1997 & 54,5 & 27,3 & 30,9 & 52,6 & 76,0 \\
1998 & 54,8 & 27,7 & 32,3 & 52,0 & 77,0 \\
1999 & 57,3 & 28,0 & 36,1 & 57,0 & 80,7 \\
2000 & 59,0 & 28,4 & 36,9 & 59,0 & 84,0 \\
\hline SKAD3 & & & & & \\
1997 & 56,8 & 26,8 & 37,4 & 57,2 & 77,0 \\
1998 & 57,0 & 27,4 & 37,4 & 56,8 & 77,1 \\
1999 & 59,6 & 27,7 & 40,0 & 59,2 & 84,0 \\
2000 & 60,7 & 28,0 & 38,7 & 61,4 & 84,3 \\
\hline SKAD4 & & & & & \\
1997 & 57,5 & 26,6 & 37,4 & 58,2 & 78,0 \\
1998 & 57,8 & 27,3 & 39,6 & 57,0 & 79,0 \\
1999 & 60,4 & 27,7 & 40,0 & 60,0 & 84,0 \\
2000 & 61,3 & 27,8 & 39,5 & 61,4 & 84,6 \\
\hline
\end{tabular}

Tab. 17: Kapitalstruktur der Sampleunternehmen (kumuliert)

Die vier größten Aktionäre hatten Ende 2000 im Durchschnitt Kapitalanteile in Höhe von 61,3 \% (Median 61,4\%) inne. Der Unterschied zum durchschnittlichen Kapitalanteil des größten Aktionärs beträgt 9,7 Prozentpunkte. Dies deutet darauf hin, dass in den Unternehmen, in denen mehrere Großaktionäre vorhanden sind, die großen Kapitalanteile gleichmäßiger verteilt sind, der größte Aktionär also entsprechend kleinere Anteile inne hat. Auffällig ist auch hier eine $\mathrm{Zu}$ nahme der Kapitalkonzentration im Zeitablauf. Dies bestätigt auch der Herfindahl-Index der Kapitalanteile, dessen arithmetisches Mittel von 0,327 auf 0,377 steigt:

975 Durchgeführt wurden neben einem ANOVA-Test auf Gleichheit der arithmetischen Mittel die nichtparametrischen Tests nach Kruskal/Wallis und van der Waerden auf Gleichheit der Mediane. Die p-Werte liegen jeweils über $30 \%$. 


\begin{tabular}{lrrrrr}
\hline In \% & Ar. Mittel & Std.abw. & 1. Quartil & Median & 3. Quartil \\
\hline $\boldsymbol{H}(\boldsymbol{K} \boldsymbol{A D})$ & & & & & \\
1997 & 0,327 & 0,286 & 0,084 & 0,255 & 0,513 \\
1998 & 0,328 & 0,287 & 0,092 & 0,255 & 0,507 \\
1999 & 0,356 & 0,304 & 0,107 & 0,259 & 0,564 \\
2000 & 0,377 & 0,317 & 0,110 & 0,278 & 0,591 \\
\hline
\end{tabular}

Tab. 18: Herfindahl-Index der Kapitalanteile (KAD)

Tatsächlich breit gestreute Unternehmen sind am deutschen Kapitalmarkt eine Ausnahmeerscheinung, wie die folgende Abbildung verdeutlicht, die die Anzahl der Gesellschaften zeigt, die einen Großaktionär mit einem Kapitalanteil von über $5 \%(10 \%, 25 \%, 50 \%, 75 \%)$ aufweisen. Demzufolge haben nur vier der 238 Unternehmen $(1,7 \%)$ keinen Aktionär mit mehr als fünf Prozent des Kapitals, mehr als die Hälfte der Unternehmen (50,8 \%) befinden sich in Mehrheitsbesitz. Immerhin noch mehr als ein Viertel der Unternehmen (27,3\%) sind sogar zu mehr als $75 \%$ ihres Kapitals in den Händen eines Aktionärs.

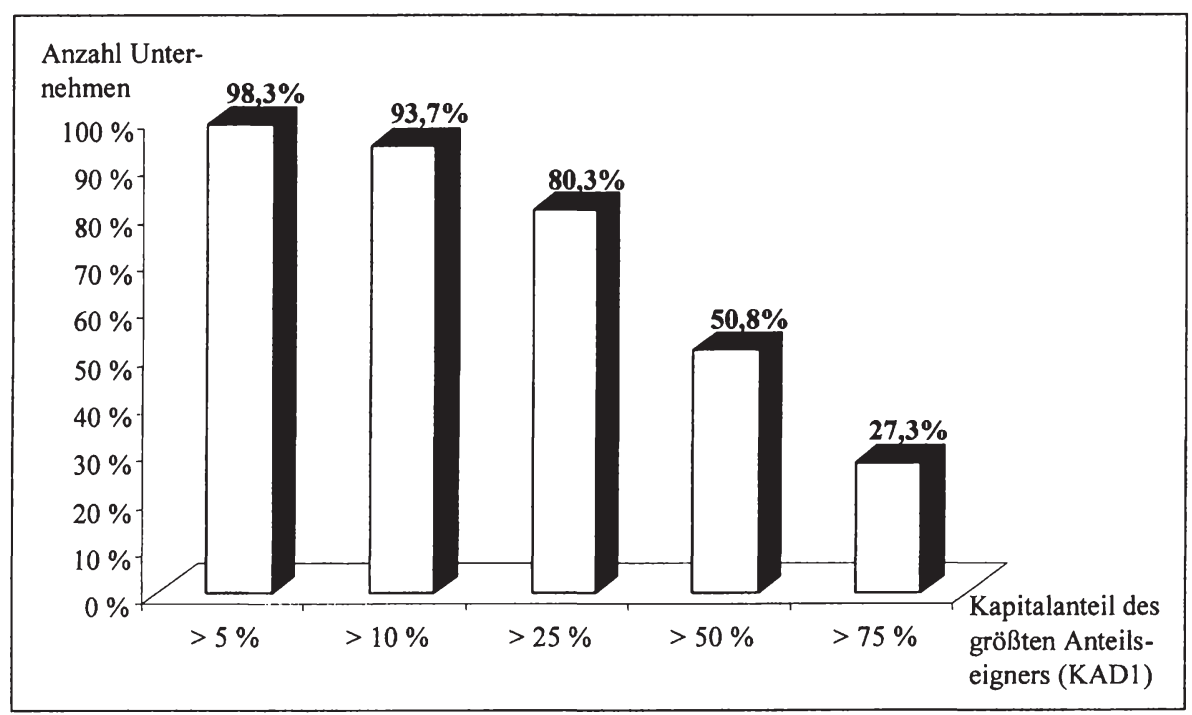

Abb. 23: Kapitalanteile des größten direkt beteiligten Anteilseigners 2000 (KADI)

Hinsichtlich der Identität des größten Aktionärs der Sampleunternehmen ergeben sich auffallende Entwicklungen im Zeitablauf, die in der folgenden Tabelle dargestellt sind: 


\begin{tabular}{|c|c|c|c|c|c|c|c|c|}
\hline $\ln \%$ & 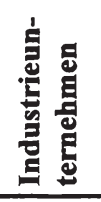 & 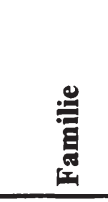 & 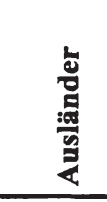 & 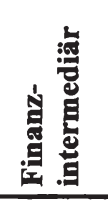 & 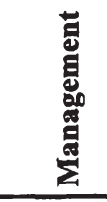 & 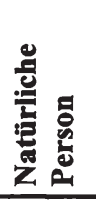 & 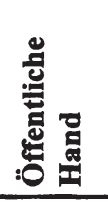 & 真 \\
\hline 1997 & $28,8 \%$ & $26,3 \%$ & $11,9 \%$ & $11,4 \%$ & $8,9 \%$ & $7,2 \%$ & $5,5 \%$ & $100 \%$ \\
\hline 1998 & $30,9 \%$ & $25,6 \%$ & $11,2 \%$ & $11,7 \%$ & $9,4 \%$ & $7,2 \%$ & $4,0 \%$ & $100 \%$ \\
\hline 1999 & $33,5 \%$ & $23,5 \%$ & $13,1 \%$ & $10,9 \%$ & $9,0 \%$ & $6,3 \%$ & $3,6 \%$ & $100 \%$ \\
\hline 2000 & $35,3 \%$ & $24,2 \%$ & $14,9 \%$ & $10,7 \%$ & $10,2 \%$ & $3,3 \%$ & $1,4 \%$ & $100 \%$ \\
\hline
\end{tabular}

Tab. 19: Identität des größten Anteilseigners, 2000 (KA1)

Die Verflechtungen von Unternehmen untereinander haben im Zeitablauf deutlich zugenommen; der Anteil der Unternehmen, bei denen ein Industrie- bzw. Dienstleistungsunternehmen den größten Aktionär stellt, ist von $28,8 \%$ in 1997 auf $35,3 \%$ in 2000 gestiegen. Ebenfalls zugenommen hat die Präsenz von Ausländern als Großaktionär an deutschen Aktiengesellschaften (1997: 11,9\%, 2000: 14,9\%) sowie die des Managements (1997: 8,9\%, 2000: 10,2\%). ${ }^{976} \mathrm{Zu}-$ rückgegangen ist die Bedeutung von Familien, sonstigen natürlichen Personen und insbesondere der öffentlichen Hand. Beteiligungen der öffentlichen Hand lagen in 1997 noch bei 5,5\% der Unternehmen vor, im Jahr 2000 nur noch bei $1,4 \% .{ }^{977}$ Die Beteiligungen von Finanzintermediären haben sich nicht wesentlich verändert. Sie stellten im Jahr 2000 bei 10,7\% der Unternehmen den größten Aktionär (11,4\% in 1997). Allein aus der Kapitalbeteiligung kann somit die vielzitierte „Macht der Banken“ nur in Einzelfällen abgeleitet werden.

\subsubsection{Stimmrechtsstrukturen}

Neben den Kapitalanteilen der vier größten Aktionäre wurden die Stimmrechtsanteile separat ausgewertet. Die sich zwischen beiden Größen ergebenden Abweichungen entstehen durch Eigenkapitalpyramiden, Vorzugsaktien und Mehrfach- bzw. Höchststimmrechte. Die folgende Tabelle gibt die Stimmrechtsanteile der vier größten Aktionäre wieder. ${ }^{978}$

\footnotetext{
976 Vgl. zum Bedeutungsgewinn von Ausländern als Aktionäre deutscher Gesellschaften auch Engelhard/Eckert (1999).

977 Der starke Rückgang der öffentlichen Beteiligungen im Jahr 2000 wird zu einem wesentlichen Teil durch den Verkauf der dritten Eigenkapital-Tranche der Deutschen Telekom $\mathrm{AG}$ durch den Bund beeinflusst.

978 Die Auswertungen des stimmrechtsbezogenen Herfindahl-Index finden sich in Anhang C (Tab. A 4).
} 


\begin{tabular}{crrrrr}
\hline In \% & Ar. Mittel & Std.abw. & 1. Quartil & Median & 3. Quartil \\
\hline StA1 & & & & & \\
1997 & 53,8 & 28,3 & 28,9 & 51,3 & 75,1 \\
1998 & 55,8 & 31,3 & 29,2 & 51,9 & 77,0 \\
1999 & 59,1 & 37,4 & 32,2 & 55,6 & 79,4 \\
2000 & 58,4 & 36,5 & 33,7 & 53,0 & 80,0 \\
\hline StA2 & & & & & \\
1997 & 17,4 & 11,0 & 10,0 & 15,0 & 25,0 \\
1998 & 17,8 & 11,1 & 10,0 & 16,0 & 25,0 \\
1999 & 17,9 & 11,2 & 10,0 & 16,4 & 25,1 \\
2000 & 20,2 & 17,3 & 10,0 & 17,1 & 25,7 \\
\hline StA3 & & & & & \\
1997 & 12,2 & 7,9 & 8,0 & 10,2 & 13,1 \\
1998 & 11,7 & 6,2 & 7,8 & 10,4 & 14,2 \\
1999 & 11,9 & 6,7 & 6,7 & 10,9 & 16,1 \\
2000 & 10,9 & 7,2 & 5,2 & 10,0 & 12,4 \\
\hline StA4 & & & & & \\
1997 & 8,3 & 4,0 & 5,2 & 7,8 & 10,2 \\
1998 & 8,9 & 4,7 & 5,5 & 8,3 & 10,3 \\
1999 & 8,5 & 4,3 & 5,5 & 7,4 & 10,1 \\
2000 & 8,6 & 4,8 & 5,0 & 7,3 & 9,7 \\
\hline
\end{tabular}

Tab. 20: Stimmrechtsstruktur der Sampleunternehmen

Der größte Aktionär hält Ende 2000 im Durchschnitt einen Stimmrechtsanteil von knapp $60 \%$, der Median liegt bei $53 \%$. Vergleicht man die Ergebnisse mit denen anderer deskriptiver Studien aus den vergangenen Jahren, so sind die Ergebnisse vergleichbar:

\begin{tabular}{|c|c|c|c|}
\hline Autor & Jahr & Sample & Ar. Mittel StA1 \\
\hline Becht/Böhmer (2001) & 1996 & DAX30 & $58,9 \%$ \\
\hline Köke (2001) & $1993-1997$ & Börsennotierte AG & $55,9 \%$ \\
\hline Bott (2002) & 1998 & Amtlicher Handel & $55,8 \%$ \\
\hline
\end{tabular}

Tab. 21: StA1 in bisherigen empirischen Studien

Die jüngste Erhebung ist von Bott (2002), die BAWe-Daten per Ende 1998 auswertet. Die ermittelte Stimmrechtskonzentration deckt sich exakt mit der im Rahmen dieser Arbeit ermittelten zum gleichen Zeitpunkt, obwohl der Untersuchung von Bott eine andere, deutlich kleinere Datenbasis zugrunde liegt. Seitdem hat die Anteilseignerkonzentration weiter zugenommen. Die zunehmende Konzentration bestätigt die deskriptiven Ergebnisse von Köke (2001), der für den Zeitraum von 1993 - 1997 eine zunehmende Blockbildung konstatiert. 
Bei der Betrachtung des Medians und der Quartile wird die praktische Bedeutung der kritischen Schwellenwerte des Aktiengesetzes deutlich. ${ }^{979}$ Bei einer Vielzahl von Unternehmen hält der größte Aktionär ein Aktienpaket, das ihm die Sperrminorität oder die Stimmrechtsmehrheit sichert. Insbesondere bei Stimmrechtskonzentrationen über $50 \%$, in geringerem Maße auch bei den Schwellenwerten $25 \%$ und $75 \%$, ist eine deutliche Häufung anzutreffen. Die Abbildung verdeutlicht die Bedeutung der Schwellenwerte:

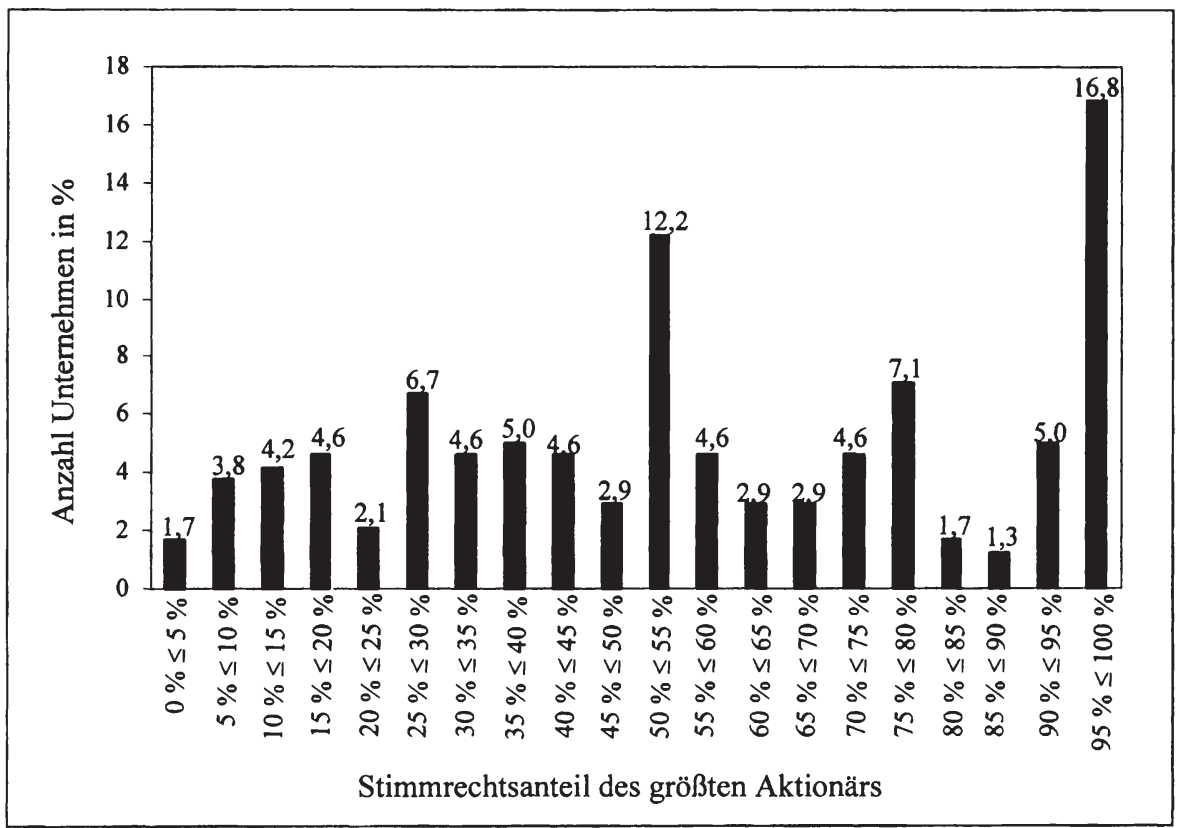

Abb. 24: Stimmrechtsanteile des größten Aktionärs nach Häufigkeiten

Das Vorhandensein eines weiteren großen Aktionärs beeinflusst in hohem Maße die Werthaltigkeit von Stimmrechtsbündelungen unter Kontrollgesichtspunkten aus Sicht des größten Aktionärs. Ein weiterer Aktionär mit einem signifikanten Stimmrechtsanteil ist unter Umständen in der Lage, seine Einflussnahmemöglichkeit zu schmälern. Die folgende Tabelle gibt daher einen Überblick über den Anteil der Unternehmen, die neben dem größten Aktionär einen weiteren Aktionär haben, dessen Stimmrechtsanteil mindestens $75 \%$ des Stimmrechtsanteils des größten Aktionärs beträgt (GA2) oder aber der einen Stimmrechtsanteil von mindestens $25 \%$ hält.

979 Vgl. hierzu die Ausführungen in Kapitel II.2. 


\begin{tabular}{|c|c|c|}
\hline & \multicolumn{2}{|c|}{ Anteil im Sample } \\
\hline & absolut & in $\%$ \\
\hline \multicolumn{3}{|l|}{$G A 2$} \\
\hline 1997 & 51 & 21,4 \\
\hline 1998 & 52 & 21,8 \\
\hline 1999 & 49 & 20,2 \\
\hline 2000 & 51 & 21,4 \\
\hline
\end{tabular}

Tab. 22: Weiterer Großaktionär

Die Ergebnisse zeigen, dass in weniger als einem Viertel der Gesellschaften neben dem größten Aktionär ein weiterer Aktionär vorhanden ist, der entweder über eine Sperrminorität verfügt oder über einen Stimmrechtsanteil, der bei Bildung von Koalitionen mit weiteren Minderheitsaktionären einen wirksamen Gegenpol zu dem kontrollierenden Aktionär bilden kann. Aus den Daten ist indes nicht unmittelbar zu erkennen, inwieweit die beiden größten Aktionäre etwa einer Unternehmensgruppe und/oder Familie angehören und sie insofern als ein Stimmrechtsblock anzusehen sein könnten.

Die Tabelle gibt die durchschnittliche Anzahl der Aktionäre an, die mit einem Stimmrechtsanteil über $5 \%$ am Unternehmen beteiligt sind (AA5). ${ }^{980}$

\begin{tabular}{crrrrr}
\hline & Ar. Mittel & Std.abw. & 1. Quartil & Median & 3. Quartil \\
\hline $\boldsymbol{A A 5}$ & & & & & \\
1997 & 1,70 & 1,01 & 1,00 & 1,00 & 2,00 \\
1998 & 1,68 & 1,01 & 1,00 & 1,00 & 2,00 \\
1999 & 1,66 & 1,01 & 1,00 & 1,00 & 2,00 \\
2000 & 1,65 & 0,97 & 1,00 & 1,00 & 2,00 \\
\hline
\end{tabular}

Tab. 23: Anzahl Großaktionäre

Die Ergebnisse deuten darauf hin, dass nur wenige Unternehmen eine Vielzahl von Aktionären mit größeren Kapitalbeteiligungen aufweisen. Das arithmetische Mittel liegt nur unwesentlich variabel im Zeitablauf bei knapp 1,7 Aktionären.

980 Da im Rahmen der vorliegenden Untersuchung nur die vier größten Aktionäre berücksichtigt wurden, können im Einzelfall mehr Aktionäre mit $>5 \%$ der Stimmrechte beteiligt sein. Entsprechend wird das arithmetische Mittel eher zu gering geschätzt sein. In den ausgewerteten Aktionärsstrukturdatenbanken wurden jedoch nur in den seltensten Fällen mehr als vier Großaktionäre ausgewiesen. 


\subsubsection{Abweichungen zwischen Kapital- und Stimmrechten}

\subsubsection{Höhe der Kapital- und Stimmrechtsanteile}

Ein Vergleich der zuvor dargestellten Stimmrechts- und Kapitalanteile zeigt, dass die gehaltenen Stimmrechte teilweise deutlich über die Kapitalanteile hinausgehen. Während der durchschnittliche Kapitalanteil des größten Aktionärs im Jahr $200051,6 \%$ beträgt, liegt der Stimmrechtsanteil bei 58,4 \%. In den Jahren 1997 - 1999 lag der durchschnittliche Kapitalanteil jeweils unter $50 \%$, die Stimmrechte hingegen deutlich über $50 \%$. Auch die folgende Abbildung zeigt die Bedeutung der Stimmrechte für die Kontrollausübung. Während nur 50,8 \% der Unternehmen einen Aktionär mit einem Kapitalanteil > 50\% aufwiesen (vgl. Abbildung 23), hat in 59,7\% der Gesellschaften der größte Aktionär einen Stimmrechtsanteil von $>50 \%$.

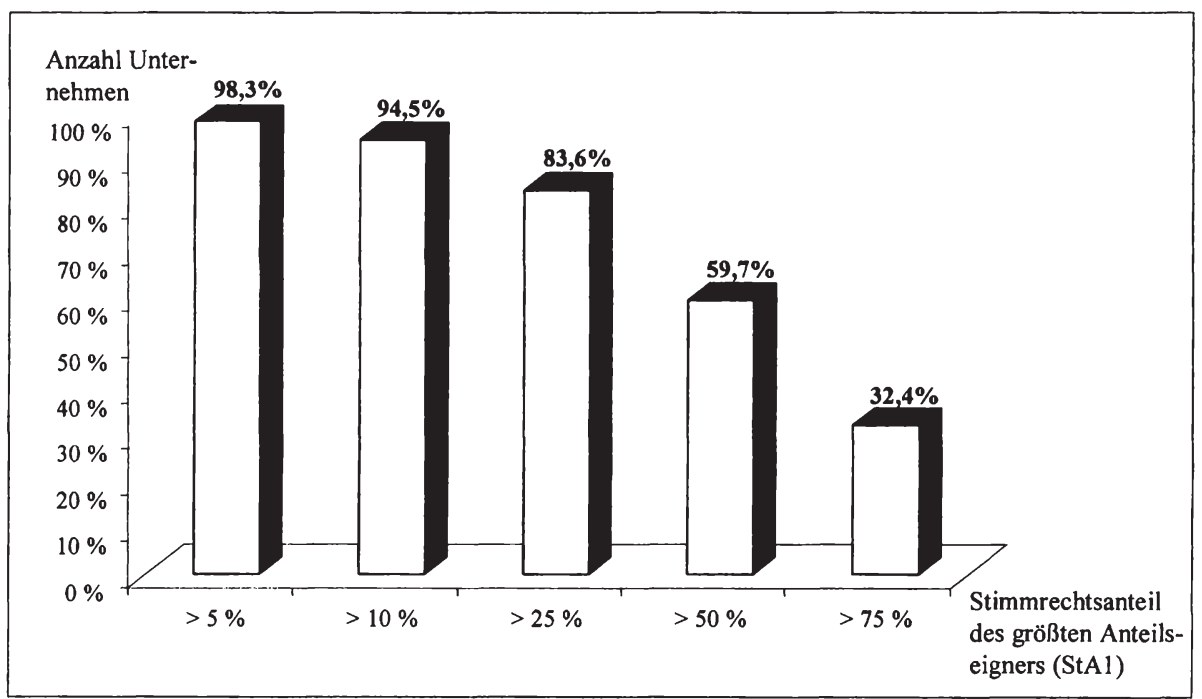

Abb. 25: Stimmrechtsanteile des größten Anteilseigners 2000 (StA1)

Die Möglichkeiten zur Schaffung überproportionaler Stimmrechte werden von Seiten der kontrollierenden Aktionäre somit zumindest teilweise genutzt. Während die Differenz zwischen Kapital- und Stimmrechten von 1997 - 1999 zugenommen hat, ist sie im Jahr 2000 zurückgegangen. Dies könnte auf die abnehmende Bedeutung von Vorzugsaktien zurückzuführen sein, was im Folgenden noch genauer zu eruieren sein wird. 
Insgesamt lagen Abweichungen zwischen Kapital- und Stimmrechten im Jahr 2000 bei $52,1 \%$ der Unternehmen vor, die entweder durch Pyramiden oder Vorzugsaktien zustande kommen. ${ }^{981}$ Als Kennzahl, die die Abweichungen zwischen Kapital- und Stimmrechten quantifiziert, wurden die sogenannten „Excess Votes“ (EV) eingeführt. Die folgende Tabelle gibt einen Überblick über die Excess Votes im Zeitablauf.

\begin{tabular}{crrrrr}
\hline & Ar. Mittel & Std.abw. & 1. Quartil & Median & 3. Quartil \\
\hline $\boldsymbol{E} \boldsymbol{V}$ (in \%) & & & & & \\
1997 & 34,8 & 82,6 & 0 & 0 & 50,0 \\
1998 & 31,9 & 59,8 & 0 & 0 & 50,0 \\
1999 & 31,2 & 60,9 & 0 & 0 & 46,5 \\
2000 & 27,6 & 54,7 & 0 & 0 & 33,3 \\
\hline
\end{tabular}

Tab. 24: Excess Votes

In den Jahren 1997 - 1999 lagen die Stimmrechte des größten Aktionärs im Durchschnitt um 27,6\% über den damit einhergehenden Cash-Flow-Rechten. Dieses weist, ebenso wie die Tatsache, dass Abweichungen zwischen Stimmund Cash-Flow-Rechten in mehr als der Hälfte der Unternehmen vorliegen, auf eine große Bedeutung der hieraus resultierenden Agency-Problematik am deutschen Kapitalmarkt hin. Insgesamt ist die Stärke der Divergenz über den Untersuchungszeitraum jedoch zurückgegangen.

\subsubsection{Instrumente zur Schaffung abweichender Kapital- und Stimm- rechtsanteile}

Nachdem zunächst Abweichungen zwischen Eigentümer- und Stimmrechtsstrukturen allgemein untersucht worden sind, sollen im Folgenden die beiden wesentlichen Instrumente zur Schaffung von Divergenzen, Vorzugsaktien und Pyramiden, separat beleuchtet werden um zu analysieren, wie der starke Rückgang abweichender Stimm- und Cash-Flow-Rechte verursacht wurde. Von den 238 Sample-Unternehmen weisen per Ende 200058 ein gespaltenes Eigenkapital mit Vorzugsaktien auf $(24,4 \%)$. Von diesen 58 Unternehmen haben 18 $(31,0 \%)$ nur Vorzugsaktien an der Börse notiert und 40 (69,0\%) Stamm- und Vorzugsaktien. Die folgende Tabelle zeigt die Verbreitung von Vorzugsaktien und Eigenkapitalpyramiden während des Untersuchungszeitraums.

$981 \mathrm{Vgl}$. auch die folgende Tabelle 25. 


\begin{tabular}{rrrrrrr}
\hline & \multicolumn{2}{c}{$\begin{array}{c}\text { Vorzugsaktien } \\
\text { (VA) }\end{array}$} & \multicolumn{2}{c}{$\begin{array}{c}\text { Pyramiden } \\
\text { (PY) }\end{array}$} & \multicolumn{2}{c}{$\begin{array}{c}\text { Abweichungen } \\
\text { KA/StA insg. }\end{array}$} \\
& absolut & in \% & absolut & in \% & absolut & in \% \\
\hline 1997 & 64 & $26,9 \%$ & 69 & $29,0 \%$ & 122 & $51,3 \%$ \\
1998 & 64 & $26,9 \%$ & 78 & $32,8 \%$ & 131 & $55,0 \%$ \\
1999 & 64 & $26,9 \%$ & 85 & $35,7 \%$ & 134 & $56,3 \%$ \\
2000 & 58 & $24,4 \%$ & 78 & $32,8 \%$ & 124 & $52,1 \%$ \\
\hline
\end{tabular}

Tab. 25: Divergenzen zwischen Kapital-und Stimmrechtsanteilen

Der Anteil von Unternehmen mit einer vom Prinzip des One-Share-One-Vote abweichenden Eigenkapitalstruktur ist im Jahr 2000 um.9,3\% zurückgegangen. Dieser Trend hat sich bis Juli 2002 fortgesetzt, der Anteil der SampleUnternehmen mit Vorzugsaktien betrug hier nur noch 21,8 \% (52 Unternehmen). Hier könnte sich die im Zuge der Corporate-Governance-Debatte immer wieder erhobene Forderung nach dem Prinzip des One-Share-One-Vote ebenso ausgewirkt haben wie die Umstellung der Börsenindizes auf die Marktkapitalisierung der einzelnen Aktiengattungen, die bei den Unternehmen Anreize zur Vereinigung schafft. ${ }^{982}$

Der Trend zur Vereinfachung der Kapital- und Stimmrechtsstrukturen spiegelt sich auch in der Entwicklung der Pyramidenbildungen wider, deren kontinuierlicher Anstieg im Jahr 2000 wieder rückläufig war. Über den gesamten Untersuchungszeitraum war jeweils rund ein Drittel der Unternehmen mindestens Enkelunternehmen im Rahmen einer mehrstufigen Kontrollkette. ${ }^{983}$ Die folgende Abbildung zeigt jedoch, dass nur selten Verflechtungen über mehr als zwei Ebenen geknüpft werden:

982 Ausgelöst durch die Diskussion um Corporate Governance und Aktionärsrechte sowie die Umstellung der großen Indizes auf Marktkapitalisierung haben verschiedenste Unternehmen ihre Vorzugsaktien durch Aktienrückkäufe vermindert oder sie gegen Stammaktien eingetauscht. Vgl. Hillebrandt/Schremper (2001). Die Forderung des One-ShareOne-Vote ist bereits in den verschiedenen, seit 2000 publizierten freiwilligen CorporateGovernance-Kodizes enthalten. Vgl. hierzu Pellens/Hillebrandt/Ulmer (2001).

983 Es liegt somit eine Konzernpyramide mit zwei oder mehr Ebenen vor. Von einer Kontrollkette wird ausgegangen, wenn der Stimmrechtsanteil des Mutterunternehmens jeweils mindestens $30 \%$ beträgt. $\mathrm{Zu}$ den Abgrenzungskriterien vgl. Kapitel IV.2.3.1.2.3. 


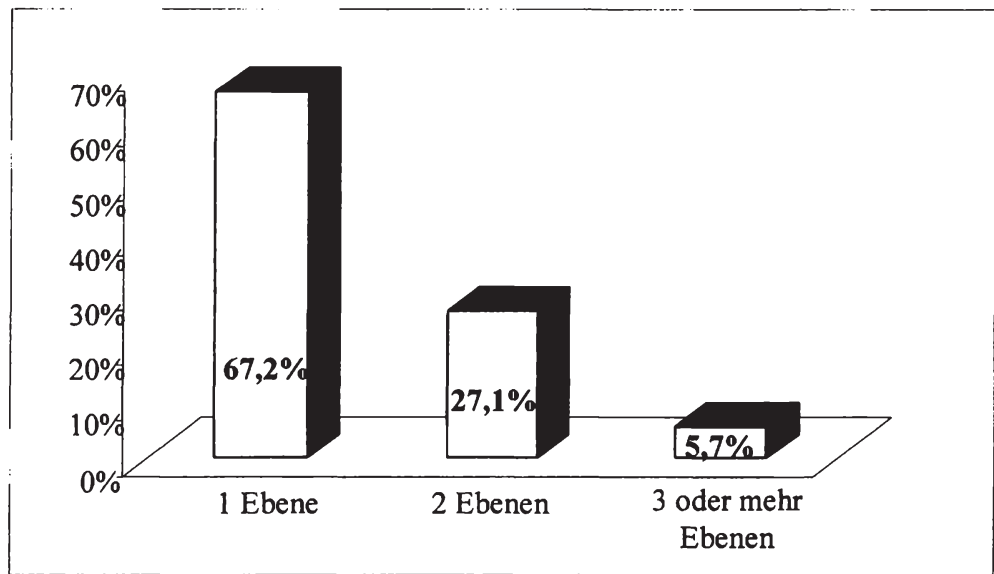

Abb. 26: Ebenen der Konzernpyramide

Eine Verflechtung über eine Ebene entspricht einer direkten Beteiligung, eine Beteiligung über zwei Ebenen der Beteiligung des Pyramidenmutterunternehmens durch ein Tochterunternehmen. Es ist davon auszugehen, dass diese Zahlen die reale Situation eher konservativ abbilden, da die Anteilseigner der Mutterunternehmen nicht in allen Fällen weiter zurückverfolgt werden konnten, insbesondere wenn die Mutterunternehmen im Ausland angesiedelt sind oder es sich um kleinere Unternehmen handelt. Zudem ist zu berücksichtigen, dass im Rahmen der vorliegenden Untersuchung mit börsennotierten Aktiengesellschaften Unternehmen analysiert werden, die selbst regelmäßig als (Teil-)Konzernmutterunternehmen fungieren und zahlreiche Tochter- und Enkelunternehmen haben. Um das gesamte Ausmaß der Pyramidenbildung zu erfassen, müssten somit die Beteiligungen der Sampleunternehmen bis in die letzte Stufe der Kontrollkette weiter verfolgt werden.

Die reine Existenz von Konzernpyramiden lässt noch keinen Schluss darüber zu, ob sie tatsächlich genutzt werden, um Einfluss geltend zu machen. Pellens (1994) zeigt jedoch, dass die Steigerung des Konzernverschuldungsgrads (Pyramiden-Effekt des Eigenkapitals), die neben der Einflussnahmemöglichkeit ein Grund für die Schaffung einer Pyramide sein könnte, in der Praxis nur geringe Relevanz besitzt. ${ }^{984}$ Geht man davon aus, dass die Schaffung solcher Konstrukte dennoch zielgerichtet erfolgt, so wäre eine Ausdehnung der Einflussnahme als Motivation für Konzernbildung zumindest denkbar. 


\subsubsection{Relevanz der Identität des Aktionärs}

Fraglich ist, ob die Instrumente zur Generierung auseinanderfallender Stimmund Cash-Flow-Rechte von allen Großaktionärstypen gleichermaßen eingesetzt werden oder ob hier Unterschiede in Abhängigkeit von der Identität des Aktionärs bestehen. Sollte letzteres der Fall sein, so könnte dies als Indiz gewertet werden, dass überproportionale Stimmrechte für bestimmte Aktionäre einen besonderen Nutzen, z.B. in Form von private benefits, beinhalten. Tab. 26 gibt die Anzahl der Unternehmen an, die von Vorzugsaktien und Pyramiden Gebrauch machen, differenziert nach Identität des größten Aktionärs.

\begin{tabular}{|c|c|c|c|c|c|c|}
\hline & \multicolumn{2}{|c|}{$\begin{array}{c}\text { Vorzugsaktien } \\
\text { (VA) }\end{array}$} & \multicolumn{2}{|c|}{$\begin{array}{l}\text { Pyramiden } \\
\text { (PY) }\end{array}$} & \multicolumn{2}{|c|}{$\begin{array}{l}\text { Abweichungen } \\
\text { KA/StA insg. }\end{array}$} \\
\hline & absolut & in $\%$ & absolut & in $\%$ & absolut & in $\%$ \\
\hline Industrieunternehmen & 13,0 & $18,1 \%$ & 22,3 & $31,0 \%$ & 33,3 & $46,3 \%$ \\
\hline Familie & 28,3 & $46,3 \%$ & 12,5 & $20,5 \%$ & 39,8 & $65,2 \%$ \\
\hline Ausländer & 6,0 & $19,4 \%$ & 12,0 & $38,7 \%$ & 14,5 & $46,8 \%$ \\
\hline Finanzintermediär & 2,8 & $10,8 \%$ & 11,8 & $46,1 \%$ & 12,8 & $50,0 \%$ \\
\hline Management & 4,8 & $22,1 \%$ & 5,3 & $24,4 \%$ & 9,5 & $44,2 \%$ \\
\hline Natürl. Person & 5,5 & $41,5 \%$ & 6,0 & $45,3 \%$ & 9,8 & $73,6 \%$ \\
\hline Öffentliche Hand & 2,3 & $20,9 \%$ & 7,8 & $72,1 \%$ & 8,3 & $76,7 \%$ \\
\hline Summe / $\varnothing$ & 62,7 & $26,3 \%$ & 77,7 & $32,6 \%$ & 128 & $53,8 \%$ \\
\hline
\end{tabular}

Tab. 26: Vorzugsaktien und Pyramiden nach Identität des größten Aktionärs

Dabei wurde der Mittelwert aus den vier Jahren des Untersuchungszeitraums gebildet. ${ }^{985}$ Die Ergebnisse zeigen deutliche Abweichungen in Abhängigkeit von der Identität des größten Aktionärs. Auffällig ist insbesondere die große Bedeutung von Vorzugsaktien für Familienunternehmen; 46,3 \% dieser Unternehmen haben ein gespaltenes Aktienkapital (gegenüber 26,3\% im Durchschnitt aller Unternehmen). Demgegenüber stehen Ausländer, Industrieunternehmen und insbesondere Finanzintermediäre Vorzugsaktien offensichtlich skeptisch gegenüber, Unternehmen mit diesen Großaktionärstypen haben zu weniger als $20 \%$ Vorzugsaktien emittiert. Weit verbreitet sind sie dagegen mit 41,5\% auch in Unternehmen, in denen eine natürliche Person den größten Aktionär stellt. In dieser Aktionärsgruppe könnten ggf. weitere Familienmitglieder enthalten sein,

985 Die Spalte „absolut“ gibt somit die Anzahl der Unternehmen mit einem bestimmten Großaktionärstypus an, die im Durchschnitt der vier Jahre Vorzugsaktien oder Pyramidenbildung aufwies. Die Spalte ,in \%“ gibt an, wie viel Prozent der Unternehmen mit einem bestimmten Großaktionärstypus Vorzugsaktien oder Pyramiden aufwiesen. 
die aufgrund fehlender Namensgleichheit nicht als solche identifiziert werden konnten.

Aufgrund der auffälligen Divergenzen in Abhängigkeit von der Aktionärsidentität wurde eine Probit-Regression mit der Dummy-Variable „Nutzung von Vorzugsaktien" als abhängiger Variablen und der Identität des größten Aktionärs als Erklärender durchgeführt. ${ }^{986}$ Die Ergebnisse sind für alle Aktionärsgruppen außer Management und öffentliche Hand mindestens auf dem $5 \%$-Niveau signifikant. Familien nutzen ein gespaltenes Aktienkapital signifikant häufiger als andere Unternehmen. Industrieunternehmen, Finanzintermediäre und Ausländer hingegen investieren signifikant seltener in Unternehmen, die Vorzugsaktien emittiert haben. Die Ergebnisse der Probit-Analyse sind in Tab. A 5 in Anhang $\mathrm{C}$ ausgewiesen.

Die Bildung von Eigenkapitalpyramiden ist bei Familienunternehmen nur vergleichsweise schwach ausgeprägt; 20,5 \% sind Bestandteil einer Eigenkapitalpyramide gegenüber 32,6 \% im Durchschnitt. Große Bedeutung haben mehrstufige Beteiligungsverhältnisse hingegen in Unternehmen, bei denen ein Finanzintermediär den größten Aktionär stellt. Diese Unternehmen sind zu 46,1 \% Bestandteil einer Konzernpyramide. Auffallend hoch ist mit 72,1\% auch die Bedeutung von Pyramiden für Unternehmen mit Beteiligungen der öffentlichen Hand. Diese Ergebnisse besitzen, wie eine Probit-Regression zeigt, ebenfalls statistische Signifikanz. $^{987}$

Die folgende Betrachtung gibt Aufschluss über das Ausmaß der Abweichungen zwischen Kapital- und Stimmrechtsanteilen. Differenziert nach den verschiedenen Aktionärstypen werden der Kapitalanteil des größten Aktionärs an der Spitze der Konzernpyramide (KA1) den Stimmrechten des größten Aktionärs (StA1) gegenübergestellt. $^{988}$

986 Vgl. zu einer ähnlichen Vorgehensweise Cronqvist/Nilsson (2002), S. 13; Ehrhardt/Nowak (2002), S. 19.

987 Vgl. zu den Regressionsergebnissen Tab. A 6 in Anhang C.

988 Die Variable KA1 beinhaltet nur den sich durch Multiplikation der Beteiligungsquoten ergebenden ultimativen Kapitalanteil des Aktionärs an der Spitze der Konzernpyramide. Die Gegenüberstellung mit der Variable StA1 zeigt somit Divergenzen aufgrund von Vorzugsaktien und Pyramidenbildung auf. Die ausgewiesenen Durchschnittswerte sind die aller Unternehmen. Sie lassen sich daher nicht als Durchschnitt der ausgewiesenen Werte rekonstruieren. 


\begin{tabular}{lrrrrr}
\hline & Ar. Mittel & Std.abw. & 1. Quartil & Median & 3. Quartil \\
\hline KA1 (in \%) & & & & & \\
Industrieunternehmen & 51,1 & 28,3 & 29,6 & 49,6 & $\mathbf{7 4 , 8}$ \\
Familie & 45,8 & 23,5 & 26,0 & 46,7 & 61,4 \\
Ausländer & 64,2 & 30,3 & 39,2 & 72,0 & 95,0 \\
Finanzintermediär & 22,2 & 17,6 & 10,4 & 16,2 & 29,4 \\
Management & 43,8 & 41,1 & 27,9 & 44,0 & 58,8 \\
Natürl. Person & 39,9 & 26,7 & 15,5 & 32,2 & 63,0 \\
Offentliche Hand & 39,0 & 31,0 & 14,2 & 25,1 & 61,7 \\
& & & & & \\
$\varnothing$ & $\mathbf{4 5 , 8}$ & $\mathbf{2 8 , 3}$ & $\mathbf{2 4 , 0}$ & $\mathbf{4 1 , 3}$ & $\mathbf{6 7 , 1}$ \\
\hline StA1 (in \%) & & & & & \\
Industrieunternehmen & 62,4 & 40,7 & 34,5 & 56,1 & $\mathbf{7 7 , 6}$ \\
Familie & 60,6 & 24,8 & 44,7 & 59,0 & $\mathbf{7 8 , 8}$ \\
Ausländer & $\mathbf{7 1 , 1}$ & $\mathbf{2 8 , 2}$ & 50,0 & $\mathbf{8 0 , 0}$ & 95,2 \\
Finanzintermediär & 28,2 & 30,6 & 11,1 & 20,0 & 36,8 \\
Management & 51,6 & 23,8 & 39,0 & 54,6 & 61,1 \\
Natürl. Person & 46,9 & 30,3 & 21,3 & 32,7 & $\mathbf{7 6 , 8}$ \\
Offentliche Hand & 47,2 & 27,5 & 25,1 & 43,7 & 61,7 \\
& & & & & \\
$\varnothing$ & $\mathbf{5 6 , 2}$ & $\mathbf{3 4 , 2}$ & $\mathbf{3 0 , 0}$ & $\mathbf{5 1 , 9}$ & $\mathbf{7 7 , 2}$ \\
\hline
\end{tabular}

Tab. 27: Kapital- und Stimmrechtsanteile nach Identität des größten Aktionärs

Die Ergebnisse machen deutlich, dass die Größe der gehaltenen Kapitalanteile je nach Identität des größten Aktionärs stark schwankt. So beträgt der Median des Kapitalanteils des größten Aktionärs 72,0 \%, wenn der Aktionär ein Ausländer ist, jedoch nur 16,2 \%, wenn ein Finanzintermediär die Anteile hält. Große Anteilspakete werden darüber hinaus von Industrieunternehmen und Familien gehalten, mit einem Median von 49,6\% bzw. 46,7 \%. Die von natürlichen Personen und von der öffentlichen Hand gehaltenen Anteile sind mit einem Median von $32,2 \%$ bzw. $25,1 \%$ deutlich geringer.

Betrachtet man zusätzlich die Stimmrechte, so fällt auf, dass Industrieunternehmen, Familien und Management jeweils einen Median der Kapitalanteile von unter $50 \%$ der Kapitalanteile halten, die entsprechenden Stimmrechtsanteile jedoch deutlich über $50 \%$ liegen. Der prozentuale Unterschied zwischen dem Kapital- und dem Stimmrechtsanteil ist bei Familienunternehmen besonders groß, er liegt gemessen am arithmetischen Mittel bei 32,3\%. Ausländer nutzen überproportionale Stimmrechte hingegen nur in geringem Umfang, sie übersteigen die Cash-Flow-Rechte nur um 10,7\%. Auffällig ist, dass die natürlichen Personen, die in großem Umfang Gebrauch von Vorzugsaktien und Pyramiden 
machen, daraus keine überdurchschnittlich hohen überproportionalen Stimmrechte ziehen. Finanzintermediäre hingegen, die zwar nur vergleichsweise kleine Kapitalanteile halten, realisieren durch die überdurchschnittlich häufige Nutzung von Konzernpyramiden um $27 \%$ höhere Stimmrechtsanteile. Die folgende Tabelle quantifiziert die überproportionalen Stimmrechte (Excess Votes) in Abhängigkeit von der Identität des Großaktionärs.

\begin{tabular}{lc}
\hline & $\mathbf{E V}$ \\
\hline Industrieunternehmen & $22,1 \%$ \\
Familie & $32,3 \%$ \\
Ausländer & $10,7 \%$ \\
Finanzintermediär & $27,0 \%$ \\
Management & $17,8 \%$ \\
Natürl. Person & $17,5 \%$ \\
Öfentliche Hand & $21,0 \%$ \\
$\varnothing$ & $22,7 \%$ \\
\hline
\end{tabular}

Tab. 28: Divergenzen zwischen Kapital- und Stimmrechtsanteilen nach Identität des größten Aktionärs (Excess Votes)

Im Ergebnis kann festgehalten werden, dass unterschiedliche Großaktionäre die verschiedenen Instrumente zur Generierung auseinanderfallender Stimm- und Cash-Flow-Rechte in unterschiedlichem Maße nutzen. Vorzugsaktien spielen insbesondere in Familienunternehmen eine dominante Rolle, Finanzintermediäre nutzen hingegen Eigenkapitalpyramiden, um ihre Stimmrechtsanteile überproportional zum Kapitalanteil zu erhöhen. Es könnte vermutet werden, dass Familienaktionäre über die Emission von Vorzugsaktien auch nach dem Börsengang die Kontrollmehrheit halten wollen. Die verstärkte Nutzung von Pyramiden durch Finanzintermediäre könnte darauf hindeuten, dass diese ihre Identität verschleiern wollen. Dafür spräche auch die übliche Einschaltung spezieller Beteiligungsgesellschaften, die regelmäßig Kunstnamen tragen, aus denen nicht auf die Identität des dahinterstehenden Aktionärs geschlossen werden kann.

Ausländische Großaktionäre stehen sowohl Vorzugsaktien als auch Pyramiden skeptisch gegenüber, die Excess Votes betragen für sie nur 10,7\% gegenüber $22,7 \%$ im Durchschnitt aller größten Aktionäre. Wenn sie sich an deutschen Aktiengesellschaften beteiligen, ist die Höhe ihrer Beteiligung indes überdurchschnittlich groß (Median des Kapitalanteils 72,0 \% ggü. 41,3\% im Durchschnitt aller Unternehmen). 


\subsubsection{Relevanz der Indexzugehörigkeit}

Des Weiteren soll eine Differenzierung nach der Indexzugehörigkeit vorgenommen werden. Von den 238 Sample-Unternehmen sind 19 im DAX notiert, 40 im MDAX und 179 sind ohne Zugehörigkeit zum DAX100 Bestandteil des CDAX ${ }^{989}$ Es stellt sich die Frage, inwieweit die Kapital- und Stimmrechtsstrukturen durch die Indexzugehörigkeit - somit also durch die mittels Marktkapitalisierung abgebildete Unternehmensgröße - determiniert werden. Die folgende Tab. 29 gibt einen Überblick über die Kapital- und Stimmrechtsanteile des größten, ultimativen Aktionärs in Abhängigkeit von der Indexzugehörigkeit:

\begin{tabular}{lccccr}
\hline & Ar. Mittel & Std.abw. & 1. Quartil & Median & 3. Quartil \\
\hline KA1 (in \%) & & & & & \\
$D A X$ & 20,4 & 17,4 & 10,1 & 12,6 & 29,4 \\
$M D A X$ & 33,8 & 19,9 & 17,6 & 30,2 & 50,1 \\
$C D A X$-Rest & 51,2 & 28,4 & 27,7 & 50,0 & 75,0 \\
$\varnothing$ & $\mathbf{4 5 , 8}$ & $\mathbf{2 8 , 3}$ & $\mathbf{2 4 , 0}$ & $\mathbf{4 1 , 3}$ & $\mathbf{6 7 , 1}$ \\
\hline StA1 (in \%) & & & & & \\
$D A X$ & 26,4 & 21,9 & 10,5 & 18,6 & 36,2 \\
$M D A X$ & 42,4 & 23,3 & 25,0 & 37,7 & 60,0 \\
$C D A X$-Rest & 61,1 & 32,5 & 38,0 & 60,0 & $\mathbf{8 7 , 7}$ \\
$\varnothing$ & $\mathbf{5 6 , 2}$ & $\mathbf{3 4 , 2}$ & $\mathbf{3 0 , 0}$ & $\mathbf{5 1 , 9}$ & $\mathbf{7 7 , 2}$ \\
\hline
\end{tabular}

Tab. 29: Kapital- und Stimmrechtsanteile nach Indexzugehörigkeit

Die Ergebnisse zeigen eine deutlich stärkere Kapital- und Stimmrechtskonzentration bei den kleineren CDAX-Unternehmen, die nicht Bestandteil von DAX oder MDAX sind. Der Median des Stimmrechtsanteils des größten Aktionärs (StA1) ist bei den kleineren CDAX-Unternehmen mit 60,0\% mehr als dreimal so groß wie bei den DAX-Unternehmen, die offensichtlich deutlich breiter gestreut sind. Bei der Betrachtung der Kapitalanteile ergibt sich ein vergleichbares Bild. Dieses Ergebnis erscheint ökonomisch plausibel, da der Erwerb eines gröBeren Anteils an einem Unternehmen mit sehr hoher Marktkapitalisierung (DAX/MDAX) einen ungleich höheren Kapitalaufwand mit sich bringen würde, als bei einem kleineren Unternehmen.

Somit ist es für Aktionäre in großen Unternehmen schwieriger, durch den Ausbau ihrer Beteiligung Kontrolle zu erlangen. Vor diesem Hintergrund liefert die

989 Indexzusammensetzung per 31.12.2000. 
Betrachtung der Divergenzen zwischen Stimm- und Cash-Flow-Rechten interessante Ergebnisse: Während nur in 51,5\% der kleineren CDAX-Gesellschaften Abweichungen zwischen Kapital- und Stimmrechtsanteil vorliegen, ist dies bei etwa $60 \%$ der DAX100-Gesellschaften der Fall. Dies wird primär durch Vorzugsaktien hervorgerufen, die in diesen Unternehmen deutlich häufiger verbreitet sind. Bei den Eigenkapitalpyramiden ergeben sich demgegenüber kaum Unterschiede.

\begin{tabular}{lrrrrrr}
\hline & $\begin{array}{c}\text { Vorzugsaktien } \\
\text { (VA) }\end{array}$ & \multicolumn{2}{c}{$\begin{array}{c}\text { Pyramiden } \\
\text { (PY) }\end{array}$} & \multicolumn{3}{c}{$\begin{array}{c}\text { Abweichungen } \\
\text { KA/StA ins. }\end{array}$} \\
& absolut & in \% & absolut & in \% & absolut & in \% \\
\hline$D A X$ & 7,8 & $40,8 \%$ & 6,3 & $32,9 \%$ & 11,0 & $57,9 \%$ \\
$M D A X$ & 15,8 & $39,4 \%$ & 12,0 & $30,0 \%$ & 24,3 & $60,6 \%$ \\
$C D A X-$ Rest & 39,0 & $21,8 \%$ & 59,0 & $33,0 \%$ & 92,3 & $51,5 \%$ \\
Summe / & $\mathbf{6 2 , 7}$ & $\mathbf{2 6 , 3} \%$ & $\mathbf{7 7 , 7}$ & $\mathbf{3 2 , 6} \%$ & $\mathbf{1 2 8}$ & $\mathbf{5 3 , 8} \%$ \\
\hline
\end{tabular}

Tab. 30: Vorzugsaktien und Pyramiden nach Indexzugehörigkeit

Die häufige Nutzung von Vorzugsaktien in den DAX- und MDAX-Unternehmen spiegelt sich auch in einer Betrachtung der Excess Votes wider, die in den kleineren Unternehmen geringer ausfallen:

\begin{tabular}{lc}
\hline & $\mathbf{E V}$ \\
\hline$D A X$ & $29,4 \%$ \\
$M D A X$ & $25,4 \%$ \\
$C D A X-$ Rest & $19,3 \%$ \\
$\varnothing$ & $\mathbf{2 2 , 7 \%}$ \\
\hline
\end{tabular}

Tab. 31: Divergenzen zwischen Kapital- und Stimmrechtsanteilen nach Indexzugehörigkeit (Excess Votes)

Die Tatsache, dass der Kontrollerwerb durch direkten Erwerb einer Mehrheitsbeteiligung in großen Unternehmen mit einem nur schwer aufzubringenden Kapitalbedarf verbunden ist, könnte somit Auslöser sein für den verstärkten Einsatz von Vorzugsaktien als Instrument zur Schaffung überproportionaler Stimmrechte.

\subsubsection{Kernergebnisse der deskriptiven Analyse}

Hinsichtlich der Eigentümer- und Stimmrechtsstrukturen deutscher Aktiengesellschaften wurden folgende Kernergebnisse erzielt:

- Die Hypothese, dass die Kontrolle deutscher Aktiengesellschaften in vielen Fällen in der Hand eines oder weniger großer Aktionäre liegt, wird für die 
Sampleunternehmen bestätigt. 83,6\% der Unternehmen hatten Ende 2000 einen Aktionär mit einem Stimmrechtsanteil von mindestens $25 \%$ : Bei mehr als der Hälfte befanden sich die Stimmrechte im Mehrheitsbesitz (59,7\%) und $32,4 \%$ wiesen sogar einen Aktionär mit einem Stimmrechtsanteil von über $75 \%$ auf. Der durchschnittliche Stimmrechtsanteil des größten direkt beteiligten Aktionärs lag im Jahr 2000 bei 58,4\% (Median = 53,0\%). Die Betrachtung im Zeitablauf deutet auf eine leichte Zunahme der Kapitalkonzentration hin.

- Der größte Aktionär wird in der Regel durch ein anderes Industrieunternehmen gestellt (35,3\% in 2000), Finanzintermediäre haben als Anteilseigner eine geringere Bedeutung als die öffentliche Diskussion vermuten lassen könnte (10,7\% in 2000). Im Zeitablauf zurückgegangen ist die Bedeutung der öffentlichen Hand und von Familien, die im Jahr 2000 1,4\% bzw. $24,2 \%$ der größten Aktionäre stellten.

- Eine differenzierte Betrachtung von Kapital- und Stimmrechten zeigt zum Teil erhebliche Abweichungen. Der durchschnittliche Kapitalanteil des größten Aktionärs liegt bei 51,6\% und ist damit 13,2\% geringer als die von ihm kontrollierten Stimmrechte. Über die Hälfte der Sampleunternehmen nutzen entweder Vorzugsaktien (24,4\% in 2000) oder Pyramiden $32,8 \%$ in 2000). Der Gebrauch von Vorzugsaktien ist jedoch im Zeitablauf rückläufig.

- Eine große Rolle spielen Vorzugsaktien nach wie vor in Familienunternehmen, die zu 46,3\% ein gespaltenes Aktienkapital aufweisen. Konzernpyramiden sind hingegen häufig anzutreffen, wenn ein Finanzintermediär die Kontrolle inne hat $(46,1 \%)$.

- Die Kapital- und Stimmrechtsbündelung tritt in kleineren Unternehmen deutlich stärker zu Tage als in den Unternehmen des DAX100. Der Median des Stimmrechtsanteils des größten Aktionärs ist bei den kleineren CDAXUnternehmen mit $60,0 \%$ mehr als dreimal so groß wie bei den DAX-Unternehmen (18,6 \%). Die Großaktionäre der Unternehmen mit großer Marktkapitalisierung nutzen jedoch in besonderem Maße Vorzugsaktien zur Erhöhung ihres Kontrollpotenzials.

Bei der Interpretation der Ergebnisse ist folgendes kritisch zu berücksichtigen: Da die Unternehmen nicht verpflichtet sind, alle Beteiligungen unabhängig vom gehaltenen Kapital- oder Stimmrechtsanteil zu publizieren, ist eine letzte Unsicherheit über die Vollständigkeit und Präzision der erhobenen Daten nicht auszuschließen. So werden, sofern Unternehmen diese Informationen nicht freiwillig publizieren, Anteile unter $5 \%$ nicht erfasst und Veränderungen innerhalb der relevanten Meldegrenzen werden nicht bekannt. Sollten viele Anteilseigner bewusst Anteile knapp unterhalb der nächst höheren Meldegrenze halten, so wür- 
den die Stimmrechtsanteile systematisch zu gering eingeschätzt. Eingeschränkte Meldepflichten von Kapitalanlagegesellschaften führen dazu, dass die Anteile von Finanzintermediären eher unterschätzt sein dürften. ${ }^{990}$ Bei der Erfassung der Konzernpyramiden ist davon auszugehen, dass nicht in allen Fällen die Kontrollkette ganz zurückverfolgt werden konnte. Insbesondere die Anteilseigner ausländischer Mutterunternehmen werden nicht immer erfasst. Es ist daher davon auszugehen, dass die hier ausgewiesenen Ergebnisse den Grad der Konzentration und Verflechtung am deutschen Kapitalmarkt eher unterschätzen.

\subsection{Eigentümer- bzw. Stimmrechtsstrukturen und Unternehmenserfolg}

\subsubsection{Deskriptive Analyse}

Zur Untersuchung des Zusammenhangs zwischen Eigentümerstruktur und Unternehmenserfolg sollen zunächst einige deskriptive Analysen durchgeführt werden, die die Transparenz über das zugrunde liegende Datenmaterial erhöhen. Dazu werden die Sampleunternehmen nach verschiedenen Dummy-Variablen in Gruppen unterteilt, für die die drei verschiedenen Rentabilitätskennziffern (Marktwert/Buchwert-Verhältnis, Eigen- und Gesamtkapitalrendite) separat ermittelt werden. Die folgende Tabelle gibt einen Überblick über die Rendite in Abhängigkeit vom Stimmrechtsanteil des größten Aktionärs (StA), vom Vorhandensein eines weiteren Großaktionärs (GA2) und der Nutzung von Pyramiden (PY) bzw. Vorzugsaktien (VA). ${ }^{991}$

\begin{tabular}{|c|c|c|c|c|c|}
\hline & Ar. Mittel & Std.abw. & 1. Quartil & Median & 3. Quartil \\
\hline \multicolumn{6}{|l|}{$M W B W$} \\
\hline StA $<25 \%$ & 1,80 & 1,98 & 1,11 & 1,36 & 1,71 \\
\hline StA25 & 1,32 & 0,62 & 0,98 & 1,11 & 1,42 \\
\hline StA50 & 1,37 & 0,63 & 1,00 & 1,23 & 1,51 \\
\hline StA75 & 1,41 & 0,71 & 1,01 & 1,21 & 1,52 \\
\hline GA2 & 1,48 & 1,19 & 1,02 & 1,23 & 1,56 \\
\hline Kein $G A 2$ & 1,45 & 1,03 & 1,01 & 1,21 & 1,53 \\
\hline$P Y$ & 1,39 & 0,70 & 1,01 & 1,20 & 1,51 \\
\hline$V A$ & 1,60 & 1,75 & 1,01 & 1,22 & 1,55 \\
\hline Weder PY noch VA & 1,42 & 0,66 & 1,03 & 1,22 & 1,57 \\
\hline$\varnothing$ & 1,45 & 1,06 & 1,01 & 1,21 & 1,54 \\
\hline \multicolumn{6}{|c|}{990 Vgl. zu den erleichterten Meldepflichten Kapitel II.3.5.1. } \\
\hline \multicolumn{6}{|c|}{$\begin{array}{l}\text { StA }<25 \% \text { beinhaltet die Unternehmen, deren größter Aktionär einen Stimmrechtsanteil } \\
<25 \% \text { hält, StA } 25 \text { die, für die gilt } 25 \% \leq \mathrm{StA}<50 \% \text { usw. Dabei liegen alle } 952 \text { Beo- } \\
\text { bachtungen der vier Jahre des Untersuchungszeitraums zugrunde. }\end{array}$} \\
\hline
\end{tabular}




\begin{tabular}{|c|c|c|c|c|c|}
\hline & Ar. Mittel & Std.abw. & 1. Quartil & Median & 3. Quartil \\
\hline \multicolumn{6}{|l|}{$\boldsymbol{E K R}$ (in \%) } \\
\hline StA $<25 \%$ & 11,81 & 19,81 & 7,07 & 12,90 & 18,73 \\
\hline StA25 & 7,17 & 17,32 & 3,58 & 8,74 & 14,29 \\
\hline StA50 & 5,13 & 29,55 & 4,22 & 9,78 & 16,52 \\
\hline StA75 & 5,82 & 21,37 & 0,27 & 7,08 & 14,65 \\
\hline$G A 2$ & 7,09 & 20,41 & 5,59 & 10,44 & 16,43 \\
\hline Kein $G A 2$ & 7,09 & 23,63 & 3,00 & 9,20 & 15,93 \\
\hline$P Y$ & 9,25 & 13,74 & 4,03 & 9,27 & 14,55 \\
\hline$V A$ & 8,54 & 21,12 & 5,59 & 10,49 & 16,50 \\
\hline Weder PY noch $V A$ & 5,27 & 28,03 & 2,23 & 9,63 & 16,69 \\
\hline$\varnothing$ & 7,09 & 22,98 & 3,36 & 9,77 & 16,23 \\
\hline \multicolumn{6}{|l|}{ GKR (in \%) } \\
\hline$S t A<25 \%$ & 5,19 & 5,08 & 3,35 & 5,52 & 7,45 \\
\hline StA25 & 3,79 & 4,64 & 1,98 & 3,83 & 5,86 \\
\hline StA50 & 4,62 & 5,51 & 2,48 & 5,00 & 7,18 \\
\hline StA75 & 3,59 & 5,59 & 0,21 & 3,37 & 6,05 \\
\hline$G A 2$ & 3,94 & 5,45 & 1,72 & 4,39 & 6,85 \\
\hline Kein $G A 2$ & 4,32 & 5,24 & 1,91 & 4,30 & 6,66 \\
\hline$P Y$ & 3,86 & 4,62 & 1,71 & 3,85 & 5,96 \\
\hline$V A$ & 5,04 & 5,82 & 2,89 & 4,78 & 6,87 \\
\hline Weder $P Y$ noch $V A$ & 4,08 & 5,42 & 1,58 & 4,35 & 7,00 \\
\hline$\varnothing$ & 4,24 & 5,28 & 1,85 & 4,32 & 6,75 \\
\hline
\end{tabular}

Tab. 32: Rentabilität nach Eigentümerstrukturkriterien

Die erste Differenzierung erfolgt nach der Höhe des Stimmrechtsanteils des größten Aktionärs. Nach allen drei Rentabilitätsmaßen weisen Unternehmen, bei denen der größte Aktionär einen Kapitalanteil unter $25 \%$ hält, die beste Performance aus. Bei Betrachtung der Mediane zeigt sich außerdem für alle drei Kennziffern eine schlechtere Rentabilitätssituation für Anteilspakete zwischen $25 \%$ und $50 \%$, eine erneut verbesserte für Pakete zwischen $50 \%$ und $75 \%$ und eine wiederum zurückgehende Performance bei Stimmrechtsanteilen über $75 \%$. Dieser Verlauf könnte ein erstes Indiz für die Gültigkeit der Nichtlinearitätshypothese am deutschen Kapitalmarkt sein, was jedoch durch weitergehende Untersuchungen zu belegen sein wird.

Die Differenzierung zwischen Unternehmen, die einen zweiten Großaktionär mit einem maßgeblichen Kapitalanteil aufweisen (GA2) und solchen, in denen 
der größte Aktionär seine Kontrolle uneingeschränkt ausüben kann, zeigt hingegen keine nennenswerten Rentabilitätsunterschiede. Bei den Unternehmen, die von Pyramiden und Vorzugsaktien Gebrauch machen, zeigt sich ein leichter Rentabilitätsvorsprung der Unternehmen mit Vorzugsaktien. Vor dem Hintergrund der Theorie zur Wirkung überproportionaler Cash-Flow-Rechte ist dies ein überraschendes Ergebnis; ob die folgenden Analysen diesen Zusammenhang bestätigen werden, bleibt abzuwarten. Unternehmen, die Bestandteil einer Konzernpyramide sind, weisen hingegen - gemessen am Median - eine leicht unterdurchschnittliche Performance aus.

Die Analyse der Rentabilitätsmaße - differenziert nach unterschiedlichen Großaktionärstypen - lässt nicht die eindeutige Schlussfolgerung $\mathrm{zu}$, dass sich ein bestimmter Großaktionärstyp besonders positiv oder negativ auswirken könnte. Die Tabelle gibt einen Überblick über die Rentabilität in Abhängigkeit vom größten Aktionär.

\begin{tabular}{lrrrrr}
\hline & Ar. Mittel & Std.abw. & 1. Quartil & Median & 3. Quartil \\
\hline MWBW & & & & & \\
Industrieunternehmen & 1,53 & 0,82 & 1,04 & 1,24 & 1,62 \\
Familie & 1,26 & 0,52 & 0,94 & 1,09 & 1,40 \\
Ausländer & 1,34 & 0,41 & 1,07 & 1,24 & 1,54 \\
Finanzintermediär & 1,36 & 0,55 & 1,04 & 1,20 & 1,50 \\
Management & 1,94 & 2,75 & 1,02 & 1,24 & 1,53 \\
Natürl. Person & 1,70 & 0,89 & 1,08 & 1,50 & 1,85 \\
Offentliche Hand & 1,27 & 0,49 & 0,95 & 1,24 & 1,45 \\
& & & & & \\
$\varnothing$ & $\mathbf{1 , 4 5}$ & $\mathbf{1 , 0 6}$ & $\mathbf{1 , 0 1}$ & $\mathbf{1 , 2 1}$ & $\mathbf{1 , 5 4}$ \\
\hline EKR (in \%) & & & & & \\
Industrieunternehmen & 6,44 & 25,67 & 3,56 & 8,32 & 16,49 \\
Familie & $\mathbf{8 , 6 3}$ & 19,29 & 4,20 & 10,29 & 15,88 \\
Ausländer & 6,67 & 22,27 & 1,41 & 7,50 & 14,37 \\
Finanzintermediär & 6,14 & 17,20 & 3,67 & 10,44 & 14,96 \\
Management & 2,25 & 34,76 & 2,02 & $\mathbf{8 , 2 5}$ & 17,55 \\
Natürl. Person & 11,64 & 16,84 & $\mathbf{8 , 3 0}$ & 13,03 & 18,45 \\
Offentliche Hand & 10,75 & 10,17 & 3,80 & 10,48 & 14,95 \\
& & & & & \\
$\varnothing$ & $\mathbf{7 , 0 9}$ & $\mathbf{2 2 , 9 8}$ & $\mathbf{3 , 3 6}$ & $\mathbf{9 , 7 7}$ & $\mathbf{1 6 , 2 3}$ \\
\hline & & & & &
\end{tabular}




\begin{tabular}{lrrrrr}
\hline & Ar. Mittel & Std.abw. & 1. Quartil & Median & 3. Quartil \\
\hline GKR (in \%) & & & & & \\
$\quad$ Industrieunternehmen & 3,98 & 4,90 & 1,59 & 4,10 & 6,64 \\
Familie & 5,06 & 5,92 & 2,37 & 4,83 & 7,23 \\
Ausländer & 2,90 & 5,72 & 0,10 & 3,66 & 5,07 \\
Finanzintermediär & 3,85 & 4,33 & 1,72 & 4,35 & 6,12 \\
Management & 4,78 & 5,74 & 2,92 & 5,56 & 7,21 \\
Natürl. Person & 5,61 & 5,14 & 3,23 & 5,72 & 7,23 \\
Offentliche Hand & 3,59 & 2,95 & 1,60 & 2,74 & 5,52 \\
& & & & & \\
$\varnothing$ & $\mathbf{4 , 2 4}$ & $\mathbf{5 , 2 8}$ & $\mathbf{1 , 8 5}$ & $\mathbf{4 , 3 2}$ & $\mathbf{6 , 7 5}$ \\
\hline
\end{tabular}

Tab. 33: Rentabilität nach Identität des Großaktionärs

Betrachtet man die durch das Marktwert/Buchwert-Verhältnis abgebildete Bewertung der Unternehmen am Kapitalmarkt, so schneiden dort Unternehmen überdurchschnittlich gut ab, deren größter Aktionär aus dem Management kommt oder eine natürliche Person ist (durchschnittliches MWBW von 1,94 bzw. 1,70). Stellen hingegen Familienmitglieder oder die öffentliche Hand den größten Aktionär, so führt dieses zu einer im Verhältnis zum Buchwert geringen Bewertung des Unternehmens am Kapitalmarkt (durchschnittliches MWBW von 1,26 bzw. 1,27). Bei den buchwertbezogenen Rentabilitätsmaßen schneiden ebenfalls die natürlichen Personen überdurchschnittlich gut ab. Hierbei ist jedoch die geringe Größe dieses Teilsamples von 16 Unternehmen bzw. 49 Beobachtungen zu berücksichtigen. Eine eher geringe Eigen- und Gesamtkapitalrentabilität weisen hingegen Unternehmen auf, deren größter Aktionär ein ausländischer Investor ist.

\subsubsection{Untersuchungsaufbau der Regressionsanalysen}

Im Folgenden soll der Zusammenhang zwischen Eigentümer- bzw. Stimmrechtsstruktur und Unternehmenserfolg im Rahmen einer Value-RelevanceUntersuchung analysiert werden. Dazu werden univariate und multivariate Regressionsanalysen eingesetzt. Der Einsatz der univariaten Regressionsanalyse dient dem Aufzeigen von grundlegenden Zusammenhängen und verschafft einen Überblick über die einzubeziehenden Variablen. Im Rahmen der multivariaten Modelle wird die gemeinsame Wirkung verschiedener Variablen untersucht. Hier soll zunächst mit einer einfachen Querschnittsanalyse begonnen werden, um darauf aufbauend den besonderen ökonometrischen Problemen von Eigentümerstrukturanalysen durch den Einsatz verfeinerter Modelle Rechnung zu tragen. Ein Vergleich der unterschiedlichen Ergebnisse wird nicht nur eine Aussage über die ökonomischen Zusammenhänge erlauben sondern darüber hinaus 
ermöglichen, den Erklärungsgehalt der verschiedenen Regressionsmodelle kritisch zu hinterfragen.

Die in Anhang $\mathrm{C}$ wiedergegebene Tabelle A 7 gibt einen Überblick über die verschiedenen multivariaten Modelle. Aufgeführt werden jeweils das zugrunde liegende ökonometrische Schätzverfahren sowie die einbezogenen Variablen. Die Vorgehensweise bei der Schätzung der unterschiedlichen multivariaten Regressionsmodelle ist wie folgt: Im Rahmen einer Querschnittsanalyse wird zunächst die korrekte funktionale Form für das Modell 1 ermittelt, das als erklärende Variable neben den Kontrollvariablen den Stimmrechtsanteil des größten Aktionärs als Eigentümerstrukturvariable beinhaltet. Anhand dieses Modells werden anschließend auch die verschiedenen Testverfahren zur Überprüfung der Regressionsvoraussetzungen erläutert. Darauf aufbauend werden die in Modell 1 eingehenden Erklärenden im Rahmen verschiedener Schätzverfahren eingesetzt, die der Konstruktion des Datensatzes als Panel Rechnung tragen. Zielsetzung ist die Analyse der Sensitivität der erzielten Ergebnisse im Hinblick auf die verschiedenen, in der Literatur angewandten Regressionsmodelle. Unterschiedliche Ergebnisse unter vergleichbaren Rahmenbedingungen könnten so erklärt werden. Darauf aufbauend werden verschiedene weitere Eigentümer- und Stimmrechtsstrukturvariablen auf ihren Einfluss untersucht. Ökonometrische Grundlage ist dabei Modell 3, das aus den alternativen Schätzverfahren als eines herausgefiltert wurde, das für die vorliegende Analyse gut geeignet ist.

\subsubsection{Einfluss der Stimmrechtsstruktur auf den Unternehmenserfolg}

\subsubsection{Univariate Regressionsanalysen}

Mittels univariater Regressionsanalysen werden zunächst die verschiedenen Regressoren auf ihren isolierten Einfluss auf die drei verschiedenen abhängigen Performancevariablen überprüft. Dabei wird ein einfaches Panel-Regressionsmodell zugrunde gelegt. Zielsetzung der univariaten Regressionen ist die Abschätzung von Korrelationen zwischen den Variablen; erste Hinweise auf bestehende Zusammenhänge sollen aufgedeckt werden. Ausgewiesen wird jeweils der Regressionskoeffizient sowie in Klammern der zugehörige Wert der t-Statistik. Die folgende Tabelle fasst die Regressionsergebnisse zusammen.

\begin{tabular}{lrrr}
\hline & MWBW & GKR & EKR \\
\hline Eigentümerstruktur & & & \\
KADl & $-0,301(-2,115)^{* *}$ & $-0,020(-3,645)^{* * *}$ & $-0,061(-2,768)^{*}$ \\
$K A 1$ & $-0,219(-1,601)$ & $-0,016(-2,794)^{* * *}$ & $-0,057(-2,523)^{* *}$ \\
$S K A D 4$ & $-2,601(-2,041)^{* *}$ & $-0,023(-3,890)^{* * *}$ & $-0,075(-3,055)^{* * *}$ \\
$H(K A D)$ & $-0,001(-0,006)$ & $-0,014(-1,165)$ & $0,066(1,516)$ \\
\hline
\end{tabular}




\begin{tabular}{|c|c|c|c|}
\hline & MWBW & GKR & EKR \\
\hline \multicolumn{4}{|c|}{ Stimmrechtsstruktur } \\
\hline$S t A l$ & $-0,079(-0,523)$ & $-0,009(-1,303)$ & $-0,028(-1,209)$ \\
\hline GA2 & $0,038(0,417)$ & $-0,004(-0,868)$ & $0,000(0,002)$ \\
\hline \multicolumn{4}{|c|}{ Abweichungen } \\
\hline$E V$ & $0,000(0,277)$ & $0,000(0,106)$ & $0,000(1,797)^{*}$ \\
\hline$V A$ & $0,202(1,788)^{*}$ & $0,011(2,591)^{* * *}$ & $0,020(1,199)$ \\
\hline$P Y$ & $-0,095(-1,539)$ & $-0,006(-1,637)$ & $0,032(2,434)^{* *}$ \\
\hline \multicolumn{4}{|l|}{ Identität } \\
\hline$F$ & $-0,233(4,172)^{* * *}$ & $0,008(1,743)^{*}$ & $0,013(0,800)$ \\
\hline$F I$ & $-0,089(-1,334)$ & $-0,004(-0,881)$ & $-0,009(-0,478)$ \\
\hline$I$ & $0,099(1,511)$ & $-0,004(-1,003)$ & $-0,009(-0,516)$ \\
\hline$\ddot{O}$ & $-0,091(-0,859)$ & $0,003(0,602)$ & $0,060(3,519)^{* * *}$ \\
\hline$n P$ & $1,224(2,601)^{* * *}$ & $0,020(2,622)^{* * *}$ & $0,058(2,404)^{* *}$ \\
\hline$M$ & $-0,056(-0,649)$ & $0,004(0,565)$ & $-0,056(-1,418)$ \\
\hline \multicolumn{4}{|l|}{ Branche } \\
\hline Mach & $-0,211(-4,193)^{* * *}$ & $0,005(0,845)$ & $0,018(0,739)$ \\
\hline Con & $-0,377(-7,832)^{* * *}$ & $-0,024(-4,442)^{* * *}$ & $-0,070(-2,464)^{* *}$ \\
\hline Retail & $-0,053(-0,846)$ & $0,011(1,718)$ & $-0,043(-1,155)$ \\
\hline Tech & $-0,205(-3,289)^{* * *}$ & $-0,005(-0,839)$ & $0,010(0,464)$ \\
\hline Ind & $-0,052(-0,590)$ & $0,009(1,463)$ & $0,027(1,118)$ \\
\hline ConCy & $-0,112(-1,166)$ & $0,007(1,054)$ & $-0,033(-1,293)$ \\
\hline FoBe & $-0,073(-1,016)$ & $-0,018(-3,405)^{* * *}$ & $-0,008(-0,380)$ \\
\hline Auto & $0,049(0,479)$ & $0,001(0,218)$ & $0,039(1,708)$ \\
\hline $\mathrm{PhHe}$ & $0,411(3,179)^{* * *}$ & $0,016(3,677)^{* * *}$ & $0,044(2,971)^{* * *}$ \\
\hline$B a R e$ & $-0,112(-1,498)$ & $-0,002(-0,238)$ & $0,017(-0,492)$ \\
\hline Util & $0,435(2,815)^{* * *}$ & $-0,005(-1,143)$ & $0,046(3,048)^{* * *}$ \\
\hline Chem & $0,123(0,935)$ & $0,013(2,163)^{* *}$ & $0,042(2,694)^{* * *}$ \\
\hline SoTeMe & $2,884(2,576)^{* *}$ & $0,012(0,802)$ & $0,027(0,637)$ \\
\hline \multicolumn{4}{|c|}{ Sonstige Kontrollvariablen } \\
\hline$U$ & $0,017(0,818)$ & $0,000(0,300)$ & $0,006(1,529)$ \\
\hline$I V G$ & $-0,001(-0,700)$ & $0,000(1,238)$ & $-0,001(-0,759)$ \\
\hline$V G$ & $-0,002(-0,886)$ & $-0,000(-2,085)^{* *}$ & $-0,001(-0,268)$ \\
\hline$A I$ & $0,002(1,434)$ & $0,000(2,014)^{* *}$ & $0,000(0,444)$ \\
\hline$W$ & $0,000(2,265)^{* *}$ & $-0,000(-2,005)^{* *}$ & $0,000(0,039)$ \\
\hline$H G B$ & $-0,201(-2,018)^{* *}$ & $0,257(0,452)$ & $-0,600(-0,512)$ \\
\hline IASUSG & $0,282(2,549)^{* *}$ & $-0,249(-0,394)$ & $0,568(0,436)$ \\
\hline
\end{tabular}

Tab. 34: Univariate Regressionsanalyse 
Die Regressionskoeffizienten weisen für die Regressoren zur Bündelung von Kapital- und Stimmrechten durchweg ein negatives Vorzeichen auf. Dies deutet - wenngleich nur auf Basis einer sehr einfachen Analyse ermittelt - auf einen negativen Einfluss von Kapital- und Stimmrechtsbündelungen und damit auf eine Bestätigung der Ausbeutungshypothese hin. Dieses Ergebnis gilt sowohl für das Marktwert/Buchwert-Verhältnis als auch für die buchwertbezogenen Kennziffern.

Überraschend ist hingegen, dass die kapitalbezogenen Kennziffern fast alle mindestens auf dem $5 \%$-Niveau signifikant sind, wohingegen der Erklärungsgehalt des Stimmrechtsanteils des größten Aktionärs nicht signifikant ist. Im Rahmen der deskriptiven Analyse wurde gezeigt, dass die Stimmrechte deutlich häufiger die kontrollkritischen Grenzen knapp überschreiten als die Kapitalanteile. Die Regressionsergebnisse könnten daher, entgegen den im theoretischen Teil formulierten Hypothesen, darauf hindeuten, dass diese Stimmrechtsbündel wirksam zur Ausübung von Kontrolle genutzt werden, auch wenn dem kein entsprechender Kapitalanteil gegenübersteht. Darauf deutet auch der Einfluss der Excess Votes hin, die entgegen der Erwartung ein positives Vorzeichen aufweisen. Entgegen der Hypothese üben auch Vorzugsaktien einen positiven Einfluss auf das Marktwert/Buchwert-Verhältnis und die Gesamtkapitalrendite aus. Der Einfluss von Pyramiden ist hingegen negativ, wenngleich nicht signifikant.

Für die Existenz eines weiteren Großaktionärs, der eventuell eigennutzorientierte Handlungen des größten Aktionärs mittels seiner Stimmrechte einschränken könnte, war ein positiver Einfluss auf die Performance erwartet worden. Die Ergebnisse der univariaten Regression sind hier jedoch nicht eindeutig und lassen keine Schlussfolgerung zu. Auch hinsichtlich der Identität des größten Aktionärs ist eine Identifikation von Aktionärstypen mit eindeutig positivem bzw. negativem Einfluss nicht möglich. Einzig eine natürliche Person als Großaktionär übt auf alle drei Performancekennzahlen einen signifikant positiven Einfluss aus. Die Koeffizienten für Finanzintermediäre sind zwar nicht signifikant, weisen jedoch in allen drei Fällen ein negatives Vorzeichen auf.

Für die Kontrollvariablen ergeben sich Hinweise auf signifikante Zusammenhänge nur in Einzelfällen. So übt eine Zugehörigkeit zur Branche Pharma \& Health einen signifikant positiven Einfluss auf den Unternehmenserfolg aus, die zur Branche Construction hingegen einen signifikant negativen. Es erstaunt hingegen, dass die Anwendung internationaler Rechnungslegungsstandards (IAS bzw. US-GAAP) zwar keinen signifikanten Einfluss auf die Eigen- und Gesamtkapitalrendite ausübt, jedoch das Marktwert/Buchwert-Verhältnis entgegen der formulierten Hypothese signifikant positiv beeinflusst. Es hätte erwartet werden können, dass die eher an den Marktwerten orientierten internationalen 
Standards zu tendenziell höheren Buchwerten und damit zu geringeren Marktwert/Buchwert-Verhältnissen führen. ${ }^{992}$ Stattdessen werden jedoch die international bilanzierenden Unternehmen im Verhältnis zu ihren Buchwerten am Markt höher bewertet. Dies könnte auf eine positive Wahrnehmung der Nutzung internationaler Bilanzierungsstandards durch den Kapitalmarkt hindeuten, die den sich aus der marktwertnäheren Bilanzierung ergebenden Effekt überkompensiert. ${ }^{993}$

\subsubsection{Querschnittsanalyse}

\subsection{Ergebnisse}

Im Rahmen der multivariaten Regressionsanalysen werden die verschiedenen erklärenden Eigentümerstrukturvariablen sowie Kontrollvariablen auf ihren gemeinschaftlichen Erklärungsgehalt für die Performance untersucht. Dabei soll zunächst eine Querschnittsanalyse durchgeführt werden, in die die Durchschnittswerte der Variablen über die vier Jahre des Untersuchungszeitraums einbezogen werden. ${ }^{994}$ Die Regression beinhaltet entsprechend 238 Beobachtungen. Vorteil dieses vereinfachenden Modells ist, dass es aufgrund der Durchschnittsbildung in geringerem Maße mit ökonometrischen Problemen (insb. Autokorrelation) verbunden ist als die Zeitreihenbetrachtung im Rahmen von PanelAnalysen. ${ }^{995}$

Zunächst wird der Stimmrechtsanteil des größten Aktionärs (StA1) mit den Kontrollvariablen ${ }^{996}$ und einer Konstanten c auf das Marktwert/BuchwertVerhältnis regressiert (Modell 1a). Der Stimmrechtsanteil des größten Aktionärs als Erklärende zur Anteilseignerstruktur wird auch in den meisten anderen Untersuchungen als zentraler Regressor herangezogen.

992 Vgl. hierzu die Quellenangaben im Rahmen der Hypothesenbildung in Kapitel IIV.2.3.1.3.

993 Vgl. zur Wahrnehmung internationaler Rechnungslegungsstandards durch den Kapitalmarkt auch die empirischen Ergebnisse von Pellens/Tomaszewski (1999); Leuz/Verrechia (2000); Bonse (2003).

994 Diese mehrstufige Vorgehensweise aufeinander aufbauender Regressionsmodelle wird auch von McConnel/Servaes (1990), Bohren/Odegaard (2001) und Lehmann/Weigand (2000) gewählt.

995 Vgl. Kennedy (1998), S. 122f.; Bohren/Odegaard (2001), S. 28.

996 Zur Definition der Kontrollvariablen vgl. Kapitel IIV.2.3.1.3. 


\begin{tabular}{lrrrr}
\hline \multirow{2}{*}{$\begin{array}{l}\text { Abhängige Variab- } \\
\text { le: MWBW } \\
\text { Erklärende }\end{array}$} & \multicolumn{4}{c}{ Modell 1a } \\
\cline { 2 - 5 } Variablen: & Koeffizient & Std.-fehler & t-Wert & p-Wert \\
\hline$c$ & 1,1649 & 0,456 & 2,557 & 0,012 \\
$S t A l$ & 0,0798 & 0,165 & 0,483 & 0,630 \\
$U$ & $-0,0012$ & 0,034 & $-0,035$ & 0,972 \\
$I V G$ & 0,0034 & 0,006 & 0,554 & 0,581 \\
$V G$ & $-0,0396$ & 0,018 & $* *-2,228$ & 0,027 \\
$A I$ & 0,0049 & 0,002 & $* * 2,493$ & 0,014 \\
$W$ & 0,0004 & 0,000 & $* * 2,335$ & 0,021 \\
\hline $\mathbf{r}^{2}$ & 0,101 & & & \\
Adj. $\mathbf{r}^{2}$ & 0,066 & & & \\
$\hat{\sigma}$ & 0,563 & & & \\
F-Statistik & 2,846 & & & \\
p-Wert & 0,012 & & & \\
(F-Statistik) & & & & \\
\hline
\end{tabular}

Tab. 35: Regressionsergebnisse Modell $1 a$

Die Nullhypothese des F-Tests, dass zwischen den Regressoren und dem Regressanden kein Zusammenhang besteht und die Regressionskoeffizienten alle null sind, wird eindeutig verworfen. Es ist daher von einem signifikanten Zusammenhang zwischen den erklärenden Variablen und dem Marktwert/Buchwert-Verhältnis auszugehen. Das $\mathrm{r}^{2}$ von $10,1 \%$ zeigt jedoch auch, dass die einbezogenen Regressoren die abhängige Variable nur unvollständig erklären.

Die Betrachtung der Regressionskoeffizienten verdeutlicht, dass den Kontrollvariablen Verschuldungsgrad (signifikant negativ), Anlagenintensität (signifikant positiv) und Wachstum (signifikant positiv) ein hoher Erklärungsgehalt mit den erwarteten Vorzeichen zukommt. Die immateriellen Vermögensgegenstände in Prozent der Bilanzsumme sowie der logarithmierte Umsatz als Proxy für Unternehmensgröße tragen jedoch nicht signifikant zur Erklärung bei. Dieses Ergebnis ändert sich nicht, wenn anstelle des Umsatzes die logarithmierte Bilanzsumme als Größenproxy eingesetzt wird. Der geringe Erklärungsgehalt der bilanzierten immateriellen Vermögensgegenstände könnte auf die bereits zuvor diskutierte mangelnde Eignung der Kennzahl als Proxy für die Gesamtheit der intangiblen Werte zurückzuführen sein. Die Verwendung internationaler Rechnungslegungsstandards wird im Rahmen der Querschnittsanalysen nicht als 
Kontrollvariable berücksichtigt, da ihre Verwendung nicht für alle Unternehmen über die vier Jahre einheitlich ist.

Der fehlende Erklärungsgehalt des Stimmrechtsanteils des größten Aktionärs deutet nach den signifikanteren Ergebnissen der univariaten Regressionsanalysen auf eine mögliche Fehlspezifikation des Modells hin. Die Folge wären verzerrte und nicht konsistente Schätzwerte. Da bereits die theoretischen Überlegungen ebenso wie die deskriptive Auswertung und die Ergebnisse anderer Studien auf einen möglicherweise nichtlinearen Zusammenhang hindeuten, soll zunächst die Linearitätsannahme (Annahme 1) überprüft werden. ${ }^{997}$

Um zu überprüfen, ob die funktionale Form des Regressionsmodells korrekt gewählt ist, kann der RESET (REgression Specification Error Test) nach Ramsey eingesetzt werden. Er überprüft die Korrektheit der Modellspezifikation, d.h. neben dem funktionalen Zusammenhang auch das Fehlen weiterer relevanter Erklärungsvariablen und die Konstanz der Parameter. ${ }^{998}$ Neben der Annahme 1 wird somit auch Annahme 2 (Vollständigkeit des Modells) überprüft. Der RESET erweitert den ursprünglichen Modellzusammenhang um zusätzliche Variablen, die aus Potenzen der ursprünglichen Variablen gebildet werden. Wird auf das Vorliegen einer konvexen bzw. konkaven Beziehung getestet, so wird die Schätzgleichung um die erklärende Variable in quadratischer Form ergänzt. ${ }^{999}$ Im vorliegenden Fall lautet somit die zu testende Gleichung:

$$
M W B W=\alpha+\beta_{1} S t A 1+\beta_{2} S t A 1 s q
$$

wobei StA1sq der quadrierte Stimmrechtsanteil des größten Aktionärs, also der Variablen StA1 ist. Es wird getestet, ob die Variablen StA1 und StA1sq gemeinsam signifikant sind. Sofern die Nullhypothese, dass $\beta_{2}=0$ ist, verworfen wird, ist das ursprüngliche Modell fehlspezifiziert. ${ }^{1000}$ Die in Anhang C (Tab. A 8) ausgewiesenen Ergebnisse des RESET deuten klar auf eine Verletzung der Linearitätsannahme der gewählten Regressionsgleichung hin, die Koeffizienten $\beta$, und $\beta_{2}$ sind beide hochgradig signifikant, ebenso wie der F-Wert. ${ }^{1001}$ Inwieweit

997 Vgl. zu den Annahmen der Regressionsanalyse die Ausführungen in Kapitel IIV.2.1.3.

998 Vgl. zum RESET grundlegend Ramsey (1969), sowie Harvey/Collier (1977), erläuternd Gujarati (2003), S. 521-523; Eckey/Kosfeld/Dreger (2001), S. 220-222.

999 Vgl. Gujarati (2003), S. 522.

1000 Vgl. Eckey/Kosfeld/Dreger (2001), S. 221.

1001 Die Linearitätsannahme wird unabhängig vom Signifikanzniveau verworfen. Eine zusätzliche Hinzunahme einer Variablen in der dritten Potenz bringt hingegen keine signifikanten Ergebnisse, sodass von einem konkaven bzw. konvexen Verlauf ausgegangen werden kann. Einen kubischen Verlauf finden Short/Keasey (1999) für den britischen Kapitalmarkt. Zur Teststatistik des RESET vgl. Gujarati (2003), S. 522. 
fehlende Parameter das Ergebnis des RESET beeinflussen, kann ohne Kenntnis eben der fehlenden Parameter nicht überprüft werden. Zur Optimierung der Modellspezifikation bietet sich daher zunächst die Veränderung der funktionalen Form an. Das oben geschätzte Modell 1a wird daher unter zusätzlicher Hinzunahme der Variable StA1 sq neu geschätzt (Modell 1b). ${ }^{1002}$

Die in Tab. 36 ausgewiesenen Ergebnisse von Modell $1 \mathrm{~b}$ weisen mit einem $\mathrm{r}^{2}$ von $19,0 \%$, das fast doppelt so hoch ist wie das von Modell 1a, insgesamt einen deutlich höheren Erklärungsgehalt auf. Dieser liegt zwar nach wie vor auf einem niedrigen Niveau, entspricht jedoch dem vergleichbarer Studien. Auch die Koeffizienten der erklärenden Stimmrechtsstrukturvariablen StA1 und StA1sq sind hochgradig signifikant (t-Werte von $-3,413$ bzw. 4,072). Hinsichtlich der Kontrollvariablen ergeben sich nur geringe Veränderungen, das Umsatzwachstum ist nicht mehr signifikant. Alternativ zum Umsatzwachstum in Prozent wurde die Variable daher testweise in logarithmierter Form einbezogen, was jedoch $\mathrm{zu}$ keiner Verbesserung der Ergebnisse führte.

Ökonomisch belegen diese Ergebnisse die Gültigkeit einer nichtlinearen Beziehung zwischen Stimmrechtskonzentration und Marktwert/Buchwert-Verhältnis für den deutschen Kapitalmarkt. Demzufolge wirkt sich eine zunehmende Stimmrechtskumulation zunächst negativ auf den Unternehmenswert aus, ab einem bestimmten Stimmrechtsanteil hingegen positiv. ${ }^{1003}$ Die Aussage der Nichtlinearitätshypothese, die von mangelnden Kontrollanreizen bei kleineren bis mittleren Kapital- bzw. Stimmrechtsblöcken ausgeht, wird somit bestätigt. Erst wenn ein ausreichend großer Anteil gehalten wird, ist die Partizipation am Cash Flow so groß, dass sich die Realisierung von private benefits nicht mehr lohnt.

1002 Vgl. ebenso McConnell/Servaes (1990), S.601; Himmelberg/Hubbard/Palia (1999), S. $374 \mathrm{f}$.

${ }^{1003}$ Vgl. ähnlich Bohren/Odegaard (2001), S. 19, $21 \mathrm{f}$. 


\begin{tabular}{lrrrr}
\hline $\begin{array}{l}\text { Abhängige Vari- } \\
\text { able: MWBW }\end{array}$ & \multicolumn{4}{c}{ Modell 1b } \\
\cline { 2 - 5 } $\begin{array}{l}\text { Erklärende } \\
\text { Variablen: }\end{array}$ & Koeffizient & Std.-fehler & t-Wert & p-Wert \\
\hline \multicolumn{1}{c}{1,4825} & 0,441 & 3,363 & 0,001 \\
StAI & $-1,1983$ & 0,351 & $* * *-3,413$ & 0,001 \\
StAlsq & 0,8904 & 0,219 & $* * * 4,072$ & 0,000 \\
$U$ & 0,0035 & 0,032 & 0,109 & 0,913 \\
IVG & 0,0037 & 0,006 & 0,630 & 0,530 \\
$V G$ & $-0,0443$ & 0,017 & $* * *-2,611$ & 0,010 \\
$A I$ & 0,0054 & 0,002 & $* * * 2,912$ & 0,004 \\
$W$ & $-0,0001$ & 0,000 & $-0,492$ & 0,624 \\
\hline $\mathbf{r}^{2}$ & 0,190 & & & \\
Adj. $\mathbf{r}^{2}$ & 0,152 & & & \\
$\hat{\sigma}$ & 0,537 & & & \\
F-Statistik & 5,056 & & & \\
p-Wert & 0,000 & & & \\
(F-Statistik) & & & & \\
\hline
\end{tabular}

Tab. 36: Regressionsergebnisse Modell $1 b$

Die Regressionsergebnisse alleine lassen jedoch noch keinen Schluss zu, bis zu welchem Stimmrechtsanteil sich Bündelungen von Kontrolle negativ auswirken und wann der positive Einfluss dominiert. Zur Identifikation des Wendepunktes wird die Gleichung für das Marktwert/Buchwert-Verhältnis

$$
M W B W=-1,198324 \cdot S t A 1+0,890360 \cdot S t A 1^{2}
$$

die sich aus den Regressionskoeffizienten des Stimmrechtsanteils in linearer und quadratischer Form ergibt, zur Variablen StA1 differenziert. ${ }^{1004}$ Demzufolge ergibt sich für StA1 ein Wert von $67,3 \%$ bis zu dem zunehmende Stimmrechtsbündelungen einen negativen Einfluss auf die Marktbewertung ausüben. Die folgende Abbildung verdeutlicht den Zusammenhang zwischen Marktwert/Buchwert-Verhältnis und Stimmrechtsanteil des größten Aktionärs. Es ergibt sich eine konvexe Funktion, nach der eine zunehmende Stimmrechtskonzentration zu sinkenden Marktwert/Buchwert-Verhältnissen führt, bis der größte Aktionär einen Anteil von etwa zwei Drittel der Stimmen innehat. Größere

${ }^{1004}$ Dabei gilt die Annahme, dass alle anderen Variablen konstant sind. Zur Vorgehensweise vgl. Short/Keasey (1999), S. 94. 
Stimmrechtsanteile führen dann wieder zu einer Verbesserung der Performance. Die höchste Marktbewertung ist demnach jedoch bei den breit gestreuten Unternehmen zu finden, was die Ergebnisse der deskriptiven Analyse bestätigt.

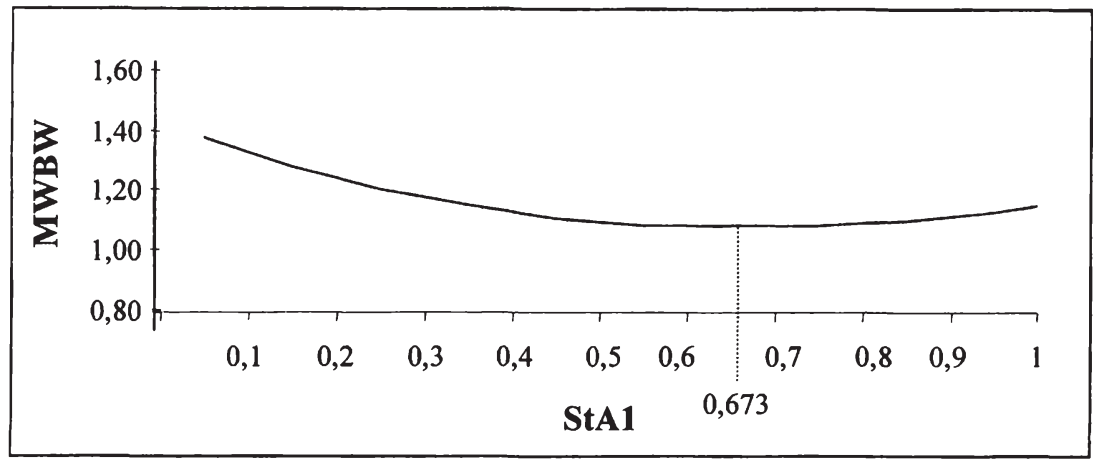

Abb. 27: Nichtlinearer Zusammenhang zwischen MWBW und StA1

Die Ergebnisse hinsichtlich der Form der nichtlinearen Beziehung entsprechen nur teilweise denen von Studien internationaler Kapitalmärkte. In verschiedenen Studien insbesondere für den US-amerikanischen Markt wird ein konkaver Verlauf der Kurve nachgewiesen, der auf einen zunächst positiven Einfluss von Stimmrechtsbündelungen schließen lässt, der mit zunehmendem Stimmrechtsanteil abnimmt und schließlich für größere Blöcke wieder zunimmt. ${ }^{1005}$ Dieser positive Effekt kleinerer Kapitalbündelungen, der mit Anreizwirkungen begründet wird, kann für das vorliegende Untersuchungssample hingegen nicht bestätigt werden. Die Ergebnisse bestätigen indes Gedajlovic/Shapiro (1998), die für das Jahr 1991 einen vergleichbaren Verlauf am deutschen Kapitalmarkt finden. Der Wendepunkt liegt in ihrer Regression bei $70 \%$, untersucht wurde der Einfluss des Kapitalanteils auf die Gesamtkapitalrendite. Ersetzt man in der obigen Regression den Stimmrechtsanteil durch den größten direkt gehaltenen Kapitalanteil (KAD1), so ergibt sich ein negativer Einfluss von Kapitalbündelungen bis zu einem Anteil von 52,3\%, bei höheren Konzentrationen verbessert sich das Marktwert/Buchwert-Verhältnis wieder. Die Vorzeichen der Regression bleiben unverändert, wenngleich die Koeffizienten von KAD1 und KAD1sq nicht signifikant sind und der gesamte Erklärungsgehalt mit einem $r^{2}$ von $11,0 \%$ geringer ausfällt als bei Modell $1 \mathrm{~b}$. Die Ergebnisse dieser Schätzung finden sich als Modell $1 \mathrm{c}$ in Tab. A 9 in Anhang C.

${ }^{1005}$ Vgl. etwa McConnell/Servaes (1990), S. 604f., sowie Short/Keasey (1999), S. 86f. Nur teilweise signifikant sind hingegen die Ergebnisse von Himmelberg/Hubbard/Palia (1999), S. 374. 
Im Ergebnis scheinen Stimmrechtsbündelungen ökonomisch somit nur in den Fällen keinen negativen Einfluss auszuüben, in denen der Aktionär von den negativen Folgen eventuell eigennutzorientierter Handlungen in großem Maße selbst betroffen ist, in denen er also die Kapitalmehrheit hält. Wie groß der Einfluss der Eigenkapital- bzw. Stimmrechtsstruktur auf die Marktbewertung ist, zeigt eine Betrachtung der Regressionskoeffizienten. Für ein Unternehmen mit einem Marktwert/Buchwert-Verhältnis von 1,12 und einem Stimmrechtsanteil des größten Aktionärs von 53,0 \% (jeweils Median der Sampleunternehmen in 2000) würde eine Veräußerung dieses Stimmrechtspakets an viele Kleinaktionäre ceteris paribus eine hypothetische Steigerung des Marktwert/BuchwertVerhältnisses um $56,7 \%$ bedeuten. ${ }^{1006}$

\subsubsection{2 Überprüfung der Regressionsvoraussetzungen}

Neben der Linearität und Vollständigkeit des Modells verlangt Annahme 3 Homoskedastizität und eine fehlende Autokorrelation der Störterme. Autokorrelation spielt primär bei Zeitreihen eine Rolle, sodass sie im Rahmen der hier vorliegenden Querschnittsanalyse kein Problem darstellt. Die Homoskedastizität des Modells, also die konstante Varianz der Residuen, wird mit Hilfe des WhiteTests überprüft. ${ }^{1007}$ Dazu werden die Residuen des ursprünglichen Modells quadriert und anschließend auf die Regressoren des Ausgangsmodells sowie deren Quadrate regressiert: ${ }^{1008}$

$$
\begin{aligned}
R E S_{t}^{2} & =\alpha+\beta_{1} \cdot S T A 1_{t}+\beta_{2} \cdot S T A 1_{t}{ }^{2}+\beta_{3} \cdot S T A 1 s q_{t}{ }^{2}+\beta_{4} \cdot V G_{t} \\
& +\beta_{5} \cdot V G_{t}{ }^{2}+\beta_{6} \cdot U_{t}+\beta_{7} \cdot U_{t}{ }^{2}+\beta_{8} \cdot I V G_{t}+\beta_{9} \cdot I V G_{t}{ }^{2} \\
& +\beta_{I 0} \cdot K I_{t}+\beta_{11} \cdot K I_{t}{ }^{2}+\beta_{12} \cdot W_{t}+\beta_{13} \cdot W_{t}{ }^{2}+u_{t}
\end{aligned}
$$

Modell $1 \mathrm{~b}$ ist robust auch im Hinblick auf eine mögliche Heteroskedastizität der Residuen. Die in Anhang C (Tab. A 10) ausgewiesenen Testergebnisse lassen eine Ablehnung der Nullhypothese, dass keine Heteroskedastizität vorliegt, nicht

${ }^{1006}$ Ermittelt aus dem Regressionskoeffizienten multipliziert mit der Minderung von StA1 dividiert durch MWBW: $-1,198 \cdot(-0,53) \div 1,12=0,5567$. Vgl. auch Cronqvist/Nilsson (2002), S. 19; Lins (2003), S. 171.

1007 Vgl. Kennedy (1998), S. 121. Vorteil des White-Tests ist seine Unempfindlichkeit gegen eine Verletzung der Normalverteilungsannahme. Vgl. Gujarati (2003), S. 413.

${ }^{1008}$ Auf den Ausweis der Variante des White-Tests, die zusätzlich auch auf die Kreuzprodukte regressiert, wird verzichtet. Bei einer ausreichend großen Anzahl Regressoren beeinflusst die Wahl der Testvariante das Ergebnis nicht. Auch hier führen beide Varianten zum gleichen Ergebnis. Vgl. Gujarati (2003), S. 414; Eckey/Kosfeld/Dreger (2001), S. $108 \mathrm{f}$. 
zu; die Koeffizienten der quadrierten Regressoren sind nicht signifikant und der p-Wert der F-Statistik des White-Tests liegt bei 0,633 .

Annahme 5 setzt voraus, dass die Regressoren nicht exakt linear abhängig sind, also keine Multikollinearität vorliegt. ${ }^{1009}$ Lineare Abhängigkeit zwischen den erklärenden Variablen liegt immer dann vor, wenn sie als Linearkombinationen der jeweils anderen darstellbar sind. Multikollinearität zwischen den Regressoren kann durch die Betrachtung der Korrelationskoeffizienten identifiziert werden. Als Faustregel gilt, dass ein Korrelationskoeffizient von $>0,8$ auf Multikollinearität zwischen zwei Variablen hindeutet. ${ }^{1010}$ In ökonometrischen Modellen stellt Multikollinearität insbesondere in den Fällen ein Problem dar, in denen Dummy-Variablen als erklärende Variablen eingesetzt werden, die sich zu eins aufaddieren. Probleme ergeben sich darüber hinaus, wenn die Anzahl der Regressoren größer ist als die der Beobachtungswerte.

$\mathrm{Da}$ in Modell $1 \mathrm{~b}$ keine Dummy-Variablen eingesetzt werden und die Anzahl der Beobachtungswerte mit 238 deutlich größer ist als die der Regressoren, stellt Multikollinearität keine Gefahr für die Effizienz der Schätzung dar. Dies zeigen auch die Ergebnisse der Korrelationsanalyse der Regressoren von Modell 1b, die in Anhang C (Tab. A 11) wiedergegeben werden. Die Korrelationskoeffizienten zwischen den Variablen sind durchweg klein, nur zwischen den Variablen StA1 und StA1sq ergibt sich ein Koeffizient von 0,899, was ökonomisch plausibel erscheint und für die Effizienz der Schätzung keine Gefahr darstellt. Sofern im Folgenden Dummy-Variablen in den Modellen eingesetzt werden, z. B. bei der Analyse von Brancheneffekten, wird eine Branche als Referenzgruppe zugrunde gelegt, sodass sich die Dummy-Variablen nicht zu eins aufaddieren und keine Multikollinearität im Sinne einer singulären Matrix entsteht.

Schließlich soll noch die Normalverteilung der Residuen überprüft werden, die zwar keine unmittelbare Voraussetzung für die Regressionsanalyse an sich ist, die jedoch für die Anwendung verschiedenster Signifikanztests erforderlich ist. ${ }^{1011}$ Die Erfüllung der Normalverteilungsannahme kann sowohl auf Basis optischer Verfahren als auch mit Hilfe verschiedener Tests überprüft werden. Der Jarque-Bera-Test stellt die Schiefe und die Wölbung (Moment dritter und vierter Ordnung) der Verteilung der Residuen der der Normalverteilung gegen-

${ }^{1009}$ Vgl. Gujarati (2003), S. 335-370; Kennedy (1998), S. 183; Greene (2003), S. 56-59; Backhaus et al. (2000), S. 41.

1010 Vgl. Eckey/Kosfeld/Dreger (2001), S. 90. Zur Identifikation von Multikollinearität ausführlich auch Chatterjee/Price (1995), S. 197-207.

1011 Vgl. Chatterjee/Price (1995), S. 5, 62; Eckey/Kosfeld/Dreger (2001), S. 222; Baltagi (2002), S. 43; Greene (2003), S. 17. 
über. ${ }^{1012}$ Er überprüft mittels einer $\chi^{2}$-verteilten Teststatistik mit zwei Freiheitsgraden die Nullhypothese, dass die Verteilung der Residuen einer Normalverteilung entspricht. ${ }^{1013}$ Da der Jarque-Bera-Test nur eine Aussage über Abweichungen der Residuenverteilung von der Normalverteilung hinsichtlich Schiefe und Wölbung liefert, sollte er jedoch nicht als einziges Testverfahren zur Überprüfung der Verteilungsannahme herangezogen werden. ${ }^{1014}$ Zusätzlich wird daher der Kolmogoroff-Smirnov-Anpassungstest durchgeführt, der die Verteilung der Residuen unmittelbar mit der der Normalverteilungskurve vergleicht und die absolute Abweichung zwischen den beiden Verteilungen als Teststatistik verwendet. $^{1015}$ Sowohl auf Basis der beiden Testverfahren als auch auf Basis der optischen Inspektion des Kerndichteschätzers sowie des Normal-Quantil-Plots muss von einer Verletzung der Normalverteilungsannahme der Residuen ausgegangen werden. ${ }^{1016}$ Die Verteilung der Residuen ist linksschief und es liegen im positiven Bereich verschiedene Ausreißer vor. ${ }^{1017}$ Alternativ wurde daher ein aus logarithmierten Daten ermitteltes Marktwert/Buchwert-Verhältnis eingesetzt, was jedoch keine wesentliche Veränderung der Ergebnisse lieferte.

Trotz der Verletzung der Normalverteilungsannahme für das vorliegende Untersuchungssample erscheint die Durchführung einer OLS-Schätzung im Rahmen der Querschnittsanalyse gerechtfertigt, die Argumentationsbasis liefert hier der zentrale Grenzwertsatz. ${ }^{1018}$ Mit zunehmender Stichprobengröße bleibt zwar die Nicht-Normalverteilung der Residuen erhalten, die Koeffizienten und die Teststatistiken sind hingegen normalverteilt, sodass die Aussagefähigkeit der Ergebnisse dennoch gewährleistet ist. ${ }^{1019}$

1012 Vgl. Greene (2003), S. 104-108; Kennedy (1998), S. 306f. Die Normalverteilung weist eine Schiefe von null und eine Wölbung von drei auf. Vgl. Eckey/Kosfeld/Dreger (2001), S. 222f.

${ }^{1013}$ Vgl. Kennedy (1998), S. 307; Eckey/Kosfeld/Dreger (2001), S. 223; Gujarati (2003), S. $148 f$.

1014 Vgl. Greene (2003), S. $104 \mathrm{f}$.

1015 Vgl. Hartung (2002), S. 183-185. Dabei wird die Anpassung nach Lilliefors (1967) eingesetzt, die der Tatsache Rechnung trägt, dass die Parameter der Normalverteilung geschätzte Größen sind. Vgl. Hartung (2002), S. 185.

1016 Vgl. zum Kerndichteschätzer Winker (1997), S. 178f.

1017 Die Darstellung der Teststatistiken finden sich ebenso wie die optischen Verfahren in Anhang C (Tab. A 12 sowie Abb. A 1)

1018 Vgl. Brown/Warner (1985), S. 10; Baltagi (2002), S. 102f.; Greene (2003), S. 17; Assenmacher (2002), S. 135f.; Gujarati (2003), S. 151.

1019 Vgl. Brown/Warner (1985), S. 25; Gujarati (2003), S. 339, sowie Schremper (2002), S. 245 m.w.N. 


\subsection{Stabilitätstests}

Zur Analyse der Stabilität der erzielten Ergebnisse soll die Untersuchung des Einflusses des Stimmrechtsanteils des größten Aktionärs auf den Unternehmenserfolg im Folgenden auch auf die buchwertbezogenen Rentabilitätskennziffern ausgedehnt werden. Darüber hinaus werden die Kontrollvariablen um eine zusätzliche Betrachtung der Branchenzugehörigkeit der Unternehmen erweitert und die vier Jahre des Untersuchungszeitraums werden separat analysiert.

Zunächst soll jedoch überprüft werden, inwieweit die Verwendung des approximativ ermittelten Marktwert/Buchwert-Verhältnisses für die 18 Unternehmen, die nur Vorzugsaktien notiert haben, die Ergebnisse beeinflusst. Modell $1 \mathrm{~b}$ wird daher - wie zuvor erläutert - im Rahmen einer Querschnittsanalyse unter Berücksichtigung des nur auf Basis der Vorzugsaktien geschätzten Marktwert/Buchwert-Verhältnisses dieser Unternehmen erneut geschätzt. ${ }^{1020}$ Diese Vorgehensweise beeinflusst das Schätzergebnis jedoch nur geringfügig, sodass im Folgenden weiterhin mit den approximierten Marktwert/BuchwertVerhältnissen für das gesamte Eigenkapital gearbeitet werden soll. ${ }^{1021}$ Entsprechend wird auch der Einfluss der Behandlung der Anteile Dritter am Eigenkapital auf seine Auswirkungen auf das Ergebnis überprüft. Diese werden im Rahmen einer Kontrollregression im Zähler des Marktwert/Buchwert-Verhältnisses zusätzlich erfasst, somit also im Sinne der Interessentheorie als Fremdkapital bewertet. ${ }^{1022}$ Der Einfluss auf das Ergebnis ist jedoch ebenfalls marginal, sodass diese Differenzierung im Folgenden nicht weitergeführt wird. ${ }^{1023}$

Nachfolgend wird auf Grundlage von Modell $1 \mathrm{~b}$ das Marktwert/BuchwertVerhältnis als Regressand ersetzt durch die Gesamtkapitalrendite (Modell 1d) und die Eigenkapitalrendite (Modell 1e). Die Ergebnisse sind in Tab. 37 wiedergegeben:

1020 Vgl. die Definition in Fußnote 967.

${ }^{1021}$ Die Schätzergebnisse sind in Tab. A 13 in Anhang C ausgewiesen.

1022 Vgl. hierzu die Ausführungen in Kapitel IIV.2.3.1.1.

${ }^{1023}$ Die Kontrollregression wird für ein Sample von 112 Unternehmen durchgeführt, für die Angaben zur Höhe der Anteile Dritter vorliegen. Die Änderung von Koeffizienten und tWerten ist marginal im Bereich der zweiten oder dritten Stelle hinter dem Komma. Die Signifikanz der einbezogenen Variablen ändert sich in keinem Fall. 


\begin{tabular}{|c|c|c|c|c|c|c|c|c|}
\hline & \multicolumn{4}{|c|}{ Modell 1d (abh. Var.: GKR) } & \multicolumn{4}{|c|}{ Modell 1e (abh. Var.: EKR) } \\
\hline & $\begin{array}{r}\text { Koeffi- } \\
\text { zient }\end{array}$ & $\begin{array}{l}\text { Std.- } \\
\text { fehler }\end{array}$ & t-Wert & p-Wert & $\begin{array}{r}\text { Koeffi- } \\
\text { zient }\end{array}$ & $\begin{array}{l}\text { Std.- } \\
\text { fehler }\end{array}$ & t-Wert & p-Wert \\
\hline$c$ & 0,083 & 0,036 & 2,333 & 0,021 & $-0,186$ & 0,820 & $-0,227$ & 0,821 \\
\hline$S t A l$ & $-0,051$ & 0,028 & $*-1,788$ & 0,076 & $-0,029$ & 0,654 & $-0,045$ & 0,964 \\
\hline StAlsq & 0,029 & 0,018 & $* 1,658$ & 0,099 & 0,164 & 0,406 & 0,403 & 0,688 \\
\hline$U$ & $-0,003$ & 0,003 & $-0,989$ & 0,324 & $-0,002$ & 0,060 & $-0,034$ & 0,973 \\
\hline$I V G$ & $-0,000$ & 0,000 & $-0,229$ & 0,819 & $-0,001$ & 0,011 & $-0,108$ & 0,914 \\
\hline$V G$ & $-0,002$ & 0,0014 & $-1,410$ & 0,161 & $-0,132$ & 0,032 & $* * *-4,191$ & 0,000 \\
\hline$A I$ & 0,000 & 0,000 & $* * 2,095$ & 0,038 & 0,011 & 0,003 & $* * * 3,227$ & 0,002 \\
\hline$W$ & $-0,000$ & 0,000 & $-0,263$ & 0,793 & $-0,000$ & 0,000 & $-0,367$ & 0,714 \\
\hline$r^{2}$ & & 0,061 & & & 0,134 & & & \\
\hline Adj. $r^{2}$ & & 0,018 & & & 0,094 & & & \\
\hline$\hat{\sigma}$ & & 0,043 & & & 0,996 & & & \\
\hline F-Statist & & 1,412 & & & 3,303 & & & \\
\hline $\begin{array}{l}\text { p-Wert } \\
\text { Statistik }\end{array}$ & & 0,204 & & & 0,003 & & & \\
\hline
\end{tabular}

Tab. 37: Regressionsergebnisse Modell 1d und Modell 1e

Die Ergebnisse legen einen nichtlinearen Einfluss des Stimmrechtsanteils des größten Aktionärs auch für die beiden buchwertbezogenen Erfolgsmaße nahe, die Koeffizientenschätzungen für die Variablen StA1 und StA1sq weisen in die gleiche Richtung wie bei Modell $1 \mathrm{~b}$. Der Einfluss auf die Gesamtkapitalrendite ist auf dem $10 \%$-Niveau signifikant, die Eigenkapitalrendite als Regressand führt hingegen nicht zu signifikanten Ergebnissen. Bei den Kontrollvariablen üben wie in Modell $1 \mathrm{~b}$ der Verschuldungsgrad und die Anlagenintensität einen signifikanten Einfluss aus. ${ }^{1024}$ Der Erklärungsgehalt der Modelle insgesamt ist mit einem $r^{2}$ von 6,1 \% (GKR) bzw. 13,4\% (EKR) jedoch deutlich geringer als der von Modell $1 \mathrm{~b}$ mit $19 \%$. Hinsichtlich der Erfüllung der Regressionsvoraussetzungen unterscheiden sich die Modelle $1 \mathrm{~d}$ und le nicht wesentlich von Modell $1 \mathrm{~b}$, die Normalverteilungsannahme ist erneut nicht erfüllt.

Als zusätzliche Kontrollvariable soll nun noch die Branchenzugehörigkeit der Unternehmen herangezogen werden, die über Dummy-Variablen in die Regression einbezogen wird (Modell 1f). Um Multikollinearität zu vermeiden, wird die Branche Software/Technology/Media als Referenzgruppe eingesetzt und der

${ }^{1024}$ Eine Berücksichtigung des Rechnungslegungsstandards als Kontrollvariable ist aufgrund der Durchschnittsbildung erneut nicht möglich. 
entsprechende Dummy in die Regression nicht mit aufgenommen. Die Regressionsergebnisse verbessern sich durch die Hinzunahme der Branchen-Dummies erheblich. Die erklärenden Variablen zur Stimmrechtsstruktur sind nach wie vor hoch signifikant und das $\mathrm{r}^{2}$ steigt auf $30 \%$ an. ${ }^{1025}$

\begin{tabular}{|c|c|c|c|c|}
\hline \multirow{2}{*}{$\begin{array}{l}\text { Abhängige Vari- } \\
\text { able: MWBW } \\
\text { Erklärende } \\
\text { Variablen: }\end{array}$} & \multicolumn{4}{|c|}{ Modell $1 f$} \\
\hline & Koeffizient & Std.-fehler & t-Wert & p-Wert \\
\hline$c$ & 2,2936 & 0,572 & 4,011 & 0,000 \\
\hline StAI & $-1,1958$ & 0,350 & $* * *-3,420$ & 0,001 \\
\hline StAlsq & 0,9667 & 0,217 & $* * * 4,448$ & 0,000 \\
\hline$U$ & $-0,0240$ & 0,034 & $-0,716$ & 0,475 \\
\hline$I V G$ & 0,0079 & 0,006 & 1,227 & 0,222 \\
\hline$G$ & $-0,0408$ & 0,017 & $* *-2,335$ & 0,021 \\
\hline$A I$ & 0,0032 & 0,002 & 1,492 & 0,138 \\
\hline$W$ & $-0,0002$ & 0,000 & $-1,151$ & 0,252 \\
\hline FoBe & $-0,3991$ & 0,354 & $-1,127$ & 0,262 \\
\hline Tech & $-0,4716$ & 0,343 & $-1,375$ & 0,171 \\
\hline Ind & $-0,5603$ & 0,343 & $-1,634$ & 0,105 \\
\hline ConCy & $-0,6882$ & 0,344 & $* *-2,001$ & 0,047 \\
\hline Mach & $-0,3838$ & 0,346 & $-1,109$ & 0,269 \\
\hline $\mathrm{PhHe}$ & $-0,5563$ & 0,408 & $-1,362$ & 0,175 \\
\hline Const & $-0,6123$ & 0,341 & ${ }^{*}-1,795$ & 0,075 \\
\hline Ret & $-0,4566$ & 0,339 & $-1,348$ & 0,180 \\
\hline Chem & $-0,5351$ & 0,406 & $-1,318$ & 0,190 \\
\hline Util & 0,1357 & 0,383 & 0,355 & 0,724 \\
\hline BaRe & $-0,4674$ & 0,370 & $-1,262$ & 0,209 \\
\hline Auto & $-0,1674$ & 0,346 & $-0,483$ & 0,630 \\
\hline $\mathbf{r}^{2}$ & 0,301 & & & \\
\hline Adj. $\mathbf{r}^{2}$ & 0,206 & & & \\
\hline$\hat{\sigma}$ & 0,519 & & & \\
\hline F-Statistik & 3,157 & & & \\
\hline $\begin{array}{l}\text { p-Wert } \\
\text { (F-Statistik) }\end{array}$ & 0,000 & & & \\
\hline
\end{tabular}

Tab. 38: Regressionsergebnisse Modell If

${ }^{1025}$ Das adj. $\mathrm{r}^{2}$ steigt von $15,2 \%$ auf $20,6 \%$ ebenfalls an, wenngleich weniger stark, da zwölf zusätzliche Regressoren in die Regression einbezogen werden. 
Das Vorliegen von Heteroskedastizität kann auf dem $10 \%$-Niveau verneint werden ( $\mathrm{p}$-Wert des White-Tests $=0,059$ ). Die Residuen erfüllen die Normalverteilungsannahme erneut nicht, sie gleichen in ihrem Verlauf denen von Modell $1 \mathrm{~b}$.

Abschließend sollen die vier Jahre des Untersuchungszeitraums dahingehend analysiert werden, ob der aufgezeigte Zusammenhang in allen Jahren Gültigkeit besaß. Da die Jahre 1997 bis 2000 durch eine starke Volatilität an den Aktienmärkten geprägt waren, ist eine Verzerrung der Ergebnisse durch Veränderungen im ökonomischen Umfeld nicht auszuschließen. ${ }^{1026}$ Grundlage für die vier separaten Schätzungen von Modell 2 ist jeweils das Modell mit dem höchsten Erklärungsgehalt, Modell 1f. Die folgende Tabelle gibt einen Überblick über die Ergebnisse der Einzelschätzungen der vier Jahre. Ausgewiesen werden jeweils die Koeffizienten der Stimmrechtsstrukturvariablen StA1 und StA1sq sowie der zugehörige Wert der t-Statistik sowie der $\mathrm{p}$-Wert. Zusätzlich wird das $\mathrm{r}^{2}$ der gesamten Schätzung angegeben.

\begin{tabular}{lrrrr}
\hline & $\begin{array}{c}\text { Modell 2a } \\
\mathbf{1 9 9 7}\end{array}$ & $\begin{array}{c}\text { Modell 2b } \\
\mathbf{1 9 9 8}\end{array}$ & $\begin{array}{c}\text { Modell 2c } \\
\mathbf{1 9 9 9}\end{array}$ & $\begin{array}{c}\text { Modell 2d } \\
\mathbf{2 0 0 0}\end{array}$ \\
\hline StAl & & & & \\
$\quad$ Koeffizient & $-0,978$ & $-1,347$ & $-0,876$ & $-0,490$ \\
$\quad \boldsymbol{t}$-Wert & $-1,134$ & $-1,660$ & $-2,713$ & $-1,613$ \\
$\quad \boldsymbol{p}$-Wert & 0,259 & $* 0,098$ & $* * * 0,007$ & $* 0,100$ \\
StAlsq & & & & \\
$\quad$ Koeffizient & 0,757 & 0,733 & 0,524 & 0,250 \\
$\quad \boldsymbol{t}$-Wert & 1,054 & 1,152 & 3,897 & 2,417 \\
$\quad \boldsymbol{p}$-Wert & 0,259 & 0,251 & $* * * 0,000$ & $* * 0,017$ \\
$\boldsymbol{r}^{2}$ & 0,217 & 0,284 & 0,273 & 0,246 \\
\hline
\end{tabular}

Tab. 39: Ergebnisse der Einzelschätzungen 1997-2000, Modell 2

Die Ergebnisse der Einzelschätzungen bestätigen den durch die Querschnittsanalyse aufgezeigten Zusammenhang zwischen dem Stimmrechtsanteil des größten Aktionärs und dem Marktwert/Buchwert-Verhältnis. Für alle vier Jahre wird ein zunächst negativer Einfluss von Stimmrechtsbündelungen gezeigt, der sich ab einem bestimmten Kapitalanteil ins positive verkehrt. Die Ergebnisse für die Jahre 1999 und 2000 sind analog zu denen der Querschnittsanalyse signifikant.

${ }^{1026}$ In 1997 und 1998 waren zunächst stark steigende Kurse zu verzeichnen (Anstieg des DAX von unter 3.000 auf über 6.000 Punkte in 18 Monaten), nach einem Zwischentief von knapp 4.000 Punkten im Oktober 1998 Anstieg auf 8.065 Punkte im März 2000, danach Abfall auf unter 6.500 Punkte zum Ende des Untersuchungszeitraums. 
Für 1997 und 1998 weisen die Koeffizienten zwar das erwartete Vorzeichen auf, die Ergebnisse sind jedoch nicht bzw. nur schwach signifikant. Das $r^{2}$ der Einzelschätzungen liegt zwischen $21,7 \%$ und $28,4 \%$. Im Ergebnis scheint der beobachtete Zusammenhang somit über die Zeit stabil zu sein, sodass von einer starken Verzerrung der Ergebnisse, die diese grundsätzlich infrage stellen würde, durch ein sich wandelndes Marktumfeld nicht auszugehen ist.

\subsubsection{Panel-Analyse}

\subsection{Panel-Modell ohne unternehmensspezifische Effekte}

Durch die Verwendung von Durchschnittsdaten im Rahmen der Querschnittsanalyse wurde die Variation der Eigentümerstrukturen über die vier betrachteten Jahre unberücksichtigt gelassen. Im Folgenden werden daher Panel-Analysen durchgeführt, die das Sample als kombinierten Querschnitts-ZeitreihenDatensatz betrachten. ${ }^{1027}$ Die Effizienz der Schätzung erhöht sich dabei im Vergleich zur Querschnittsanalyse, da die Anzahl Freiheitsgrade zunimmt. ${ }^{1028}$ Dabei wird zunächst davon ausgegangen, dass die unternehmensspezifischen Effekte konstant und für alle Unternehmen gleich sind (Modell 3). ${ }^{1029}$ Die Schätzung erfolgt mit Hilfe eines OLS-Schätzers. Für die Schätzung werden die Modelle herangezogen, die im Rahmen der Querschnittsanalyse die besten Ergebnisse erzielten. Modell 3a entspricht daher hinsichtlich der Variablenauswahl Modell $1 \mathrm{~b}$, zusätzlich werden jedoch Dummy-Variablen für die Untersuchungsjahre und für die Verwendung eines internationalen Rechnungslegungsstandards (IAS/USGAAP) berücksichtigt. Das Jahr 2000 fungiert als Referenzjahr. Grundlage der Panel-Schätzung sind nicht wie bei der Querschnittsanalyse 238 Durchschnittswerte sondern 952 Beobachtungen.

Die Ergebnisse der Schätzung von Modell 3a werden in Anhang C (Tab. A 14) ausgewiesen. Der im Rahmen der Querschnittsanalyse aufgezeigte nichtlineare Zusammenhang zwischen Stimmrechtsanteil des größten Aktionärs und Marktwert/Buchwert-Verhältnis bleibt bei Betrachtung der Panel-Daten in vollem Umfang erhalten, die Koeffizienten für StA1 und StA1sq weisen die bekannten Vorzeichen auf und sind hochgradig signifikant. Die Auswirkung der Kontrollvariablen ändert sich durch die Verwendung des Panel-Ansatzes ebenfalls nicht wesentlich. Der zusätzlich hinzugefügte Dummy für die Anwendung von IAS/US-GAAP übt einen auf dem 1\%-Niveau signifikanten, positiven Einfluss

\footnotetext{
${ }^{1027}$ Vgl. zu den Nachteilen einer reinen Querschnittsanalyse auch Bohren/Odegaard (2001), S. 28.

${ }^{1028}$ Vg. Hsiao (1986), S. 2; Baltagi (2001), S. 6.

1029 Vgl. ebenso Lehmann/Weigand (2000), S. 180.
} 
auf das Marktwert/Buchwert-Verhältnis aus, was auf eine positive Wahrnehmung der Nutzung internationaler Rechnungslegungsstandards durch die Kapitalmarktteilnehmer hindeutet. Das Ergebnis aus den univariaten Regressionsanalysen wird somit, entgegen der formulierten Hypothese, bestätigt. Da der Erklärungsgehalt des gesamten Modells mit einem $\mathrm{r}^{2}$ von 4,5\% wie erwartet unbefriedigend ist, wird analog zu Modell $1 \mathrm{f}$ das Modell $3 \mathrm{~b}$ geschätzt, das zusätzlich Branchen-Dummies enthält. ${ }^{1030}$ Die Schätzergebnisse von Modell 3b, das einen Erklärungsgehalt von $21,8 \%\left(\operatorname{adj} . \mathrm{r}^{2}=19,6 \%\right)$ entfaltet, sind im Folgenden ausgewiesen:

\begin{tabular}{|c|c|c|c|c|}
\hline \multicolumn{2}{|c|}{$\begin{array}{l}\text { Abhängige Vari- } \\
\text { able: MWBW }\end{array}$} & \multicolumn{2}{|c|}{ Modell 3b } & \multirow[b]{2}{*}{ p-Wert } \\
\hline $\begin{array}{l}\text { Erklärende } \\
\text { Variablen: }\end{array}$ & Koeffizient & $\begin{array}{l}\text { Std.- } \\
\text { fehler }\end{array}$ & t-Wert & \\
\hline$c$ & 4,732 & $\begin{array}{r}0,378 \\
(1,723)\end{array}$ & $\begin{array}{l}* * * 12,503 \\
* * *(2,745)\end{array}$ & $\begin{array}{r}0,000 \\
(0,006)\end{array}$ \\
\hline$S t A I$ & $-0,675$ & $\begin{array}{r}0,166 \\
(0,232)\end{array}$ & $\begin{array}{r}* * *-4,058 \\
* * *(-2,906)\end{array}$ & $\begin{array}{r}0,000 \\
(0,004)\end{array}$ \\
\hline StAlsq & 0,358 & $\begin{array}{r}0,073 \\
(0,070)\end{array}$ & $\begin{array}{r}* * * 4,974 \\
* * *(5,125)\end{array}$ & $\begin{array}{r}0,000 \\
(0,000)\end{array}$ \\
\hline$A I$ & 0,002 & $\begin{array}{r}0,001 \\
(0,002)\end{array}$ & $\begin{array}{r}* 1,562 \\
(1,544)\end{array}$ & $\begin{array}{r}0,119 \\
(0,123)\end{array}$ \\
\hline$I V G$ & $-0,016$ & $\begin{array}{r}0,004 \\
(0,010)\end{array}$ & $\begin{array}{r}* * *-4,075 \\
(-1,590)\end{array}$ & $\begin{array}{r}0,000 \\
(0,112)\end{array}$ \\
\hline$U$ & $-0,047$ & $\begin{array}{r}0,020 \\
(0,029)\end{array}$ & $\begin{array}{r}* *-2,362 \\
(-1,607)\end{array}$ & $\begin{array}{r}0,018 \\
(0,108)\end{array}$ \\
\hline$V G$ & $-0,001$ & $\begin{array}{r}0,002 \\
(0,002)\end{array}$ & $\begin{array}{r}-0,380 \\
(-0,502)\end{array}$ & $\begin{array}{r}0,704 \\
(0,616)\end{array}$ \\
\hline$W$ & 0,000 & $\begin{array}{r}0,000 \\
(0,000)\end{array}$ & $\begin{array}{r}1,484 \\
* *(2,437)\end{array}$ & $\begin{array}{r}0,138 \\
(0,015)\end{array}$ \\
\hline IASUSG & 0,449 & $\begin{array}{r}0,112 \\
(0,194)\end{array}$ & $\begin{array}{l}* * * 4,016 \\
* *(2,319)\end{array}$ & $\begin{array}{r}0,000 \\
(0,021)\end{array}$ \\
\hline 1997 & 0,114 & $\begin{array}{r}0,092 \\
(0,060)\end{array}$ & $\begin{array}{r}1,237 \\
*(1,903)\end{array}$ & $\begin{array}{r}0,217 \\
(0,057)\end{array}$ \\
\hline 1998 & 0,127 & $\begin{array}{r}0,083 \\
(0,062)\end{array}$ & $\begin{array}{r}1,523 \\
* *(2,053)\end{array}$ & $\begin{array}{r}0,128 \\
(0,040)\end{array}$ \\
\hline 1999 & 0,072 & $\begin{array}{r}0,082 \\
(0,038)\end{array}$ & $\begin{array}{r}0,883 \\
*(1,894)\end{array}$ & $\begin{array}{r}0,378 \\
(0,059)\end{array}$ \\
\hline
\end{tabular}

${ }^{1030}$ Das Jahr 2000 fungiert dabei als Basisjahr. 


\begin{tabular}{lrl}
\hline $\mathbf{r}^{2}$ & 0,218 & Branchen-Dummies werden nicht ausge- \\
Adj. $\mathbf{r}^{2}$ & 0,196 & wiesen, die Koeffizienten sind alle auf \\
$\hat{\sigma}$ & 0,882 & dem 1\%-Niveau signifikant. \\
F-Statistik & 10,124 & Robuste Standardfehler, t-Werte und \\
p-Wert & 0,000 & Branchen-Dummies verlieren unter Ne- \\
(F-Statistik) & & wey-West zum Teil an Signifikanz. \\
\hline
\end{tabular}

Tab. 40: $\quad$ Regressionsergebnisse Modell $3 b$

Analog zur Querschnittsanalyse werden auch für den Panel-Ansatz die Regressionsvoraussetzungen überprüft. Die Annahme der Normalverteilung der Residuen ist aufgrund einzelner Ausreißer erneut nicht erfüllt, was aufgrund des mit knapp tausend Beobachtungen nunmehr sehr großen Samples die Aussagefähigkeit der Ergebnisse jedoch nicht einschränken dürfte.

Im Gegensatz zur Querschnittsanalyse besteht bei der Analyse von Zeitreihendaten die Gefahr autokorrelierter Störterme. Ein Standardverfahren zur Überprüfung von Autokorrelation ist der Durbin-Watson-Test. ${ }^{1031}$ Die Teststatistik wird dabei wie folgt berechnet:

$$
D W=\frac{\sum_{t=2}^{T}\left(\hat{u}_{t}-\hat{u}_{t-1}\right)^{2}}{\sum_{t=1}^{T} \hat{u}_{t}{ }^{2}}
$$

Der Durbin-Watson-Wert von 0,437 deutet auf eine signifikant positive Autokorrelation der Störterme hin, was aufgrund der Zeitreihenkomponente des Datensatzes zu erwarten war. ${ }^{1032}$ Da der Durbin-Watson-Test nur auf Autokorrelation erster Ordnung überprüft, wird zusätzlich der Breusch-Godfrey-Test eingesetzt. ${ }^{1033}$ Dabei wird der Störterm der zu überprüfenden Schätzung im Rahmen der Testschätzung als zu erklärende Variable durch die Residuen (RES) der Vorperiode(n) erklärt. ${ }^{1034}$ Überprüft wird die Nullhypothese, dass keine Autokorrelation vorliegt. Ergeben sich signifikante Koeffizienten für die Residuen

${ }^{1031}$ Niedrige Werte des Durbin-Watson-Tests deuten auf eine positive Autokorrelation hin, hohe Werte auf eine negative. Je näher der Testwert bei 2 liegt, desto geringer sind die Hinweise auf Autokorrelation. Vgl. zum Verfahren Greene (2003), S. 270; Eckey/Kosfeld/Dreger (2001), S. 112-115; Assenmacher (2002), S. 169-172.

1032 Eine solche Autokorrelation ist charakteristisch für Eigentümerstrukturstudien. Vgl. etwa Lehmann/Weigand (2000), S. 178. Zur Interpretation der Ergebnisse des Testverfahrens vgl. Greene (2003), S. 270f.; Eckey/Kosfeld/Dreger (2001), S. 113; Kennedy (1998), S. 123-125.

${ }^{1033}$ Zu den Grenzen des Durbin-Watson-Tests vgl. Greene (2003), S. 270.

${ }^{1034}$ Zum Verfahren des weniger restriktiven Breusch-Godfrey-Test vgl. Greene (2003), S. 269f.; Eckey/Kosfeld/Dreger (2001), S. 116-118. 
der Vorperioden, so kann von Autokorrelation der Störterme ausgegangen werden. ${ }^{1035}$ Formal gilt für die Überprüfung von Modell $3 \mathrm{~b}:{ }^{1036}$

$$
\begin{aligned}
R E S_{t} & =\alpha+\beta_{1} \cdot S T A 1_{t}+\beta_{2} \cdot S T A 1 s q_{t}+\beta_{3} \cdot V G_{t}+\beta_{4} \cdot U_{t}+\beta_{5} \cdot I V G_{t} \\
& +\beta_{6} \cdot A I_{t}+\beta_{7} \cdot W_{t}+\beta_{8} \text { IASUSG }_{t}+\gamma_{1} \cdot R E S_{t-1}+\gamma_{2} \cdot R E S_{t-2}+u_{t}
\end{aligned}
$$

Der resultierende Wert der Teststatistik ist asymptotisch $\chi^{2}$-verteilt, die Anzahl Freiheitsgrade entspricht der Anzahl der Regressoren inklusive der Konstante minus eins. ${ }^{1037}$ Der Breusch-Godfrey-Test bestätigt das Ergebnis des DurbinWatson-Tests, dass die Residuen die Voraussetzung der Unkorreliertheit nicht erfüllen. Er deutet auf eine positive Autokorrelation der Residuen für das erste und zweite Jahr in Modell 3b hin $(\mathrm{t}$-Wert $=14,218$ bzw. 8,169). Das dritte Jahr ist nicht mehr signifikant $(\mathrm{t}-$ Wert $=-0,776) .{ }^{1038}$ Somit sind die erzielten Schätzergebnisse zwar unverzerrt, aber nicht mehr varianzminimal. ${ }^{1039}$

Die Homoskedastizität des Modells wird erneut mittels eines White-Tests überprüft. Die Nullhypothese, dass die Residuen eine konstante Varianz aufweisen und somit keine Autokorrelation vorliegt, muss abgelehnt werden. ${ }^{1040}$ Im Ergebnis sind damit in der vorliegenden Regressionsschätzung zwei wesentliche Modellannahmen der OLS-Schätzung verletzt.

Zur Kontrolle sowohl der Heteroskedastizität als auch der Autokorrelation wird daher das Verfahren von Newey-West eingesetzt, das auch bei Verletzung dieser Modellannahmen robuste Standardfehler und t-Werte liefert. ${ }^{1041}$ Die Ergebnisse der robusten Schätzung werden in der obigen Tabelle in Klammern ausgewiesen. Die Verwendung des Korrekturverfahrens nach Newey-West hat auf die Ergebnisse hinsichtlich des Zusammenhangs von Stimmrechtsanteil und Marktwert/Buchwert-Verhältnis keinen Einfluss. Der signifikant nichtlineare Zusammenhang wird nach wie vor bestätigt. Im Folgenden werden aufgrund der Annahmenverletzung alle Panel-Modelle unter Nutzung des Korrekturverfahrens nach Newey-West geschätzt.

\footnotetext{
1035 Vgl. Greene (2003), S. 269.

1036 Zusätzlich werden die Jahres-Dummies berücksichtigt.

1037 Vgl. Greene (2003), S. 269f.

${ }^{1038}$ Die Testergebnisse im Detail sind in Tab A 15 in Anhang C ausgewiesen.

1039 Die BLUE-Eigenschaften sind nicht mehr erfüllt. Vgl. Gujarati (2003), S. 441, 453f.; ausführlich auch Eckey/Kosfeld/Dreger (2001), S. 96-138.

1040 Die Ergebnisse des White-Tests sind in Anhang C (Tab. A 16) ausgewiesen. Die Testergebnisse weisen auch bei Einbeziehung der Cross-Terms auf Heteroskedastizität hin.

1041 Vgl. zum Verfahren des Autokorrelations-konsistenten Schätzers von Newey-West, Greene (2003), S. 198-201; Kennedy (1998), S. 121, 134.
} 
Da der Erklärungsgehalt der Kontrollvariablen in Modell $3 b$ teilweise sehr gering ist, wird zusätzlich die Modellvariante $3 \mathrm{c}$ geschätzt, in der der logarithmierte Umsatz und der Verschuldungsgrad unberücksichtigt bleiben. Die verbleibenden Kontrollvariablen (IVG, AI, W, IASUSG) sind in dem neuen Modell alle signifikant und das adj. $\mathrm{r}^{2}$ liegt nahezu unverändert bei 19,3\% (das $\mathrm{r}^{2}$ sinkt unwesentlich von 21,8\% auf 21,2\%). Die Ergebnisse sind in Anhang C (Tab. A 17) ausgewiesen. Zusätzlich wird außerdem anhand der Modelle 3d und 3e, die strukturgleich zu Modell 3c aufgebaut sind, der Einfluss des Stimmrechtsanteils auf die Gesamt- und die Eigenkapitalrendite untersucht. Für die Eigenkapitalrendite ergibt sich ein nichtlinearer Zusammenhang, der vom Verlauf her dem Einfluss auf das Marktwert/Buchwert-Verhältnis entspricht. Die Koeffizienten sind jedoch nicht signifikant (p-Wert für StA1 =0,316, für StA1 sq =0,293). Für die Gesamtkapitalrendite lässt sich bei positiven Koeffizienten beider Variablen ebenfalls kein Zusammenhang nachweisen (p-Werte von 0,707 bzw. 0,497). ${ }^{1042}$ Der verwandte Rechnungslegungsstandard übt keinen Einfluss auf die buchwertbezogenen Rentabilitäten aus, die entsprechende Kontrollvariable ist nicht signifikant.

Im Rahmen der Modelldiskussionen wurde das Problem einer möglichen Endogenität der abhängigen Variablen bisher vernachlässigt. Im Folgenden sollen daher verschiedene Untersuchungen durchgeführt werden, die einer möglichen Endogenität Rechnung tragen.

\subsection{Panel-Modell mit unternehmensspezifischen Effekten}

Im Rahmen von Fixed-Effects-Modellen stellen eventuelle Korrelationen zwischen den nicht beobachtbaren unternehmensspezifischen Effekten und den erklärenden Variablen kein Problem dar, die Schätzergebnisse sind im Gegensatz zur gewöhnlichen OLS-Regression somit auch bei Endogenität unverzerrt. ${ }^{1043}$ Sofern mit Hilfe einer Fixed-Effects-Schätzung signifikante Ergebnisse erzielt werden könnten, wären diese hinsichtlich eventuell endogener Zusammenhänge entsprechend unempfindlich. Die Güte der Schätzung wird für alle Fixed-Effects gemeinsam mit Hilfe eines F-Tests überprüft. Da die unternehmensspezifischen Effekte alle Einflüsse bündeln, die die Unternehmen voneinander unterscheiden aber über die Zeit konstant sind, können im Rahmen von Fixed-EffectsModellen keine Dummy-Variablen einbezogen werden, die wie die unternehmensspezifischen Effekte selbst über die Zeit konstant sind. Damit ist eine Er-

1042 Die Regressionsergebnisse für die Modelle 3d und 3e sind in Anhang C (Tab. A 18) ausgewiesen.

1043 Vgl. Cronquist/Nilsson (2002), S. 17; Baltagi (2001), S. $13 \mathrm{f}$. 
fassung der Branchenzugehörigkeit über Dummy-Variablen nicht möglich. ${ }^{1044}$ Auch der Dummy für die Verwendung von IAS/US-GAAP als für fast alle Unternehmen über die Zeit konstante Variable wird nicht berücksichtigt. Modell 4 entspricht abgesehen von den Dummy-Variablen vom Aufbau her Modell 3b. ${ }^{1045}$ Das zu schätzende Modell hat somit folgende Form: ${ }^{1046}$

$$
\begin{aligned}
M W B W_{i t}= & \beta_{1} S t A 1_{i t}+\beta_{2} S t A 1 s q_{i t}+\beta_{3} U_{i t}+\beta_{4} I V G_{i t}+\beta_{5} V G_{i t}+\beta_{6} A I_{i t} \\
& +\beta_{7} W_{i t}+\beta_{8} 1997_{i t}+\beta_{9} 1998_{i t}+\beta_{10} 1999_{i t}+a_{i}+\varepsilon_{i t}
\end{aligned}
$$

Die Konstante entfällt, stattdessen wird der Störterm aufgespalten in die unternehmensspezifischen Effekte $a_{i}$ und den White-Noise-Störterm $\varepsilon_{i t}$.

\begin{tabular}{lrrrr}
\hline $\begin{array}{l}\text { Abhängige Variab- } \\
\text { le: MWBW }\end{array}$ & \multicolumn{4}{c}{ Modell 4 } \\
\cline { 2 - 5 } $\begin{array}{l}\text { Erklärende } \\
\text { Variablen: }\end{array}$ & Koeffizient & Std.-fehler & t-Wert & p-Wert \\
\hline StAl & 0,1006 & 0,160 & 0,630 & 0,529 \\
StAlsq & 0,0054 & 0,075 & 0,718 & 0,473 \\
$U$ & $-0,2001$ & 0,051 & $* * *-3,962$ & 0,000 \\
$I V G$ & $-0,0090$ & 0,005 & $*-1,933$ & 0,054 \\
$V G$ & 0,0004 & 0,000 & 0,965 & 0,335 \\
$A I$ & $-0,0004$ & 0,002 & $-0,143$ & 0,887 \\
$W$ & 0,0000 & 0,000 & 0,979 & 0,328 \\
1997 & 0,1674 & 0,030 & $* * * 5,583$ & 0,000 \\
1998 & 0,0840 & 0,031 & $* * * 2,721$ & 0,007 \\
1999 & 0,0522 & 0,029 & $* 1,829$ & 0,068 \\
\hline $\mathbf{r}^{2}$ & 0,889 & & & \\
Adj. $\mathbf{r}^{2}$ & 0,844 & & & \\
$\hat{\sigma}$ & 0,388 & & & \\
F-Statistik & 92,249 & & & \\
p-Wert & 2,630 & & & \\
(F-Statistik) & & & & \\
\hline
\end{tabular}

Tab. 41: Regressionsergebnisse Modell 4

1044 Vgl. Lehmann/Weigand (2000), S. 177, 181, 185.

1045 Ähnliche Modelle verwenden auch Cronqvist/Nilsson (2002); Himmelberg et al. (1999); Lins (2003), sowie Lehmann/Weigand (2000).

${ }^{1046}$ Es wird ein sogenannter Least-Squares-Dummy-Variable-Estimator eingesetzt. Vgl. hierzu Greene (2003), S. 287, sowie die Ausführungen in Kapitel IV.2.2.1.2.2. m.w.N. 
Durch die Berücksichtigung der unternehmensspezifischen Effekte steigt der Erklärungsgehalt der Schätzung deutlich an, das $\mathrm{r}^{2}$ liegt bei 88,9\% (adj. $\mathrm{r}^{2}=$ $84,4 \%$ ). Die Koeffizienten für die erklärenden Eigentümerstrukturvariablen (StA1 und StA1sq) sind jedoch nicht mehr signifikant, was auf Endogenität der erklärenden Variablen hindeutet. ${ }^{1047}$ Dieses Phänomen ist auch bei den Untersuchungen von Himmelberg et al. zu beobachten, deren signifikante Ergebnisse durch Verwendung eines Fixed-Effects-Modells ebenfalls insignifikant werden. ${ }^{1048}$

Die Berücksichtigung der unternehmensspezifischen Effekte in der Regression führt dazu, dass die Schwankungen zwischen den Unternehmen eliminiert werden und nur die unternehmensindividuelle Schwankung über die Zeit („within“) regressiert wird. Performanceunterschiede in Abhängigkeit vom Stimmrechtsanteil des größten Aktionärs sind jedoch eher zwischen den Unternehmen als innerhalb der vier Jahre zu erwarten. ${ }^{1049}$ Die eigentliche Zielsetzung dieser Studie, die Erklärung von Unterschieden in der Performance zwischen verschiedenen Unternehmen durch die Analyse der Eigentümer- und Stimmrechtsstruktur, kann somit mit Hilfe von Fixed-Effects-Modellen nicht erreicht werden. ${ }^{1050}$

Die Ableitung signifikanter Aussagen aus der alleinigen Analyse der „WithinVariation" ist um so schwieriger, je geringer die Schwankungen im Zeitablauf sind. ${ }^{1051}$ Probleme ergeben sich auch dann, wenn die Zeitreihenkomponente des Datensatzes nur gering ist. Je geringer die Anzahl beobachteter Jahre ist, desto geringer fällt die „Within-Variation“ aus, die nach Elimination der unternehmensspezifischen Effekte für die Analyse der Auswirkungen der Stimmrechtsstrukturen verbleibt. Eine Ableitung von Aussagen allein aus der „WithinVariation" des hier betrachteten Zeithorizontes von vier Jahren erscheint, betrachtet man die geringe Variabilität von Eigentümerstrukturen, schwer möglich. ${ }^{1052}$ Bei Zhou heisst es: „The ownership-performance relationship, when it exists, is likely to be a cross-sectional phenomenon. ${ }^{\text {" }}{ }^{1053}$ Im Ergebnis erscheinen

1047 Vgl. Börsch-Supan/Köke (2002), S. 300.

1048 Vgl. Himmelberg et al. (1999), S. 373, sowie Zhou (2001). Auch die Ergebnisse von La Porta et al. verlieren unter Verwendung eines Fixed-Effects-Schätzers erheblich an Signifikanz. Vgl. La Porta et al. (2002), S. 1166.

1049 Mit einer ähnlichen Argumentation lehnen auch Hermalin/Weisbach (1991) den Ansatz ab. Vgl. S. 107.

1050 Vgl. Börsch-Supan/Köke (2002), S. 303.

1051 Vgl. Zhou (2001), S. 563.

1052 Das arithmetische Mittel von StA1 steigt von 53,8 \% in 1997 auf 58,4 \% in 2000 (Veränderung des Median von 51,3\% auf 53,0\%). Die Standardabweichung beträgt 28,3 bzw. 36,5. Die Variabilität des Stimmrechtsanteils des größten Aktionärs ist somit eher gering.

${ }^{1053}$ Zhou (2001), S. 560. 
Fixed-Effects-Modelle zur Analyse des hier vorliegenden Datensatzes nur begrenzt geeignet, weshalb dieser Ansatz nicht weiter verfolgt werden soll.

\subsection{4 Überprüfung auf Endogenität - Einfluss des Unternehmenserfolgs auf die Stimmrechtsstruktur}

\subsubsection{Umkehrung der Kausalität}

Nachdem eine Schätzung mittels Fixed-Effects-Modellen keine signifikanten Ergebnisse erbracht hat, soll die Endogenität der abhängigen Variablen im Folgenden genauer untersucht werden um zu überprüfen, inwieweit die mit Hilfe der Modelle $1-3$ erzielten Ergebnisse als valide angesehen werden können. ${ }^{1054}$ Auch wenn ökonomische Überlegungen auf eine mögliche Endogenität hindeuten, muss diese nicht zwangsläufig vorliegen. Ist dies nicht der Fall, ist der Schätzung mit OLS der Vorzug gegenüber alternativen Verfahren zu geben. ${ }^{1055}$ Zunächst soll daher der Einfluss des Marktwert/Buchwert-Verhältnisses auf den Stimmrechtsanteil des größten Aktionärs mittels einer Umkehrung der Kausalität im Rahmen einer Regressionsanalyse untersucht werden. Anschließend wird eine mögliche Endogenität mit Hilfe verschiedener Testverfahren analysiert und die Ergebnisse der OLS-Regressionen werden im Rahmen eines Stabilitätstests unter Verwendung des Two-Stage-Least-Squares-Verfahrens überprüft.

Ein erster Schritt zur Analyse der Stärke und Richtung einer wechselseitigen Beziehung bietet die Umkehrung der durchgeführten Regressionen. Der Regressor, bei dem eine umgekehrte Kausalität vermutet wird, geht in eine neue Schätzung als Regressand ein und wird durch die unabhängige Variable der Ausgangsgleichung erklärt. Dazu wird hier eine Schätzung entsprechend Modell 3b durchgeführt, ${ }^{1056}$ jedoch geht das Marktwert/Buchwert-Verhältnis als Regressor in die Gleichung ein und StA1 ist die zu erklärende Variable (Modell 5a). ${ }^{1057}$ Durch die Umkehrung der Kausalität kann nicht nur eine mögliche Endogenität

${ }^{1054}$ Die Folge von Endogenität sind verzerrte bzw. inkonsistente Schätzwerte. Vgl. BörschSupan/Köke (2002), S. 298.

1055 Bei Davidson/MacKinnon (1993), S. 237, heisst es: „Sometimes economic theory suggests that certain explanatory variables could be endogenous, but does not unambiguously indicate that they are. [...] Since least squares is somewhat easier to use than IV and yields more efficient estimates, one would prefer to use it if possible."

${ }^{1056} \mathrm{Da}$ die Determinanten der Aktionärsstruktur möglichst breit überprüft werden sollen, wird hier wieder das Modell unter Nutzung aller Kontrollvariablen herangezogen.

1057 Vgl. ebenso Lehmann/Weigand (2000), S. 178-180, sowie Kole (1996), S. 135-141. 
identifiziert werden, sie stellt auch eine Erweiterung des Untersuchungsgegenstandes um eine Erklärung der Determinanten der Aktionärsstruktur dar. ${ }^{1058}$

Die Ergebnisse können die Hypothese, dass Großaktionäre in der Lage sind, Unternehmen mit einer guten Performance zu identifizieren und bevorzugt in diese $\mathrm{zu}$ investieren, nicht stützen. Das Marktwert/Buchwert-Verhältnis entfaltet im Rahmen einer multivariaten Regression keinen Erklärungsgehalt für den Stimmrechtsanteil des größten Aktionärs, der p-Wert liegt bei 0,980. ${ }^{1059}$ Mit einzelnen der Kontrollvariablen kann hingegen der Stimmrechtsanteil zum Teil gut erklärt werden. Der logarithmierte Umsatz, immaterielle Vermögenswerte und der Verschuldungsgrad üben einen signifikant negativen Einfluss auf den Stimmrechtsanteil aus. Aktionäre halten demzufolge große Stimmrechtsanteile bevorzugt in kleineren Unternehmen mit einem geringen Anteil immaterieller Vermögenswerte und einem niedrigen Verschuldungsgrad. Anlagenintensität, Umsatzwachstum und Branchenzugehörigkeit haben keinen Erklärungsgehalt für den Stimmrechtsanteil des größten Aktionärs. Der Erklärungsgehalt der gesamten Regression ist mit einem $r^{2}$ von $12,4 \%$ (adj. $\left.r^{2}=10,1 \%\right)$ eher gering.

In der Literatur wird dem unternehmensindividuellen Risiko teilweise ein hoher Erklärungsgehalt für die Aktionärsstruktur des Unternehmens beigemessen. ${ }^{1060}$ Das individuelle Risiko eines Aktionärs ist bei Investition des Kapitals in nur ein Unternehmen aufgrund mangelnder Diversifikationsmöglichkeiten des unsystematischen Risikos ohnehin höher als bei Streuung des Kapitals auf mehrere Unternehmen. Großaktionäre könnten daher zur Minderung ihrer Risikoposition Anreize haben, in risikoärmere Unternehmen zu investieren. Es soll daher ein Modell $5 b$ geschätzt werden, in dem neben den bereits im Rahmen von Modell 5a signifikanten Erklärenden der Beta-Faktor als Ausdruck des unsystematischen Risikos des Unternehmens aufgenommen wird. ${ }^{1061}$ Die Ergebnisse erklären den Stimmrechtsanteil des größten Aktionärs besser als Modell 5a und das durch den Betafaktor abgebildete Risiko liefert einen hoch signifikanten Erklärungsbeitrag mit erwartet negativem Vorzeichen. Der Erklärungsgehalt des Modells insgesamt liegt bei einem $r^{2}$ von 13,9\% (adj. $r^{2}=13,3 \%$ ). Die Ergebnisse der Schätzung sind in der folgenden Tabelle ausgewiesen:

1058 Vgl. auch die Studien von Kole (1996); Loderer/Martin (1997); Himmelberg/Hubbard/Palia (1999); Coles et al. (2002), S. 26f.

1059 Die Regressionsergebnisse für Modell 5a sind in Tab. A 19 in Anhang C ausgewiesen.

1060 Vgl. etwa Loderer/Martin (1997); Cho (1998); Bohren/Odegaard (2001); Demsetz/Villalonga (2001); Lins (2003).

1061 Eingesetzt wird das 250-Tage CDAX-Beta. 


\begin{tabular}{lrrrr}
\hline $\begin{array}{l}\text { Abhängige Va- } \\
\text { riable: StA1 }\end{array}$ & \multicolumn{5}{c}{ Modell 5b } \\
\cline { 2 - 5 } $\begin{array}{l}\text { Erklärende } \\
\text { Variablen: }\end{array}$ & Koeffizient & Std.-fehler & t-Wert & p-Wert \\
\hline$c$ & 1,1425 & 0,146 & 7,822 & 0,000 \\
$U$ & $-0,0351$ & 0,011 & $* * *-3,115$ & 0,002 \\
$I V G$ & $-0,0018$ & 0,002 & $-1,121$ & 0,262 \\
$V G$ & $-0,0019$ & 0,000 & $* * *-4,558$ & 0,000 \\
Beta & $-0,2525$ & 0,053 & $* * *-4,780$ & 0,000 \\
\hline $\mathbf{r}^{2}$ & 0,139 & Die nicht ausgewiesenen Jahres- \\
Adj. $\mathbf{r}^{2}$ & 0,133 & Dummies liefern keine signifikanten \\
$\hat{\sigma}$ & 0,320 & Ergebnisse. & \\
F-Statistik & 21,244 & & & \\
p-Wert & 0,000 & & & \\
(F-Statistik) & & & & \\
\hline
\end{tabular}

Tab. 42: Regressionsergebnisse Modell $5 b$

Großaktionäre scheinen ihre Investitionsentscheidung somit nicht auf die aktuelle Bewertung des Unternehmens am Kapitalmarkt abzustellen, sondern durch Auswahl von Unternehmen mit geringem Verschuldungsgrad und Betafaktor den potenziellen Risikogehalt zu berücksichtigen. Darüber hinaus scheint die Unternehmensgröße einen negativen Einfluss auf den Anreiz zum Erwerb größerer Beteiligungen auszuüben. Dieses Ergebnis erscheint plausibel, wenn man berücksichtigt, wie groß der Kapitalbedarf ist, den ein einzelner Investor für den Erwerb der Kapitalmehrheit etwa an einem DAX-Unternehmen aufbringen müsste.

Im Ergebnis kann festgehalten werden, dass der Stimmrechtsanteil des größten Aktionärs weniger durch den Unternehmenserfolg als vielmehr durch die Unternehmensgröße sowie das sich in Betafaktor und Verschuldungsgrad widerspiegelnde unternehmensindividuelle Risiko determiniert wird. Lehmann/Weigand stellen in ihrer Untersuchung des deutschen Kapitalmarktes ebenfalls fest, dass die Performancevariablen „are of little help in explaining the variation of ownership concentration across firms and over time "1062. Weiter heißt es: "There is no gain by endogenizing OC [ownership concentration]. Put differently, OC can be taken as an exogenous variable in the ROA [return on assets] regression." 1063 Ein Indiz, das ebenfalls gegen einen maßgeblichen Einfluss der Performance auf die Anteilseignerstruktur sprechen könnte, ist die nur geringe Veränderung der

\footnotetext{
1062 Lehmann/Weigand (2000), S. 181.

1063 Lehmann/Weigand (2000), S. 181.
} 
Aktionärsstruktur im Zeitablauf. Wenn etwa performanceorientierte Großaktionäre jeweils in aktuell renditestarke Unternehmen investieren würden, so wäre eine stärkere Variabilität in den Aktionärsstrukturen zu erwarten. ${ }^{1064}$ Unter Verwendung einer Regressionsanalyse kann somit kein Einfluss des Marktwert/Buchwert-Verhältnisses auf den Stimmrechtsanteil des größten Aktionärs nachgewiesen werden, was zunächst gegen eine Endogenität der Stimmrechtsstrukturvariablen spricht.

\subsubsection{Granger- und Durbin-Wu-Hausman-Test}

Im Folgenden soll das Vorliegen von Endogenität noch einmal mittels spezieller Testverfahren überprüft werden. Dazu wird zunächst der GrangerKausalitätstest herangezogen. ${ }^{1065}$ Die Vorgehensweise des Tests ist wie folgt: Sofern die Variable MWBW einen Einfluss auf StA1 ausübt, sollten Veränderungen des MWBW Veränderungen in StA1 bewirken. Diese werden sich immer dann ergeben, wenn in einer Regression von StAl auf vergangene Werte von StA1, die Ergänzung vergangener Werte von MWBW signifikant zum Erklärungsgehalt der Regression beiträgt. ${ }^{1066}$ Für das vorliegende Datensample kann die Nullhypothese, dass zwischen MWBW und StA1 eine Kausalität besteht, für die um ein bzw. zwei Jahre verzögerten Werte in beide Richtungen nicht abgelehnt werden:

\begin{tabular}{lcccccc}
\hline \multicolumn{7}{c}{ Granger Kausalitätstest } \\
\hline & \multicolumn{2}{c}{ Lags: 1 } & \multicolumn{2}{c}{ Lags: 2} & \multicolumn{2}{c}{ Lags: 3 } \\
Nullhypothese & F-Stat. & p-Wert & F-Stat. & p-Wert & F-Stat. & p-Wert \\
\hline $\begin{array}{l}\text { MWBW hat keinen kau- } \\
\text { salen Einfluss auf StA1 }\end{array}$ & 0,509 & 0,476 & 0,461 & 0,631 & 3,066 & 0,029 \\
$\begin{array}{l}\text { StA1 hat keinen kausalen } \\
\text { Einfluss auf MWBW }\end{array}$ & 1,142 & 0,286 & 0,912 & 0,403 & 4,832 & 0,003 \\
\hline
\end{tabular}

Tab. 43: Granger Kausalitätstest

Für die um drei Jahre verzögerten Werte wird die Nullhypothese, dass der Stimmrechtsanteil keinen kausalen Einfluss auf das Marktwert/BuchwertVerhältnis ausübt, eindeutig abgelehnt. Für den umgekehrten Zusammenhang

1064 So begründet Wiwattanakantang (2001), dass in seinem Datensample Endogenität keine Rolle spiele. Vgl. S. 358.

1065 Vgl. Granger (1969), erläuternd Eckey/Kosfeld/Dreger (2001), S. 362-365; Köke (2002), S. 15; Greene (2003), S. 592f.

1066 Vgl. Greene (2003), S. 592; Börsch-Supan/Köke (2002), S. 300f., jeweils auch mit einer formalen Darstellung der verschiedenen Testgleichungen. Die Nullhypothese, dass keine Kausalität zwischen den Variablen steht, wird mit Hilfe eines F-Tests überprüft. 
wird $\mathrm{H}_{0}$ ebenfalls abgelehnt, jedoch weniger signifikant. Insgesamt deuten die in allen Fällen niedrigeren p-Werte für die Kausalität von StA1 nach MWBW darauf hin, dass der Einfluss eher vom Stimmrechtsanteil zur Marktbewertung verläuft als umgekehrt. Eine eindeutige Annahme oder Ablehnung der Endogenitätshypothese ist anhand der Ergebnisse des Granger-Tests jedoch nicht möglich.

Im Folgenden soll daher zusätzlich der Durbin-Wu-Hausman-Test auf Endogenität eingesetzt werden. ${ }^{1067}$ Der Durbin-Wu-Hausman-Test überprüft die Konsistenz der mit Hilfe eines OLS-Schätzers erzielten Ergebnisse, wenn Endogenität vorliegen könnte. Sind die Ergebnisse der OLS-Schätzung nicht konsistent, ist die Verwendung von Instrumentalvariablen erforderlich. Der Test geht so vor, dass zunächst die potenziell endogenen Variablen (hier StA1 bzw. StA1sq) auf alle exogenen Regressoren regressiert und die Residuen gespeichert werden. Am Beispiel von StA1 gilt:

$$
\begin{aligned}
S t A 1_{i t}= & \alpha+\beta_{1} U_{i t}+\beta_{2} I V G_{i t}+\beta_{3} V G_{i t}+\beta_{4} \text { Beta }_{i t}+\beta_{5} A I_{i t} \\
& +\beta_{6} W_{i t}+\sum_{j=1}^{J} \beta_{j 7} \text { Branche }_{j i}+\sum_{t=1}^{T} \beta_{t 8} \text { Jahr }_{t}+u_{i t}
\end{aligned}
$$

Die Residuen dieser Schätzung (RES01) werden dann in die Schätzung des Modells einbezogen, für das überprüft werden soll, ob Endogenität vorliegt. Hier wird Modell $3 \mathrm{c}$ herangezogen, das wie folgt geschätzt wird:

$$
\begin{aligned}
M W B W_{i t}= & \alpha+\gamma_{1} S t A 1_{i t}+\gamma_{2} S t A 1 s q_{i t}+\gamma_{3} I V G_{i t}+\gamma_{4} A I_{i t}+\gamma_{5} W_{i t} \\
& +\gamma_{6} \text { IASUSG }_{i t}+\sum_{j=1}^{J} \gamma_{j 7} \text { Branche }_{j i}+\sum_{t=1}^{T} \gamma_{t 8} J a h r_{t} \\
& +\gamma_{9} \text { RESOI }_{i t}+u_{i t}
\end{aligned}
$$

Sofern $\gamma_{9}$ signifikant von null verschieden ist, führt eine OLS-Schätzung zu inkonsistenten Ergebnissen. Der t-Wert des Koeffizienten von RES01 beträgt 0,518. Die Nullhypothese, dass $\gamma_{9}$ gleich null ist, wird mit einem p-Wert von 0,605 unabhängig vom Signifikanzniveau nicht verworfen. ${ }^{1068}$ Der Endogeni-

${ }^{1067}$ Vgl. auch Cronqvist/Nilsson (2002), S. 17. Verschiedene Tests mit ähnlicher Zielsetzung finden sich in der Literatur als „Hausman-Tests“ wieder und basieren auf der Arbeit von Hausman (1978). In der hier spezifizierten Form werden Ansätze von $W u$ (1981) und Durbin (1954) mit berücksichtigt, sodass sich die Bezeichnung Durbin-Wu-HausmanTest herausgebildet hat. Vgl. Davidson/MacKinnon (1993), S. 237. Ausführlich zum Testverfahren dort S. 237-242.

${ }^{1068}$ Die Ergebnisse der beiden Regressionen sind in Anhang C (Tab. A 20) ausgewiesen. 
tätstest nach Durbin-Wu-Hausman deutet somit, ebenso wie die mit umgekehrter Kausalität durchgeführten Regressionsschätzungen, nicht darauf hin, dass eine Endogenität von StA1 die Ergebnisse der OLS-Schätzungen verzerren könnte. Dementsprechend sollten Schätzverfahren, die einer möglichen Endogenität explizit Rechnung tragen, nicht zu wesentlich geänderten Ergebnissen führen. Um dieses zu überprüfen, wird im Folgenden ein Stabilitätstest mit dem Two-StageLeast-Squares-Verfahren (2SLS) durchgeführt. Diese Art von Verfahren kommt in verschiedenen Eigentümerstrukturstudien zur Anwendung. ${ }^{1069}$

\subsubsection{Stabilitätstest mit 2SLS}

Für ein simultanes Gleichungssystem, das mit Hilfe von 2SLS geschätzt werden soll, müssen zunächst die beiden Gleichungssysteme unter Berücksichtigung der erforderlichen Instrumentalvariablen spezifiziert werden. Instrumentalvariablen sollten dadurch gekennzeichnet sein, dass sie mit der (potenziell) endogenen Variablen stark korreliert sind, jedoch nicht mit den Störvariablen; dass sie also nicht gleichzeitig einen Einfluss auf den Regressanden ausüben. Vorteil der 2SLS-Methode ist, dass sie aus der Gesamtheit der exogenen Variablen sowie zusätzlich hinzugefügter Instrumentalvariablen diejenigen mit dem höchsten Erklärungsgehalt herausfiltert. Es ist daher nicht erforderlich, etwa für die Variable StA1 eine einzige Instrumentalvariable zu spezifizieren. Vielmehr werden als Instrumentalvariablen alle in der ursprünglich zu schätzenden Gleichung exogenen Variablen herangezogen sowie zusätzlich exogene Variablen, denen ein hoher Erklärungsgehalt für die endogene Variable beigemessen wird. ${ }^{1070}$

Hinsichtlich der Variablenauswahl basiert die 2SLS-Regression (Modell 6) auf Modell 3c:

$$
\begin{aligned}
M W B W_{i t}= & \alpha_{i}+\gamma_{1} S_{t A l_{i t}}+\gamma_{2} S t A 1 s q_{i t}+\gamma_{3} I V G_{i t}+\gamma_{4} A I_{i t}+\gamma_{5} W_{i t} \\
& +\gamma_{6} I A S U S G+\sum_{i=1}^{I} \gamma_{j 7} \text { Branche }_{i}+\sum_{i=1}^{I} \gamma_{j 8} J a h r_{i}+u_{i t}
\end{aligned}
$$

Als Instrumente für die Variablen StA1 und StA1sq werden die exogenen Variablen der obigen Schätzung herangezogen sowie die Variablen, die in Modell 5b

1069 Simultane Gleichungssysteme werden z. B. von Loderer/Martin (1997); Cho (1998); Bohren/Odegaard (2001); Demsetz/Villalonga (2001) und Lins (2003) eingesetzt.

${ }^{1070}$ Hinsichtlich der Variablenauswahl in verschiedenen Literaturbeiträgen ist kritisch anzumerken, dass die Zuordnung der exogenen Variablen zu den Gleichungssystemen regelmäßig wenig theoriegestützt erfolgt. Vgl. auch die kritischen Anmerkungen von Bohren/Odegaard (2001), S. 33, die feststellen: „As there exists no proper theoretical basis for establishing instruments, we test out three different instrument sets and find that the qualitative conclusions are sensitive to the choice of instruments". 
einen hohen Erklärungsgehalt für den Stimmrechtsanteil des größten Aktionärs entwickelt haben (VG, U, Beta, Jahres-Dummies). Zusätzlich werden verzögerte Werte von StA1 und StA1sq als Instrumente genutzt. ${ }^{1071}$ Um die Gleichung identifizierbar zu gestalten, muss die Anzahl der einbezogenen Instrumente mindestens so groß sein wie die Anzahl der Koeffizienten in der zu schätzenden Gleichung. Ergänzend werden daher auch die Branchen-Dummies hinzugezogen. Die Ergebnisse der 2SLS-Schätzung sind in der folgenden Tabelle wiedergegeben:

\begin{tabular}{|c|c|c|c|c|}
\hline \multirow{2}{*}{$\begin{array}{l}\text { Abhängige Vari- } \\
\text { able: MWBW } \\
\text { Erklärende } \\
\text { Variablen: }\end{array}$} & \multicolumn{4}{|c|}{ Modell 6} \\
\hline & Koeffizient & Std.-fehler & t-Wert & p-Wert \\
\hline$c$ & 4,693 & 1,978 & $* * 2,373$ & 0,018 \\
\hline$S t A l$ & $-0,747$ & 0,284 & $* * *-2,628$ & 0,009 \\
\hline StAlsq & 0,363 & 0,084 & $* * * 4,337$ & 0,000 \\
\hline$A I$ & 0,002 & 0,002 & 1,292 & 0,200 \\
\hline$I V G$ & $-0,021$ & 0,010 & $* *-2,049$ & 0,041 \\
\hline$W$ & 0,000 & 0,000 & $* * * 6,562$ & 0,000 \\
\hline IASUSG & 0,373 & 0,191 & $* 1,951$ & 0,052 \\
\hline \multicolumn{5}{|c|}{$\begin{array}{ll}\text { Instrumentalvariablen: } & c, \text { StA(-1), StAsq(-1), VG, U, IVG, Beta, AI, W, } \\
& \text { IASUSG, Branchen-Dummies, Jahres-Dummies } \\
\end{array}$} \\
\hline$r^{2}$ & 0,255 & \multirow{4}{*}{\multicolumn{3}{|c|}{$\begin{array}{l}\text { Die nicht ausgewiesenen Branchen- } \\
\text { Dummies liefern überwiegend schwach } \\
\text { signifikante Ergebnisse, die Jahres- } \\
\text { Dummies sind nicht signifikant. }\end{array}$}} \\
\hline Adj. $\mathbf{r}^{2}$ & 0,233 & & & \\
\hline$\hat{\sigma}$ & 0,919 & & & \\
\hline F-Statistik & Dummies sind nicht signitikant. & & & \\
\hline $\begin{array}{l}\text { p-Wert } \\
\text { (F-Statistik) }\end{array}$ & \multicolumn{4}{|l|}{0,000} \\
\hline
\end{tabular}

Tab. 44: Regressionsergebnisse Modell 6

Die Ergebnisse der zweistufigen Schätzung steigern das $r^{2}$ im Vergleich zu Modell $3 \mathrm{c}$ von $21,2 \%$ auf $25,5 \%$, die erklärenden Stimmrechtsstrukturvariablen sind weiterhin hoch signifikant mit den erwarteten Vorzeichen, die t-Werte fast aller Regressoren steigen leicht an. Der positive Erklärungsgehalt deutet auf eine

1071 Die Verwendung von ,lagged values“ als Instrumentalvariablen bietet sich insb. in den Fällen an, in denen andere Instrumente schwer zu identifizieren sind bzw. aufgrund von Datenmängeln nicht beschafft werden können. Die Aktionärsstruktur des Jahres 1 ist in der Regel mit der des Jahres 0 korreliert, ohne jedoch mit den Störtermen korreliert zu sein. Vgl. Börsch-Supan/Köke (2002), S. 304f. 
sachgerechte Auswahl der Instrumentalvariablen hin. ${ }^{1072}$ Ein Vergleich mit den Schätzergebnissen von Modell 3c zeigt nur marginale Veränderungen der Koeffizienten. Der Stabilitätstest mittels 2SLS bestätigt somit die Aussagefähigkeit der OLS-Ergebnisse ebenfalls.

\subsubsection{Zwischenfazit}

Die alternativen Verfahren bestätigen durchgängig einen zunächst negativen Einfluss steigender Stimmrechtsanteile auf die Marktbewertung, der ab einem Anteil von etwa drei Viertel der Stimmrechte wieder positiv wird. Verschiedene Testverfahren bestätigen keine die Aussagefähigkeit von OLS-Schätzungen einschränkende Endogenität. Schätzverfahren, die diese explizit berücksichtigen wie die 2SLS-Methode, führen zu Ergebnissen, die sich nur geringfügig von den mittels OLS erzielten unterscheiden. Mit Hilfe von Fixed-Effects-Schätzungen konnte kein signifikanter Zusammenhang erzielt werden, was aufgrund der geringen Schwankung der Stimmrechtsanteile über den Untersuchungszeitraum jedoch plausibel erklärbar ist.

Im Ergebnis werden somit Hypothese la und 1c bestätigt, am deutschen Kapitalmarkt ist für die Jahre 1997 - 2000 ein hochsignifikanter nichtlinearer Zusammenhang zwischen Stimmrechtsbündelungen und Unternehmenserfolg nachweisbar. Das $r^{2}$ der gesamten Regression liegt jeweils um $20 \%$, was insgesamt unbefriedigend ist, jedoch dem Niveau anderer Value-Relevance-Studien entspricht. Im Folgenden sollen die weiteren Hypothesen auf ihre Gültigkeit überprüft werden. Die zu testenden Variablen sind ebenso wie StA1 Ausdruck der Eigentümer- und/oder Stimmrechtsstruktur. Sie unterliegen vergleichbaren Schwankungen und entwickeln sich im Zeitablauf weitgehend parallel. ${ }^{1073} \mathrm{Da}$ die verschiedenen Analysen am Beispiel der Variablen StA1 keine Hinweise auf gravierende Endogenitätsprobleme ergeben haben, sollen die weiteren Betrachtungen auf Basis von OLS-Schätzungen erfolgen. Dabei wird analog zu Modell 3 der Panel-Datensatz zugrunde gelegt und das Korrekturverfahren von NeweyWest eingesetzt.

1072 In verschiedenen empirischen Studien mit simultanen Gleichungssystemen geht hingegen der Erklärungsgehalt im Vergleich zu Einzelschätzungen deutlich zurück, was in der Regel mit unzulänglichen Instrumentalvariablen begründet wird. Vgl. etwa Agrawal/Knoeber (1996); Cho (1998); Demsetz/Villalonga (2001); Bohren/Odegaard (2001).

1073 Vgl. hierzu die deskriptiven Auswertungen zu den verschiedenen Variablen in Kapitel IV.3.1. 


\subsubsection{Einfluss sonstiger Eigentümerstrukturvariablen auf den Unter- nehmenserfolg}

\subsubsection{Konzentrationsmaße}

Nachdem bisher ausschließlich der Stimmrechtsanteil des größten Aktionärs betrachtet wurde, sollen im Folgenden alternative Maßgrößen der Eigentümer- und Stimmrechtskonzentration im Rahmen der Regression eingesetzt werden. Mit der Variablen StA1 wurde der Stimmrechtsanteil bisher in kardinal skalierter Form in die Regression einbezogen. Alternativ werden in verschiedenen Studien Dummy-Variablen eingesetzt, die den Stimmrechtsanteil verschiedenen Klassen zuordnen. ${ }^{1074}$ Dazu werden hier die Variablen StA0_5 $(0 \% \leq \mathrm{StA}<5 \%)$, StA5_25 $(5 \% \leq \mathrm{StA}<25 \%)$, StA25_50 $(25 \% \leq \mathrm{StA}<50 \%)$, StA50_75 $(50 \%$ $\leq \mathrm{StA}<75 \%$ ) und StA75_100 (StA $\geq 75 \%)$ genutzt. Die Ergebnisse bestätigen wie erwartet den signifikant negativen Einfluss mittelgroßer und großer Stimmrechtsbündelungen: ${ }^{1075}$

\begin{tabular}{lrrrr}
\hline $\begin{array}{l}\text { Abhängige Vari- } \\
\text { able: MWBW }\end{array}$ & \multicolumn{4}{c}{ Modell 7a } \\
\cline { 2 - 5 } $\begin{array}{l}\text { Erklärende } \\
\text { Variablen: }\end{array}$ & Koeffizient & Std.-fehler & t-Wert & p-Wert \\
\hline StA5_25 & 0,065 & 0,213 & 0,303 & 0,762 \\
StA25_50 & $-0,483$ & 0,134 & $* * *-3,610$ & 0,000 \\
StA50_75 & $-0,429$ & 0,117 & $* * *-3,671$ & 0,000 \\
StA75_100 & $-0,352$ & 0,120 & $* * *-2,938$ & 0,003 \\
\hline
\end{tabular}

Die nicht ausgewiesenen Kontrollvariablen sowie die Jahres- und Branchen-Dummies liefern überwiegend schwach signifikante Ergebnisse.

Tab. 45: Regressionsergebnisse Modell $7 a$

Der Einfluss kleinerer Stimmrechtsbündelungen ist demnach positiv, wenngleich nicht signifikant, die Koeffizienten der anderen Kontrollklassen sind hoch signifikant negativ, wenngleich die Signifikanz der am stärksten konzentrierten Klasse wieder abnimmt.

Eine alternative Maßgröße für die Anteilseignerkonzentration ist der HerfindahlIndex der Stimmrechtsanteile (HStA), der in Modell $7 \mathrm{~b}$ als erklärende Variable herangezogen wird. Die in Anhang C (Tab. A 21) ausgewiesenen Schätzergebnisse weisen einen schwach signifikanten, positiven Einfluss auf das Markt-

1074 Vgl. etwa Lamba/Stapledon (2001), S. 14; Wiwattanakantang (2001), S. 349.

1075 StA0_5 fungiert als Referenzgruppe und wird daher nicht mitgeschätzt. Das $r^{2}$ der Schätzung liegt bei $22,6 \%\left(\operatorname{adj} . r^{2}=20,2 \%\right)$. 
wert/Buchwert-Ergebnis aus, wenn der Herfindahl-Index nur in linearer Form in die Regression einbezogen wird. In nichtlinearer Form bestätigt sich der bereits bekannte Verlauf der Regression, der auf einen zunächst negativen Einfluss zusätzlicher Stimmrechtskumulation hindeutet, der ab einem bestimmten Anteil wieder positiv wird. Die Koeffizienten sind jedoch nicht signifikant. Die Ursache hierfür könnte in der Berechnungsweise des Herfindahl-Index liegen. ${ }^{1076}$ Sie führt dazu, dass gerade sehr große Stimmrechtsanteile mit überproportional hohen Indexwerten verbunden sind. Dies könnte begründen, dass der negative Einfluss, der sich bei der Variablen StA1 für mittlere bis große Kapitalanteile ergeben hat, nicht in gleichem Maße auch für den Herfindahl-Index zum Tragen kommt. Zudem berücksichtigt der Herfindahl-Index die Stimmrechtsanteile nicht nur eines sondern aller Großaktionäre. Es könnte sich daher ein eventuell positiver Einfluss weiterer Großaktionäre auswirken, was im Folgenden näher zu untersuchen sein wird. Eine Nutzung von Eigen- und Gesamtkapitalrendite als abhängige Variable brachte ebenfalls keine signifikanten Ergebnisse.

Neben den Stimmrechtsanteilen sind die Kapitalanteile Ausdruck der Anteilseignerkonzentration. Dabei wurde im Rahmen der Hypothesenbildung vermutet, dass sich ein zwischen Stimmrechtsanteilen und Unternehmenserfolg ergebender negativer Zusammenhang in abgeschwächter Form für die Kapitalanteile bestätigen wird. Ein abgeschwächter Verlauf wäre zu erwarten, da mit Kapitalbündelungen in stärkerem Maße positiv wirkende Kontrollanreize verbunden sind als mit (reinen) Stimmrechtsbündelungen. Die empirischen Ergebnisse bestätigen die theoretischen Überlegungen. Zwischen dem Kapitalanteil des größten direkt beteiligten Großaktionärs und dem Marktwert/Buchwert-Verhältnis ergibt sich ein nichtlinearer Zusammenhang von geringerer Signifikanz als unter Verwendung der Stimmrechtsvariablen. Der Koeffizient des Kapitalanteils KAD1 liegt bei $-1,121$ ( $\mathrm{p}$-Wert $=0,080$ ), der des quadrierten Anteils KAD1sq bei 0,856 ( $p$-Wert $=0,128$ ). Hypothese $1 \mathrm{~b}$ wird somit ebenfalls bestätigt. Die vollständigen Regressionsergebnisse von Modell 7c sind in Anhang C (Tab. A 22) ausgewiesen.

\subsubsection{Multiple Großaktionäre}

Theoretische Überlegungen ${ }^{1077}$ deuten ebenso wie verschiedene empirische Untersuchungen auf internationalen Kapitalmärkten ${ }^{1078}$ darauf hin, dass das Vorhandensein eines oder mehrerer weiterer Großaktionäre neben dem größten Ak-

\footnotetext{
1076 Vgl. Kapitel IV.2.3.1.2.1.

1077 Vgl. Zwiebel (1995); Pagano/Röell (1998); Bennedsen/Wolfenzon (2000); Edwards/Weichenrieder (2000).

1078 Vgl. Edwards/Weichenrieder (2000); Gutiérrez/Tribó (2002); Maury/Pajuste (2002).
} 
tionär einen positiven Einfluss auf die Unternehmenskontrolle ausübt. Zur Überprüfung dieser Hypothese bieten sich erneut verschiedene Variablen an. Zunächst kann die Existenz eines weiteren Großaktionärs über eine DummyVariable abgebildet werden. Die hier verwandte Variable GA2 ist gleich eins, wenn neben dem Aktionär mit den meisten Stimmrechten ein weiterer Aktionär mindestens drei Viertel der Stimmrechte des größten Aktionärs oder einen Stimmrechtsanteil von mindestens $25 \%$ hält. Voraussetzung ist außerdem, dass kein Aktionär die Stimmrechtsmehrheit hält. Dieses Kriterium soll gewährleisten, dass der Einfluss des zweiten Großaktionärs tatsächlich groß genug ist, um die Aktivitäten des größten Aktionärs zu kontrollieren. Die Regressionsergebnisse bestätigen den erwartet positiven Einfluss eines solchen Aktionärs jedoch nicht. Der Koeffizient der Dummy-Variablen GA2 ist nicht signifikant bei negativem Vorzeichen. Die Regressionsergebnisse von Modell 7d sind in Anhang C (Tab. A 23) ausgewiesen.

Zieht man alternativ den Stimmrechtsanteil des zweitgrößten Aktionärs (StA2) als kardinal skalierte Variable zusätzlich zur Variable StA1 in die Regression mit ein (Modell 7e), bestätigt sich das Ergebnis der Dummy-basierten Analyse, dass ein zweiter großer Aktionär am deutschen Kapitalmarkt keinen positiven Einfluss auf den Unternehmenserfolg ausübt. Wird StA2 ausschließlich in linearer Form einbezogen (Variante 1), ist der Koeffizient bei negativem Vorzeichen schwach signifikant, das Vorzeichen von StA1 ist nach wie vor negativ, jedoch nicht mehr signifikant. Bezieht man StA1 und StA2 jeweils zusätzlich in quadrierter Form in die Schätzung mit ein (Variante 2), so ergibt sich für den Anteil des zweitgrößten Aktionärs ein nichtlinearer Zusammenhang mit negativem Vorzeichen für StA2 und negativem für StA2sq; wenngleich beide nicht signifikant sind. Die Koeffizienten von StAl und StAlsq sind beide nicht signifikant negativ. ${ }^{1079}$

Zieht man die Summe der Stimmrechtsanteile der vier größten Aktionäre (SStA4) als Regressor heran (Modell 7f), so ergibt sich ebenfalls ein negatives Vorzeichen. Die Variable entfaltet jedoch keinen signifikanten Erklärungsgehalt, sodass die Ergebnisse hier nicht weiter betrachtet werden. ${ }^{1080}$

Im Ergebnis muss die Gültigkeit von Hypothese 3 für das vorliegende Untersuchungssample klar abgelehnt werden. Ein positiver Einfluss weiterer Großaktionäre neben dem größten Aktionär auf den Unternehmenserfolg konnte nicht festgestellt werden. Die verschiedenen Variablen deuten stattdessen auf einen

\footnotetext{
1079 Die Ergebnisse beider Schätzungen von Modell 7e sind ebenfalls in Anhang C ausgewiesen (Tab. A 24).

${ }^{1080}$ Gleiches gilt für die Summe der Kapitalanteile der vier größten Aktionäre (SKAD4).
} 
negativen Einfluss auch dieser zusätzlichen Großaktionäre hin, wobei die Ergebnisse keine bzw. nur geringe Signifikanz aufweisen. Interpretiert man den eher negativen Einfluss zusätzlicher Großaktionäre vorsichtig, so könnte man eine Koalitionsbildung zwischen den Großaktionären vermuten. Alternativ wäre auch denkbar, dass sich die verschiedenen Aktionäre gegenseitig bei der Durchsetzung sinnvoller Entscheidungen blockieren.

\subsubsection{Identität des Großaktionärs}

An verschiedenen Stellen wurde bereits darauf hingewiesen, dass unterschiedliche Großaktionärstypen möglicherweise über unterschiedlich starke Anreize verfügen, entweder ihre Kontrollfunktion wahrzunehmen oder aber im eigenen Interesse nutzenmaximierend zu agieren und private benefits $\mathrm{zu}$ vereinnahmen. Sofern den theoretischen Überlegungen für das vorliegende Untersuchungssample Gehalt zukommt, sollte sich ein unterschiedlicher Einfluss verschiedener Aktionärstypen auf den Unternehmenserfolg nachweisen lassen.

Für die empirische Überprüfung der Relevanz der Identität des größten Aktionärs bieten sich zwei Varianten an. Einmal kann die Identität in Form von Dummy-Variablen in der Regression erfasst werden, alternativ wird die Schätzung separat für die verschiedenen, nach Aktionärstypen differenzierten Teilsamples durchgeführt.

Zunächst wird die Identität des größten Aktionärs über Dummy-Variablen berücksichtigt. Modellgrundlage ist erneut Modell 3c, die Dummy-Variablen für die Branche werden durch die Identitätskennungen ersetzt. Die Regressionsergebnisse sind in Tab. 46 ausgewiesen: ${ }^{1081}$ Die Ergebnisse deuten auf einen auf dem 5 \%-Niveau signifikanten positiven Einfluss von Industrie- bzw. Dienstleistungsunternehmen als Großaktionär hin. Für natürliche Personen und Ausländer wird ebenfalls ein schwach signifikant positiver Einfluss diagnostiziert. Die anderen Dummy-Variablen sind nicht signifikant, der Koeffizient von Finanzintermediären ist jedoch negativ.

${ }^{1081}$ Als Referenzgruppe dient die Gruppe der Unternehmen, deren Großaktionär Ausländer ist. 


\begin{tabular}{|c|c|c|c|c|}
\hline \multirow{2}{*}{$\begin{array}{l}\text { Abhängige Variable: } \\
\text { MWBW } \\
\text { Erklärende } \\
\text { Variablen: }\end{array}$} & \multicolumn{4}{|c|}{ Modell 8a - Variante I } \\
\hline & Koeffizient & Std.-fehler & t-Wert & p-Wert \\
\hline$c$ & 1,252 & 0,163 & $* * * 7,675$ & 0,000 \\
\hline StAl & $-0,771$ & 0,259 & $* * *-2,970$ & 0,003 \\
\hline StAlsq & 0,380 & 0,078 & $* * * 4,859$ & 0,000 \\
\hline$A I$ & 0,004 & 0,002 & $* * * 2,731$ & 0,007 \\
\hline$I V G$ & $-0,008$ & 0,004 & $*-1,690$ & 0,091 \\
\hline$W$ & 0,000 & 0,000 & $* * * 3,612$ & 0,000 \\
\hline IASUSG & 0,301 & 0,175 & $* 1,716$ & 0,087 \\
\hline Ausländer & 0,193 & 0,113 & $* 1,706$ & 0,089 \\
\hline Familie & 0,068 & 0,108 & 0,629 & 0,530 \\
\hline Finanzintermediär & $-0,031$ & 0,125 & $-0,250$ & 0,803 \\
\hline Industrieunternehmen & 0,307 & 0,120 & $* * 2,563$ & 0,011 \\
\hline Management & 0,243 & 0,151 & 1,612 & 0,107 \\
\hline Natürliche Person & 1,188 & 0,674 & $* 1,763$ & 0,078 \\
\hline Offentliche Hand & 0,055 & 0,183 & 0,301 & 0,763 \\
\hline $\mathbf{r}^{2}$ & 0,115 & \multirow{5}{*}{\multicolumn{3}{|c|}{$\begin{array}{l}\text { Nicht ausgewiesene Jahres- } \\
\text { Dummies sind nicht signifikant. }\end{array}$}} \\
\hline Adj. $\mathbf{r}^{2}$ & 0,099 & & & \\
\hline$\hat{\sigma}$ & 0,929 & & & \\
\hline F-Statistik & 7,031 & & & \\
\hline p-Wert (F-Statistik) & 0,000 & & & \\
\hline
\end{tabular}

Tab. 46: Regressionsergebnisse Modell 8a-Variante I

Aufgrund der teilweise schwierigen Zuordnung der Großaktionäre zu den einzelnen Klassen und der nicht überschneidungsfreien Abgrenzung insbesondere zwischen Management, natürlichen Personen und Familien wird in einer weiteren Schätzung (Variante II von Modell 8a) eine Klassifizierung genutzt, die ausschließlich zwischen Industrieunternehmen, Finanzintermediären, öffentlicher Hand und einer zusammengefassten Gruppe aus Management, natürlichen Personen und Familien differenziert. Die Schätzergebnisse bestätigen erneut den signifikant positiven Einfluss von Industrieunternehmen (signifikant auf dem $1 \%$-Niveau); Finanzintermediäre behalten ihr negatives Vorzeichen. Die zusammengefasste Gruppe von Management, natürlichen Personen und Familien übt einen auf dem $5 \%$-Niveau signifikanten, positiven Einfluss auf das Marktwert/Buchwert-Verhältnis aus. Gleiches gilt für ausländische Aktionäre. ${ }^{1082}$

${ }^{1082}$ Die Schätzergebnisse werden in Tab. A 25 in Anhang C ausgewiesen. 
Im Folgenden werden Teilsamples differenziert nach der Identität des größten Aktionärs gebildet und jeweils auf die Variablen StA1, IVG, AI, W, IASUSG sowie die Jahres-Dummies regressiert (Modell 8b). Diese Vorgehensweise erlaubt eine Aussage darüber, wie sich Stimmrechtsbündelungen spezifischer Anteilseignertypen auswirken. So wäre es beispielsweise denkbar, dass sich der beobachtete nichtlineare Verlauf nicht für alle Aktionärsgruppen ergibt. Daher wird für die verschiedenen Teilsamples jeweils eine Regression geschätzt, in der StA1 nur in linearer Form einbezogen wird, in einer weiteren Schätzung wird StA1 zusätzlich in quadrierter Form berücksichtigt. Die Ergebnisse der verschiedenen, in Anhang $\mathrm{C}$ ausgewiesenen Schätzungen sind überwiegend nicht signifikant. ${ }^{1083}$ Der positive Einfluss von Industrieunternehmen als Großaktionär wird jedoch erneut bestätigt. Der bekannte nichtlineare Verlauf findet sich in den meisten Fällen ebenfalls. Für Beteiligungen der öffentlichen Hand sind die Koeffizienten von StA1 und StA1sq beide negativ, sodass hier auch größere Beteiligungen keinen positiven Einfluss auszuüben scheinen. Kleinere Stimmrechtsanteile von Familien üben hingegen einen positiven Einfluss aus, größere jedoch einen negativen. Aufgrund der fehlenden Signifikanz der Koeffizienten sowie der teilweise kleinen Teilsamples sollten die Ergebnisse der TeilsampleSchätzungen jedoch nicht überinterpretiert werden.

Im Ergebnis kann festgehalten werden, dass die Beteiligung von Industrieunternehmen als Großaktionär einen positiven Einfluss auf den Unternehmenserfolg auszuüben scheint; Hypothese $4 \mathrm{~d}$ wird somit bestätigt. Dieses könnte auf eine erhöhte Sachkompetenz branchenverwandter Unternehmen bei der Kontrollausübung zurückzuführen sein. Alternativ könnten neben der Beteiligung bestehende Beziehungen der Unternehmen untereinander eine Realisierung von private benefits verhindern. Positiven Einfluss übt auch die Beteiligung von natürlichen Personen und Ausländern aus, womit Hypothese $4 \mathrm{c}$ bestätigt und Hypothese $4 \mathrm{f}$ verworfen wird. Für weitere Aktionärsgruppen sind die Ergebnisse weniger eindeutig. Bei Beteiligungen von Finanzintermediären sind die Ergebnisse zwar nicht signifikant, weisen jedoch in den verschiedenen Modellvarianten jeweils negative Vorzeichen auf. Eindeutige Ergebnisse sind daher nicht ableitbar, wenngleich die negativen Vorzeichen ein Indiz für einen eher negativen Einfluss dieses Großaktionärstyps auf den Unternehmenserfolg entsprechend der Hypothese $4 \mathrm{e}$ sein könnte. Die kritische Sichtweise gerade von Beteiligungen durch Kreditinstitute würde demnach bestätigt, was die Vermutung einer möglichen Interessenkollision aufgrund zusätzlicher Kreditengagements stützen könnte. Für die anderen Großaktionärstypen sind die Ergebnisse nicht eindeutig genug, um Aussagen ableiten zu können, sodass die Hypothesen zum Einfluss von Fa-

${ }^{1083} \mathrm{Vgl}$. Tab. A 26. Ausgewiesen werden die Koeffizienten sowie die zugehörigen t-Werte für die Variablen StA1 und StA1sq. 
milien (4a), Management (4b) und der öffentlichen Hand (4g) weder bestätigt noch verworfen werden können.

\subsubsection{Relevanz der Indexzugehörigkeit}

Im Folgenden soll untersucht werden, ob der Einfluss der Stimmrechtsstruktur auf den Unternehmenserfolg abhängig ist von der Indexzugehörigkeit des Unternehmens. Es wird daher das bewährte Modell 3b für zwei separate Teilsamples erneut regressiert (Modell 9). Dabei umfasst das erste Sample die 59 Unternehmen des DAX100 und das zweite die 179 kleineren CDAX-Gesellschaften. ${ }^{1084}$ Die Schätzergebnisse für beide Teilsamples gibt Tab. 47 wieder.

\begin{tabular}{|c|c|c|c|c|c|c|c|c|}
\hline & \multicolumn{4}{|c|}{ Modell 9 (Sample: DAX100) } & \multicolumn{4}{|c|}{ Modell 9 (Sample: CDAX-Rest) } \\
\hline & $\begin{array}{c}\text { Koef- } \\
\text { fi- } \\
\text { zient }\end{array}$ & $\begin{array}{l}\text { Std.- } \\
\text { fehler }\end{array}$ & t-Wert & p-Wert & $\begin{array}{c}\text { Koeffi- } \\
\text { zient }\end{array}$ & $\begin{array}{l}\text { Std.- } \\
\text { fehler }\end{array}$ & t-Wert & p-Wert \\
\hline$c$ & 14,564 & 4,346 & $* * * 3,351$ & 0,001 & 2,996 & 0,470 & $* * * 6,373$ & 0,000 \\
\hline StAl & $-2,510$ & 1,675 & $-1,499$ & 0,136 & $-0,369$ & 0,155 & $* *-2,381$ & 0,018 \\
\hline StAlsq & 1,602 & 1,672 & 0,958 & 0,339 & 0,284 & 0,054 & $* * * 5,293$ & 0,000 \\
\hline$A I$ & $-0,037$ & 0,017 & $*-2,234$ & 0,027 & 0,002 & 0,001 & $* 1,806$ & 0,071 \\
\hline$I V G$ & $-0,013$ & 0,011 & $-1,154$ & 0,250 & $-0,000$ & 0,005 & $-0,022$ & 0,982 \\
\hline$U$ & $-0,261$ & 0,151 & $*-1,723$ & 0,087 & $-0,091$ & 0,024 & $* * *-3,761$ & 0,000 \\
\hline$V G$ & $-0,035$ & 0,041 & $-0,869$ & 0,386 & $-0,001$ & 0,002 & $-0,654$ & 0,514 \\
\hline$W$ & 0,011 & 0,006 & ${ }^{*} 1,848$ & 0,067 & 0,000 & 0,000 & $* * 2,394$ & 0,017 \\
\hline IASUSG & 0,258 & 0,279 & 0,925 & 0,356 & 0,111 & 0,098 & 1,136 & 0,257 \\
\hline $\mathbf{r}^{2}$ & & 0,594 & & & 0,242 & & & \\
\hline Adj. $r^{2}$ & & 0,535 & & & 0,216 & & & \\
\hline$\hat{\sigma}$ & & 1,200 & & & 0,539 & & & \\
\hline F-Statistik & & 9,941 & & & 9,125 & & & \\
\hline $\begin{array}{l}\text { p-Wert } \\
\text { (F-Statistil }\end{array}$ & & 0,000 & & & 0,000 & & & \\
\hline
\end{tabular}

Tab. 47: Regressionsergebnisse Modell 9

${ }^{1084}$ Um eine ausreichende Samplegröße zu gewährleisten werden die Unternehmen des DAX und des MDAX zusammengefasst. 
Der nichtlineare Einfluss des Stimmrechtsanteils des größten Aktionärs wird für die großen ebenso wie für die kleinen Unternehmen bestätigt. Für die großen Gesellschaften des DAX100 ist der Zusammenhang jedoch nicht signifikant, wohingegen für die kleinen Unternehmen hochgradig signifikante Ergebnisse erzielt werden. Berücksichtigt man die deskriptiven Ergebnisse aus Kapitel IV.3.1.4.4 so wird deutlich, dass der erwartete nichtlineare Zusammenhang somit insbesondere für das Teilsample festgestellt werden kann, dessen Unternehmen durch eine deutlich höhere Anteilseignerkonzentration gekennzeichnet sind als die der Vergleichsgruppe. Wird der quadratische Term in der Regression für das DAX100-Sample unberücksichtigt gelassen, so ergibt sich ein negativer Einfluss der Variablen StA1 (Koeffizient: -0,736, t-Wert: -1,502).

Betrachtet man den durch das $\mathrm{r}^{2}$ gemessenen gesamten Erklärungsgehalt der Regressionen, so wird deutlich, dass die im Rahmen dieser Studie gewählten Kontrollvariablen für die Unternehmen des DAX100 einen deutlich höheren Erklärungsgehalt entfalten als für die kleineren Unternehmen. Während für die DAX100-Unternehmen die Variabilität des Marktwert/Buchwert-Verhältnisses zu $60 \%$ durch die einbezogenen Variablen erklärt werden kann, so liegt der Vergleichswert für die Kontrollgruppe bei $24,2 \%$, was in etwa dem Durchschnitt der zuvor durchgeführten Regressionen für das Gesamtsample entspricht. Die Marktbewertung kleinerer Unternehmen wird demnach stärker durch hier nicht berücksichtigte Faktoren determiniert. Alternativ könnte vermutet werden, dass die Informationsverarbeitung des Kapitalmarktes für kleinere Unternehmen weniger effizient ist.

\subsubsection{Einfluss abweichender Stimm- und Cash-Flow-Rechte auf den Unternehmenswert}

\subsubsection{Excess Votes}

Auf Basis der theoretischen Überlegungen ebenso wie unter Berücksichtigung der Ergebnisse internationaler Studien wäre ein negativer Einfluss divergierender Stimm- und Cash-Flow-Rechte auf den Unternehmenserfolg zu erwarten. ${ }^{1085}$ Als kardinal skalierte Variable, die auch die Stärke der Abweichung von Kapital- und Stimmrechtsanteil misst, wurde die Kennzahl Excess Votes eingeführt, die den Prozentsatz angibt, um den der Stimmrechtsanteil des größten Aktionärs

\footnotetext{
1085 Vgl. Claessens et al. (1999); Guedes/Loureiro (2002); Gugler et al. (2002); Lins (2003); Mitton (2002).
} 
dessen Kapitalanteil übersteigt. ${ }^{1086}$ Sie wird im Rahmen von Modell 10a als zusätzliche erklärende Variable herangezogen:

\begin{tabular}{|c|c|c|c|c|}
\hline \multirow{2}{*}{$\begin{array}{l}\text { Abhängige Vari- } \\
\text { able: MWBW } \\
\text { Erklärende } \\
\text { Variablen: }\end{array}$} & \multicolumn{4}{|c|}{ Modell 10a } \\
\hline & Koeffizient & Std.-fehler & t-Wert & p-Wert \\
\hline$c$ & 4,029 & 1,712 & $* * 2,354$ & 0,019 \\
\hline$E V$ & 0,000 & 0,000 & $-0,405$ & 0,685 \\
\hline StAl & $-0,624$ & 0,231 & $* * *-2,696$ & 0,007 \\
\hline StAlsq & 0,353 & 0,067 & $* * * 5,249$ & 0,000 \\
\hline$A I$ & 0,003 & 0,002 & $* 1,717$ & 0,086 \\
\hline$I V G$ & $-0,017$ & 0,009 & $*_{-1,790}$ & 0,074 \\
\hline$W$ & 0,000 & 0,000 & $* * * 2,709$ & 0,007 \\
\hline IASUSG & 0,375 & 0,198 & $* * 1,895$ & 0,059 \\
\hline $\mathbf{r}^{2}$ & 0,212 & \multirow{5}{*}{\multicolumn{3}{|c|}{$\begin{array}{l}\text { Nicht ausgewiesene Jahres- und } \\
\text { Branchen-Dummies sind nicht } \\
\text { bzw. schwach signifikant. }\end{array}$}} \\
\hline Adj. $\mathbf{r}^{2}$ & 0,192 & & & \\
\hline$\hat{\sigma}$ & 0,880 & & & \\
\hline F-Statistik & 10,487 & & & \\
\hline $\begin{array}{l}\text { p-Wert } \\
\text { (F-Statistik) }\end{array}$ & 0,000 & & & \\
\hline
\end{tabular}

Tab. 48: Regressionsergebnisse Modell 10a

Die Ergebnisse lassen entgegen den Erwartungen nicht eindeutig darauf schließen, dass überproportionale Stimmrechte mit einem geringeren Marktwert/Buchwert-Verhältnis einhergehen. Der Koeffizient für die Excess Votes weist zwar das erwartet negative Vorzeichen auf, ist jedoch nicht signifikant. Signifikante Ergebnisse ergeben sich auch nicht, nachdem versuchsweise Ausreißer bereinigt wurden und nur stark überproportionale Stimmrechte in die Analyse einbezogen wurden.

Ergänzend wird nicht die Höhe der Abweichung zwischen Stimm- und CashFlow-Rechten analysiert, sondern Unternehmen werden mit Hilfe von DummyVariablen in Abhängigkeit davon klassifiziert, ob bei Ihnen divergierende Stimm- und Cash-Flow-Rechte vorliegen oder nicht. So wäre es theoretisch denkbar, dass zwar kein Zusammenhang zwischen der Höhe der Divergenz und dem Unternehmenserfolg nachweisbar ist, dass jedoch Unternehmen in Abhän-

1086 Ähnliche Variablen verwenden auch Claessens et al. (1999); Cronqvist/Nilsson (2002); Guedes/Loureiro (2002), sowie Lins (2003). 
gigkeit dieses Kriteriums vom Kapitalmarkt unterschiedlich bewertet werden. ${ }^{1087}$ Es werden daher verschiedene Dummy-Variablen für überproportionale Stimmrechte gebildet. Neben dem reinen Vorhandensein von Excess Votes werden auch verschiedene Kategorien hinsichtlich der Ausprägung der überproportionalen Stimmrechte berücksichtigt. Die Ergebnisse sind jedoch durchweg nicht signifikant.

Der Kapitalmarkt scheint somit überproportionale Stimmrechte, gleich welcher Intensität, nicht mit Bewertungsabschlägen zu sanktionieren - zumindest besteht kein signifikanter Zusammenhang zwischen dem Ausmaß der Divergenz und dem Unternehmenserfolg. Auch ein Einfluss überproportionaler Stimmrechte auf die buchwertbezogenen Renditen ist nicht nachweisbar; der Zusammenhang zwischen Excess Votes und Eigen- bzw. Gesamtkapitalrendite ist ebenfalls nicht signifikant. Hypothese 2a, die besagt, dass überproportionale Stimmrechtsbündelungen einen negativen Einfluss auf den Unternehmenserfolg ausüben, kann somit nicht bestätigt werden.

Die Ergebnisse sind vor dem Hintergrund der theoretischen Überlegungen ebenso wie auf Basis bisheriger empirischer Forschungsergebnisse überraschend. $\mathrm{Zu}$ berücksichtigen ist jedoch, dass bisherige Untersuchungen, die einen negativen Einfluss abweichender Stimm- und Cash-Flow-Rechte nachgewiesen haben, fast ausschließlich in Ländern mit schwach ausgeprägten Aktionärsschutzbestimmungen durchgeführt wurden. ${ }^{1088}$ Cronqvist/Nilsson (2002), die den schwedischen Kapitalmarkt mit einer ähnlichen Variablen untersuchen, finden hingegen ebenfalls keine signifikanten Ergebnisse. ${ }^{1089}$

\subsubsection{Vorzugsaktien und Pyramiden}

Im Folgenden sollen die beiden Ursachen abweichender Stimm- und CashFlow-Rechte, Vorzugsaktien und Konzernpyramiden, separat betrachtet werden. Es ist theoretisch denkbar, dass zwar die Existenz überproportionaler Stimmrechte insgesamt keinen negativen Einfluss ausübt, dass jedoch eine Differenzie-

${ }^{1087}$ Zur Verwendung von Dummy-Variablen zur Analyse divergierender Stimm- und CashFlow-Rechte vgl. auch Lins (2003), S. 165; Wiwattanakantang (2001), S. 352; Gugler et al. (2002), S. 22.

1088 Vgl. Claessens et al. (1999) für Ostasien; Gugler et al. für 61 Nationen; Mitton (2002) für Ostasien; Volpin (2002) für Italien; Lemmon/Lins (2003) für Ostasien; Lins (2003) für 18 Entwicklungsländer.

1089 Vgl. Cronqvist/Nilsson (2002), S. 31. Die internationale Vergleichsstudie von La Porta et $a l$. bescheinigt Schweden einen etwas besseren Aktionärsschutz als Deutschland. Vgl. La Porta et al. (1998), S. 1130f. Keine signifikanten Ergebnisse unter Verwendung einer ähnlichen Variable finden auch Wiwattanakantang (2001); Mitton (2002). 
rung der Analyse nach Instrumenten die Analyse weiter bringt. Im Rahmen von Modell 10b wird zunächst analysiert, ob die Tatsache, dass ein Unternehmen Bestandteil einer Konzernpyramide ist, einen Einfluss auf das Marktwert/Buchwert-Verhältnis ausübt. Die Ergebnisse von Modell 10b finden sich in der folgenden Tabelle:

\begin{tabular}{lrrrr}
\hline $\begin{array}{l}\text { Abhängige Vari- } \\
\text { able: MWBW }\end{array}$ & \multicolumn{5}{c}{ Modell 10b } \\
\cline { 2 - 5 } $\begin{array}{l}\text { Erklärende } \\
\text { Variablen: }\end{array}$ & Koeffizient & Std.-fehler & t-Wert & p-Wert \\
\hline$c$ & 4,032 & 1,707 & $* * 2,363$ & 0,018 \\
$P Y$ & $-0,055$ & 0,063 & $-0,872$ & 0,385 \\
StAI & $-0,610$ & 0,223 & $* * *-2,730$ & 0,007 \\
StAlsq & 0,350 & 0,069 & $* * * 5,040$ & 0,000 \\
AI & 0,003 & 0,002 & $* 1,738$ & 0,083 \\
$I V G$ & $-0,017$ & 0,009 & $*-1,829$ & 0,068 \\
$W$ & 0,000 & 0,000 & $* * * 2,635$ & 0,009 \\
IASUSG & 0,371 & 0,198 & $* 1,876$ & 0,061 \\
\hline $\mathbf{r}^{2}$ & 0,213 & \multicolumn{4}{c}{ Nicht ausgewiesene Jahres- und } \\
Adj. $\mathbf{r}^{2}$ & 0,192 & Branchen-Dummies sind nicht \\
$\hat{\sigma}$ & 0,879 & bzw. schwach signifikant. & \\
F-Statistik & 10,519 & & & \\
p-Wert & 0,000 & & & \\
(F-Statistik) & & & & \\
\hline
\end{tabular}

Tab. 49: Regressionsergebnisse Modell 10b

Der Koeffizient der Dummy-Variablen PY ist entsprechend der formulierten Hypothese $2 \mathrm{~b}$ negativ, jedoch nicht signifikant. ${ }^{1090}$ Die Ergebnisse deuten mit einem $t$-Wert von $-0,872$ jedoch zumindest darauf hin, dass Unternehmen, die Bestandteil verschachtelter Konzerstrukturen sind, vom Kapitalmarkt geringer bewertet werden. Dies würde die negative Wahrnehmung der "Deutschland $\mathrm{AG}^{\text {“ }}$ in der Öffentlichkeit empirisch stützen. Da die Ergebnisse nicht signifikant sind, kann eine solche Aussage jedoch nicht zweifelsfrei abgeleitet werden.

Im Folgenden soll analysiert werden, ob die Tatsache, dass ein Unternehmen durch die Emission von Vorzugsaktien vom Prinzip des One-Share-One-Vote abweicht, Einfluss auf den Unternehmenserfolg hat. Die Dummy-Variable VA

${ }^{1090}$ Die gleiche Vorgehensweise wählt auch Wiwattanakantang für den thailändischen Kapitalmarkt, der jedoch ebenfalls keine signifikanten Ergebnisse erzielt. Vgl. Wiwattanakantang (2001), S. 352. 
ist somit gleich eins, wenn ein Unternehmen mehr als eine Aktiengattung aufweist. Die in der nachfolgenden Tabelle wiedergegebenen Regressionsergebnisse von Modell 10c legen jedoch nahe, dass auch dieses Instrument zur Schaffung überproportionaler Stimmrechte keinen eindeutigen Einfluss auf den Unternehmenserfolg hat:

\begin{tabular}{|c|c|c|c|c|}
\hline \multirow{2}{*}{$\begin{array}{l}\text { Abhängige Vari- } \\
\text { able: MWBW } \\
\text { Erklärende } \\
\text { Variablen: }\end{array}$} & \multicolumn{4}{|c|}{ Modell 10c } \\
\hline & Koeffizient & Std.-fehler & t-Wert & p-Wert \\
\hline$c$ & 4,003 & 1,664 & $* * 2,405$ & 0,016 \\
\hline$V A$ & 0,192 & 0,148 & 1,302 & 0,193 \\
\hline StAl & $-0,659$ & 0,245 & $* * *-2,691$ & 0,007 \\
\hline StAlsq & 0,363 & 0,075 & $* * * 4,840$ & 0,000 \\
\hline$A I$ & 0,002 & 0,002 & 1,467 & 0,143 \\
\hline$I V G$ & $-0,017$ & 0,009 & $*-1,828$ & 0,068 \\
\hline$W$ & 0,000 & 0,000 & $* * * 2,715$ & 0,007 \\
\hline$I A S U S G$ & 0,374 & 0,195 & ${ }^{*} 1,916$ & 0,056 \\
\hline $\mathbf{r}^{2}$ & 0,219 & \multirow{5}{*}{\multicolumn{3}{|c|}{$\begin{array}{l}\text { Nicht ausgewiesene Jahres- und } \\
\text { Branchen-Dummies sind nicht } \\
\text { bzw. schwach signifikant. }\end{array}$}} \\
\hline Adj. $\mathbf{r}^{2}$ & 0,199 & & & \\
\hline$\hat{\sigma}$ & 0,876 & & & \\
\hline F-Statistik & 10,914 & & & \\
\hline $\begin{array}{l}\text { p-Wert } \\
\text { (F-Statistik) }\end{array}$ & 0,000 & & & \\
\hline
\end{tabular}

Tab. 50: Regressionsergebnisse Modell 10c

Der Koeffizient des Vorzugsaktien-Dummies VA ist nicht signifikant, weist jedoch entgegen den Erwartungen ein positives Vorzeichen auf. Es findet somit trotz der negativen Wahrnehmung von Vorzugsaktien in der Öffentlichkeit keine Sanktionierung der Unternehmen, die sie nutzen, durch den Kapitalmarkt statt. Die zusätzliche Betrachtung des Einflusses auf Eigen- und Gesamtkapitalrendite liefert ebenfalls keine signifikanten Ergebnisse. Die Gestaltung der Eigenkapitalstruktur scheint somit entgegen den Erwartungen am deutschen Kapitalmarkt keinen Einfluss auf den Unternehmenserfolg auszuüben.

Im Ergebnis liefert auch die Betrachtung von Dummy-Variablen keine eindeutigen Aussagen über den Einfluss abweichender Stimm- und Cash-Flow-Rechte auf den Erfolg der Sample-Unternehmen; die Hypothesen 2b und 2c können weder eindeutig bestätigt noch verworfen werden. Bei Hypothese $2 b$, die einen negativen Einfluss von Pyramiden auf den Unternehmenserfolg erwarten ließ, entspricht jedoch zumindest die Richtung des Einflusses den Erwartungen. Der aus den theoretischen Überlegungen abgeleitete Anreiz zur Generierung von 
private benefits für Großaktionäre, die in höherem Maße über Stimmrechte als über Cash Flows verfügen, ist jedoch offensichtlich nicht so groß, als dass er sich in einem signifikant geringeren Erfolg der Unternehmen niederschlagen würde. Zwar üben Stimmrechtsbündelungen grundsätzlich einen negativen Einfluss aus, dieser scheint sich jedoch nicht signifikant zu verstärken, wenn damit unterproportionale Kapitalanteile verbunden sind. Im Rahmen der theoretischen Analyse wurde argumentiert, dass die Gefahr eines negativen Einflusses überproportionaler Stimmrechte aus Sicht der Minderheitsaktionäre in Volkswirtschaften besonders groß ist, die über schwach ausgeprägte Aktionärsschutzbestimmungen verfügen. Dies bestätigen auch bisherige empirische Analysen. ${ }^{1091}$ Die Tatsache, dass diese Mechanismen für die Sampleunternehmen nicht mit einem signifikant geringeren Unternehmenserfolg verbunden sind, könnte somit dahingehend interpretiert werden, dass die Aktionärsschutzbestimmungen am deutschen Kapitalmarkt zumindest so gut sind, dass sie verhindern, dass Großaktionäre mit überproportionalen Stimmrechten signifikant mehr private benefits realisieren können, als andere Großaktionäre. Alternativ wäre denkbar, dass ein unzureichendes Informationsniveau der Kapitalmarktteilnehmer eine Reaktion in die erwartete Richtung verhindert.

\subsubsection{Kernergebnisse der Regressionsanalysen}

Zielsetzung der vorangegangenen Analyse war die Identifikation von Zusammenhängen zwischen der Eigentümer- und Stimmrechtsstruktur börsennotierter deutscher Aktiengesellschaften und dem Unternehmenserfolg. Für die Untersuchung wurde ein Panel-Datensatz mit 238 Unternehmen über die Jahre 1997 2000 herangezogen. Eingesetzt wurden ökonometrische Verfahren, mittels derer eine eventuelle Endogenität der abhängigen Stimmrechtsstrukturvariablen identifiziert und behandelt werden kann. Im Einzelnen wurden folgende zentrale Ergebnisse erzielt:

- Zwischen dem Stimmrechtsanteil des größten Aktionärs und dem Unternehmenserfolg gemessen durch das Marktwert/Buchwert-Verhältnis besteht ein hoch signifikanter nichtlinearer Zusammenhang. Zunehmende Stimmrechtskonzentrationen wirken sich für kleinere und mittlere Anteile negativ aus, erst wenn der Großaktionär mehr als zwei Drittel der Stimmrechte inne hat, hat eine zunehmende Konzentration wieder einen positiven Einfluss.

- Die Ergebnisse werden unter Verwendung verschiedener Verfahren bestätigt (Querschnittsanalyse, Panel-Studie, 2SLS). Der durch das $\mathrm{r}^{2}$ gemessene Er-

${ }^{1091}$ Vgl. Gugler/Stomper/Zechner (2000); Zingales (1994); Aganin/Volpin (1998); Lins (2003); Claessens et al. (1999); Barca/Becht (2001); La Porta et al. (2002). 
klärungsgehalt der verschiedenen Regressionen liegt in der Regel zwischen $20 \%$ und $25 \%$. Bei einer ausschließlichen Betrachtung der im DAX100 notierten Sample-Unternehmen steigt es auf 59,4\% an. Die Verwendung eines Fixed-Effects-Schätzers leistet hingegen keinen sinnvollen Beitrag zur Erklärung des Einfluss der Eigentümerstruktur auf den Unternehmenserfolg.

- Der nichtlineare Einfluss des Stimmrechtsanteils des größten Aktionärs wird für die im DAX100 notierten Gesellschaften ebenso bestätigt wie für die kleinen Unternehmen. Für die DAX100-Unternehmen ist der Zusammenhang jedoch nicht signifikant, wohingegen für die kleinen Unternehmen hochgradig signifikante Ergebnisse erzielt werden.

- Die Analyse einer potenziell umgekehrten Kausalität zeigt, dass das Marktwert/Buchwert-Verhältnis im Rahmen einer multivariaten Regressionsanalyse keinen signifikanten Einfluss auf den Stimmrechtsanteil des größten Aktionärs entfaltet. Auch der Granger-Kausalitätstest und der Durbin-WuHausman-Test können die Vermutung einer Endogenität nicht eindeutig belegen. Signifikant negativen Einfluss auf den Stimmrechtsanteil des größten Aktionärs üben hingegen die Unternehmensgröße, der Verschuldungsgrad und der Betafaktor aus.

- Für im Verhältnis zum Kapitalanteil überproportionale Stimmrechte konnte kein signifikanter Einfluss auf den Unternehmenserfolg nachgewiesen werden. Das negative Vorzeichen der Excess Votes könnte jedoch auf einen eher negativen Zusammenhang hindeuten. Auch die Zugehörigkeit eines Unternehmens zu einer Konzernpyramide oder die Nutzung von Vorzugsaktien übt keinen signifikanten Einfluss aus. Betrachtet man die Vorzeichen der Variablenkoeffizienten, so könnten Pyramiden einen eher negativen, Vorzugsaktien einen eher positiven Einfluss auf den Unternehmenserfolg ausüben.

- Die Identität des größten Aktionärs scheint für die Richtung des Einflusses auf den Erfolg Relevanz zu besitzen. Ein Industrie- bzw. Dienstleistungsunternehmen als größter Aktionär übt einen signifikant positiven Einfluss auf das Marktwert/Buchwert-Verhältnis aus. Positiven Einfluss auf die Kapitalmarktbewertung üben auch natürliche Personen und Ausländer als Großaktionär aus. Für andere Aktionärstypen sind die Ergebnisse weniger eindeutig, deuten jedoch für Finanzintermediäre auf einen negativen Einfluss hin.

- Hinsichtlich des Aussagegehaltes der Eigentümer- bzw. Stimmrechtsstruktur für den Unternehmenserfolg muss abschließend kritisch festgehalten werden, dass ein solcher nur für den am Kapitalmarkt bewerteten Erfolg, gemessen durch das Marktwert/Buchwert-Verhältnis, konstatiert werden konnte. Für die 
buchwertbezogenen Rentabilitätskennziffern Eigen- und Gesamtkapitalrendite konnten keine signifikanten Ergebnisse erzielt werden.

Die folgende Tabelle fasst die formulierten Hypothesen und die erzielten Ergebnisse noch einmal zusammen:

\section{Hypothese}

Vorzeichen Signi-
erw. ist fikanz

1a Zwischen Stimmrechtsbündelungen bei Großaktionären und Unternehmenserfolg besteht ein Zusammenhang

1b Zwischen Kapitalbündelungen bei Großaktionären und Unternehmenserfolg besteht ein Zusammenhang

1c Zwischen Stimmrechtsbündelungen bei Großaktionären und -/+ -/+ Unternehmenserfolg besteht ein nichtlinearer Zusammenhang

1d Zwischen Kapitalbündelungen bei Großaktionären und Unter- -/+ nehmenserfolg besteht ein nichtlinearer Zusammenhang

2a Stimmrechtsbündelungen, die nicht von entsprechenden CashFlow-Bündelungen begleitet werden, haben einen negativen Einfluss auf den Unternehmenserfolg

2b Die Einbindung eines Unternehmens in eine Konzernpyramide hat einen negativen Einfluss auf den Unternehmenserfolg

2c Unternehmen mit Stamm- und Vorzugsaktien weisen einen geringeren Unternehmenserfolg auf als solche, die nur Stammaktien haben

3 Die Präsenz mehrerer großer Aktionäre, von denen keiner eine Stimmrechtsmehrheit hält, hat einen positiven Einfluss auf den Unternehmenserfolg

4a Ein Großaktionär in Form eines Familienmitglieds hat einen negativen Einfluss auf den Unternehmenserfolg

4b Kapitalblöcke in den Händen des Managements haben einen Einfluss auf den Unternehmenserfolg

4c Kapitalblöcke in den Händen von natürlichen Personen haben einen positiven Einfluss auf den Unternehmenserfolg

4d Ein Großaktionär in Form eines Industrieunternehmens hat einen positiven Einfluss auf den Unternehmenserfolg

4e Ein Großaktionär in Form eines Finanzintermediärs hat einen negativen Einfluss auf den Unternehmenserfolg

$4 \mathbf{f}$ Kapitalblöcke in den Händen von Ausländern haben einen negativen Einfluss auf den Unternehmenserfolg

$4 \mathrm{~g}$ Kapitalblöcke in den Händen der öffentlichen Hand haben einen negativen Einfluss auf den Unternehmenserfolg

*/*****: signifikant auf dem 10\%-, $5 \%$-, $1 \%$-Niveau

Tab. 51: Zusammenfassung der Hypothesen und Ergebnisse 


\section{Zusammenfassung der Ergebnisse und Ausblick}

\section{Thesenförmige Zusammenfassung}

Ziel der vorliegenden Arbeit war es, einen möglicherweise vorliegenden $\mathrm{Zu}$ sammenhang zwischen der Eigentümer- bzw. Stimmrechtsstruktur börsennotierter Aktiengesellschaften und dem Unternehmenserfolg am deutschen Kapitalmarkt theoretisch und empirisch zu untersuchen. Hiermit sollte die vielfach emotional geführte Diskussion um die Beteiligungsstrukturen innerhalb der sogenannten „Deutschland AG“ wissenschaftlich objektiviert werden. Zentraler Untersuchungsgegenstand war neben der grundsätzlichen Analyse von Blockbildungen auch die Betrachtung divergierender Stimm- und Cash-Flow-Rechte.

Die folgenden Thesen fassen den Gedankengang sowie die wichtigsten Ergebnisse sowohl der theoretischen als auch der empirischen Analyse zusammen:

- Die Aktiengesellschaft als Rechtsform ist von ihrer Konstruktion her grundsätzlich geeignet, die Interessen aller Aktionäre gleichermaßen zu berücksichtigen. Die Rechte und Interessen des Aktionärs werden durch verschiedene Schutzregelungen des Aktiengesetzes gesichert und über die Hauptversammlung können die Aktionäre durch ihre Entscheidungsbefugnis in Grundsatzfragen - zumindest de jure - eine Kontrolle über das Management ausüben.

- Die unter Berücksichtigung der Koordinationsstrukturen innerhalb der Aktiengesellschaft de facto vorhandenen Anreize der Aktionäre zur Einflussnahme auf die Unternehmenspolitik lassen die de jure gegebenen Einflussmöglichkeiten dennoch wenig wirksam erscheinen. Als Instrumentarium zur theoretischen Analyse der Anreizstrukturen wird hier die Neue Institutionenökonomik gewählt, da sie hinsichtlich ihrer Vorgehensweise (methodologischer Individualismus) und Verhaltensannahmen (begrenzte Rationalität, individuelle Nutzenmaximierung, unvollkommene Märkte, Informationsasymmetrien) in der Realität beobachtbare Handlungen besser abbildet, als neoklassisch geprägte Modelle.

- Die Einflussnahme von Aktionären auf die Unternehmenspolitik wird im Rahmen dieser Arbeit mit dem Begriff Aktionärskontrolle beschrieben. Aktionärskontrolle als auf das Management gerichtete Kontrolle durch die Aktionäre beinhaltet dabei neben einer Ex-post-Kontrolle insbesondere auch die Beeinflussung unternehmerischer Grundsatzentscheidungen. Ihre Ausübung erfolgt über das Drohpotenzial der „Exit-“ oder die Wahrnehmung der 
„Voice-Option“ des Aktionärs, sodass sie Element sowohl der internen als auch der externen Corporate Governance des Unternehmens ist.

- In Publikumsgesellschaften ergibt sich die Notwendigkeit für eine Aktionärskontrolle aus der bereits seit langem diskutierten Trennung von Eigentum und Verfügungsmacht. Für angestellte Manager bestehen Anreize, im Eigeninteresse nutzenmaximierend zu Lasten der Aktionäre zu agieren, was aufgrund geringer Kontrollanreize von den Kleinaktionären nur begrenzt verhindert wird (Free-Rider-Problem).

- Die resultierende rationale Apathie der Kleinaktionäre führt dazu, dass Aktionärskontrolle nur unzureichend ausgeübt wird. Als alternative Managementkontrollinstrumente stehen verschiedene, marktorientierte und unternehmensinterne Mechanismen zur Verfügung, deren Bedeutung und Wirksamkeit von der Beschaffenheit des Kapitalmarktes sowie der internen Corporate Governance eines Landes abhängen. Bisher vorliegende empirische Ergebnisse deuten jedoch darauf hin, dass sie weder einzeln noch in ihrer Summe geeignet sind, unmittelbare Aktionärskontrolle vollständig zu substituieren.

- Das Kontrolldefizit ist potenziell in Unternehmen geringer, die einen Großaktionär haben, dessen Kapitalanteil so groß ist, dass er ihm einen ausreichenden monetären Anreiz zur Ausübung der Monitoringfunktion bietet.

- Solange Großaktionäre ihre Kontrollfunktion tatsächlich wahrnehmen, ist ihre Präsenz in der Gesellschaft auch im Interesse der Kleinaktionäre (Interessenkonvergenzhypothese). Probleme entstehen jedoch, wenn der Großaktionär sein Einflusspotenzial nicht zur Wahrnehmung der Aktionärskontrolle sondern zur Realisierung privater Vorteile nutzt (Ausbeutungshypothese).

- Diese konfliktären Theorien prognostizieren in unterschiedlicher Art und Weise die Wirkung von Großaktionären auf den Unternehmenserfolg. Die Nichtlinearitätshypothese als Kombination von Interessenkonvergenz- und Ausbeutungshypothese geht von einer homogenen Interessenlage aller Eigenkapitalgeber erst ab einem bestimmten Kapitalanteil aus, der ausreichende monetäre Anreize zur Ausübung der Kontrollfunktion verspricht, sodass sich ein nichtlinearer Zusammenhang zwischen Aktionärsstruktur und Unternehmenserfolg ergibt.

- Besonderen Einfluss auf die Anreizstruktur des Großaktionärs übt das Verhältnis von Stimm- und Cash-Flow-Rechten aus. Durch die Emission von Vorzugsaktien kommen den Stammaktionären im Verhältnis zum Kapitalanteil überproportionale Stimmrechte zu. Darüber hinaus werden Eigenkapitalpyramiden genutzt, die den Großaktionären des Mutterunternehmens durch 
den stufenweisen Erwerb von Beteiligungen den Einfluss über alle Unternehmen der Pyramide mit nur einmaligem Kapitaleinsatz sichern. Somit können einzelne Aktionäre die Kontrolle über die Gesellschaft innehaben, ohne jedoch auch über eine Kapitalmehrheit zu verfügen. Die Interessenkonvergenzhypothese basiert jedoch auf dem monetären Anreiz des Großaktionärs zur Kontrollausübung, der sich aus seiner hohen Partizipation an den ausschüttbaren Cash Flows ergibt. Aus der theoretischen Argumentation ist daher ein geringerer Monitoringanreiz bei erhöhtem Anreiz zur Realisierung von private benefits für den Fall überproportionaler Stimmrechte des Großaktionärs abzuleiten.

- Die Transparenz über Aktionärsstrukturen in Deutschland ergibt sich im Wesentlichen aus dem WpHG. Eine Offenlegungspflicht besteht jedoch erst ab einem Stimmrechtsanteil von $5 \%$; bis die Meldung über eine Veränderung des Stimmrechtsanteils den Kapitalmarkt erreicht, vergehen bis zu 16 Tage. Eine empirische Analyse der freiwilligen Berichterstattung über die Aktionärsstruktur in den $2001 \mathrm{er}$ Geschäftsberichten der DAX100-Unternehmen hat ergeben, dass viele - insbesondere der großen Gesellschaften - Angaben zur Aktionärsstruktur machen. Die Angaben sind jedoch oft sehr unpräzise und wenig detailliert.

Im Rahmen der empirischen Analyse wurde zunächst die Bedeutung von Blockbildungen sowie von divergierenden Stimm- und Cash-Flow-Rechten einer deskriptiven Analyse unterzogen. Anschließend wurde der Zusammenhang zwischen Eigentümer- bzw. Stimmrechtsstruktur und Unternehmenserfolg mit Hilfe einer multivariaten Regressionsanalyse anhand eines Panel-Datensatzes untersucht. Das Sample umfasst 238 deutsche börsennotierte NichtFinanzdienstleister, die während des gesamten Untersuchungszeitraums von 1997 - 2000 ununterbrochen im CDAX notiert waren. Unter Berücksichtigung der restriktiven Prämissen eines solchen Untersuchungsdesigns und der nur eingeschränkten Verallgemeinerbarkeit für alle Unternehmen lassen sich die folgenden Aussagen ableiten:

- Die Kontrolle deutscher Aktiengesellschaften liegt in vielen Fällen in der Hand eines oder weniger großer Aktionäre. 83,6\% der Sampleunternehmen hatten Ende 2000 einen Aktionär mit einem Stimmrechtsanteil von mindestens $25 \%$. Bei mehr als der Hälfte befanden sich die Stimmrechte im Mehrheitsbesitz $(59,7 \%)$ und $32,4 \%$ wiesen sogar einen Aktionär mit einem Stimmrechtsanteil von über $75 \%$ auf. Der durchschnittliche Stimmrechtsanteil des größten direkt beteiligten Aktionärs lag im Jahr 2000 bei 58,4 \% (Me$\operatorname{dian}=53,0 \%$ ). Die Betrachtung im Zeitablauf deutet auf eine leichte Zunahme der Stimmrechtskonzentration hin. 
- Der größte Aktionär wird in der Regel durch ein anderes Industrieunternehmen gestellt (35,3\% in 2000); Finanzintermediäre spielen als Großaktionär eine geringere Bedeutung als die öffentliche Diskussion vermuten lassen könnte $(10,7 \%)$. Im Zeitablauf zurückgegangen ist die Bedeutung von öffentlicher Hand und Familien, die im Jahr 2000 1,4 \% bzw. 24,2 \% der größten Aktionäre stellten.

- Eine differenzierte Betrachtung von Cash-Flow- und Stimmrechten zeigt erhebliche Abweichungen. Der durchschnittliche Kapitalanteil des größten Aktionärs liegt bei $51,6 \%$, und ist damit $13,2 \%$ geringer als die von ihm kontrollierten Stimmrechte. Über die Hälfte der Sampleunternehmen nutzen entweder Pyramiden (32,8\% in 2000) oder Vorzugsaktien (24,4\%); der Gebrauch letzterer ist jedoch im Zeitablauf rückläufig.

- Eine große Bedeutung haben Vorzugsaktien nach wie vor in Familienunternehmen, die zu 46,3\% ein gespaltenes Aktienkapital aufweisen. Konzernpyramiden sind hingegen häufig anzutreffen, wenn ein Finanzintermediär die Kontrolle innehat $(46,1 \%)$.

- Die Kapital- und Stimmrechtsbündelung tritt in kleineren Unternehmen deutlich stärker zu Tage als in den Unternehmen des DAX100. Der Median des Stimmrechtsanteil des größten Aktionärs ist bei den kleineren CDAXUnternehmen mit $60,0 \%$ mehr als dreimal so groß wie bei den DAXUnternehmen (18,6\%). Die Großaktionäre der Unternehmen mit großer Marktkapitalisierung nutzen jedoch in besonderem Maße Vorzugsaktien zur Erhöhung ihres Kontrollpotenzials.

Neben der deskriptiven Analyse der Eigentümer- und Stimmrechtsstrukturen wurde der Zusammenhang zum Unternehmenserfolg mit folgenden zentralen Ergebnissen analysiert:

- Zwischen dem Stimmrechtsanteil des größten Aktionärs und dem Unternehmenserfolg gemessen durch das Marktwert/Buchwert-Verhältnis besteht ein hoch signifikanter nichtlinearer Zusammenhang. Zunehmende Stimmrechtskonzentrationen wirken sich für kleinere und mittlere Anteile negativ aus, erst wenn der Großaktionär mehr als zwei Drittel der Stimmrechte innehat, scheint eine zunehmende Konzentration wieder einen positiven Einfluss auszuüben. Dieses Ergebnis wird unter Verwendung verschiedener Verfahren bestätigt (Querschnittsanalyse, Panel-Studie, 2SLS). Die Verwendung eines FixedEffects-Schätzers bringt diesbezüglich hingegen keine signifikanten Ergebnisse. Der nichtlineare Zusammenhang bestätigt sich auch bei einer Differenzierung nach Indexzugehörigkeit für beide Teilsamples, wobei er jedoch nur 
für die kleineren, nicht im DAX100 notierten Unternehmen, die durch vergleichsweise große Anteilseignerkonzentration gekennzeichnet sind, signifikant ist.

- Die Erklärung des Stimmrechtsanteils des größten Aktionärs mittels einer multivariaten Regressionsanalyse zeigt keinen signifikanten Einfluss des durch das Marktwert/Buchwert-Verhältnis abgebildeten Unternehmenserfolgs auf die Stimmrechtskonzentration, sodass die Vermutung einer umgekehrten Kausalität nicht bestätigt wird. Der Stimmrechtsanteil des größten Aktionärs wird stattdessen durch die Unternehmensgröße sowie das sich in Betafaktor und Verschuldungsrad widerspiegelnde unternehmensindividuelle Risiko determiniert. Großaktionäre sind signifikant häufiger in kleineren Unternehmen mit geringem Risiko anzutreffen. Auch der Granger-Kausalitätstest und der Durbin-Wu-Hausman-Test können die Vermutung einer Endogenität nicht eindeutig belegen.

- Für im Verhältnis zum Kapitalanteil überproportionale Stimmrechte konnte entgegen der Erwartung kein signifikanter Einfluss auf den Unternehmenserfolg nachgewiesen werden. Das negative Vorzeichen der Excess Votes könnte jedoch auf einen eher negativen Zusammenhang hindeuten. Auch die Zugehörigkeit eines Unternehmens zu einer Konzernpyramide oder die Nutzung von Vorzugsaktien übt keinen signifikannten Einfluss aus. Betrachtet man die Vorzeichen der Variablenkoeffizienten, so könnten Pyramiden einen eher negativen, Vorzugsaktien einen eher positiven Einfluss auf den Unternehmenserfolg ausüben.

- Die Identität des größten Aktionärs scheint für die Art des Einflusses auf den Erfolg Relevanz zu besitzen. Ein Industrie- bzw. Dienstleistungsunternehmen als größter Aktionär übt ebenso wie ausländische Aktionäre und natürliche Personen einen signifikant positiven Einfluss auf das Marktwert/BuchwertVerhältnis aus. Für andere Aktionärstypen sind die Ergebnisse weniger eindeutig, deuten jedoch für Finanzintermediäre auf einen negativen Einfluss hin.

- Hinsichtlich des Aussagegehaltes der Eigentümer- bzw. Stimmrechtsstruktur für den Unternehmenserfolg muss abschließend kritisch festgehalten werden, dass ein solcher nur für den am Kapitalmarkt bewerteten Erfolg, gemessen durch das Marktwert/Buchwert-Verhältnis, konstatiert werden konnte. Für die buchwertbezogenen Rentabilitätskennziffern Eigen- und Gesamtkapitalrendite konnten keine signifikanten Ergebnisse erzielt werden. 


\section{Rechtspolitische Schlussfolgerungen und Ausblick}

Nachdem die zentralen Aussagen und Ergebnisse der vorliegenden Arbeit noch einmal zusammengefasst wurden, stellt sich die Frage nach den daraus eventuell resultierenden rechtspolitischen Schlussfolgerungen.

Die öffentliche Wahrnehmung der durch Großaktionäre geprägten Aktionärstrukturen deutscher Unternehmen ist überwiegend negativ. Verschiedene Initiativen haben daher in der jüngeren Vergangenheit auf eine Aufweichung dieser Strukturen hingewirkt. Ziel des Steuersenkungsgesetzes, das die Gewinne aus der Veräußerung von Beteiligungen steuerfrei stellt, ist die Auflösung von Beteiligungsverflechtungen, ${ }^{1092}$ die hochrangige EU-Expertenkommission nimmt kritisch Stellung zur Bildung von Konzernpyramiden, ${ }^{1093}$ der Deutsche Corporate Governance Kodex empfiehlt das Prinzip des One-Share-One-Vote ${ }^{1094}$ und die Neugestaltung der Börsenindizes bestraft Unternehmen mit multiplen Aktiengattungen. ${ }^{1095}$ Auch die empirischen Ergebnisse der hier vorliegenden Untersuchung lassen die verflochtenen Strukturen des deutschen Kapitalmarktes in einem kritischen Licht erscheinen.

Dennoch erscheint fraglich, ob ein Eingreifen der öffentlichen Hand mit dem Ziel einer Veränderung der aktionärsstrukturbezogenen deutschen Corporate Governance sinnvoll ist. So könnte etwa ein generelles Verbot von Vorzugsaktien für bestimmte Unternehmen Grund sein, von einem Börsengang gänzlich Abstand zu nehmen. Eine solche Lenkungswirkung würde dem erklärten Ziel einer Förderung des organisierten Kapitalmarktes jedoch widersprechen. Die Auswirkungen einer Einschränkung des Erwerbs von größeren Beteiligungen am deutschen Kapitalmarkt sind ebenfalls schwer prognostizierbar. Zwar weisen die empirischen Ergebnisse auf einen eher negativen Einfluss von Stimmrechtsbündelungen hin. Welche Auswirkungen jedoch eine Sanktionierung von Blockbildungen auf das Gesamtsystem der deutschen Corporate Governance hätte, ist nicht absehbar. Hier ist zu berücksichtigen, dass die alternativen, insbesondere marktorientierten Kontrollmechanismen wie etwa der Markt für Unternehmenskontrolle am deutschen Kapitalmarkt ihre Funktion bisher nur sehr einge-

\footnotetext{
1092 Vgl. van Lishaut (2000); Rose (2000); Wenger (2000), sowie Hillebrandt (2001), S. 711 . m.w.N. Bundeskanzler Gerhard Schröder formulierte als Ziel, die ,in den Depots von Kapitalgesellschaften schlummernden Beteiligungen zu neuem Leben zu erwecken“. Vgl. Bundespresseamt (2000).

1093 Vgl. Expertengruppe Europäisches Gesellschaftsrecht (2002), S. 35.

1094 Vgl. Regierungskommission DCGK (2002), Abschnitt 2.1.2.

1095 Vgl. Deutsche Börse AG (2000), S. 6; Hoffknecht (2001), S. 24; Schnell (2002), S. 11; Berrar (2001), S. 139-243.
} 
schränkt wahrnehmen. Die Auflösung aller Stimmrechtsblöcke könnte somit ein Kontrolldefizit zur Folge haben. Davon abgesehen lassen unzureichende rentable Alternativinvestitionen aus Sicht der aktuellen Anteilseigner sowie eine mangelnde Aufnahmefähigkeit des Kapitalmarktes ein solches Szenario unrealistisch erscheinen. Sprechen aus Sicht des Großaktionärs strategische Überlegungen für eine große Beteiligung, so würde eine Veräußerungspflicht dieser Beteiligung zudem keine Anreize mit sich bringen, freiwerdende Mittel in viele Kleinstbeteiligungen zu investieren. ${ }^{1096}$

Da somit eine Sanktionierung großer Beteiligungen und überproportionaler Stimmrechte nicht unproblematisch erscheint, könnte sich eine weitere Erhöhung der Transparenzanforderungen als gangbare Alternative erweisen. Sofern dem Kapitalmarkt der Aufbau von potenziell die Interessen der Minderheitsaktionäre schädigenden Corporate-Governance-Strukturen innerhalb eines Unternehmens bekannt wird, können die Kapitalmarktteilnehmer durch Verkauf ihrer Anteile („exit“) bzw. Nicht-Kauf neuer Anteile entsprechend reagieren. Wünschenswert wären konkret:

- Eine Ausdehnung der Transparenzanforderungen des WpHG auf Kapitalanteile. Die meldepflichtigen Grenzwerte sollten zudem deutlich engmaschiger geknüpft werden und die Meldepflicht sollte für alle kapitalmarktorientierten Unternehmen gelten.

- Die Frist von bis zu 16 Tagen, mit der eine Änderung der Anteilseignerstruktur an den Kapitalmarkt kommuniziert wird, sollte verkürzt werden. Denkbar wäre etwa eine Verpflichtung zur Ad-hoc-Meldung von Änderungen in der Aktionärsstruktur.

- Die Verpflichtung zur Abgabe einer Comply-or-Explain-Erklärung zum Deutschen Corporate Governance Kodex gemäß $\S 161$ AktG sollte auf unterjährige Berichterstattungen ausgedehnt werden, sofern sich relevante Veränderungen ergeben.

- Die Transparenzanforderungen im Geschäftsbericht sollten ausgeweitet werden. Erforderlich scheint nicht nur die Berichterstattung über Änderungen der Aktionärsstruktur (WpHG-Meldungen) sondern darüber hinaus auch die Offenlegung der gesamten Anteilseignerstruktur nach festgelegten Kriterien, sofern sie dem Unternehmen, etwa durch Namensaktien, bekannt ist. Zusätzlich

1096 Windolf/Beyer (1995) weisen nach, dass ein Großteil der Verflechtungen in Deutschland horizontaler Natur sind, also zwischen Wettbewerbern bestehen. 
sollte publiziert werden, welche Beziehungen etwa aus Aufsichtsratsmandaten oder Geschäftsbeziehungen zu den einzelnen Großaktionären bestehen. ${ }^{1097}$

- Die aktuelle Aktionärsstruktur sowie die Struktur des Eigenkapitals sollte zusätzlich über das Internet jederzeit verpflichtend verfügbar gemacht werden.

Um neben der „exit-“ auch die Ausübung der „,voice-Alternative“ zu erleichtern, wäre eine verpflichtende Stimmabgabemöglichkeit über das Internet wünschenswert. Die vereinfachte Abstimmung ändert zwar die mangelnden Anreize der Kleinaktionäre zur Informationsbeschaffung nicht, erleichtert jedoch insbesondere ausländischen Aktionären die Wahrnehmung ihrer Herrschaftsrechte.

Insgesamt bleibt festzuhalten, dass die Aktionärs- und Stimmrechtsstruktur als ein am deutschen Kapitalmarkt vergleichsweise unerforschtes Phänomen sowohl im positiven als auch im negativen Sinne Einfluss auf den Erfolg des Unternehmens ausüben kann. Sie sollte daher stärker als bisher als Element der Corporate Governance wahrgenommen und - im Rahmen der Möglichkeiten - bewusst gestaltet werden. Denn wie Colin Mayer es formuliert: „Ownership matters“. ${ }^{1098}$ Entsprechend stellte der Aufsichtsratsvorsitzende der Deutschen Bank Breuer jüngst fest: „Man muss sich die richtigen Aktionäre aussuchen“. ${ }^{1099}$ Das Argument, eine Einflussnahme auf die Aktionärsstruktur sei nicht möglich, lässt er nicht gelten: ,die Equity Story macht den Aktionärskreis“. ${ }^{1100}$

\footnotetext{
1097 Dieser Forderung wurde durch Verabschiedung des DRS-11 „Angaben zu nahe stehenden Personen" bereits teilweise nachgekommen. Vgl. Zimmermann (2002); Küting/Weber/Gattung (2003); Schütte (2003).

1098 So der Titel des Beitrags von Mayer (2000).

${ }^{1099}$ Rolf E. Breuer auf der Jahrestagung der wissenschaftlichen Kommission internationales Management an der Universität Gießen. Vgl. o.V. (2003a), S. 21.

${ }^{1100}$ Vgl. ebenda.
} 


\section{Anhang}


Anhang A: Theoretische Modelle zur Anreizwirkung alternativer Kapital- und Stimmrechtsstrukturen

\begin{tabular}{|c|c|c|c|c|}
\hline Studie & $\begin{array}{l}\text { Verteilung } \\
\text { Cash-Flow- } \\
\text { /Stimmrechte }\end{array}$ & $\begin{array}{l}\text { Eigentümer } \\
\text { der Aktien }\end{array}$ & $\begin{array}{l}\text { Modellierte Anreize/ } \\
\text { Handelnder Akteur }\end{array}$ & Zentrale Ergebnisse \\
\hline $\begin{array}{l}\text { Jensen/Meck- } \\
\text { ling (1976) }\end{array}$ & $1: 1$ & $\begin{array}{l}\text { Eigentümer- } \\
\text { Manager und } \\
\text { Kleinaktionäre }\end{array}$ & $\begin{array}{l}\text { Anreize des Eigentümer- } \\
\text { Managers, zur Finanzierung } \\
\text { neben Fremdkapital auch } \\
\text { Kleinaktionäre heranzuziehen }\end{array}$ & $\begin{array}{l}\text { - Großaktionär nimmt Monitoringfunktion wahr, hat je- } \\
\text { doch ab einem bestimmten Kapitalanteil Anreize, } \\
\text { private benefits zu realisieren } \\
\text { - Optimaler Anteil breit gestreuten Eigenkapitals ergibt } \\
\text { sich an der Stelle, an der die Agency-Kosten des Eigen- } \\
\text { kapitals und die des Fremdkapitals minimiert werden }\end{array}$ \\
\hline $\begin{array}{l}\text { Shleifer/Vishny } \\
(1986)\end{array}$ & $1: 1$ & $\begin{array}{l}\text { Großer Minder- } \\
\text { heitsaktionär und } \\
\text { Kleinaktionäre }\end{array}$ & $\begin{array}{l}\text { Anreize des Minderheitsakti- } \\
\text { onärs, das Management zu } \\
\text { überwachen bzw. ein neues } \\
\text { einzusetzen }\end{array}$ & $\begin{array}{l}\text { - Großer Minderheitsaktionär kann Free-Rider-Problem } \\
\text { mindern } \\
\text { - Erwartete Gewinne um so größer, je größer der Anteil } \\
\text { des Minderheitsaktionärs } \\
\text { - Unterstellt Interessenkonvergenz zwischen Aktionären }\end{array}$ \\
\hline $\begin{array}{l}\text { Grossman/Hart } \\
\text { (1988) }\end{array}$ & $\begin{array}{l}\text { n Aktiengattun- } \\
\text { gen mit ver- } \\
\text { schiedenen CF- } \\
\text { und Stimmrech- } \\
\text { ten }\end{array}$ & Kleinaktionäre & $\begin{array}{l}\text { Übernahmekampf zwischen } \\
\text { Management bzw. seinem } \\
\text { weißen Ritter und einem } \\
\text { feindlichen Bieter }\end{array}$ & $\begin{array}{l}\text { - Je mehr CF-Rechte den Aktionären zukommen, desto } \\
\text { eher werden sie sich einem feindlichen Bieter mit } \\
\text { private benefits in den Weg stellen } \\
\text { - One Share - One Vote ist aus individualwirtschaftlicher } \\
\text { Sicht i.d.R. optimale Struktur }\end{array}$ \\
\hline $\begin{array}{l}\text { Harris/Raviv } \\
\text { (1988a) } \\
\text { [ähnlich Har- } \\
\text { ris/Raviv (1988, } \\
\text { 1989)] }\end{array}$ & $\begin{array}{l}\text { c Aktiengattun- } \\
\text { gen mit ver- } \\
\text { schiedenen CF- } \\
\text { und Stimmrech- } \\
\text { ten }\end{array}$ & Kleinaktionäre & $\begin{array}{l}\text { Übernahmekampf zwischen } \\
\text { Management bzw. seinem } \\
\text { weißen Ritter und einem } \\
\text { feindlichen Bieter }\end{array}$ & $\begin{array}{l}\text { - One Share - One Vote ist aus gesamtwirtschaftlicher } \\
\text { Sicht immer optimale Struktur } \\
\text { - Zur Maximierung des Gesamtwerts der Wertpapiere } \\
\text { wäre ein separater Handel von CF- und Stimmrechten } \\
\text { unter Inkaufnahme eines schlechten Managements sinn- } \\
\text { voll }\end{array}$ \\
\hline
\end{tabular}




\begin{tabular}{|c|c|c|c|c|}
\hline Studie & $\begin{array}{l}\text { Verteilung } \\
\text { Cash-Flow- } \\
\text { /Stimmrechte }\end{array}$ & $\begin{array}{l}\text { Eigentümer } \\
\text { der Aktien }\end{array}$ & $\begin{array}{l}\text { Modellierte Anreize/ } \\
\text { Handelnder Akteur }\end{array}$ & Zentrale Ergebnisse \\
\hline$\overline{\text { Stulz (1988) }}$ & $1: 1$ & $\begin{array}{l}\text { Management } \\
\text { und Kleinaktio- } \\
\text { näre }\end{array}$ & $\begin{array}{l}\text { Anreize des Eigentümer- } \\
\text { Managers in Abhängigkeit } \\
\text { von der Höhe des Anteilsbe- } \\
\text { sitzes in Bezug auf Abwehr } \\
\text { feindlicher Übernahmen }\end{array}$ & $\begin{array}{l}\text { - Marktwert des Unternehmens steigt mit zunehmendem } \\
\text { Anteilsbesitz des Managements zunächst, fällt dann } \\
\text { wieder ab }\end{array}$ \\
\hline Black (1990) & $1: 1$ & $\begin{array}{l}\text { Minderheitsakti- } \\
\text { onär und Klein- } \\
\text { aktionäre }\end{array}$ & $\begin{array}{l}\text { Anreize zur Ausübung von } \\
\text { Aktionärskontrolle in Abhän- } \\
\text { gigkeit von der Größe des } \\
\text { Kapitalanteils }\end{array}$ & $\begin{array}{l}\text { - Kapitalkonzentration mindert Free-Rider-Problem } \\
\text { - Je geringer die Monitoringkosten, desto mehr Kontrolle } \\
\text { - Kontrollausübung leichter für breit diversifizierte Akti- } \\
\text { onäre }\end{array}$ \\
\hline $\begin{array}{l}\text { Zeckhauser/ } \\
\text { Pound (1990) }\end{array}$ & $1: 1$ & $\begin{array}{l}\text { Großer Minder- } \\
\text { heitsaktionär und } \\
\text { Kleinaktionäre }\end{array}$ & $\begin{array}{l}\text { Einflussnahme von Großakti- } \\
\text { onären auf die Ergebnisges- } \\
\text { taltung }\end{array}$ & $\begin{array}{l}\text { - Unternehmen mit Großaktionären werden im Verhältnis } \\
\text { zum Ergebnis höher bewertet } \\
\text { - Großaktionäre setzen ihre Präferenz für Ergebnisver- } \\
\text { schiebung in die Zukunft durch, sind weniger kurzfristig } \\
\text { orientiert als Kleinaktionäre }\end{array}$ \\
\hline Israel (1992) & $1: 1$ & $\begin{array}{l}\text { Management } \\
\text { und Kleinaktio- } \\
\text { näre }\end{array}$ & $\begin{array}{l}\text { Anreize zur Ausübung von } \\
\text { Aktionärskontrolle durch den } \\
\text { Eigentümer-Manager in Ab- } \\
\text { hängigkeit von der Größe des } \\
\text { Kapitalanteils }\end{array}$ & $\begin{array}{l}\text { Durch die Erhöhung des eigenen Kapitalanteils kann der } \\
\text { Eigentümer-Manager künftige feindliche Übernahmen } \\
\text { blockieren und Erträge des Raiders vereinnahmen }\end{array}$ \\
\hline Huddart (1993) & $1: 1$ & $\begin{array}{l}\text { Kontrollierender } \\
\text { Großaktionär } \\
\text { und Kleinaktio- } \\
\text { näre }\end{array}$ & $\begin{array}{l}\text { Anreize des Großaktionärs } \\
\text { zur Ausübung von Monito- } \\
\text { ring und zum Abbau der Ka- } \\
\text { pitalbeteiligung mit dem Ziel } \\
\text { des Free Riding }\end{array}$ & $\begin{array}{l}\text { - Konzentrierte Aktionärsstruktur vorteilhaft, wenn Un- } \\
\text { ternehmenserträge wenig risikobehaftet und Monito- } \\
\text { ringkosten gering } \\
\text { - Jeder Großaktionär hat Anreiz, von optimaler Eigner- } \\
\text { struktur abzuweichen und selbst zum Free Rider zu } \\
\text { werden } \\
\text { - Unterstellt Interessenkonvergenz aller Aktionäre }\end{array}$ \\
\hline
\end{tabular}

Einflussnahme von Großaktiheitsaktionär und onären auf die Ergebnisges-

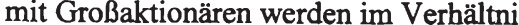

schiebung in die Zukunft durch, sind weniger kurzfristig und Kleinaktio- Aktionärskontrolle durch den Eigentümer-Manager künftige feindliche Übernahmen

Arionärs ring und zum Abbau der Kapitalbeteiligung mit dem $\mathrm{Zie}$ des Free Riding ternehmenserträge wenig risikobehaftet und Monitostruktur abzuweichen und selbst zum Free Rider zu - Unterstellt Interessenkonvergenz aller Aktionäre 


\begin{tabular}{|c|c|c|c|c|}
\hline Studie & $\begin{array}{l}\text { Verteilung } \\
\text { Cash-Flow- } \\
\text { /Stimmrechte }\end{array}$ & $\begin{array}{l}\text { Eigentümer } \\
\text { der Aktien }\end{array}$ & $\begin{array}{l}\text { Modellierte Anreize/ } \\
\text { Handelnder Akteur }\end{array}$ & Zentrale Ergebnisse \\
\hline Zwiebel (1995) & $1: 1$ & $\begin{array}{l}\text { Verschiedene } \\
\text { Minderheitsakti- } \\
\text { onäre und Klein- } \\
\text { aktionäre }\end{array}$ & $\begin{array}{l}\text { Anreize von Minderheitsakti- } \\
\text { onären, trotz mangelnder Di- } \\
\text { versifikations- und Kontroll- } \\
\text { möglichkeiten Blockbildung } \\
\text { zu betreiben }\end{array}$ & $\begin{array}{l}\text { - Minderheitsaktionäre bilden Koalitionen, die Kontroll- } \\
\text { ausübung und damit die Realisierung von private bene- } \\
\text { fits ermöglichen } \\
\text { - Private benefits werden zwischen den Minderheitsaktio- } \\
\text { nären aufgeteilt }\end{array}$ \\
\hline $\begin{array}{l}\text { Burkhard/ } \\
\text { Gromb/ } \\
\text { Panunzi (1997) }\end{array}$ & $1: 1$ & $\begin{array}{l}\text { Kontrollierender } \\
\text { Großaktionär } \\
\text { und Kleinaktio- } \\
\text { näre }\end{array}$ & $\begin{array}{l}\text { Anreize des Managements zu } \\
\text { Engagement und unterneh- } \\
\text { mensspezifischen Investitio- } \\
\text { nen in Abhängigkeit von der } \\
\text { Aktionärsstruktur }\end{array}$ & $\begin{array}{l}\text { - Wirkung des Großaktionärs als Trade-off zwischen } \\
\text { Kontrolle und Initiative des Managements } \\
\text { - Großaktionär kann zwar ex post private Vorteilsnahme } \\
\text { verhindern, ex ante aber die Anreize des Managements } \\
\text { einschränken } \\
\text { - Unterstellt Interessenkonvergenz aller Aktionäre }\end{array}$ \\
\hline $\begin{array}{l}\text { Bolton/von } \\
\text { Thadden } \\
\text { (1998) }\end{array}$ & $1: 1$ & $\begin{array}{l}\text { Kontrollierender } \\
\text { Großaktionär } \\
\text { und Kleinaktio- } \\
\text { näre }\end{array}$ & $\begin{array}{l}\text { Unternehmenswert in Abhän- } \\
\text { gigkeit alternativer Eigentü- } \\
\text { merstrukturen und Kapital- } \\
\text { marktumfelder, statische Be- } \\
\text { trachtung }\end{array}$ & $\begin{array}{l}\text { - Optimale Aktionärsstruktur unter Berücksichtigung der } \\
\text { Kapitalmarktliquidität } \\
\text { - Trade-off zwischen Liquidität (Streubesitz) und Kon- } \\
\text { trolle (Blockbildung) } \\
\text { - Sofern einmal Streubesitz etabliert ist, bilden sich auch } \\
\text { bei schlechter Performance keine Blöcke heraus } \\
\end{array}$ \\
\hline $\begin{array}{l}\text { Bolton/von } \\
\text { Thadden } \\
\text { (1998a) }\end{array}$ & $1: 1$ & $\begin{array}{l}\text { Kontrollierender } \\
\text { Großaktionär } \\
\text { und Kleinaktio- } \\
\text { näre }\end{array}$ & $\begin{array}{l}\text { Unternehmenswert in Abhän- } \\
\text { gigkeit alternativer Eigentü- } \\
\text { merstrukturen und Kapital- } \\
\text { marktumfelder, dynamische } \\
\text { Betrachtung }\end{array}$ & $\begin{array}{l}\text { - Großaktionär führt zu geringerer Liquidität bei besserem } \\
\text { Monitoring } \\
\text { - Optimale Aktionärsstruktur ergibt sich somit als Trade- } \\
\text { off zwischen Liquidität und Kontrolle } \\
\text { - Börsennotierung sinnvoll insbesondere für breit gestreu- } \\
\text { te Unternehmen }\end{array}$ \\
\hline
\end{tabular}




\begin{tabular}{|c|c|c|c|c|}
\hline Studie & $\begin{array}{l}\text { Verteilung } \\
\text { Cash-Flow- } \\
\text { /Stimmrechte }\end{array}$ & $\begin{array}{l}\text { Eigentümer } \\
\text { der Aktien }\end{array}$ & $\begin{array}{l}\text { Modellierte Anreize/ } \\
\text { Handelnder Akteur }\end{array}$ & Zentrale Ergebnisse \\
\hline $\begin{array}{l}\text { Mello/Parsons } \\
\text { (1998) }\end{array}$ & $1: 1$ & $\begin{array}{l}\text { Entrepreneur, } \\
\text { Groß- und } \\
\text { Kleinaktionäre }\end{array}$ & $\begin{array}{l}\text { Gesamtwirtschaftlich optima- } \\
\text { ler Verkaufsprozess der Akti- } \\
\text { en im Rahmen des IPO und } \\
\text { danach }\end{array}$ & $\begin{array}{l}\text { - Beim IPO sollte die endgültige Aktionärsstruktur bereits } \\
\text { berücksichtigt werden (Prozessbezug) } \\
\text { - Separate Verkaufspreise für Klein- und Großaktionäre } \\
\text { aus Sicht aller Aktionäre sinnvoll } \\
\text { - Je nach Höhe der private benefits zahlt Großaktionär } \\
\text { Paketauf- oder } \\
\text {-abschlag }\end{array}$ \\
\hline $\begin{array}{l}\text { Pagano/Röell } \\
\text { (1998) }\end{array}$ & $1: 1$ & Entrepreneur & $\begin{array}{l}\text { Anreize des Entrepreneurs, } \\
\text { zur weiteren Finanzierung } \\
\text { entweder Groß- oder Kleinak- } \\
\text { tionäre zu akquirieren }\end{array}$ & $\begin{array}{l}\text { - Entscheidung über ein breit gestreutes IPO als Trade-off } \\
\text { zwischen geringerem Monitoring eines weiteren Groß- } \\
\text { aktionärs und Kosten des IPO } \\
\text { - Anreiz zum IPO um so größer, je größer der externe } \\
\text { Finanzierungsbedarf }\end{array}$ \\
\hline $\begin{array}{l}\text { Bebchuk } \\
\text { (1999) }\end{array}$ & $\begin{array}{l}\text { Zunächst } 1: 1 \text {, } \\
\text { Erweiterung auf } \\
\text { divergierende } \\
\text { CF- und Stimm- } \\
\text { rechte }\end{array}$ & Entrepreneur & $\begin{array}{l}\text { Anreize des Entrepreneurs, } \\
\text { Teile des Unternehmens } \\
\text { durch IPO zu veräußern }\end{array}$ & $\begin{array}{l}\text { - Je größer die private benefits desto weniger ist der En- } \\
\text { trepreneur bereit, i.R.d. IPO Kontrolle aufzugeben } \\
\text { - Abweichende CF- und Stimmrechte werden insbesonde- } \\
\text { re in Unternehmen mit kontrollierendem Aktionär ge- } \\
\text { nutzt }\end{array}$ \\
\hline $\begin{array}{l}\text { BebchukJ } \\
\text { Kraakman/ } \\
\text { Triantis (1999) }\end{array}$ & $\begin{array}{l}\text { Abweichend } \\
\text { aufgrund von } \\
\text { Vorzugsaktien, } \\
\text { Kreuzverflech- } \\
\text { tungen und Py- } \\
\text { ramiden }\end{array}$ & $\begin{array}{l}\text { Kontrollierender } \\
\text { Minderheitsakti- } \\
\text { onär und Klein- } \\
\text { aktionäre }\end{array}$ & $\begin{array}{l}\text { Anreiz des Aktionärs zur Ge- } \\
\text { nerierung abweichender CF- } \\
\text { und Stimmrechte sowie Aus- } \\
\text { wirkungen auf die Agency- } \\
\text { Kosten }\end{array}$ & $\begin{array}{l}\text { - Abweichende CF- und Stimmrechte führen zu höheren } \\
\text { Agency-Kosten als nur ein kontrollierender Großaktio- } \\
\text { när } \\
\text { - Agency-Kosten um so größer, je geringer der CF-Anteil } \\
\text { des kontrollierenden Minderheitsaktionärs }\end{array}$ \\
\hline Fluck (1999) & $1: 1$ & Entrepreneur & $\begin{array}{l}\text { Anreize des Eigentümer- } \\
\text { Managers, Teile des Eigenka- } \\
\text { pitals an außenstehende In- } \\
\text { vestoren abzugeben }\end{array}$ & $\begin{array}{l}\text { - Höhe des optimal abzugebenden Anteils abhängig von } \\
\text { der Höhe der private benefits und der Wahrscheinlich- } \\
\text { keit einer feindlichen Übernahme } \\
\text { - Optimaler Kapitalanteil des Managers außerdem abhän- } \\
\text { gig vom Anlagehorizont der beteiligten Aktionäre }\end{array}$ \\
\hline
\end{tabular}
gig vom Anlagehorizont der beteiligten Aktionäre 


\begin{tabular}{|c|c|c|c|c|}
\hline Studie & $\begin{array}{l}\text { Verteilung } \\
\text { Cash-Flow- } \\
\text { /Stimmrechte }\end{array}$ & $\begin{array}{l}\text { Eigentümer } \\
\text { der Aktien }\end{array}$ & $\begin{array}{l}\text { Modellierte Anreize/ } \\
\text { Handelnder Akteur }\end{array}$ & Zentrale Ergebnisse \\
\hline $\begin{array}{l}\text { Wolfenzon } \\
(1999)\end{array}$ & $\begin{array}{l}\text { Abweichend } \\
\text { aufgrund von } \\
\text { Pyramidenbil- } \\
\text { dung }\end{array}$ & Entrepreneur & $\begin{array}{l}\text { Anreize des Entrepreneurs } \\
\text { seine Unternehmensgruppe } \\
\text { horizontal oder als Pyramide } \\
\text { zu strukturieren }\end{array}$ & $\begin{array}{l}\text { - In einer Konzernpyramide realisiert Entrepreneur priva- } \\
\text { te benefits alleine, teilt negative Auswirkungen jedoch } \\
\text { mit den Minderheitsaktionären } \\
\text { - Je größer die realisierbaren private benefits, desto eher } \\
\text { wählt der Entrepreneur die Pyramide als Konzernstruk- } \\
\text { tur }\end{array}$ \\
\hline $\begin{array}{l}\text { Bebchuk/ } \\
\text { Zingales } \\
(2000)\end{array}$ & $\begin{array}{l}\text { Zunächst } 1: 1 \text {, } \\
\text { Erweiterung auf } \\
\text { divergierende } \\
\text { CF- und Stimm- } \\
\text { rechte }\end{array}$ & Entrepreneur & $\begin{array}{l}\text { Anreize zur Ausgestaltung } \\
\text { der Anteilseignerstruktur im } \\
\text { Rahmen des IPO }\end{array}$ & $\begin{array}{l}\text { - Im Rahmen des IPO gewählte Anteilseignerstruktur ist } \\
\text { nicht immer auch gesamtwirtschaftlich optimal } \\
\text { - Großaktionär wählt Struktur so, dass er private benefits } \\
\text { realisieren kann, ggf. verstärkt durch Vorzugsaktien und } \\
\text { Pyramiden }\end{array}$ \\
\hline $\begin{array}{l}\text { Bennedsen/ } \\
\text { Wolfenzon } \\
(2000)\end{array}$ & $1: 1$ & Entrepreneur & $\begin{array}{l}\text { Anreize des Entrepreneurs, } \\
\text { zur weiteren Finanzierung } \\
\text { zusätzliche Großaktionäre zu } \\
\text { akquirieren }\end{array}$ & $\begin{array}{l}\text { - Für Entrepreneur ist es effizient, Kapital an verschiede- } \\
\text { ne Großaktionäre zu veräußern, die zur Ausübung von } \\
\text { Kontrolle Koalitionen bilden müssen (Signalisierungs- } \\
\text { funktion) } \\
\text { - Durch die Koalitionsbildung wird die Realisierung von } \\
\text { private benefits verhindert und Kontrolle effizient aus- } \\
\text { geübt }\end{array}$ \\
\hline $\begin{array}{l}\text { Edwards/Wei- } \\
\text { chenrieder } \\
(2000)\end{array}$ & $\begin{array}{l}\text { Abweichend } \\
\text { aufgrund von } \\
\text { Vorzugsaktien } \\
\text { und Absentis- } \\
\text { mus der Klein- } \\
\text { aktionäre auf der } \\
\text { Hauptversamm- } \\
\text { lung }\end{array}$ & $\begin{array}{l}\text { Großaktionär } \\
\text { und Kleinaktio- } \\
\text { näre }\end{array}$ & $\begin{array}{l}\text { Monitoringanreize des Groß- } \\
\text { aktionärs unter Berücksichti- } \\
\text { gung von private benefits }\end{array}$ & $\begin{array}{l}\text { - Positiver Einfluss zunehmender CF-Rechte des Großak- } \\
\text { tionärs auf Dividende } \\
\text { - Unklarer Einfluss zunehmender Stimmrechte des Groß- } \\
\text { aktionärs auf Dividende } \\
\text { - Unklarer Einfluss eines zweiten großen Aktionärs auf } \\
\text { Dividende }\end{array}$ \\
\hline
\end{tabular}




\begin{tabular}{|c|c|c|c|c|}
\hline Studie & $\begin{array}{l}\text { Verteilung } \\
\text { Cash-Flow- } \\
\text { /Stimmrechte } \\
\end{array}$ & $\begin{array}{l}\text { Eigentümer } \\
\text { der Aktien }\end{array}$ & $\begin{array}{l}\text { Modellierte Anreize/ } \\
\text { Handelnder Akteur }\end{array}$ & Zentrale Ergebnisse \\
\hline $\begin{array}{l}\text { Heinrich } \\
(2000)\end{array}$ & $1: 1$ & $\begin{array}{l}\text { Großaktionär } \\
\text { und Kleinaktio- } \\
\text { näre }\end{array}$ & $\begin{array}{l}\text { Monitoringanreize des Groß- } \\
\text { aktionärs unter Berücksichti- } \\
\text { gung von Diversifikationsef- } \\
\text { fekten }\end{array}$ & $\begin{array}{l}\text { - Zunehmender Kapitalanteil des Großaktionärs führt auf- } \\
\text { grund mangelnder Diversifikation zu risikoaverser Be- } \\
\text { urteilung der Projekte } \\
\text { - Negative Auswirkungen von Blockbildung können } \\
\text { durch gleichzeitigen Einsatz anderer Agency-Kosten re- } \\
\text { duzierender Instrumente gemildert werden (z.B. Ver- } \\
\text { schuldung) }\end{array}$ \\
\hline Maug (2000) & $1: 1$ & Entrepreneur & $\begin{array}{l}\text { Anreiz des Entrepreneurs zur } \\
\text { Aufgabe seiner Kontroll- } \\
\text { mehrheit über IPO }\end{array}$ & $\begin{array}{l}\text { - Optimale Eignerstruktur ändert sich im Zeitablauf } \\
\text { - IPO wird dann vorteilhaft, wenn Entrepreneur keine } \\
\text { Spezialisierungsvorteile i.R.d. Kontrollausübung besitzt }\end{array}$ \\
\hline Nenova (2000) & $\begin{array}{l}\text { Zwei Aktiengat- } \\
\text { tungen mit ver- } \\
\text { schiedenen CF- } \\
\text { und Stimmrech- } \\
\text { ten }\end{array}$ & $\begin{array}{l}\text { Aktionäre zweier } \\
\text { unterschiedlicher } \\
\text { Aktiengattungen }\end{array}$ & $\begin{array}{l}\text { Anreize zum Erwerb von } \\
\text { stimmrechtsbegünstigten Ak- } \\
\text { tien in Abhängigkeit vom } \\
\text { Aktionärsschutz }\end{array}$ & $\begin{array}{l}\text { - Der Wert des Stimmrechts einer Aktie ist positiv korre- } \\
\text { liert mit der zukünftigen Übernahmewahrscheinlichkeit } \\
\text { - Der Wert des Stimmrechts einer Aktie ist negativ korre- } \\
\text { liert mit der Güte des Aktionärsschutzes sowie CF- } \\
\text { Vorteilen der stimmrechtsbeschränkten Aktien } \\
\end{array}$ \\
\hline $\begin{array}{l}\text { Shleifer/ } \\
\text { Wolfenzon } \\
(2000)\end{array}$ & $1: 1$ & Entrepreneur & $\begin{array}{l}\text { Anreize des Entrepreneurs in } \\
\text { Bezug auf zu veräußernde } \\
\text { Anteile und Größe des ge- } \\
\text { planten Projektes in Abhän- } \\
\text { gigkeit vom Aktionärsschutz }\end{array}$ & $\begin{array}{l}\text { - Länder mit gutem Aktionärsschutz haben größere und } \\
\text { wertvollere Unternehmen, die höhere Dividenden zah- } \\
\text { len } \\
\text { - Guter Aktionärsschutz führt zu geringerer Kapitalkon- } \\
\text { zentration und besser entwickelten Aktienmärkten }\end{array}$ \\
\hline $\begin{array}{l}\text { Bloch/Hege } \\
(2001)\end{array}$ & $1: 1$ & Entrepreneur & $\begin{array}{l}\text { Anreize des Entrepreneurs, } \\
\text { Aktien an weiteren Großakti- } \\
\text { onär zu veräußern in Abhän- } \\
\text { gigkeit von der zu veräußern- } \\
\text { den Blockgröße }\end{array}$ & $\begin{array}{l}\text { - Zwei Großaktionäre führen zu einer Minderung der pri- } \\
\text { vate benefits und sind daher im Interesse der Minder- } \\
\text { heitsaktionäre } \\
\text { - Optimale Aktionärsstruktur gewährt zweitem Aktionär } \\
\text { gerade so viele Stimmrechte, dass er effizient Kontrolle } \\
\text { ausüben kann }\end{array}$ \\
\hline
\end{tabular}




\begin{tabular}{|c|c|c|c|c|}
\hline Studie & $\begin{array}{l}\text { Verteilung } \\
\text { Cash-Flow- } \\
\text { /Stimmrechte }\end{array}$ & $\begin{array}{l}\text { Eigentümer } \\
\text { der Aktien }\end{array}$ & $\begin{array}{l}\text { Modellierte Anreize/ } \\
\text { Handelnder Akteur }\end{array}$ & Zentrale Ergebnisse \\
\hline $\begin{array}{l}\text { Gomes/Novaes } \\
(2001)\end{array}$ & $1: 1$ & Entrepreneur & $\begin{array}{l}\text { Anreize des Entrepreneurs, im } \\
\text { Rahmen des IPO Anteile an } \\
\text { Minderheitsaktionäre oder } \\
\text { einen oder mehrere Großakti- } \\
\text { onäre veräußern }\end{array}$ & $\begin{array}{l}\text { - Zwei Großaktionäre sind sinnvoll insb. in Unternehmen } \\
\text { mit hohen Ausbeutungskosten und Finanzierungsbedarf } \\
\text { - Optimale Aktionärsstruktur beinhaltet auch Minder- } \\
\text { heitsaktionäre } \\
\text { - Mehrere Großaktionäre als Trade-off zwischen positi- } \\
\text { vem Einfluss auf das Management und Ineffizienzen } \\
\text { zwischen den Großaktionären }\end{array}$ \\
\hline $\begin{array}{l}\text { La Porta et al. } \\
(2002)\end{array}$ & $1: 1$ & $\begin{array}{l}\text { Eigentümer- } \\
\text { Manager und } \\
\text { Kleinaktionäre }\end{array}$ & $\begin{array}{l}\text { Anreize zur Generierung von } \\
\text { private benefits in Abhängig- } \\
\text { keit von Aktionärsschutz und } \\
\text { Kapitalanteil }\end{array}$ & $\begin{array}{l}\text { - Besserer Aktionärsschutz führt zu geringerer Ausbeu- } \\
\text { tung der Kleinaktionäre und zu höherer Bewertung der } \\
\text { Unternehmen } \\
\text { - Höhere CF-Rechte des Entrepreneurs führen zu geringe- } \\
\text { rer Ausbeutung und zu höherer Bewertung der Unter- } \\
\text { nehmen }\end{array}$ \\
\hline $\begin{array}{l}\text { Vinaimont } \\
(2002)\end{array}$ & $\begin{array}{l}\text { n Aktiengattun- } \\
\text { gen mit ver- } \\
\text { schiedenen CF- } \\
\text { und Stimmrech- } \\
\text { ten }\end{array}$ & Kleinaktionäre & $\begin{array}{l}\text { Übernahmekampf zwischen } \\
\text { Management bzw. seinem } \\
\text { weißen Ritter und einem } \\
\text { feindlichen Bieter }\end{array}$ & $\begin{array}{l}\text { - Erweiterung der Modelle von Grossman/Hart und Har- } \\
\text { ris/Raviv um private benefits bei Bieter und Zielgesell- } \\
\text { schaft } \\
\text { - Aus Sicht des Veräußerers sind multiple Aktiengattun- } \\
\text { gen optimal }\end{array}$ \\
\hline $\begin{array}{l}\text { Burkart/Pa- } \\
\text { nunzi/Shleifer } \\
(2003)\end{array}$ & $1: 1$ & Entrepreneur & $\begin{array}{l}\text { Anreize des Entrepreneurs zur } \\
\text { Durchführung eines IPO in } \\
\text { Abhängigkeit vom Aktionärs- } \\
\text { schutz }\end{array}$ & $\begin{array}{l}\text { - Guter Aktionärsschutz führt zu hohem Streubesitz } \\
\text { - Mäßiger Aktionärsschutz führt zu Streubesitz unter Ein- } \\
\text { beziehung der Gründerfamilien als Monitor } \\
\text { - Schlechter Aktionärsschutz führt zum Verbleib der Kon- } \\
\text { trolle bei der Gründerfamilie }\end{array}$ \\
\hline
\end{tabular}




\section{Anhang B: Empirische Studien zum Aktionärsstruktur-Performance-Zusammenhang B.1 Internationale Studien}

\begin{tabular}{|c|c|c|c|c|c|}
\hline Studie & $\begin{array}{l}\text { Zeitraum und } \\
\text { Stichprobe }\end{array}$ & Erklär. Variable(n) & $\begin{array}{l}\text { Abhängige } \\
\text { Variable }\end{array}$ & $\begin{array}{l}\text { Kontroll- } \\
\text { variablen }\end{array}$ & Zentrale Ergebnisse \\
\hline $\begin{array}{l}\text { Berle/Means } \\
\text { (1932) }\end{array}$ & $\begin{array}{l}1929 \\
200 \text { größte US- } \\
\text { Industrieunter- } \\
\text { nehmen }\end{array}$ & $\mathrm{GAK} \geq 20 \%$ & \multicolumn{2}{|c|}{ Entfällt } & $\begin{array}{l}\text { 44\% unterliegen nicht der GAK und sind somit } \\
\text { managerkontrolliert }\end{array}$ \\
\hline Gordon (1945) & $\begin{array}{l}1937 \\
176 \text { der } 200 \\
\text { größten US- } \\
\text { Industrieunter- } \\
\text { nehmen }\end{array}$ & $\begin{array}{l}\text { Verschiedene Kate- } \\
\text { gorien }\end{array}$ & \multicolumn{2}{|c|}{ Entfällt } & $\begin{array}{l}\text { - Neuinterpretation einer älteren SEC-Studie, } \\
\text { rund zwei Drittel der Unternehmen sind mana- } \\
\text { gerkontrolliert }\end{array}$ \\
\hline Larner (1966) & $\begin{array}{l}1963 \\
200 \text { größte US- } \\
\text { Industrieunter- } \\
\text { nehmen }\end{array}$ & $\mathrm{GAK} \geq 10 \%$ & \multicolumn{2}{|c|}{ Entfällt } & $\bullet 83,5 \%$ sind managerkontrolliert \\
\hline $\begin{array}{l}\text { Kamerschen } \\
\text { (1968) }\end{array}$ & $\begin{array}{l}1959-1964 \\
200 \text { größte US- } \\
\text { Industrieunter- } \\
\text { nehmen }\end{array}$ & $\mathrm{GAK} \geq 10 \%$ & EK-Rendite & Branche, Größe & $\begin{array}{l}\text { - Keine signifikanten Unterschiede in der Per- } \\
\text { formance zwischen GAK und MK } \\
\text { - Wechsel von GAK zu MK hat signifikant posi- } \\
\text { tiven Einfluss auf Performance }\end{array}$ \\
\hline $\begin{array}{l}\text { Monsen/Chiw } \\
\text { Cooley (1968) }\end{array}$ & $\begin{array}{l}1952-1963 \\
72 \text { große US- } \\
\text { Unternehmen }\end{array}$ & $\begin{array}{l}\text { GAK } \geq 10 \% \text { bei akti- } \\
\text { ver Kontrolle, GAK } \\
\geq 20 \%\end{array}$ & $\begin{array}{l}\text { EK-, GK-, } \\
\text { Um- } \\
\text { satzrendite, } \\
\text { FK-quote }\end{array}$ & Branche, Größe & $\begin{array}{l}\text { - Positiver Einfluss von GAK auf Performance- } \\
\text { kennzahlen }\end{array}$ \\
\hline Larner (1970) & $\begin{array}{l}1956-1962 \\
187 \text { große US- } \\
\text { Industrieunter- } \\
\text { nehmen }\end{array}$ & $\mathrm{GAK} \geq 10 \%$ & $\begin{array}{l}\text { EK-Rendite, } \\
\text { Varianz der } \\
\text { EK-Rendite }\end{array}$ & & $\begin{array}{l}\text { - Gering positiver Einfluss von GAK auf EK- } \\
\text { Rendite } \\
\text { - Kein signifikanter Einfluss auf Varianz }\end{array}$ \\
\hline
\end{tabular}

nehmen 


\begin{tabular}{|c|c|c|c|c|c|}
\hline Studie & $\begin{array}{l}\text { Zeitraum und } \\
\text { Stichprobe }\end{array}$ & Erklär. Variable(n) & $\begin{array}{l}\text { Abhängige } \\
\text { Variable }\end{array}$ & $\begin{array}{l}\text { Kontroll- } \\
\text { variablen }\end{array}$ & Zentrale Ergebnisse \\
\hline Radice (1971) & $\begin{array}{l}1957-1967 \\
86 \text { UK-Unter- } \\
\text { nehmen }\end{array}$ & GAK $>15 \%$ & $\begin{array}{l}\text { GK-Rendite, } \\
\text { Wachstum }\end{array}$ & Branche, Größe & $\begin{array}{l}\text { Positiver Einfluss von GAK auf Performance } \\
\text { und Wachstum, jedoch nur für einzelne Bran- } \\
\text { chen signifikant }\end{array}$ \\
\hline Elliott (1972) & $\begin{array}{l}1964-1967 \\
66 \text { US-Unterneh- } \\
\text { men }\end{array}$ & $\begin{array}{l}\text { GAK } \geq 10 \% \text { bei akti- } \\
\text { ver Kontrollaus- } \\
\text { übung, sonst GAK } \geq \\
20 \%\end{array}$ & $\begin{array}{l}\text { EK-Rendite, } \\
\text { JÜ, Dividen- } \\
\text { de u.a. }\end{array}$ & Branche, Größe & $\begin{array}{l}\text { - Kein Einfluss der Aktionärsstruktur auf Per- } \\
\text { formance nachweisbar }\end{array}$ \\
\hline $\begin{array}{l}\text { Boudreaux } \\
\text { (1973) }\end{array}$ & $\begin{array}{l}\text { 1952-1963 } \\
72 \text { US-Industrie- } \\
\text { unternehmen }\end{array}$ & $\begin{array}{l}\text { GAK } \geq 10 \% \text { bei akti- } \\
\text { ver Kontrollaus- } \\
\text { übung, sonst GAK } \geq \\
20 \%\end{array}$ & EK-Rendite & $\begin{array}{l}\text { Branche, Größe, } \\
\text { Risiko }\end{array}$ & $\begin{array}{l}\text { - Positiver Einfluss von GAK auf Performance, } \\
\text { jedoch bei größerem Risiko }\end{array}$ \\
\hline Palmer (1973) & $\begin{array}{l}\text { 1961-1969 } \\
\text { Fortune-500- } \\
\text { Unternehmen }\end{array}$ & $\begin{array}{l}\text { GAK, zwei Klassen } \\
(10-29 \% \text { und } \geq 30 \%)\end{array}$ & EK-Rendite & $\begin{array}{l}\text { Größe, Monopol- } \\
\text { stellung }\end{array}$ & $\begin{array}{l}\text { - Kein Zusammenhang zwischen GAK und Per- } \\
\text { formance } \\
\text { - Positiver Einfluss ergibt sich für sehr große } \\
\text { GAK-Unternehmen }\end{array}$ \\
\hline Holl (1975) & $\begin{array}{l}1948-1960 \\
183 \text { UK-Unter- } \\
\text { nehmen }\end{array}$ & GAK $\geq 20 \%$ & $\begin{array}{l}\text { EK-Rendite, } \\
\text { Wachstum, } \\
\text { Risiko, Divi- } \\
\text { dende }\end{array}$ & Branche, Größe & $\begin{array}{l}\text { - Keine signifikanten Unterschiede in der Per- } \\
\text { formance zwischen GAK und MK } \\
\text { - } 69,4 \% \text { der Unternehmen unterliegen MK }\end{array}$ \\
\hline $\begin{array}{l}\text { Mc Eachern } \\
\text { (1975) }\end{array}$ & $\begin{array}{l}1963-1972 \\
48 \text { große US-In- } \\
\text { dustrieunter- } \\
\text { nehmen }\end{array}$ & $\begin{array}{l}\text { MK }>4 \% \text { und Board- } \\
\text { Sitz, GAK }>4 \% \text { oh- } \\
\text { ne Board-Sitz }\end{array}$ & $\begin{array}{l}\text { Aktienrendi- } \\
\text { te, Betafak- } \\
\text { tor, Aus- } \\
\text { schüttungs- } \\
\text { quote }\end{array}$ & $\begin{array}{l}\text { Branche, Unter- } \\
\text { nehmensalter }\end{array}$ & $\begin{array}{l}\text { - Positiver Einfluss von MK und GAK auf Ren- } \\
\text { dite } \\
\text { - Geringeres Risiko bei GAK } \\
\text { - Geringere Ausschüttungsquote bei GAK }\end{array}$ \\
\hline Ware (1975) & $\begin{array}{l}1960-1970 \\
74 \text { große US- } \\
\text { Unternehmen }\end{array}$ & $\begin{array}{l}\text { GAK } \geq 25 \% \text { bzw. } \geq \\
15 \% \text { bei Repräsen- } \\
\operatorname{tanz} \text { im Board }\end{array}$ & $\begin{array}{l}\text { EK-Rendite } \\
\text { u.a. }\end{array}$ & $\begin{array}{l}\text { Branche, Größe, } \\
\text { Kontrollform } \\
\text { normiert um } \\
\text { Größe } \\
\end{array}$ & - Negativer Einfluss von GAK auf Performance \\
\hline
\end{tabular}




\begin{tabular}{|c|c|c|c|c|c|}
\hline Studie & $\begin{array}{l}\text { Zeitraum und } \\
\text { Stichprobe }\end{array}$ & Erklär. Variable(n) & $\begin{array}{l}\text { Abhängige } \\
\text { Variable }\end{array}$ & $\begin{array}{l}\text { Kontroll- } \\
\text { variablen }\end{array}$ & Zentrale Ergebnisse \\
\hline Round (1976) & $\begin{array}{l}1962-1964 \\
289 \text { australische } \\
\text { Unternehmen }\end{array}$ & $\mathrm{GAK}>10 \%$ & GK-Rendite & $\begin{array}{l}\text { Größe, Anzahl } \\
\text { Boardmitglieder, } \\
\text { ausl. Eigner, } \\
\text { Wachstum }\end{array}$ & $\begin{array}{l}\text { - Kein signifikanter Einfluss von GAK auf Per- } \\
\text { formance, jedoch leichter Vorteil z.G. GAK }\end{array}$ \\
\hline Holl (1977) & $\begin{array}{l}1962-1972 \\
343 \text { Fortune- } \\
500-\text { Un- } \\
\text { ternehmen }\end{array}$ & $\begin{array}{l}\text { GAK, zwei Klassen } \\
(10-29 \% \text { und } \geq 30 \%)\end{array}$ & Aktienrendite & & $\begin{array}{l}\text { - GAK übt in den Fällen signifikant positiven } \\
\text { Einfluss auf Performance aus, in denen MfU } \\
\text { seine Kontrollfunktion nicht effektiv wahr- } \\
\text { nehmen kann }\end{array}$ \\
\hline $\begin{array}{l}\text { Steer/Cable } \\
\text { (1978) }\end{array}$ & $\begin{array}{l}1967-1971 \\
82 \text { UK-Unter- } \\
\text { nehmen }\end{array}$ & $\begin{array}{l}\mathrm{GAK} \geq 15 \%, \mathrm{MK} \geq \\
3 \%\end{array}$ & $\begin{array}{l}\text { GK-Rendite, } \\
\text { Umsatzrendi- } \\
\text { te }\end{array}$ & $\begin{array}{l}\text { Organisation, } \\
\text { Größe, Wachs- } \\
\text { tum, Branche, } \\
\text { Board-Zusam- } \\
\text { mensetzung }\end{array}$ & $\begin{array}{l}\text { - Positiver Einfluss von GAK auf Performance } \\
\text { - Organisationsform zusätzlich bedeutend }\end{array}$ \\
\hline $\begin{array}{l}\text { Bothwell } \\
(1980)\end{array}$ & $\begin{array}{l}1960-1967 \\
150 \text { US-Unter- } \\
\text { nehmen }\end{array}$ & $\begin{array}{l}\text { GAK, zwei Klassen } \\
(10-29 \% \text { und } \geq 30 \%)\end{array}$ & $\begin{array}{l}\text { EK- und risi- } \\
\text { koadj. Um- } \\
\text { satzrendite }\end{array}$ & & - Positiver Effekt von GAK auf EK-Rendite \\
\hline $\begin{array}{l}\text { Jacqumin/ } \\
\text { de Ghellinck } \\
(1980)\end{array}$ & $\begin{array}{l}1970-1974 \\
103 \text { französische } \\
\text { Unternehmen }\end{array}$ & FK & $\begin{array}{l}\text { CF/EK- } \\
\text { Rendite }\end{array}$ & Größe, Branche & $\begin{array}{l}\text { - Kein Zusammenhang zwischen FK und Per- } \\
\text { formance } \\
\text { - Positiver Einfluss ergibt sich für sehr große } \\
\text { FK-Unternehmen }\end{array}$ \\
\hline $\begin{array}{l}\text { Levin/Levin } \\
\text { (1982) }\end{array}$ & $\begin{array}{l}1967-76 \\
200 \text { große US- } \\
\text { Unternehmen }\end{array}$ & $\begin{array}{l}\text { GAK }>10 \% \text {, } \\
\text { IIK bei Erfiullung } \\
\text { best. Voraussetzun- } \\
\text { gen }\end{array}$ & $\begin{array}{l}\text { EK-Rendite, } \\
\text { Aktienrendite }\end{array}$ & $\begin{array}{l}\text { Standardabwei- } \\
\text { chung der Erträ- } \\
\text { ge, Umsatz- } \\
\text { wachstum, Bran- } \\
\text { che u.a. }\end{array}$ & $\begin{array}{l}\text { - Positiver Effekt von GAK auf Performance } \\
\text { - Kontrolle besitzt größeren Einfluss bei nicht- } \\
\text { diversifizierten Unternehmen }\end{array}$ \\
\hline $\begin{array}{l}\text { Demsetz/Lehn } \\
\text { (1985) }\end{array}$ & $\begin{array}{l}1976-1980 \\
511 \text { US-Unter- } \\
\text { nehmen }\end{array}$ & GAK & EK-Rendite & $\begin{array}{l}\text { Größe, Volatili- } \\
\text { tät, Branche, } \\
\text { Investitionen }\end{array}$ & $\begin{array}{l}\text { - Kein Zusammenhang zwischen GAK und Per- } \\
\text { formance } \\
\text { - Eigentümerstruktur ist endogen }\end{array}$ \\
\hline
\end{tabular}




\begin{tabular}{|c|c|c|c|c|c|}
\hline Studie & $\begin{array}{l}\text { Zeitraum und } \\
\text { Stichprobe }\end{array}$ & Erklär. Variable(n) & $\begin{array}{l}\text { Abhängige } \\
\text { Variable }\end{array}$ & $\begin{array}{l}\text { Kontroll- } \\
\text { variablen }\end{array}$ & Zentrale Ergebnisse \\
\hline $\begin{array}{l}\text { Lloyd/Jahera/ } \\
\text { Goldstein } \\
(1986)\end{array}$ & $\begin{array}{l}1978-1981 \\
779 \text { US- } \\
\text { Unternehmen } \\
\end{array}$ & GAK, 10 Klassen & Aktienrendite & $\begin{array}{l}\text { Unternehmens- } \\
\text { größe }\end{array}$ & $\begin{array}{l}\text { - Kein Zusammenhang zwischen GAK und Per- } \\
\text { formance nachweisbar }\end{array}$ \\
\hline $\begin{array}{l}\text { Holderness/ } \\
\text { Sheehan } \\
\text { (1988) }\end{array}$ & $\begin{array}{l}\text { 1978-1984 } \\
114 \text { US- } \\
\text { Unternehmen im } \\
\text { Mehrheitsbesitz }\end{array}$ & $\begin{array}{l}\text { MAK }>50 \% \text { und }< \\
95 \%, \text { Streubesitz }< \\
20 \%\end{array}$ & $\begin{array}{l}\text { Tobin's Q, } \\
\text { EK-Rendite }\end{array}$ & & $\begin{array}{l}\text { - Kein Zusammenhang zur Performance nach- } \\
\text { weisbar } \\
\text { - Sofern Mehrheitsaktionär natürliche Person } \\
\text { ergibt sich signifikant negativer Einfluss auf } \\
\text { Performance }\end{array}$ \\
\hline $\begin{array}{l}\text { Kim/Lee/ } \\
\text { Francis (1988) }\end{array}$ & $\begin{array}{l}1975-1978 \\
270 \text { US- } \\
\text { Unternehmen }\end{array}$ & $\begin{array}{l}\text { MK, Bildung von } 4 \\
\text { Klassen }\end{array}$ & Aktienrendite & EPS, Größe & $\begin{array}{l}\text { Positiver Zusammenhang zwischen MK und } \\
\text { Performance }\end{array}$ \\
\hline $\begin{array}{l}\text { Morck/ } \\
\text { Shleifer/ } \\
\text { Vishny (1988) }\end{array}$ & $\begin{array}{l}1980 \\
371 \text { Fortune- } \\
500- \\
\text { Unternehmen }\end{array}$ & $\begin{array}{l}\text { MK, Bildung von } \\
\text { drei Klassen, schritt- } \\
\text { weise Regression }\end{array}$ & Tobin's Q & $\begin{array}{l}\text { F\&E- u. Werbe- } \\
\text { aufwendungen, } \\
\text { Größe, FK/BBV, } \\
\text { Branche }\end{array}$ & $\begin{array}{l}\text { - Positiver Effekt bei MK 0,2 bis }<5,0 \% \text {, nega- } \\
\text { tiver bei MK 5,0 bis < } 25 \% \text {, positiver bei MK } \\
>25 \% \\
\text { - Familienmitglied im Board hat bei älteren Un- } \\
\text { ternehmen positiven Einfluss auf Performance }\end{array}$ \\
\hline $\begin{array}{l}\text { Cosh/Hughes } \\
\text { (1989) }\end{array}$ & $\begin{array}{l}1968-1972 \text { und } \\
1975-1980 \\
131 \text { UK- } \\
\text { Unternehmen }\end{array}$ & $\begin{array}{l}\text { GAK, FK, MAK, } \\
\text { nach versch. Krite- } \\
\text { rien }\end{array}$ & $\begin{array}{l}\text { GK-, Aktien-, } \\
\text { Umsatzrendi- } \\
\text { te, Tobin's Q }\end{array}$ & $\begin{array}{l}\text { Größe, Wachs- } \\
\text { tum, VG, Investi- } \\
\text { tionen }\end{array}$ & - Positiver Einfluss von GAK auf Performance \\
\hline $\begin{array}{l}\text { MuraliWelch } \\
\text { (1989) }\end{array}$ & $\begin{array}{l}\text { 1977-1981 } \\
126 \text { US-Unter- } \\
\text { nehmen ( } 43 \\
\text { MAK, } 83 \mathrm{MK} \text { ) }\end{array}$ & $\mathrm{MAK}>50 \%$ & $\begin{array}{l}\text { Aktien-, EK-, } \\
\text { GK-Rendite, } \\
\text { Performan- } \\
\text { cemaße } \\
\end{array}$ & $\begin{array}{l}\text { Größe, Investiti- } \\
\text { onen, Werbe- } \\
\text { aufwendungen, } \\
\text { F\&E }\end{array}$ & $\begin{array}{l}\text { Kein Einfluss von MAK auf buchhalterische } \\
\text { und kapitalmarktbezogene Performancegrößen } \\
\text { nachweisbar }\end{array}$ \\
\hline $\begin{array}{l}\text { McConnell } \\
\text { Servaes (1990) }\end{array}$ & $\begin{array}{l}1976 \text { und } 1986 \\
1173 \text { bzw. } 1903 \\
\text { US-Unter- } \\
\text { nehmen }\end{array}$ & IIK, GAK, MK & Tobin's Q & & $\begin{array}{l}\text { - Outperformance bei MK bis zu } 45 \% \text {, dann Un- } \\
\text { derperformance (konkave Funktion von Q zu } \\
\text { MK) } \\
\text { - Outperformance bei IIK } \\
\text { - GAK nicht signifikant }\end{array}$ \\
\hline
\end{tabular}




\begin{tabular}{|c|c|c|c|c|c|}
\hline Studie & $\begin{array}{l}\text { Zeitraum und } \\
\text { Stichprobe }\end{array}$ & Erklär. Variable(n) & $\begin{array}{l}\text { Abhängige } \\
\text { Variable }\end{array}$ & $\begin{array}{l}\text { Kontroll- } \\
\text { variablen }\end{array}$ & Zentrale Ergebnisse \\
\hline $\begin{array}{l}\text { Zeckhauser/ } \\
\text { Pound (1990) }\end{array}$ & $\begin{array}{l}\text { 1986-1989 } \\
286 \text { US- } \\
\text { Unternehmen }\end{array}$ & $\mathrm{GAK}>15 \%$ & $\begin{array}{l}\text { JÜ/Aktien- } \\
\text { kurs }\end{array}$ & & $\begin{array}{l}\text { - Kein grundsätzlicher Zusammenhang zwischen } \\
\text { GAK und Performance } \\
\text { - Positiver Einfluss ergibt sich für GAK bei Un- } \\
\text { ternehmen mit wenig spezifischen Produkten }\end{array}$ \\
\hline $\begin{array}{l}\text { Chaganti } \\
\text { Damanpour } \\
(1991)\end{array}$ & $\begin{array}{l}1983-1985 \\
88 \text { US-Unterneh- } \\
\text { men }\end{array}$ & IIK & $\begin{array}{l}\text { EK-, GK-, } \\
\text { Aktienrendi- } \\
\text { te, PER }\end{array}$ & & $\begin{array}{l}\text { - Kein Einfluss von IIK auf Aktienrendite nach- } \\
\text { weisbar, positiver Einfluss auf EK-Rendite }\end{array}$ \\
\hline $\begin{array}{l}\text { Hermalin/ } \\
\text { Weisbach } \\
(1991)\end{array}$ & $\begin{array}{l}\text { 1971-1983 } \\
142 \text { NYSE-Un- } \\
\text { ternehmen }\end{array}$ & $\begin{array}{l}\text { MK (Bildung von } \\
\text { vier Klassen, schritt- } \\
\text { weise Regression) } \\
\end{array}$ & Tobin's Q & $\begin{array}{l}\text { Branche, Größe, } \\
\text { F\&E-Ausgaben }\end{array}$ & $\begin{array}{l}\text { - Positiver Effekt bei MK bis } 1 \% \text {, negativer Ef- } \\
\text { fekt bei MK von } 1-5 \% \text { sowie }>20 \% \text {. Bereich } \\
\text { zwischen } 5 \text { und } 20 \% \text { nicht signifikant }\end{array}$ \\
\hline $\begin{array}{l}\text { Leech/Leahy } \\
\text { (1991) }\end{array}$ & $\begin{array}{l}1983-1985 \\
470 \text { UK-Unter- } \\
\text { nehmen }\end{array}$ & $\begin{array}{l}\text { GAK, versch. Vari- } \\
\text { ablen für nominelle } \\
\text { und tatsächliche Kon- } \\
\text { trollmöglichkeit }\end{array}$ & $\begin{array}{l}\text { Versch. Per- } \\
\text { formancein- } \\
\text { dikatoren }\end{array}$ & $\begin{array}{l}\text { Risiko, Größe, } \\
\text { Diversifikation, } \\
\text { Alter, Export- } \\
\text { quote, Kapitalin- } \\
\text { tensität }\end{array}$ & $\begin{array}{l}\text { - Unternehmen mit Großaktionär haben höhere } \\
\text { Profitabilität und höheres Wachstum } \\
\text { - Große Stimmrechtsbündelungen haben } \\
\text { schwach negativen Einfluss } \\
\text { - Identifiziert Stimmrechte als exogen, Cash } \\
\text { Flow-Rechte als endogen }\end{array}$ \\
\hline $\begin{array}{l}\text { Oswald/Jahera } \\
\text { (1991) }\end{array}$ & $\begin{array}{l}\text { 1982-1987 } \\
645 \text { US-Unter- } \\
\text { nehmen }\end{array}$ & MK & $\begin{array}{l}\mathrm{EK}-, \mathrm{GK}-\text {, } \\
\text { risikoadjus- } \\
\text { tierte Über- } \\
\text { rendite }\end{array}$ & Größe & - Positiver Effekt von MK auf Performance \\
\hline $\begin{array}{l}\text { Belkaoui } \\
\text { Pavlik (1992) }\end{array}$ & $\begin{array}{l}1987 \\
228 \text { Fortune- } \\
500 \text {-Unter- } \\
\text { nehmen }\end{array}$ & $\begin{array}{l}\text { MK, GAK, Bildung } \\
\text { von drei Klassen, } \\
\text { schrittweise Regres- } \\
\text { sion }\end{array}$ & $\begin{array}{l}\text { Marktkapita- } \\
\text { lisierung, JÜ }\end{array}$ & $\begin{array}{l}\text { Diversifikations- } \\
\text { grad, Größe }\end{array}$ & $\begin{array}{l}\text { - Positiver Effekt bei MK 0,2 bis < 5,0\% } \\
\text { - Negativer Effekt bei MK 5,0 bis < 25\% } \\
\text { - Positiver Effekt bei MK > 25\% }\end{array}$ \\
\hline Prowse (1992) & $\begin{array}{l}1979-1984 \\
134 \text { große japa- } \\
\text { nische Unter- } \\
\text { nehmen }\end{array}$ & GAK & EK-Rendite & $\begin{array}{l}\text { Größe, F\&E- } \\
\text { Ausgaben, Vari- } \\
\text { anz der EK- } \\
\text { Rendite }\end{array}$ & - Kein Einfluss von GAK auf EK-Rendite \\
\hline
\end{tabular}




\begin{tabular}{|c|c|c|c|c|c|}
\hline Studie & $\begin{array}{l}\text { Zeitraum und } \\
\text { Stichprobe }\end{array}$ & Erklär. Variable(n) & $\begin{array}{l}\text { Abhängige } \\
\text { Variable }\end{array}$ & $\begin{array}{l}\text { Kontroll- } \\
\text { variablen }\end{array}$ & Zentrale Ergebnisse \\
\hline $\begin{array}{l}\text { Denis/Denis } \\
\text { (1994) }\end{array}$ & $\begin{array}{l}1985 \\
72 \text { US-Unterneh- } \\
\text { men }\end{array}$ & MK & En & tfällt & $\begin{array}{l}\text {-Unternehmen mit MK weisen keine Dominanz } \\
\text { anderer Kontrollinstrumente auf } \\
\text { - Keine unternehmensspezifischen Besonderhei- } \\
\text { ten von MK-Unternehmen }\end{array}$ \\
\hline $\begin{array}{l}\text { Lichtenberg/ } \\
\text { Pushner (1994) }\end{array}$ & $\begin{array}{l}1976-1989 \\
1.241 \text { japanische } \\
\text { Industrieuntern. }\end{array}$ & IIK, FK & $\begin{array}{l}\text { GK-Rendite, } \\
\text { Produktivität }\end{array}$ & Keine Angaben & $\begin{array}{l}\text { - Negativer Einfluss von GAK auf Performance } \\
\text { - Positiver Einfluss von IIK und FK }\end{array}$ \\
\hline $\begin{array}{l}\text { Agrawal } \\
\text { Knoeber (1996) }\end{array}$ & $\begin{array}{l}1987 \\
383 \text { US- } \\
\text { Unternehmen }\end{array}$ & GAK, MK, IIK & Tobin's Q & $\begin{array}{l}\text { F\&E- u. Werbe- } \\
\text { aufwendungen, } \\
\text { Größe }\end{array}$ & $\begin{array}{l}\text { - Kein Einfluss von GAK auf Performance } \\
\text { - Schwach positiver Einfluss von MK auf Per- } \\
\text { formance } \\
\text { - Untersucht Zusammenspiel versch. Kontroll- } \\
\text { mechanismen }\end{array}$ \\
\hline $\begin{array}{l}\text { Górriz/Fumás } \\
\text { (1996) }\end{array}$ & $\begin{array}{l}1990 \\
81 \text { span. Untern. }\end{array}$ & FK & $\begin{array}{l}\text { Produktivität, } \\
\text { EK-Rendite }\end{array}$ & Größe, VG & $\begin{array}{l}\text { - Positiver Einfluss von FK auf Produktivität } \\
\text {-Kein Einfluss von FK auf EK-Rendite } \\
\end{array}$ \\
\hline Kole (1996) & $\begin{array}{l}1980 \\
371 \text { Fortune- } \\
500 \text {-Unterneh- } \\
\text { men }\end{array}$ & $\begin{array}{l}\text { MK, Bildung von } \\
\text { drei Klassen, schritt- } \\
\text { weise Regression }\end{array}$ & $\begin{array}{l}\text { Tobin's Q, } \\
\text { GK-Rendite }\end{array}$ & $\begin{array}{l}\text { F\&E- und Wer- } \\
\text { beaufwand, } \\
\text { FK/BBV, Größe }\end{array}$ & $\begin{array}{l}\text { - Neuauswertung der Daten von } \\
\text { Morck/Shleifer/Vishny (1988), negativer Ein- } \\
\text { fluss von MK auf Performance insb. in Unter- } \\
\text { nehmen mit viel F\&E } \\
\text {-Umkehr der Kausalität }\end{array}$ \\
\hline $\begin{array}{l}\text { Loderer/Martin } \\
\text { (1997) }\end{array}$ & $\begin{array}{l}1978-1988 \\
867 \text { US-Unter- } \\
\text { nehmen }\end{array}$ & MK, GAK, IIK & Tobin's Q & $\begin{array}{l}\text { Größe, Volatili- } \\
\text { tät, Akquisi- } \\
\text { tionserfolg }\end{array}$ & $\begin{array}{l}\text { - Kein positiver Einfluss von MK, GAK und IIK } \\
\text { auf Performance } \\
\text {-Umkehr der Kausalität }\end{array}$ \\
\hline $\begin{array}{l}\text { Mikkelson/ } \\
\text { Partch/Shah } \\
\text { (1997) }\end{array}$ & $\begin{array}{l}1980-1983 \\
283 \text { US-Neu- } \\
\text { emissionen }\end{array}$ & MK & GK-Rendite & & $\begin{array}{l}\text { - Kein Zusammenhang zwischen Höhe der MK } \\
\text { und Performance nach dem IPO } \\
\text { - Kein Zusammenhang zwischen Volumen des } \\
\text { Eigentümerwechsels und Performance } \\
\end{array}$ \\
\hline
\end{tabular}




\begin{tabular}{|c|c|c|c|c|c|}
\hline Studie & $\begin{array}{l}\text { Zeitraum und } \\
\text { Stichprobe }\end{array}$ & Erklär. Variable(n) & $\begin{array}{l}\text { Abhängige } \\
\text { Variable }\end{array}$ & $\begin{array}{l}\text { Kontroll- } \\
\text { variablen }\end{array}$ & Zentrale Ergebnisse \\
\hline $\begin{array}{l}\text { Nickell/Nico- } \\
\text { litsas/Dryden } \\
(1997)\end{array}$ & $\begin{array}{l}1982-1994 \\
580 \text { UK-Unter- } \\
\text { nehmen }\end{array}$ & $\begin{array}{l}\text { GAK, IIK, Variablen } \\
\text { analog Leech/Leahy } \\
\text { (1991) }\end{array}$ & $\begin{array}{l}\text { Produktivi- } \\
\text { tätswachstum }\end{array}$ & $\begin{array}{l}\text { Kapitalmarkt- } \\
\text { druck, Wettbe- } \\
\text { werbsintensität } \\
\text { (diverse Variab- } \\
\text { len), Branche }\end{array}$ & $\begin{array}{l}\text { - Positiver Einfluss von IIK auf Produktivitäts- } \\
\text { wachstum } \\
\text {-Außerdem hohe Bedeutung der Wettbewerbs- } \\
\text { intensität }\end{array}$ \\
\hline $\begin{array}{l}\text { Cole/Mehran } \\
\text { (1998) }\end{array}$ & $\begin{array}{l}1983-1987 \\
94 \text { US- } \\
\text { Kreditgenos- } \\
\text { senschaften }\end{array}$ & $\begin{array}{l}\text { MK, GAK, IIK, je- } \\
\text { weils als Anteil des } \\
\text { größten Aktionärs }\end{array}$ & Aktienrendite & & $\begin{array}{l}\text {-Positive Performanceentwicklung nach Aufhe- } \\
\text { bung von Restriktionen bzgl. der Eignerstruk- } \\
\text { tur und Wechsel zu mehr MK } \\
\text { - Kein Zusammenhang zwischen Performance } \\
\text { und IIK/GAK }\end{array}$ \\
\hline Cho (1998) & $\begin{array}{l}1991 \\
326 \text { bzw. } 230 \\
\text { Fortune-500- } \\
\text { Unternehmen }\end{array}$ & MK & $\begin{array}{l}\text { Investitionen, } \\
\text { Tobin's Q }\end{array}$ & $\begin{array}{l}\text { Größe, Kapital- } \\
\text { struktur, Branche }\end{array}$ & $\begin{array}{l}\text { - Signifikant positiver Zusammenhang zwischen } \\
\text { MK und Performance, sowie zwischen Investi- } \\
\text { tionen und Performance } \\
\text {-Weist Endogenität der Eignerstruktur über } \\
\text { zweistufige Regression nach } \\
\end{array}$ \\
\hline $\begin{array}{l}\text { Gedajlovic/ } \\
\text { Shapiro (1998) }\end{array}$ & $\begin{array}{l}1991 \\
1.030 \text { Unter- } \\
\text { nehmen aus } \\
\text { USA, UK, F, D } \\
\text { und C }\end{array}$ & $\begin{array}{l}\text { GAK, Anteil des } \\
\text { größten Aktionärs }\end{array}$ & $\begin{array}{l}\text { Vermögens- } \\
\text { rendite }\end{array}$ & $\begin{array}{l}\text { Diversifikation, } \\
\text { Wachstum, Grö- } \\
\text { Be, Branche, Ex- } \\
\text { portquote, In- } \\
\text { dustrieklima }\end{array}$ & $\begin{array}{l}\text {-Zusammenhang zwischen GAK und Perfor- } \\
\text { mance abhängig von nationaler Corporate Go- } \\
\text { vernance } \\
\text { - Positiver Einfluss von GAK auf Performance } \\
\text { in USA (jedoch nur bei starker Konzentration), } \\
\text { in geringem Maße auch in Deutschland }\end{array}$ \\
\hline $\begin{array}{l}\text { Li/Simerly } \\
\text { (1998) }\end{array}$ & $\begin{array}{l}1990-1993 \\
90 \text { US-Unterneh- } \\
\text { men aus } 2 \text { ver- } \\
\text { schieden dy- } \\
\text { namischen Bran- } \\
\text { chen }\end{array}$ & MK & $\begin{array}{l}\text { operative } \\
\text { Vermö- } \\
\text { gensrendite, } \\
\text { EK-Rendite, } \\
\text { GK-Rendite }\end{array}$ & $\begin{array}{l}\text { Dynamik d. wirt- } \\
\text { schaftlichen Um- } \\
\text { feldes, VG, Di- } \\
\text { versifikation, } \\
\text { IIK, Größe, Alter }\end{array}$ & $\begin{array}{l}\text { - Positiver Einfluss von MK auf Performance } \\
\text { - Positiver Einfluss der MK ist besonders groß } \\
\text { für Unternehmen in sehr dynamischem wirt- } \\
\text { schaftlichem Umfeld }\end{array}$ \\
\hline
\end{tabular}




\begin{tabular}{|c|c|c|c|c|c|}
\hline Studie & $\begin{array}{l}\text { Zeitraum und } \\
\text { Stichprobe }\end{array}$ & Erklär. Variable(n) & $\begin{array}{l}\text { Abhängige } \\
\text { Variable }\end{array}$ & $\begin{array}{l}\text { Kontroll- } \\
\text { variablen }\end{array}$ & Zentrale Ergebnisse \\
\hline $\begin{array}{l}\text { Chirinko et al. } \\
\text { (1999) }\end{array}$ & $\begin{array}{l}\text { 1992-1996 } \\
94 \text { NL-Unter- } \\
\text { nehmen }\end{array}$ & $\begin{array}{l}\text { IIK, Anteil des größ- } \\
\text { ten Aktionärs }\end{array}$ & GK-Rendite & $\begin{array}{l}\text { Branche, Ein- } \\
\text { schränkung von } \\
\text { Stimmrechten, } \\
\text { Größe, VG }\end{array}$ & $\begin{array}{l}\text { - Bei linearer Regression kein Zusammenhang } \\
\text { zwischen IIK und Performance nachweisbar } \\
\text { - Positiver Einfluss von Kreditinstituten auf Per- } \\
\text { formance bis zu Anteil von 14\%, danach nega- } \\
\text { tiver Einfluss }\end{array}$ \\
\hline $\begin{array}{l}\text { Claessens/ } \\
\text { Djankov/ } \\
\text { Fan/Lang } \\
\text { (1999) }\end{array}$ & $\begin{array}{l}1996 \\
2.980 \text { ostasiati- } \\
\text { sche Unterneh- } \\
\text { men }\end{array}$ & $\begin{array}{l}\text { GAK } \geq 10 \% \text { (Cash } \\
\text { Flow- und Stimm- } \\
\text { rechtsanteile des } \\
\text { größten Aktionärs) }\end{array}$ & $\begin{array}{l}\text { Marktbewer- } \\
\text { tung }\end{array}$ & $\begin{array}{l}\text { Kapitalkos- } \\
\text { ten/Umsatz }\end{array}$ & $\begin{array}{l}\text { - Stimmrechtsanteil von } 20 \% \text { kann mit Kapital- } \\
\text { anteil von 19,7\% realisiert werden } \\
\text { - Positiver Einsfluss hoher CF-Rechte auf Per- } \\
\text { formance } \\
\text { - Negativer Einfluss fehlender Kongruenz von } \\
\text { CF- und Stimmrechten auf Performance }\end{array}$ \\
\hline $\begin{array}{l}\text { Duggal/Millar } \\
\text { (1999) }\end{array}$ & $\begin{array}{l}1985-1990 \\
120 \text { US-Unter- } \\
\text { nehmen (Bieter } \\
\text { bei Übernah- } \\
\text { men) }\end{array}$ & IIK & $\begin{array}{l}\text { CAR des } \\
\text { Bieters }\end{array}$ & $\begin{array}{l}\text { MK, Größe, Art } \\
\text { der Übernahme, } \\
\text { Größe und IIK } \\
\text { des Targets, To- } \\
\text { bin's Q }\end{array}$ & $\begin{array}{l}\text { - Kein positiver Einfluss von IIK auf Perfor- } \\
\text { mance nachweisbar }\end{array}$ \\
\hline Gugler (1999) & $\begin{array}{l}1991-1995 \\
214 \text { österr. In- } \\
\text { dustrieunter- } \\
\text { nehmen } \\
1975-1994 \\
94 \text { österr. Un- } \\
\text { tern. }\end{array}$ & $\begin{array}{l}\text { GAK, Anteil des } \\
\text { größten Aktionärs }\end{array}$ & $\begin{array}{l}\text { Umsatzrendi- } \\
\text { te, interner } \\
\text { Zins }\end{array}$ & $\begin{array}{l}\text { Identität des Ak- } \\
\text { tionärs, Branche, } \\
\text { Größe, Investiti- } \\
\text { onen, Volatilität } \\
\text { der UR, Bran- } \\
\text { chenrisiko }\end{array}$ & $\begin{array}{l}\text { - Negativer Einfluss von Großaktionär auf Per- } \\
\text { formance } \\
\text { - Positiver Einfluss von ausländischen Aktionä- } \\
\text { ren auf Performancekennzahlen }\end{array}$ \\
\hline
\end{tabular}




\begin{tabular}{|c|c|c|c|c|c|}
\hline Studie & $\begin{array}{l}\text { Zeitraum und } \\
\text { Stichprobe }\end{array}$ & Erklär. Variable(n) & $\begin{array}{l}\text { Abhängige } \\
\text { Variable }\end{array}$ & $\begin{array}{l}\text { Kontroll- } \\
\text { variablen }\end{array}$ & Zentrale Ergebnisse \\
\hline $\begin{array}{l}\text { Himmelberg/ } \\
\text { Hubbard/ } \\
\text { Palia (1999) }\end{array}$ & $\begin{array}{l}\text { 1982-1992 } \\
\text { 293-427 US- } \\
\text { Unternehmen }\end{array}$ & $\begin{array}{l}\text { MK, Bildung von } \\
\text { drei Klassen, schritt- } \\
\text { weise Regression }\end{array}$ & $\begin{array}{l}\text { Tobin's Q, } \\
\text { GK-Rendite }\end{array}$ & $\begin{array}{l}\text { Größe, Kapitalin- } \\
\text { tensität, F\&E- } \\
\text { Ausgaben, Inves- } \\
\text { titionsquote, CF, } \\
\text { Risiko, Branche }\end{array}$ & $\begin{array}{l}\text { - Kein signifikanter Zusammenhang zwischen } \\
\text { GAK und Performance, sonst wie } \\
\text { Morck/Shleifer/Vishny (1988) } \\
\text {-Eigentümerstruktur ist endogen und wird durch } \\
\text { versch. Variablen im wirtsch. Umfeld des Unt. } \\
\text { determiniert } \\
\text {-Umgekehrter Zusammenhang: Aktionärsstruk- } \\
\text { tur durch Performance determiniert }\end{array}$ \\
\hline $\begin{array}{l}\text { Holderness/ } \\
\text { Kroszner/ } \\
\text { Sheehan } \\
(1999)\end{array}$ & $\begin{array}{l}1935 \text { und } 1995 \\
1.419 \text { bzw. } 4.202 \\
\text { US-Unterneh- } \\
\text { men }\end{array}$ & $\mathrm{MK} \geq 5 \%$ bzw. $25 \%$ & Tobin's Q & $\begin{array}{l}\text { Größe, VG, } \\
\text { Branche }\end{array}$ & $\begin{array}{l}\text { - Nichtlineare Beziehung zwischen MK und Per- } \\
\text { formance für 1935, analog } \\
\text { Morck/Shleifer/Vishny (1988), } 1995 \text { nicht sig- } \\
\text { nifikant } \\
\text { - MK wird } 1995 \text { durch vergleichbare Faktoren } \\
\text { determiniert wie } 1935 \text { und hat über die Jahre } \\
\text { zugenommen }\end{array}$ \\
\hline $\begin{array}{l}\text { Palial } \\
\text { Lichtenberg } \\
\text { (1999) }\end{array}$ & $\begin{array}{l}1982-1993 \\
255 \text { US- } \\
\text { Ind.untern. }\end{array}$ & $\begin{array}{l}\text { MK, Bildung von } \\
\text { drei Klassen }\end{array}$ & Produktivität & Jahr & $\begin{array}{l}\text { - Änderungen in MK führen zu positiven Pro- } \\
\text { duktivitätsveränderungen }\end{array}$ \\
\hline $\begin{array}{l}\text { Pedersen/ } \\
\text { Thomsen } \\
\text { (1999) }\end{array}$ & $\begin{array}{l}1990-1993 \\
518 \text { europäische } \\
\text { Industrieunter- } \\
\text { nehmen aus } 12 \\
\text { Ländern }\end{array}$ & $\begin{array}{l}\text { GAK, Anteil des } \\
\text { größten Aktionärs }\end{array}$ & EK-Rendite & $\begin{array}{l}\text { Größe, Volatilität } \\
\text { der Ergebnisse, } \\
\text { Branche, Land, } \\
\text { Kapitalintensität, } \\
\text { F\&E }\end{array}$ & $\begin{array}{l}\text { - Kein Zusammenhang zwischen GAK und Per- } \\
\text { formance } \\
\text {-Eigentümerstruktur ist endogen } \\
\text { - Kontrollsystem wird beeinflusst durch Nationa- } \\
\text { lität des Unternehmens, Größe, Ergebnisvolati- } \\
\text { lität }\end{array}$ \\
\hline
\end{tabular}




\begin{tabular}{|c|c|c|c|c|c|}
\hline Studie & $\begin{array}{l}\text { Zeitraum und } \\
\text { Stichprobe } \\
\end{array}$ & Erklär. Variable(n) & $\begin{array}{l}\text { Abhängige } \\
\text { Variable } \\
\end{array}$ & $\begin{array}{l}\text { Kontroll- } \\
\text { variablen }\end{array}$ & Zentrale Ergebnisse \\
\hline $\begin{array}{l}\text { Short/Keasey } \\
\text { (1999) }\end{array}$ & $\begin{array}{l}1988-1992 \\
225 \text { UK-Unter- } \\
\text { nehmen }\end{array}$ & $\begin{array}{l}\text { MK (linearer, qua- } \\
\text { dratischer und kubi- } \\
\text { scher Term), IIK, } \\
\text { GAK }\end{array}$ & $\begin{array}{l}\text { MW/BW, } \\
\text { EK-Rendite }\end{array}$ & $\begin{array}{l}\text { Größe, Wachs- } \\
\text { tum, FK-Quote, } \\
\text { F\&E }\end{array}$ & $\begin{array}{l}\text { - Nichtlinearer Zusammenhang zwischen MK } \\
\text { und Performance } \\
\text { - Negativer Einfluss von MK, bei höheren Betei- } \\
\text { ligungsquoten stärker ausgeprägt als in den } \\
\text { USA } \\
\text { - Kein Einfluss von GAK und IIK auf Perfor- } \\
\text { mance }\end{array}$ \\
\hline $\begin{array}{l}\text { Morck/Nakam } \\
\text { ura/Shivdsani } \\
(2000)\end{array}$ & $\begin{array}{l}1986 \\
373 \text { japanische } \\
\text { Industrieunter- } \\
\text { nehmen }\end{array}$ & GAK, MK, IIK & Tobin's Q & $\begin{array}{l}\text { Branche, Größe, } \\
\text { VG, F\&E }\end{array}$ & $\begin{array}{l}\text { - Positiver Einfluss von GAK und MK auf Per- } \\
\text { formance } \\
\text { - Negativer Einfluss von IIK auf Performance } \\
\text { - Nichtlineare Beziehung zwischen Anteilseig- } \\
\text { nerstruktur und Performance }\end{array}$ \\
\hline $\begin{array}{l}\text { Thomsen/ } \\
\text { Pedersen } \\
(2000)\end{array}$ & $\begin{array}{l}1990-1995 \\
435 \text { europäische } \\
\text { Großunterneh- } \\
\text { men }\end{array}$ & GAK, IIK & $\begin{array}{l}\text { Tobin's Q, } \\
\text { GK-Rendite, } \\
\text { Umsatz- } \\
\text { wachstum } \\
\end{array}$ & $\begin{array}{l}\text { Branche, Kapi- } \\
\text { talstruktur, Nati- } \\
\text { onalität }\end{array}$ & $\begin{array}{l}\text {-Zunächst positiver, dann negativer und wieder } \\
\text { positiver Effekt von GAK auf Performance } \\
\text { - Identität des GA entscheidend, positiver Ein- } \\
\text { fluss besonders groß bei IIK }\end{array}$ \\
\hline $\begin{array}{l}\text { Bohren/ } \\
\text { Odegaard } \\
(2001)\end{array}$ & $\begin{array}{l}1989-1997 \\
\text { ca. } 100 \text { norwegi- } \\
\text { sche Industrieun- } \\
\text { ternehmen }\end{array}$ & GAK, MK & $\begin{array}{l}\text { Tobin's Q, } \\
\text { GK-Rendite, } \\
\text { Aktienrendite }\end{array}$ & $\begin{array}{l}\text { Investitionen, } \\
\text { Liquidität, Vola- } \\
\text { tilität der Aktie, } \\
\text { Größe, Branche, } \\
\text { VG } \\
\end{array}$ & $\begin{array}{l}\text { - Negativer Einfluss von GAK auf die Perfor- } \\
\text { mance, insb. auf Tobin's Q (nichtlinearer Ein- } \\
\text { fluss) } \\
\text { - Positiver Einfluss von MK bis Beteiligung von } \\
\text { ca. } 60 \%\end{array}$ \\
\hline $\begin{array}{l}\text { DemsetzVilla- } \\
\text { longa } \\
(2001)\end{array}$ & $\begin{array}{l}1976-1980 \\
223 \text { US-Unter- } \\
\text { nehmen }\end{array}$ & $\begin{array}{l}\text { Anteil der fünf größ- } \\
\text { ten Aktionäre, MK }\end{array}$ & $\begin{array}{l}\text { Tobin's Q, } \\
\text { EK-Rendite }\end{array}$ & $\begin{array}{l}\text { Werbeaufw., } \\
\text { F\&E, Investitio- } \\
\text { nen, FKQ, Kon- } \\
\text { zentration, Risi- } \\
\text { ko, Größe, Bran- } \\
\text { che }\end{array}$ & $\begin{array}{l}\text { - Kein Zusammenhang zwischen GAK und Per- } \\
\text { formance } \\
\text { - Aktionärsstruktur ist endogen }\end{array}$ \\
\hline
\end{tabular}




\begin{tabular}{|c|c|c|c|c|c|}
\hline Studie & $\begin{array}{l}\text { Zeitraum und } \\
\text { Stichprobe }\end{array}$ & Erklär. Variable(n) & $\begin{array}{l}\text { Abhängige } \\
\text { Variable }\end{array}$ & $\begin{array}{l}\text { Kontroll- } \\
\text { variablen }\end{array}$ & Zentrale Ergebnisse \\
\hline $\begin{array}{l}\text { Franks/Mayer/ } \\
\text { Renneboog } \\
(2001)\end{array}$ & $\begin{array}{l}\text { 1988-1993 } \\
>100 \text { UK- } \\
\text { Unternehmen }\end{array}$ & $\mathrm{GAK} \geq 5 \%$ & $\begin{array}{l}\text { Vorstands- } \\
\text { wechsel }\end{array}$ & $\begin{array}{l}\text { Performance (JF, } \\
\text { Dividende, Akti- } \\
\text { enrendite) }\end{array}$ & $\begin{array}{l}\text { - Kein Zusammenhang zwischen Anzahl Vor- } \\
\text { standswechsel nach schlechter Performance } \\
\text { und GAK } \\
\text { - Negativer Einfluss von MK auf Anzahl Vor- } \\
\text { standswechsel }\end{array}$ \\
\hline $\begin{array}{l}\text { Wiwattanakan- } \\
\text { tang }(2001)\end{array}$ & $\begin{array}{l}1996 \\
270 \text { thailändi- } \\
\text { sche Unterneh- } \\
\text { men }\end{array}$ & $\mathrm{GAK} \geq 25 \%$ & $\begin{array}{l}\text { Operative } \\
\text { GK-Rendite, } \\
\text { Umsatz/GK, } \\
\text { Tobin's Q }\end{array}$ & $\begin{array}{l}\text { Wachstum, Grö- } \\
\text { Be, Alter, FKQ, } \\
\text { Branche }\end{array}$ & $\begin{array}{l}\text { - Positiver Effekt von GAK auf buchhalterische } \\
\text { Performancemaße, kein Effekt auf Tobin's Q } \\
\text { - Negativer Einfluss von GA im Management bis } \\
\text { zu 50\% } \\
\text { - Kein Einfluss von abweichenden Kontroll- und } \\
\text { CF-Rechten } \\
\end{array}$ \\
\hline $\begin{array}{l}\text { Guedes/ } \\
\text { Loureiro } \\
\text { (2002) }\end{array}$ & $\begin{array}{l}1999 \\
204 \text { große euro- } \\
\text { päische Indust- } \\
\text { rieunternehmen }\end{array}$ & $\begin{array}{l}\text { GAK (Shapley Va- } \\
\text { lue) }\end{array}$ & Tobin's Q & $\begin{array}{l}\text { Größe, VG, } \\
\text { Branche, Natio- } \\
\text { nalität }\end{array}$ & $\begin{array}{l}\text { - Negativer Einfluss von GAK bei Beteiligungen } \\
>27 \% \text {, bei kleineren Beteiligungen nicht sig- } \\
\text { nifikant } \\
\text { - Negativer Einfluss abweichender Kontroll- und } \\
\text { CF-Rechte; aber: keine Berücksichtigung von } \\
\text { Pyramiden }\end{array}$ \\
\hline $\begin{array}{l}\text { Gugler/ } \\
\text { Mueller/ } \\
\text { Yurtoglu } \\
(2002)\end{array}$ & $\begin{array}{l}\text { Verschiedene } \\
\text { Zeiträume } \\
19.000 \text { Unter- } \\
\text { nehmen aus } 61 \\
\text { Ländern }\end{array}$ & $\begin{array}{l}\mathrm{GAK} \geq 10 \%(\mathrm{MK} \\
\mathrm{FK})\end{array}$ & $\begin{array}{l}\text { Marginales Q } \\
=\text { Investiti- } \\
\text { onsrendite/ } \\
\text { Kapitalkosten }\end{array}$ & $\begin{array}{l}\text { Branche, } 3 \\
\text { Variablen zum } \\
\text { "legal envi- } \\
\text { ronment" }\end{array}$ & $\begin{array}{l}\text { - Negativer Einfluss von GAK in Ländern mit } \\
\text { Rechtssystem deutschen oder skandinavischen } \\
\text { Ursprungs } \\
\text { - Positiver Einfluss von FK in Ländern mit eng- } \\
\text { lischem Rechtssystem } \\
\text { - Nichtlinearer Einfluss von MK in den USA } \\
\text { - Negativer Einfluss abweichender Kontroll- und } \\
\text { CF-Rechte sowie von Pyramidenbildung } \\
\end{array}$ \\
\hline
\end{tabular}




\begin{tabular}{|c|c|c|c|c|c|}
\hline Studie & $\begin{array}{l}\text { Zeitraum und } \\
\text { Stichprobe } \\
\end{array}$ & Erklär. Variable(n) & $\begin{array}{l}\text { Abhängige } \\
\text { Variable } \\
\end{array}$ & $\begin{array}{l}\text { Kontroll- } \\
\text { variablen }\end{array}$ & Zentrale Ergebnisse \\
\hline $\begin{array}{l}\text { Gutiérrez/Tribó } \\
\text { (2002) }\end{array}$ & $\begin{array}{l}1998 \\
4000 \text { spanische } \\
\text { Unternehmen }\end{array}$ & $\begin{array}{l}\text { GAK }>20 \% \text {, zweiter } \\
\text { Großaktionär }>10 \%\end{array}$ & $\begin{array}{l}\text { GKR (als } \\
\text { JÜ/GK) }\end{array}$ & $\begin{array}{l}\text { Größe, VG, Fa- } \\
\text { milie, Branche }\end{array}$ & $\begin{array}{l}\text { - Mehrere Großaktionäre existieren insb. in Un- } \\
\text { ternehmen mit hohem Forschungsaufwand und } \\
\text { hohem Monitoringbedarf } \\
\text { - Positiver Einfluss mehrerer Großaktionäre auf } \\
\text { die Performance }\end{array}$ \\
\hline $\begin{array}{l}\text { Himmelberg/ } \\
\text { Hubbard/Love } \\
\text { (2002) }\end{array}$ & $\begin{array}{l}\text { 1988-1998, } \\
\text { Unternehmen } \\
\text { aus } 38 \text { Ländern } \\
\text { (3 Samples) }\end{array}$ & MK & Kapitalkosten & $\begin{array}{l}\text { Aktionärsschutz, } \\
\text { Investitionen, } \\
\text { Umsatz, Bran- } \\
\text { che, F\&E }\end{array}$ & $\begin{array}{l}\text { - MK dominiert in Ländern mit schwachem Ak- } \\
\text { tionärsschutz } \\
\text { - Je größer der Anteil MK desto höher die Kapi- } \\
\text { talkosten (Entgelt für übernommenes unsyste- } \\
\text { matisches Risiko) }\end{array}$ \\
\hline $\begin{array}{l}\text { LaPorta et al. } \\
(2002)\end{array}$ & $\begin{array}{l}1995 \text { o. } 1996 \\
539 \text { Unterneh- } \\
\text { men aus } 27 \text { In- } \\
\text { dustriestaaten }\end{array}$ & GAK $>10 \%$ & $\begin{array}{l}\text { Tobin's Q } \\
\text { (industry ad- } \\
\text { justed) }\end{array}$ & $\begin{array}{l}\text { Aktionärsschutz, } \\
\text { Investitionen, } \\
\text { Größe, Wachs- } \\
\text { tum }\end{array}$ & $\begin{array}{l}\text { - Separation von Kontroll- und CF-Rechten hat } \\
\text { negativen Einfluss auf Performance } \\
\text { - Positiver Einfluss von GAK bei schlechtem } \\
\text { Aktionärsschutz } \\
\text { - Guter Aktionärsschutz führt zu höherer Bewer- } \\
\text { tung }\end{array}$ \\
\hline $\begin{array}{l}\text { Maury/Pajuste } \\
\text { (2002) }\end{array}$ & $\begin{array}{l}1993-2000 \\
\text { bis zu } 174 \text { finni- } \\
\text { sche Unterneh- } \\
\text { men }\end{array}$ & $\begin{array}{l}\text { GAK (Stimmrechts- } \\
\text { anteil der drei größ- } \\
\text { ten Aktionäre) }\end{array}$ & Tobin's Q & $\begin{array}{l}\text { VG, Größe, } \\
\text { Wachstum, im- } \\
\text { mat. VG, Alter }\end{array}$ & $\begin{array}{l}\text { - Negativer Einfluss von GAK auf Performance } \\
\text { - Positiver Einfluss von mehreren Großaktionä- } \\
\text { ren, die im Wettbewerb um die Kontrolle ste- } \\
\text { hen }\end{array}$ \\
\hline Mitton (2002) & $\begin{array}{l}1997 \\
301 \text { ostasiatische } \\
\text { Industrieunter- } \\
\text { nehmen }\end{array}$ & $\begin{array}{l}\text { GAK (Anteil des } \\
\text { größten Aktionärs; } \\
\text { Anteil aller Aktionäre } \\
>5 \% \text { ) }\end{array}$ & Aktienrendite & $\begin{array}{l}\text { Land, VG, Bran- } \\
\text { che, Größe }\end{array}$ & $\begin{array}{l}\text { - Positiver Einfluss von externen Großaktionären } \\
\text { auf Aktienrendite während der Asienkrise } \\
\text { - Negativer Einfluss von überproportionalen } \\
\text { Stimmrechten }\end{array}$ \\
\hline $\begin{array}{l}\text { Ohnishi/Chujo } \\
(2002)\end{array}$ & $\begin{array}{l}2001 \\
1.156 \text { japanische } \\
\text { Industrieunter- } \\
\text { nehmen }\end{array}$ & MK, IIK; AK; GAK & $\mathrm{MW} / \mathrm{BW}$ & Größe & $\begin{array}{l}\text { - Negativer Einfluss von langfristigen großen } \\
\text { Beteiligungen sowie Überkreuzverflechtungen } \\
\text { auf die Performance } \\
\text { - Nichtlinearer Einfluss von GAK auf die Perfor- } \\
\text { mance }\end{array}$ \\
\hline
\end{tabular}




\begin{tabular}{|c|c|c|c|c|c|}
\hline Studie & $\begin{array}{l}\text { Zeitraum und } \\
\text { Stichprobe }\end{array}$ & Erklär. Variable(n) & $\begin{array}{l}\text { Abhängige } \\
\text { Variable }\end{array}$ & $\begin{array}{l}\text { Kontroll- } \\
\text { variablen } \\
\end{array}$ & Zentrale Ergebnisse \\
\hline $\begin{array}{l}\text { Seifert/Go- } \\
\text { nenc/Wright } \\
(2002)\end{array}$ & $\begin{array}{l}1999 \\
\text { US, UK, D, J; } \\
\text { Anzahl Unter- } \\
\text { nehmen unklar }\end{array}$ & GAK, MK, IIK & JU/GK & Größe, VG, F\&E & $\begin{array}{l}\text { - Linearer, positiver Zusammenhang zwischen } \\
\text { MK und Performance } \\
\text { - Kein Zusammenhang zwischen GAK, IIK und } \\
\text { Performance }\end{array}$ \\
\hline Volpin (2002) & $\begin{array}{l}1986-1997 \\
205 \text { italienische } \\
\text { Industrieunter- } \\
\text { nehmen }\end{array}$ & $\begin{array}{l}\text { MK, GAK, Anteil } \\
\text { des größten Aktio- } \\
\text { närs }\end{array}$ & Tobin's Q & $\begin{array}{l}\text { Größe, Identität } \\
\text { des Großaktio- } \\
\text { närs, Pyramiden, }\end{array}$ & $\begin{array}{l}\text { - Separation von Kontroll- und CF-Rechten hat } \\
\text { negativen Einfluss auf Performance (insb. Py- } \\
\text { ramidenbildung) } \\
\text { - MK hat negativen, GAK positiven Einfluss auf } \\
\text { Performance } \\
\text { - Positiver Einfluss von Stimmrechtsverbindun- } \\
\text { gen } \\
\text { - Kein Einfluss eines großen Minderheitsaktio- } \\
\text { närs }\end{array}$ \\
\hline Woidtke (2002) & $\begin{array}{l}1989-1993 \\
359 \text { US-Unter- } \\
\text { nehmen }\end{array}$ & $\begin{array}{l}\text { IIK, Anteil des größ- } \\
\text { ten Aktionärs }\end{array}$ & $\begin{array}{l}\text { Tobin's Q } \\
\text { (industry ad- } \\
\text { justed) }\end{array}$ & $\begin{array}{l}\text { Branche, F\&E, } \\
\text { MK, VG, Wer- } \\
\text { beausgaben, Bi- } \\
\text { lanzsumme }\end{array}$ & $\begin{array}{l}\text { - Negativer Einfluss von IIK auf Performance } \\
\text { bei öffentlichen Pensionsfonds, positiver bei } \\
\text { privaten } \\
\text { - Unterschiede in Abhängigkeit von Art der IIK }\end{array}$ \\
\hline $\begin{array}{l}\text { Anderson/Reeb } \\
\text { (2003) }\end{array}$ & $\begin{array}{l}1992-1999 \\
403 \text { US- } \\
\text { Industrieunter- } \\
\text { nehmen }\end{array}$ & $\begin{array}{l}\text { FK (Dummy-Vari- } \\
\text { able, die Einfluss } \\
\text { über StA oder Sitz im } \\
\text { Board abbildet) }\end{array}$ & $\begin{array}{l}\text { Tobin's Q, } \\
\text { GKR }\end{array}$ & $\begin{array}{l}\text { Branche, Größe, } \\
\text { Wachstum, Risi- } \\
\text { ko, VG, Alter, } \\
\text { sonst. Großakti- } \\
\text { onäre }\end{array}$ & $\begin{array}{l}\text { - Positiver Einfluss von FK auf Performance } \\
\text { - Positiver Einfluss von Familienmitgliedern im } \\
\text { Management } \\
\text { - Nichtlinearer Zusammenhang zur Performance }\end{array}$ \\
\hline $\begin{array}{l}\text { Chirinko et al. } \\
(2003)\end{array}$ & $\begin{array}{l}1992-1996 \\
93 \text { NL Industrie- } \\
\text { unternehmen }\end{array}$ & $\begin{array}{l}\text { GAK (Anteil des } \\
\text { größten Aktionärs, } 2 \\
\text { Dummy-Variablen }> \\
20 \% \text { und }>40 \% \text { ) }\end{array}$ & GKR & $\begin{array}{l}\text { Aktionärsschutz, } \\
\text { Branche, CF, } \\
\text { VG, Größe }\end{array}$ & $\begin{array}{l}\text { - Kein Einfluss von GAK auf Performance } \\
\text { - Negativer Einfluss von Aktionärsschutzbe- } \\
\text { stimmungen auf Performance }\end{array}$ \\
\hline
\end{tabular}




\begin{tabular}{|c|c|c|c|c|c|}
\hline Studie & $\begin{array}{l}\text { Zeitraum und } \\
\text { Stichprobe }\end{array}$ & Erklär. Variable(n) & $\begin{array}{l}\text { Abhängige } \\
\text { Variable }\end{array}$ & $\begin{array}{l}\text { Kontroll- } \\
\text { variablen }\end{array}$ & Zentrale Ergebnisse \\
\hline $\begin{array}{l}\text { Cronquist } \\
\text { Nilsson } \\
(2003)\end{array}$ & $\begin{array}{l}1991-1997 \\
309 \text { schwedische } \\
\text { Unternehmen }\end{array}$ & $\begin{array}{l}\text { GAK } \geq 25 \% \text { der } \\
\text { Stimmrechte, }\end{array}$ & $\begin{array}{l}\text { Tobin's Q, } \\
\text { GK-Rendite }\end{array}$ & $\begin{array}{l}\text { Identität des GA, } \\
\text { Größe, Alter, } \\
\text { GKR, VG, Um- } \\
\text { satz/GK, Investi- } \\
\text { tionen, Sach- } \\
\text { anlagenquote }\end{array}$ & $\begin{array}{l}\text { - Negativer Einfluss von überproportionalen } \\
\text { Stimmrechten auf Performance } \\
\text { - Negativer Einfluss insb. bei FK, weniger bei } \\
\text { IIK } \\
\text { - Kein Einfluss des Auseinanderfallens von Kon- } \\
\text { troll- und Cash-Flow-Rechten nachweisbar }\end{array}$ \\
\hline Joh (2003) & $\begin{array}{l}\text { 1993-1997 } \\
5.829 \text { koreani- } \\
\text { sche Industrieun- } \\
\text { ternehmen }\end{array}$ & $\begin{array}{l}\text { GAK (Anteil des } \\
\text { größten Aktionärs) }\end{array}$ & GKR, UR & $\begin{array}{l}\text { VG, Größe, } \\
\text { Branche, Markt- } \\
\text { anteil u.a. }\end{array}$ & $\begin{array}{l}\text { - Positiver Einfluss von GAK auf Performance } \\
\text {-Negativer Einfluss überproportionaler Stimm- } \\
\text { rechte auf Performance }\end{array}$ \\
\hline $\begin{array}{l}\text { Lemmon/Lins } \\
(2003)\end{array}$ & $\begin{array}{l}1997 / 1998 \\
800 \text { ostasiatische } \\
\text { Unternehmen }\end{array}$ & $\begin{array}{l}\text { MK (überproportio- } \\
\text { nale Stimmrechte) }\end{array}$ & Aktienrendite & $\begin{array}{l}\text { Größe, VG, } \\
\text { Branche, } \\
\text { BWMW, Beta, } \\
\text { Land }\end{array}$ & $\begin{array}{l}\text { - Negativer Einfluss überproportionaler Stimm- } \\
\text { rechte, wenn Manager hohe Stimmrechtsantei- } \\
\text { le hält } \\
\text {-Zusammenhang ist nur für Zeit der Ostasien- } \\
\text { krise stabil }\end{array}$ \\
\hline Lins (2003) & $\begin{array}{l}1995 \\
\text { insg. } 1.448 \text { Un- } \\
\text { ternehmen ( } 2 \\
\text { Panel) aus } 18 \\
\text { Entwicklungs- } \\
\text { ländern }\end{array}$ & $\begin{array}{l}\text { MK, GAK (separat } \\
\text { untersucht) }\end{array}$ & Tobin's Q & $\begin{array}{l}\text { Größe, Kapital- } \\
\text { struktur, Investi- } \\
\text { tionen, Aktio- } \\
\text { närsschutz }\end{array}$ & $\begin{array}{l}\text { - Separation von Kontroll- und CF-Rechten hat } \\
\text { negativen Einfluss auf Performance } \\
\text { - MK hat negativen, GAK positiven Einfluss auf } \\
\text { Performance, nichtlinearer Verlauf } \\
\text { - GAK insb. bei schlechtem Aktionärsschutz } \\
\text { wirksam }\end{array}$ \\
\hline Shahid (2003) & $\begin{array}{l}2000 \\
90 \text { große ägypti- } \\
\text { sche Unterneh- } \\
\text { men }\end{array}$ & Streubesitzanteil & $\begin{array}{l}\text { Tobin's Q, } \\
\text { EK-Rendite, } \\
\text { GK-Rendite }\end{array}$ & Identität, VG & $\begin{array}{l}\text { - Kein signifikanter Zusammenhang zwischen } \\
\text { Streubesitzanteil und Performancemaßen } \\
\text { - Positiver Einfluss von Holdinggesellschaften } \\
\text { als Großaktionär, negativer Einfluss von MK } \\
\text { und FK }\end{array}$ \\
\hline
\end{tabular}




\begin{tabular}{|c|c|c|c|c|c|}
\hline Studie & $\begin{array}{l}\text { Zeitraum und } \\
\text { Stichprobe }\end{array}$ & Erklär. Variable(n) & $\begin{array}{l}\text { Abhängige } \\
\text { Variable }\end{array}$ & $\begin{array}{l}\text { Kontroll- } \\
\text { variablen }\end{array}$ & Zentrale Ergebnisse \\
\hline $\begin{array}{l}\text { Singh/ } \\
\text { Davidson } \\
(2003)\end{array}$ & $\begin{array}{l}1992 \text { und } 1994 \\
118 \text { US-Indus- } \\
\text { trieunternehmen }\end{array}$ & $\begin{array}{l}\text { MK, GAK (log. An- } \\
\text { teil) }\end{array}$ & $\begin{array}{l}\text { Agency- } \\
\text { Kosten (Um- } \\
\text { satz/BS, Auf- } \\
\text { wandsquote } \\
\end{array}$ & $\begin{array}{l}\text { Größe, Board- } \\
\text { Zusammenset- } \\
\text { zung; VG, Bran- } \\
\text { che }\end{array}$ & $\begin{array}{l}\text { - MK senkt Agency-Kosten (nur teilweise signi- } \\
\text { fikant) } \\
\text { - Kein Einfluss von GAK auf Agency-Kosten }\end{array}$ \\
\hline $\begin{array}{l}\text { AK } \\
\text { IIK } \\
\text { ÖK }\end{array}$ & $\begin{array}{l}\text { durch ausländiscl } \\
\text { durch institutione } \\
\text { durch die öffentli }\end{array}$ & $\begin{array}{l}\text { len Aktionär } \\
\text { lle Investoren } \\
\text { che Hand }\end{array}$ & $\begin{array}{ll}\text { FK } & \text { Familier } \\
\text { MAK } & \text { Mehrhe }\end{array}$ & $\begin{array}{l}\text { nkontrolle } \\
\text { itsaktionärskontrolle }\end{array}$ & $\begin{array}{ll}\text { GAK } & \text { Großaktionärskontrolle } \\
\text { MK } & \text { Managementkontrolle }\end{array}$ \\
\hline
\end{tabular}




\section{Anhang B.2: Regressionsanalysen zum Aktionärsstruktur-Performance-Zusammenhang in Deutsch- land - Allgemein ausgerichtete Studien}

\begin{tabular}{|c|c|c|c|c|c|}
\hline Studie & $\begin{array}{l}\text { Zeitraum und } \\
\text { Stichprobe } \\
\end{array}$ & Erklär. Variable(n) & $\begin{array}{l}\text { Abhängige } \\
\text { Variable } \\
\end{array}$ & $\begin{array}{l}\text { Kontroll- } \\
\text { variablen }\end{array}$ & Zentrale Ergebnisse \\
\hline $\begin{array}{l}\text { Thonet }(1977) \\
\text { Thonet/Poens- } \\
\text { gen (1979) }\end{array}$ & $\begin{array}{l}\text { 1961-1970 } \\
52-92 \text { börsenno- } \\
\text { tierte Industrie- } \\
\text { AG }\end{array}$ & $\begin{array}{l}\mathrm{FK}>25 \%, \text { GAK } \geq \\
25 \%\end{array}$ & $\begin{array}{l}\text { EK-Rendite, } \\
\text { MW/BW }\end{array}$ & $\begin{array}{l}\text { Größe, Monopol- } \\
\text { stellung }\end{array}$ & $\begin{array}{l}\text { - Negativer Effekt von FK auf EK-Rendite } \\
\text { - Kein Effekt auf Aktienrendite } \\
\text { - Positiver Effekt von FK auf MW/BW- } \\
\text { Verhältnis }\end{array}$ \\
\hline $\begin{array}{l}\text { Kaulmann } \\
\text { (1987) }\end{array}$ & $\begin{array}{l}1975-1984 \\
100 \text { Industrie- } \\
\text { AG aus D, F, } \\
\text { GB }\end{array}$ & $\mathrm{GAK} \geq 25 \%$ & $\begin{array}{l}\text { Umsatzrendi- } \\
\text { te, EK- } \\
\text { Rendite, } \\
\text { GK-Rendite }\end{array}$ & $\begin{array}{l}\text { Größe, Branche, } \\
\text { EK-Quote, Land }\end{array}$ & $\begin{array}{l}\text { - Keine Performanceunterschiede zwischen MK } \\
\text { und GAK } \\
\text { - Schlechtere Rentabilitäten bei breit gestreuten } \\
\text { Unternehmen }\end{array}$ \\
\hline Lipka (1995) & $\begin{array}{l}1982-1988 \\
72 \text { börsennotier- } \\
\text { te Industrie- } A G\end{array}$ & $\begin{array}{l}\text { GAK, Bildung von } \\
\text { vier Gruppen }\end{array}$ & $\begin{array}{l}\text { Aktienkurs, } \\
\text { EK-Rendite, } \\
\text { GK-Rendite }\end{array}$ & $\begin{array}{l}\text { Branche, Größe, } \\
\text { Kostenstruktur, } \\
\text { VG, Konzentra- } \\
\text { tion }\end{array}$ & $\begin{array}{l}\text { - Kein Einfluss von GAK auf EK-Rendite } \\
\text { - Positiver Einfluss von GAK auf GK-Rendite }\end{array}$ \\
\hline Nowak (1997) & $\begin{array}{l}1985-1994 \\
44 \text { börsennotier- } \\
\text { te Industrie-AG }\end{array}$ & $\begin{array}{l}\text { Dummy für kon- } \\
\text { trollierenden Aktio- } \\
\text { när }(\geq 25 \%)\end{array}$ & $\begin{array}{l}\text { Marktkapita- } \\
\text { lisierung }\end{array}$ & $\mathrm{F} \& \mathrm{E}$ & - Keine signifikanten Ergebnisse \\
\hline $\begin{array}{l}\text { Gedajlovic/ } \\
\text { Shapiro (1998) }\end{array}$ & $\begin{array}{l}1991 \\
1.030 \text { Unter- } \\
\text { nehmen aus } \\
\text { USA, UK, F, D } \\
\text { und C }\end{array}$ & $\begin{array}{l}\text { GAK, Anteil des } \\
\text { größten Aktionärs }\end{array}$ & $\begin{array}{l}\text { Vermögens- } \\
\text { rendite }\end{array}$ & $\begin{array}{l}\text { Diversifikation, } \\
\text { Wachstum, Grö- } \\
\text { ße, Branche, Ex- } \\
\text { portquote, In- } \\
\text { dustrieklima }\end{array}$ & $\begin{array}{l}\text { - Zusammenhang zwischen GAK und Perfor- } \\
\text { mance abhängig von nationaler Corporate Go- } \\
\text { vernance } \\
\text { - Positiver Einfluss von starker GAK auf Per- } \\
\text { formance in USA, in geringem Maße auch in } \\
\text { D. }\end{array}$ \\
\hline
\end{tabular}




\begin{tabular}{|c|c|c|c|c|c|}
\hline Studie & $\begin{array}{l}\text { Zeitraum und } \\
\text { Stichprobe }\end{array}$ & Erklär. Variable(n) & $\begin{array}{l}\text { Abhängige } \\
\text { Variable } \\
\end{array}$ & $\begin{array}{l}\text { Kontroll- } \\
\text { variablen } \\
\end{array}$ & Zentrale Ergebnisse \\
\hline $\begin{array}{l}\text { Schmid/Seger } \\
\text { (1998) }\end{array}$ & $\begin{array}{l}1976,1987, \\
1991 \\
160 \text { börsenno- } \\
\text { tierte Industrie- } \\
\text { AG }\end{array}$ & $\begin{array}{l}\text { GAK, Herfindahl- } \\
\text { Index, Unterschei- } \\
\text { dung zwischen IIK, } \\
\text { SK }\end{array}$ & $\mathrm{MW/BW}$ & $\begin{array}{l}\text { Größe, Branche, } \\
\text { Mitbestimmung }\end{array}$ & $\begin{array}{l}\text { - Positiver Einfluss von GAK und IIK auf Per- } \\
\text { formance } \\
\text { - Einfluss von SK auf Performance ist negativ, } \\
\text { aber nicht signifikant }\end{array}$ \\
\hline Wolf (1999) & $\begin{array}{l}1986-1992 \\
237 \text { börsenotier- } \\
\text { te Industrie-AG }\end{array}$ & $\mathrm{GAK} \geq 25 \%$ & $\begin{array}{l}\text { MW/BW, } \\
\text { EK-Rendite, } \\
\text { GK-Rendite, } \\
\text { Sharpe-Maß }\end{array}$ & $\begin{array}{l}\text { Branche, Größe, } \\
\text { VG, Index, } \\
\text { Dividende }\end{array}$ & $\begin{array}{l}\text { - Uneinheitliche Ergebnisse je nach verwende- } \\
\text { tem Performancemaß } \\
\text { - Für buchwertbezogene Performancemaße ne- } \\
\text { gativer Einfluss von GAK auf Performance }\end{array}$ \\
\hline $\begin{array}{l}\text { Edwards/Wei- } \\
\text { chenrieder } \\
(2000)\end{array}$ & $\begin{array}{l}1992 \\
97 \text { Industrieun- } \\
\text { ternehmen }\end{array}$ & $\begin{array}{l}\text { GAK, Cash Flow- } \\
\text { bzw. Stimmrechtsan- } \\
\text { teil des größten und } \\
\text { zweitgrößten Aktio- } \\
\text { närs }\end{array}$ & $\mathrm{MW} / \mathrm{BW}$ & $\begin{array}{l}\text { FK-Quote, Beta, } \\
\text { Branche }\end{array}$ & $\begin{array}{l}\text { - Positiver Effekt von GAK auf Performance } \\
\text { - Existenz eines zweiten größeren Aktionärs übt } \\
\text { positiven Einfluss aus } \\
\text { - Betrachtet Kontroll- und Cash Flow-Rechte } \\
\text { separat } \\
\text { - Negativer Einfluss überproportionaler Stimm- } \\
\text { rechte }\end{array}$ \\
\hline $\begin{array}{l}\text { Edwards/ } \\
\text { Nibler }(2000)\end{array}$ & $\begin{array}{l}1991 \\
103 \text { börsenno- } \\
\text { tierte AG }\end{array}$ & $\begin{array}{l}\text { GAK, Anteil der drei } \\
\text { größten Aktionäre, } \\
\text { Differenzierung nach } \\
\text { Identität des Aktio- } \\
\text { närs } \\
\end{array}$ & $\mathrm{MW} / \mathrm{BW}$ & $\begin{array}{l}\text { Größe, Branche, } \\
\text { Mitbestimmung, } \\
\text { Rückstellungen, } \\
\text { Risiko, VG }\end{array}$ & $\begin{array}{l}\text { - Positiver Einfluss auf Performance, wenn Fa- } \\
\text { milie oder natürliche Person Minderheitsanteil } \\
\text { hält } \\
\text { - Schwach positiver Einfluss eines zweiten und } \\
\text { dritten Großaktionärs, kein Einfluss von IIK }\end{array}$ \\
\hline $\begin{array}{l}\text { Lehmann/ } \\
\text { Weigand } \\
(2000)\end{array}$ & $\begin{array}{l}1991-1996 \\
361 \text { Industrieun- } \\
\text { ternehmen (AG } \\
\text { und } \mathrm{GmbH})\end{array}$ & $\begin{array}{l}\text { GAK } \geq 5 \% \text {, Unter- } \\
\text { scheidung in GAK, } \\
\text { MK, FK, IIK, AK }\end{array}$ & $\begin{array}{l}\text { GK-Rendite, } \\
\text { EK-Rendite }\end{array}$ & $\begin{array}{l}\text { Börsennotierung, } \\
\text { Größe, Wachs- } \\
\text { tum, VG, Bran- } \\
\text { che, Identität } \\
\text { Vorstandsmit- } \\
\text { glieder, Wettbe- } \\
\text { werbsintensität } \\
\end{array}$ & $\begin{array}{l}\text { - Negativer Effekt von GAK auf Performance, } \\
\text { besonders ausgeprägt bei nicht börsennotierten } \\
\text { Unternehmen } \\
\text { - Positiver Effekt von IIK auf Performance } \\
\text { - Keine Endogenität der GAK nachweisbar }\end{array}$ \\
\hline
\end{tabular}




\begin{tabular}{|c|c|c|c|c|c|}
\hline Studie & $\begin{array}{l}\text { Zeitraum und } \\
\text { Stichprobe }\end{array}$ & Erklär. Variable(n) & $\begin{array}{l}\text { Abhängige } \\
\text { Variable }\end{array}$ & $\begin{array}{l}\text { Kontroll- } \\
\text { variablen }\end{array}$ & Zentrale Ergebnisse \\
\hline $\begin{array}{l}\text { Gorton/Schmid } \\
(2002)\end{array}$ & $\begin{array}{l}1989-1993 \\
250 \text { börsenno- } \\
\text { tierte Industrie- } \\
\text { AG }\end{array}$ & $\begin{array}{l}\text { GAK, Anteil des } \\
\text { größten Aktionärs, } \\
\text { Unterscheidung in } \\
\text { MK, IIK, FK, SK }\end{array}$ & $\begin{array}{l}\text { EK-Rendite, } \\
\text { GK-Rendite, } \\
\text { MW/BW }\end{array}$ & $\begin{array}{l}\text { Größe, Branche, } \\
\text { Mitbestimmung }\end{array}$ & $\begin{array}{l}\text { - Positiver Einfluss von GAK und IIK, jedoch } \\
\text { nur teilweise signifikant } \\
\text { - Negativer Einfluss von SK }\end{array}$ \\
\hline $\begin{array}{l}\text { Seifert/Go- } \\
\text { nenc/Wright } \\
(2002)\end{array}$ & $\begin{array}{l}1999 \\
\text { US, UK, D, J; } \\
\text { Anzahl Unter- } \\
\text { nehmen unklar }\end{array}$ & GAK, MK, IIK & JÜ/GK & Größe, VG, F\&E & $\begin{array}{l}\text { - Linearer, positiver Zusammenhang zwischen } \\
\text { MK und Performance } \\
\text { - Kein Zusammenhang zwischen GAK, IIK und } \\
\text { Performance }\end{array}$ \\
\hline $\begin{array}{l}\text { Clark/Wójcik } \\
(2003)\end{array}$ & $\begin{array}{l}1997-2001 \\
\text { DAX100-Unter- } \\
\text { nehmen }\end{array}$ & $\begin{array}{l}\text { GAK (Anteil des } \\
\text { größten Aktionärs, } \\
\text { Herfindahl-Index) } \\
\end{array}$ & $\begin{array}{l}\text { Aktienrendi- } \\
\text { te, Sharpe- } \\
\text { Ratio }\end{array}$ & $\begin{array}{l}\text { SHV-Index, } \\
\text { Größe, DAX30, } \\
\text { Bundesland } \\
\end{array}$ & $\begin{array}{l}\text { - Negativer Einfluss von GAK auf Aktienrendite } \\
\text { - Bündelung der GAK-Unternehmen in wenigen } \\
\text { Bundesländern }\end{array}$ \\
\hline $\begin{array}{ll}\text { AK } & \text { Kontrol } \\
\text { IIK } & \text { Kontrol } \\
\text { ÖK } & \text { Kontrol }\end{array}$ & $\begin{array}{l}\text { durch ausländisch } \\
\text { durch institutione } \\
\text { durch die öffentli }\end{array}$ & $\begin{array}{l}\text { len Aktionär } \\
\text { lle Investoren } \\
\text { che Hand }\end{array}$ & $\begin{array}{ll}\text { FK } & \text { Familie } \\
\text { MAK } & \text { Mehrhe }\end{array}$ & $\begin{array}{l}\text { nkontrolle } \\
\text { itsaktionärskontrolle }\end{array}$ & $\begin{array}{ll}\text { GAK } & \text { Großaktionärskontrolle } \\
\text { MK } & \text { Managementkontrolle }\end{array}$ \\
\hline
\end{tabular}




\section{Anhang B.3: Regressionsanalysen zum Aktionärsstruktur-Performance-Zusammenhang in Deutsch- land - Studien für eine spezielle Aktionärsgruppe}

\begin{tabular}{|c|c|c|c|c|c|}
\hline Studie & $\begin{array}{l}\text { Zeitraum und } \\
\text { Stichprobe } \\
\end{array}$ & Erklär. Variable(n) & $\begin{array}{l}\text { Abhängige } \\
\text { Variable } \\
\end{array}$ & $\begin{array}{l}\text { Kontroll- } \\
\text { variablen }\end{array}$ & Zentrale Ergebnisse \\
\hline $\begin{array}{l}\text { Böbel } \\
\text { Dirrheimer } \\
\text { (1984) }\end{array}$ & $\begin{array}{l}1970-1981 \\
293 \text { Unterneh- } \\
\text { men }\end{array}$ & $\begin{array}{l}\text { GAK, SK, Herfin- } \\
\text { dahl-Index }\end{array}$ & $\begin{array}{l}\text { Umsatzrendi- } \\
\text { te }\end{array}$ & $\begin{array}{l}\text { Branche, Diver- } \\
\text { sifikation, } \\
\text { Rechtsform, } \\
\text { Aufsichtsrats- } \\
\text { struktur } \\
\end{array}$ & $\begin{array}{l}\text { - Kein Einfluss der Eigentümerkonzentration auf } \\
\text { Vorstandsbezüge }\end{array}$ \\
\hline Bühner (1985) & $\begin{array}{l}4 \text { Jahre aus dem } \\
\text { Zeitraum 1966- } \\
1981 \\
40 \text { Industrie-AG } \\
\end{array}$ & IIK (Banken), FK & $\begin{array}{l}\text { EK-Rendite, } \\
\text { GK-Rendite }\end{array}$ & $\begin{array}{l}\text { Größe, Wachs- } \\
\text { tum, Aufsichts- } \\
\text { ratsstruktur, Or- } \\
\text { ganisation }\end{array}$ & $\begin{array}{l}\text { - Positiver Einfluss von GAK auf Performance } \\
\text { - Kein Einfluss von IIK und FK auf Performance }\end{array}$ \\
\hline Cable (1985) & $\begin{array}{l}1968-1972 \\
48 \text { Unternehmen }\end{array}$ & IIK (Banken) & JÜ/GK & $\begin{array}{l}\text { HV- } \\
\text { Stimmrechte, } \\
\text { Bankvertreter im } \\
\text { Aufsichtsrat, } \\
\text { Verbind- } \\
\text { lichkeiten } \\
\end{array}$ & $\begin{array}{l}\text { - Positiver Einfluss von IIK und Stimmrechtsein- } \\
\text { fluss von Banken auf Performance }\end{array}$ \\
\hline $\begin{array}{l}\text { Perlitz/Seger } \\
\text { (1994) } \\
\text { Seger (1996) }\end{array}$ & $\begin{array}{l}1990 \\
110 \text { Unterneh- } \\
\text { men }\end{array}$ & $\begin{array}{l}\text { IIK (Banken), Bil- } \\
\text { dung von } 2 \text { Klassen }\end{array}$ & $\begin{array}{l}\text { EK-Rendite, } \\
\text { GK-Rendite }\end{array}$ & $\begin{array}{l}\text { HV- } \\
\text { Stimmrechte, } \\
\text { Bankenvertreter } \\
\text { im Aufsichtsrat, } \\
\text { VG }\end{array}$ & $\begin{array}{l}\text { - Negativer Einfluss von Bankeneinfluss auf } \\
\text { Performance } \\
\text { - Seger (1997): Nichtlinearer Einfluss auf die } \\
\text { Performance }\end{array}$ \\
\hline $\begin{array}{l}\text { Schmid } \\
(1996)\end{array}$ & $\begin{array}{l}1974 \text { und } 1985 \\
88 \text { bzw. } 57 \text { Un- } \\
\text { ternehmen }\end{array}$ & IIK (Banken), GAK & $\begin{array}{l}\text { GK-Rendite, } \\
\text { EK-Rendite }\end{array}$ & $\begin{array}{l}\text { Größe, Branche, } \\
\text { HV- } \\
\text { Stimmrechte, } \\
\text { Stimmrechtsbe- } \\
\text { schränkungen }\end{array}$ & $\begin{array}{l}\text { - Neuauswertung der Daten von Cable (1985) } \\
\text { - Positiver Einfluss von Banken nur 1974er } \\
\text { Stichprobe } \\
\text { - Positiver Einfluss von GAK nur in 1985er } \\
\text { Stichprobe }\end{array}$ \\
\hline
\end{tabular}




\begin{tabular}{|c|c|c|c|c|c|}
\hline Studie & $\begin{array}{l}\text { Zeitraum und } \\
\text { Stichprobe }\end{array}$ & Erklär. Variable(n) & $\begin{array}{l}\text { Abhängige } \\
\text { Variable }\end{array}$ & $\begin{array}{l}\text { Kontroll- } \\
\text { variablen }\end{array}$ & Zentrale Ergebnisse \\
\hline Nibler (1998) & $\begin{array}{l}1988-1992 \\
158 \text { Industrieun- } \\
\text { ternehmen }\end{array}$ & $\begin{array}{l}\text { IIK (Banken), GAK } \\
\text { (Anteil der } 5 \text { größten } \\
\text { Nicht-IIK-Aktionäre) }\end{array}$ & GK-Rendite & $\begin{array}{l}\text { Größe, Wachs- } \\
\text { tum, Branche, } \\
\text { div. Variablen } \\
\text { zum Bank- } \\
\text { einfluss }\end{array}$ & $\begin{array}{l}\text { - Kein signifikanter Zusammenhang zwischen } \\
\text { IIK und Performance }\end{array}$ \\
\hline $\begin{array}{l}\text { Wenger/ } \\
\text { Kaserer (1998) }\end{array}$ & $\begin{array}{l}1973-1993 \\
48 \text { börsennotier- } \\
\text { te Industrie-AG }\end{array}$ & $\begin{array}{l}\text { IIK (Banken), Dum- } \\
\text { my für bankdominiert } \\
\text { vs. nicht-bankdomi- } \\
\text { niert }\end{array}$ & Aktienrendite & $\begin{array}{l}\text { Bankenvertreter } \\
\text { im Aufsichtsrat, } \\
\text { Indexrendite }\end{array}$ & $\begin{array}{l}\text { - Negativer Einfluss von IIK auf Performance } \\
\text { - IIK wirkt sich insb. dann negativ aus, wenn } \\
\text { verschiedene Einflussmöglichkeiten des Kre- } \\
\text { ditinstituts }\end{array}$ \\
\hline $\begin{array}{l}\text { Gorton/Schmid } \\
(2000)\end{array}$ & $\begin{array}{l}1975,1986 \\
\text { versch. Samples, } \\
\text { Industrieuntern. }\end{array}$ & $\begin{array}{l}\text { IIK (Banken), Her- } \\
\text { findahl-Index }\end{array}$ & $\begin{array}{l}\text { MW/BW, } \\
\text { EK-Rendite }\end{array}$ & $\begin{array}{l}\text { Größe, Branche, } \\
\text { Mitbestimmung }\end{array}$ & $\begin{array}{l}\text { - Positiver Einfluss von IIK, MK und GAK auf } \\
\text { Performance, jedoch nicht durchgängig signi- } \\
\text { fikant }\end{array}$ \\
\hline $\begin{array}{l}\text { Kontrolle } \\
\text { Kontrolle } \\
\text { Kontrolle }\end{array}$ & $\begin{array}{l}\text { durch ausländisch } \\
\text { durch institutionel } \\
\text { durch die öffentlic }\end{array}$ & $\begin{array}{l}\text { len Aktionär } \\
\text { lle Investoren } \\
\text { che Hand }\end{array}$ & $\begin{array}{ll}\text { FK } & \text { Familien } \\
\text { MAK } & \text { Mehrhei }\end{array}$ & kontrolle & $\begin{array}{ll}\text { GAK } & \text { Großaktionärskontrolle } \\
\text { MK } & \text { Managementkontrolle }\end{array}$ \\
\hline
\end{tabular}


Anhang B.4: Regressionsanalysen zum Aktionärsstruktur-Performance-Zusammenhang in Deutschland - Einfluss der Aktionärsstruktur auf performanceverwandte Variablen

\begin{tabular}{|c|c|c|c|c|c|}
\hline Studie & $\begin{array}{l}\text { Zeitraum und } \\
\text { Stichprobe }\end{array}$ & Erklär. Variable(n) & $\begin{array}{l}\text { Abhängige } \\
\text { Variable }\end{array}$ & $\begin{array}{l}\text { Kontroll- } \\
\text { variablen }\end{array}$ & Zentrale Ergebnisse \\
\hline Elston (1993) & $\begin{array}{l}1968-1984 \\
150 \mathrm{AG}\end{array}$ & IIK (Banken) & $\begin{array}{l}\text { Investitions- } \\
\text { verhalten }\end{array}$ & $\begin{array}{l}\text { Marktwert, } \\
\text { Sachanlagever- } \\
\text { mögen, CF, Grö- } \\
\text { ße } \\
\end{array}$ & $\begin{array}{l}\text {-GAK durch Banken mindert die Liquiditätsbe- } \\
\text { schränkungen und beeinflusst so das Investiti- } \\
\text { onsverhalten }\end{array}$ \\
\hline $\begin{array}{l}\text { Franks/Mayer } \\
(1997 / 2001)\end{array}$ & $\begin{array}{l}1989-1994 \\
75 \mathrm{AG}\end{array}$ & $\begin{array}{l}\text { GAK (vier Katego- } \\
\text { rien) }\end{array}$ & $\begin{array}{l}\text { Anzahl Vor- } \\
\text { standswech- } \\
\text { sel }\end{array}$ & $\begin{array}{l}\text { Bankeinfluss, } \\
\text { Aktienumsatz, } \\
\text { Performance }\end{array}$ & $\begin{array}{l}\text { - Kein Einfluss von GAK auf die Anzahl Mana- } \\
\text { gementwechsel }\end{array}$ \\
\hline Becht (1999) & $\begin{array}{l}1996-1998 \\
100 \text { börsenno- } \\
\text { tierte AG }\end{array}$ & GAK $\geq 25 \%$ & $\begin{array}{l}\text { Liquidität } \\
\text { (Umsatz/ } \\
\text { Marktkapita- } \\
\text { lisierung) }\end{array}$ & keine & $\begin{array}{l}\text { - Konzentrierte Aktionärsstruktur hat negativen } \\
\text { Einfluss auf Aktienliquidität }\end{array}$ \\
\hline $\begin{array}{l}\text { Januszewski et } \\
\text { al. (1999) }\end{array}$ & $\begin{array}{l}\text { 1986-1994 } \\
164 \text { Kapitalge- } \\
\text { sellschaften }\end{array}$ & $\begin{array}{l}\text { Dummy-Variable für } \\
\text { dominanten Großak- } \\
\text { tionär }\end{array}$ & $\begin{array}{l}\text { Produktivi- } \\
\text { tätswachstum }\end{array}$ & $\begin{array}{l}\text { Wettbewerbsin- } \\
\text { tensität (vier Va- } \\
\text { riablen) }\end{array}$ & $\begin{array}{l}\text { - Kapitalbündelungen haben einen schwach ne- } \\
\text { gativen Einfluss auf das Produktivitätswachs- } \\
\text { tum }\end{array}$ \\
\hline $\begin{array}{l}\text { Ossadnik/ } \\
\text { Dorenkamp } \\
(1999) \\
\end{array}$ & $\begin{array}{l}1993-1997 \\
28 \text { Industrie-AG }\end{array}$ & GAK $\geq 25 \%$ & $\begin{array}{l}\text { Akquisitions- } \\
\text { tätigkeit }\end{array}$ & $\begin{array}{l}\text { Keine (Kontin- } \\
\text { genztest) }\end{array}$ & $\begin{array}{l}\text { - Eigentümer mit einer Beteiligungsquote von } \\
\text { mehr als } 25 \% \text { verstärken die Akquisitionstä- } \\
\text { tigkeit }\end{array}$ \\
\hline $\begin{array}{l}\text { Weigand/Au- } \\
\text { dretsch (1999) }\end{array}$ & $\begin{array}{l}1991-1996 \\
344 \text { Kapitalge- } \\
\text { sellschaften }\end{array}$ & $\begin{array}{l}\text { GAK (Anteil der drei } \\
\text { größten Aktionäre) }\end{array}$ & $\begin{array}{l}\text { Liquiditäts- } \\
\text { beschränkun- } \\
\text { gen }\end{array}$ & $\begin{array}{l}\text { F\&E, Investitio- } \\
\text { nen, CF-Rendite, } \\
\text { Größe, u.a. }\end{array}$ & $\begin{array}{l}\text { - Unternehmen mit konzentrierter Aktionärs- } \\
\text { struktur haben größere Liquiditätsprobleme als } \\
\text { managerkontrollierte Unternehmen }\end{array}$ \\
\hline $\begin{array}{l}\text { Haid/Waigand } \\
(2001)\end{array}$ & $\begin{array}{l}1987-1993 \\
106 \text { Kapitalge- } \\
\text { sellschaften } \\
\end{array}$ & $\begin{array}{l}\text { GAK (vier Katego- } \\
\text { rien) }\end{array}$ & Investitionen & $\begin{array}{l}\text { Größe, Wachs- } \\
\text { tum, VG, Wett- } \\
\text { bewerbsint. u.a. }\end{array}$ & $\begin{array}{l}\text { - Unternehmen mit konzentrierter Aktionärs- } \\
\text { struktur haben größere Finanzierungsbeschrän- } \\
\text { kungen als managerkontrollierte Unternehmen }\end{array}$ \\
\hline
\end{tabular}




\begin{tabular}{|c|c|c|c|c|c|}
\hline Studie & $\begin{array}{l}\text { Zeitraum und } \\
\text { Stichprobe }\end{array}$ & Erklär. Variable(n) & $\begin{array}{l}\text { Abhängige } \\
\text { Variable }\end{array}$ & $\begin{array}{l}\text { Kontroll- } \\
\text { variablen }\end{array}$ & Zentrale Ergebnisse \\
\hline $\begin{array}{l}\text { Kökel } \\
\text { Renneboog } \\
(2003)\end{array}$ & $\begin{array}{l}1986-1996 \\
304 \mathrm{dt} ., 770 \mathrm{UK}- \\
\text { Industrieuntern. }\end{array}$ & $\begin{array}{l}\text { GAK (Dummy- } \\
\text { Variable, Anteil des } \\
\text { größten Aktionärs, } \\
\text { Herfindahl-Index) }\end{array}$ & $\begin{array}{l}\text { Produktivi- } \\
\text { tätswachstum }\end{array}$ & $\begin{array}{l}\text { Identität, VG, } \\
\text { Wettbewerbsin- } \\
\text { tensität, Bonität, } \\
\text { Branche }\end{array}$ & $\begin{array}{l}\text { - Positiver Einfluss von IIK auf Produktivitäts- } \\
\text { wachstum in Deutschland } \\
\text {-GAK und Wettbewerbsintensität wirken in UK } \\
\text { als Kontrollsubstitute, in D als Komplementäre }\end{array}$ \\
\hline $\begin{array}{l}\text { AK } \\
\text { IIK } \\
\text { ÖK }\end{array}$ & $\begin{array}{l}\text { durch institutione } \\
\text { durch die öffentlic }\end{array}$ & $\begin{array}{l}\text { en Aktionär } \\
\text { lle Investoren } \\
\text { che Hand }\end{array}$ & $\begin{array}{ll}\text { FK } & \text { Familie } \\
\text { MAK } & \text { Mehrhe }\end{array}$ & $\begin{array}{l}\text { nkontrolle } \\
\text { itsaktionärskontroll }\end{array}$ & 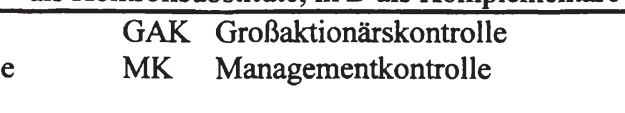 \\
\hline
\end{tabular}




\section{Anhang C: Tabellen}

\begin{tabular}{lrrrrr}
\hline & Ar. Mittel & Std.abw. & 1. Quartil & Median & 3. Quartil \\
\hline Marktkapitalisierung (Mio. 6 ) & 2.502 & 9.864 & 51 & 182 & 772 \\
\hline Performancedaten & & & & & \\
MWBW & 1,44 & 0,89 & 1,00 & 1,19 & 1,53 \\
EKR (\%) & 8,52 & 20,49 & 3,85 & 10,03 & 16,02 \\
GKR (\%) & 4,26 & 4,96 & 2,03 & 4,49 & 6,85 \\
\hline Jahresabschlussdaten & & & & & \\
Umsatz (Mio. 6 ) & 2.932 & 8.478 & 141 & 466 & 1.792 \\
Bilanzsumme (Mio. $\epsilon)$ & 3.066 & 10.224 & 111 & 369 & 1.270 \\
IVG (\%) & 6,58 & 9,79 & 0,69 & 2,17 & 8,69 \\
VG & 5,16 & 22,86 & 1,22 & 2,29 & 3,73 \\
AI (\%) & 44,27 & 24,98 & 28,76 & 40,96 & 54,88 \\
W (\%) & 5,30 & 44,34 & $-7,19$ & 3,73 & 11,22 \\
\hline
\end{tabular}

Tab. A 1: Allgemeine Unternehmenscharakteristika der Sampleunternehmen, $1999^{1101}$

\begin{tabular}{lrrrrr}
\hline & Ar. Mittel & Std.abw. & 1. Quartil & Median & 3. Quartil \\
\hline Marktkapitalisierung (Mio. $\epsilon$ ) & 2.897 & 15.649 & 53 & 171 & 700 \\
\hline Performancedaten & & & & & \\
MWBW & 1,47 & 1,23 & 1,02 & 1,21 & 1,57 \\
EKR (\%) & 7,25 & 22,92 & 3,97 & 9,99 & 15,50 \\
GKR (\%) & 4,06 & 5,16 & 1,59 & 4,38 & 6,55 \\
\hline Jahresabschlussdaten & & & & & \\
Umsatz (Mio. $\epsilon$ ) & 2.740 & 7.803 & 150 & 449 & 1.737 \\
Bilanzsumme (Mio. $\epsilon)$ & 2.592 & 8.747 & 112 & 323 & 1.201 \\
IVG (\%) & 5,91 & 9,78 & 0,46 & 1,63 & 7,46 \\
VG & 3,42 & 9,05 & 1,22 & 2,11 & 3,42 \\
AI (\%) & 44,78 & 25,37 & 28,69 & 39,93 & 56,80 \\
W (\%) & 54,08 & 639,74 & $-3,02$ & 4,45 & 14,78 \\
\hline
\end{tabular}

${ }^{1101}$ Die ausgewiesenen Eigen- und Gesamtkapitalrenditen beziehen sich auf das Jahr 2000. Vgl. hierzu Kapitel IV.2.3.1. 
Tab. A 2: Allgemeine Unternehmenscharakteristika der Sampleunternehmen, $1998^{1102}$

\begin{tabular}{lrrrrr}
\hline & Ar. Mittel & Std.abw. & 1. Quartil & Median & 3. Quartil \\
\hline Marktkapitalisierung (Mio. $\epsilon$ ) & 1.926 & 7.082 & 59 & 191 & 678 \\
\hline Performancedaten & & & & & \\
MWBW & 1,54 & 1,13 & 1,07 & 1,30 & 1,63 \\
EKR (\%) & 10,75 & 15,35 & 5,64 & 11,69 & 17,26 \\
GKR (\%) & 4,98 & 5,08 & 2,40 & 4,67 & 6,93 \\
\hline Jahresabschlussdaten & & & & & \\
Umsatz (Mio. $\epsilon$ ) & 2.591 & 7.211 & 151 & 427 & 1.674 \\
Bilanzsumme (Mio. $\epsilon$ ) & 2.451 & 8.395 & 108 & 307 & 1.120 \\
IVG (\%) & 5,35 & 9,14 & 0,48 & 1,59 & 6,13 \\
VG & 2,54 & 4,66 & 1,14 & 2,05 & 3,30 \\
AI (\%) & 44,65 & 24,39 & 28,96 & 40,80 & 56,33 \\
W (\%) & 75,51 & 814,19 & $-2,05$ & 5,35 & 4,11 \\
\hline
\end{tabular}

Tab. A 3: Allgemeine Unternehmenscharakteristika der Sampleunternehmen, $1997^{1103}$

\begin{tabular}{rrrrrr}
\hline In \% & Ar. Mittel & Std.abw. & 1. Quartil & Median & 3. Quartil \\
\hline $\boldsymbol{H}$ (StA) & & & & & \\
1997 & 0,395 & 0,307 & 0,130 & 0,331 & 0,580 \\
1998 & 0,433 & 0,429 & 0,135 & 0,329 & 0,603 \\
1999 & 0,519 & 0,875 & 0,149 & 0,355 & 0,638 \\
2000 & 0,506 & 1,049 & 0,166 & 0,350 & 0,659 \\
\hline
\end{tabular}

Tab. A 4: Herfindahl-Index der Stimmrechtsanteile (StA)

${ }^{1102}$ Die ausgewiesenen Eigen- und Gesamtkapitalrenditen beziehen sich auf das Jahr 1999. Vgl. hierzu Kapitel IV.2.3.1.

${ }^{1103}$ Die ausgewiesenen Eigen- und Gesamtkapitalrenditen beziehen sich auf das Jahr 1998. Vgl. hierzu Kapitel IV.2.3.1. 


\begin{tabular}{lcccc}
\hline $\begin{array}{l}\text { Abhängige Variable: } \\
\text { VA }\end{array}$ & \multicolumn{4}{c}{$\begin{array}{c}\text { Probit-Regression } \\
\text { Nutzung von Vorzugsaktien nach } \\
\text { Großaktionärsidentität }\end{array}$} \\
\cline { 2 - 5 } $\begin{array}{l}\text { Erklärende } \\
\text { Variablen: }\end{array}$ & $\begin{array}{c}\text { Koeffi- } \\
\text { zient }\end{array}$ & $\begin{array}{c}\text { Std.- } \\
\text { fehler }\end{array}$ & $\begin{array}{c}\text { z-Sta- } \\
\text { tistik }\end{array}$ & p-Wert \\
\hline$c$ & $-0,453$ & 0,117 & $* * *-3,683$ & 0,000 \\
Industrieunternehmen & $-0,471$ & 0,146 & $* * *-3,228$ & 0,001 \\
Ausländer & $-0,338$ & 0,177 & $*-1,909$ & 0,056 \\
Familie & 0,315 & 0,145 & $* * 2,171$ & 0,030 \\
Finanzintermediär & $-0,773$ & 0,204 & $* * *-3,798$ & 0,000 \\
Management & $-0,298$ & 0,192 & $-1,555$ & 0,120 \\
Öffentliche Hand & $-0,113$ & 0,277 & $-0,407$ & 0,684 \\
\hline McFadden $\mathbf{r}^{2}$ & 0,058 & & & \\
LR statistic & 63,953 & & & \\
\hline
\end{tabular}

Tab. A 5: Probit Regression - Nutzung von Vorzugsaktien nach Identität

\begin{tabular}{lrrrr}
\hline $\begin{array}{l}\text { Abhängige Variable: } \\
\text { PY }\end{array}$ & \multicolumn{4}{c}{$\begin{array}{c}\text { Probit-Regression } \\
\text { Nutzung von Pyramiden nach } \\
\text { Großaktionärsidentität }\end{array}$} \\
\cline { 2 - 5 } Erklärende & $\begin{array}{c}\text { Koefri- } \\
\text { zient }\end{array}$ & $\begin{array}{c}\text { Std.- } \\
\text { fehler }\end{array}$ & $\begin{array}{c}\text { z-Sta- } \\
\text { tistik }\end{array}$ & p-Wert \\
\hline Variablen: & $-0,499$ & 0,118 & $* * *-4,218$ & 0,000 \\
Industrieunternehmen & 0,013 & 0,141 & 0,093 & 0,926 \\
Ausländer & 0,319 & 0,168 & $* 1,899$ & 0,058 \\
Familie & $-0,288$ & 0,152 & $*-1,899$ & 0,058 \\
Finanzintermediär & 0,373 & 0,173 & $* * 2,162$ & 0,031 \\
Management & $-0,176$ & 0,190 & $* *-0,925$ & 0,355 \\
Öffentliche Hand & 1,173 & 0,283 & $* * * 4,141$ & 0,000 \\
\hline McFadden $\mathbf{r}^{2}$ & 0,040 & & & \\
LR statistic & 48,577 & & & \\
\hline
\end{tabular}

Tab. A 6: Probit Regression - Nutzung von Pyramiden nach Identität 


\begin{tabular}{ll}
\hline Modell & \multicolumn{1}{c}{ Untersuchungsaufbau } \\
\hline 1 & Querschnittsanalyse, Variablen werden als Durchschnitt der Variablen \\
der vier Einzeljahre gebildet (238 Beobachtungen), OLS-Schätzung \\
1a: MWBW = f(C, StA1, VG, U, IVG, AI, W) \\
1b: MWBW = f(C, StA1, StA1sq, VG, U, IVG, AI, W) \\
1c: MWBW = f (C, KAD1, KAD1sq, VG, U, IVG, AI, W) \\
1d: GKR = f (C, StA1, StA1sq, VG, U, IVG, AI, W) \\
1e: EKR = f(C, StA1, StA1sq, VG, U, IVG, AI, W) \\
1f: MWBW = f (C, StA1, StA1sq, VG, U, IVG, AI, W, Branchen- \\
Dummies)
\end{tabular}

2 Querschnittsanalyse der Einzeljahre 1997 - 2000 (238 Beobachtungen), OLS-Schätzung

MWBW $=\mathrm{f}(\mathrm{C}, \mathrm{StA} 1$, StAlsq, VG, U, IVG, AI, W, Branchen-Dummies)

2a: Sample 1997

2b: Sample 1998

2c: Sample 1999

2d: Sample 2000

3 Panel Daten (952 Beobachtungen), unternehmensspezifische Effekte sind konstant und für alle Unternehmen gleich, OLS-Schätzung mit Korrekturverfahren nach Newey-West (für $3 \mathrm{a}$ und $3 \mathrm{~b}$ zusätzlich unkorrigierte OLS-Schätzung)

3a: MWBW = f (C, StA1, StA1sq, VG, U, IVG, AI, W, IASUSG, Jahres-Dummies)

3b: MWBW = f(C, StA1, StA1sq, VG, U, IVG, AI, W, IASUSG, Jahres-Dummies, Branchen-Dummies)

3c: $M W B W=f(C$, StA1, StA1sq, IVG, AI, W, IASUSG, JahresDummies, Branchen-Dummies)

3d: GKR = f (C, StA1, StA1sq, IVG, AI, W, IASUSG, Jahres-Dummies, Branchen-Dummies)

3e: $E K R=f(C$, StA1, StA1sq, IVG, AI, W, IASUSG, Jahres-Dummies, Branchen-Dummies)

4 Panel Daten (952 Beobachtungen), unternehmensspezifische Effekte sind über die Zeit konstant (238 unternehmensspezifische Konstanten), Fixed-Effects-Schätzung mit Korrekturverfahren nach White (1980)

4: $\quad$ MWBW $=f($ StA1, StA1sq, VG, U, IVG, AI, W, Jahres-Dummies) 


\section{Modell Untersuchungsaufbau}

5 Panel Daten (952 Beobachtungen), unternehmensspezifische Effekte sind konstant und für alle Unternehmen gleich, OLS-Schätzung mit Korrekturverfahren nach Newey-West; Untersuchungsaufbau analog Modell 3 mit Umkehrung der Kausalität von MWBW und StA1

5a: StAl = f(C, MWBW, VG, U, IVG, AI, W, IASUSG, Jahres-Dummies, Branchen-Dummies)

5b: StA1 = f (C, VG, U, IVG, Beta, Jahres-Dummies)

6 Simultanes Gleichungssystem (2-Stage-Least-Squares-Modell) auf Basis der Panel Daten (952 Beobachtungen), unternehmensspezifische Effekte sind konstant und für alle Unternehmen gleich, 2SLSSchätzung mit Korrekturverfahren nach Newey-West

6: $\mathrm{MWBW}=\mathrm{f}(\mathrm{C}, \mathrm{StA} 1$, StA1sq, IVG, AI, W, IASUSG, JahresDummies, Branchen-Dummies)

Instrumentalvariablen: C, StA1(-1), StAlsq(-1), VG, U, AI, IVG, Beta, W, IASUSG, Branchen-Dummies, Jahres-Dummies)

7 Panel Daten (952 Beobachtungen), unternehmensspezifische Effekte sind konstant und für alle Unternehmen gleich, OLS-Schätzung mit Korrekturverfahren nach Newey-West

7a: MWBW $=\mathrm{f}(\mathrm{C}, \mathrm{StA} 5$ 25, StA25_50, StA50_75, StA75_100, IVG, AI, W, IASUSG, Branchen-Dummies, Jahres-Dummies)

7b: $M W B W=f(C$, HStA1, (HStA1sq), IVG, AI, W, IASUSG, Branchen-Dummies, Jahres-Dummies)

7c: $M W B W=f(C, K A D 1, K A D 1 s q, I V G, A I, W$, IASUSG, Branchen-Dummies, Jahres-Dummies)

7d: MWBW $=\mathrm{f}(\mathrm{C}, \mathrm{GA} 2, \mathrm{IVG}, \mathrm{AI}, \mathrm{W}, \mathrm{IASUSG}$, Branchen-Dummies, Jahres-Dummies)

7e: $\mathrm{MWBW}=\mathrm{f}(\mathrm{C}, \mathrm{StA} 1,(\mathrm{StA} 1 \mathrm{sq}), \mathrm{StA} 2,(\mathrm{StA} 2 \mathrm{sq})$, IVG, AI, W, IASUSG, Branchen-Dummies, Jahres-Dummies)

7f: MWBW = f (C, SStA4, IVG, AI, W, IASUSG, Branchen-Dummies, Jahres-Dummies) 


\section{Modell Untersuchungsaufbau}

8 Panel Daten (952 Beobachtungen), unternehmensspezifische Effekte sind konstant und für alle Unternehmen gleich, OLS-Schätzung mit Korrekturverfahren nach Newey-West

8a: MWBW $=f(C$, StA1, StA1sq, IVG, AI, W, IASUSG, IdentitätsDummies, Jahres-Dummies)

8b: MWBW $=\mathrm{f}(\mathrm{C}$, StA1, StA1sq, IVG, AI, W, IASUSG, JahresDummies)

geschätzt für sieben Teilsamples differenziert nach der Identität des größten Aktionärs

9 Panel Daten (952 Beobachtungen), unternehmensspezifische Effekte sind konstant und für alle Unternehmen gleich, OLS-Schätzung mit Korrekturverfahren nach Newey-West

9: $\mathrm{MWBW}=\mathrm{f}(\mathrm{C}, \mathrm{StA1}, \mathrm{StA} 1 \mathrm{sq}, \mathrm{U}, \mathrm{VG}, \mathrm{IVG}, \mathrm{AI}, \mathrm{W}, \mathrm{IASUSG}$, Branchen-Dummies, Jahres-Dummies) geschätzt für zwei Teilsamples differenziert nach der Indexzugehörigkeit

10 Panel Daten (952 Beobachtungen), unternehmensspezifische Effekte sind konstant und für alle Unternehmen gleich, OLS-Schätzung mit Korrekturverfahren nach Newey-West

10a: MWBW $=\mathrm{f}(\mathrm{C}, \mathrm{EV}, \mathrm{IVG}, \mathrm{AI}, \mathrm{W}, \mathrm{IASUSG}$, Branchen-Dummies, Jahres-Dummies)

10b: MWBW = f (C, PY, IVG, AI, W, IASUSG, Branchen-Dummies, Jahres-Dummies)

10c: $M W B W=f(C, V A, I V G, A I, W$, IASUSG, Branchen-Dummies, Jahres-Dummies)

Tab. A 7: $\quad$ Regressionsmodelle 


\begin{tabular}{lrrrr}
\hline $\begin{array}{l}\text { Abhängige Vari- } \\
\text { able: MWBW }\end{array}$ & \multicolumn{5}{c}{ Ramsey RESET-Test } \\
\cline { 2 - 5 } $\begin{array}{l}\text { Erklärende } \\
\text { Variablen: }\end{array}$ & $\begin{array}{r}\text { Koeffi- } \\
\text { zient }\end{array}$ & $\begin{array}{r}\text { Std.- } \\
\text { fehler }\end{array}$ & t-Wert & p-Wert \\
\hline$c$ & $-137,704$ & 44,901 & $* * *-3,067$ & 0,002 \\
StAl & 20,774 & 6,742 & $* * * 3,081$ & 0,002 \\
StA1sq & 60,222 & 19,422 & $* * * 3,101$ & 0,002 \\
\hline $\mathbf{r}^{2}$ & 0,041 & \multicolumn{4}{|c}{ Ramsey RESET Test: } \\
Adj. $\mathbf{r}^{2}$ & 0,032 & F-Statistik & 9,615 & \\
$\hat{\sigma}$ & 0,987 & p-Wert (F-Statistik) & 0,002 & \\
F-Statistik & 4,977 & & & \\
p-Wert & 0,008 & & & \\
(F-Statistik) & & & & \\
\hline
\end{tabular}

Tab. A 8: RESET-Test (MWBW und StA1)

\begin{tabular}{lrrrr}
\hline $\begin{array}{l}\text { Abhängige Vari- } \\
\text { able: MWBW }\end{array}$ & \multicolumn{4}{c}{ Modell 1c } \\
\cline { 2 - 5 } $\begin{array}{l}\text { Erklärende } \\
\text { Variablen: }\end{array}$ & Koeffizient & Std.-fehler & t-Wert & p-Wert \\
\hline$c$ & 1,3804 & 0,475 & $* * * 2,906$ & 0,004 \\
$K A D I$ & $-0,9018$ & 0,780 & $-1,157$ & 0,249 \\
$K A D l s q$ & 0,8623 & 0,675 & 1,278 & 0,203 \\
$U$ & $-0,0017$ & 0,034 & $-0,052$ & 0,959 \\
$I V G$ & 0,0036 & 0,006 & 0,581 & 0,562 \\
$V G$ & $-0,0398$ & 0,018 & $* *-2,239$ & 0,027 \\
$K I$ & 0,0053 & 0,002 & $* * * 2,678$ & 0,008 \\
$W$ & 0,0004 & 0,000 & $* * * 2,718$ & 0,007 \\
\hline $\mathbf{r}^{2}$ & 0,110 & & & \\
Adj. $\mathbf{r}^{2}$ & 0,069 & & & \\
$\hat{\sigma}$ & 0,562 & & & \\
F-Statistik & 2,669 & & & \\
p-Wert & 0,012 & & & \\
(F-Statistik) & & & \\
\hline
\end{tabular}

Tab. A 9: Regressionsergebnisse Modell $1 c$ 


\begin{tabular}{|c|c|c|c|c|}
\hline \multirow{2}{*}{$\begin{array}{l}\text { Abhängige } \\
\text { Variable: } e_{t}^{2} \\
\text { Erklärende } \\
\text { Variablen: }\end{array}$} & \multicolumn{4}{|c|}{$\begin{array}{c}\text { Modell 1b } \\
\text { White-Test }\end{array}$} \\
\hline & Koeffizient & Std.-fehler & t-Wert & p-Wer \\
\hline$c$ & $-2,6670$ & 4,116 & $-0,648$ & 0,518 \\
\hline StAl & $-1,8358$ & 1,448 & $-1,268$ & 0,207 \\
\hline St $A 1^{2}$ & 1,3745 & 1,320 & 1,041 & 0,300 \\
\hline StAlsq $q^{2}$ & $-0,1175$ & 0,137 & $-0,860$ & 0,392 \\
\hline$V G$ & $-0,1371$ & 0,067 & $* *-2,048$ & 0,042 \\
\hline$V G^{2}$ & 0,0055 & 0,004 & 1,404 & 0,162 \\
\hline$U$ & 0,4708 & 0,6492 & 0,725 & 0,470 \\
\hline$U^{2}$ & $-0,0157$ & 0,025 & $-0,625$ & 0,533 \\
\hline$I V G$ & 0,0018 & 0,021 & 0,084 & 0,933 \\
\hline$I V G^{2}$ & $-0,0001$ & 0,001 & $-0,175$ & 0,861 \\
\hline$A I$ & 0,0100 & 0,006 & $* 1,724$ & 0,087 \\
\hline$A I^{2}$ & 0,0000 & 0,000 & $-0,999$ & 0,320 \\
\hline$W$ & 0,0012 & 0,002 & 0,496 & 0,620 \\
\hline$W^{2}$ & $-0,0000$ & 0,000 & $-0,547$ & 0,585 \\
\hline $\mathbf{r}^{2}$ & 0,069 & Obs. $r^{2}$ & 10,950 & \\
\hline Adj. $r^{2}$ & $-0,015$ & p-Wert (Obs. $\left.\mathbf{r}^{2}\right)$ & 0,615 & \\
\hline$\hat{\sigma}$ & 0,868 & & & \\
\hline F-Statistik & 0,825 & & & \\
\hline $\begin{array}{l}\text { p-Wert } \\
\text { (F-Statistik) }\end{array}$ & 0,633 & & & \\
\hline
\end{tabular}

Tab. A 10: White-Test (Modell 1b)

\begin{tabular}{r|rrrrrrrr}
\hline & MWBW & StA1 & StA1sq & VG & U & IVG & AI & W \\
\hline MWBW & 1 & 0,130 & 0,261 & $-0,084$ & $-0,073$ & 0,033 & 0,142 & 0,218 \\
StA1 & 0,130 & 1 & 0,900 & $-0,009$ & $-0,132$ & $-0,151$ & 0,042 & 0,419 \\
StA1sq & 0,261 & 0,900 & 1 & $-0,008$ & $-0,152$ & $-0,133$ & 0,008 & 0,616 \\
VG & $-0,084$ & $-0,009$ & $-0,008$ & 1 & 0,169 & 0,448 & 0,495 & $-0,038$ \\
$\mathbf{U}$ & $-0,073$ & $-0,132$ & $-0,152$ & 0,169 & 1 & 0,075 & $-0,017$ & $-0,143$ \\
IVG & 0,033 & $-0,151$ & $-0,133$ & 0,448 & 0,075 & 1 & 0,399 & $-0,037$ \\
AI & 0,142 & 0,042 & 0,008 & 0,495 & $-0,017$ & 0,399 & 1 & $-0,024$ \\
W & 0,218 & 0,419 & 0,616 & $-0,038$ & $-0,143$ & $-0,037$ & $-0,024$ & 1 \\
\hline
\end{tabular}

Tab. A 11: Korrelationskoeffizienten 

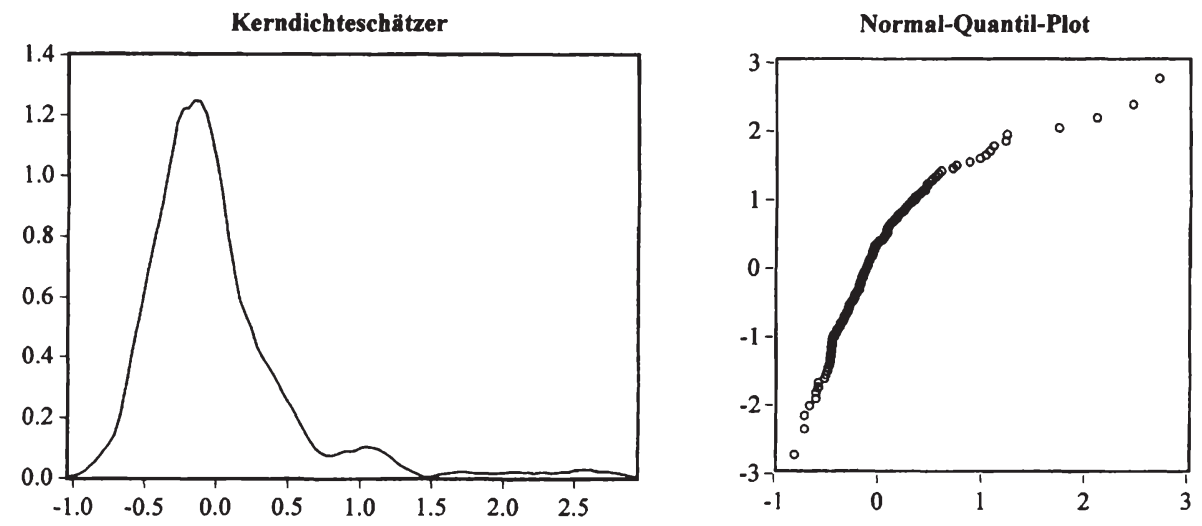

Abb. A 1: Kerndichteschätzer und Normal-Quantil-Plot (Modell lb)

\begin{tabular}{lr}
\hline Mittelwert & $-1,98 E-16$ \\
Median & $-0,1103$ \\
Maximum & 2,6979 \\
Minimum & $-0,7967$ \\
Standardabweichung & 0,5246 \\
Schiefe & 2,3716 \\
Wölbung & 10,8710 \\
\hline Jarque-Bera & 559,48 \\
p-Wert & 0,0000 \\
\hline Kolmogorov-Smirnov & 0,1642 \\
p-Wert & 0,0000 \\
\hline
\end{tabular}

Tab. A 12: Überprüfung der Normalverteilungsannahme (Modell 1b) 


\begin{tabular}{|c|c|c|c|c|}
\hline \multirow{2}{*}{$\begin{array}{l}\text { Abhängige Vari- } \\
\text { able: MWBW } \\
\text { Erklärende } \\
\text { Variablen: }\end{array}$} & \multicolumn{4}{|c|}{$\begin{array}{l}\text { Modell 1b- } \\
\text { MWBW nur auf Basis der Vorzugsaktien } \\
\text { ermittelt, sofern nur eine Gattung notiert }\end{array}$} \\
\hline & Koeffizient & Std.-fehler & t-Wert & p-Wert \\
\hline$c$ & 1,5166 & 0,427 & $* * * 3,548$ & 0,001 \\
\hline$S t A l$ & $-1,0346$ & 0,340 & $* * *-3,040$ & 0,003 \\
\hline StAlsq & 0,8180 & 0,212 & $* * * 3,859$ & 0,000 \\
\hline$U$ & $-0,0079$ & 0,031 & $-0,251$ & 0,802 \\
\hline$I V G$ & 0,0055 & 0,006 & 0,963 & 0,337 \\
\hline$V G$ & $-0,0425$ & 0,0165 & $* *-2,580$ & 0,011 \\
\hline$A I$ & 0,0044 & 0,002 & $* * 2,417$ & 0,017 \\
\hline$W$ & 0,0001 & 0,000 & $-0,362$ & 0,718 \\
\hline$r^{2}$ & 0,187 & & & \\
\hline Adj. $r^{2}$ & 0,149 & & & \\
\hline$\hat{\sigma}$ & 0,520 & & & \\
\hline F-Statistik & 4,963 & & & \\
\hline $\begin{array}{l}\text { p-Wert } \\
\text { (F-Statistik) }\end{array}$ & 0,000 & & & \\
\hline
\end{tabular}

Tab. A 13: Regressionsergebnisse Modell 3b, MWBW nur auf Basis der Vorzugsaktien 


\begin{tabular}{|c|c|c|c|c|}
\hline \multirow{2}{*}{$\begin{array}{l}\text { Abhängige Vari- } \\
\text { able: MWBW } \\
\text { Erklärende } \\
\text { Variablen: }\end{array}$} & \multicolumn{4}{|c|}{ Modell 3a } \\
\hline & Koeffizient & Std.-fehler & t-Wert & p-Wert \\
\hline$c$ & 1,508 & $\begin{array}{r}0,304 \\
(0,281)\end{array}$ & $\begin{array}{r}* * * 4,963 \\
* * *(5,368)\end{array}$ & $\begin{array}{r}0,000 \\
(0,000)\end{array}$ \\
\hline StAl & $-0,696$ & $\begin{array}{r}0,179 \\
(0,229)\end{array}$ & $\begin{array}{r}* * *-3,887 \\
* * *(-3,032)\end{array}$ & $\begin{array}{r}0,000 \\
(0,003)\end{array}$ \\
\hline StAlsq & 0,362 & $\begin{array}{r}0,079 \\
(0,072)\end{array}$ & $\begin{array}{r}* * * 4,614 \\
* * *(5,067)\end{array}$ & $\begin{array}{r}0,000 \\
(0,000)\end{array}$ \\
\hline$A I$ & 0,003 & $\begin{array}{r}0,001 \\
(0,003)\end{array}$ & $\begin{array}{r}* * 2,327 \\
* *(1,987)\end{array}$ & $\begin{array}{r}0,020 \\
(0,047)\end{array}$ \\
\hline$I V G$ & $-0,008$ & $\begin{array}{r}0,004 \\
(0,005)\end{array}$ & $\begin{array}{l}*-1,955 \\
(-1,514)\end{array}$ & $\begin{array}{r}0,051 \\
(0,130)\end{array}$ \\
\hline$U$ & $-0,004$ & $\begin{array}{r}0,021 \\
(0,025)\end{array}$ & $\begin{array}{r}-0,198 \\
(-0,163)\end{array}$ & $\begin{array}{r}0,843 \\
(0,871)\end{array}$ \\
\hline$V G$ & $-0,002$ & $\begin{array}{r}0,003 \\
(0,002)\end{array}$ & $\begin{array}{r}-0,665 \\
(-0,943)\end{array}$ & $\begin{array}{r}0,506 \\
(0,346)\end{array}$ \\
\hline$W$ & 0,000 & $\begin{array}{r}0,000 \\
(0,000)\end{array}$ & $\begin{array}{r}1,407 \\
* *(2,552)\end{array}$ & $\begin{array}{r}0,160 \\
(0,011)\end{array}$ \\
\hline IASUSG & 0,368 & $\begin{array}{r}0,118 \\
(0,210)\end{array}$ & $\begin{array}{l}* * * 3,109 \\
*(1,758)\end{array}$ & $\begin{array}{r}0,002 \\
(0,079)\end{array}$ \\
\hline 1997 & 0,117 & $\begin{array}{r}0,101 \\
(0,057)\end{array}$ & $\begin{array}{r}1,162 \\
* *(2,070)\end{array}$ & $\begin{array}{r}0,245 \\
(0,039)\end{array}$ \\
\hline 1998 & 0,126 & $\begin{array}{r}0,091 \\
(0,066)\end{array}$ & $\begin{array}{r}1,387 \\
*(1,908)\end{array}$ & $\begin{array}{r}0,166 \\
(0,057)\end{array}$ \\
\hline 1999 & 0,071 & $\begin{array}{r}0,090 \\
(0,041)\end{array}$ & $\begin{array}{r}0,794 \\
*(1,763)\end{array}$ & $\begin{array}{r}0,427 \\
(0,078)\end{array}$ \\
\hline $\begin{array}{l}\mathbf{r}^{2} \\
\text { Adj. } \mathbf{r}^{2}\end{array}$ & $\begin{array}{l}0,045 \\
0,033\end{array}$ & $\begin{array}{l}\text { Robuste Stan } \\
\text { Werte nach N }\end{array}$ & $\begin{array}{l}\text { lardfehler, } t-W \\
\text { ewey-West in }\end{array}$ & $\begin{array}{l}\text { und p- } \\
\text { mmern. }\end{array}$ \\
\hline$\hat{\sigma}$ & 0,967 & & & \\
\hline F-Statistik & 3,676 & & & \\
\hline $\begin{array}{l}\text { p-Wert } \\
\text { (F-Statistik) }\end{array}$ & 0,000 & & & \\
\hline
\end{tabular}

Tab. A 14: Regressionsergebnisse Modell $3 a$ 


\begin{tabular}{|c|c|c|c|c|}
\hline \multirow{2}{*}{$\begin{array}{l}\text { Abhängige } \\
\text { Variable: } e_{t} \\
\text { Erklärende } \\
\text { Variablen: }\end{array}$} & \multicolumn{4}{|c|}{$\begin{array}{c}\text { Modell 3b } \\
\text { Breusch-Godfrey-Test }\end{array}$} \\
\hline & Koeffizient & \multirow{2}{*}{$\frac{\text { Std.-fehler }}{0,314}$} & t-Wert & p-Wert \\
\hline $\bar{c}$ & $-0,071$ & & $-0,227$ & 0,820 \\
\hline StAl & 0,187 & 0,138 & 1,358 & 0,175 \\
\hline StAlsq & $-0,133$ & 0,060 & $* *-2,207$ & 0,028 \\
\hline$A I$ & $-0,000$ & 0,001 & $-0,084$ & 0,933 \\
\hline$I V G$ & 0,000 & 0,003 & 0,108 & 0,914 \\
\hline$U$ & 0,001 & 0,016 & 0,054 & 0,957 \\
\hline$V G$ & 0,002 & 0,002 & 0,901 & 0,368 \\
\hline$W$ & $-0,000$ & 0,000 & $-0,713$ & 0,476 \\
\hline IASUSG & $-0,228$ & 0,093 & $* *-2,454$ & 0,014 \\
\hline$e_{t-1}$ & 0,539 & 0,038 & $* * * 14,218$ & 0,000 \\
\hline$e_{t-2}$ & 0,368 & 0,045 & $* * * 8,167$ & 0,000 \\
\hline$e_{t-3}$ & $-0,040$ & 0,051 & $-0,776$ & 0,438 \\
\hline$\overline{\mathbf{r}^{2}}$ & 0,321 & \multicolumn{3}{|c|}{ Breusch-Godfrey-Test: } \\
\hline Adj. $\mathbf{r}^{2}$ & 0,300 & F-Statistik & \multicolumn{2}{|c|}{131,602} \\
\hline$\hat{\sigma}$ & 0,728 & \multicolumn{3}{|c|}{ p-Wert (F-Statistik) $\quad 0,000$} \\
\hline $\begin{array}{l}\text { F-Statistik } \\
\text { p-Wert } \\
\text { (F-Statistik) }\end{array}$ & $\begin{array}{r}15,185 \\
0,000\end{array}$ & \multicolumn{3}{|c|}{$\begin{array}{l}\text { Branchen- und Jahres-Dummies werden } \\
\text { nicht ausgewiesen, die Koeffizienten } \\
\text { sind alle insignifikant. }\end{array}$} \\
\hline
\end{tabular}

Tab. A 15: Breusch-Godfrey-Test (Modell 3b) 


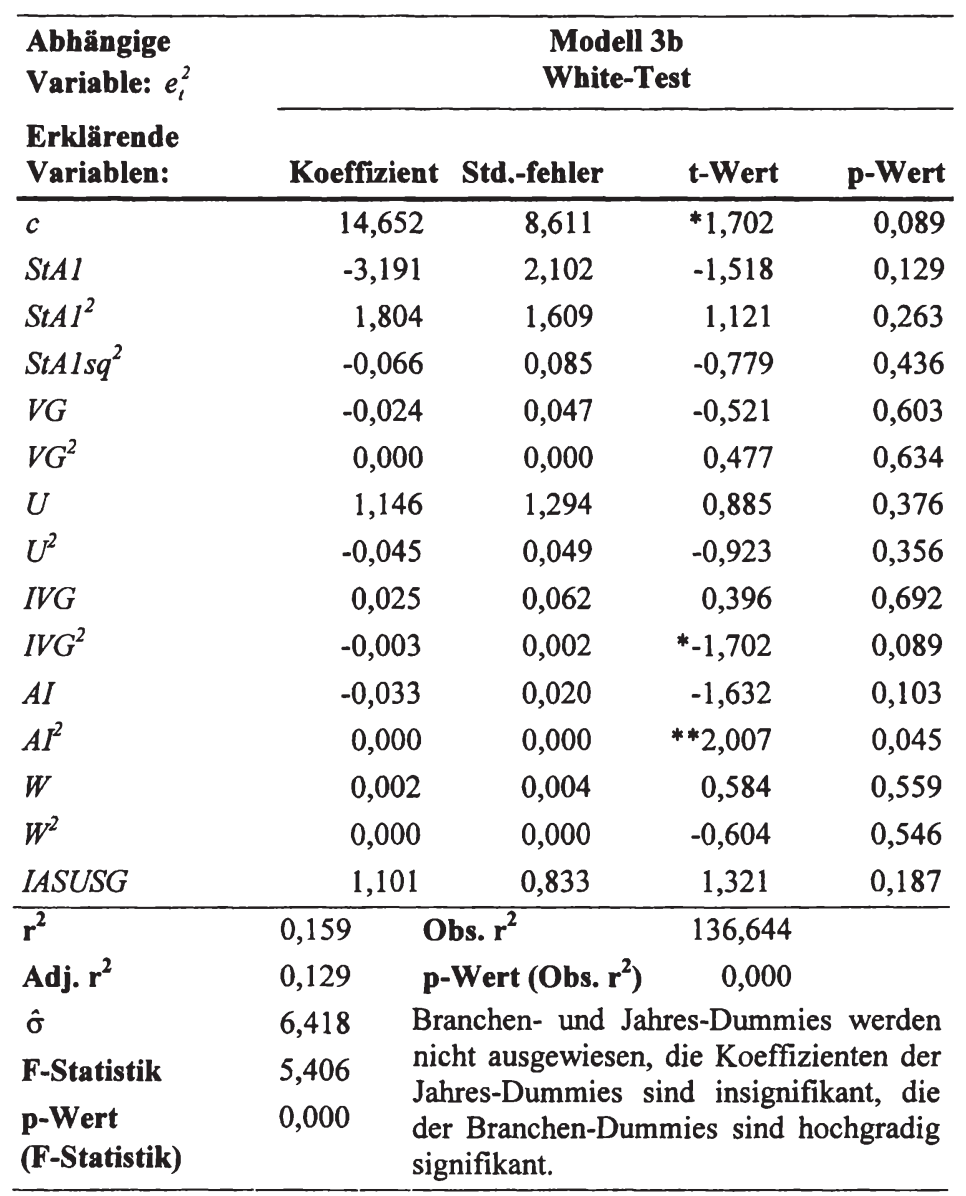

Tab. A 16: White-Test (Modell 3b) 


\begin{tabular}{|c|c|c|c|c|}
\hline \multirow{2}{*}{$\begin{array}{l}\text { Abhängige Vari- } \\
\text { able: MWBW } \\
\text { Erklärende } \\
\text { Variablen: }\end{array}$} & \multicolumn{4}{|c|}{ Modell 3c } \\
\hline & Koeffizient & Std.-fehler & t-Wert & p-Wert \\
\hline$c$ & 4,032 & 1,706 & $* * 2,363$ & 0,018 \\
\hline StAl & $-0,626$ & 0,228 & $* * *-2,739$ & 0,006 \\
\hline StAlsq & 0,351 & 0,070 & $* * * 5,040$ & 0,000 \\
\hline$A I$ & 0,003 & 0,002 & $* 1,719$ & 0,086 \\
\hline$I V G$ & $-0,017$ & 0,009 & $*-1,827$ & 0,068 \\
\hline$W$ & 0,000 & 0,000 & $* * * 2,720$ & 0,007 \\
\hline IASUSG & 0,375 & 0,197 & $* 1,903$ & 0,057 \\
\hline $\mathbf{r}^{2}$ & 0,212 & & & \\
\hline Adj. $r^{2}$ & 0,193 & & & \\
\hline$\hat{\sigma}$ & 0,879 & & & \\
\hline F-Statistik & 10,993 & & & \\
\hline $\begin{array}{l}\text { p-Wert } \\
\text { (F-Statistik) }\end{array}$ & 0,000 & & & \\
\hline
\end{tabular}

Tab. A 17: Regressionsergebnisse Modell 3c

\begin{tabular}{|c|c|c|c|c|c|c|c|c|}
\hline & \multicolumn{4}{|c|}{ Modell 3d (abh. Var.: GKR) } & \multicolumn{4}{|c|}{ Modell 3e (abh. Var.: EKR) } \\
\hline & $\begin{array}{r}\text { Koeffi- } \\
\text { zient }\end{array}$ & $\begin{array}{l}\text { Std.- } \\
\text { fehler }\end{array}$ & t-Wert & p-Wert & $\begin{array}{r}\text { Koeffi- } \\
\text { zient }\end{array}$ & $\begin{array}{l}\text { Std.- } \\
\text { fehler }\end{array}$ & t-Wert & p-Wert \\
\hline$c$ & $-0,2269$ & 0,311 & $-0,729$ & 0,466 & 0,4844 & 0,998 & 0,485 & 0,628 \\
\hline StAl & 0,0322 & 0,086 & 0,376 & 0,707 & $-3,4956$ & 3,486 & $-1,003$ & 0,316 \\
\hline StAlsq & 0,0140 & 0,021 & 0,679 & 0,497 & 0,8608 & 0,819 & 1,051 & 0,293 \\
\hline$A I$ & 0,0088 & 0,009 & 1,028 & 0,304 & 0,0394 & 0,034 & 1,166 & 0,244 \\
\hline$I V G$ & $-0,0122$ & 0,011 & $-1,073$ & 0,284 & $-0,0273$ & 0,021 & $-1,285$ & 0,199 \\
\hline$W$ & $-0,0000$ & 0,000 & $-0,700$ & 0,484 & 0,0003 & 0,000 & 0,832 & 0,406 \\
\hline IASUSG & 0,0408 & 0,054 & 0,761 & 0,447 & $-0,1910$ & 0,355 & $-0,539$ & 0,590 \\
\hline$r^{2}$ & & 0,043 & & 0,023 & \multirow{5}{*}{\multicolumn{4}{|c|}{$\begin{array}{l}\text { Branchen- und Jahres-Dummies } \\
\text { werden nicht ausgewiesen, die } \\
\text { Koeffizienten sind überwiegend } \\
\text { nicht signifikant. }\end{array}$}} \\
\hline Adj. $\mathbf{r}^{2}$ & & 0,020 & & $-0,001$ & & & & \\
\hline$\hat{\sigma}$ & & 1,125 & & 12,975 & & & & \\
\hline F-Statisti & & 1,846 & & 0,942 & & & & \\
\hline $\begin{array}{l}\text { p-Wert } \\
\text { (F-Statist }\end{array}$ & & 0,012 & & 0,536 & & & & \\
\hline
\end{tabular}

Tab. A 18: Regressionsergebnisse Modell 3d und Modell $3 e$ 


\begin{tabular}{lcccr}
\hline $\begin{array}{l}\text { Abhängige Vari- } \\
\text { able: StA1 }\end{array}$ & \multicolumn{5}{c}{ Modell 5a } \\
\cline { 2 - 5 } $\begin{array}{l}\text { Erklärende } \\
\text { Variablen: }\end{array}$ & Koeffizient & Std.-fehler & t-Wert & p-Wert \\
\cline { 2 - 5 }$c$ & 1,198 & 0,236 & $* * * 5,079$ & 0,000 \\
$M W B W$ & 0,007 & 0,029 & 0,026 & 0,980 \\
$A I$ & 0,001 & 0,001 & 0,872 & 0,384 \\
$I V G$ & $-0,004$ & 0,002 & $*-1,835$ & 0,067 \\
$U$ & $-0,045$ & 0,011 & $* * *-4,027$ & 0,000 \\
$V G$ & $-0,002$ & 0,000 & $* * *-4,504$ & 0,000 \\
$W$ & 0,000 & 0,000 & 0,806 & 0,420 \\
$I A S U S G$ & $-0,045$ & 0,045 & $-0,998$ & 0,319 \\
\hline $\mathbf{r}^{2}$ & 0,124 & \multicolumn{5}{c}{ Nicht ausgewiesene Branchen- } \\
Adj. $\mathbf{r}^{2}$ & 0,101 & und Jahres-Dummies sind je- \\
$\hat{\sigma}$ & 0,328 & weils nicht signifikant. & \\
F-Statistik & 5,379 & & & \\
p-Wert & 0,000 & & & \\
(F-Statistik) & & & \\
\hline
\end{tabular}

Tab. A 19: Regressionsergebnisse Modell $5 a$ 


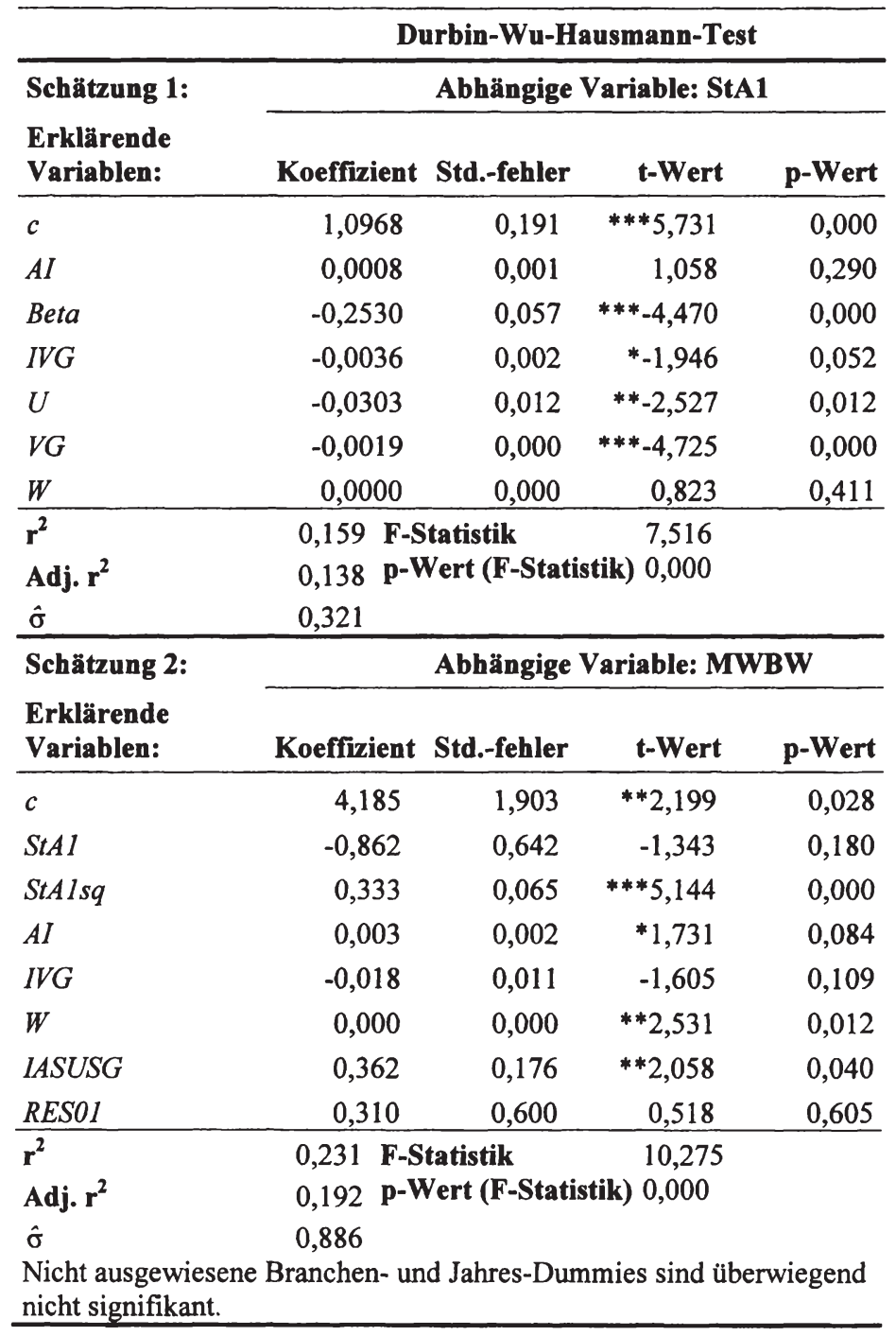

Tab. A 20: Durbin-Wu-Hausmann-Test 


\begin{tabular}{|c|c|c|c|c|c|c|c|c|}
\hline \multirow{2}{*}{$\begin{array}{l}\text { Abh. Var. } \\
\text { MWBW } \\
\text { Erkl. } \\
\text { Var.: }\end{array}$} & \multicolumn{4}{|c|}{ Modell 7b (Variante I) } & \multicolumn{4}{|c|}{ Modell 7b (Variante II) } \\
\hline & $\begin{array}{r}\text { Koeffi- } \\
\text { zient }\end{array}$ & $\begin{array}{l}\text { Std.- } \\
\text { fehler }\end{array}$ & t-Wert & p-Wert & $\begin{array}{r}\text { Koeffi- } \\
\text { zient }\end{array}$ & $\begin{array}{l}\text { Std.- } \\
\text { fehler }\end{array}$ & t-Wert & p-Wert \\
\hline$c$ & 3,784 & 1,681 & $* * 2,250$ & 0,025 & 3,844 & 1,686 & $* * 2,281$ & 0,023 \\
\hline$H S t A$ & 0,116 & 0,068 & $* 1,701$ & 0,089 & $-0,046$ & 0,147 & $-0,314$ & 0,753 \\
\hline HStAsq & & & & & 0,016 & 0,011 & 1,479 & 0,140 \\
\hline$A I$ & 0,002 & 0,002 & 1,370 & 0,171 & 0,002 & 0,002 & $* * * 1,575$ & 0,006 \\
\hline$I V G$ & $-0,015$ & 0,009 & $*-1,680$ & 0,093 & $-0,016$ & 0,009 & $*-1,760$ & 0,079 \\
\hline$W$ & 0,000 & 0,000 & $* * * 3,378$ & 0,001 & 0,000 & 0,000 & $* * * 2,636$ & 0,009 \\
\hline IASUSG & 0,412 & 0,203 & $* * 2,029$ & 0,043 & 0,397 & 0,199 & $* * 1,988$ & 0,047 \\
\hline $\mathbf{r}^{2}$ & & & \multicolumn{2}{|c|}{0,198} & 0,203 & & & \\
\hline Adj. $r^{2}$ & & & \multicolumn{2}{|c|}{0,179} & 0,183 & & & \\
\hline$\hat{\sigma}$ & & & \multicolumn{2}{|c|}{0,886} & 0,883 & & & \\
\hline F-Statistik & & & \multicolumn{2}{|c|}{10,608} & 10,403 & & & \\
\hline p-Wert (F- & Statistik) & & \multicolumn{2}{|c|}{0,000} & 0,000 & & & \\
\hline
\end{tabular}

Branchen- und Jahres-Dummies werden nicht ausgewiesen, die Koeffizienten sind zum größten Teil schwach signifikant.

Tab. A 21: Regressionsergebnisse Modell $7 b$

\begin{tabular}{|c|c|c|c|c|}
\hline \multirow{2}{*}{$\begin{array}{l}\text { Abhängige Vari- } \\
\text { able: MWBW } \\
\text { Erklärende } \\
\text { Variablen: }\end{array}$} & \multicolumn{4}{|c|}{ Modell 7c } \\
\hline & Koeffizient & Std.-fehler & t-Wert & p-Wert \\
\hline$c$ & 4,100 & 1,746 & $* * 2,348$ & 0,019 \\
\hline$K A D 1$ & $-1,121$ & 0,639 & $*-1,755$ & 0,080 \\
\hline$K A D 1 s q$ & 0,856 & 0,562 & 1,523 & 0,128 \\
\hline$A I$ & 0,003 & 0,002 & 1,603 & 0,109 \\
\hline$I V G$ & $-0,017$ & 0,009 & $*-1,801$ & 0,072 \\
\hline$W$ & 0,000 & 0,000 & $* * 2,424$ & 0,016 \\
\hline IASUSG & 0,371 & 0,195 & $* 1,908$ & 0,057 \\
\hline $\mathbf{r}^{2}$ & \multicolumn{3}{|c|}{0,198} & anchen- \\
\hline Adj. $\mathbf{r}^{2}$ & \multicolumn{3}{|c|}{0,178} & ind je- \\
\hline$\hat{\sigma}$ & \multicolumn{3}{|c|}{0,886} & \\
\hline F-Statistik & \multicolumn{3}{|c|}{10,110} & \\
\hline p-Wert (F-Statistik) & \multicolumn{2}{|c|}{0,000} & & \\
\hline
\end{tabular}

Tab. A 22: Regressionsergebnisse Modell 7c 


\begin{tabular}{lcccc}
\hline $\begin{array}{l}\text { Abhängige Vari- } \\
\text { able: MWBW }\end{array}$ & \multicolumn{5}{c}{ Modell 7d } \\
\cline { 2 - 5 } $\begin{array}{l}\text { Erklärende } \\
\text { Variablen: }\end{array}$ & Koeffizient & Std.-fehler & t-Wert & p-Wert \\
\hline $\boldsymbol{c}$ & 3,909 & 1,682 & $* * 2,324$ & 0,050 \\
$G A 2$ & $-0,155$ & 0,115 & $-1,353$ & 0,177 \\
$A I$ & 0,002 & 0,002 & 1,260 & 0,208 \\
$I V G$ & $-0,016$ & 0,009 & $*-1,828$ & 0,068 \\
$W$ & 0,000 & 0,000 & $* * 2,300$ & 0,022 \\
IASUSG & 0,395 & 0,204 & $* 1,939$ & 0,053 \\
\hline $\mathbf{r}^{2}$ & 0,194 & & Nicht ausgewiesene Branchen- \\
Adj. $\mathbf{r}^{2}$ & 0,175 & und Jahres-Dummies sind je- \\
$\hat{\sigma}$ & 0,888 & weils schwach signifikant. \\
F-Statistik & 10,354 & & & \\
p-Wert & 0,000 & & & \\
(F-Statistik) & & & & \\
\hline
\end{tabular}

Tab. A 23: $\quad$ Regressionsergebnisse Modell 7d

\begin{tabular}{|c|c|c|c|c|c|c|c|c|}
\hline \multirow{2}{*}{$\begin{array}{l}\text { Abh. Var. } \\
\text { MWBW } \\
\text { Erkl. } \\
\text { Var.: }\end{array}$} & \multicolumn{4}{|c|}{ Modell 7e (Variante I) } & \multicolumn{4}{|c|}{ Modell 7e (Variante II) } \\
\hline & $\begin{array}{r}\text { Koeffi- } \\
\text { zient }\end{array}$ & $\begin{array}{l}\text { Std.- } \\
\text { fehler }\end{array}$ & t-Wert & p-Wert & $\begin{array}{r}\text { Koeffi- } \\
\text { zient }\end{array}$ & $\begin{array}{l}\text { Std.- } \\
\text { fehler }\end{array}$ & t-Wert & p-Wert \\
\hline$c$ & 5,395 & 2,375 & $* * 2,272$ & 0,024 & 5,465 & 2,445 & $* * 2,236$ & 0,026 \\
\hline StAl & $-0,244$ & 0,228 & $-1,072$ & 0,284 & $-0,071$ & 0,968 & $-0,074$ & 0,941 \\
\hline StAlsq & & & & & $-0,175$ & 0,917 & $-0,191$ & 0,849 \\
\hline StA2 & $-0,810$ & 0,477 & $*_{-1,698}$ & 0,090 & $-1,417$ & 0,892 & $-1,588$ & 0,113 \\
\hline StA2sq & & & & & 0,718 & 0,543 & 1,323 & 0,187 \\
\hline$A I$ & 0,004 & 0,003 & 1,085 & 0,279 & 0,004 & 0,003 & 1,054 & 0,293 \\
\hline$I V G$ & $-0,036$ & 0,018 & $* *-2,039$ & 0,042 & $-0,037$ & 0,018 & $* *-2,038$ & 0,042 \\
\hline$W$ & $-0,001$ & 0,001 & $-0,784$ & 0,434 & $-0,001$ & 0,001 & $-0,800$ & 0,424 \\
\hline LASUSG & 0,543 & 0,274 & $* * 1,978$ & 0,049 & 0,538 & 0,272 & $* * 1,979$ & 0,049 \\
\hline $\mathbf{r}^{2}$ & & 0,315 & & & 0,316 & \multirow{5}{*}{\multicolumn{3}{|c|}{$\begin{array}{l}\text { Branchen- und Jahres- } \\
\text { Dummies werden nicht } \\
\text { ausgewiesen, die Koeffi- } \\
\text { zienten sind zum größten } \\
\text { Teil schwach signifikant. }\end{array}$}} \\
\hline Adj. $r^{2}$ & & 0,277 & & & 0,274 & & & \\
\hline$\hat{\sigma}$ & & 1,050 & & & 1,051 & & & \\
\hline F-Statistik & & 8,304 & & & 7,594 & & & \\
\hline $\begin{array}{l}\text { p-Wert } \\
\text { (F-Statistik) }\end{array}$ & & 0,000 & & & 0,000 & & & \\
\hline
\end{tabular}

Tab. A 24: $\quad$ Regressionsergebnisse Modell 7e 


\begin{tabular}{|c|c|c|c|c|}
\hline \multirow{2}{*}{$\begin{array}{l}\text { Abhängige Variab- } \\
\text { le: MWBW } \\
\text { Erklärende } \\
\text { Variablen: }\end{array}$} & \multicolumn{4}{|c|}{ Modell 8a - Variante II } \\
\hline & Koeffizient & Std.-fehler & t-Wert & p-Wert \\
\hline$c$ & 1,303 & 0,179 & $* * * 7,297$ & 0,000 \\
\hline StAl & $-0,884$ & 0,311 & $* * *-2,844$ & 0,005 \\
\hline StAlsq & 0,413 & 0,094 & $* * * 4,417$ & 0,000 \\
\hline$A I$ & 0,004 & 0,002 & $* * 2,273$ & 0,023 \\
\hline$I V G$ & $-0,009$ & 0,005 & $*-1,729$ & 0,084 \\
\hline$W$ & 0,000 & 0,000 & $* * * 3,589$ & 0,000 \\
\hline IASUSG & 0,383 & 0,235 & 1,628 & 0,104 \\
\hline Ausländer & 0,206 & 0,114 & $* 1,802$ & 0,072 \\
\hline Industrieunternehmen & 0,310 & 0,118 & $* * 2,618$ & 0,050 \\
\hline Finanzintermediär & $-0,058$ & 0,131 & $-0,446$ & 0,656 \\
\hline $\begin{array}{l}\text { Management/Familie/ } \\
\text { Natürliche Person }\end{array}$ & 0,273 & 0,152 & $* 1,793$ & 0,073 \\
\hline Öffentliche Hand & 0,049 & 0,183 & 0,270 & 0,787 \\
\hline $\mathbf{r}^{2}$ & 0,061 & \multirow{5}{*}{\multicolumn{3}{|c|}{$\begin{array}{l}\text { Nicht ausgewiesene Jahres- } \\
\text { Dummies sind nicht signifi- } \\
\text { kant. }\end{array}$}} \\
\hline Adj. $r^{2}$ & 0,046 & & & \\
\hline$\hat{\sigma}$ & 0,956 & & & \\
\hline F-Statistik & 4,025 & & & \\
\hline p-Wert (F-Statistik) & 0,000 & & & \\
\hline
\end{tabular}

Tab. A 25: Regressionsergebnisse Modell 8a-Variante II

Regressionsergebnisse Modell 8b-

für sieben Teilsamples in Abhängigkeit von der Identität des größten Aktionärs

\begin{tabular}{l|rrrrrrr}
\hline & $\boldsymbol{I}$ & $\boldsymbol{F I}$ & $\boldsymbol{F}$ & $\boldsymbol{n P}$ & $\boldsymbol{M}$ & $\boldsymbol{S}$ & $\boldsymbol{A}$ \\
\hline \multirow{2}{*}{ StAl } & 0,376 & $-0,181$ & $-0,046$ & $-3,155$ & $-0,254$ & $-0,604$ & 0,064 \\
& $(1,363)$ & $(-1,576)$ & $(-0,234)$ & $(-1,412)$ & $(-0,529)$ & $(-0,714)$ & $(0,312)$ \\
\hline \multirow{2}{*}{ StA1 } & $-0,336$ & $-0,466$ & 0,026 & $-5,002$ & $-1,056$ & $-0,833$ & $-0,763$ \\
& $(-0,857)$ & $(-0,967)$ & $(0,041)$ & $(-0,738)$ & $(-0,435)$ & $(-0,236)$ & $(-0,762)$ \\
StAlsq & 0,274 & 0,153 & $-0,061$ & 1,833 & 0,722 & 0,221 & 0,684 \\
& $(* * * 2,731)$ & $(0,736)$ & $(-0,107)$ & $(0,349)$ & $(0,382)$ & $(0,081)$ & $(0,786)$ \\
\hline
\end{tabular}

Ausgewiesen werden die Koeffizienten und die zugehörigen t-Werte in Klammern.

Abhängige Variable: MWBW. Nicht ausgewiesen werden die Kontrollvariablen IVG, AI, W und die Jahres-Dummies.

Tab. A 26: Regressionsergebnisse Modell $8 b$ 


\section{Anhang D: Liste der Sampleunternehmen}

A. Moksel AG

A. Springer AG

ABB AG

Actris AG

Adcapital AG

Adidas-Salomon AG

AG Kühn K. u. K. AG

Ahlers AG

Alcatel SEL AG

Allweiler AG

Alno AG

Altana AG

Andreae-Noris Zahn AG

Apcoa Parking AG

Armstrong DLW AG

ATB Antriebstechnik AG

Audi AG

Autania AG

AVA AG

B.U.S Berzelius AG

Babcock Borsig AG

Babcock-BSH AG

Barmag AG

BASF AG

Bayer AG

Baywa AG

BBS Kraftfahrzeug AG

Beiersdorf AG

Berentzen AG

Berliner Kindl Brauerei AG

Bertrandt AG

Bewag AG
BHS Tabletop AG

Bien-Haus AG

Bijou Brigitte AG

Bilfinger \& Berger AG

Binding Brauerei AG

Biotest AG

Blaue Quellen AG

BMW AG

Boewe Systec AG

Bremer Woll-Kämmerei AG

Brau und Brunnen AG

Brauerei Moninger AG

Brilliant AG

Buderus AG

Burgbad AG

Carl Schenck AG

Ceag AG

Compugroup Holding AG

Contigas AG

Continental AG

Creaton AG

Custodia Holding AG

Deutsche Steinzeug AG

Data Modul AG

Degussa AG

Deutz AG

Didier-Werke AG

Dierig Holding AG

Douglas Holding AG

Draegerwerk AG

Dt. Lufthansa AG

Dt. Telekom AG 
Dt. Beteiligungs AG

Dt. Effekten- u. Wechsel-Bet. AG

Dt. Eisenhandel AG

Duerkopp Adler AG

Duerr AG

Dyckerhoff AG

EFF-EFF Fritz Fuss AG

Ehlebracht AG

Eisen- u. Huettenwerke AG

Elektra Beckum AG

Energie Baden-Wue. AG

Escada AG

Eurobike AG

FAG Kugelfischer AG

Felten + Guilleaume AG

Fielmann AG

FMC AG

Fresenius AG

Friatec AG

Fuchs Petrolub AG

Garant Schuh + Mode AG

Gardena Holding AG

Gea AG

Gehe AG

Gelsenwasser AG

Gerresheimer Glas AG

Gerry Weber Internat. AG

Gildemeister AG

Glunz AG

Goldschmidt AG

Grammer AG

Graphitwerke Kropfmühl AG

$\mathrm{H}+\mathrm{R}$ Wasag AG
Hach AG

Hagen Batterie AG

Hans Einhell AG

Harpen AG

HBG Hochbahn AG

Heidelberger Zement AG

Henkel KGaA

HEW AG

Hindrichs Auffermann AG

HIT Intern. Trading AG

Hochtief AG

Hoechst AG

Holsten Brauerei AG

Hornbach Holding AG

Hornbach Baumarkt AG

Hucke AG

Hugo Boss AG

Hymer AG

Ikon AG

Indus Holding AG

Innotec TSS AG

Interglas Technol. AG

Iwka AG

J. Voegele AG

Jado AG

Jean Pascale AG

Jil Sander AG

Jungheinrich AG

$\mathrm{K}+\mathrm{S}$ AG

Kampa-Haus AG

Kap-Beteiligungs AG

Karstadt Quelle AG

Kaufhalle AG 
Kögel Fahrzeug AG

Koenig + Bauer AG

Kolbenschmidt Pierburg AG

Konrad Hornschuch AG

Kraftwerke Rheinfelden AG

Krones AG

KSB AG

Kulmbacher Brauerei AG

Lechwerke AG

Leica Camera AG

Leifheit AG

Leoni AG

Linde AG

Lindner Holding KGAA

M. Tech T.U.B. AG

Mainova AG

MAN AG

MAN Roland Druckmaschinen AG

Maschinenfabrik B. Hermle AG

Maternus-Kliniken AG

MCS Systeme AG

MDB AG

Merck KGaA

MG Technologies AG

MG Vermögensverwaltung AG

Michael Weinig AG

Mineralbrunnen Ueberkingen AG

Moebel Walther AG

Neckarwerke Stuttgart AG

Oppermann Versand AG

Otavi Minen AG

Otto Reichelt AG

Park u. Bellheimer AG

Pfleiderer AG
Phoenix AG

Piper Deutschland AG

Pirelli Deutschland AG

Plettac AG

Pongs + Zahn AG

Porsche AG

Praktiker Bau- und Heimwerker AG

Preussag AG

Progress-Werk AG

Puma AG

Rheinmetall AG

Rhoen-Klinikum AG

Rieter Ingolstadt AG

Rinol AG

Robert Cordier AG

Rosenthal AG

Rothenberger AG

Ruetgers AG

RWE AG

RWE-Dea AG

SAI Automotive AG

Saint-Gobain Isover AG

Saint-Gobain Oberland AG

Salamander AG

Salzgitter AG

SAP AG

Sartorius AG

SCA AG

Schaltbau Holding AG

Schering AG

Schleicher + Co. AG

Schmalbach-Lubeca AG

Schoen + Cie. AG

Schumag AG 
Schwälbchen Molkerei AG

Schwarz Pharma AG

Schweizer Electr. AG

Sektkellerei Schloss Wachenheim AG

SGL Carbon AG

Siemens AG

Simona AG

Sinn Leffers AG

Sixt AG

Spar Handels AG

STO AG

Stoehr + Co. AG

Stollwerck AG

Strabag AG

Stuttgarter Hofbräu AG

Südzucker AG

TA Triumph Adler AG

Tarkett Sommer AG

Thuega AG

ThyssenKrupp AG
Tiptel AG

Triumph International AG

Turbon AG

Varta AG

VBH Holding AG

VDN AG

Verseidag AG

VGT Industrie AG

Vogt Electronic AG

Vossloh AG

VW AG

Walter AG

Walter Bau AG

Wanderer Werke Aktien AG

Wella AG

Weru AG

Westag + Getalit AG

WMF AG

Ymos AG

Zanders Feinpapiere AG 


\section{Literaturverzeichnis}

63. DJT (2000): Beschlüsse des 63. Deutschen Juristentages, Leipzig 2000, Wirtschaftsrecht. In: DB, 53. Jg., S. 2108-2110.

Adams, Michael (1990): Höchststimmrechte, Mehrfachstimmrechte und sonstige wundersame Hindernisse auf dem Markt für Unternehmenskontrolle. In: AG, 35. Jg., S. 63-78.

Adams, Michael (1994): Die Usurpation von Aktionärsbefugnissen mittels Ringverflechtung in der „Deutschland AG“. In: AG, 39. Jg., S. 148-158.

Adams, Michael (1997): Corporate Governance: Vertragen sich die deutsche Unternehmensverfassung und das Shareholder-Prinzip? In: ZfB, 67. Jg., Ergänzungsheft 4/1997, S. 21-30.

Adams, Michael (1999): Cross holdings in Germany. In: JITE, Vol. 155, S. 80109.

Adams, Michael (2002): Ökonomische Theorie des Rechts, Frankfurt.

Adelman, Michael A. (1969): A note on the H-measure as a numbers equivalent. In: RoES, Vol. 51, S. 99-101.

Aganin, Alexander/Volpin, Paolo (1998): On the Origin and Evolution of Pyramidal Groups: An Empirical Evaluation. Working paper, Harvard University, Cambridge, MA.

Agrawal, Anup/Knoeber, Charles R. (1996): Firm Performance and Mechanisms to Control Agency Problems between Managers and Shareholders. In: JFQA, Vol. 31, S. 377-397.

Akerlof, George A. (1970): The Market for 'Lemons': Quality Uncertainty and the Market Mechanism. In: QJoE, Vol. 84, S. 488-500.

Albach, Horst (2001): Shareholder Value und Unternehmenswert - Theoretische Anmerkungen zu einem aktuellen Thema. In: ZfB, 71. Jg., S. 643674.

Albart, Robert (1955): Die stimmrechtslose Vorzugsaktie, München. 
Albrecht, Angelika (1984): Grundlegende Instrumente der quantitativen Analyse: Die Regressionsanalyse. In: Holler, M. J. (Hrsg.): Wahlanalyse, München, S. 213-230.

Alchian, Armen A. (1984): Specifity, Specialization, and Coalitions. In: JITE, Vol. 140, S. 34-49.

Alchian, Armen A./Demsetz, Harold (1972): Production, Information Costs, and Economic Organization. In: AER, Vol. 72, S. 777-795.

Alecke, Björn (1997): Regressionsanalyse mit Panel-Daten: Eine Einführung. In: Zentralarchiv für Empirische Sozialforschung (Hrsg.): ZA-Information 40, Mai 1997, S. 87-121, Köln.

Aleff, Hans-Jörg/Steden, Philipp (2001): Die Verflechtungen deutscher Unternehmen - Konsequenzen mehrstufiger Beteiligungen. In: ÖBA, 48. Jg., S. $665-670$.

Alexander, David/Archer, Simon (2001): Miller 2002 International Accounting Standards Guide, New York u.a.

Alexander, Cindy R./Cohen, Mark A. (1999): Why do corporations become criminals? Ownership, hidden actions, and crime as an agency cost. In: JoCF, Vol. 5, S. 1-34.

Altman, Edward I. (1968): Financial ratios, discriminant analysis and the prediction of corporate bankruptcy. In: JoF, Vol. 23, S. 589-609.

Amihud, Yakov/Mendelson, Haim (2000): The Liquidity Route to a Lower Cost of Capital. In: JoACF, Vol. 12, No. 4, S. 13.

Ammenwerth, Michael (1997): Die Kommanditgesellschaft auf Aktien (KGaA), Frankfurt/M.

Anderson, Ronald C./Reeb, David M. (2003): Founding-Family Ownership and Firm Performance: Evidence from the S\&P 500. Erscheint in: JoF, Vol. 58, Juni 2003.

Anderson, Ronald C./Mansi, Sattar A./Reeb, David M. (2003): Founding Family Ownership and the Agency Cost of Debt. In: JoFE, Vol. 65, S. 263285. 
Andreae, Karl (1930): Das Stimmrecht in der Aktiengesellschaft, Leipzig.

Andrews, William D. (1965): The Stockholder's Right to Equal Opportunity in the Sale of Shares. In: HLR, Vol. 78, S. 505-563.

Ang, James S./Cole, Rebel A./Lin, James Wuh (2000): Agency Costs and Ownership Structure. In: JoF, Vol. 12, S. 81-106.

Ang, James S.Megginson, William L. (1989): Restricted Voting Shaares, Ownership Structure, and the Market Value of Dual-Class Firms. In: JoFR, Vol. 12, S. 301-318.

APCIMS (2002) (Hrsg.): Shareholders Rights - A Legal Comparison, Resarch Report, October 2002, London.

Apenbrink, Rudolf E.W. (1993): Empirische Kapitalmarktuntersuchung zu Unternehmensakquisitionen in Deutschland, Wien.

Arends, Volker (2000): Die Offenlegung von Aktienbesitz nach deutschem Recht, Wiesbaden.

Arminger, Gerhard/Müller, Franz (1990): Analyse von Paneldaten, Opladen.

Arnold, Christian (1998): Deutsche Aktienrechtsreform 1997 - Die Reform des Vollmachtsstimmrechts. In: SWI, 9. Jg., S. 272-281.

Arrow, Kenneth J. (1969): The Organization of Economic Activity, $91^{\text {st }}$ congress, $1^{\text {st }}$ session, Bd.1: PBB-System, Joint Economic Committee, Washington, DC.

Arrow, Kenneth J. (1985): The Economics of Agency. In: Pratt, J.W./Zeckhauser, R.J. (Hrsg.): Principals and Agents, Boston, S. 37-51.

Arrow, Kenneth J. (1986): Agency and the Market. In: Arrow, K.J./Intriligator, M.D. (Hrsg.): Handbook of Mathematical Economics, Vol. III, NorthHolland, S. 1183-1195.

Assenmacher, Walter (2002): Einführung in die Ökonometrie, 6. Aufl., München.

Assmann, Heinz-Dieter (1992): Kommentierungen zum Aktiengesetz. In: Hopt, K.J. (Hrsg.): Großkommentar zum Aktiengesetz, 4. Aufl., Berlin u.a. 
Assmann, Heinz-Dieter (2002): Erwerbs-, Übernahme- und Pflichtangebote nach dem Wertpapiererwerbs- und Übernahmegesetz aus der Sicht der Bietergesellschaft. In: AG, 47. Jg., S. 114-123.

Assmann, Heinz-Dieter/Kirchner, Christian/Schanze, Erich (1993): Ökonomische Analyse des Rechts, Tübingen.

Atanasov, Vladimir (2002): Valuation of Large Blocks of Shares and the Private Benefits of Control. Working Paper, Penn State University, University Park, PA.

Auerbach, $\boldsymbol{W}$. (1873): Das Actienwesen, Frankfurt/M.

Aussenegg, Wolfgang/Grünbichler, Andreas (1999): Der Size-Effekt am österreichischen Aktienmarkt. In: ZfbF, 51. Jg., S. 636-661.

Ayres, Ian/Cramton, Peter (1994): Relational Investing and Agency Theory. In: CLR, Vol. 15, S. 1033-1066.

Bachmann, Gregor (1999): Namensaktie und Stimmrechtsvertretung. In: WM, 53. Jg., S. 2100-2108.

Backhaus, Klaus/Erichson, Bernd/Plinke, Wulff/Weiber, Rolf (2000) (Hrsg.): Multivariate Analysemethoden, 9. Aufl., Berlin u.a.

Baetge, Jörg/Kirsch, Hans-Jürgen/Thiele, Stefan (2002): Konzernbilanzen, 6. Aufl., Düsseldorf.

Bainbridge, Stephen M. (1995): The Politics of Corporate Governance. In: HJLPP, Vol. 18, S. 671-734.

Ball, Ben C. (1987): The mysterious disappearance of retained earnings. In: HBR, Vol. 65, S. 56-63.

Ball, Ray/Brown, Philip (1968): An empirical evaluation of accounting income numbers. In: JoAR, Vol. 6, S. 159-178.

Ballwieser, Wolfgang (1994): Adolf Moxter und der Shareholder Value-Ansatz. In: Ballwieser, W./Drukarczyk, J./Schmidt, R.H. (Hrsg.): Bilanzrecht und Kapitalmarkt, Festschrift Moxter, Düsseldorf, S. 1377-1405. 
Ballwieser, Wolfgang (2001): Konzernrechnungslegung und Wettbewerb. In: DBW, 61. Jg., S. 640-657.

Baltagi, Badi H. (2002): Econometrics. $3^{\text {rd }}$ ed., Berlin et al.

Baltagi, Badi H. (2001): Econometric Analysis of Panel Data, $2^{\text {nd }}$ ed., West Sussex.

Bamberg, Günter/Baur, Franz (2001): Statistik, 11. Aufl., München.

Banz, Rolf $\boldsymbol{W}$. (1981): The relationship between return and market value of common stocks. In: JoFE, Vol. 9, S. 3-18.

Barca, Fabrizio/Becht, Marco (2001): The Control of Corporate Europe, Oxford/New York.

Barclay, Michael J./Holderness, Clifford G. (1989): Private Benefits of Control from Public Corporations. In: JoFE, Vol. 25, S. 371-395.

Barclay, Michael J./Holderness, Clifford G./Sheehan, Dennis P. (2001): The Block Pricing Puzzle, Working Paper, University of Rochester, The Bradley Policy Research Center, No. FR 01-05, Rochester.

Bassen, Alexander (2002): Einflussnahme institutioneller Anleger auf Corporate Governance und Unternehmensführung - Ergebnisse einer empirischen Untersuchung. In: ZBB, 14. Jg., S. 430-436.

Bassen, Alexander (2002a): Institutionelle Investoren und Corporate Governance. Analyse der Einflussnahme unter besonderer Berücksichtigung börsennotierten Wachstumsunternehmen, Wiesbaden.

Bassen, Alexander/Hauck, Michael (2001): Systematisierung institutioneller Investoren. In: Achleitner, A.-K./Thoma, G.: Handbuch Corporate Finance, Köln, S. 1-22.

Baumol, William J. (1959): Business behavior, value and growth, New York.

Baums, Theodor et al. (1993) (Hrsg.): Institutional Investors and Corporate Governance, Berlin/New York.

Baums, Theodor (1994): Vorzugsaktien, Ausgliederung und Konzernfinanzierung. In: AG, 39. Jg., S. 1-12. 
Baums, Theodor (1996): Rechtstatsachen zu „Institutionelle Investoren und Publikumsgesellschaft". In: Feddersen, D. u.a. (Hrsg.): Corporate Governance, Köln, S. 324-330.

Baums, Theodor (1997): Shareholder Representation and Proxy Voting in the European Union: A Comparative Study. Paper presented at the Conference on Comparative Corporate Governance, Max-Planck-Institut für Ausländisches und Internationales Privatrecht, Hamburg, 15.-17. Mai 1997.

Baums, Theodor/Fraune, Christian (1995): Institutionelle Anleger und Publikumsgesellschaft - Eine empirische Untersuchung. In: AG, 40. Jg, S. 97112.

Baums, Theodor/Randow, Philipp v. (1995): Der Markt für Stimmrechtsvertreter. In: AG, 40. Jg., S. 145-162.

Baums, Theodor/Schmitz, Rainer (1998): Shareholder Voting in Germany, Arbeitspapier Nr. 76, Institut für Handels- und Wirtschaftsrecht der Universität Osnabrück, Osnabrück.

$\boldsymbol{B} A \boldsymbol{W}$ (2001): Erläuterungen zu den Stimmrechtsanteilen. URL: www.bawe.de/ stimmrechte_erl.htm (19.8.2002).

$\boldsymbol{B A W e}$ (2001a): Erweiterte Meldepflichten für Inhaber von Stimmrechten an börsennotierten Unternehmen. Pressemitteilung vom 19.12.2002, URL: www.bawe.de/pm01_17.htm (19.8.2002).

Beaver, William H. (1968): The information content of annual earnings announcements. In: JoAR, Vol. 6, Supplement, S. 67-92.

Bebchuk, Lucian A. (1999): A Rent-protection Theory of Corporate Ownership and Control, NBER Working Paper No. 7203, Cambridge.

Bebchuk, Lucian A. (2003): The Case for Empowering Shareholders, Working Paper, Harvard Law School, Cambridge.

Bebchuk, Lucian A./Kraakman, Reinier/Triantis, George (2000): Stock Pyramids, Cross-Ownership, and Dual Class Equity: The Creation and Agency Costs of Separating Control from Cash Flow Rights In: Morck, R.K. (ed.): Concentrated Corporate Ownership, Chicago/London, S. 295-315. 
Bebchuk, Lucian A./Roe, Marc (1999): A Theory of Path Dependence in Corporate Ownership and Governance. In: SLR, Vol. 52, S. 127-170.

Bebchuk, Lucian A./Zingales, Luigi (2000): Corporate Ownership Structures: Private versus Social Optimality. In: Morck, R.K. (ed.): Concentrated Corporate Ownership, Chicago/London, S. 55-75.

Becht, Marco (1997): Strong Blockholders, Weak Owners and the Need for a European Mandatory Disclosure, European Corporate Governance Executive Report, Brüssel.

Becht, Marco (1999): European corporate governance: Trading off liquidity against control. In: EER, Vol. 43, S. 1049-1056.

Becht, Marco/Böhmer, Ekkehart (1999): Transparency of Ownership and Control in Germany. Arbeitspapier Nr. 69, Institut für Handels- und Wirtschaftsrecht der Universität Osnabrück, Osnabrück.

Becht, Marco/Böhmer, Ekkehart (2001): Ownership and Voting Power in Germany. In: Barca, F./Becht, M. (Hrsg.): The Control of Corporate Europe, S. 128-153.

Becht, Marco/Böhmer, Ekkehart (2003): Voting Control in German Corporations. In: IRLE, Vol. 23, S. 1-29.

Becht, Marco/Bolton, Patrick/Röell, Ailsa (2002): Corporate Governance and Control, ecgi Finance Working Paper No. 2/2002, Brüssel.

Becht, Marco/Chapelle, Ariane/Renneboog, Luc (2001): Shareholding Cascades: The Separation of Ownership and Control in Belgium. In: Barca, F./ Becht, M. (Hrsg.): The Control of Corporate Europe, Oxford, S. 71-105.

Becht, Marco/Röell, Ailsa (1999): Blockholdings in Europe: An international comparison. In: EER, Vol. 43, S. 1049-1056.

Beck, Thorsten/Levine, Ross (2002): Industry growth and capital allocation: does having a market- or bank-based system matter? In: JoFE, Vol. 64, S. 147-180.

Becker, Gary S. (1957): The economics of discrimination, Chicago. 
Becker, Gary S. (1993): Der ökonomische Ansatz zur Erklärung menschlichen Verhaltens, 2. Aufl., Tübingen.

Beiker, Hartmut (1993): Überrenditen und Risiken kleiner Aktiengesellschaften. Eine theoretische und empirische Analyse des deutschen Kapitalmarktes von 1966 bis 1989, Köln.

Belkaoui, Ahmed/Pavlik, Ellen (1992): The Effects of Ownership Structure and Diversification Strategy on Performance. In: MDE, Vol. 13, S. 343-352.

Bennedsen, Morten/Wolfenzon, Daniel (2000): The balance of power in closely held corporations. In: JoFE, Vol. 58, S. 113-139.

Berglöf, Erik (1997): Reforming corporate governance: redirecting the European agenda. In: EP, Vol. 24, S. 93-123.

Bergström, Clas/Rydqvist, Kristian (1990): Ownership of Equity in Dual-Class Firms. In: JoBF, Vol. 14, S. 255-269.

Berhold, Marvin (1971): A theory of linear profit sharing incentives. In: QJoE, Vol. 85, S. 460-482.

Berle, Adolf A./Means, Gardiner C. (1932): The Modern Corporation and Private Property, New York.

Berliner Initiativkreis German Code of Corporate Governance (2000): German Code of Corporate Governance. In: v. Werder, A. (Hrsg.): German Code of Corporate Governance (GCCG), Stuttgart, S. 29-85.

Berndsen, Rudolf (1959): Der Depotbesitz an deutschen Aktien. In: Wirtschaft und Statistik, o. Jg., S. 417-419.

Berndsen, Rudolf (1961): Das Eigentum am Kapital der deutschen Aktiengesellschaften. In: Wirtschaft und Statistik, o. Jg., S. 282-285.

Berrar, Carsten (2001): Die Entwicklung der Corporate Governance in Deutschland im internationalen Vergleich, Baden-Baden.

Bertrand, Marianne/Mehta, Paras/Mullainathan, Sendhil (2002): Ferreting out Tunneling: An Application to Indian Business Groups. In QJoE, Vol. 117, S. 121-148. 
Bessler, Wolfgang/Kaen, Fred R./Sherman, Heidemarie C. (1998): Going public: A corporate governance perspective - The state of the art and emerging research. In: Hopt, K. J. et al. (Hrsg.): Comparative corporate governance, Oxford, S. 569-605.

Bessler, Wolfgang/Kurth, Andreas/Thies, Stefan (2001): Zur Bedeutung der Kapital- und Aktionärsstruktur beim Going Public am Neuen Markt. In: Achleitner, A./Bassen, A. (Hrsg.): Investor Relations am Neuen Markt, Stuttgart, S. 225-263.

Beyer, Jürgen (1996): Governance Structures - Unternehmensverflechtungen und Unternehmenserfolg in Deutschland. In: ZfB, 66. Jg., Ergänzungsheft 3/1996, S. 79-101.

Beyer, Jürgen (1998): Managerherrschaft in Deutschland? „Corporate Governance" unter Verflechtungsbedingungen, Wiesbaden.

Beyer, Jürgen (2002): Deutschland AG a. D.: Deutsche Bank, Allianz und das Verflechtungszentrum großer deutscher Unternehmen. Max-Planck-Institut für Gesellschaftsforschung, Working Paper 02/4, Köln.

Bezzenberger, Tilman (1991): Vorzugsaktien ohne Stimmrecht, Köln u.a.

Bezzenberger, Tilman (1991a): Zum Bezugsrecht stimmrechtsloser Vorzugsaktien. In: Westermann, H.P. (Hrsg.): Festschrift Karlheinz Quack, Berlin, S. 153-166.

Bhagat, Sanjai/Brickley, James A. (1984): Cumulative voting: The value of minority shareholder voting rights. In: JoLE, Vol. 27, S. 339-365.

Bhagat, Sanjai/Jefferis, Richard H. (2002): The Econometrics of Corporate Governance Studies, Cambridge, MA.

Bianchi, Marcello/Bianco, Magda/Enriques, Luca (2001): Pyramidal Groups and the Separation between Ownership and Control in Italy. In: Barca, F./ Becht, M. (Hrsg.): The Control of Corporate Europe, Oxford, S. 154-187.

Bischof, Stefan (1998): Aktionärsschutz. In: Lück, W. (Hrsg.): Lexikon der Rechnungslegung und Abschlußprüfung, 4. Aufl., München, S. 25-26.

Bischoff, Jörg (1994): Das Shareholder Value Konzept, Wiesbaden. 
Black, Bernard S. (1990): Shareholder Passivity Reexamined. In: MLR, Vol. 89, S. 520-608.

Black, Bernard S. (1992): Agents Watching Agents: The Promise of Institutional Investor Voice. In: UCLA Law Review, Vol. 39, S. 811-893.

Blair, Margaret M. (1995): Ownership and Control, Washington.

Blättchen, Wolfgang (1981): Risque et rendement pour les actionnaires des sociétés engagées dans des opérations de fusion-absorption: Le cas allemand 1970-1976, Paris.

Bleymüller, Josef/Gehlert, Günther/Gülicher, Herbert (2002): Statistik für Wirtschaftswissenschaftler, 13. Aufl., München.

Blies, Peter (2000): Corporate Governance im deutsch-japanischen Vergleich, Wiesbaden.

Bloch, Francis/Hege, Ulrich (2001): Multiple Shareholders and Control Contests. Working Paper, Ecole de Hautes Etudes en Sciences Sociales Universités d'Aix Marseille (GREQAM), No. 01A16, Marseille.

Böbel, Ingo/Dirrheimer, Manfred J. (1984): Eigentumsrechte, Managementmotivation und Marktverhalten: Ein Beitrag zur Erweiterung der Theorie der Unternehmung. In: Neumann, M. (Hrsg.): Ansprüche, Eigentums- und Verfügungsrechte, Schriften des Vereins für Socialpolitik, Bd. 140, Berlin, S. 157-177.

Böckli, Peter (2000): Corporate Governance auf Schnellstraßen und Holzwegen. In: Der Schweizer Treuhänder, 74. Jg., S. 133-152.

Bodem, Oskar (1932): Die Vorzugsaktie ohne Stimmrecht nach dem Aktienrechtsentwurf des Reichsjustizministeriums von 1930, München.

Böhmer, Ekkehart (2000): Business Groups, Bank Control, and Large Shareholders: An Analysis of German Takeovers. In: JoFI, Vol. 9, S. 117-148.

Böhmer, Ekkehart (2001): Corporate governance in Germany: Institutional background and empirical results. In: Gugler, K. (Hrsg.): Corporate Governance and Economic Performance, Oxford/New York, S. 96-120. 
Böhmer, Ekkehart/Löffler, Yvonne (1999): Kursrelevante Ereignisse bei Unternehmensübernahmen: Eine empirische Analyse des deutschen Kapitalmarktes. In: ZfbF, 51. Jg., S. 299-324.

Böhmer, Thomas (1986): Die Verpflichtung zur Publizität der Konzernrechnungslegung nach dem Publizitätsgesetz, Mainz.

Bohren, Oyvind/Odegaard, Arne (2001): Corporate governance and economic performance: A closer look. Working paper, The Norwegian School of Management BI, Sandvika.

Bolton, Patrick/von Thadden, Ernst-Ludwig (1998): Blocks, Liquidity, and Corporate Control. In: JoF, Vol. 53, S. 1-25.

Bolton, Patrick/von Thadden, Ernst-Ludwig (1998a): Liquidity and Control: A Dynamic Theory of Corporate Ownership Structure. In: JITE, Vol. 154, S. 177-211.

Bonse, Andreas (2003): Informationsgehalt von Konzernabschlüssen nach HGB, IAS und US-GAAP, Frankfurt/M. u.a.

Boot, Arnoud W.A./Macey, Jonathan R. (2000): Objectivity, Proximity and Adaptability in Corporate Governance, Working Paper, University of Amsterdam and Cornell University School of Law, Amsterdam/Ithaca, NY.

Booth, James R./Cornett, Marcia Millon/Tehranian, Hassan (2002): Boards of directors, ownership, and regulation. In: JoBF, Vol. 26, S. 1973-1996.

Börsch-Supan, Axel/Köke, Jens (2002): An Applied Econometricians' View of Empirical Corporate Governance Studies. In: GER, Vol. 3, S. 295-326.

Bosse, Christian (2002): TransPuG: Änderungen zu den Berichtspflichten des Vorstands und zur Aufsichtsratstätigkeit. In: DB, 55, S. 1592-1595.

Bothwell, James L. (1980): Profitability, Risk, and the Separation of Ownership from Control. In: JIE, Vol. 28, S. 303-311.

Botosan, Christine A. (2000): Evidence that greater Disclosure lowers the Cost of Equity Capital. In: JoACF, Vol. 12, No. 4, S. 61.

Bott, Claudia (2002): Aktionärsstruktur, Kontrolle und Erfolg von Unternehmen, Wiesbaden. 
Bott, Claudia/Schleef, Michael (1998): Transparenz von Beteiligungsverhältnissen nach dem Wertpapierhandelsgesetz - Nutzen für den Anleger? In: ZBB, 10. Jg., S. 330-334.

Boudreaux, Kenneth J. (1973) : Managerialism and Risk-Return Performance. In: SEJ, Vol. 39, S. 366-372.

Braeß, Paul/Karten, Walter (1967): Kapital- und Gewinnströme bei verflochtenen Kapitalgesellschaften. In: Zeitschrift für die gesamte Versicherungswissenschaft, 56. Jg., S. 261-313.

Brailsford, Timothy J./Oliver, Barry R./Pua, Sandra L. (2002): On the relation between ownership structure and capital structure. In: Accounting and Finance, Vol. 42, S. 1-26.

Brancato, Caroly K. (1997): Institutional Investors and Corporate Governance, Chicago.

Brannath, Werner/Futschik, Andreas (2001): Statistik für Wirtschaftswissenschaftler, 3. Aufl., Wien.

Brealey, Richard A./Myers, Stewart C. (2000): Principles of Corporate Finance, 6. Aufl., New York et al.

Brendel, Gregor (2001): Zur Macht der Banken in Deutschland, Münster.

Breuer, Rolf E. (1998): The Role of Financial Intermediaries and Capital Markets. In: Hopt, K.J. (Hrsg.): Comparative Corporate Governance, Oxford.

Brink, Hans-Josef (1992): Kontrolle, Organisation der. In: Frese, E. (Hrsg.): Handwörterbuch der Organisation Stuttgart, 3. Aufl., Sp. 1143-1151.

Brown, Gene (2000): Management Control. In: Helms, M. (Hrsg.): Encyclopedia of management, $4^{\text {th }}$ ed., Farmington Hills, MI, S. 535-537.

Brown, Philip (2001): Capital Markets-based Research in Accounting: An Introduction. Electronic edition, University of Western Australia, Perth.

Brown, Stephen J./Warner, Jerold B. (1985): Using daily stock returns: The case of event studies. In: JoFE, Vol. 14, S. 3-31. 
Bühner, Rolf (1984): Rendite-Risiko-Effekte der Trennung von Eigentum und Leitung im diversifizierten Großunternehmen. In: ZfbF, 36. Jg., S. 812824.

Bühner, Rolf (1990): Reaktionen des Aktienmarktes auf Unternehmenszusammenschlüsse. Eine empirische Untersuchung. In: ZfbF, 42. Jg., S. 295316.

Bühner, Rolf (1992): Aktionärsbeurteilung grenzüberschreitender Zusammenschlüsse. In: ZfbF, 44. Jg., S. 445-461.

Bühner, Rolf/Tuschke, Anja (1997): Zur Kritik am Shareholder Value - eine ökonomische Analyse. In: BFuP, 49. Jg., S. 499-516.

Bundesjustizministerium (2001) (Hrsg.): Bundesministerium der Justiz - Entwurf eines Gesetzes zur weiteren Reform des Aktien- und Bilanzrechts, zu Transparenz und Publizität (Transparenz- und Publizitätsgesetz), mit Begründung, Stand: 26.11.2001. URL: www.bmj.de (1.6.2002).

Bundesjustizministerium (2003) (Hrsg.): Pressemitteilung Nr. 10/03 des Bundesministerium der Justiz und des Bundesministerium der Finanzen vom 25.2.2003.

Bundespresseamt (2000) (Hrsg.): Pressemitteilung Nr. 173/00 des Bundespresseamtes vom 14.4.2000.

Burgard, Ulrich (1990): Die Offenlegung von Beteiligungen, Abhängigkeitsund Konzernlagen bei der Aktiengesellschaft, Berlin..

Burgard, Ulrich (1992): Die Offenlegung von Beteiligungen bei der Aktiengesellschaft. In: AG, 37. Jg., S. 41-55.

Burkart, Mike/Gromb, Denis/Panunzi, Fausto (1997): Large Shareholders, Monitoring, and the Value of the Firm. In: QJoE, Vol. 112, S. 693-728.

Burkart, Mike/Panunzi, Fausto/Shleifer, Andrei (2003): Family Firms. Discussion Paper No. 1944, Harvard University, Cambridge, MA, erscheint in: JoF, Vol. 58, Oktober 2003.

Busse von Colbe, Walther (2000): Konzernrechnungslegung. In: Busse von Colbe, W. u.a. (Hrsg.): Betriebswirtschaft für Führungskräfte, Stuttgart, S. 297-329. 
Busse von Colbe, Walther (2002): Kleine Reform der Konzernrechnungslegung durch das TransPuG. In: BB, 57. Jg., S. 1583-1588.

Busse von Colbe, Walther/Pellens, Bernhard (1998): Lexikon des Rechnungswesens, 4. Aufl., München.

Cable, John R. (1985): Capital Market Information and Industrial Performance: The Role of West German Banks. In: EJ, Vol. 95, S. 118-132.

Cahn, Andreas (1997): Probleme der Mitteilungs- und Veröffentlichungspflichten nach dem WpHG bei Veränderungen des Stimmrechtsanteils an börsennotierten Gesellschaften. In: AG, 42. Jg., S. 502-512.

Cahn, Andreas/Senger, Michael (2002): Das Gesetz zur Regelung von öffentlichen Angeboten zum Erwerb von Wertpapieren und von Unternehmensübernahmen. In: FB, 4. Jg., S. 277-295.

Carlsson, Rolf H. (2001): Ownership and Value Creation - Strategic Corporate Governance in the New Economy, Chichester et al.

Carney, William J. (1987): The theory of the firm: Investor coordination costs, control premiums and capital structure. In: WULQ, Vol. 65, S. 1-67.

Carver, Thomas N. (1925): The Present Economic Revolution in the United States, Boston.

Cary, William L. (1974): Federalism and corporate law: reflections upon Delaware. In: QLJ, Vol. 83, S. 663-707.

Cassier, Siegfried C. (1962): Wer bestimmt die Geschäftspolitik der Großunternehmen? Das Verhältnis zwischen Kapitaleigentum und Entscheidungsgewalt, Frankfurt/M.

Charkham, Jonathan P. (1994): Keeping Good Company - A Study of Corporate Governance in Five Countries, Oxford.

Chatterjee, Samprit/Price, Bertram (1995): Praxis der Regressionsanalyse, 2. Aufl., München/Wien.

Cheffins, Brian R. (2000): Does Law Matter?: The Separation of Ownership and Control in the United Kingdom, Working Paper, ESRC Centre for Business Research University of Cambridge, No. 172, Cambridge. 
Cheffins, Brian R. (2002): Corporate Law and Ownership Structure: A Darwinian Link?, Working Paper, Faculty of Law, University of Cambridge, Cambridge.

Chirinko, Robert S./Ees, Hans van/Garretsen, Harry/Sterken, Elmer (2003): Investor Protections and Concentrated Ownership: Assessing Corporate Control Mechanisms in the Netherlands. CESifo Working Paper No. 864, Groningen.

Chirinko, Robert S./Elston, Julie Ann (1996): Finance, Control and Profitability: An Evaluation of German Bank Influence. WZB discussion paper FS IV $96-5$, Berlin.

Chirinko, Robert S./Elston, Julie Ann (1996a): Banking relationships in Germany: Empirical results and policy implication. Discussion paper No. RWP 96-05, Federal Reserve Bank of Kansas City, Kansas City.

Chirinko, Bob et al. (1999): Firm Performance, Financial Institutions and Corporate Governance in the Netherlands, Working Paper, CESifo No. 210, München.

Chirinko, Bob et al. (2003): Investor Protections and Concentrated Ownership: Assessing Corporate Control Mechanisms in the Netherlands, Working Paper, CESifo No. 864, München.

Cho, Myeong-Hyeon (1998): Ownership structure, investment, and the corporate value: an empirical analysis. In: JoFE, Vol. 47, S. 103-121.

Chung, Kee H./Kim, Jeong-Kuk (1999): Corporate ownership and the value of a vote in an emerging market. In: JoCF, Vol. 5, S. 35-54.

Claessens, Stijn/Djankov, Simeon/Fan, Joseph/Lang, Larry (1999): Expropriation of Minority Shareholders in East Asia, Working Paper, World Bank, Washington, DC.

Claessens, Stijn/Djankov, Simeon/Fan, Joseph/Lang, Larry (2000): The separation of ownership and control in East Asian Corporations. In: JoFE, Vol. 58, S. 81-112.

Clark, Gordon L./Wójcik, Dariusz (2003): Financial valuation of the German (regional) model: the negative relationship between ownership concentration and stock market returns, 1997-2001. Working Paper, University of Oxford, Oxford. 
Claussen, Carsten P. (1996): Aktienrechtsreform 1997. In: AG, 41. Jg., S. 481494.

Claussen, Carsten P. (1998): Wie ändert das KonTraG das Aktiengesetz? In: DB, 51. Jg., S. 177-186.

Claussen, Carsten P./Bröcker, Norbert (2000): Corporate Governance-Grundsätze in Deutschland - nützliche Orientierungshilfe oder regulatorisches Übermaß? In: AG, 45. Jg., S. 481-491.

Coase, Ronald H. (1937): The Nature of the Firm. In: Econometrica N.S., Vol. 4, S. 386-405.

Coase, Ronald H. (1960): The problem of social cost. In: JoLE, Vol. 3, S. 1-44.

Coffee, John C. Jr. (1990): Unstable Coalitions: Corporate Governance as a Multi-Player Game. In: GLJ, Vol. 78, S. 1495-1515.

Coffee, John C. Jr. (1991): Liquidity versus Control: The Institutional Investor as Corporate Monitor. In: ColLR, Vol. 91, S. 1277-1368.

Coffee, John C. Jr. (1996): Organhaftung im amerikanischen Recht. In: Feddersen, D. u.a. (Hrsg.): Corporate Governance, Köln, S. 165-208.

Coffee, John C. Jr. (1999): Privatization and corporate governance: the lessons from securities market failure. In: JCL, Vol. 25, S. 1-39.

Cole, Rebel A./Mehran, Hamid (1998): The effect of changes in ownership structure on performance: Evidence from the thrift industry. In: JoFE, Vol. 50, S. 291-317.

Coles, Jeffrey L./Lemmon, Michael L./Meschke, J. Felix (2002): Structural Models and Endogeneity in Corporate Finance. Working Paper, Arizona State University, Tempe, AZ.

Core, John E./Larcker, David F. (2002): Performance consequences of mandatory increases in executive stock ownership. In: JoFE, Vol. 64, S. 317340.

Corsten, Hans (1999): Integration von Finanzdienstleistungen: BankAssurance - AssuranceBanking - Allfinanz, Wiesbaden. 
Cotter, James F./Peck, Sarah W. (2001): The structure of debt and active equity investors: The case of the buyout specialist. In: JoFE, Vol. 59, S. 101-147.

Crama, Yves et al. (2000): Corporate governance structures, control and performance in European markets: A tale of two systems. Working Paper, University of Liège, Liège.

Crasselt, Nils (2000) Stock Options. In: DBW, 60. Jg., S. 135-137.

Crasselt, Nils (2003): Wertorientierte Managemententlohnung, Unternehmensrechnung und Investitionssteuerung - Analyse unter Berücksichtigung von Realoptionen, Frankfurt/M.

Crespi-Cladera, Rafel/Renneboog, Luc (2003): Corporate monitoring by shareholder coalitions in the UK. ecgi Finance Working Paper No. 12/2003, Brüssel.

Cronqvist, Henrik/Nilsson, Mattias (2002): Agency Costs of Controlling Minority Shareholders, SSE/EFI Working Paper Series in Economics and Finance, No. 364, Stockholm School of Economics, Stockholm. Erscheint in: JFQA 2003.

Cubbin, John/Leech, Dennis (1983): The effect of shareholding dispersion on the degree of control in British companies: Theory and Measurement. In: EJ, Vol. 93, S. 351-369.

Dahl, Gabriele (1995): Zwischenberichterstattung börsennotierter Unternehmen, Wiesbaden.

Dahmann, Wilhelm (1919): Das Stimmrecht des Aktionärs, Greifswald.

DAI (2002): DAI-Factbook 2002 - Statistiken, Analysen und Graphiken zu Aktionären, Aktiengesellschaften und Börsen, Frankfurt/M.

Daske, Stefan/Ehrhardt, Olaf (2002): Kursunterschiede und Renditen deutscher Stamm- und Vorzugsaktien. SFB Discussion Paper, Humbold-Universität, Nr. 5/2002, Berlin.

Davidson, Russel/MacKinnon, James G. (1993): Estimation and Inference in Econometrics, New York/Oxford. 
Davies, Paul (2001): Struktur der Unternehmensführung in Großbritannien und Deutschland: Konvergenz oder fortbestehende Divergenz. In: ZGR, 30. Jg., S. 268-293.

Deakin, Simon/Hughes, Alan (1997): Comparative corporate governance: an interdisciplinary agenda. In: JLS, Vol. 24, S. 1-9.

DeAngelo, Harry/DeAngelo, Linda (1985): Managerial ownership of voting rights: A study of public corporations with dual classes of common stock. In: JoFE, Vol. 14, S. 33-70.

DeAngelo, Harry/DeAngelo, Linda (2000): Controlling stockholders and the disciplinary role of corporate payout policy: a study of the Times Mirror Company. In: JoFE, Vol. 56, S. 153-207.

Decker, Rolf O. A. (1994): Eine Prinzipal-Agenten-theoretische Betrachtung von Eigner-Manager-Konflikten in der Kommanditgesellschaft auf Aktien und in der Aktiengesellschaft, Köln.

Deckert, Martina R./Rüden, Jens von (1998): Anlegerschutz durch Europäisches Kapitalmarktrecht. In: EWS, 9. Jg., S. 46-54.

Delaney, Patrick R./Epstein, Barry J./Nach, Ralph/Weiss Budak, Susan (2001): GAAP 2002 - Interpretation and Application of Generally Accepted Accounting Principles, New York u.a.

DeMott, Deborah A. (1997): Agency Principles and Large Block Shareholders. In: CLR, Vol. 19, S. 321-340.

Demsetz, Harold (1968): The Cost of Transacting. In: QJoE, Vol. 82, S. 33-53.

Demsetz, Harold (1983): The Structure of Ownership and the Theory of the Firm. In: JoLE, Vol. 26, S. 375-390.

Demsetz, Harold/Lehn, Kenneth (1985): The Structure of Corporate Ownership: Causes and Consequences. In: JoPE, Vol. 93, S. 1155-1177.

Demsetz, Harold/Villalonga, Belen (2001): Ownership Structure and Corporate Performance. In: JoCF, Vol. 7, S. 209-233.

Denis, David J./Denis, Diane K. (1994): Majority owner-managers and organizational efficiency. In: JoCF, Vol. 1, S. 91-118. 
Denis, Diane K./McConnell, John J. (2003): International Corporate Governance. Erscheint in: JFQA, Vol. 38, März 2003.

Deutsche Börse AG (2000) (Hrsg.): Regelwerk Neuer Markt, Frankfurt/M., Stand 1.7.2000.

Deutsche Börse AG (2002) (Hrsg.): Composite DAX - CDAX, Frankfurt/M., Stand 11.7.2002.

Dilger, Alexander/Frick, Bernd (2000): Kapitalmarktreaktionen auf Veränderungen und Veröffentlichungen der Stimmrechtsverteilung. In: zfo, 69. Jg., S. 18-24.

Dinauer, Josef (2001): Allfinanz: Grundzüge des Finanzdienstleistungsmarkts, München u.a.

Dittmann, Ingolf (2003): Measuring Private Benefits of Control from the Returns of Voting and Non-Voting Shares. Working Paper, HumboldtUniversität, Berlin.

Dodd, Peter/Leftwich, Richard (1980): The Market for Corporate Charters: "Unhealthy Competition" versus Federal Regulation. In: JoB, Vol. 53, S. 259-283.

Doerks, Wolfgang (1992): Der Kursunterschied zwischen Stamm- und Vorzugsaktien in der BRD: eine empirische Untersuchung, Köln.

Doidge, Craig (2003): U.S. Cross-listings and the Private Benefits of Control: Evidence From Dual Class Firms. Working Paper, University of Toronto.

Dorfs, Joachim (2001): In deutsche Unternehmen kommt Bewegung. In: Handelsblatt vom 30.7.2001, Nr. 116, S. 2.

Dose, Stefan (1975): Die Rechtsstellung der Vorstandsmitglieder einer Aktiengesellschaft, 3. Aufl., Köln.

Drobetz, Wolfgang/Schillhofer, Andreas (2003): Gute Corporate Governance senkt die Kapitalkosten. In: FAZ vom 13.1.03, Nr. 10, S. 20.

Drobetz, Wolfgang/Schillhofer, Andreas/Zimmermann, Heinz (2003): Corporate Governance and Expected Stock Returns: Evidence from Germany. 
University of Basel, WWZ/Department of Finance, Working Paper No. 2/03, Basel.

DSW (2000): DSW-Pressekonferenz am 26.9.2000. URL: www.dsw-info.de/ index_dsw.php (17.2.2002).

Duggal, Rakesh/Millar, James A. (1999): Institutional ownership and firm performance: The case of bidder returns. In: JoCF, Vol. 5, S. 103-117.

Dunlavy, Colleen A. (1998): Corporate Governance in late $19^{\text {th }}$-Century Europe and the U.S. In: Hopt, K.-J. u.a. (Hrsg.): Comparative Corporate Governance, Oxford, S. 5-39.

Durbin, J. (1954): Errors in variables. In: RoISI, Vol. 22, S. 23-32.

Dyck, Alexander/Zingales, Luigi (2002): Private Benefits of Control: An International Comparison. NBER Working Paper No. 8711, Cambridge.

Dziobek, Claudia/Garrett, John R. (1998): Convergence of financial systems and regulatory policy challenges in Europe and in the US. In: Black, S./Moersch, M. (Hrsg.): Competition and convergence in financial markets, Amsterdam, S. 195-217.

Easterbrook, Frank H. (1984): Two Agency-Cost Explanations of Dividends. In: AER, Vol. 74, S. 650-659.

Easterbrook, Frank H./Fischel, Daniel R. (1983): Voting in Corporate Law. In: JoLE, Vol. 26, S. 395-427.

Easterbrook, Frank H./Fischel, Daniel R. (1991): The Economic Structure of Corporate Law, Cambridge, MA.

Ebenroth, Carsten T./Wilken, Oliver (1993): Zum Auskunftsrecht des Aktionärs im Konzern. In: BB, 48. Jg., S. 1818-1823.

Ebke, Werner F. (1994): Unternehmenskontrolle durch Gesellschafter und Markt. In: Sandrock, O./Jäger, W. (Hrsg.): Internationale Unternehmenskontrolle und Unternehmenskultur: Festschrift Großfeld, S. 7-35.

Eckardt, Jürgen (1999): Kurz- und langfristige Kurseffekte beim Erwerb von Beteiligungen deutscher börsennotierter Aktiengesellschaften, Lohmar/Köln. 
Eckey, Hans-Friedrich/Kosfeld, Reinhold/Dreger, Christian (2001): Ökonometrie, 2. Aufl., Wiesbaden.

Edwards, Jeremy S./Fischer, Klaus (1994): Banks, finance and investment in Germany, Cambridge.

Edwards, Jeremy S./Nibler, Marcus (2000): Corporate governance in Germany: The role of banks and ownership concentration. In: EP, Vol. 31, S. 239267.

Edwards, Jeremy S./Weichenrieder, Alfons J. (2000): Private Benefits versus Better Monitoring, Working Paper, University of Cambridge/Universität München, München.

Ehrhardt, Olaf/Nowak, Eric (2002): Private Benefits and Minority Shareholder Expropriation - Empirical Evidence from IPOs of German Family-Owned Firms. Working Paper, Humboldt Universität Berlin/ Goethe-Universität Frankfurt, Berlin/Frankfurt.

Ehrhardt, Olaf/Nowak, Eric (2002a): Evolution von Aktionärsstrukturen, Kontrolltransfers und Performanceunterschiede bei Börsengängen deutscher Familienunternehmen. In: ZfB, 73. Jg., Ergänzungsheft 2/2002, S. 25-31.

Eisenhardt, Kathleen M. (1989): Agency Theory: An Assessment and Review. In: AMR, Vol. 14, S. 57-74.

Eisolt, Dirk (1993): Konzernrechnungslegungspflicht nach HGB und US-amerikanischen Vorschriften. In: WPg, 46. Jg., S. 344-353.

Elliott, Walter J. (1972): Control, Size, Growth, and Financial Performance in the Firm. In: JFQA, Vol. 7, S. 1309-1320.

Elschen, Rainer (1987): Die Kritik von Rechtsnormen durch modellgestützte Analyse ökonomischer Sachgerüste. In: Schmidt, R.H./Schor, G. (Hrsg.): Modelle in der Betriebswirtschaftslehre, Wiesbaden, S. 215-242.

Elschen, Rainer (1988): Die getrennte Handelbarkeit von Aktienstimmrechten. In: ZfbF, 40. Jg., S. 1009-1036.

Elschen, Rainer (1991): Gegenstand und Anwendungsmöglichkeiten der Agency-Theorie. In: ZfbF, 43. Jg., S. 1002-1012. 
Elston, Julie A. (1993): Firm Ownership Structure and Investment: Theory and Evidence from German Panel Data. Working Paper FS IV 93-28, Wissenschaftszentrum Berlin, Berlin.

Engel, Uwe/Reinecke, Jost (1994): Panelanalyse, Berlin/New York.

Engelhard, Johann/Eckert, Stefan (1999): The Ownership Structure of Large German Corporations: Towards an Increasing Denationalization? In: Urban, S. (Hrsg.): Relations of Complex Organizational Systems, Wiesbaden, S. 279-343.

Epstein, Rolf/Ruhwedel, Peter (2002): Aufsichtsratspraxis in Deutschland Aktueller Stand und zukünftige Herausforderungen. Studie Deloitte Consulting, Eschborn/Düsseldorf.

Erlei, Mathias/Leschke, Martin/Sauerland, Dirk (1999): Neue Institutionenökonomik, Stuttgart.

Ernst, Christoph/Seibert, Ulrich/Stuckert, Fritz (1998): KonTraG, KapAEG, StückAG, EuroEG, Düsseldorf.

Esser, Helmut (1938): Das Stimmrecht des Aktionärs in der Hauptversammlung, Düsseldorf.

Ewert, Ralf/Wagenhofer, Alfred (2003): Interne Unternehmensrechnung, 5. Aufl., Berlin.

Expertengruppe Europäisches Gesellschafisrecht (2002): Moderne gesellschaftsrechtliche Rahmenbedingungen in Europa - Ein Konsultationspapier der Hochrangigen Expertengruppe auf dem Gebiet des Gesellschaftsrechts, Brüssel.

Faccio, Mara/Lang, Larry H.P. (2002): The Ultimate Ownership of Western European Corporations. In: JoFE, Vol. 65, S. 365-395.

Faccio, Mara/Lang, Larry H.P./Young, Leslie (2001): Dividends and Expropriation. In: AER, Vol. 91, S. 54-78.

Faccio, Mara/Lasfer, M. Ameziane (2000): Do occupational pension funds monitor companies in which they hold large stakes? In: JoCF, Vol. 6, S. 71-110. 
Fahrmeir, Ludwig/Hamerle, Alfred/Tutz, Gerhard (Hrsg.) (1996): Multivariate statistische Verfahren, 2. Aufl., Berlin/New York.

Fama, Eugene F. (1970): Efficient Capital Markets: A Review of Theory and Empirical Work. In: JoF, Vol. 25, S. 383-417.

Fama, Eugene F. (1980): Agency Problems and the Theory of the Firm. In: JoPE, Vol. 88, S. 288-307.

Fama, Eugene F. (1991): Efficient Capital Markets: II. In: JoF, Vol. 46, S. $1575-1617$.

Fama, Eugene F./Jensen, Michael C. (1983): Separation of ownership and control. In: JoLE, Vol. 26, S. 301-325.

Fama, Eugene F./Jensen, Michael C. (1983a): Agency Problems and Residual Claims. In: JoLE, Vol. 26, S. 327-349.

Fan, Joseph P.H./Wong, T.J. (2002): Corporate ownership structure and the informativeness of accounting earnings in East Asia. In: JoAE, Vol. 33, S. 401-425.

Feddersen, Dieter (2000): Neue gesetzliche Anforderungen an den Aufsichtsrat. In: AG, 45. Jg., S. 385-396.

Feddersen, Dieter/Hommelhoff, Peter/Schneider, Uwe H. (1996): Corporate Governance: Optimierung der Unternehmensführung und der Unternehmenskontrolle im deutschen und amerikanischen Aktienrecht, Köln.

Fillmann, Andreas (1991): Treuepflichten der Aktionäre, Frankfurt/M. u.a.

Firth, Michael/Fung, Peter M.Y./Rui, Oliver M. (2002): Simultaneous Relationships among Ownership, Corporate Governance, and Financial Performance. Working Paper, Hong Kong Polytechnic University, Hong Kong.

Flassak, Hansjörg (1995): Der Markt für Unternehmenskontrolle - Eine ökonomische Analyse vor dem Hintergrund des deutschen Gesellschaftsrechts, Bergisch Gladbach.

Fluck, Zsuzsanna (1999): The Dynamics of the Management-Shareholder Conflict. In: RoFS, Vol. 12, S. 379-404. 
Franke, Günter (1997): Kritik an der Kritik an der Publikumsgesellschaft. In: Gahlen, B./Hesse, H./Ramser, H. (Hrsg.): Finanzmärkte, Tübingen, S. 5782.

Franks, Julian R./Mayer, Colin (1996): Hostile takeovers and the correction of managerial failure. In: JoFE, Vol. 40, S. 163-181.

Franks, Julian R./Mayer, Colin P. (1997): Ownership, control and the Performance of German Corporations, Working Paper, London Business School and University of Oxford, London/Oxford.

Franks, Julian R./Mayer, Colin P. (1997a): Corporate Ownership and Control in the U.K., Germany and France. In: JoACF, Vol. 9, S. 30-45.

Franks, Julian R./Mayer, Colin P. (1998): Bank control, takeovers and corporate governance in Germany. In: JoBF, Vol. 22, S. 1385-1403.

Franks, Julian R./Mayer, Colin P. (2001): Ownership and Control of German Corporations. In: RoFS, Vol. 14, S. 943-977.

Franks, Julian R./Mayer, Colin P./Renneboog, Luc (2001): Who Disciplines Management in Poorly Performing Companies? In: JoFI, Vol. 10, S. 209248.

Fraune, Christian (1996): Der Einfluß institutioneller Anleger auf der Hauptversammlung, Köln u.a.

Frick, Bernd (1999): Corporate governance and corporate takeovers. A German perspective. In: Funk, L. (Hrsg.): The economics and the politics of the third way: Essays in honour of Eric Owen Smith, Hamburg, S. 134-151.

Fülbier, Rolf Uwe (1998): Regulierung der Ad-hoc-Publizität - Ein Beitrag zur ökonomischen Analyse des Rechts, Wiesbaden.

Fülbier, Rolf Uwe (1999): Regulierung - Ökonomische Betrachtung eines allgegenwärtigen Phänomens. In: WiSt, 28. Jg., S. 468-473.

Furubotn, Eirik G./Pejovich, Svetozar (1972): Property Rights and Economic Theory: A Survey of Recent Literature. In: JEL, Vol. 10, S. 1137-1162. 
Furubotn, Eirik G./Richter, Rudolf (1995): The New Institutional Economics: An Assessment. In: Williamson, O.E./Masten, Scott E. (Hrsg.): Transaction Cost Economics, London, S. 611-642.

Gaida, Michael (2002): Venture Capital in Deutschland und den USA, Wiesbaden.

Garza-Gómez, Xavier (2001): The Information Content of the Book-to-Market Ratio. In: FAJ, Vol. 57, S. 78-95.

Gassen, Joachim (2000): Datenbankgestützte Rechnungslegungspublizität - Ein Beitrag zur Evolution der Rechnungslegung, Frankfurt/M. u.a.

Gawrisch, Volker (2000): Ermessensentscheidungen des Aufsichtsrates und ihre gerichtliche Kontrolle, Frankfurt/M. u.a.

Gedajlovic, Eric R./Shapiro, Daniel M. (1998): Management and ownership effects: Evidence from five countries. In: SMJ, Vol. 19, S. 533-553.

Gehrke, Norman (1994): Tobins q - Die Beziehung zwischen Buch- und Marktwerten deutscher Aktiengesellschaften, Wiesbaden.

Geldmacher, Detlef (2000): Marktorientierte Managerkontrolle - Stimmrechte als Kontrollinstrument, Wiesbaden.

Gerke, Wolfgang (2002): Übernahmegesetz - Deutschland AG voll intakt. In: DBW, 62. Jg., S. 1-3.

Gerke, Wolfgang/Garz, Hendrik/Oerke, Marc (1995): Die Bewertung von Unternehmensübernahmen auf dem deutschen Aktienmarkt. In: ZfbF, 47. Jg., S. 805-820.

Gerson, Jos/Barr, Graham (1996): The Structure of Corporate Control and Ownership in a Regulatory Environment Unbiased toward One-Share-OneVote. In: CG, Vol. 4, S. 78-93.

Gerster, Max (1997): Stimmrechtsaktien, Zürich.

Gierl, Heribert/Praxmarer, Sandra (2001): Kursstabilität durch Einflussnahme auf die Aktionärsstruktur. In: FB, 3. Jg., S. 272-276. 
Gillan, Stuart L./Starks, Laura T. (2000): Corporate governance proposals and shareholder activism: the role of institutional investors. In: JoFE, Vol. 57, S. 275-305.

Gode, Wolfgang (1996): Institutionelle Anleger und ihre Erwartungen gegenüber den Gesellschaften. In: Feddersen, D. u.a. (Hrsg.): Corporate Governance, Köln, S. 316-323.

Goedsche, Marcus (2002): Das Recht der Namensaktie und die Öffnung des Aktienrechts für moderne Kommunikationsmittel, Frankfurt/M. u.a.

Goergen, Marc (1998): Corporate Governance and Financial Performance - A Study of German and UK Initial Public Offerings, Cheltenham.

Goergen, Marc/Renneboog, Luc (2001): Investment policy, internal financing and ownership concentration in the UK. In: JoCF, Vol. 7, S. 257-284.

Goergen, Marc/Renneboog, Luc (2002): The Social Responsibility of Major Shareholders. Working Paper, University of Manchester and Tilburg University, Manchester/Tilburg.

Golland, Frank/Heckemüller, Carsten (2002): Secondary Private Equity-Transaktionen und Private Equity-Securitisation. In: FB, 4. Jg., S. 524-530.

Gomes, Armando (2000): Going Public without Governance: Managerial Reputation Effects. In: JoF, Vol. 55, S. 615-646.

Gomes, Armando/Novaes, Walter (2001): Sharing of Control as a Corporate Governance Mechanism. Working paper, Wharton School, University of Pennsylvania (CARESS), No. 01/06, Philadelphia, PA.

Gompers, Paul/Ishii, Joy/Metrick, Andrew (2003): Corporate Governance and Equity Prices. In: QJoE, Vol. 118, S. 107-155.

Gordon, Robert A. (1945): Business Leadership in the Large Corporation, $2^{\text {nd }}$ printing 1966, Berkeley/Los Angeles.

Gordon, Jeffrey, N. (1991): Shareholder Initiative: A Social Choice and Game Theoretic Approach to Corporate Law. In: University of Cincinnati Law Review, Vol. 60, S. 347-385. 
Görling, Helmut (1993): Die Verbreitung zwei- und mehrstufiger Unternehmensverbindungen. In: AG, 38. Jg., S. 538-547.

Górriz, Carmen G./Fumás, Vicente S. (1996): Ownership Structure and Firm Performance: Some Empirical Evidence from Spain. In: MDE, Vol. 17, S. 575-586.

Gorton, Gary/Schmid, Frank A. (2000): Universal Banking and the Performance of German Firms. In: JoFE, Vol. 58, S. 29-80.

Gorton, Gary/Schmid, Frank A. (2002): Class struggle inside the firm: A study of German codetermination. NBER Working Paper No. 5453, Cambridge.

Gottschlich, Klaus J. (1996): Die Eigentümerkontrolle in der modernen Publikumsgesellschaft, München.

Grafmüller, Frank (1994): Die Kommanditgesellschaft auf Aktien als geeignete Rechtsform für börsenwillige Familienunternehmen, Frankfurt/M.

Grandjean, Birgitt (1992): Unternehmenszusammenschlüsse und die Verteilung der abnormalen Aktienrenditen zwischen den Aktionären der übernehmenden und übernommenen Gesellschaften. Frankfurt/M.

Granger, Clive W.J. (1969): Investigating Causal Relations by Econometric Models and Cross-Spectral Methods. In: Econometrica, Vol. 37, S. 424438.

Greene, William H. (2003): Econometric Analysis, $5^{\text {th }}$ ed., Upper Saddle River, NJ.

Griliches, Zvi/Hausman, Jerry A. (1986): Errors in Variables in Panel Data. In: JoE, Vol. 31, S. 93-118.

Groß, Wolfang (1997): Informations- und Auskunftsrecht des Aktionärs. In: AG, 42. Jg., S. 97-107.

Großfeld, Bernhard (1968): Aktiengesellschaft, Unternehmenskonzentration und Kleinaktionär, Tübingen.

Großmann, Adolf (1980): Unternehmensziele im Aktienrecht, Köln u.a. 
Großmann, Klaus/Nikoleyczik, Tobias (2002): Praxisrelevante Änderungen des Wertpapierhandelsgesetzes - Die Auswirkungen des Vierten Finanzmarktförderungsgesetzes. In: DB, 55. Jg., S. 2031-2037.

Grossman, Sanford J./Hart, Oliver D. (1980): Takeover bids, the free-rider problem, and the theory of the corporation. In: BJoE, Vol. 11, S. 42-64.

Grossman, Sanford J./Hart, Oliver D. (1982): Corporate financial structure and managerial incentives. In: McCall, J. (Hrsg.): The Economics of Information and Uncertainty, Chicago, S. 107-140.

Grossman, Sanford J./Hart, Oliver D. (1986): The Costs and Benefits of Ownership: A Theory of Vertical and Lateral Integration. In: JoPE, Vol. 94, S. 691-719.

Grossman, Sanford J./Hart, Oliver D. (1988): One Share - One Vote and the Market for Corporate Control. In: JoFE, Vol. 20, S. 175-202.

Groves, Theodore/Ledyard, John O. (1977): Optimal Allocation of Public Goods: A solution to the 'Free Rider Problem'. In: Econometrica, Vol. 45, S. 783-809.

Grundsatzkommission Corporate Governance (2000): Corporate Governance Grundsätze ('Code of Best Practice') für börsennotierte Gesellschaften. In: DB, 53. Jg., S. 238-241.

Grunmann, Marc-Olaf/Soehlke, Raphael (2001): Namensaktie und Hauptversammlung. In: DB, 54. Jg., S. 576-579.

Guedes, José C./Loureiro, Gilberto (2002): Are European Corporations Fleecing Minority Shareholders? Working Paper Universidade Católica Portugesa, Lisbon.

Gugler, Klaus (1999): Eigentümerstruktur und Profitabilität - Eine Analyse österreichischer Unternehmen. In: Wirtschaftspolitische Blätter, 46. Jg., S. 583-589.

Gugler, Klaus (2001): Corporate Governance and Economic Performance, Oxford.

Gugler, Klaus/Mueller, Dennis C./Yurtoglu, B. Burcin (2002): Corporate Governance, Capital Market Discipline and the Returns on Investment. Working Paper, University of, Vienna. 
Gugler, Klaus/Stomper, Alex/Zechner, Josef (2000): Corporate Governance, Ownership, and Board Structure in Austria. In: ZfB, 71. Jg., Ergänzungsheft 1/2000, S. 23-43.

Gujarati, Damodar N. (2003): Basic Econometrics, $4^{\text {th }}$ ed., New York u.a.

Gutiérrez, Maria/Tribo, Josep A. (2002): Multiple Large Shareholders in Corporate Control: Evidence for Spain. Working Paper, Universidad Carlos III de Madrid, Madrid.

Habersack, Mathias (2001): Der Finanzplatz Deutschland und die Rechte der Aktionäre. In: ZIP, 22. Jg., S. 1230-1239.

Hadden, Tom (1993): Corporate Governance by Institutional Investors? In: Baums, T. u.a. (Hrsg.): Institutional Investors and Corporate Governance, Berlin/New York, S. 89-102.

Haid, Alfed/Weigand, Jürgen (2001): R\&D, Liquidity Constraints, and Corporate Governance. In: Jahrbücher für Nationalökonomie und Statistik, 221. Bd., S. 145-167.

Hallett, Graham (1990): West Germany. In: Graham, A./Seldon, A. (eds.): Government and Economies in the Post-War World, London, chapter 5.

Halpern, Paul J.N. (2000): Systemic perspectives on corporate governance systems. In: Cohen, S./Boyd, G. (Hrsg.): Corporate governance and globalization, S. 1-58.

Hannah, Leslie/Kay, John (1977): Concentration in Modern Industry, Houndmills.

Hansen, Herbert (1976): Beteiligungen an Industrie-Aktiengesellschaften. In: AG, 21. Jg., S. 295-297.

Hansmann, Henry (1988): Ownership of the Firm. In: JLEO, Vol. 4, S. 267304.

Harris, Milton/Raviv, Artur (1978): Some Results on Incentive Contracts with Applications to Education and Employment, Health Insurance, and Law Enforcement. In: AER, Vol. 68, S. 20-30. 
Harris, Milton/Raviv, Artur (1988): Corporate control contests and capital structure. In: JoFE, Vol. 20, S. 55-86.

Harris, Milton/Raviv, Artur (1988a): Corporate Governance, Voting Rights and Majority Rules. In: JoFE, Vol. 20, S. 203-235.

Harris, Milton/Raviv, Artur (1989): The Design of Securities. In: JoFE, Vol. 24, S. 255-287.

Harris, Milton/Raviv, Artur (1990): Capital Structure and the Informational Role of Debt. In: JoF, Vol. 45, S. 321-349.

Hart, Oliver (1983): The Market Mechanism as an Incentive Scheme. In: BJoE, Vol. 14, S. 366-382.

Hart, Oliver (1995): Firms, Contracts, and Financial Structure, London.

Hart, Oliver (1995a): Corporate Governance: Some Theory and Implications. In: EJ, Vol. 105, S. 678-689.

Hartmann-Wendels, Thomas (1989): Principal-Agent-Theorie und asymmetrische Informationsverteilung. In: ZfB, 59. Jg., S. 714-734.

Hartmann-Wendels, Thomas (2001): Kontrollrechte der Gesellschafter. In: Gerke, W./Steiner, M. (Hrsg.): Handwörterbuch des Bank- und Finanzwesens, 3. Aufl., Stuttgart, Sp. 1342-1350.

Hartmann-Wendels, Thomas/von Hinten, Peter (1989): Marktwert von Vorzugsaktien. In: ZfbF, 41. Jg., S. 263-293.

Hartung, Joachim (2002): Statistik, 13. Aufl., München.

Harvey, Andrew C./Collier, Paul (1977): Testing for Functional Misspecification in Regression Analysis. In: JoE, Vol. 6, S. 103-119.

Hasselbach, Kai/Schumacher, Stephan (2000): Hauptversammlung im Internet. In: ZGR, 29. Jg., S. 258-286.

Hauser, Heinz (1993): Harmonisierung oder Wettbewerb nationaler Regulierungssysteme in einem integrierten Wirtschaftsraum. In: Aussenwirtschaft, 48. Jg., S. 459-476. 
Hausman, Jerry A. (1978): Specification Tests in Econometrics. In: Econometrica, Vol. 46, S. 1251-1271.

Hawley, James P./Williams, Andrew T. (1996): Corporate Governance in the United States: The Rise of Fiduciary Capitalism - A review of the Literature. Discussion Paper, Graduate Business Programs, Saint Mary's College, Moraga, CA.

Hax, Herbert (1991): Theorie der Unternehmung - Information, Anreize und Vertragsgestaltung. In: Ordelheide, D. et al. (Hrsg.): Betriebswirtschaftslehre und ökonomische Theorie, Stuttgart, S. 51-72.

Hayek, Friedrich A. von (1968): Der Wettbewerb als Entdeckungsverfahren, Kiel.

Heaney, Richard/Holmen, Martin (2002): Shareholder Diversification and the Value of Control. Working paper, Australian National University/Stockholm School of Business, Canberra,Stockholm.

Heckman, James J. (1979): Sample selection bias as a specification error. In: Econometrica, Vol. 47, S. 153-161.

Heckman, James J. (1997): Instrumental Variables. In: JHR, Vol. 32, S. 441462.

Hefermehl, Wolfgang (1977): Umfang und Grenzen des Auskunftsrechts des Aktionärs in der Hauptversammlung. In: Pawlowski, H.M./Wiese, G./Wüst, G. (Hrsg.): Festschrift Duden, München, S. 109-135.

Heinemann, Bernd/Gröninger, Benno/Augat, Thomas (2001): Übernahmen stärken Wachstumskräfte. In: Handelsblatt vom 15.8.2001, Nr. 156, S. 13.

Heinrich, Ralph P. (2000): Complementarities in Corporate Governance: Ownership Concentration, Capital Structure, Monitoring and Pecuniary Incentives, Institut für Weltwirtschaft Kiel, Working Paper No. 968, Kiel.

Heiss, Florian/Köke, Jens (2001): Dynamics in Ownership and Firm Survival: Evidence from Corporate Germany, ZEW Discussion Paper No. 01-63, Mannheim.

Heits, Wilhelm (1940): Das Stimmrecht des Aktionärs in eigener Angelegenheit, Köln. 
Hellwig, Martin (2000): On the Economics and Politics of Corporate Finance and Corporate Control. In: Vives, X. (Hrsg.): Corporate Governance, Cambridge, S. 95-134.

Henes, Frank (1995): Börsenrechtliche Zwischenberichtspublizität, Stuttgart.

Henn, Günter (1998): Handbuch des Aktienrechts, 6. Aufl., Heidelberg.

Henze, Hartwig (2002): Pünktlich zur Hauptversammlungssaison: Ein Rechtsprechungsüberblick zu Informations- und Auskunftsrechten. In: BB, 57. Jg., S. 893-903.

Hering, Thomas/Olbrich, Michael (2001): Zur Bewertung von Mehrstimmrechten. In: ZfbF, 53. Jg., S. 20-38.

Hermalin, Benjamin E. (1992): The Effects of Competition on Executive Behavior. In: RJE, Vol. 23, S. 350-365.

Hermalin, Benjamin E./Weisbach, Michael S. (1988): The Determinants of Board Composition. In: RJE, Vol. 19, S. 589-606.

Hermalin, Benjamin E./Weisbach, Michael S. (1991): The Effects of Board Composition and Direct Incentives on Firm Performance. In: FM, Vol. 20, S. 101-112.

Heße, Manfred/Enders, Theodor (2001): Gesellschaftsrecht, Stuttgart.

Hidding, Bruno (2000): Neuer Markt - ein Baustein der deutschen Aktienkultur. In: Beyer, S. (Hrsg.): Praxisrelevante Fragestellungen aus Investmentanalyse und Finanzierung: Festschrift Hielscher, Stuttgart, S. 69-84.

Hillebrandt, Franca (2001): Entflechtung der „Deutschland AG“ durch Steuerfreiheit von Veräußerungserlösen? In: DBW, 61. Jg., S. 713-728.

Hillebrandt, Franca (2001a): Multiplikatorverfahren. In: DBW, 61. Jg., S. 618621.

Hillebrandt, Franca/Schremper, Ralf (2001): Analyse des Gleichbehandlungsgrundsatzes beim Rückkauf von Vorzugsaktien. In: BB, 56. Jg., S. 533538. 
Hillebrandt, Franca /Sellhorn, Thorsten (2002): Pro-Forma-Earnings: Umsatz vor Aufwendungen? - Eine kritische Analyse aktueller Forschungsergebnisse und Regulierungsbemühungen. In: KoR, 2. Jg., S. 153-154.

Hillebrandt, Franca /Sellhorn, Thorsten (2002a): "Earnings before bad stuff" Pro forma earnings disclosure in German annual reports. Diskussionspapier 11/2002 des Lehrstuhls für Internationale Unternehmensrechnung, Bochum 2002.

Himmelberg, Charles P./Hubbard, R. Glenn/Love, Inessa (2002): Investor Protection, Ownership, and the Cost of Capital. Working Paper, Columbia University, NBER and World Bank, Cambridge.

Himmelberg, Charles P./Hubbard, R. Glenn/Palia, Darius (1999): Understanding the determinants of managerial ownership and the link between ownership and performance. In: JoFE, Vol. 53, S. 353-384.

Hirschman, Albert O. (1970): Exit, Voice, and Loyalty, Cambridge, MA.

Hoffknecht, Petra (2001): Mehr Transparenz. In: Handelsblatt vom 3. Dezember 2001, Nr. 233, S. 24.

Hoffmann, Jochen (1999): Systeme der Stimmrechtsvertretung in der Publikumsgesellschaft, Baden-Baden.

Hoffmann-Becking, Michael (2001): Defizite des aktienrechtlichen Anfechtungs- und Organhaftungsrechts und Möglichkeiten zur Verbesserung. In: WPg-Sonderheft 2001, 54. Jg., S. 121-139.

Hoffmann-Burchardi, Ulrike (1999): Corporate governance rules and the value of control - A study of German dual-class shares. London School of Economics, FMG Discussion Paper No. 315, London.

Hofmann, Rolf (1998): Corporate Governance: Überwachungseffizienz und Führungskompetenz in Kapitalgesellschaften, München u.a.

Höher, Konrad (1929): Das Stimmrecht in der Generalversammlung der A.G., Köln.

Holderness, Clifford G. (2003): A Survey of Blockholders and Corporate Control. In: EPR, Vol. 9, S. 51-64. 
Holderness, Clifford G./Kroszner, Randall S./Sheehan, Dennis P. (1999): Were the Good Old Days That Good? Changes in Managerial Stock Ownership Since the Great Depression. In: JoF, Vol. 54, S. 435-469.

Holderness, Clifford G./Sheehan, Dennis P. (1988): The Role of Majority Shareholders in Publicly Held Corporations. In: JoFE, Vol. 20, S. 317346.

Holderness, Clifford G./Sheehan, Dennis P. (2000): Constraints on LargeBlock Shareholders. In: Morck, R.K. (ed.): Concentrated Corporate Ownership, Chicago/London, S. 139-175.

Holl, Peter (1975): Effect of Control Type on the Performance of the Firm in the U.K. In: JoIE, Vol. 23, S. 257-271.

Holl, Peter (1977): Control Type and the Market for Corporate Control in Large U.S. Corporations. In: JoIE, Vol. 25, S. 259-273.

Holmström, Bengt (1979): Moral hazard and observability. In: BJoE, Vol. 10, S. 74-91.

Holmström, Bengt/Tirole, Jean (1989): The Theory of the Firm. In: Schmalensee, R./Willig, R.D. (Hrsg.): Handbook of Industrial Organization, S. 61133.

Holmström, Bengt/Tirole, Jean (1993): Market Liquidity and Performance Monitoring. In: JoPE, Vol. 101, S. 678-709.

Holthausen, Robert W./Watts, Ross $\boldsymbol{L}$. (2001): The relevance of the value-relevance literature for financial accounting standard setting. In: JoAE, Vol. 31, S. 3-75.

Holzer, Erich (2001): Informationseffizienz des deutschen und österreichischen Kapitalmarktes - Eine empirische Untersuchung, Wien.

Hommel, Ulrich/Riemer-Hommel, Petra (1999): Die Evolution der nationalen Unternehmensüberwachungssysteme. In: Kutschker, M. (Hrsg.): Management verteilter Kompetenzen in multinationalen Unternehmen, Wiesbaden, S. 149-176.

Hommelhoff, Peter/Mattheus, Daniela (1998): Corporate Governance nach dem KonTraG. In: AG, 43. Jg., S. 249-259. 
Hoppenstedt (div. Jahre): Handbuch der Aktiengesellschaften, Darmstadt.

Hoppenstedt (div. Jahre): Handbuch der Großunternehmen, Darmstadt.

Hopt, Klaus J. (1977): Vom Aktien- und Börsenrecht zum Kapitalmarktrecht? Teil 2: Die deutsche Entwicklung im internationalen Vergleich. In: ZHR, 141. Jg., S. 389-441.

Hopt, Klaus J. (1995): Grundsatz- und Praxisprobleme nach dem Wertpapierhandelsgesetz. In: ZHR, 159. Jg., S. 135-163.

Hopt, Klaus J. (1996): Corporate Governance und deutsche Universalbanken. In: Feddersen, D. u.a. (Hrsg.): Corporate Governance, Köln, S. 243-263.

Hopt, Klaus J. (1998): Europäisches Gesellschaftsrecht - Krise und neue Anläufe. In: ZIP, 19. Jg., S. 96-106.

Hopt, Klaus J. (2000): Gemeinsame Grundsätze der Corporate Governance in Europa? In: ZGR, 29. Jg., S. 779-818.

Hopt, Klaus J. (2000a): Corporate Governance: Aufsichtsrat oder Markt? In: Hommelhoff, P. et al. (Hrsg.): Max-Hachenburg - Dritte Gedächtnisvorlesung 1998, S. 9-47.

Hopt, Klaus J./Wymeersch, Eddy (1997): Comparative Corporate Governance Essays and Materials, Berlin/New York.

Hsiao, Cheng (1986): Analysis of panel data, Cambridge.

Huddart, Steven (1993): The Effect of a Large Shareholder on Corporate Value: In: Management Science, Vol. 39, S. 1407-1421.

Hueck, Alfred (1947): Der Treuegedanke im modernen Privatrecht, München.

Huep, Tobias (2000): Die Renaissance der Namensaktie. In: WM, 54. Jg., S. 1623-1630.

Hüffer, Uwe (1999): § 141 AktG. In: Beck'sche Kurz-Kommentare, Bd. 53, 4. Aufl., München.

Hüffer, Uwe (2002): Aktiengesetz mit Erläuterungen, 5. Aufl., München. 
Hulle, Karel van (2000): Aktuelle Entwicklungen im europäischen Gesellschaftsrecht. In: EWS, 11. Jg., S. 521-526.

Hypobank (div. Jahre): Bayrische Hypotheken- und Wechsel-Bank: Wegweiser durch deutsche Aktiengesellschaften, München.

Iber, Bernhard (1985): Zur Entwicklung der Aktionärsstruktur in der Bundesrepublik Deutschland (1963-1983). In: ZfB, 55. Jg., S. 1101-1119.

Iber, Bernhard (1987): Entwicklung der Aktionärsstruktur börsennotierter deutscher Aktiengesellschaften, Kiel.

Inderst, Roman/Müller, Holger M. (1999): Ownership Concentration, Monitoring, and the Agency Cost of Debt. Working Paper, Universität Mannheim.

Israel, Ronen (1992): Capital and Ownership Structures, and the Market for Corporate Control. In: RoFS, Vol. 5, S. 181-198.

Jacobi, Robert (2000): Steigende Gewinne bei US-Großbanken. In: Süddeutsche Zeitung vom 24.1.2000, Nr. 21, S. 25.

Jacquemin, Alexis/Ghellinck, Elisabeth de (1980): Familial Control, Size and Performance in the Largest French Firms. In: EER, Vol. 13, S. 81-91.

Jahn, Andreas/Herfs-Röttgen, Ebba (2001): Die Europäische Aktiengesellschaft. In: DB, 54. Jg., S. 631-638.

Jahr, Volker (2002): Transparenz- und Publizitätspflichten deutscher Unternehmen, Frankfurt/M. u.a.

Jansch, Torsten A. (1999): Die Rolle der Aktionäre in Publikumsgesellschaften, Wiesbaden.

Janßen, Michael (2001): Bedeutung von persönlichen Kontakten zu Investoren und Analysten bei der Ausgestaltung einer erfolgreichen Investor-Relations-Arbeit. In: Achleitner, A.-K./Bassen, A. (Hrsg.): Investor Relations am Neuen Markt, Stuttgart, S. 565-575.

Januszewski, Silke I./Köke, F. Jens/Winter, Joachim K. (1999): Product market competition, corporate governance and firm performance: An empirical analysis for Germany. ZEW Discussion Paper No. 99-63, Mannheim. 
Jarrell, Greg A./Brickley, James A./Netter, Jeffry M. (1988): The Market for Corporate Control: The Empirical Evidence since 1980. In: JEP, Vol. 2, S. 49-68.

Jenkinson, Tim/jungqvist, Alexander (2001): The role of hostile stakes in German corporate governance. In: JoCF, Vol. 7, S. 397-446.

Jensen, Michael C. (1983): Organization Theory and Methodology. In: AR, Vol. 58, S. 319-339.

Jensen, Michael C. (1986): Agency Costs of Free Cash Flow, Corporate Finance and Takeovers. In: AER, Vol. 76, S. 323-329.

Jensen, Michael C. (1986a): The takeover controversy: Analysis and evidence. In: MCFJ, Vol. 4, S. 6-32.

Jensen, Michael C. (1989): Eclipse of the public corporation. In: HBR, Vol. 67, S. 61-74.

Jensen, Michael C. (1993): The Modern Industrial Revolution, Exit, and the Failure of Internal Control Systems. In: JoF, Vol. 48, S. 831-880.

Jensen, Michael C.Meckling, William H. (1976): Theory of the Firm: Managerial Behavior, Agency Costs and Ownership Structure. In: JoFE, Vol. 3, S. 305-360.

Jensen, Michael C./Murphy, Kevin J. (1990): Performance Pay and TopManagement Incentives. In: JoPE, Vol. 98, S. 225-264.

Jensen, Michael C./Ruback, Richard S. (1983): The Market for Corporate Control. In: JoFE, Vol. 11, S. 5-50.

Jensen, Michael C./Smith, Clifford W. Jr. (1984): The theory of corporate finance: A historical overview. In: Jensen, M.C./Smith, C.W. (Hrsg.): The modern theory of corporate finance, New York, S. 2-20.

Jensen, Michael C./Warner, Jerold B. (1988): The Distribution of Power Among Corporate Managers, Shareholders, and Directors. In: JoFE, Vol. 20, S. 3-24. 
Joh, Sung, Wook (2003): Corporate Governance and firm profitability: evidence from Korea before the economic crisis. In: JoFE, Vol. 68, S. 287322.

Johnson, Simon/ La Porta, Rafael/Lopez-de-Silanes, Florencio/Shleifer, Andrei (2000): Tunneling. In: AER, Vol. 90, Papers \& Proceedings, S. 2227.

Jörs, Bernd (2002): Der Pyramiden-Effekt. In: WiSt, 31. Jg., S. 91-95.

Judge, George $G$. et al. (1985): The Theory and Practice of Econometrics. $2^{\text {nd }}$ ed., New York u.a.

Juhnke, Robbin (1995): Die Trennung von Eigentum und Verfügungsgewalt in der deutschen Publikums-Aktiengesellschaft und der Funktionswandel ihrer Organe, Frankfurt/M. u.a.

Junge, Werner (1993): Anzeigepflicht und Publizität beim Beteiligungserwerb. In: Bierich, M. u.a. (Hrsg.): Festschrift Semler, Berlin, S. 473-484.

Kahle, Holger (2002): Informationsversorgung des Kapitalmarkts über internationale Rechnungslegungsstandards. In: KoR, 2. Jg., S. 95-107.

Kahn, Charles/Winton, Andrew (1998): Ownership Structure, Speculation, and Shareholder Intervention. In: JoF, Vol. 53, S. 99-129.

Kallmeyer, Harald (2000): Ausschluß von Minderheitsaktionären. In: AG, 45. Jg., S. 59-61.

Kalss, Susanne (1993): Die Offenlegung von Beteiligungen. In: ÖBA, 41. Jg., S. 615-629.

Kamerschen, David R. (1968): The Influence of Ownership and Control on Profit Rates. In: AER, Vol. 58, S. 432-447.

Kammerath, Jens (2000): Zur quantitativen Analyse von Kapitalverflechtungen. In: IFO Schnelldienst, 53. Jg., Heft 16/17, 2000, S. 15-20.

Kaplan, Steven N. (1994): Top Executives, Turnover and Firm Performance in Germany. In: JoLEO, Vol. 10, S. 142-159.

Karst, Christina (1982): Reform des Vollmachtstimmrechts? Berlin. 
Kau, Wolfgang M. (2000): Haftung von Vorstands- und Aufsichtsratsmitgliedern bei Pflichtverletzungen nach dem Aktiengesetz. In: BB, 55. Jg., S. 1045-1050.

Kennedy, Peter (1998): A Guide to Econometrics, $4^{\text {th }}$ ed., Cambridge, MA.

Kim, Wi Saeng/Lee, Jae Won/Francis, Jack Clark (1988): Investment Performance of Common Stocks in Relation to Insider Ownership. In: FR, Vol. 23, S. 53-64.

Kindl, Johann (2000): Die Notwendigkeit einer einheitlichen Entscheidung über aktienrechtliche Anfechtungs- und Nichtigkeitsklagen. In: ZGR, 29. Jg., S. 166-185.

Kirchner, Cristian (1984): Ansätze zu einer ökonomischen Analyse des Konzernrechts. In: Boettcher, E. u.a. (Hrsg.): Jahrbuch für Neue Politische Ökonomie, Bd. 3, Tübingen, S. 223-250.

Klapper, Leora F./Love, Inessa (2002): Corporate Governance, Investor Protection and Performance in Emerging Markets. Working Paper, World Bank, Washington, DC.

Klein, Benjamin/Crawford, Robert/Alchian, Armen A. (1978): Vertical Integration, Appropriable Rents, and the Competitive Contracting Process. In: JoLE, Vol. 22, S. 297-326.

Klein, Gabriele (1981): Vorzugsaktien in der Bundesrepublik Deutschland und den Vereinigten Staaten von Amerika, Köln.

Kluth, Winfried (1997): Abschaffung von Mehrstimmrechtsaktien verfassungswidrig? In: ZIP, 18. Jg., S. 1217-1223.

Koch, Alexander (2001): Tobins Q. In: Controlling, 13. Jg., S. 583-584.

Koch, Hans-Dieter/Schmidt, Reinhard H. (1981): Ziele und Instrumente des Anlegerschutzes. In: BFuP, 33. Jg., S. 231-250.

Kole, Stacey R. (1996): Managerial Ownership and Firm Performance. In: AFE, Vol. 2, S. 119-149. 
Kole, Stacey R./Lehn, Kenneth (1997): Deregulation, the Evolution of Corporate Governance Structure and Survival. In: AER, Papers and Proceedings, Vol. 87, S. 421-425.

Köke, Jens (2000): Control transfers in corporate Germany: Their frequency, causes and consequences. ZEW Discussion Paper No. 00-67, Mannheim.

Köke, Jens (2001): New Evidence on Ownership Structures in Germany. In: KK, 34. Jg., S. 257-292.

Köke, Jens (2002): Corporate Governance in Germany - An Empirical Investigation, Heidelberg.

Köke, Jens/Renneboog, Luc (2003): Does good corporate governance lead to stronger productivity growth? ecgi Working Paper No. 14/2003, Brüssel.

Köndgen, Johannes (1993): Die Relevanz der ökonomischen Theorie der Unternehmung für rechtswissenschaftliche Fragestellungen. In: Ott, C./Schäfer, H.-B. (Hrsg.): Ökonomische Analyse des Unternehmensrechts, Heidelberg, S. 117-138.

Kothari, Sanjay P. (2001): Capital markets research in accounting. In: JoAE, Vol. 31, S. 105-231.

Kraft, Alfons (1988): § 11 AktG. In: Zöllner, W. (Hrsg.): Kölner Kommentar zum Aktiengesetz, Bd. 1, 2. Aufl., Köln u.a.

Kraft, Volker (2001): Private-Equity-Investitionen in Turnarounds und Restrukturierungen, Frankfurt/M.

Kratz, Norbert (1995): Kapitalstrukturgestaltung im Konzern, Bergisch Gladbach/Köln.

Kreps, David (2000): A course in microeconomic theory, Harlow.

Kretschmann, Axel (1976): Der Einfluss der Aktionärsstruktur auf die Kursbildung, Mainz.

Kruiniger, Hugo (2002): On the Estimation of Panel Regression Models with Fixed Effects. Working Paper No. 450, Queen Mary University of London, Dept. of Economics, London. 
Kübler, Friedrich (1999): Gesellschaftsrecht, 5. Aufl., Heidelberg.

Kugler, Stefan/Rittler, Thomas (2002): Viertes Finanzmarktförderungsgesetz Aufbruch zu neuen Ufern im Investmentrecht? In: BB, 57. Jg., S. 10011006.

Kunz, Alexis H./Pfaff, Dieter (2002): Agency theory, performance evaluation, and the hypothetical construct of intrinsic motivation. In: Accounting, Organizations and Society, Vol. 27, S. 275-295.

Küting, Karlheinz/Harth, Hans-Jörg/Leinen, Markus (2001): Anmerkungen zur international vergleichenden Jahresabschlussanalyse. In: WPg, 54. Jg., S. 861-867.

Küting, Karlheinz/Weber, Claus-Peter/Gattung, Andreas (2003): Nahe stehende Personen (related parties) nach nationalem und internationalem Recht. In: KoR, 3. Jg., S. 53-66.

Lamba, Asjeet/Stapledon, Geof (2001): The Determinants of Corporate Ownership Structure: Australian Evidence. University of Melbourne, Faculty of Law, Working Paper No. 20, Melbourne.

Lang, Marc H./Maydew, Edward L./Shackelford, Douglas A. (2001): Bringing Down the Other Berlin Wall: Germany's Repeal of the Corporate Capital Gains Tax, Working Paper, University of North Carolina, North Carolina.

Langner, Sabine (2001): Die Gestaltung der Kapitalstruktur und der Dividendenpolitik - Eine Frage der Aktionärsstruktur? In: ZfB, 71. Jg., S. 301319.

La Porta, Rafael et al. (1997): Legal Determinants of External Finance. In: JoF, Vol. 52, S. 1131-1150.

La Porta, Rafael et al. (1998): Law and Finance. In: JoPE, Vol. 106, S. 11131155.

La Porta, Rafael et al. (1999): Corporate Ownership Around the World. In: JoF, Vol. 54, S. 471-517.

La Porta, Rafael et al. (1999a): Agency Problems and Dividend Policies around the World. In: JoF, Vol. 55, S. 1-33. 
La Porta, Rafael et al. (2000): Investor protection and corporate governance. In: JoFE, Vol. 58, S. 3-27.

La Porta, Rafael et al. (2002): Investor Protection and Corporate Valuation. In: JoF, Vol. 57, S. 1147-1170.

La Porta, Rafael et al. (2002a): Government Ownership of Banks. In: JoF, Vol. 57, S. 265-301.

Larner, Robert J. (1966): Ownership and Control in the 200 Largest Nonfinancial Corporations, 1929 and 1963. In: AER, Vol. 56, S. 777-787.

Larner, Robert J. (1970): Management Control and the Large Corporation, New York.

Latham, Mark (1999): The Road to Shareowner Power, Arbeitspapier Nr. 81, Institut für Handels- und Wirtschaftsrecht der Universität Osnabrück, Osnabrück.

Laux, Christian (1996): Kapitalstruktur und Verhaltenssteuerung. Finanzierungsverträge als Bindungs- und Anreizinstrumente, Wiesbaden.

Lease, Ronald C./McConnell, John J./Mikkelson, Wayne H. (1983): The market value of control in publicly-traded corporations. In: JoFE, Vol. 11, S. 439-471.

Lease, Ronald C./McConnell, John J.Mikkelson, Wayne H. (1984): The market value of control in closely held corporations. In: JoB, Vol. 57, S. 443467.

Leech, Dennis/Leahy, John (1991): Ownership Structure, Control Type Classifications and the Performance of Large British Companies. In: EJ, Vol. 101, S. 1418-1437.

Lehmann, Erik/Warning, Susanne/Weigand, Jürgen (2002): Efficient Governance Structures, Corporate Investment, and Profitability. Discussion Paper No. 02-07, German Economic Association of Business Administration (GEABA), Konstanz/Koblenz.

Lehmann, Erik/Weigand, Jürgen (2000): Does the Governed Corporation Perform Better? Governance Structures and Corporate Performance in Germany. In: EFR, Vol. 4, S. 157-195. 
Lehmann, Friedrich Karl (1935): Das Stimmrecht in den Konzerngesellschaften, Mannheim u.a.

Lehmann, Karl (1898): Das Recht der Aktiengesellschaften, Band 1, Neudruck 1964, Berlin.

Lehmann, Karl (1895): Die geschichtliche Entwicklung des Aktienrechts bis zum Code de Commerce, Neudruck 1968, Berlin.

Leland, Hayne/Pyle, David (1977): Informational Asymmetries, Financial Structure and Financial Intermediation. In: JoF, Vol. 32, S. 371-387.

Lemmon, Michael L./Lins, Karl V. (2003): Ownership Structure, Corporate Governance and Firm Value: Evidence from the East Asian Financial Crisis. Erscheint in: JoF, Vol. 58, August 2003.

Lenssen, Willi (1938): Das Stimmrecht des Aktionärs unter besonderer Berücksichtigung der Treuepflicht, Bochum.

Leuz, Christian/Verrechia, Robert (2000): The Economic Consequence of Increased Disclosure. In: JoAR, Vol. 38, Supplement, S. 91-124.

Levin, Sharon G./Levin, Stanford L. (1982): Ownership and Control of Large Industrial Firms: Some New Evidence. In: RBER, Vol. 18, S. 37-49.

Li, Mingfang/Simerly, Roy L. (1998): The Moderating Effect of Environmental Dynamism on the Ownership and Performance Relationship. In: SMJ, Vol. 19, S. 169-179.

Lichtenberg, Frank R./Pushner, George M. (1994): Ownership structure and corporate performance in Japan. In: JWE, Vol. 6, S. 239-261.

Lilliefors, Hubert $\boldsymbol{W}$. (1967): On the Kolmogoroff-Smirnoff test for normality with mean and variance unknown. In: JoASA, Vol. 62, S. 399-402.

Lindenberg, Eric B./Ross, Steven A. (1981): Tobin's q ratio and industrial organization. In: JoB, Vol. 51, S. 1-31.

Lins, Karl V. (2003): Equity Ownership and Firm Value in Emerging Markets. In: JFQA, Vol. 38, S. 159-184. 
Lipka, Sabine (1995): Managementeffizienz und Kapitalmarktkontrolle. Empirische Tests neuerer Ansätze der Theorie der Firma. Frankfurt/M. u.a.

Lippmann, Walter (1914): Drift and Mastery, New York.

Ljungqvist, Alexander P. (1996): Can firms outwit the market? Timing ability and the long-run performance of IPOs. In: Levis, M. (Hrsg.): Empirical issues in raising equity capital, Amsterdam, S. 215-244.

Lloyd, William P./Jahera, John S./Goldstein, Steven J. (1986): The Relation Between Returns, Ownership Structure, and Market Value. In: JoFR, Vol. 9, S. 171-177.

Loderer, Claudio/Martin, Kenneth (1997): Executive stock ownership and performance - Tracking faint traces. In: JoFE, Vol. 45, S. 223-255.

Lück, Wolfgang (1998): Kontrolle. In: Lück, W. (Hrsg.): Lexikon der Rechnungslegung und Abschlussprüfung, 4. Aufl., München, S. 459-460.

Lücke, Wolfgang (2001): Zielgrößen für Unternehmen, Stakeholder und Shareholder. In: ZfP, 12. Jg., S. 47-72.

Luther, Thomas (2002): Neuer Spielraum. In: Handelsblatt vom 28.3.2002, S. I 3.

Lutter, Marcus (1980): Theorie der Mitgliedschaft. In: AcP, 180. Jg., S. 84-159.

Lutter, Marcus (1985): Organzuständigkeiten im Konzern. In: Lutter, M. u.a. (Hrsg.): Festschrift Stimpel, S. 825-854.

Lutter, Marcus (1988): § 58 AktG. In: Zöllner, W. (Hrsg.): Kölner Kommentar zum Aktiengesetz, Bd. 1, 2. Aufl., Köln u.a.

Lutter, Marcus (1994): Das neue „Gesetz für kleine Aktiengesellschaften und zur Deregulierung des Aktienrechts“. In: AG, 39. Jg., S. 429-447.

Lutter, Marcus (1995): Das dualistische System der Unternehmensverwaltung. In: Scheffler, E. (Hrsg.): Corporate Governance, SzU, Bd. 56, Wiesbaden, S. 5-26.

Lutter, Marcus (2000): Das Europäische Unternehmensrecht im 21. Jahrhundert. In: ZHR, 29. Jg., S. 1-18. 
Lutter, Marcus/Zöllner, Wolfgang (1998): § 53 AktG. In: Zöllner, W. (Hrsg.): Kölner Kommentar zum Aktiengesetz, Bd. 1, 2. Aufl., Köln u.a.

Macharzina, Klaus (1999): Unternehmensführung, 3. Aufl., Wiesbaden.

Macneil, Ian R. (1974): The Many Futures of Contract. In: SCLR, Vol. 47, S. 691-816.

Malik, Fredmund (1997): Wirksame Unternehmensaufsicht - Corporate Governance in Umbruchzeiten, Frankfurt/M.

Mallin, Chris (2001): Institutional Investors and Voting Practices: An international comparison. In: CG, Vol. 9, S. 118-126.

Manne, Henry G. (1964): Some theoretical aspects of share voting. In: ColLR, Vol. 64, S. 1427-1445.

Manne, Henry G. (1965): Mergers and the market for Corporate Control. In: JoPE, Vol. 73, S. 110-120.

Marris, Robin (1964): The Economic Theory of "Managerial" Capitalism, London.

Marsch-Barner, Reinhard (1999): Die Abschaffung von Mehrstimmrechten und Stimmrechtsbeschränkungen. In: Dörner, D./Menold, D./Pfitzer, N. (Hrsg.): Reform des Aktienrechts, der Rechnungslegung und Prüfung, Stuttgart, S. 283-296.

Martens, Knuth (2000): Managementüberwachung durch den Aufsichtsrat, Lohmar.

Matschke, Xenia (2001): Das Prinzipal-Agent-Modell adverser Selektion. In: WiSt, 30. Jg., S. 435-437.

Matthes, Jürgen (2000): Das deutsche Corporate-Governance-System, Institut der deutschen Wirtschaft, Köln, Beiträge zur Wirtschafts- und Sozialpolitik Nr. 259, Köln.

Maug, Ernst (1998): Large Shareholders as Monitors: Is There a Trade-Off between Liquidity and Control? In: JoF, Vol. 53, S. 65-98. 
Maug, Ernst (2000): Ownership Structure and the Life-cycle of the Firm: A Theory of the Decision to go Public. Working paper Fuqua School of Business, Duke University, Durham, NC.

Maug, Ernst (2002): Insider trading legislation and corporate governance. In: EER, Vol. 46, S. 1569-1597.

Maug, Ernst/Yilmaz, Bilge (2003): Two-Class Voting: A Mechanism for Conflict Resolution. In: AER, Vol. 92, S. 1448-1471.

Maury, C. Benjamin/Pajuste, Anete (2002): Multiple Controlling Shareholders and Firm Value. Working Paper, Stockholm School of Economics, Stockholm.

Mayer, Colin (1998): Financial Systems and Corporate Governance - A Review of the International Evidence. In: JITE, Vol. 154, S. 144-176.

Mayer, Colin (2000): Ownership Matters, Working Paper, University of Oxford, Oxford.

McConnell, John J./Servaes, Henri (1990): Additional evidence on equity ownership and corporate value. In: JoFE, Vol. 27, S. 595-612.

McEachern, William A. (1975): Managerial Control and Performance, Lexington et al.

McKinsey \& Co. (2002): Global Investor Opinion Survey: Key Findings, July 2002. URL: www.mckinsey.com/governance (10.7.2002).

Megginson, William L. (1997): Corporate Finance Theory, Reading/MA.

Mehrfeld, Peter (1984): Kapitalbeteiligungen an Aktiegesellschaften im verarbeitenden Gewerbe der Bundesrepublik Deutschland, Saarbrücken.

Meinhövel, Harald (1999): Defizite der Principal-Agent-Theorie, Lohmar/Köln.

Mello, Antonio S./Parsons, John E. (1998): Going public and the ownership structure of the firm. In: JoFE, Vol. 49, S. 79-109.

Merkt, Hanno (1991): US-amerikanisches Gesellschaftsrecht, Heidelberg. 
Merkt, Hanno (2000): Die Geschichte der Namensaktie. In: von Rosen, R./Seifert, W. (Hrsg.): Die Namensaktie, DAI Schriften zum Kapitalmarkt, Band 3, Frankfurt/M.

Merkt, Hanno (2001): Entwicklungen des Gesellschafts- und Kapitalmarktrechts in den USA - Vorbild für Deutschland und Europa? In: KoR, 1. Jg., S. $142-150$.

Merkt, Hanno (2003): Zum Verhältnis von Kapitalmarktrecht und Gesellschaftsrecht in der Diskussion um die Corporate Governance. In: AG, 48. Jg., S. 126-136.

Mertens, Hans-Joachim (1996): Kommentierungen zum Aktiengesetz. In: Zöllner, W. (Hrsg.): Kölner Kommentar zum Aktiengesetz, 2. Aufl., Bd. 2, Köln u.a.

Mertens, Hans-Joachim (1996a): Organhaftung. In: Feddersen, D. u.a. (Hrsg.): Corporate Governance, Köln, S. 155-164.

Meyer-Landrut, Joachim (1970): Großkommentar zum Aktiengesetz, 3. Aufl., Berlin u.a.

Mikkelson, Wayne H./Partch, M. Megan/Shah, Kshitij (1997): Ownership and operating performance of companies that go public. In: FE, Vol.44, S. 281-307.

Mildenberger, Myria (2002): Vorzugsaktien verkommen zum Auslaufmodell. In: HB vom 13.6.2002, Nr. 111, S. 35.

Mitton, Todd (2002): A cross-firm analysis of the impact of corporate governance on the East Asian financial crisis. In: JoFE, Vol. 64, S. 215-241.

Modigliani, Franko/Miller, Merton H. (1958): The Cost of Capital, Corporation Finance, and the Theory of Investment. In: AER, Vol. 48, S. 261-297.

Modigliani, Franko/Miller, Merton H. (1963): Corporate Income Taxes and the Cost of Capital. In: AER, Vol. 53, S. 433-443.

Moerland, Pieter W. (1995): Corporate Ownership and Control Structures: An International Comparison. In: RoIO, Vol. 10, S. 443-464. 
Möller, Hans Peter (1985): Die Informationseffizienz des deutschen Aktienmarktes - eine Zusammenfassung und Analyse empirischer Untersuchungen. In: ZfbF, 37. Jg., S. 500-518.

Möllers, Thomas M. (1999): Kapitalmarkttauglichkeit des deutschen Gesellschaftsrechts. In: AG, 44. Jg., S. 433-442.

Monks, Robert A.G.Minow, Nell (1996): Watching the Watchers: Corporate Governance for the $21^{\text {st }}$ Century, Cambridge, MA.

Monsen, R. Joseph/Chiu, John S./Cooley, David E. (1968): The Effect of Separation of Ownership and Control on the Performance of the Large Firm. In: QJoE, Vol. 82, S. 435-451.

Morck, Randall/Nakamura, Masao/Shivdasani, Anil (2000): Banks, Ownership Structure, and Firm Value in Japan. In: JoB, Vol. 73, S. 539-567.

Morck, Randall/Shleifer, Andrei/Vishny, Robert W. (1988): Management Ownership and Market Valuation - An Empirical Analysis. In: JoFE, Vol. 20, S. 293-315.

Morck, Randall/Shleifer, Andrei/Vishny, Robert W. (1989): Alternative Mechanisms for Corporate Control. In: AER, Vol. 79, S. 842-852.

Moxter, Adolf (1964): Präferenzstruktur und Aktivitätsfunktion des Unternehmens. In: ZfbF, 16. Jg., S. 6-35.

Mujkanovic, Robin (2002): Fair Value in Financial Statements nach International Accounting Standards, Stuttgart.

Mülbert, Peter O. (1996): Aktiengesellschaft, Unternehmensgruppe und Kapitalmarkt, 2. Aufl., München.

Mülbert, Peter O. (1996a): Empfehlen sich gesetzliche Regelungen zur Einschränkung des Einflusses der Kreditinstitute auf Aktiengesellschaften. In: Verhandlungen des 61. DJT, Band I, München, S. E 1-E 119.

Mülbert, Peter O. (1998): Bank Equity Holdings in Non-Financial Firms and Corporate Governance. In: Hopt, K.J. (Hrsg.): Comparative Corporate Governance, Oxford, S. 445-497. 
Müller, Klaus-Peter (2002): Banken, Analysten und Großaktionäre - ein Dreiecksverhältnis. In: ZfgK, 55. Jg., S. 506-510.

Murali, Ramaswami/Welch, Johnathan B. (1989): Agents, Owners, Control and Performance. In: JoBFA, Vol. 16, S. 385-398.

Muus, Christian K. (1998): Non-voting shares in France: An empirical analysis of the voting premium. Working Paper Series Finance \& Accounting, No. 22, Goethe-Universität, Frankfurt/M.

Myers, Stewart C. (2000): Outside Equity. In: JoF, Vol. 55, S. 1005-1037.

Myers, Stewart C./Majluf, Nicholas S. (1984): Corporate Financing and Investment Decision when Firms have Informations that Investors do not have. In: JoFE, Vol. 13, S. 187-221.

Nassauer, Frank (2000): Corporate Governance und die Internationalisierung von Unternehmungen, Frankfurt/M.

Nemec, Edith (1999): Kapitalstruktur und Corporate Governance in bankorientierten Finanzsystemen, Wiesbaden.

Nenova, Tatiana (2000): The Value of Corporate Votes and Control Benefits: A Cross-country Analysis. Working Paper, Harvard University, Cambridge, MA.

Nenova, Tatiana (2003): The value of corporate voting rights and control: A cross-country analysis. In: JoFE, Vol. 68, S. 325-351.

Neus, Werner (2001): Einführung in die Betriebswirtschaftslehre aus institutionenökonomischer Sicht, 2. Aufl., Tübingen.

Neye, Hans-Werner (1996): Harmonisierung der Mitteilungspflichten zum Beteiligungsbesitz von börsennotierten Aktiengesellschaften. In: ZIP, 17. Jg., S. 1853-1857.

Nibler, Marcus (1998): Bank Control and Corporate Performance in Germany, unpublished dissertation, University of Cambridge, Cambridge.

Nickell, Stephen/Nicolitsas, Daphne/Dryden, Neil (1997): What makes firms perform well? In: EER, Vol. 41, S. 783-796. 
Nicodano, Giovanna (1998): Corporate groups, dual-class shares and the value of voting rights. In: JoBF, Vol. 22, S. 1117-1137.

Nicodano, Giovanna/Sembenelli, Alessandro (2000): Private Benefits, Block Transaction Premiums and Ownership Structure. Working Paper, Università di Torino, Torino.

Niedenhoff, Horst-Udo (2002): Mitbestimmung in der Bundesrepublik Deutschland, 13. Aufl., Köln.

Noack, Ulrich (2002): Neuerungen im Recht der Hauptversammlung durch das Transparenz- und Publizitätsgesetz und den Deutschen Corporate Governance Kodex. In: DB, 55. Jg., S. 620-626.

North, Douglass C. (1990): Institutions, Institutional Change and Economic Performance, Cambridge.

Noth, Corinna (1996): Die Eigenkapitalausstattung deutscher Gesellschaften mit beschränkter Haftung - Eine theoretische und empirische Analyse, Köln.

Nottmeier, Horst/Schäfer, Holger (1997): Praktische Fragen im Zusammenhang mit $\S \S 21,22 \mathrm{WpHG}$. In: AG, 42. Jg., S. 87-96.

Nowak, Erik (1997): On Investment Performance and Corporate Governance, Bern u.a.

Oberender, Peter/Cachej, Monty (1999): Wettbewerb der Systeme. In: WiSt, 28. Jg., S. 577-581.

Obermüller, Walter/Werner, Winfried/Winden, Kurt (2001): Die Hauptversammlung der Aktiengesellschaft, 4. Aufl., Stuttgart.

OECD (1999): OECD Principles of Corporate Governance. URL: www.oecd.org/daf/governance/principles.pdf (8.3.2002).

Ohnishi, Atsushi/Chujo, Yoshimi (2002): Ownership Structure, Corporate Governance, and Stock Price of the Japanese Firm: An Explanation from the Accounting Valuation Model, Working paper, Nagoya University, Nagoya. 
Olson, Mancur (1965): The Logic of Collective Action. Public Goods and the Theory of Groups, Cambridge, MA.

Ossadnik, Wolfgang/Dorenkamp, Axel (1999): Eigentümerstruktur und Akquisitionsaktivitäten bei Kapitalgesellschaften. Working Paper Nr. 9901, Universität Osnabrück, Osnabrück.

Oswald, Sharon L./Jahera, John S. (1991): The Influence of Ownership on Performance: An Empirical Study. In: SMJ, Vol. 12, S. 321-326.

o.V. (2002): Brüssel nimmt VW-Gesetz ins Visier. In: Handelsblatt vom 21.6.2002, Nr. 117, S. 1.

o.V. (2002a): Allianz kommt mit Entflechtung nicht voran. In: Frankfurter Allgemeine Zeitung vom 26.11.2002, Nr. 275, S. 21.

o.V. (2003): Banken scheuen Mühen der Stimmabgabe. In: FAZ vom 17.1.2003, Nr. 14, S. 19.

o.V. (2003a): „Die richtigen Aktionäre aussuchen“. In: FAZ vom 10.3.2003, Nr. 58, S. 21.

o.V. (2003b): EU leitet Verfahren gegen VW-Gesetz ein. In: HB vom 20.3.2003, Nr. 56, S. 6.

Padberg, Max (1995): Der Einfluß von Kapitalerhöhungen auf den Marktwert deutscher Aktiengesellschaften. Eine theoretische und empirische Analyse, Köln.

Pagano, Marco/Röell, Ailsa (1998): The Choice of Stock Ownership Structure: Agency Costs, Monitoring, and the Decision to go Public. In: QJoE, Vol. 113, S. 187-225.

Palia, Darius/Lichtenberg, Frank (1999): Managerial ownership and firm performance: A re-examination using productivity measurement. In: JoCF, Vol. 5, S. 323-339.

Palmer, John (1973): The profit-performance effects of the separation of ownership from control in large U.S. industrial corporations. In: BJoEMS, Vol. 4, S. 293-303. 
Park, Tido (2001): Börsenstrafrechtliche Risiken für Vorstandsmitglieder von börsennotierten Aktiengesellschaften. In: BB, 56. Jg., S. 2069-2076.

Paul, Stephan (1995): Ansätze zur Erklärung der Existenz und der Verdrängung von Kreditinstituten. In: Köhler, M./Keith, U. (Hrsg.): Banken, Konjunktur und Politik, Essen, S. 156-173.

Paul, Stephan (1999): Finanzintermediation: Theoretische Fundierung. In: Thießen, F. (Schriftleitung): Knapps Enzyklopädisches Lexikon des Geld, Bank- und Börsenwesens, Bd. 1, 4. Aufl., Frankfurt/M., S. 649-667.

Paul, Stephan (2001): Der Konzentrationsprozess am europäischen Bankenmarkt. In: Rolfes, B./Fischer, Thomas R. (Hrsg.): Handbuch der europäischen Finanzdienstleistungsindustrie, Frankfurt/M., S. 228-238.

Paul, Stephan/Horsch, Andreas (2002): Finanzmanagement. In: Busse von Colbe, W. et al. (Hrsg.): Betriebswirtschaft für Führungskräfte, 2. Aufl., Stuttgart, S. 217-255.

Pedersen, Torben/Thomsen, Steen (1999): Economic and Systemic Explanations of Ownership Concentration among Europe's Largest Companies. In: IJoEB, Vol. 6, S. 367-381.

Pellens, Bernhard (1989): Der Informationswert von Konzernabschlüssen - Eine empirische Untersuchung deutscher Börsengesellschaften, Wiesbaden.

Pellens, Bernhard (1994): Aktionärsschutz im Konzern - Empirische und theoretische Analyse der Reformvorschläge der Konzernverfassung, Wiesbaden.

Pellens, Bernhard (2001): Internationale Rechnungslegung, 4. Aufl., Stuttgart.

Pellens, Bernhard/Bonse, Andreas (1999): Annäherung des deutschen Aktionärsschutzes an US-amerikanische Vorstellungen. In: Hübner, U./Ebke, W. (Hrsg.), Festschrift Großfeld, Heidelberg, S. 851-874.

Pellens, Bernhard/Crasselt, Nils/Rockholtz, Carsten (1998): Wertorientierte Entlohnungssysteme für Führungskräfte - Anforderungen und empirische Evidenz. In: Pellens, B. (Hrsg.), Unternehmenswertorientierte Entlohnungssysteme, Stuttgart, S. 1-28.

Pellens, Bernhard/Fülbier, Rolf Uwe (2000): Ansätze zur Erfassung immaterieller Werte in der kapitalmarktorientierten Rechnungslegung. In: Baetge, 
J.: Zur Rechnungslegung nach International Accounting Standards (IAS), Vorträge und Diskussionen zum 15. Münsterischen Tagesgespräch des Gesprächskreises Rechnungslegung und Prüfung e.V. am 10. Juni 1999, Düsseldorf 2000, S. 35-77.

Pellens, Bernhard/Fülbier, Rolf Uwe (2000a): Differenzierung der Rechnungslegungsregulierung nach Börsenzulassung. In: ZGR, 29. Jg., S. 572-593.

Pellens, Bernhard/Fülbier, Rolf Uwe/Sellhorn, Thorsten (2001): Immaterielle Werte in der kapitalmarktorientierten Rechnungslegung. In: Coenenberg, A. G./Pohle, K.: Internationale Rechnungslegung, Konsequenzen für Unternehmensführung, Rechnungswesen, Standardsetting, Prüfung und Kapitalmarkt, Kongress-Dokumentation, 54. Deutscher BetriebswirtschafterTag 2000, Stuttgart 2001, S. 81-114.

Pellens, Bernhard/Gassen, Joachim (1998): Die Bereitstellung von Rechnungslegungssystemen - Eine Aufgabe des Staates oder des Marktes? In: Möller, H.P./Schmidt, F. (Hrsg.): Rechnungswesen als Instrument für Führungsentscheidungen, Stuttgart, S. 633-650.

Pellens, Bernhard/Hillebrandt, Franca (2001): Vorzugsaktien vor dem Hintergrund der Corporate Governance-Diskussion. In: AG, 46. Jg., S. 57-67.

Pellens, Bernhard/Hillebrandt, Franca/Tomaszewski, Claude (2000): Value Reorting - Eine empirische Analyse der DAX-Unternehmen. In: Wagenhoer, A./Hrebicek, G. (Hrsg.): Wertorientiertes Management - Konzepte und Umsetzungen zur Unternehmenswertsteigerung, Stuttgart, S. 177207.

Pellens, Bernhard/Hillebrandt, Franca/Ulmer, Björn (2001): Umsetzung von Cororate-Governance-Richtlinien in der Praxis - Eine empirische Analyse der DAX 100-Unternehmen. In: BB, 56. Jg., S. 1243-1250.

Pellens, Bernhard /Tomaszewski, Claude (1999): Kapitalmarktreaktionen auf den Rechnungslegungswechsel zu IAS bzw. US-GAAP. In: Gebhardt, G./Pellens, B. (Hrsg.): Rechnungswesen und Kapitalmarkt - Festschrift Busse von Colbe, ZfbF, Sonderheft 41, S. 199-228.

Peltzer, Martin/von Werder, Axel (2001): Der „German Code of Corporate Governance (GCCG)" des Berliner Initiativkreises. In: AG, 46. Jg., S. 1-15.

Perlitz, Manfred/Seger, Frank (1994): The Role of Universal Banks in German Corporate Governance. In: BCW, Vol. 6, S. 49-67. 
Picot, Arnold/Dietl, Helmut/Franck, Egon (1997): Organisation: eine öko-nomische Perspektive, Stuttgart.

Poddig, Thorsten/Dichtl, Hubert/Petersmeier, Kerstin (2000): Statistik, Ökonometrie, Optimierung, Bad Soden/Ts.

Posner, Richard A. (1998): Economic Analysis of Law, $5^{\text {th }}$ ed., New York.

Potthoff, Erich/Trescher, Karl (2001): Das Aufsichtsratsmitglied, 5. Aufl., Stuttgart.

Pratt, John W./Zeckhauser, Richard J. (1985): Principal and Agents: An Overview. In: Pratt, J.W./Zeckhauser, R.J. (Hrsg.): Principal and Agents - The Structure of Business, Boston, S. 1-35.

Prigge, Stefan (1999): Corporate Governance. In: DBW, 59. Jg., S. 148-151.

Preuschl, Manuela (1997): Unternehmensübernahmen als Instrument der Managementkontrolle? Regensburg.

Pross, Helge (1965): Manager und Aktionäre in Deutschland, Frankfurt/M.

Prowse, Stephen D. (1992): The Structure of Corporate Ownership in Japan. In: JoF, Vol. 47, S. 1121-1140.

Qian, Hailong/Schmidt, Peter (1999): Improved instrumental variables and generalized method of moments estimators. In: JoE, Vol. 91, S. 145-169.

Quack, Karlheinz (1996): Das Rederecht des Aktionärs in der Hauptversammlung - Eine Selbstverständlichkeit? In: Pfeiffer, G. (Hrsg.): Festschrift Brandner, Köln, S. 113-119.

Radice, H.K. (1971): Control Type, Profitability and Growth in Large Firms: An Empirical Study. In: EJ, Vol. 81, S. 547-562.

Ragazzi Giorgio (1981): On the Relation between Ownership Dispersion and the Firm's Market Value. In: JoBF, Vol. 36, S. 261-276.

Raiser, Thomas (2001): Recht der Kapitalgesellschaften, 3. Aufl., München.

Rajan, Raghuram G./Zingales, Luigi (1998): Financial Dependence and Growth. In: AER, Vol. 88, S. 559-586. 
Ramsey, James B. (1969): Tests for Specification Errors in Classical Linear Least Squares Analysis. In: JoRSS, Series B, Vol. 31, S. 350-371.

Rathenau, Walther (1918): Vom Aktienwesen, Berlin.

Rechenberg, Wolf-Georg von (1986): Die Hauptversammlung als oberstes Organ der Aktiengesellschaft, Heidelberg.

Reckinger, Gabriele (1983): Vorzugsaktien in der Bundesrepublik. In: AG, 28. Jg., S. 216-222.

Regierungskommission DCGK (2002): Regierungskommission Deutscher Corporate Governance-Kodex: Deutscher Corporate Governance Kodex. In: AG, 47. Jg., S. 236-239.

Reichert, Jochem/Harbarth, Stephan (2001): Stimmrechtsvollmacht, Legitimationszession und Stimmrechtsausschlussvertrag in der AG. In: AG, 46. Jg., S. 447-455.

Reinganum, Marc R. (1992): A revival of the small-firm effect: Far from being dead. In: JoPM, Vol. 18, S. 55-62.

Reinholz, Stefan (1997): Aktive Beteiligungsgesellschaften - Investmentvehikel zur Reduktion der Corporate Governance Problematik, St. Gallen.

Renner, Wolfgang (1999): Die Publikums-Aktiengesellschaft im Spannungsfeld von Markt- und Anreizstrukturen, Wiesbaden.

Richter, Rudolf (1990): Sichtweise und Fragestellungen der Neuen Institutionenökonomik. In: ZWS, 110. Jg., S. 571-591.

Richter, Rudolf (1991): Institutionenökonomische Aspekte in der Theorie der Unternehmung. In: Ordelheide, D. u.a. (Hrsg.): Betriebswirtschaftslehre und ökonomische Theorie, Stuttgart, , S. 395-429.

Richter, Rudolf/Bindseil, Ulrich (1995): Neue Institutionenökonomik. In: WiSt, 24. Jg., S. 132-140.

Richter, Rudolf/Furubotn, Eirik G. (1999): Neue Institutionenökonomik, 2. Aufl., Tübingen. 
Ridder-Aab, Christa-M. (1980): Die moderne Aktiengesellschaft im Lichte der Theorie der Eigentumsrechte, Frankfurt/M.

Riess, Rainer/Altmann, Jan (2001): Internationale Kapitalmarktbedingungen als Basis für ein Börsensegment. In: Achleitner, A./Bassen, A. (Hrsg.): Investor Relations am Neuen Markt, Stuttgart, S. 195-209.

Ripley, William Z. (1927): Main Street and Wall Street, Boston.

Ritzberger, Klaus/Shorish, Jamesheed (2002): Cross-Ownership Among Firms: Some Determinants of the Separation of Ownership from control. Working Paper, Institut für höhere Studien (HIS) Wien, Reihe Ökonomie, Nr. 113, Wien.

Rock, Edward B. (1994): Controlling the Dark Side of Relational Investing. In: CLR, Vol. 15, S. 987-1031.

Roe, Mark J. (1991): A Political Theory of American Corporate Finance. In: ColLR, Vol. 91, S. 10-67.

Roe, Marc J. (1993): Some Differences in Corporate Structure in Germany, Japan, and the Unites States. In: YLJ, Vol. 102, S. 1927-2003.

Roe, Marc J. (1994): Strong Managers, Weak Owners: The Political Roots of American Corporate Finance, Princeton.

Roe, Marc J. (1996): Chaos and Evolution in Law and Economics. In: HLR, Vol. 109, S. 641-668.

Roe, Marc J. (2000): Political Preconditions to Separating Ownership from Corporate Control. In: SLR, Vol. 53, S. 539-606.

Roe, Marc J. (2002): Delaware's Competition. Working Paper No. 049, Harvard Law School, Cambridge.

Romano, Roberta (1991): The Shareholder Suit: Litigation Without Foundation? In: JoLEO, Vol. 7, S. 55-87.

Romano, Roberta (1993): Public Pension Fund Activism in Corporate Governance Reconsidered. In: Baums, T. u.a. (Hrsg.): Institutional Investors and Corporate Governance, Berlin/New York, S. 105-159. 
Romano, Roberta (1993a): Foundations of Corporate Law, Oxford u.a.

Rose, Manfred (2000): Sinn und Unsinn einer Besteuerung von Gewinnen aus der Veräußerung von Anteilen an Unternehmen. In: BB, 55. Jg., S. $1062-$ 1068.

Ross, Stephen A. (1973): The Economic Theory of Agency: The Principal's Problem. In: AER, Papers and Proceedings, Vol. 63, S. 134-139.

Roth, Stefan (2001): Screening- und Signalling-Modelle. In: WiSt, 30. Jg., S. 372-378.

Rothschild, Michael/Stiglitz, Joseph E. (1976): Equilibrium in Competitive Insurance Market: An Essay on the Economics of Imperfect Information. In: QJoE, Vol. 90, S. 629-649.

Round, David K. (1976): The Effect of the Separation of Ownership and Control on Large Firm Profit Rates in Australia. In: Riviste Internazionale die Scienze Economiche e Commerciale, Vol. 23, S. 426-436.

Rubach, Michael J./Sebora, Terence C. (1998): Comparative Corporate Governance: Competitive Implications of an Emerging Convergence. In: JoWB, Vol. 33, S. 167-185.

Rudolph, Bernd (2002): Viertes Finanzmarktförderungsgesetz - ist der Name Programm? In: BB, 57. Jg., S. 1036-1041.

Ruhwedel, Franca/Schultze, Wolfgang (2002): Value Reporting - Theoretische Konzeption und Umsetzung bei den DAX100-Unternehmen. In: ZfbF, 54. Jg., S. 602-632.

Ruhwedel, Peter (2002): Aufsichtsratsplanungssysteme - Theoretische Grundlagen und praktische Ausgestaltung in Publikumsaktiengesellschaften, Frankfurt/M. u.a.

Ruhwedel, Peter/Epstein, Rolf (2003): Eine empirische Analyse der Strukturen und Prozesse in den Aufsichtsräten deutscher Aktiengesellschaften. In: BB, 58. Jg., S. 161-166.

Ruffner, Markus (2000): Die ökonomischen Grundlagen eines Rechts der Publikumsgesellschaft, Zürich. 
Rust, Walter L./Ulbert, Udo (1995): Die kleine Aktiengesellschaft, Freiburg.

Saenger, Ingo (1997): Mehrstimmrechte bei Aktiengesellschaften. In: ZIP, 18. Jg., S. 1813-1820.

Saenger, Ingo (2002): Aktienrechtliche Anfechtungsklagen: Verfahrenseffizienz und Kosten. In: AG, 47. Jg., S. 536-543.

Salzberger, Wolfgang (1999): Institutionelle Investoren und Corporate Governance in den USA. In: ZfB, 68. Jg., Ergänzungsheft 2/1999, S. 87-106.

Salzberger, Wolfgang (2000): Wechselwirkungen zwischen Corporate Governance und Besteuerung. In: DBW, 60. Jg., S. 210-221.

Schanbacher, Dietmar (1999): Actio pro socio - zur Dogmatik der Gesellschafterklage. In: AG, 44. Jg., S. 21-28.

Scharfstein, David (1988): The disciplinary role of takeovers. In: RoES, Vol. 55, S. 185-199.

Scheffler, Eberhard (2000): Zum Rollenverständnis der Aufsichtsräte. In: DB, 53. Jg., S. 433-437.

Scheffler, Wolfram (2002): Korrektur von unangemessenen Vertragsbeziehungen zwischen einer Kapitalgesellschaft und ihren Anteilseignern. In: BB, 57. Jg., S. 543-550.

Scheller, K. Randolf (1999): Performance of corporate acquisitions over the medium term in Germany, Wiesbaden.

Schenk, Gerald (1997): Ökonomische Analyse des Minderheitenschutzes im Konzern. In: ZfbF, 49. Jg., S. 652-673.

Schenk, Gerald (1997a): Konzernbildung, Interessenkonflikte und ökonomische Effizienz, Frankfurt/M. u.a.

Schierenbeck, Henner (1980): Der Pyramiden-Effekt im verschachtelten Konzern. In: DBW, 40. Jg., S. 249-258.

Schiessl, Maximilian (1999): Ist das deutsche Aktienrecht kapitalmarkttauglich? In: AG, 44. Jg., S. 442-452. 
Schmid, Frank A. (1996): Banken, Aktionärsstruktur und Unternehmenssteuerung. In: KK, 29. Jg., S. 402-427 und 545-564.

Schmid, Frank A. (1997): Vorstandsbezüge, Aufsichtsratsvergütung und Aktionärsstruktur. In: ZfB, 67. Jg., S. 67-83.

Schmid, Frank A./Seger, Frank (1998): Arbeitnehmermitbestimmung, Allokation von Entscheidungsrechten und Shareholder Value. In: ZfB, 68. Jg., S. 453-473.

Schmidt, Hartmut et al. (1997): Corporate Governance in Germany, BadenBaden.

Schmidt, Hartmut/Prigge, Stefan (2002): Übernahmekonzeptionen und Übernahmegesetz. In: DBW, 62. Jg., S. 225-241.

Schmidt, Karsten (2002): Gesellschaftsrecht, 4. Aufl., Köln u.a.

Schmidt, Klaus (1996): The costs and benefits of privatization. In: JoLEO, Vol. 12, S. 1-24.

Schmidt, Michael (1994): Die Stimmrechtsvertretung durch Kreditinstitute, Hamburg.

Schmidt, Reinhard H. (1997a): Corporate Governance: The Role of Other Constituencies, Paper Presented at the Conference on Workable Corporate Governance: Cross-Border Perspectives, Paris, March 17.-19.

Schmidt, Reinhard H./Grohs, Stefanie (1999): Angleichung der Unternehmensverfassung in Europa - ein Forschungsprogramm. Working Paper Series Finance \& Accounting, No. 43, Goethe-Universität, Frankfurt/M.

Schmidt, Reinhard H./Hackethal, Andreas/Tyrell, Marcel (2002): Angleichung der Finanzsysteme in Europa. In: ZfB, 72. Jg., Ergänzungsheft 2/2002, S. 13-22.

Schmidt, Reinhard H./Schor, Gabriel (1987): Modell und Erklärung in den Wirtschaftswissenschaften. In: Schmidt, R.H./Schor, G. (Hrsg.): Modelle in der Betriebswirtschaftslehre, S. 9-36. 
Schmidt, Reinhard H./Spindler, Gerald (1997): Shareholder Value zwischen Ökonomie und Recht. In: Assmann, H.-K. et al. (Hrsg.): Festschrift Kübler, Heidelberg, S. 515-555.

Schmidt, Reinhard H./Spindler, Gerald (1999): Path Dependence, Working Paper Series Finance \& Accounting No. 27, Goethe-Universität, Frankfurt/M.

Schmidt, Stefan M. (2001): Corporate Governance in deutschen und amerikanischen Aktiengesellschaften, Frankfurt/M. u.a.

Schmidtchen, Dieter (1991): Jenseits von Maximierung, Gleichgewicht und Effizienz: Neuland für die ökonomische Analyse des Rechts. In: Ott, C./Schäfer, H.B. (Hrsg.): Ökonomische Probleme des Zivilrechts, S. 316343.

Schmoller, Gustav von (1900): Grundriß der Allgemeinen Volkswirtschaftslehre, München.

Schneider, Dieter (1986): Ausweichhandlungen vor Regulierungen auf Finanzmärkten als Prüfstein wettbewerbspolitischer Konzepte. In: ORDO, Bd. 37, S. 155-181.

Schneider, Dieter (1987): Modell-Platonismus in der Kapitalmarktgleichgewichtstheorie. In: Schmidt, R.H./Schor, G. (Hrsg.): Modelle in der Betriebswirtschaftslehre, Stuttgart, S. 159-196.

Schneider, Dieter (1989): Agency Costs and Transaction Costs: Flops in the Principal-Agent-Theory of Financial Markets. In: Bamberg, G./Spremann, K. (Hrsg.): Agency Theory, Information, and Incentives, Berlin, S. 481494.

Schneider, Dieter (1995): Betriebswirtschaftslehre, Bd. 1: Grundlagen, 2. Aufl., München/Wien.

Schneider, Dieter (2001): Betriebswirtschaftslehre, Band 4: Geschichte und Methoden der Wirtschaftswissenschaft, München/Wien.

Schneider, Jürgen (2000): Erfolgsfaktoren der Unternehmensüberwachung, Berlin.

Schneider, Kristian (1991): Erfolgswirkungen der Kapitalstruktur, Frankfurt/M. u.a. 
Schneider, Sabine (2001a): Viele Unternehmen ziehen aus der Krise offenbar die richtigen Schlüsse. In: HB vom 19.9.01, Nr. 180, S. B1.

Schneider, Uwe H. (1999): Mitteilungs- und Veröffentlichungspflichten bei Veränderungen des Stimmrechtsanteils an börsennotierten Gesell-schaften. In: Assmann, H.D./Schneider, U.H. (Hrsg.): Wertpapierhandelsgesetz - Kommentar, §§ 21-29.

Schneider, Uwe H. (2000a): Kapitalmarktorientierte Corporate GovernanceGrundsätze. In: DB, 53. Jg., S. 2413-2417.

Schneider, Uwe H. (2002): Die Zielgesellschaft nach Abgabe eines Übernahmeoder Pflichtangebots. In: AG, 47. Jg., S. 125-131.

Schneider, Uwe H./Burgard, Ulrich (1996): Transparenz als Instrument der Steuerung des Einflusses der Kreditinstitute auf Aktiengesellschaften. In: DB, 49. Jg., S. 1761-1767.

Schneider, Uwe H./Strenger, Christian (2000): Die „Corporate GovernanceGrundsätze" der Grundsatzkommission Corporate Governance (German Panel on Corporate Governance). In: AG, 45. Jg., S. 106-113.

Schnell, Christian (2002): Index-Neugewichtung - Eine Anpassung mit vielen Chancen. In: Handelsblatt vom 22. Juni 2002, Nr. 117, S. 11.

Schön, Wolfgang (1996): Mindestharmonisierung im europäischen Gesellschaftsrecht. In: ZHR, 160. Jg., S. 221-249.

Schremper, Ralf (2002): Aktienrückkauf und Kapitalmarkt - Eine theoretische und empirische Analyse deutscher Aktienrückkaufprogramme, Frankfurt/M. u.a.

Schremper, Ralf (2002a): Informationseffizienz des Kapitalmarkts. In: WiSt, 31. Jg., S. 687-692.

Schreyögg, Georg/Steinmann, Horst (1981): Zur Trennung von Eigentum und Verfügungsgewalt - Eine empirische Analyse der Beteiligungsverhältnisse in deutschen Großunternehmen. In: ZfB, 51. Jg., S. 533-558.

Schröder, Oliver (2001): Unternehmenspublizität und Kapitalmärkte, Baden Baden. 
Schulte, Jörn (1996): Rechnungslegung und Aktienkursentwicklung, Wiesbaden.

Schulz, Andreas/Geismar, Bernhard (2001): Die Europäische Aktiengesellschaft - Eine kritische Bestandsaufnahme. In: DStR, 93. Jg., S. 10781086.

Schütte, Jens (2003): Zur erweiterten Berichterstattung nach DRS-11. In: DB, 56. Jg., S. 457-461.

Seger, Frank (1997): Banken, Erfolg und Finanzierung, Wiesbaden.

Seibert, Ulrich (1999): OECD Principles of Corporate Governance - Grundsätze der Unternehmensführung und -kontrolle für die Welt. In: AG, 44. Jg., S. 337-350.

Seibert, Ulrich (2002): Im Blickpunkt: Der Deutsche Corporate Governance Kodex ist da. In: BB, 57. Jg., S. 581-584.

Seifert, Bruce/Gonenc, Halit/Wright, Jim (2002): The International Evidence on Performance and Equity Ownership by Insiders, Blockholders, and Institutions. Working Paper, Old Dominion University, Norfolk, VA.

Sellhorn, Thorsten (2000): Ansätze zur bilanziellen Behandlung des Goodwill im Rahmen einer kapitalmarktorientierten Rechnungslegung, in: DB, 53. Jg., S. 885-892.

Semler, Johannes (1996): Leitung und Überwachung der Aktiengesellschaft, Köln u.a.

Semler, Johannes (1999): Vorschlags- und Wahlverfahren, Entsenden und Ausscheiden. In: Semler, J. (Hrsg.): Arbeitshandbuch für Aufsichtsratsmitglieder, München, S. 67-88.

Shahid, Shahira A. (2003): Does Ownership Structure affect Firm Value? Evidence from the Egyptian Stock Market. Working Paper, Cairo \& Alexandria Stock Exchanges, Cairo.

Shavell, Steven (1979): Risk sharing and incentives in the principal and agent relationship. In: BJoE, Vol. 10, S. 55-73. 
Shleifer, Andrei/Vishny, Robert W. (1986): Large Shareholders and Corporate Control. In: JoPE, Vol. 94, S. 461-488.

Shleifer, Andrei/Vishny, Robert W. (1988): Value Maximization and the Acquisition Process. In: JEP, Vol. 2, S. 7-20.

Shleifer, Andrei/Vishny, Robert W. (1997): A Survey of Corporate Governance. In: JoF, Vol. 52, S. 737-783.

Shleifer, Andrei/Wolfenzon, Daniel (2002): Investor Protection and Equity Marktes. In: JoFE, Vol. 66, S. 3-27.

Short, Helen (1994): Ownership, Control, Financial Structure and the Performance of Firms. In: JoES, Vol. 8, S. 203-249.

Short, Helen/Keasey, Kevin (1999): Managerial ownership and the performance of firms: Evidence from the UK. In: JoCF, Vol. 5, S. 79-101.

Short, Helen/Zhang, Hao/Keasey, Kevin (2002): The link between dividend policy and institutional ownership. In: JoCF, Vol. 8, S. 105-122.

Shubik, Martin (1988): Corporate Control, Efficient Markets and the Public Good. In: Coffee, J. C. et al.: Knights, Raiders, and Targets, New York, S. 31-35.

Siebel, Ulf R. (1997): Vorzugsaktien als „Hybride“ Finanzierungsform und ihre Grenzen. In: ZHR, 161. Jg., S. 628-664.

Sieber, Martin (1985): Zur Verletzung von Modellannahmen in der Regressionsanalyse. In: Schweizerische Zeitschrift für Soziologie, 11. Jg., S. 515-529.

Siepelt, Stefan (1995): Das Rederecht des Aktionärs und dessen Beschränkung. In: AG, 40. Jg., S. 254-260.

Simon, Herbert A. (1962): New developments in the theory of the firm. In: AER, Vol. 52, S. 1-15.

Simon, Herbert A. (1972): Theories of bounded rationality. In: McGuire, C./Radner, R. (Hrsg.): Decision and organization, Amsterdam, S. 161176. 
Singh, Manohar/Davidson, Wallace N. (2003): Agency costs, ownership structure and corporate governance mechanisms. In: JoBF, Vol. 27, S. 793816.

Sinn, Hans-Werner (1990): The Limits to Competition Between Economic Regimes. In: Empirica, Vol. 17, S. 3-14.

Slovin, Myron B./Sushka, Marie E. (1993): Ownership Concentration, Corporate Control Activity, and Firm Value. In: JoF, Vol. 48, S. 1293-1321.

Smart, Scott B./Zutter, Chad J. (2000): Control as a Motivation for Underpricing - A Comparison of Dual- and Single-Class IPOs. Working Paper, Kelley School of Business, Indiana University, Indiana.

Smith, Adam (1776): An Inquiry into the Nature and the Causes of the Wealth of Nations, Neudruck der 3. Aufl., hrsg. v. Capbell, R.H./Skinner, A.S., Oxford.

Smith, Michael P. (1996): Shareholder Activism by Institutional Investors: Evidence from CalPERS. In: JoF, Vol. 51, S. 227-252.

Smith, Clifford/Warner, Jerold (1979): On financial contracting: An analysis of bond covenants. In: JoFE, Vol. 7, S. 117-161.

Söhler, Karen (2001): Deutschland AG löst sich auf und formiert sich neu. In: Welt am Sonntag vom 28.1.2001, Nr. 4, S. 50.

Sombart, Werner (1917): Der moderne Kapitalismus, Band 2, 2. Aufl., München/Leipzig.

Spence, Michael (1973): Job Market Signaling. In: QJoE, Vol. 87, S. 355-374.

Spindler, Gerald (1998): Deregulierung des Aktienrechts? In: AG, 43. Jg., S. 53-74.

Spindler, Gerald (2000): Internet und Corporate Governance - ein neuer virtueller (T)Raum? Zum Entwurf des NaStraG. In: ZGR, 29. Jg., S. 420-445.

Spindler, Gerald (2002): Neuregelungen des Kapitalmarkt- und Börsenrechts zum Anlegerschutz? - Zur gesellschafts- und wirtschaftsrechtlichen Abteilung des 64. Deutschen Juristentages. In: DStR, 40. Jg., S. 1576-1587. 
Spremann, Klaus (1987): Zur Reduktion von Agency-Kosten. In: Schneider, D. (Hrsg.): Kapitalmarkt und Finanzierung, Berlin, S. 341-350.

Spremann, Klaus (1990): Asymmetrische Information. In: ZfB, 60. Jg., S. 561586.

Stapledon, Geof P. (1996): Institutional Shareholders and Corporate Governance, New York.

Steer, Peter/Cable, John (1978): Internal Organization and Profit: An Empirical Analysis of Large U.K. Companies. In: JoIE, Vol. 27, S. 13-30.

Stehle, Richard (1997): Der Size-Effekt am deutschen Aktienmarkt. In: ZBB, 9. Jg., S. 237-269.

Steiger, Max (2000): Institutionelle Investoren im Spannungsfeld zwischen Aktienmarktliquidität und Corporate Governance, Baden-Baden.

Steiner, Manfred (1998): Börsenzulassungsprospekt. In: Busse von Colbe, W. et al (Hrsg.): Lexikon des Rechnungswesens, 4. Aufl., München, S. 139141.

Steinitzer, Erwin (1908): Ökonomische Theorie der Aktiengesellschaft, Leipzig.

Stigler, George J./Friedland, Claire (1983): The Literature of Economics: The Case of Berle and Means. In: JoLE, 26. Jg., S. 237-268.

Stiglitz, Joseph E. (1985): Credit Markets and the Control of Capital. In: JoMCB, Vol. 17, S. 133-152.

Stiglitz, Joseph E./Weiss, Andrew (1981): Credit Rationing in Markets with Imperfect Information. In: AER, Vol. 81, S. 393-410.

Strenger, Christian (2001): Einflussmöglichkeiten professioneller Anleger auf die Unternehmen. In: IDW (Hrsg.): Kapitalmarktorientierte Unternehmensüberwachung, S. 65-84.

Stulz, Rene M. (1988): Managerial control of voting rights. In: JoFE, Vol. 20, S. 25-54.

Süchting, Joachim/Paul, Stephan (1998): Bankmanagement, 4. Aufl., Stuttgart. 
Sudmeyer, Jan (2002): Mitteilungs- und Veröffentlichungspflichten nach $\S \S 21$, 22 WpHG. In: BB, 57. Jg., S. 685-692.

Sun, Qian/Tong, Wilson H.S./Tong, Jing (2002): How Does Government Ownership Affect Firm Performance? Evidence from China's Privatization Experience. In: JoBFA, Vol. 29, S. 1-27.

Sünner, Eckart (2000): Effizienz von Unternehmensorganen als Grundsatz der Corporate Governance. In: AG, 45. Jg., S. 492-498.

Sürken, Silke (1999): Abgrenzung der wirtschaftlichen Einheit nach US-GAAP, Frankfurt/Main.

Suter, Reto (2000): Corporate Governance \& Management Compensation, Zürich.

Taga, Karim/Forstner, Anton K. (2002): Erfolgreich Unternehmensgründung mit venture capital, Weinheim.

Teall, John L. (1997): The one-share-one-vote-rule and managerial compensation. In: RoFS, Vol. 6, S. 211-223.

Teichmann, Christoph (2001): Corporate Governance in Europa. In: ZGR, 30. Jg., S. 645-679.

Terberger, Eva (1994): Neo-institutionalistische Ansätze - Entstehung und Wandel - Anspruch und Wirklichkeit, Wiesbaden.

Theurl, Theresia/Polster, Dirk (2002): Pfadabhängigkeit im Finanzsystem. In: WISU, 32. Jg., S. 1134-1139.

Thies, Stefan (2000): Finanzierungsentscheidungen, Informationseffekte und Long-Run-Performance am deutschen Kapitalmarkt, Wiesbaden.

Thom, Norbert (1993): Kontrolle. In: Chmielewicz, K./Schweitzer, M. (Hrsg.): Handwörterbuch des Rechnungswesens, Stuttgart 3. Aufl., Sp. 1140-1145.

Thome, Helmut (1992): Regressionsanalyse mit Zeitreihendaten. In: Zentralarchiv für Empirische Sozialforschung (Hrsg.): ZA-Information 30, Mai 1992, S. 80-111. 
Thomsen, Steen/Pedersen, Torben (2000): Ownership Structure and Economic Performance in the Largest European Companies. In: SMJ, Vol. 21, S. 689-705.

Thonet, Peter J. (1977): Managerialismus und Unternehmenserfolg. Ein empirischer Beitrag, Saarbrücken.

Thonet, Peter J./Poensgen, Otto H. (1979): Managerial Control and Economic Performance in Western Germany. In: JoIE, Vol. 28, S. 23-37.

Tian, Guoqiang (2001): A Theory of Ownership Arrangements and Smooth Transition to a Free Market Economy. In: JITE, Vol. 157, S. 380-412.

Titzrath, Alfons (1995): Die Bedeutung des Going Public. In: ZfB, 65. Jg., S. 133-151.

Tobin, James (1968): Money, Capital and other stores of value. In: AER, Vol. 51, No. 2, S. 26-37.

Traisbach, Julius (1934): Das Stimmrecht der Muttergesellschaften und Tochtergesellschaften im Aktienrecht, Coburg.

Treu, Florian/Sidler, Patrik (2000): Neue Verrechnungspreisbestimmungen zu Kostenumlagen und Dokumentationen in Deutschland. In: Der Schweizer Treuhänder, 74. Jg., S. 351-356.

Trouet, Klaus (1986): Die Hauptversammlung - Organ der Aktiengesellschaft oder Forum der Aktionäre? In: NJW, 39. Jg., S. 1302-1307.

Turnbull, Shann (1997): Corporate Governance. In: CG, 5. Jg., S. 180-205.

Uhlmann, Reinhard (2000): Eine kuriose Allianz von Union und SPD-Linken. In: Handelsblatt vom 22.5.2000, Nr. 98, S. 2.

Uhrig-Homburg, Marliese (2001): Fremdkapitalkosten, Bonitätsrisiken und optimale Kapitalstruktur, Wiesbaden.

Ulmer, Peter (1999): Entwicklungen im Kapitalgesellschaftsrecht. In: ZGR, 28. Jg., S. 751-780.

Ulmer, Peter (1999a): Die Aktionärsklage als Instrument zur Kontrolle des Vorstands- und Aufsichtsratshandelns. In: ZGR, 28. Jg., S. 290-342. 
Ulmer, Peter (2002): Der Deutsche Corporate Governance Kodex - Ein neues Regulierungsinstrument für börsennotierte Aktiengesellschaften. In: ZHR, 166. Jg., S. 150-181.

Valcárcel, Sylvia (2002): Theorie der Unternehmung und Corporate Governance, Wiesbaden.

van der Elst, Christoph (2000): The Equity Markets, Ownership Structures and Control: Towards an International Harmonisation? Working Paper, University of Gent, Financial Law Institute, Gent.

van Lishaut, Ingo (2000): Die Reform der Unternehmensbesteuerung aus Gesellschaftersicht. In: StuW, o.Jg., Heft 2, S. 182-196.

Varga von Kibed, Gabriele (2001): Konflikte zwischen Aktionären und Managern - Lösungsmöglichkeiten im Rahmen des deutschen und britischen Corporate-Governance-Modells, Wiesbaden.

Veblen, Torstein (1923): Absentee Ownership and Business Enterprise in Recent Times, New York.

Vinaimont, Tom (2002): Voting Structure: One Share - One Vote revisited, Working Paper, Catholic University of Leuven, Leuven.

Vogel, Wolfgang (1980): Aktienrecht und Aktienwirklichkeit - Organisation und Aufgabenteilung von Vorstand und Aufsichtsrat, Baden-Baden.

Volk, Gerrit (2001): Deutsche Corporate Governance-Konzepte. In: DStR, 39. Jg., S. 412-416.

Volpin, Paolo F. (2002): Governance with poor investor protection: evidence from top executive turnover in Italy. In: JoFE, Vol. 64, S. 61-90; 159-160.

Wagner, Jürgen (1998): Aufsichtsgremien im Gesellschaftsrecht, Stuttgart.

Ware, Robert F. (1975): Performance of Manager- Versus Owner-Controlled Firms in the Food and Beverage Industry. In: QRoEB, Vol. 15, S. 81-92.

Weigand, Jürgen/Audretsch, David B. (1999): Does science make a difference? Investment, finance and corporate governance in German industries. Discussion Paper No. 2056, Centre for Economic Policy Research, London.

Weikert, Dorit (2001): Corporate Governance und das Auftragsstimmrecht der Banken, Lohmar/Köln. 
Weisgerber, Thomas (1998): Das dritte Finanzmarktförderungsgesetz und das Richtlinienumsetzungsgesetz, Köln.

Weizsäcker, Carl Christian v. (1998): Alle Macht den Aktionären. In: FAZ vom 27.6.1998, Nr. 146, S. 15.

Wellkamp, Ludger (1998): Aktionärsschutz, Bonn.

Wellkamp, Ludger (1998a): Das Stimmrecht des Aktionärs als uneigennütziges Individualrecht. In: INF, 52. Jg., S. 367-371.

Wellkamp, Ludger (2000): Vorstand, Aufsichtsrat und Aktionär, 2. Aufl., Bonn.

Wenger, Ekkehard (1997): Im Selbstbedienungsladen des Konzernmanagements wird der Privatanleger noch immer verhöhnt. In: Wirtschaftsdienst, 77. Jg., S. 254-258.

Wenger, Ekkehard (2000): Die Steuerfreiheit von Veräußerungsgewinnen: Systemwidrigkeiten und systematische Notwendigkeiten. In: StuW, o. Jg., Heft 2, S. 177-181.

Wenger, Ekkehard/Kaserer, Christoph (1998): The German system of corporate governance - A model which should not be imitated. In: Black, S. W./Moersch, M. (Hrsg.): Competition and convergence in financial markets, Amsterdam, S. 41-84.

Wenger, Ekkehard/Kaserer, Christoph/Hecker, Renate (2001): Konzernbildung und Ausschluss von Minderheiten im neuen Übernahmerecht: Eine verpasste Chance für einen marktorientierten Minderheitenschutz. In: ZBB, 13. Jg., S. 317-334.

Wentges, Paul (2001): Corporate Governance. In: WISU, 30. Jg., S. 1109.

Werner, Winfried (1971): Die Beschlußfassung der Inhaber von stimmrechtslosen Vorzugsaktien. In: AG, 16. Jg., S. 69-76.

Werth, Heinz-Jürgen (1960): Vorstand und Aufsichtsrat in der Aktiengesellschaft, Düsseldorf.

Westermann, Harm Peter (1986): Grundfragen der Rechtsfortbildung im Aktienkonzernrecht. In: Hofmann, P. u.a. (Hrsg.): Festschrift Pleyer, Köln u.a., S. 421-444. 
Westermann, Harm Peter (1996): Vollmachtstimmrecht und Streubesitzaktionäre in der Hauptversammlung deutscher Aktiengesellschaften. In: Feddersen, D. u.a. (Hrsg.): Corporate Governance, Köln, S. 264-288.

White, Halbert (1980): A heteroscedasticity-consistent covariance matrix estimator and a direct test for heteroscedasticity. In: Econometrica, Vol. 48, S. 817-838.

White, Gerald I./Sondhi, Ashwinpaul C./Fried, Dov (1997): The analysis and use of financial statements, $2^{\text {nd }}$ ed., New York.

Wiebe, Andreas (2002): Vorstandsmacht statt Bankenmacht? In: ZHR, 161. Jg., S. 182-210.

Wiedemann, Herbert (1980): Gesellschaftsrecht, Band I, München.

Wiesner, Peter M. (2003): Neue Brüsseler Impulse für Corporate Governance und Gesellschaftsrecht. In: BB, 58. Jg., S. 213-217.

Wiethölter, Rudolf (1961): Interessen und Organisation der Aktiengesellschaft im amerikanischen und deutschen Recht, Karlsruhe.

Wilhelm, Jan (2001): Inkompetenz des Aktionärs und Auskunfts- und Klagerecht. In: DB, 54. Jg., S. 520-522.

Williamson, Oliver $\boldsymbol{E}$. (1964): The economics of discretionary behavior: Managerial objectives in a theory of the firm, Englewood Cliffs.

Williamson, Oliver E. (1975): Markets and Hierarchies: Analysis and Antitrust Implications, New York u.a.

Williamson, Oliver $\boldsymbol{E}$. (1979): Transaction-Cost Economics: The governance of Contractual Relations. In: JoLE, Vol. 22, S. 233-261.

Williamson, Oliver E. (1984): Corporate Governance. In: YLJ, Vol. 93, S. $1197-1230$.

Williamson, Oliver E. (1985): The Economic Institutions of Capitalism: Firms, Markets, Relational Contracting, New York u.a.

Williamson, Oliver E. (1990): A Comparison of Alternative Approaches to Economic Organization. In: JITE, Vol. 146, S. 61-71. 
Wilsing, Hans-Ulrich (1995): Wiederaufleben des Stimmrechts aus Vorzugsaktien und Mitteilungspflicht nach $\S 21$ Abs. 1 WpHG. In: BB, 50. Jg., S. 2277-2280.

Wilson, Robert (1969): The Structure of Incentives for Decentralization under Uncertainty. In: Guilbaud, G. (Hrsg.): La Decision: Agregation et Dynamique des Ordres de Preference, Paris, S. 287-307.

Windolf, Paul/Beyer, Jürgen (1995): Kooperativer Kapitalismus - Unternehmensverflechtungen im internationalen Vergleich. In: KZSS, 47. Jg., S. 136.

Winker, Peter (1997): Empirische Wirtschaftsforschung, Berlin u.a.

Witt, Carl-Heinz (1996): Übernahmen von Aktiengesellschaften und Transparenz von Beteiligungsverhältnissen, Köln u.a.

Witt, Carl-Heinz (1998): Vorschlag für eine Zusammenfügung der $\S \S 21 \mathrm{ff}$. WpHG und des $\S 20 \mathrm{AktG}$ zu einem einzigen Regelungskomplex. In: AG, 43. Jg., S. 171-182.

Witt, Peter (2000): Corporate Governance im Wandel. In: ZFO, 69. Jg., S. 159163.

Witt, Peter (2001): Konsistenz und Wandlungsfähigkeit von Corporate Governance-Systemen.. In: ZfB, 72. Jg., Ergänzungsheft 4/2001, S. 73-97.

Witte, Eberhard (1981): Der Einfluß der Anteilseigner auf die Unternehmenspolitik. In: ZfB, 51. Jg., S. 733-779.

Wiwattanakantang, Yupana (2001): Controlling shareholders and corporate value: Evidence from Thailand. In: PBFJ, Vol. 9, S. 323-362.

Woidtke, Tracie (2002): Agents watching agents?: evidence from pension fund ownership and firm value. In: JoFE, Vol. 63, S. 99-131.

Wójcik, Dariusz (2001): Change in the German Model of Corporate Governance: Evidence from Blockholdings, 1997-2001, Working Paper, University of Oxford, Oxford. 
Wolf, J. Benedict (1999): The effects of agency problems on the financial behavior, performance, and efficiency of German industrial stock corporations. Frankfurt/M.

Wolfenzon, Daniel (1999): A Theory of Pyramidal Ownership, Working Paper, University of Michigan Business School, Michigan.

Wolff, Ulrik (2000): Beteiligungsbesitz und Corporate Governance, Wiesbaden.

Wormser, Isaac M. (1931): Frankenstein, Incorporated, New York/London.

Wosnitza, Michael (1991): Das Agency-theoretische Unterinvestitionsproblem in der Publikumsgesellschaft, Heidelberg.

Wruck, Karen (1988): Stock prices and top management changes, JoFE, Vol. 20, S. 461-492.

Wüstemann, Jens (2002): Institutionenökonomik und internationale Rechnungslegungsordnungen, Tübingen.

$\boldsymbol{W u}, \mathbf{C h i e n - F u}$ (1981): Asymptotic theory of nonlinear least squares estimation. In: Annals of Statistics, Vol. 9, S. 501-513.

Wymeersch, Eddy (1995): Unternehmensführung in Westeuropa. In: AG, 40. Jg., S. 299-316.

Wymeersch, Eddy (2001): Gesellschaftsrecht im Wandel: Ursachen und Entwicklungslinien. In: ZGR, 30. Jg., S. 294-324.

Zeckhauser, Richard J./Pound, John (1990): Are Large Shareholders Effective Monitors? An Investigation of Share Ownership and Corporate Performance. In: Hubbard, R.G. (ed.): Asymmetric information, corporate finance, and investment, Chicago, S. 149-180.

Zhou, Xianming (2001): Understanding the determinants of managerial ownership and the link between ownership and performance: comment. In: JoFE, Vol. 62, S. 559-571.

Zimmermann, Jochen (2002): Die Berichterstattung über Beziehungen zu nahe stehende Personen nach DRS 11. In: StuB, 4. Jg., S. 889-895. 
Zingales, Luigi (1994): The Value of the Voting Right: A Study of the Milan Stock Exchange Experience. In: RoFS, Vol. 7, S. 125-148.

Zingales, Luigi (1995): What determines the Value of Corporate Votes? In: QJoE, Vol. 109, S. 1047-1073.

Zingales, Luigi (2000): In Search of New Foundations. In: JoF, Vol. 55, S. 1623-1653.

Zöllner, Wolfgang (1994): Aktienrechtsreform in Permanenz - Was wird aus den Rechten des Aktionärs? In: AG, 39. Jg, S. 336-342.

Zöllner, Wolfgang (2000): Zur Problematik der aktienrechtlichen Anfechtungsklage. In: AG., 45. Jg., S. 145-157.

Zöllner, Wolfgang/Noack, Ulrich (1991): One share - one vote? In: AG, 36. Jg, S. 117-131.

Zwiebel, Jeffrey (1995): Block Investment and Partial Benefits of Corporate Control. In: RoES, Vol. 62, S. 161-185.

Zwiebel, Jeffrey (1996): Dynamic Capital Structure Under Managerial Entrenchment. In: AER, Vol. 86, S. 1197-1215. 


\section{Verzeichnis der Rechtsquellen}

ADHGB: Einführungsgesetz zum Allgemeinen Deutschen Handelsgesetzbuch vom 24.6.1861, GS. 1861, S. 449.

AktG: Aktiengesetz vom 6.9.1965, BGBl. I 1965, S. 1089.

AktG 1937: Aktiengesetz 1937: Gesetz über Aktiengesellschaften und Kommanditgesellschaften auf Aktien vom 30.1.1937, RGBl. 1937, S. 107.

Aktienrechtsnovelle 1870: Gesetz betreffend die Kommanditgesellschaften auf Aktien und die Aktiengesellschaften vom 11.6.1870, BGBl. des Norddeutschen Bundes 1870, S. 375.

Aktienrechtsnovelle 1884: Gesetz betreffend die Kommanditgesellschaften auf Aktien und die Aktiengesellschaften vom 18.7.1884, RGBl. 1884, S. 123.

Aktienrechtsnovelle 1931: Verordnung des Reichspräsidenten über Aktienrecht, Bankenaufsicht und über eine Steueramnestie, RGBl. I 1931, S. 493.

Entwurf Aktienrechtsnovelle 1884: Entwurf eines Gesetzes betreffend die Kommanditgesellschaften auf Aktien und die Aktiengesellschaften, Allgemeine Begründung. In: Schubert, W. u.a. (Hrsg.): Hundert Jahre modernes Aktienrecht, Berlin/New York 1985, S. 407-501.

Beteiligungstransparenz-Richtlinie: Richtlinie 88/627/EWG vom 12.12. 1988 über die bei Erwerb und Veräußerung einer bedeutenden Beteiligung an einer börsennotierten Gesellschaft zu veröffentlichenden Informationen, ABl. EG L 348, S. 62.

BGHZ 83: Entscheidungssammlung des BGH in Zivilsachen, Band 83, S. 122. In: AG, 27. Jg. (1982), S. $158 \mathrm{ff}$.

BörsG: Börsengesetz vom 27. Mai 1908, RGBl. 1908, S. 215, in der Fassung von 1993, zuletzt geändert durch Art. 41 des EWR-Ausführungsgesetzes vom 27.4.1993, BGBl. I 1993, S. 512

BörsZulV: Verordnung über die Zulassung von Wertpapieren zur amtlichen Notierung an einer Wertpapierbörse (Börsenzulassungs-Verordnung) vom 15.4.1987, S. 1052, in der Fassung von 1993, zuletzt geändert durch 
Art. 41 des EWR-Ausführungsgesetzes vom 27.4.1993, BGBl. I 1993, S. 512 .

DRS 11: Deutscher Rechnungslegungs Standard Nr. 11 (DRS 11): „Angaben zu nahe stehenden Personen", bekannt gemacht durch das BMJ am 10.4.2002, BAnz. Nr. 67, Beilage 67a.

FGG: Gesetz über die Angelegenheiten der freiwilligen Gerichtsbarkeit vom 17.5.1898, RGBl. 1898, S. 189.

FinDAG: Gesetz über die Bundesanstalt für Finanzdienstleistungsaufsicht - Finanzdienstleistungsaufsichtsgesetz vom 22.4.2002, BGBl. I S. 1310.

Gesetzenwurf Wp $\ddot{U} G$ : Entwurf eines Gesetzes zur Regelung von öffentlichen Angeboten zum Erwerb von Wertpapieren und von Unternehmensübernahmen. In: Bundestags-Drucksache 14/7034 vom 5.10. 2001.

$\boldsymbol{G W B}$ : Gesetz gegen Wettbewerbsbeschränkungen, in der Fassung der Bekanntmachung vom 26.8.1998, BGBl. I S. 2546.

HGB: Handelsgesetzbuch vom 10.5.1897, RGBl. 1897, S. 219.

KAGG: Gesetz über Kapitalanlagegesellschaften, in der Fassung der Bekanntmachung vom 9.9.1998, BGBl. I 1998, S. 2726.

KapCoRiLiG: Kapitalgesellschaften- und Co-Richtlinie-Gesetz vom 24.2. 2000, BGB1. I 2000, S. 154.

KonTraG: Gesetz zur Kontrolle und Transparenz im Unternehmensbereich vom 27.4.1998, BGBI. I 1998, S. 786.

$\boldsymbol{K} \boldsymbol{W} \boldsymbol{G}$ : Gesetz über das Kreditwesen in der Fassung der Bekanntmachung vom 9.9.1998, BGBl. I 1998, S. 2776.

NaStraG: Gesetz zur Namensaktie und zur Erleichterung der Stimmrechtsausübung vom 18.1.2001, BGBl. I 2001, S. 123.

PublG: Gesetz über die Rechnungslegung von bestimmten Unternehmen und Konzernen (Publizitätsgesetz) vom 15.8.1969, BGBl. I 1969, S. 1189, ber. BGBI 1970 I S. 1113 mit späteren Änderungen. 
Preußisches Gesetz über die Aktiengesellschaften, vom 9.11.1843, GS. 1843, S. 341 .

Regelwerk Neuer Markt: Gruppe Deutsche Börse, Stand 21.5.2001.

Regierungsentwurf KonTraG: Regierungsentwurf zur Änderung des Aktiengesetzes („KonTraG“). In: ZIP, 18. Jg., S. 2059-2068.

Steuersenkungsgesetz: Gesetz zur Senkung der Steuersätze und zur Reform der Unternehmensbesteuerung vom 23.10.2000, BGB1. I 2000, S. 1433.

TransPuG: Gesetz zur weiteren Reform des Aktien- und Bilanzrechts, zu Transparenz und Publizität (Transparenz- und Publizitätsgesetz) vom 19.7.2002, BGBl I 2002, S. 2681.

UmwG: Umwandlungsgesetz vom 28.10.1994, BGBl. I 1994, S. 3210, ber. BGBl. 1995 I, S. 428.

Viertes Finanzmarktförderungsgesetz: Gesetz zur weiteren Fortentwicklung des Finanzplatzes Deutschland (Viertes Finanzmarktförderungsgesetz) vom 21.6.2002, BGB1 I 2002, S. 2010.

WpHG: Gesetz über den Wertpapierhandel (Wertpapierhandelsgesetz) vom 26.7.1994, BGBl. I 1994, S. 1749.

Wp $\ddot{U} G$ : Gesetz zur Regelung von öffentlichen Angeboten zum Erwerb von Wertpapieren und von Unternehmensübernahmen, vom 20.12.2001, BGB1. I 2001, S. 3822.

Zweites Finanzmarktförderungsgesetz: Gesetz über den Wertpapierhandel und zur Änderung börsenrechtlicher und wertpapierrechtlicher Vorschriften (Zweites Finanzmarktförderungsgesetz) vom 26.7.1994, BGB1 I 1994, S. 1749. 


\section{Bochumer Beltrăge zur Unternehmungsführung und Unternehmensforschung}

Herausgegeben vom Direktorium des Instituts für Unternehmungsführung und Unternehmensforschung der Ruhr-Universität Bochum

Band 1 Busse von Colbe, Walther/Mattessich, Richard (Hrsg.): Der Computer im Dienste der Unternehmungsführung (1968)

Band 2 Busse von Colbe, Walther/Meyer-Dohm, Peter (Hrsg.): Unternehmerische Planung und Entscheidung (1969)

Band 3 Anthony, Robert N.: Harvard-Fälle aus der Praxis des betrieblichen Rechnungswesens. Herausgegeben von Richard V. Mattessich unter Mitarbeit von Klaus Herrnberger und Wolf Lange (1969)

Band 4 Mattessich, Richard: Die wissenschaftlichen Grundlagen des Rechnungswesens (1970)

Band 5 Schweim, Joachim: Integrierte Unternehmungsplanung (1969)

Band 6 Busse von Colbe, Walther (Hrsg.): Das Rechnungswesen als Instrument der Unternehmungsführung (1969)

Band 7 Domsch, Michel: Simultane Personal- und Investitionsplanung im Produktionsbereich (1970)

Band 8 Leunig, Manfred: Die Bilanzierung von Beteiligungen. Eine bilanztheoretische Untersuchung (1970)

Band 9 Franke, Reimund: Betriebsmodelle. Rechensystem für Zwecke der kurzfristigen Planung, Kontrolle und Kalkulation (1972)

Band 10 Wittenbrink, Hartwig: Kurzfristige Erfolgsplanung und Erfolgskontrolle mit Betriebsmodellen (1975)

Band 11 Lutter, Marcus (Hrsg.): Recht und Steuer der internationalen Unternehmensverbindungen (1972)

Band 12 Niebling, Helmut: Kurzfristige Finanzrechnung auf der Grundlage von Kosten- und Erlösmodellen (1973)

Band 13 Perlitz, Manfred: Die Prognose des Unternehmenswachstums aus Jahresabschlüssen deutscher Aktiengesellschaften (1973)

Band 14 Niggemann, Walter: Optimale Informationsprozesse in betriebswirtschaftlichen Entscheidungssituationen (1973)

Band 15 Richardt, Harald: Der aktienrechtliche Abhängigkeitsbericht unter ökonomischen Aspekten (1974)

Band 16 Backhaus, Klaus: Direktvertrieb in der Investitionsgüterindustrie - Eine Marketing-Entschejung (1974)

Band 17 Plinke, Wulff: Kapitalsteuerung in Filialbanken (1975)

Band 18 Steffen, Rainer: Produktionsplanung bei Fließbandfertigung (1977)

Band 19 Kolb, Jürgen: Industrielle Erlösrechnung - Grundlagen und Anwendungen (1978)

Band 20 Busse von Colbe, Walther/Lutter, Marcus (Hrsg.): Wirtschaftsprüfung heute: Entwicklung oder Reform? (1977)

Band 21 Uphues, Peter: Unternehmerische Anpassung in der Rezession (1979) 
Band 22 Gebhardt, Günther: Insolvenzprognosen aus aktienrechtlichen Jahresabschlüssen (1980)

Band 23 Domsch, Michel: Systemgestützte Personalarbeit (1980)

Band 24 Schmied, Volker: Alternativen der Arbeitsgestaltung und ihre Bewertung (1982)

Band 25 Wäscher, Gerhard: Innerbetriebliche Standortplanung bei einfacher und mehrfacher Zielsetzung (1982)

Band 26 Weber, Martin: Entscheidungen bei Mehrfachzielen - Verfahren zur Unterstützung von Individual- und Gruppenentscheidungen (1983)

Band 27 Kroesen, Alfred: Instandhaltungsplanung und Betriebsplankostenrechnung (1983)

Band 28 Plinke, Wulf: Erlösplanung im industriellen Anlagengeschäft (1985)

Band 29 Chamoni, Peter: Simulation störanfälliger Systeme (1986)

Band 30 Arning, Andreas: Die wirtschaftliche Bewertung der Zentrenfertigung - Dargestellt am Beispiel einer Fertigungsinsel (1987)

Band 31 Gebhardt, Günther: Finanzielle Planung und Kontrolle bei internationaler Unternehmenstätigkeit

Band 32 Markiewicz, Michael: Ersatzteildisposition im Maschinenbau - Betriebswirtschaftliche Methoden der Planung und Überwachung (1988)

Band 33 Pellens, Bernd: Der Informationswert von Konzernabschlüssen - Eine empirische Untersuchung deutscher Börsengesellschaften (1989)

Band 34 Mrotzek, Rüdiger: Bewertung direkter Auslandsinvestitionen mit Hilfe betrieblicher Investitionskalküle (1989)

Band 35 Deppe, Joachim: Quality Circle und Lernstatt - Ein integrativer Ansatz (1989, 3. Auflage 1993)

Band 36 Rademacher, Michael: Arbeitszeitverkürzung und -flexibilisierung - Formen und betriebliche Auswirkungen (1990)

Band 37 Kaiser, Klaus: Kosten- und Leistungsrechung bei automatisierter Produktion (1991, 2. Auflage 1993)

Band 38 Müller, Hermann: Industrielle Abfallbewältigung - Entscheidungsprobleme aus betriebswirtschaftlicher Sicht (1991)

Band 39 Schörner, Peter: Gesetzliches Insiderhandelsverbot - Eine ordnungspolitische Analyse (1991)

Band 40 Bentler, Martin: Grundsätze ordnungsmäßiger Bilanzierung für die Equitymethode (1991)

Band 41 Brüggerhoff, Jürgen: Management von Desinvestitionen (1992)

Band 42 Bröker, Erich W.: Erfolgsrechnung im industriellen Anlagengeschäft - Ein dynamischer Ansatz auf Zahlungsbasis - (1993)

Band 43 Frankenberg, Peter: Transnationale Analyse US-amerikanischer und deutscher Jahresabschlüsse - Eine theoretische und empirische Untersuchung (1993)

Band 44 Kleinaltenkamp, Michael: Standardisierung und Marktprozeß - Entwicklungen und Auswirkungen im CIM-Bereich (1993)

Band 45 Pellens, Bernhard: Aktionärsschutz im Konzern - Empirische und theoretische Analyse der Reformvorschläge der Konzernverfassung (1994)

Band 46 Reckenfelderbäumer, Martin: Marketing-Accounting im Dienstleistungsbereich - Konzeption eines prozeßkostengestützten Instrumentariums (1995) 
Band 47 Knittel, Friedrich: Technikgestützte Kommunikation und Kooperation im Büro. Entwicklungshindernisse - Einsatzstrategien - Gestaltungskonzepte (1995)

Band 48 Riezler, Stephan: Lebenszyklusrechnung - Instrument des Controlling strategischer Projekte (1996)

Band 49 Schulte, Jörn: Rechnungslegung und Aktienkursentwicklung - Erklärung und Prognose von Aktienrenditen durch Einzel- und Konzernabschlußdaten (1996)

Band 50 Muhr, Martin: Zeitsparmodelle in der Industrie - Grundlagen und betriebswirtschaftliche Bedeutung mehrjähriger Arbeitszeitkonten (1996)

Band 51 Brotte, Jörg: US-amerikanische und deutsche Geschäftsberichte. Notwendigkeit, Regulierung und Praxis jahresabschlußergänzender Informationen (1997)

Band 52 Gersch, Martin: Vernetzte Geschäftsbeziehungen. Die Nutzung von EDI als Instrument des Geschäftsbeziehungsmanagement (1998)

Band 53 Währisch, Michael: Kostenrechnungspraxis in der deutschen Industrie. Eine empirische Studie (1998)

Band 54 Völkner, Peer: Modellbasierte Planung von Geschäftsprozeßabläufen (1998)

Band 55 Fülbier, Rolf Uwe: Regulierung der Ad-hoc-Publizität. Ein Beitrag zur ökonomischen Analyse des Rechts (1998)

\section{Band 1 - 55 erschlenen belm Gabler Verlag Wiesbaden}

Band 56 Ane-Kristin Reif-Mosel: Computergestützte Kooperation im Büro. Gestaltung unter Berücksichtigung der Elemente Aufgabe, Struktur, Technik und Personal (2000)

Band 57 Claude Tomaszewski: Bewertung strategischer Flexibilität beim Unternehmenserwerb. Der Wertbeitrag von Realoptionen (2000)

Band 58 Thomas Erler: Business Objects als Gestaltungskonzept strategischer Informationssystemplanung (2000)

Band 59 Joachim Gassen: Datenbankgestützte Rechnungslegungspublizität. Ein Beitrag zur Evolution der Rechnungslegung (2000)

Band 60 Frauke Streubel: Organisatorische Gestaltung und Informationsmanagement in der lernenden Unternehmung. Bausteine eines Managementkonzeptes organisationalen Lernens (2000)

Band 61 Andreas von der Gathen: Marken in Jahresabschluß und Lagebericht (2001)

Band 62 Lars Otterpohl: Koordination in nichtlinearen dynamischen Systemen (2002)

Band 63 Ralf Schremper: Aktienrückkauf und Kapitalmarkt. Eine theoretische und empirische Analyse deutscher Aktienrückkaufprogramme (2002)

Band 64 Peter Ruhwedel: Aufsichtsratsplanungssysteme. Theoretische Grundlagen und praktische Ausgestaltung in Publikumsaktiengesellschaften (2002)

Band 65 Jens Thorn: Taktisches Supply Chain Planning. Planungsunterstützung durch deterministische und stochastische Optimierungsmodelle (2002)

Band 66 Dirk Beier: Informationsmanagement aus Sicht der Betriebswirtschaftslehre. Theoretische Ansätze und das Beispiel Mobile Business. (2002)

Band 67 Nils Crasselt: Wertorientierte Managemententlohnung, Unternehmensrechnung und Investitionssteuerung. Analyse unter Berücksichtigung von Realoptionen. (2003) 
Band 68 Franca Ruhwedel: Eigentümerstruktur und Unternehmenserfolg. Eine theoretische und empirische Analyse deutscher börsennotierter Unternehmen. (2003) 


\section{Wertorientierte}

\section{Managemententlohnung, Unternehmensrechnung und Investitionssteuerung}

\section{Analyse unter Berücksichtigung von Realoptionen}

Frankfurt am Main, Berlin, Bern, Bruxelles, New York, Oxford, Wien, 2003.

XXI, 228 S., zahlr. Formeln, Tab. und Graf.

Bochumer Beiträge zur Unternehmungsführung und Unternehmensforschung. Herausgegeben vom Direktorium des Instituts für Unternehmungsführung und Unternehmensforschung der Ruhr-Universität Bochum. Bd. 67

(1) ISBN 3-631-50833-6 · br. € 40.40

Im Rahmen des Shareholder-Value-Konzepts soll durch erfolgsabhängige Entlohnungsverträge sichergestellt werden, dass Führungskräfte ihre Handlungen und Entscheidungen trotz Informationsvorsprüngen und Interessendivergenzen am Ziel der Unternehmenswertsteigerung ausrichten. Als Bemessungsgrundlage für die variable Entlohnung wählen dabei viele Unternehmen Erfolgskennzahlen des Rechnungswesens. In dieser Arbeit wird untersucht, wie der Periodenerfolg zu definieren ist, damit rechnungswesenbasierte Entlohnungsverträge Anreize für optimale Investitionsentscheidungen bieten. Hierbei werden neben „normalen” Investitionen auch Projekte mit Optionscharakter betrachtet, bei denen flexible Investitionsstrategien zu entwerfen und zu bewerten sind.

Aus dem Inhalt: Investitionsbewertung für "normale" Investitionen und Realoptionen · Zu- sammenhänge zwischen Investitions- und Periodenerfolgsrechnung Rechnungswesenbasierte Entlohnungsverträge für "normale" Investitionen und Realoptionen

Frankfurt am Main - Berlin - Bern - Bruxelles - New York · Oxford · Wien

Auslieferung: Verlag Peter Lang AG

Moosstr. 1, $\mathrm{CH}-2542$ Pieterlen

Telefax 0041 (0) 32 / 3761727

*inklusive der in Deutschland gültigen Mehrwertsteuer

Preisänderungen vorbehalten

Homepage http://wum.peterlang.de 
Franca Ruhwedel - 978-3-631-75497-9 